\title{
On the modelling and analysis of converting existing Canadian residential communities to net-zero energy
}

\author{
by \\ Adam D. Wills, B.A.Sc., Mechanical Engineering \\ University of Windsor \\ M.A.Sc., Sustainable Energy Engineering \\ Carleton University \\ A thesis submitted to the \\ Faculty of Graduate and Postdoctoral Affairs \\ in partial fulfillment of the requirements for the degree of
}

Doctor of Philosophy in Applied Science in Mechanical Engineering

Department of Mechanical and Aerospace Engineering

Carleton University

Ottawa, Ontario

April, 2018

(C)Copyright

Adam D. Wills, 2018 
The undersigned hereby recommends to the

Faculty of Graduate and Postdoctoral Affairs acceptance of the thesis

\title{
On the modelling and analysis of converting existing Canadian residential communities to net-zero energy
}

\author{
submitted by Adam D. Wills, B.A.Sc., Mechanical Engineering \\ University of Windsor \\ M.A.Sc., Sustainable Energy Engineering \\ Carleton University
}

in partial fulfillment of the requirements for the degree of

Doctor of Philosophy in Applied Science in Mechanical Engineering

Professor Ian Beausoleil-Morrison, Thesis Co-supervisor, Department of Mechanical and Aerospace Engineering

Professor V. Ismet Ugursal, Thesis Co-supervisor, Department of Mechanical and Aerospace Engineering

Professor Ronald E. Miller, Chair,

Department of Mechanical and Aerospace Engineering

Department of Mechanical and Aerospace Engineering

Carleton University

May, 2018 


\section{Abstract}

Rising energy costs and international pressure has motivated governments and homeowners to reduce the energy consumption and greenhouse gas (GHG) emissions of new and existing dwellings. A popular technical approach to this problem is the adoption of net-zero energy targets, which can achieve substantial energy and GHG emissions reductions. Often focused on new builds, there is growing interest in retrofitting existing buildings to net-zero. Addressing existing stock is essential since they will continue to be a significant portion of the building stock for several decades.

Net-zero is not limited to single buildings, and potential benefits of communityscale retrofit projects include greater economic viability and economies of scale. However, challenges faced by such projects include few demonstrations in practice, and the need of detailed analytical models to analyze techno-economic feasibility. Another challenge is the lack of consensus on formal net-zero definitions.

This research was conducted to explore the feasibility and performance of retrofitting Canadian residential communities to net-zero, and the impact of netzero definition on design. To meet this objective, a new modelling approach was developed which builds upon the detailed and validated Canadian Hybrid Residential End-Use Energy and GHG Emissions Model (CHREM). A new Canadian residential appliance and lighting bottom-up model was developed and integrated into CHREM which realistically captures the behaviour, variability and aggregate electrical demands of communities. Building envelope retrofit models, ground-source heat pump (GSHP) space heating, and heat pump hot water models were incorporated into CHREM. A new methodology was developed to estimate the impact of envelope retrofits on airtightness. 
Retrofit community-scale energy systems considered included solar thermal and photovoltaic (PV) systems, district heating and thermal energy storage, and microturbine cogeneration. Detailed models of these systems were developed in the TRNSYS energy simulation tool. An optimization algorithm was used to determine the cost-optimal net-zero solutions for representative residential communities. Commonly used site and source net-zero energy definitions were considered. The results indicate that deep envelope upgrades and PV and GSHP system retrofits have potential to achieve net-zero and significant GHG reductions. The results also indicate that site net-zero likely realizes more GHG reductions compare to source net-zero. 
For Mémé 


\section{Acknowledgments}

It has been my pleasure to have spent the last few years working and studying at Carleton. I have learned and grown so much, and met so many kind, wonderful, and intelligent people. I am eternally grateful to my supervisors Dr. Ian BeausoleilMorrison and Dr. V. Ismet Ugursal for taking me on as a student. Their mentorship, encouragement, and support in this endeavour has been incredible. While I am happy to be completing my studies, I will miss working closely along side them.

I was also very fortunate to have worked with several amazing and intelligent colleagues over the years. I want to thank my fellow grad students in SBES and 3103A for lending your patient ears when I needed to vent about ESP-r or segmentation faults. Ahmed, Andrea Pietila, b, Jayson Bursill, Courtney Edwards, Curtis Meister, Evan Boucher, Flannel, Geoff Johnson, Hiha, Ifaz, John Kopf, Lumi Dumitrascu, Seb, Skedwards, Suzan, Tiwa Lawal, and Yawen Han, you guys made coming into campus everyday so much better.

Through the generosity of so many people I could collect data and access resources that moved this work forward. Id like to thank the following people for sharing their time, knowledge, and resources with me: Alex Ferguson and Julia Purdy of the Housing R\&D team at NRCan CanmetENERGY, Sylvain Pitre and Ryan Taylor at Carleton Research Computing Services, Lukas Swan, Dane George, Rasoul Asaee, and Sara Nikoofard at Dalhousie University, Jan Hensen and his research group at TU/e, Ms. Lorraine Gautheir from the Now House Project, and the Mechanical and Aerospace administration and technical staff.

Id also like to thank Dr. Cynthia A. Cruickshank and her research group for their advice, friendship and microwave over the years. In particular, thanks to Chris 
Baldwin, David Ouellette, and Patrick Smith. I would also to acknowledge my gratitude to Dr. Liam OBrien and Dr. Burak Gunay for their guidance and support throughout this study. Dr. Iain A. MacDonald and my colleagues at NRC have also been extremely supportive as I wrapped this work up. I am privileged to work with such an amazing group.

To my friends in Ottawa and back in Windsor, I want to thank you for cheering me on through this thesis. I feel so blessed to know so many great people. In particular I'd like to thank Simon, Patrice, and the Alpha Ducks for keeping me going. Finally, I would like to thank my family. You have been an endless well of support and love. Mom and Dad, your encouraging words inspired me to stick with it in times I was ready to give up. I could not have done this without you. Spencer, thanks for taking care of everyone back home. 


\section{Table of Contents}

Abstract

Acknowledgments vi vi

Table of Contents viii

List of Tables $\quad$ xiv

List of Figures $\quad$ xx

Nomenclature $\quad$ xxiv

1 Introduction 1

1.1 Motivation ........................ 1

1.2 Background on Net-Zero Definitions . . . . . . . . . . . . . . . . 7

1.3 Research Methods . . . . . . . . . . . . . . . . . 10

1.3.1 Building Performance Simulation . . . . . . . . . . . . 10

1.3.2 Energy System Simulation . . . . . . . . . . . . . . . 12

1.3.3 Optimization Tools ................. 13

1.4 Thesis Objectives . . . . . . . . . . . . . . . . . . 15

1.5 Thesis Overview . . . . . . . . . . . . . . . 16

2 Literature Review $\quad 18$

2.1 Review of Building Stock Modelling Methodologies . . . . . . . . . . 18

2.1.1 Engineering Bottom-up Approaches . . . . . . . . . . . 20

viii 
2.1.2 Statistical Bottom-up Approaches . . . . . . . . . . . . 22

2.1.3 Applicability of Approaches . . . . . . . . . . . . . 25

2.2 Previous Simulation Studies on Residential Stock Retrofits . . . . . . 28

2.3 Community-scale Retrofit Projects in Practice . . . . . . . . . . . . . 32

2.4 On-site and Renewable Energy Generation Options . . . . . . . . . . 36

2.4.1 Geothermal Energy . . . . . . . . . . . . . . . . . 38

2.4 .2 Solar Energy _ . . . . . . . . . . . . . . . . . . 39

2.4 .3 Microturbines . . . . . . . . . . . . . . . . . . . . . 44

2.5 Existing Net-Zero Communities . . . . . . . . . . . . . . 46

2.6 Thesis Tasks . . . . . . . . . . . . . . . . . . . . . . . . . . . . . 48

3 Simulation Methodologies of Dwelling-scale Retrofit Options $\quad 53$

3.1 ESP-r Solution Methodology . . . . . . . . . . . . . . . . . 54

3.1.1 Thermal Simulation Domain . . . . . . . . . . . . . . . 55

3.1 .2 Air Flow Simulation Domain . . . . . . . . . . . . 56

3.2 Summary of Dwelling-scale Retrofits Considered . . . . . . . . . . 58

3.2.1 Retrofit Insulation on Dwelling Envelopes _. . . . . . . . . . 59

3.2 .2 Glazing Retrofit . . . . . . . . . . . . . . . . . . 68

3.2.3 Ground Source Heat Pump Retrofit . . . . . . . . . . . . . . . 72

3.2.4 Heat Pump DHW System Retrofit . . . . . . . . . . . . . 74

3.2 .5 Envelope Airtightness _ . . . . . . . . . . . . . 75

3.2 .6 Mechanical Ventilation . . . . . . . . . . . . . . . . . 91

3.3 Description of Case Study Communities _ . . . . . . . . . . . . 92

3.4 Final Remarks . . . . . . . . . . . . . . . . . . . . . . . 96

4 Community-scale Retrofit Systems Considered and Modelling Methodologies $\quad 98$

4.1 TRNSYS Simulation Methodology _. . . . . . . . . . . . . . . 99

4.2 Community Energy System Overview . . . . . . . . . . . . . . . . . 101

4.3 Solar Thermal Loop Simulation Methodology _ . . . . . . . . . . . 106

4.3 .1 Solar Thermal Loop Controls . . . . . . . . . . . . . . 107 
4.3.2 Evacuated Tube Collectors Simulation Methodology and Inputs 110

4.3.3 Solar Thermal Collector Eligibility Criteria . . . . . . . . . . 112

4.4 Solar PV Simulation Methodology and Inputs . . . . . . . . . . . 114

4.4 .1 Modelling Methodology . . . . . . . . . . . . . . . . 114

4.4 .2 Model Parameters . . . . . . . . . . . . . . . . . . . . . . 116

4.5 Solar Collector Roof-mounting Algorithm . . . . . . . . . . . . . . . 119

4.6 Thermal Energy Storage Simulation Methodology and Inputs . . . . . 123

4.6.1 Modelling Methodology . . . . . . . . . . . . . . . . . . 124

4.6 .2 Model Parameters . . . . . . . . . . . . . . . . 126

4.7 Microturbine Simulation Methodology and Inputs . . . . . . . . . 130

4.7 .1 Modelling methodology . . . . . . . . . . . . . . . . 130

4.7 .2 Model Parameters . . . . . . . . . . . . . . . . . . . . . . 132

4.7.3 Exhaust Heat Recovery Simulation Methodology and Inputs . 134

4.7.4 Microturbine Operation Strategies . . . . . . . . . . . 136

4.8 District Heating Simulation Methodology and Inputs . . . . . . . . 140

4.8 .1 Temperature Control . . . . . . . . . . . . . . . . . . 142

4.8 .2 Flow Control . . . . . . . . . . . . . . . . . . . . . 144

4.8 .3 Auxiliary Heater . . . . . . . . . . . . . . . . . . . 145

4.9 Solar Roof-Mounting Parameters . . . . . . . . . . . . . . . . . . 147

4.10 Final Remarks . . . . . . . . . . . . . . . . . . . . . . . . . . 149

5 Model Boundary Conditions $\quad 150$

5.1 Domestic Hot Water Demands . . . . . . . . . . . . . . . . . 152

5.2 Appliance and Lighting Demands . . . . . . . . . . . . . . 154

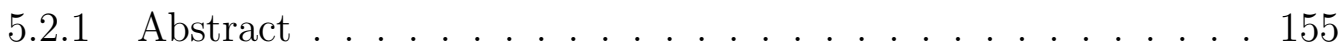

5.2 .2 Introduction . . . . . . . . . . . . . . . . . 156

5.2 .3 Model summary . . . . . . . . . . . . . . . . . . . . . . . 165

5.2 .4 Model validation . . . . . . . . . . . . . . . . . . 175

5.2 .5 Impact of baseload implementation . . . . . . . . . . . . 190

5.2 .6 Conclusions . . . . . . . . . . . . . . . . . . . . . 192

5.2 .7 Recommendations and Future Work . . . . . . . . . . . . 194 
5.3 Temporal Matching of Boundary Conditions . . . . . . . . . . . . 196

5.4 Final Remarks . . . . . . . . . . . . . . . . . . . . . . 197

6 Simulation Framework and Performance Metrics 198

6.1 Simulation Framework . . . . . . . . . . . . . . . . . . . . . . 199

6.1.1 The Optimization Problem . . . . . . . . . . . . . 200

6.1.2 The Objective Function Cost Model . . . . . . . . . . . . . . . 205

6.1.3 Summary of Varied Parameters . . . . . . . . . . . . . . . 214

6.2 Definitions of Net-Zero Considered . . . . . . . . . . . . . . 215

6.2.1 Building System Boundary . . . . . . . . . . . . . . 216

6.2 .2 Net-zero Balance . . . . . . . . . . . . . . . . . . . 217

6.2.3 Weighting System . . . . . . . . . . . . . . . . . . . 217

6.2.4 Primary energy factors . . . . . . . . . . . . . . . . . 219

6.3 Secondary Performance Metrics . . . . . . . . . . . . . . . . . 227

6.3.1 Load Matching . . . . . . . . . . . . . . . . . 228

6.3.2 Grid Interaction . . . . . . . . . . . . . . . . . . . 229

6.3.3 Occupant Comfort . . . . . . . . . . . . . . 230

6.3.4 Emissions ..................... 231

6.4 A Note on Timestep and Simulation Period . . . . . . . . . . . . 233

6.5 Final Remarks . . . . . . . . . . . . . . . . . . . . . . 234

7 Results and Discussion $\quad 235$

7.1 Base Energy Consumption and GHG Emissions of the Communities . 236

7.2 District Heating Retrofit . . . . . . . . . . . . . . . . . . . . 238

7.2.1 Toronto 1940-1960 Community DH Retrofit . . . . . . . . . . 239

7.2.2 Toronto 1981-1990 Community DH Retrofit . . . . . . . . . . 252

7.2.3 Discussion of Results . . . . . . . . . . . . . . . 263

7.2 .4 Microturbine . . . . . . . . . . . . . . 267

7.3 Electrical Only Systems . . . . . . . . . . . . . . . . . 277

7.3.1 Montréal Community . . . . . . . . . . . . . 278

7.3.2 Toronto 1981-1990 Community . . . . . . . . . . . . 287 
7.4 Final Remarks . . . . . . . . . . . . . . . . . . . . . . 295

8 Conclusions, Contributions and Future Work 299

8.1 Future Work . . . . . . . . . . . . . . . . . . . . . . . 306

$\begin{array}{ll}\text { References } & 310\end{array}$

Appendix A AIM-2 Simulation Methodology 353

A.1 Infiltration Characterization . . . . . . . . . . . . 356

A.2 Infiltration Model Inputs . . . . . . . . . . . . . 357

A.2.1 Shielding and Terrain Data . . . . . . . . . . 358

A.2.2 Leakage Description . . . . . . . . . . . . . . . . . . 359

A.2.3 Leakage Distribution . . . . . . . . . . . . . . . 360

Appendix B Solar Collector Sensitivity Studies 362

B.1 Solar Collector Tilt Sensitivity . . . . . . . . . . . . . . . . . . 363

B.1.1 Photovoltaic Panel . . . . . . . . . . . . . . . . . . . . . 363

B.1.2 Solar Thermal Collector . . . . . . . . . . . . . . . . 366

B.2 Solar Thermal Array Network Configuration Sensitivity Study . . . . 369

Appendix C Method to Determine Retrofit Foundation Configuration Type

Appendix D Analysis of Modelled Aggregate Domestic Hot Water De$\begin{array}{ll}\text { mands } & 379\end{array}$

Appendix E Optical and Thermal Properties of Retrofit Glazing Systems

Appendix F Impact of Envelope Retrofits on Dwelling Airtightness 385

F.1 Cluster Analysis . . . . . . . . . . . . . . . . . . . . . 385

F.1.1 Ceiling Insulation Retrofits . . . . . . . . . . . . . 386

F.1.2 Exterior Wall Insulation Retrofits . . . . . . . . . . . . 387

F.1.3 Basement Insulation Retrofits . . . . . . . . . . . . . . . 388 
F.1.4 Window Retrofits . . . . . . . . . . . . . . . . . 389

F.2 HRV Retrofit Parameters . . . . . . . . . . . . . . . . . 389

Appendix G Modelling Methodologies of Minor Community-scale System Components 391

G.1 District Heating Circulation Pump . . . . . . . . . . . . . . . 391

G.2 Back-up Boiler . . . . . . . . . . . . . . . . . . . . . 394

Appendix H Microturbine Performance Curves and Thermal Load

Following Control 395

H.1 Microturbine Performance Curves . . . . . . . . . . . . . . . . 395

H.1.1 Electrical Power Modifier Curve . . . . . . . . . . . . . . 396

H.1.2 Electrical Efficiency of the Microturbine . . . . . . . . . 397

H.1.3 Exhaust Gas Flow Rate of the Microturbine . . . . . . . . 398

H.1.4 Exhaust Gas Temperature of the Microturbine . . . . . . . . 399

H.2 Microturbine Thermal Following Control . . . . . . . . . . . . 400

Appendix I Procedure for Allocation of Solar Collectors on Eligible

$\begin{array}{ll}\text { Surfaces } & 403\end{array}$

Appendix J Description of A\&L Model Inputs 406

J.1 GSS Activity Codes . . . . . . . . . . . . . . . . . . . 406

J.2 Estimated Appliance Inputs . . . . . . . . . . . . . . . . 406

Appendix K Transmission Connected Generation in Ontario 409

K.1 Data Tables . . . . . . . . . . . . . . . . . . . . . . . . . . . . 409

K.2 References . . . . . . . . . . . . . . . . . . . . . 411

Appendix L Comparison of Measured and Modelled Aggregate Whole-Dwelling Electrical Demands 413 


\section{List of Tables}

2.1 Summary of residential building envelope upgrades from Guler et al.

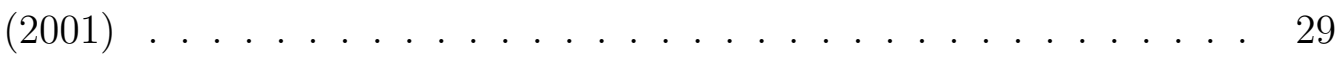

2.2 Summary of other CHREM retrofit studies . . . . . . . . . . 31

2.3 Now House Windsor 5 Retrofit Measures . . . . . . . . . . . . . . 35

2.4 Efficacy of Now House Windsor 5 retrofits for reducing annual fuel

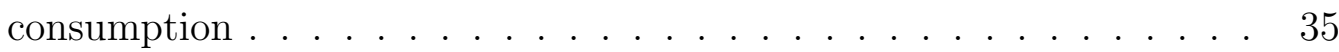

3.1 Ceiling insulation retrofit levels considered . . . . . . . . . . . 61

3.2 Ceiling insulation thermophysical properties . . . . . . . . . . 62

3.3 Exterior wall insulation retrofit levels considered . . . . . . . . . . 64

3.4 Exterior wall retrofit layers thermophysical properties . . . . . . . . 65

3.5 Basement insulation retrofit levels considered . . . . . . . . . . . 66

3.6 Retrofit glazing systems centre-of-glass performance metrics _ . . . 70

3.7 Four-digit CHREM window identifier code, adapted from Nikoofard et al. (2013) . . . . . . . . . . . . . . . . . . . . . . 71

3.8 Ground heat exchanger model parameters, adapted from Kummert

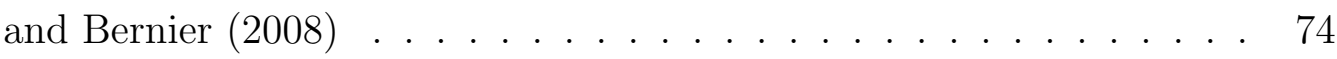

3.9 Retrofit heat pump hot water tank model inputs . . . . . . . . . 75

3.10 Energy Efficiency Database subset retrofit options and sample sizes . 77

3.11 Number of storey descriptors in database . . . . . . . . . . . 81

3.12 ANN regression analysis for determining $\triangle A C H_{50}$ for ceiling insulation retrofits . . . . . . . . . . . . . . . . . 82

$3.13 \triangle \mathrm{ACH}_{50}$ for ceiling insulation retrofits in Québec dwellings, by dwelling vintage . . . . . . . . . . . . . . . 83

xiv 
3.14 Comparison of annual space heating and cooling demand estimates for the case study dwelling including and excluding airtightness effects 88

3.15 Comparison of PPD estimates for the case study dwelling considering and neglecting airtightness increases . . . . . . . . . . . . . . . . 89

3.16 General characteristics of the case study communities . . . . . . . . . 96

4.1 ETC model parameters for Type 538 . . . . . . . . . . . . . . . . . . 111

4.2 PV model parameters for Type 194 . . . . . . . . . . . . . . . . 117

4.3 TES model parameters for Type 534 . . . . . . . . . . . . . . . . 126

4.4 Model parameters for the Capstone microturbines . . . . . . . . . . . 133

5.1 Number of 24-hour diaries from the GSS 2010 . . . . . . . . . . . . . 167

5.2 Cold appliance inputs . . . . . . . . . . . . . . . . . . . . . 174

5.3 Average annual energy consumption percentage errors . . . . . . . . . 177

6.1 Particle Swarm Algorithm Parameters . . . . . . . . . . . . . . . . . 202

6.2 Summary of dwelling-scale retrofit capital costs . . . . . . . . . . . . 208

6.3 Summary of community-scale retrofit capital costs . . . . . . . . . . . 209

6.4 Summary of community-scale retrofit annual O\&M costs . . . . . . . 210

6.52016 Ontario natural gas tiered rates . . . . . . . . . . . . . 211

6.62016 tiered electricity rates . . . . . . . . . . . . . . . . . 212

6.7 Assumed service life of retrofit generation technologies . . . . . . . . 213

6.8 Independent variables varied by the optimization algorithm . . . . . . 215

6.92016 shares of annual electricity generation by fuel type and province 222

6.10 Ontario natural gas-fired generator performance and emissions characteristics . . . . . . . . . . . . . . . . . . . 224

6.112016 shares of annual Ontario natural gas-fired generation by plant type224

6.12 Summary of derived annual average primary energy factors . . . . . . 226

6.132016 annual average EIF values for electricity generation . . . . . . . 232

7.1 Community annual secondary energy use and emissions intensities . . 237

7.2 Summary of near net-zero DH system retrofit measures applied to the Toronto 1946-1960 community . . . . . . . . . . . . . . . . . . . . . . 240

7.3 Summary of the annual energy and economic performance of the near net-zero DH system retrofit applied to the Toronto 1946-1960 community243 
7.4 Summary of the annual technology performance of the near net-zero DH system retrofit applied to the Toronto 1946-1960 community . . . 248

7.5 Summary of the annual emissions performance of the near net-zero DH system retrofit applied to the Toronto 1946-1960 community . . . 250

7.6 Summary of the annual load matching and grid interaction performance of the near net-zero DH system retrofit applied to the Toronto 1946-1960 community . . . . . . . . . . . . . . . . . . 251

7.7 Summary of near net-zero DH system retrofit measures applied to the Toronto 1981-1990 community . . . . . . . . . . . . . . . . . . 253

7.8 Summary of the annual energy and economic performance of the near net-zero DH system retrofit applied to the Toronto 1981-1990 community256

7.9 Summary of the annual technology performance of the near net-zero DH system retrofit applied to the Toronto 1981-1990 community . . . 260

7.10 Summary of the annual emissions performance of the near net-zero DH system retrofit applied to the Toronto 1981-1990 community . . . 261

7.11 Summary of the annual load matching and grid interaction performance of the near net-zero DH system retrofit applied to the Toronto 1981-1990 community . . . . . . . . . . . . . . . . . . 262

7.12 Summary of near net-zero microturbine system retrofit measures applied to the Toronto 1981-1990 community . . . . . . . . . . . . 268

7.13 Summary of the annual energy and economic performance of the near net-zero microturbine system retrofit applied to the Toronto 1981-1990 community . . . . . . . . . . . . . . . . . . 270

7.14 Summary of the annual technology performance of the near net-zero microturbine system retrofit applied to the Toronto 1981-1990 community . . . . . . . . . . . . . . . . . . . 272

7.15 Summary of the annual emissions performance of the near net-zero microturbine system retrofit applied to the Toronto 1981-1990 community . . . . . . . . . . . . . . . . . . . . . 273 
7.16 Summary of the annual load matching and grid interaction performance of the near net-zero microturbine system retrofit applied to the Toronto 1981-1990 community . . . . . . . . . . . . . . . . . . 274

7.17 Summary of near net-zero system retrofit measures applied to the Montréal 1981-1990 community . . . . . . . . . . . . . . . . . . . 279

7.18 Comparison of first and last generation minimum solutions for the MT 81-90 net-zero community . . . . . . . . . . . . . . . . 280

7.19 Summary of the annual energy and economic performance of near net-zero system retrofit applied to the Montréal 1981-1990 community 282

7.20 Summary of the annual emissions performance of the near net-zero system retrofit applied to the Montréal 1981-1990 community . . . 284

7.21 Summary of the annual load matching and grid interaction performance of the near net-zero system retrofit applied to the Montréal 1981-1990 community . . . . . . . . . . . . . . . . . . . . 285

7.22 Summary of cost-optimal net-zero system retrofit measures applied to the Toronto 1981-1990 community . . . . . . . . . . . . . . . . . . 288

7.23 Summary of the annual energy and economic performance of the costoptimal net-zero system retrofit applied to the Toronto 1981-1990 community . . . . . . . . . . . . . . . . . . . 290

7.24 Summary of the annual technology performance of the cost-optimal net-zero system retrofit applied to the Toronto 1981-1990 community

7.25 Summary of the annual load matching and grid interaction performance of the cost-optimal net-zero system retrofit applied to the Toronto 1981-1990 community . . . . . . . . . . . . . . . . 293

7.26 Summary of the annual emissions performance of the cost-optimal net-zero system retrofit applied to the Toronto 1981-1990 community 295

B.1 Model parameters for Canadian Solar CS54-200M . . . . . . . . . . . 365

B.2 Numerical results of the PV tilt study . . . . . . . . . . . . . . 366

B.3 Numerical results of the flat-plate collector tilt study . . . . . . . . . 368

B.4 Results of the solar thermal collector array configuration sensitivity study with 15 nodes per collector . . . . . . . . . . . . . 371 
B.5 Results of the solar thermal collector array configuration sensitivity study with 1 node per collector . . . . . . . . . . . . . . . . 373

F.1 Percent decrease of $A C H_{50}$ for ceiling insulation retrofits in Ontario dwellings, by dwelling vintage . . . . . . . . . . . . . . . . . . . . 386

F.2 Percent decrease of $A C H_{50}$ for ceiling insulation retrofits in Québec dwellings, by dwelling vintage . . . . . . . . . . . . . . . . 386

F.3 Percent decrease of $A C H_{50}$ for exterior wall insulation retrofits in Ontario dwellings, by dwelling vintage . . . . . . . . . . . . . 387

F.4 Percent decrease of $A C H_{50}$ for exterior wall insulation retrofits in Québec dwellings, by dwelling vintage . . . . . . . . . . . . 387

F.5 Percent decrease of $\mathrm{ACH}_{50}$ for basement insulation retrofits in Ontario dwellings, by dwelling vintage . . . . . . . . . . . . . . . . . . 388

F.6 Percent decrease of $A C H_{50}$ for basement insulation retrofits in Québec dwellings, by dwelling vintage . . . . . . . . . . . . . . . . . 388

F.7 Percent decrease of $A C H_{50}$ for window retrofits in Ontario dwellings, by dwelling vintage . . . . . . . . . . . . . . . . . . . . . . 389

F.8 Percent decrease of $A C H_{50}$ for window retrofits in Québec dwellings, by dwelling vintage . . . . . . . . . . . . . . . . . . . . . 389

F.9 HRV model parameters, derived from HVI (2017) . . . . . . . . . . . 390

H.1 Coefficients of the microturbine electrical power modifier curve . . . . 397

H.2 Coefficients of the microturbine electrical efficiency-temperature modifier curve . . . . . . . . . . . . . . . . . . . . . . . . . . . . . . . . 398

H.3 Coefficients of the microturbine electrical efficiency modifier curve . . 398

H.4 Coefficients of the microturbine exhaust air flow rate-temperature curve399

H.5 Coefficients of the microturbine exhaust air flow rate-PLR curve . . . 399

H.6 Coefficients of the microturbine exhaust air temperature-temperature curve . . . . . . . . . . . . . . . . . . 4400

H.7 Coefficients of the microturbine exhaust air temperature-PLR curve . 400

J.1 GSS 2010 activity codes associated with each activity represented in the A\&L model . . . . . . . . . . . . . . . . . . . . . . . . . . 407

J.2 Appliance inputs . . . . . . . . . . . . . . . . . . 408 
K.1 2016 annual output of Ontario gas generators without CHP . . . . . 410

K.2 2016 annual output of Ontario gas generators with CHP . . . . . . 411

L.1 Average daily whole-dwelling electrical demand and metadata of the Windsor smart-meter electrical demand measurements from Bas-

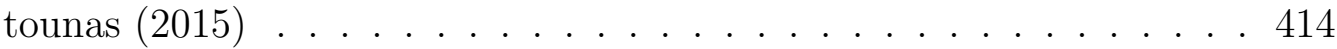

L.2 Comparison of measured and modelled peak and baseload aggregate electrical hourly demands . . . . . . . . . . . . . . . . 4 417 


\section{List of Figures}

1.12014 Canadian sectors energy use and emissions . . . . . . . . . . 2

1.22014 Canadian residential sector secondary energy use . . . . . . . . . 3

1.32011 Canadian occupied dwelling vintages . . . . . . . . . . . 4

1.4 May $11^{\text {th }}, 2017$ Ontario power generation . . . . . . . . . . . . 8

2.1 Classification hierarchy of residential energy sector modelling . . . . . 19

2.2 Simple vertical borehole GSHP system . . . . . . . . . . . . . . . . 39

2.3 Cross-section of heat pipe evacuated collector . . . . . . . . . . . . . 42

2.4 Cross-section of PV silicon cell . . . . . . . . . . . . . . . . . . 44

2.5 Recuperated Brayton cycle . . . . . . . . . . . . . . 45

3.1 ESP-r discretization of an external opaque wall . . . . . . . . . . 56

3.2 Roof geometries considered in CHREM . . . . . . . . . . . . . . 60

3.3 Typical CHREM ceiling multi-layer construction with retrofit insulation 61

3.4 Exterior wall insulation retrofit . . . . . . . . . . . . . 63

3.5 Typical CHREM exterior wall assemblies and retrofit insulation placement . . . . . . . . . . . . . . . . . . . 64

3.6 Example of BASESIMP foundation configurations . . . . . . . . . . 67

3.7 Multi-layer feed-forward artificial neural network . . . . . . . . . . . . 79

3.8 Two-storey 1946-1960 Toronto single-detached dwelling rendered in ESP-r . . . . . . . . . . . . . . . . 86

3.9 Changes in annual dwelling energy demands due to envelope retrofits, with and without considering airtightness . . . . . . . . . . . . 87

3.10 Distributions of single-detached dwelling vintages . . . . . . . . . . . 94

4.1 TRNSYS type and networking . . . . . . . . . . . . . . . . 100 
4.2 TRNSYS solution method . . . . . . . . . . . . . . . . . . 101

4.3 Schematic of the community thermal energy network modelled in TRNSYS . . . . . . . . . . . . . . . . . . . . 103

4.4 Schematic of the community electrical network modelled in TRNSYS 106

4.5 Solar thermal loop . . . . . . . . . . . . . . . . . . . 108

4.6 TRNSYS Type 2 control logic . . . . . . . . . . . . . . . . . . 109

4.7 Three-dimensional renderings of CSDDRD dwellings . . . . . . . . . . 113

4.8 Solar orientation angles . . . . . . . . . . . . . . . . . . . 114

4.9 Equivalent PV circuit . . . . . . . . . . . . . . . . . . . . . 115

$4.10 \mathrm{PV}$ packing on triangular roof roof surfaces . . . . . . . . . . . . 121

4.11 Roof-mounted ETC system ． . . . . . . . . . . . . . . . . . . 122

4.12 Solar collector dimensions . . . . . . . . . . . . . . . . . . . . . . . . 122

4.13 One-dimensional discretization of a stratified tank . . . . . . . . . 124

4.14 Tank node control volume energy balance . . . . . . . . . . . . . . 125

4.15 Port locations of the community TES system . . . . . . . . . . . 129

4.16 Flow schematic of the HRM model . . . . . . . . . . . . . . 135

4.17 District heating loop . . . . . . . . . . . . . . . . . . . . . 141

4.18 District heating outdoor reset curve . . . . . . . . . . . . . . . 144

5.1 Normalized complex appliance cycle profiles . . . . . . . . . . . . 171

5.2 Distribution of annual appliance and lighting load parameters for the measured and modelled sets . . . . . . . . . . . . . . . . 179

5.3 Annual mean daily demand profiles for all 22 demand profiles . . . . 181

5.4 Weekend seasonal mean daily demand profiles for all 22 demand profiles 183

5.5 Overall monthly mean daily AL demand . . . . . . . . . . . . . . . 184

5.6 Distribution of weekday daily AL demands . . . . . . . . . . . . 185

5.7 Distribution of measured and modelled weekday and weekend daily load factors . . . . . . . . . . . . . . . . . . . 187

5.8 Weekday and weekend daily coincidence factors _ . . . . . . . . . . 189

5.9 Comparison of annual mean daily weekday demand profiles with and without baseload input . . . . . . . . . . . . . . . . . 191

6.1 Simulation framework and data exchange between models . . . . . . . 199 
6.2 Simplified energy flow from fuel source to electricity transmission system219

6.3 Simplified energy flow from transmission system to consumer . . . . . 220

7.1 Base communities annual secondary energy consumption intensities . 236

7.2 Annual thermal energy balance of the near net-zero retrofits for the Toronto 1946-1960 community . . . . . . . . . . . . . . . 246

7.3 Annual electrical energy balance of the near net-zero retrofits for the Toronto 1946-1960 community . . . . . . . . . . . . . . . . 247

7.4 Distribution of eligible roof surface area by orientation for the Toronto case study communities . . . . . . . . . . . . . . . . . 254

7.5 Annual thermal energy balance of the near net-zero retrofits for the Toronto 1981-1990 community . . . . . . . . . . . . . . . . . 258

7.6 Annual electrical energy balance of the near net-zero retrofits for the Toronto 1981-1990 community . . . . . . . . . . . . . . . . . 259

7.7 Utility of incident solar over gross collector area . . . . . . . . . 266

7.8 Annual energy balance of the near source net-zero microturbine retrofit for the Toronto 1981-1990 community . . . . . . . . . . . 269

7.9 Annual mean daily electrical demand and on-site generation profiles for the 1981-1990 Toronto community . . . . . . . . . . . . 276

7.10 Annual energy balance of the near net-zero retrofit for the Montréal 1981-1990 community . . . . . . . . . . . . . . . . . . . 283

7.11 Annual mean daily electrical demand and on-site generation profiles for the 1981-1990 Montréal community . . . . . . . . . . . . . 286

7.12 Annual energy balance of the cost-optimal net-zero retrofit for the Toronto 1981-1990 community . . . . . . . . . . . . . . . . . . 291

7.13 Increase in $f_{l c, e}$ with respect to south-biased PV collectors mounted in the retrofit Toronto 1981-1990 community . . . . . . . . . . . . 294

B.1 4 parameter PV cell equivalent circuit . . . . . . . . . . . . . . . . 364

B.2 Annual PV module electrical energy production versus module tilt angle365

B.3 One-dimensional discretization of a solar thermal collector . . . . . . 367

B.4 Annual flate-plate collector useful energy gain versus module tilt . . . 368

B.5 Solar thermal collector array configurations considered . . . . . . . 370 
B.6 Variation of collector annual useful gain with collector discretization . 372

C.1 BASESIMP foundation configuration retrofit mapping rules . . . . . 376

C.2 BASESIMP foundation configuration retrofit mapping rules, cont'd . 377

C.3 BASESIMP foundation configuration retrofit mapping rules, cont'd . 378

D.1 DHW load-duration curves for the aggregate demand of 50 Windsor dwellings . . . . . . . . . . . . . . . . . . . . . 380

E.1 Configurations of the retrofit glazing systems . . . . . . . . . . . . . . 382

E.2 Optical properties of the retrofit glazing systems . . . . . . . . . . . . 384

G.1 DH system boiler efficiency curves . . . . . . . . . . . . . . . . . 394

H.1 Thermal load-duration curve for the 1981-1990 Toronto community . 401

I.1 Flowchart for solar collector allocation in existing communities . . . . 405

L.1 Distributions of measured and modelled average daily whole-dwelling electrical demand intensities . . . . . . . . . . . . . . . . . . . . 415

L.2 Hourly electrical load-duration curves for the aggregate demand of 10 dwellings . . . . . . . . . . . . . . . . . . . . . 416 


\section{Nomenclature}

\section{Symbols}

\begin{tabular}{|c|c|}
\hline$A$ & Area $\left[\mathrm{m}^{2}\right]$ \\
\hline$B F$ & Coil bypass factor [-] \\
\hline$C_{0}$ & Leakage coefficient $\left[\mathrm{m}^{3} / \mathrm{s} \cdot \mathrm{Pa}^{n}\right]$ \\
\hline$C_{\text {appl,calibrate }}$ & Appliance calibration scalar [-] \\
\hline$C_{\text {coll }}$ & Collector capacitance $[\mathrm{kJ} / \mathrm{K}]$ \\
\hline$C_{\text {coll,bias }}$ & Collector type bias [-] \\
\hline$C_{i, a p p l}$ & Scalar for appliance $i[-]$ \\
\hline$C_{\text {light,calibrate }}$ & Lighting calibration scalar [-] \\
\hline$C_{\text {orient }, \text { bias }}$ & Collector orientation bias [-] \\
\hline$c_{p}$ & Specific heat for constant pressure $[\mathrm{J} / \mathrm{kg} \cdot \mathrm{K}]$ \\
\hline$D$ & Currency amount [CAD] \\
\hline$E_{m p p}$ & Voltage at MPP and STC [V] \\
\hline$E_{o c}$ & Open-circuit voltage at STC $[\mathrm{V}]$ \\
\hline$E I F_{A}$ & Average annual overall EIF $\left[\mathrm{g} \mathrm{CO}_{2 \mathrm{e}} / \mathrm{kWh}_{\mathrm{e}}\right.$ ] \\
\hline$E I F_{M}$ & Average annual marginal EIF $\left[\mathrm{g} \mathrm{CO}_{2 \mathrm{e}} / \mathrm{kWh}_{\mathrm{e}}\right.$ ] \\
\hline$F_{\text {loss }}$ & Fraction of DH system losses [-] \\
\hline$F_{\text {penalty }}$ & Penalty function $[\mathrm{CAD}]$ \\
\hline$f$ & Inflation [-] \\
\hline$f_{l c}$ & Load cover factor [-] \\
\hline$f_{\text {load }}$ & Load factor $[-]$ \\
\hline$f_{\text {coinc }}$ & Coincidence factor [-] \\
\hline$f_{\text {grid }, i}$ & Grid interaction factor [-] \\
\hline
\end{tabular}


$G_{T} \quad$ Total solar radiation incident on the collector $\left[\mathrm{W} / \mathrm{m}^{2}\right]$

GM Generation multiple [-]

$H \quad$ Height $[\mathrm{m}]$

$I_{D} \quad$ Diode reverse saturation current $[\mathrm{A}]$

$I_{L} \quad$ Light current $[\mathrm{A}]$

$I_{m p p} \quad$ Current at MPP and STC [A]

$I_{s c} \quad$ Short-circuit current at STC $[\mathrm{A}]$

$i_{G} \quad$ Current generation number [-]

$k \quad$ Thermal conductivity $[\mathrm{W} / \mathrm{m} \cdot \mathrm{K}]$

$L C C_{N P V} \quad$ NPV of incremental life cycle cost [2017 CAD]

$L O L P_{b} \quad$ Loss of load probability [\%]

$l \quad$ Thickness [m]

$M \quad$ Mass [g]

$M A R R_{A} \quad$ Actual minimum acceptable rate of return [-]

$M A R R_{R} \quad$ Real minimum acceptable rate of return [-]

$\dot{m} \quad$ Mass flow rate $[\mathrm{kg} / \mathrm{s}]$

$N \quad$ Integer amount [-]

$n \quad$ building leakage exponent [-]

$P \quad$ Pressure $[\mathrm{Pa}]$

$Q \quad$ Energy $[\mathrm{J}]$

$\dot{Q} \quad$ Energy transfer rate $[\mathrm{W}]$

$\bar{Q} \quad$ Mean energy transfer rate $[\mathrm{W}]$

$R_{s} \quad$ Series resistance $[\Omega]$

$R_{s h} \quad$ Shunt resistance $[\Omega]$

RSI Thermal resistance $\left[\mathrm{m}^{2} \cdot \mathrm{K} / \mathrm{W}\right]$

$r \quad$ Radius [m]

T Temperature $\left[{ }^{\circ} \mathrm{C}\right]$

$t \quad$ Time [s]

$U \quad$ Thermal conductance $\left[\mathrm{W} / \mathrm{m}^{2} \cdot \mathrm{K}\right]$

$U A \quad$ Overall heat transfer coefficient $[\mathrm{W} / \mathrm{K}]$

UEC Unit energy consumption [] 


\begin{tabular}{|c|c|}
\hline$V$ & Volume $\left[\mathrm{m}^{3}\right]$ \\
\hline$\dot{V}$ & Volumetric flow rate $\left[\mathrm{m}^{3} / \mathrm{s}\right]$ \\
\hline$w$ & Scalar weight $[-]$ \\
\hline \multicolumn{2}{|r|}{ Greek Letters } \\
\hline$\alpha$ & Angle $\left[^{\circ}\right]$ \\
\hline$\alpha_{P V}$ & Modified idealty factor [-] \\
\hline$\beta$ & Angle $\left[^{\circ}\right]$ \\
\hline$\gamma$ & Angle $\left[^{\circ}\right]$ or fractional quantity [-] \\
\hline$\varepsilon$ & Heat exchanger effectiveness [-] \\
\hline$\zeta_{a}$ & Estimated error $[\%]$ \\
\hline$\eta$ & Efficiency $[\%]$ \\
\hline$\theta$ & Angle $\left[^{\circ}\right]$ \\
\hline$\rho$ & Density $\left[\mathrm{kg} / \mathrm{m}^{3}\right]$ \\
\hline$\tau_{v i s}$ & Visible light transmittance [-] \\
\hline \multicolumn{2}{|r|}{ Subscripts } \\
\hline act & Actual \\
\hline$a m b$ & Ambient \\
\hline ancil & Ancillary \\
\hline ann & Annual \\
\hline appl & Appliance \\
\hline $\mathrm{CHP}$ & Combined heat and power \\
\hline coll & Collector \\
\hline$c o m b$ & Combustion \\
\hline $\operatorname{conv}$ & Conversion \\
\hline cross & Cross-section \\
\hline$D H$ & District heating \\
\hline$D H W$ & Domestic hot water \\
\hline dwell & Dwelling \\
\hline elec & Electric \\
\hline elev & Elevation \\
\hline exh & Exhaust \\
\hline
\end{tabular}

xxvi 


\begin{tabular}{ll} 
exp & Export \\
$F L$ & Full load \\
$G$ & Ground or Generation \\
gen & Power Generation \\
$H$ & High \\
$h x$ & Heat exchanger \\
imp & Import \\
inf & Infiltration \\
ins & insulation \\
L & Low \\
leak & Leakage \\
lim & Limit \\
nom & Nominal \\
NPV & Net present value \\
O\&M & Operation and maintenance \\
$p$ & Particle \\
opt & Optimal \\
ref & Reference \\
std.dev & Standard deviation \\
sup & Supply \\
surf & Surface \\
TES & Thermal energy storage \\
th & Thermal \\
theo & Theoretical \\
turb & Turbine \\
vent & Ventilation \\
\hline & \\
ACH & Air changes per hour \\
AIM-2 & Alberta infiltration model \\
AL & Appliance and lighting \\
ANN & Artificial neural network \\
& \\
& \\
& \\
\hline
\end{tabular}


$\mathrm{BIPV} / \mathrm{T} \quad$ Building integrated photovoltaic/thermal

BPS Building performance simulation

CDA Conditional demand analysis

CFL Compact fluorescent lamp

CHP Combined heat and power

CHREM Canadian Hybrid Residential End-use Energy and GHG Emissions Model

COP Coefficient of performance

CREEM Canadian Residential Energy End-use Model

CREST Centre for Renewable Energy Systems Technology

CSDDRD Canadian Single-Detached and Double/Row Housing Database

DG Distributed generation

DH district heating

DHW Domestic hot water

DLSC Drake Landing Solar Community

DOE Department of Energy

DR Double/row

EGHD EnerGuide for Houses Database

EIF Emission intensity factor

ESP-r Environmental Systems Performance: Research Version

ETC Evacuated tube collector

FIT Feed-in tariff

FPC Flat plate collector

GHG Greenhouse gas

GHX Ground heat exchanger

GIS Geographic information systems

GSHP Ground-source heat pump

GWP Global warming potential

HRM Heat recovery module

HVAC Heating, ventilation, and air conditioning

IEA International Energy Agency

IPCC Intergovernmental Panel on Climate Change 
LBNL Lawrence Berkeley National Laboratory

LCC Life cycle costs

LDC Local distribution company

LED Light-emitting diode

MARR Minimum acceptable rate of return

MLC Multi-layer construction

MPP Maximum power point

MSE Mean squared error

MT Montréal

net-ZEB Net-zero energy building

net-ZEC Net-zero energy community

NPV Net present value

O\&M Operation and maintenance

PEF Primary energy factor

PEMFC Proton-exchange membrane fuel cell

PLR Part-load ratio

PMV Predicted mean vote

PPD Predicted percentage of dissatisfied

PSO Particle Swarm Optimization

PV Photovoltaic

REUM Canadian Residential End-Use Model

SD Single-detached

SHEU Survey of Household Energy Use

SHGC Solar heat gain coefficient

STC Standard testing conditions

T\&D Transmission and distribution

TEDI Thermal energy demand intensity

TES Thermal energy storage

TO Toronto

TOU Time-of-use

TPM Transition probability matrix

xxix 
WWR Window-to-wall ratio

XPS Extruded polystyrene 


\section{Chapter 1}

\section{Introduction}

\subsection{Motivation}

While some may disagree, there continues to be a growing consensus among climate scientists and policy makers that climate change is real and is largely anthropogenic. The 2013 Intergovernmental Panel on Climate Change (IPCC) Working Group 1 report "The Physical Science Basis" (IPCC, 2013) stated, with 95\% confidence, that human activity is the significant cause of observed global warming trends since the mid- $20^{\text {th }}$ century. The principal driver for climate change and global warming is the increased concentration of $\mathrm{CO}_{2}$ in the atmosphere that has been observed since 1750 (IPCC, 2013). The implications of climate change are complex and diverse. Some observed changes that have been attributed to climate change include glacial shrinkage across western and northern North America, and increase of wildfire activity in subartic conifer forests and tundra (IPCC, 2014). Key risks associated with climate change through the remainder of the the $21^{\text {st }}$ century in North America include heatrelated human mortality, flooding in urban areas along coastal and riverine areas, and ecological and economical damages from wildfire activity (IPCC, 2014). Even if $\mathrm{CO}_{2}$ emissions ceased, the impacts of climate change are anticipated to persist for several centuries (IPCC, 2013).

In 2013 Canada contributed 1.6\% of global emitted greenhouse gas (GHG), or 738 Mt of carbon dioxide equivalent $\left(\mathrm{CO}_{2 \mathrm{e}}\right)$, placing it within the top ten GHG emitting 
regions in the world (ECCC, 2017a). On a per capita basis, Canadians produced 4.12 metric tons of carbon per person in 2014, ranking $16^{\text {th }}$ out of 220 nations behind the United States, Australia, and Quatar (Boden et al., 2017). Following the Paris Agreement, Canadian First Ministers met in March 2016 and agreed to take action to reduce Canada's GHG emissions by 30\% relative to 2005 levels. To move toward this goal, Environment and Climate Change Canada published the Pan-Canadian Framework on Clean Growth and Climate Change (ECCC, 2016). This document was developed in partnership with the provinces ${ }^{1}$ and territories.

One of the actions identified in the framework is addressing emissions related to the built environment. One of the approaches to address building stock emissions was to retrofit existing buildings to improve energy efficiency. One promising segment of the existing building stock for retrofit is the residential sector. In 2014, the residential sector accounted for $17.1 \%$ of secondary energy ${ }^{2}$ use, corresponding to $15.6 \%$ of $\mathrm{CO}_{2 \mathrm{e}}$ emissions $^{3}$ (OEE, 2017), shown in Figure 1.1.

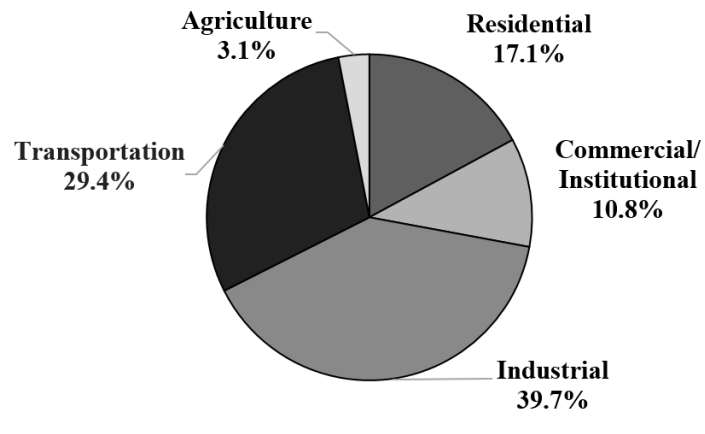

(a) Secondary energy use

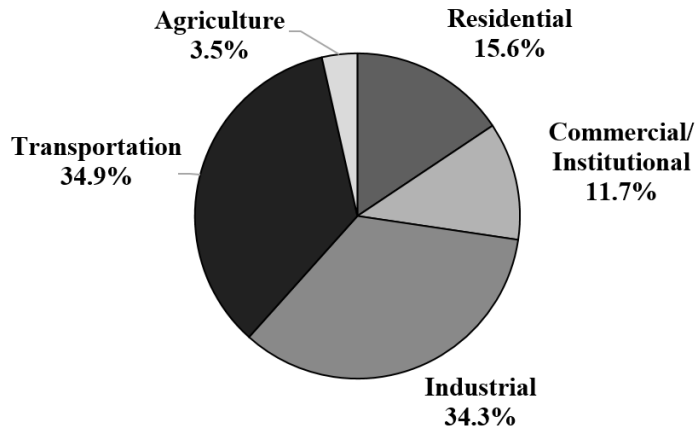

(b) $\mathrm{CO}_{2 \mathrm{e}}$ emissions

Figure 1.1: 2014 Canadian sectors energy use and emissions, data from OEE (2017)

A beneficial characteristic of the residential sector compared to the other sectors in Figure 1.1 is that the energy end-uses of dwellings tend to have little variability

\footnotetext{
${ }^{1}$ At the time of writing Saskatchewan has not adopted the framework

${ }^{2}$ secondary energy is the energy used by the final consumer, excluding exports, self-consumption of energy producers, and non-energy uses (NRCan, 2014a)

3 including emissions from electricity use
} 
within the building stock. Residential energy is generally allocated to space heating and cooling, domestic hot water (DHW) preparation, and appliance and lighting (AL) loads, shown in Figure 1.2. Space heating and DHW preparation is the largest portion, representing $83.1 \%$ of residential end-use energy consumption. Swan (2010) stated that because of the standardized aspect of the sector energy usage, successful strategies and technologies which reduced a specific dwelling's energy consumption will likely have a similar energy savings performance in other dwellings within a geographically similar region.

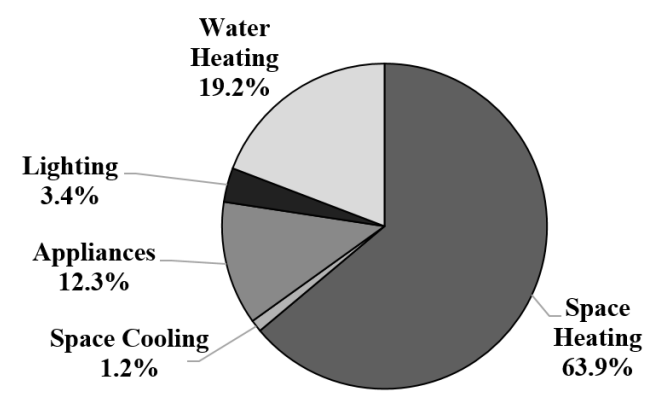

(a) By end-use

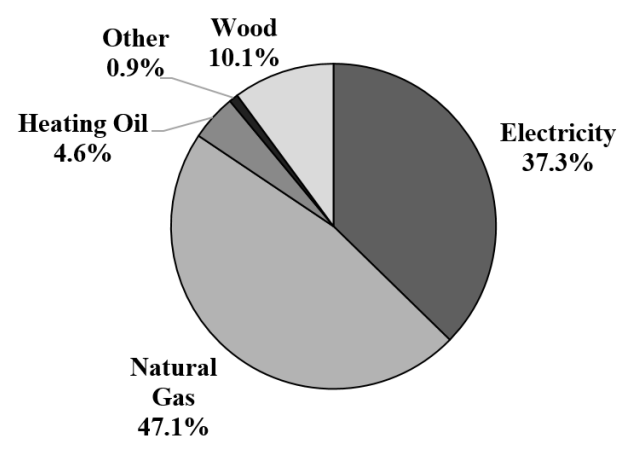

(b) By fuel type

Figure 1.2: 2014 Canadian residential sector secondary energy use, data from OEE (2017)

One potential strategy for reducing residential sector energy consumption is the use of a net-zero energy building (net-ZEB) target. Salom et al. (2011) stated that a net-ZEB may be broadly defined as a "grid-connected building that generates as much energy as it uses over a year." This energy balance is achieved by utilizing renewable energy systems and applying energy conservation and efficiency measures. By requiring a building to "produce as much as it consumes", designers are given incentive to reduce building energy demands in order to minimize energy system size and cost.

Typically, a net-ZEB target is decided upon during the design phase of a new building. However the largest portion of the residential building stock is comprised 
of older dwellings. The amount of new buildings added to the stock in a given year is minimal compared to existing buildings. Figure 1.3 illustrates the vintages of occupied Canadian dwellings in 2011. Vintages bin ranges are defined by changes in the applicable standards and codes (Parekh, 2005). What Figure 1.3 indicates is that $71.6 \%$ of the stock in 2011 was 20 years or older (Statistics Canada, 2011). Between 2001 and 2006 average annual growth rate of dwellings in Canadian metropolitan areas was $7.6 \%$ (CMHC, 2008). Therefore, in order to have a meaningful impact on energy consumption and GHG emissions in the residential sector in the near future, the current stock needs to be addressed.

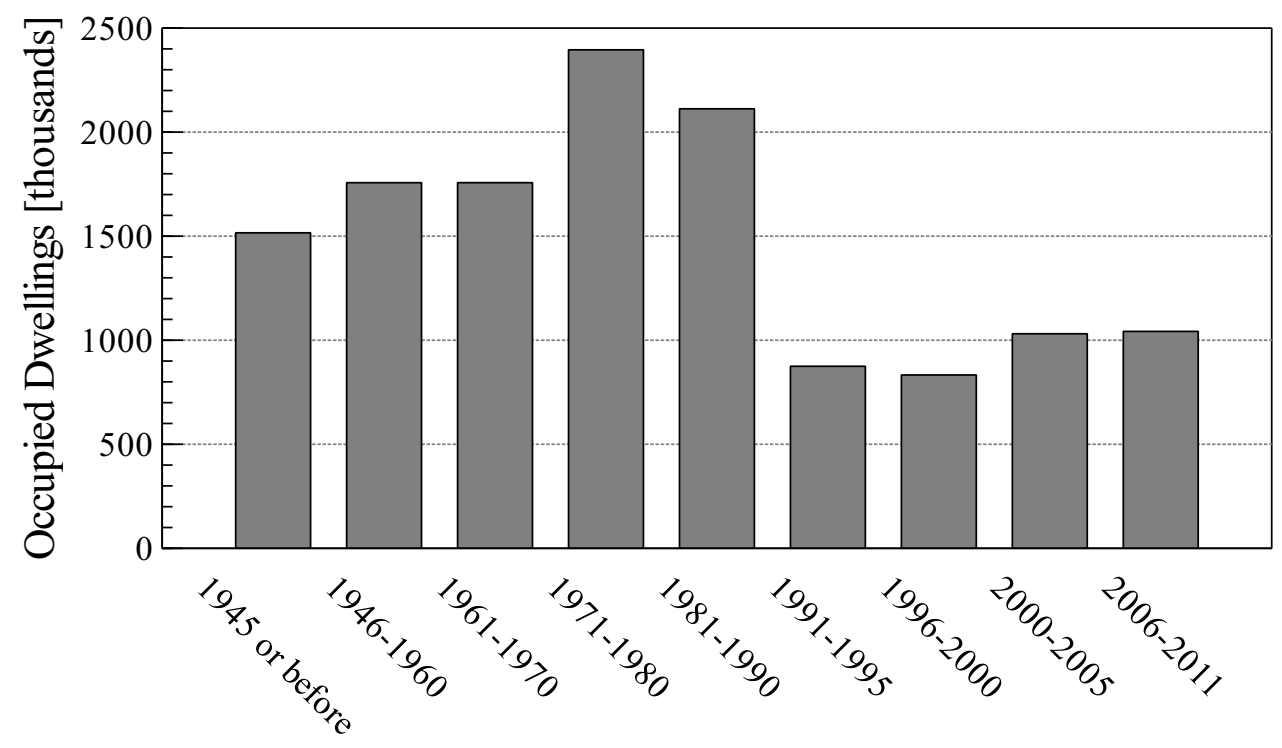

Vintage

Figure 1.3: 2011 Canadian occupied dwelling vintages, data from Statistics Canada (2011)

The concept of a net-zero energy balance however, is not limited to a single building. Sartori et al. (2012) stated that the physical boundary of a net zero balance may also be considered as clusters of buildings, where a synergy exists between the buildings which are not necessarily net-zero by themselves. Authors such as Finkelor et al. (2010) and Managan (2012) also stated that a net-zero target at a 
community-scale may be a more economically viable than single Net-ZEBs. Net-zero energy communities (net-ZEC) would benefit from "economies of scale" in technology procurement and deployment (Managan, 2012). This has been demonstrated in the Windsor 5 and Windsor 95 projects (Now House, 2017). These projects performed energy retrofits, such as efficient $\mathrm{HVAC}^{4}$ equipment, increased dwelling airtightness and insulation, new windows, and solar energy systems, on 5 and 95 60-year old bungalows located in Windsor, Ontario (Gauthier, 2014; Steele, 2013). It was found that the cost per dwelling to apply the retrofits reduced by approximately $47 \%$ when 95 instead of 5 dwellings were considered.

According to Finkelor et al. (2010), there have been few net-ZECs realized in practice compared to net-ZEBs. One example is the Kaupuni Village in Oahu, Hawai'i (NREL, 2012). This community of 19 single-detached dwellings and a community resource centre was found to come within 1\% of its net-zero energy target (Norton et al., 2013). Another is the zHome in Issaquah, Washington (King County, 2017). This is a 10-unit townhouse complex was designed to achieve net-zero energy and use $60 \%$ less water. Over a two year operating period this community produced more electricity then it consumed (MBA, 2015).

In Canada there has been an increased interest in net-zero and low-energy community projects. Work recently began on the West 5 community project in London, Ontario (Sifton, 2017), which is a planned mixed-use community of 2000 residential units $^{5}$, and 32,500 $\mathrm{m}^{2}$ of commercial and office space (CEKAP, 2017a). The objective of this project is to achieve net-zero energy through installation of micro-grid solar photovoltaic (PV) systems, advanced construction methods and materials to reduce building energy demands, and possibly installation of a DH system (CEKAP, 2017a). Another planned net-ZEC is the Zibi Net Zero Community project (Windmill Developments, 2017) located in both Gatineau, Québec and Ottawa, Ontario. This is also going to be a mixed-use community with 1200 residential units, and $16400 \mathrm{~m}^{2}$ of retail and office space. The objective of the project is to achieve net-zero "carbon" by 2020 (CEKAP, 2017b).

\footnotetext{
${ }^{4}$ Heating, ventilation, and air conditioning.

${ }^{5}$ Apartments, townhouses, and condos.
} 
One barrier to the widespread adoption of net-zero buildings and communities in Canada is the country's vast and diverse geography and climate. The implication of this is that one single net-zero "solution" cannot be universally applied across the country. Proof-of-concept studies are useful for exploring net-zero solutions, but face large financial barriers which also limits the variety of technologies and retrofit options that can be considered.

What is required is a robust simulation methodology for designing and analyzing retrofit net-ZEC projects capable of accounting for regional variations of climate, construction practices, and energy supply options. Additionally, such a methodology should be of sufficient complexity and detail in order to estimate the efficacy of energy retrofits at the dwelling-scale, as well as the coupled interaction of these retrofits with the aggregate community energy demand and district energy system performance. This is a non-trivial task. The efficacy of building-scale energy technologies is often calculated using a single building or small set of representative buildings, and energy performance is not considered in the context of a larger cluster of buildings. Conversely district energy performance calculations often use historical statistical or metered data to size and design district energy systems, creating difficulties to estimating the impact of new technologies in the building stock on the aggregate energy demand.

Another barrier to widespread adoption of net-zero is the lack of a formal definition and calculation procedure for determining net-zero. While conceptually simple, implementation in practice and the precise manner in which net-zero is determined is often ambiguous. It is understood that varying the definition of net-zero will influence the design and performance of the project; however, this impact has not been explicitly explored in the literature.

The following section provides background information pertaining to definitions of net-zero found in the literature. Following that is a section which introduces the candidate simulation tools from the literature which were considered in the current work to form the foundation of the simulation methodology for designing and analyzing retrofit net-ZEC projects. This chapter concludes with a statement of the thesis objectives and an overview of the remaining chapters. 


\subsection{Background on Net-Zero Definitions}

Various literature reviews concerned with the definition of net-ZEBs have been conducted, most notably by Marszal et al. (2011) under the framework of the International Energy Agency Solar Heating \& Cooling Programme (IEA-SHC) Task 40 (IEA-SHC, 2014), and Torcellini et al. (2006). Both reviews concluded that despite the popularity of net-ZEBs within the international policy community, there lacked a common definition or understanding of "net-zero". What can generally be said about net-zero is that the term "net" implies the existence of interactions between a building and connected energy infrastructure. It is also understood that energy consumed by a net-ZEB is offset by the export of locally generated energy over some balancing period, typically taken as one year (Marszal et al., 2011). What remains unclear is what energy carriers, such as natural gas or electricity, and what end-uses should be considered when calculating a net-zero balance. There is also a question of whether minimum energy efficiency requirements should be adopted. Marszal et al. (2011) pointed out that commercially used definitions of net-ZEBs may be limited or biased in scope, leading to, for example, potential scenarios where energy inefficient buildings reach net-zero via an over-sized solar PV system.

Torcellini et al. (2006) described four different well-documented definitions of netzero: net-zero site energy, net-zero source energy, net-zero energy costs, and net-zero energy emissions. A site net-ZEB simply consumes as much energy on its building site as it produces on site over the balancing period. This definition was found to be the most generalizable, since the balance is not influenced by local energy prices or the infrastructure energy mix (coal, hydro, etc.), and can be verified relatively easily with on-site measurements. The insensitivity of prices and energy mix may also be considered drawbacks of the definition. Without proper peak energy management, a site net-ZEB may still incur considerable energy costs and GHG emissions if energy is imported during peak price periods. Large volumes of export during off-peak demands may also lead to issues managing the local electrical distribution system.

Source net-ZEB uses a broader scope, where on-site energy production is balanced with imported energy as measured at the source. The challenges of this approach 
are the determination of the mix of source energy used in a local energy grid, the generation conversion efficiencies, and transmission losses. These characteristics not only vary with region, but also with time. The energy mix of a local power grid will vary as peaking load power plants are dispatched and modulated to meet changing energy demands. For example, consider the variation in Ontario power generation shown in Figure 1.4, where gas power plants and hydro are dispatched to meet peak demands. Torcellini et al. (2006) also noted that determining electric generator efficiencies, and transmission and distribution (T\&D) losses is non-trivial, as this data may not always be publicly available.

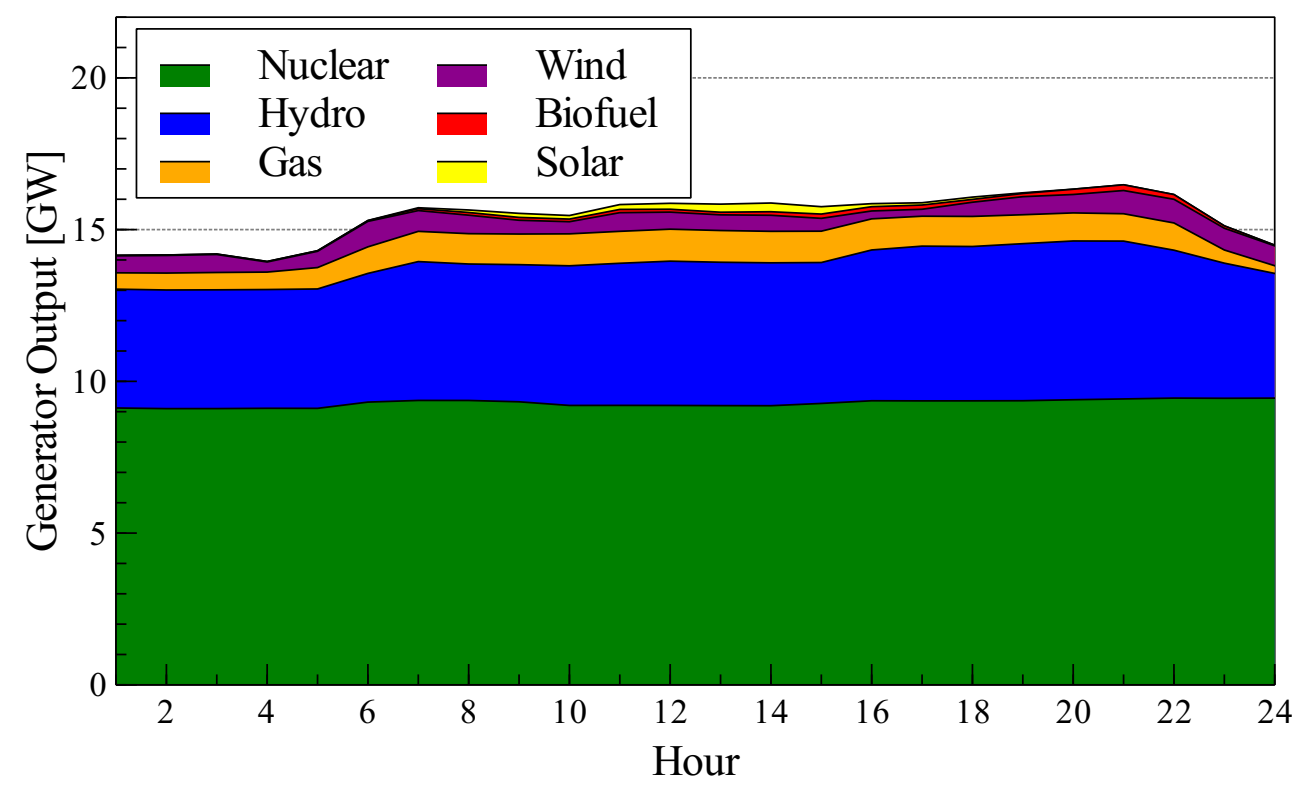

Figure 1.4: May $11^{\text {th }}, 2017$ Ontario power generation, data sourced from IESO $(2017 \mathrm{~b})$

The cost net-ZEB is an economically driven target which seeks to balance the cost of importing energy to the site with the revenue generation from exporting on-site generation. This type of balance is relatively easy to implement and measure, and building owners/operators could verify the performance of the system from utility bills (Torcellini et al., 2006). Torcellini et al. (2006) pointed out that due to varying 
utility costs, a building with consistent energy performance may achieve the cost netZEB one year and not the next. At large scale deployments, Torcellini et al. (2006) states that cost net-ZEBs would limit the financial resources available to utilities needed to maintain their infrastructure, potentially leading to utilities raising fixed and demand charges.

Finally, the emissions net-ZEB balance seeks to produce at least as much emissions-free renewable energy as the building consumes from emissions-emitting sources (Torcellini et al., 2006). Torcellini et al. (2006) argued that under this definition a building connected to a utility using a large portion of low to non-emitting energy sources, such as hydro or nuclear, would benefit from this definition. Any energy imported to the building site from these sources would not have to be offset by on-site renewable generation, reducing system generation capacity requirements. Torcellini et al. (2006) does not explicitly address the issue of differing GHG emissions intensities among energy carriers. For example, one Joule of electricity from coal will have higher associated $\mathrm{CO}_{2 \mathrm{e}}$ emissions compared to natural gas. Additionally this definition suffers from the same challenges as source net-ZEB, where an understanding of the utility dispatch strategies, energy source mix, and conversion and transmission factors is required.

Carlisle et al. (2009) considered net-zero balances at community-scales. Instead of the four net-zero definitions described by Torcellini et al. (2006), Carlisle et al. (2009) proposed a hierarchy of energy supply options to move communities toward net-zero:

1. Reduce on-site energy consumption and increase energy efficiency;

2. Install renewable energy systems on the built environment or unusable brownfields sites;

3. Install renewable energy systems on undeveloped greenfield sites;

4. Import renewable energy produced off-site;

5. Purchase renewable energy credits. 
Carlisle et al. (2009) then defined different classifications of net-ZECs as combinations of the energy supply options, where option one was common to all classifications.

Carlisle et al. (2009) conceded that determining whether a net-ZEC achieved its energy target is non-trivial. Year-to-year climate and community occupancy behaviours will cause under and overshoots of net-zero. If the community is able to produce at least $75 \%$ of its on-site energy demands, then the community may be considered "near" zero (Carlisle et al., 2009). From the perspective of the developer or community leader, a judgement needs to be made concerning what counts when determining if the community has achieved net-zero. These stakeholders play a direct role in the design of the buildings and embedded energy systems, but have less influence on the occupants of the community (Carlisle et al., 2009). They may optionally choose to determine net-zero in terms of aspects of community energy use which they directly control.

For the current work two types of net-zero balances were considered and contrasted: site and source net-zero. Site net-zero was considered due to its widespread adoption in practice and its simplicity. Source net-zero provides a broader view of the energy balance by considering the generation mix of the local electrical infrastructure. It was noted that source net-zero is not widely used due to difficulties in determining electrical infrastructure efficiencies. Several regions in Canada have made data publicly available which would enable estimation of these efficiencies and source net-zero balances. The formalized definitions of net-zero considered in the current work, as well as their calculation methods, are described in Chapter 6 .

\subsection{Research Methods}

\subsubsection{Building Performance Simulation}

The challenge of designing net-ZECs is that the scale of such projects does not lend itself easily to experimental studies, facing both practical and economic barriers. Instead, building performance simulation (BPS) tools are often heavily involved in the design of net-ZEBs to test various design options (Robert and Kummert, 2012). The 
capability and modelling resolution of BPS tools vary, but typical simulation capabilities include energy flows through building envelopes, building interactions with local climate, HVAC system operation and control, building-site fuel consumption, and occupant behaviours. The advantage of BPS tools have over experimental tests is the potential capability to output specific energy flows, such as solar gains through glazing, which allows for in-depth analysis of building system interactions that would be non-trivial to measure in practice.

Numerous BPS tools are available in the literature, each developed with varying degrees of modelling resolution and capabilities. For the current work, it is of interest to simulate retrofits in existing residential buildings in Canada. In order to achieve this objective, a BPS tool is needed that is able to evaluate the efficacy of building envelopes and HVAC systems retrofits on energy performance. Swan et al. (2013) had previously developed the Canadian Hybrid Residential End-use Energy and GHG Emissions Model (CHREM) for evaluating the impact of new residential energy technologies on the residential building stock secondary energy consumption and GHG emissions. This model was adopted for the current work to determine the energy demands of existing communities of dwellings, and the impact of dwellingscale retrofits on energy performance and GHG emissions.

CHREM uses an underlying detailed building simulation engine to calculate the energy consumption of existing dwellings. To represent existing dwellings in this simulation engine, CHREM is coupled with the Canadian Single-Detached and Double/Row Housing Database (CSDDRD) developed by Swan et al. (2009). This database is a subset of the EnerGuide for Houses Database (EGHD) from Natural Resources Canada (NRCan) (Blais et al., 2005), which contained files for over 200,000 single-detached (SD) and double/row (DR) Canadian houses. All data in the EGHD was collected by energy auditors which were accredited by Natural Resources Canada while conducting on-site energy audits, and each record had over 162 information fields pertaining to a dwelling's "location, dimensions, building envelope insulation levels, type of windows and doors, type of heating and hot water systems and their energy efficiencies, energy analysis results, potential recommended upgrades, energy efficiency ratings and so on" (Blais et al., 2005). 
Swan et al. (2013) validated CHREM by comparing residential sector energy consumption and GHG emissions estimates published in the SHEU-03 and the Energy Use Data Handbook from OEE (2013). Values published in the Energy Use Data Handbook were calculated using the Canadian Residential End-Use Model (REUM), which uses aggregate consumption data from Statistics Canada and allocates it to various energy end-uses using housing stock characteristics and estimated appliance unit energy consumption (Swan et al., 2013). Swan et al. (2013) found that the CHREM consistently estimated higher housing stock energy consumption compare to both SHEU-03 and REUM. For total energy consumption CHREM estimates were $11 \%$ and $14 \%$ higher than SHEU-03 and REUM estimates, respectively. Swan et al. (2013) suggested several reasons for the discrepancies between CHREM and other published data including the accuracy of SHEU-03 and REUM, the fact that the CHREM uses a fixed $21{ }^{\circ} \mathrm{C}$ heating setpoint, and the CHREM does not account for periods of non-occupancy. The latter two would cause over-estimation of energy consumption since many residential occupants reduce their heating setpoint during the night to conserve energy, and non-occupancy would reduce AL loads. Swan et al. (2013) stated that these were not considered in the model since there is a lack of reliable data. Base on their comparison of CHREM with SHEU-03 and REUM, Swan et al. (2013) concluded that CHREM was in reasonable agreement.

\subsubsection{Energy System Simulation}

Considering community-scale energy projects in the current work requires a methodology which allows for the evaluation of district or community-scale energy systems. ESP-r is a robust BPS tool, but the scope of ESP-r is largely focused on the individual building-scale. The majority of mechanical and energy transfer system component models contained within ESP-r are typical for building-scale systems. For the current work, the research tool TRNSYS 17 (SEL, 2017) was used to simulate the energy performance of community-scale energy systems. TRNSYS is a commercially available research simulation tool used to analyze the transient response of dynamic energy systems. Initially developed to model solar thermal systems, TRNSYS has evolved 
to include modelling capabilities of other mechanical system components, such as air-source heat pumps and solar PV. TRNSYS uses a modular software structure, where an executive routine interacts with several component models (Klein et al., 1975). The complexity of component models can vary from simple steady-state to multi-dimensional transient systems. Details of the TRNSYS solution methodology are provided later in Chapter 4.

In terms of applicability to the current work, TRNSYS has been used in several district and community-scale energy analyses published in the literature. Both Sibbitt et al. (2012) and Quintana and Kummert (2015) used TRNSYS to simulate the solar thermal system at the Drake Landing Solar Community (DLSC) in Okotoks, Alberta. DLSC is a suburban community of 52 SD homes which achieved over $90 \%$ of its space heating and $50 \%$ of its DHW needs from a solar thermal district heating (DH) system (McDowell and Thorton, 2008; Sibbitt et al., 2012; Wamboldt, 2009). The system is supplied with 2,293 $\mathrm{m}^{2}$ of solar flat plate collectors (FPC) connected to a central borehole thermal energy storage (TES) system.

\subsubsection{Optimization Tools}

Deciding upon combinations of design, technology, and control options for net-zero buildings is a non-trivial task. The built environment is complex with several interacting sub-systems (domains), such as the envelope, HVAC system, etc. When seeking an "optimal" net-zero solution, the various design options need to be considered concurrently (Attia et al., 2013). BPS tools like ESP-r are useful since they consider the building domains in an integrated manner, but a method is needed for exploring the possible design solution space. Typically the solution space is searched to find the optimal point, subject to some set of performance criteria. In BPS optimization studies these criteria, typically referred to as objective functions, are based on energy consumption or economics (Attia et al., 2013).

A point in a solution space may be thought of as optimal if the objective functions are at their global maximums or minimums. In the current study, the economic performance metric life cycle cost (LCC) is used as the single objective function. 
Realization of low-energy buildings in practice relies upon design teams establishing cost-effective energy goals (Hayter et al., 2001). Economic performance criteria are often the principal determinate for viability of projects. LCC methods involve the determination of the cumulative total of implementing, operating, maintaining, and retiring costs of a project (ASHRAE, 2007). These costs are typically expressed as a net present value (NPV), where the costs have been adjusted to consider the time value of money (influenced by factors such as inflation). Another common economic objective function is simple payback period. Unlike LCC, simple payback period ignores both the time value of money and expected service life of equipment (Fraser et al., 2006). ASHRAE (2007) additionally stated that LCC provides a more accurate comprehensive evaluation of different project compared to simple payback. Several building optimization research studies in the literature have used LCC as at least one of the objective functions, such as Wang et al. (2005), Hasan et al. (2008), Tuhus-Dubrow and Krarti (2010), and Bucking (2013).

Locating the optimal point by evaluating every point within a solution space is typically computationally intensive and impractical. Often optimization algorithms are coupled with BPS tools to search for optimal designs. For the current work, the single-objective optimization program GenOpt ${ }^{\circledR}$ (Wetter, 2016) was selected. GenOpt ${ }^{\circledR}$ is an open-source generic optimization tool capable of handling discrete or continuous variables, or both. It is a generic optimization tool, which can be coupled with any simulation program which uses text-based input files. GenOpt ${ }^{\circledR}$ contains a library of single objective optimization algorithms for solving one and multi-dimensional problems, but is limited to single objective optimization problems.

One set of algorithms in GenOpt ${ }^{\circledR}$ are particle swarm optimization (PSO) (Eberhart and Kennedy, 1995). PSO are stochastic algorithms, meaning that random choices are used in seeking out the optimal point in the solution space (Spall, 2003). Conceptually, PSO algorithms are based upon flocks of birds or schools of fish (Wetter, 2016). The "particles" are sets of randomly assigned inputs that are seeded in the optimization search space (Eberhart and Kennedy, 1995; Wetter, 2016). They are also initialized with a random velocity which is used to "fly" them through the solution space (Eberhart and Kennedy, 1995). The number of particles in the space 
is user defined, and the group of particles is typically referred to as the "population". For each "generation", the particles evaluate the objective function for their location in the search space, then update their location and velocity based on a particle update equation. This update equation functions to accelerate the particle toward the "best" point found in the solution space thus far (Eberhart and Kennedy, 1995). PSO algorithms were used in the current work, and are described later in Chapter 6.

\subsection{Thesis Objectives}

For the current work, two major objectives of this thesis were defined. The first is the development of a detailed simulation tool capable of modelling both building and community-scale retrofits for achieving net-zero. CHREM was identified as a candidate tool, but it will be shown later in Chapter 2 that modifications to the model are required to make it suitable for modelling community-scale demands. It was also noted above that CHREM was not developed to model community-scale energy systems. TRNSYS was identified as an additional potential simulation tool

to model these systems. Lastly, the optimization tool GenOpt ${ }^{\circledR}$ was described as a method to determine the most desirable combination of retrofit options. A simulation framework was developed in this thesis which integrated these three tools to model and compare community net-zero retrofit options, and is described later in Chapter 6.

Once a simulation methodology is established for modelling the energy performance of retrofit Canadian communities, the second objective of this thesis is to use this tool to examine and quantify the impact of different net-zero definitions and retrofit measures. Case studies for communities located in Ontario and Québec, Canada are considered. An interesting feature of these two provinces is that they are geographically close with similar climate, but their building energy supply characteristics are notably different. Québec electricity is primarily sourced from hydroelectricity (Hydro-Québec, 2017), whereas Ontario uses a mix of primarily hydro, nuclear, and natural gas (IESO, 2017b). Also Ontario dwellings mostly use natural 
gas for space heating and DHW, whereas Québec dwellings primarily use electricity for those end-uses (OEE, 2017).

To meet these objectives, several tasks were identified and completed. These tasks are described at the conclusion of Chapter 2.

\subsection{Thesis Overview}

This section provides a brief overview of the remainder of this thesis. Chapter 2 provides a relevant literature review focused on existing building stock modelling, on-site and renewable energy generation options, and existing net-zero communities research and demonstration projects. Chapter 2 concludes with a statement of the formal research objectives for the current thesis.

Chapter 3 provides details on solution methodology used by the BPS tool ESP-r to estimate building energy consumption. Also described is the methodology used by CHREM to represent existing Canadian dwellings in ESP-r. Chapter 3 then presents the dwelling-scale retrofits considered in the current work and modelled in ESP-r. The methodology used to represent these retrofits in the ESP-r models is described, along with relevant model parameters and assumptions. Eligibility criteria for dwelling retrofits that were integrated into the CHREM are also defined. These eligibility heuristics are use to determine what and how much of a specific retrofit measure an existing dwelling can receive. Chapter 3 ends with a description of the case study communities and a summary of the dwelling-scale parameters to be considered in the optimization.

Chapter 4 then describes the modelling methodology used by TRNSYS. The schematics of the community energy system retrofits options are also presented, along with the underlying simulation methodology of the pertinent system components. Parameters defining the energy system are described, and the parameters to be considered within the optimization are listed at the conclusion of the chapter.

Chapter 5 discusses the boundary conditions used in the simulations. In BPS, 
there are typically two primary boundary conditions which needs to be specified: occupant driven loads, and climate. As part of the current work, a stochastic bottomup appliance and lighting model was implemented into CHREM. Validation of this model was carried out using available measured data. The model structure, implementation, and validation is described in this chapter. Consideration of DHW demands in the CHREM were also updated using recently available measured data relevant to Canada. These data sets and their integration into CHREM are presented. Chapter 5 concludes with a brief discussion of the climate data used in the current work.

The first half of Chapter 6 provides descriptions of the performance metrics used in this study. These include the definitions of net-zero considered, and the weighting factors used for different energy carriers and how they were derived. The calculation method and data sources used to determine tertiary performance metrics such as GHG emissions and grid interaction factors are also presented. The second half of Chapter 6 then describes the simulation framework used to model and optimize the retrofit case study communities, and ends with a description of the PSO algorithm, objective function, and penalty function used in the optimization problem.

Chapter 7 presents the findings and results of the current work, along with discussion of the work. Lastly, Chapter 8 provides the conclusions of the thesis and summarizes the contributions made to the literature. This chapter concludes with a discussion of future work. 


\section{Chapter 2}

\section{Literature Review}

\subsection{Review of Building Stock Modelling Method- ologies}

Building stock scale models have been shown to have higher accuracy compared to analyses of single-building energy consumption. Reinhart and Davila (2016) recently surveyed 12 publications which simulated and validated building stock models. They found that models which considered large groups of buildings showed good agreement, but at the individual building scale the discrepancies were much higher. For example, Fonseca and Schlueter (2015) used statistics and simple analytical models to estimate the end-use energy consumption of a city district in Switzerland. At the individual building-scale, they found estimation errors between 4 and 66\%, whereas at the neighbourhood and district scale the error was between 1 and $19 \%$.

Several building stock models have been developed for various applications, including informing energy conservation and policy initiatives, forecasting energy supply needs, estimating GHG emissions, or planning distributed energy generation. Recent literature reviews on residential building stock models have been conducted by Swan and Ugursal (2009), Zhao and Magoulès (2012), and Reinhart and Davila (2016). The current section provides a summary of building stock modelling techniques. For an extensive review of building stock modelling techniques the interested 
reader is directed to Swan and Ugursal (2009), Zhao and Magoulès (2012), and Reinhart and Davila (2016).

Swan and Ugursal (2009) categorized building stock modelling techniques using the hierarchy illustrated in Figure 2.1.

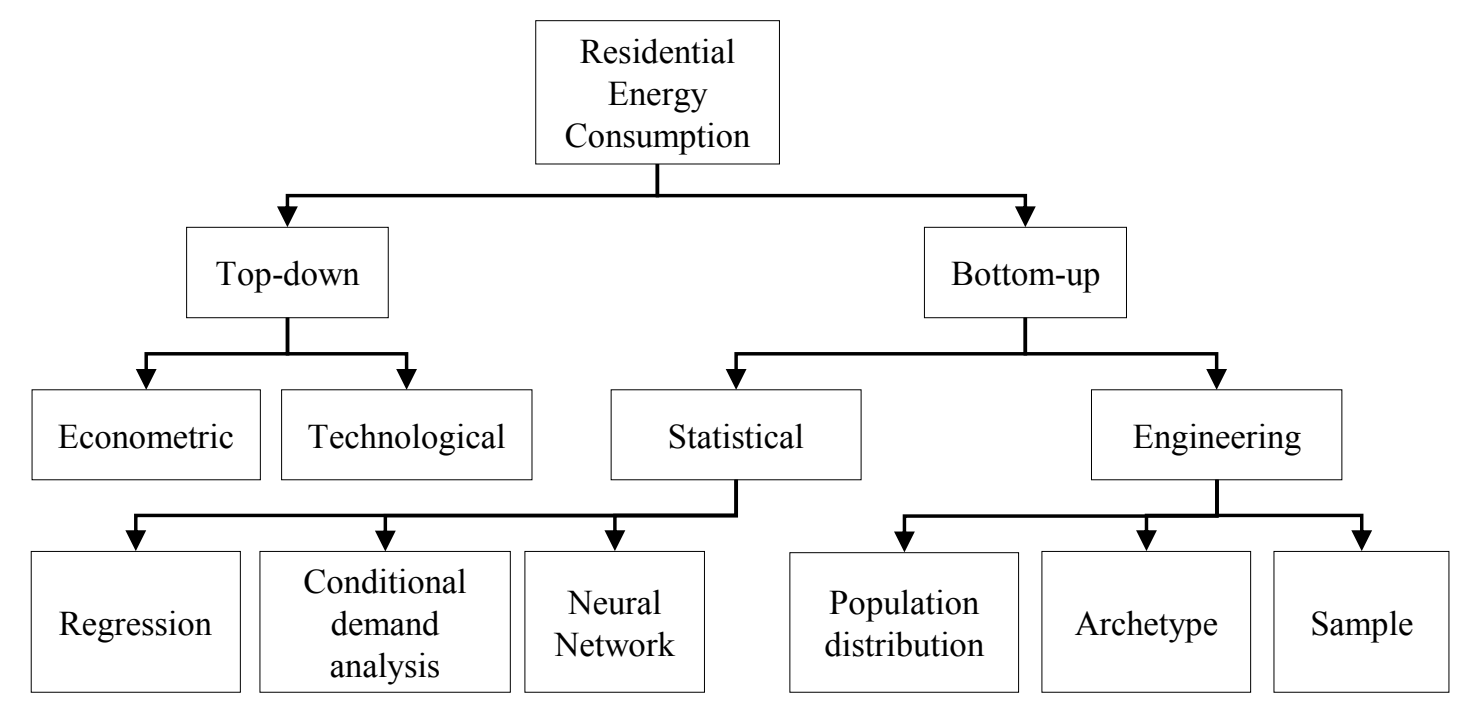

Figure 2.1: Classification hierarchy of residential energy sector modelling, adapted from Swan and Ugursal (2009)

At the highest levels, the residential sector energy consumption models are broadly classified as either "top-down" and "bottom-up". Swan and Ugursal (2009) derived this terminology based on the hierarchal level of the model input values relative to the sector as a whole. Top down models are largely driven by historical data and trends. They are characterized by the use of overall sector data, such as gross domestic product or number of units in the sector, to derive estimates of energy consumption. Typically these methods were developed for energy supply planning and forecasting. Swan and Ugursal (2009) concluded that the reliance of these models on historical information does not make them suitable for analyzing the potential impact of new technologies in the building sector. Also, top-down approaches typically do not 
attribute energy consumption to specific end-use, limiting the usefulness of these models in identifying potential targets of energy conservation within the sector.

Bottom-up models is defined by Swan and Ugursal (2009) as those which estimate residential sector energy consumption using extrapolated results from individual buildings or energy end-uses, or small segments of the sector. A common characteristic of these models is that they rely on inputs which come from a hierarchical level which is less than the sector as a whole. Swan and Ugursal (2009) sub-categorized bottom-up models as either "engineering" or "statistical" based on their underlying calculation principles and inputs. Common inputs include building stock geometry and envelope characteristics, installed equipment, climate data, and occupancy schedules. Unlike top-down approaches, Swan and Ugursal (2009) stated that bottom-up models have the ability to estimate the potential energy impact of new technologies implemented in the building sector. The following subsections summarize building stock bottom-up energy modelling techniques.

\subsubsection{Engineering Bottom-up Approaches}

Bottom-up engineering methods encompass approaches which explicitly use equipment power ratings and usage data and/or heat transfer or thermodynamic principles to estimate sector energy consumption. Swan and Ugursal (2009) stated that a benefit of bottom-up modelling methods is that they have the potential capability of estimating the energy consumption of various sector end-uses, allowing for the identification of specific areas in the sector where energy efficiency improvements may be made. Additionally, bottom-up approaches do not necessarily rely on historical data, allowing for the consideration of energy impacts of new technologies in the sector.

Swan and Ugursal (2009) identified three sub-categories of bottom-up engineering methods: population distribution, archetype, and sample. Population distribution method uses the distribution of appliance ownership, along with common appliance ratings, to estimate the energy consumption for specific end-uses. Aggregate calculations of appliance energy consumption may then be used to estimate regional or national sector energy consumption. Archetyping uses broad characteristics of the 
residential building stock, such as vintage, HVAC system type, number of storeys, etc., to classify the sector building stock. Single building archetypes are meant to represent several buildings within the stock. The end-use energy consumption of these archetypes are typically derived using BPS.

There is no clear consensus on what building characteristics should be used when developing archetypes, or how many archetypes are sufficient. Parekh (2005) stated that the three basic parameters for creating archetypes are geometric configurations, thermal characteristics, and operating parameters. The thermal characteristics include the construction composition of the envelope, ventilation and airtightness, and the type of space heating and DHW equipment used. Operating parameters are related to occupant behaviour: thermostat control and settings, appliance and lighting loads, number of occupants, and DHW loads.

When Swan et al. (2009) developed the CSDDRD, introduced previously in Chapter 1, characteristics such as number of dwelling storeys, vintage, and space heating and DHW fuel sources were used to develop a database of over 17,000 dwellings that was representative of housing in Canada. A more recent literature review conducted by Reinhart and Davila (2016) identified a two-step process to archetyping: segmentation and characterization. For the segmentation step, the building stock is grouped based on building vintage, shape, usage (commercial, institutional, etc.), climate, and HVAC systems. The characterization step involves defining thermal properties of buildings in the segment, occupancy profiles, and details of the HVAC systems.

Based on a review of 17 archetype studies in the literature, Reinhart and Davila (2016) found that single archetype buildings were used to represent less than 50 buildings up to 500,000 . This variation was related to the degree of segmentation and characterization used by the researcher. Reinhart and Davila (2016) stated that the process used to segment and characterize the building stock is crucial to the reliability of energy use estimates, but the process continues to be "ad hoc", relying on generic assumptions. They attributed this to the lack of available data on actual measured data from individual buildings.

Sampling techniques encompass methods which use detailed measured energy 
consumption data from a relatively small portion of the building stock. If the sample size is sufficiently large and diverse, the measured data may be weighted and scaled to estimate the energy consumption of the entire building stock. Swan and Ugursal (2009) stated that benefit of this approach is that it can potentially capture the high degree of energy consumption variation which cannot be reasonably captured with the archetyping approach. Gathering a sufficiently large sample size with an appropriate data resolution is intensive, and as a result this approach is not widely used (Swan and Ugursal, 2009).

\subsubsection{Statistical Bottom-up Approaches}

Statistical bottom-up approaches use historical data and regressions to determine the energy consumption for specific end-uses in the sector. These regressions may then be used to determine the energy consumption of representative dwellings in the residential stock and extrapolated to estimate overall sector energy consumption. Swan and Ugursal (2009) sub-divided this approach into regression, conditional demand analysis (CDA), and neural networks.

For building stock regression models, variables are selected which are expected to influence sector energy consumption (Swan and Ugursal, 2009). An example is the Canadian residential sector space heating fuel consumption model developed by Douthitt (1989). They used a sample of 370 Canadian dwellings surveyed by Energy, Mines and Resources Canada (EMR). This sample included an in-person survey, dwelling energy audit by trained professionals, and annual utility billing information. Douthitt (1989) also gathered relevant utility rate and price structures.

They developed separate correlations to estimate residential space heating fuel consumption for electricity, natural gas, and oil. Two separate correlations for electricity consumption were developed, based on whether the consumer had access to natural gas in their area or not. Economic independent variables included costs of heating fuels and total energy expenditures. Dwelling characteristic independent variables considered included number of storeys, wall and window areas, thermal resistance of envelope components, interior temperature design setpoint, efficiency of 
heating equipment, and number of occupants.

Douthitt (1989) stated that their regression models had significant explanatory power, justified by the standard F-statistic and adjusted coefficients of determination values, $R^{2}$, they determined. For heating oil and electricity where natural gas service was unavailable, $R^{2}$ values were 0.76 and 0.79 , respectively. For natural gas and electricity where natural gas service was available, however, $R^{2}$ values were 0.52 and 0.37, respectively. Douthitt (1989) also noted that inclusion of economic dependent variables enabled analysis of responses to changes in fuel prices.

CDA is also a regression technique. In the context of building energy modelling, Swan and Ugursal (2009) stated that CDA approaches typically involve the regression of building appliance ownership and total building energy consumption to determine unit appliance energy consumption contributions. A strength of this approach is that simple surveys may be used to determine appliance ownership in the stock; however, large sample sizes are required in order to determine the individual contribution of appliances with reasonable accuracy.

CDA was initially used by Parti and Parti (1980) to model residential electricity demand. They used electrical billing records of 5,000 San Diego, California dwellings, climate data, detailed appliance ownership information, and demographic data to develop correlations of owning an appliance and its contribution to total dwelling electrical demand. Parti and Parti (1980) expressed monthly total dwelling electrical demand, $Q_{\text {dwell,elec,total }}[\mathrm{kWh} / \mathrm{month}]$ as:

$$
Q_{d w e l l, e l e c, t o t a l} \equiv Q_{d w e l l, e l e c, 0}+\sum_{i=1}^{N} Q_{d w e l l, e l e c, i}
$$

where $Q_{\text {dwell,elec,0 }}[\mathrm{kWh} / \mathrm{month}]$ is an unattributed electrical demand, and $Q_{\text {dwell,elec,i }}$ $[\mathrm{kWh} / \mathrm{month}]$ is the annual electrical demand of appliance $i$. For each appliance $i$, $Q_{\text {dwell,elec, } i}$ is determined using the conditional expression:

$$
Q_{d w e l l, e l e c, i}=\left\{\begin{array}{l}
f_{i} \boldsymbol{X} \text { if the } \mathrm{i}^{\text {th }} \text { appliance is owned by dwelling; } \\
0 \text { otherwise. }
\end{array}\right.
$$


The final statistical method identified by Swan and Ugursal (2009) is neural networks. Often referred to as artificial neural networks (ANN), this approach uses networks of simplified mathematical models which may be used to determine causal relationships among large quantities of parameters (Aydinalp-Koksal and Ugursal, 2008). Like other bottom-up statistical approaches presented here, ANNs are a type of specialized regression models. ANNs have been dubbed "universal approximators" (Du and Swamy, 2014; Hornik et al., 1989), able to approximate any measurable function with acceptable accuracy (Hornik et al., 1989). This ability stems from the non-linearities used within neuron models (Du and Swamy, 2014).

ANNs are fundamentally based upon biological neural networks. The most basic element is the neuron, which receives several input values and produces a single scalar output. Networks are constructed by linking neuron outputs to other neuron inputs. These inputs may be multiplied and/or added to constant values which act as connection weights or biases. These weight and bias values are calibrated to "train" the network to minimize output error.

Aydinalp et al. (2002) and Aydinalp et al. (2004) previously used ANNs to model Canadian residential sector appliance, lighting, and space cooling energy consumption, and space heating and DHW consumption, respectively. Both models were developed using data from the 1993 Survey of Household Energy Use (SHEU-93) (Statistics Canada, 1995) and 1993 Canadian heating and cooling degree days. Aydinalp et al. (2002) and Aydinalp et al. (2004) divided their data into training and validation sets, and tested different ANN configurations, activation functions, and learning algorithms to find the topology with the best estimation performance.

Each ANN was trained to take a dwelling's characteristics, such as appliance stock and socio-economic factors, and estimate the dwelling's annual fuel energy consumption for a specific end-use. For the appliance, lighting, and space cooling ANN, Aydinalp et al. (2002) were able to achieve good agreement with the data, reporting $R^{2}=0.909$. Aydinalp et al. (2004) developed two separate models for space heating and DHW annual fuel energy consumption. Both were also found to have good agreement with SHEU-93 data, with $R^{2}$ values of 0.91 and 0.87 , respectively. 


\subsubsection{Applicability of Approaches}

Bottom-up statistical approaches provide insight to the various end-uses of energy consumption, and are supported by historical trends and statistical data. The reliance on historical data again limits the abilities of these methods in estimating the potential performance of new technologies within the sector. Like top-down approaches, bottom-up models may also include socio-economic factors within their methodology. Data sources for these models are not as commonly available as for top-down approaches, but can be derived from billing records and surveys. A challenge of data collection is that a large enough sample size of the stock needs to be taken to capture the variations present in the sector population.

A primary strength of bottom-up engineering approaches is the ability to consider the energy impacts of new technologies (Swan and Ugursal, 2009). Bottom-up engineering approaches often incorporate BPS, which has a large spectrum of model resolution to fit different modelling objectives. Detailed or coarse estimates may be made regarding energy flows and end-uses within buildings and the residential sector as a whole. A weakness of this approach is that detailed input information is often required which is not easily or readily available. BPS tools typically required detailed information on geometry, envelope thermophysical properties, HVAC systems and efficiencies, and other details which are difficult to obtain. Modelling of occupant-driven loads, such as appliance and lighting, also has large uncertainty in bottom-up engineering approaches. Additionally, this approach is more computationally intensive compared to the other methods described by Swan and Ugursal (2009).

\subsubsection{CHREM Modelling Approach}

Based on their literature review, Swan and Ugursal (2009) concluded that the most appropriate method for modelling performance of new and innovative technologies implemented in building stocks is the bottom-up engineering approach. Swan and Ugursal (2009) also stated that such approaches face challenges when accounting for occupant behaviours. Several researchers agree that occupant behaviour is a major 
source of uncertainty when estimating building performance, and can have significant impacts on estimated values (Gram-Hanssen, 2010; Hoes et al., 2009; O'Brien and Gunay, 2014).

CHREM, developed by Swan et al. (2013), is a bottom-up model created to simulate the impact of new technologies on residential sector energy consumption and GHG emissions. Rather than use either a statistical or engineering approach, Swan et al. (2013) employed a hybrid engineering/statistical method to capitalize on the strengths of both. This hybrid approach is described below.

Bottom-up Engineering Approach To model the thermal energy transfer and HVAC system performance of existing residential Canadian dwellings, CHREM uses a bottom-up engineering approach with BPS tool Environmental Systems Performance: Research Version (ESP-r) (ESRU, 2017). Initially developed in the 1970's, ESP-r is an open-source research tool which continues to experience ongoing development by an international group of code developers. ESP-r has expanded to include additional modelling capabilities such as acoustics, moisture and air flow, indoor air quality and electrical networks (ESRU, 2017), and has been extensively validated (Strachan et al., 2008).

The challenge of using ESP-r is that it requires detailed information on building geometry and thermophysical properties, and characteristics and performance of building HVAC systems. This data requirement was met by the CSDDRD from Swan et al. (2009), which contains over 17,000 detailed records of existing Canadian dwellings. Swan et al. (2009) built the CSDDRD from EGHD introduced previously in Chapter 1. The EGHD contained only SD and DR dwelling types; however, Swan et al. (2009) noted that $80 \%$ of Canadian dwellings could be classified as SD or DR, representing over $85 \%$ of sector energy consumption (OEE, 2006). To populate the CSDDRD Swan et al. (2009) selected dwellings from the EGHD such that the CSDDRD would have statistically similar national and regional distributions of key parameters published in the Survey of Household Energy Use 2003 (SHEU-03) (OEE, 2006). 
Bottom-up Statistical Approach To estimate the occupant-driven appliance and lighting (AL) and DHW demands, Swan et al. (2013) used a bottom-up statistical approach. The annual AL and DHW demands were determined for each record in the CSDDRD using the ANNs developed previously by Aydinalp et al. (2002) and Aydinalp et al. (2004), respectively. Since ESP-r calculates the transient building energy transfer at discrete timesteps, these annual estimates needed to be converted to sub-hourly demands in order to function as simulation boundary conditions. To accomplish this, Swan (2010) developed a library of annual sub-hourly AL and DHW energy demand profiles from the literature

AL demand profiles were sourced from Armstrong et al. (2009). Armstrong et al. (2009) synthetically derived AL demand profiles for the Canadian residential sector using a bottom-up approach based upon "annual consumption of the households, the appliance stock and characteristics and occupant usage patterns" (Armstrong et al., 2009). Armstrong et al. (2009) disaggregated AL demands such as clothes dryer, cook stove, and other. For each demand type, they generated three annual profiles to represent low, medium, and high demand. Swan (2010) created nine AL demand profiles using all possible combinations of AL demand types and demand levels. Each CSDDRD record was paired with an AL demand profile with similar annual energy consumption. The profile is then linearly scaled to precisely match the ANN annual consumption estimate.

Sub-hourly DHW demand profiles were sourced from Jordan and Vajen (2001a). Using German and Swiss residential DHW consumption statistics from previous studies (Jordan and Vajen, 2001b), Jordan and Vajen (2001a) constructed probability distribution functions for DHW draw flow rates and times of draw occurrence. Annual dwelling DHW draw profiles were generated using a cumulative frequency method, stochastically assigning occurrences and flow rates of DHW draws throughout the year. The associated draw flow rate was then stochastically determined.

Swan (2010) incorporated three different profiles generated by Jordan and Vajen (2001a). Each DHW profile was specified by its nominal daily DHW consumption per day: 100, 200, and 300 L/day. For each CSDDRD record, Swan et al. (2013) estimated annual DHW energy consumption using the ANN model developed previously 
by Aydinalp et al. (2004). The dwelling annual DHW energy consumption, $Q_{D H W, a n n}$ $[\mathrm{J}]$, estimated by the ANN model was expressed as an annual volume consumption, $V_{\text {DHW,ann }}\left[\mathrm{m}^{3}\right]$, using Equation 5.1 (Swan, 2010):

$$
V_{D W H, a n n}=\frac{Q_{D H W, a n n} \cdot \eta}{\rho \cdot c_{p}\left(55-T_{G, a n n}\right)}
$$

where $55{ }^{\circ} \mathrm{C}$ is the assumed setpoint temperature of DHW, $T_{G \text {,ann }}\left[{ }^{\circ} \mathrm{C}\right]$ is the annual average ground temperature, and $\rho\left[\mathrm{kg} / \mathrm{m}^{3}\right]$ and $c_{p}[\mathrm{~J} / \mathrm{kg} \mathrm{K}]$ are the density and specific heat, respectively. The system energy factor values, $\eta[\%]$, were taken from Aydinalp et al. (2004). This factor accounted for the conversion between fuel source and supplied thermal energy. Similar to AL demands, sub-hourly DHW demand profiles were allocated to the each CSDDRD record with similar annual volume consumption. DHW profiles were also linearly scaled to precisely match the ANN annual DHW volume consumption estimate.

\subsection{Previous Simulation Studies on Residential Stock Retrofits}

Carlisle et al. (2009) proposed that the first energy supply option when designing net-ZECs was to reduce on-site energy consumption and increase efficiency. It will be shown later in Section 2.5 that net-ZECs realized in practice used designs which first reduced on-site energy consumption by approximately 40 to $70 \%$ compared to baseline estimates. When considering retrofits of the existing stock, technical and economic barriers create challenges to implementing net-zero design options typically considered in new-builds. For example, existing stock geometry and orientation is largely fixed, hindering implementation of passive solar and natural ventilation options.

Several studies have previously considered the efficacy of residential building retrofit options on stock energy consumption and GHG emissions. Guler et al. (2001) 
and Guler et al. (2008) assessed the impact of energy efficiency upgrades on residential energy use and GHG emissions in Canada using the Canadian Residential Energy End-use Model (CREEM) developed by Farahbakhsh et al. (1998). The CREEM was populated with 8767 Canadian houses modelled in HOT2000 (NRCan, 2014b), based on data from SHEU-93 (Statistics Canada, 1995).

Both Guler et al. (2001) and Guler et al. (2008) examined dwelling envelope upgrades to ceilings, exterior walls, and basement insulation, as well as replacing windows. Each upgrade was applied to CREEM independently, and the impact on energy consumption and cost savings were determined. For each building envelope upgrade Guler et al. (2001) considered, Table 2.1 summarizes the most effective retrofit measure, the average annual energy savings of the retrofitted dwellings, and the fraction of the existing residential stock eligible for each upgrade.

Table 2.1: Summary of residential building envelope upgrades from Guler et al. (2001)

\begin{tabular}{|c|c|c|c|}
\hline $\begin{array}{l}\text { Envelope } \\
\text { Upgrade }\end{array}$ & $\begin{array}{l}\text { Energy Savings } \\
\text { [GJ/yr/dwelling }]\end{array}$ & $\begin{array}{l}\text { Eligible } \\
\text { Stock }[\%]\end{array}$ & Description \\
\hline Basement & 20.6 & $8 \%$ & $\begin{array}{l}\text { Add R-30 to unheated } \\
\text { uninsulated basement }\end{array}$ \\
\hline Window & 13.5 & $11 \%$ & $\begin{array}{l}\text { Replace single-glazed with } \\
\text { argon-filled low-e triple glazed }\end{array}$ \\
\hline Exterior Wall & 9.6 & $4 \%$ & $\begin{array}{l}\text { Increase wall to } \mathrm{R}-13 \text { with } \\
\text { blown-in insulation into cavity }\end{array}$ \\
\hline Ceiling & 5.4 & $92 \%$ & $\begin{array}{l}\text { Increase ceiling insultion } \\
\mathrm{R}-50\end{array}$ \\
\hline
\end{tabular}

The energy savings in Table 2.1 need to be viewed in the context of eligible stock. While the basement retrofit yielded the largest in energy savings, this upgrade was only applicable to $8 \%$ of Canadian dwellings. Conversely, ceiling insulation had the smallest decrease in energy performance, but is applicable to the majority of the stock. For the current work, all types of envelope upgrades listed in Table 2.1 were 
considered. The details of the upgrade, along with eligibility criteria are described below.

Guler et al. (2001) and Guler et al. (2008) also consider the retrofit of higher efficiency space heating and DHW systems in the Canadian residential stock. Replacing standard efficiency space heating equipment with high efficiency was found to have the largest annual energy savings of $31.6 \mathrm{GJ} / \mathrm{yr} / \mathrm{dwelling}$, and the largest reduction in entire sector energy consumption (8.2\%) despite being applied to only $37 \%$ of the stock. Replacing DHW equipment had a higher applicability in the stock (87\%), but nominal annual energy savings of $1.6 \mathrm{GJ} / \mathrm{yr} /$ dwelling.

CHREM has also been used extensively to determine the efficacy of retrofitting new and innovative technologies in the Canadian residential building stock. Nikoofard et al. (2013) considered the retrofit of five different glazing systems, from doubleglazed with argon fill, to triple-glazed low-e with argon fill. Window upgrades were not applied to every dwelling model in CHREM; rather Nikoofard et al. (2013) established eligibility criteria rules to determine which glazing surfaces could be upgraded. This was done to, for example, prevent an existing triple-glazed window being replaced with a double-glazed system. Nikoofard et al. (2013) found that replacing all eligible glazing surfaces with triple-glazed low-e windows reduced sector energy consumption and GHG emissions by 7 and $8 \%$, respectively.

Nikoofard et al. (2014b) later considered the impact of retrofit window shading systems on sector space heating and cooling demands. As a default, CHREM does not consider any window or exterior shading devices (Swan, 2010). Nikoofard et al. (2014b) considered both light and dark aluminium Venetian blinds, mounted inside and outdoors. They also considered different blind control algorithms based on room temperatures or solar radiation levels. Nikoofard et al. (2014b) demonstrated that up to 2.3 and $2.7 \%$ reductions in residential sector energy consumption and GHG emissions, respectively, could be achieved. Nikoofard et al. (2015) also considered the retrofit of phase change material embedded under the dwelling main floor. The only retrofit eligibility criterion defined by Nikoofard et al. (2015) was that there must be windows on the south, southeast, and southwest façades to provide passive solar thermal energy to the floor. Potential sector energy consumption and GHG 
emissions reductions were found to be approximately $2.5 \%$

Nikoofard et al. (2014a) and Asaee et al. (2016) used CHREM to study the performance of retrofitted solar DHW and solar combi-systems ${ }^{1}$, respectively. For both studies, roof-mounted solar flat plate collectors (FPC) were considered. Nikoofard et al. (2014a) stated that 30\% of Canadian SD and DR dwellings were able to retrofit solar DHW systems, based on suitable roof geometry and orientation. Applying the retrofit, Nikoofard et al. (2014a) found total sector energy consumption and GHG reductions of approximately $2 \%$.

Table 2.2 summarizes other retrofit studies conducted using the CHREM. For each technology, the percentage of total single-detached and double/row residential stock receiving the retrofit is indicated, along with the potential savings in energy consumption and GHG emissions.

Table 2.2: Summary of other CHREM retrofit studies

\begin{tabular}{|c|c|c|c|c|}
\hline \multirow[t]{3}{*}{ Study } & \multirow{3}{*}{$\begin{array}{l}\text { Retrofit } \\
\text { Technology }\end{array}$} & \multirow{3}{*}{$\begin{array}{l}\% \text { of } \\
\text { Eligible } \\
\text { Stock }\end{array}$} & \multicolumn{2}{|c|}{ Reductions } \\
\hline & & & Secondary & GHG \\
\hline & & & Energy & Emissions \\
\hline Nikoofard et al. (2014a) & Solar DHW & $30 \%$ & $2 \%$ & $2 \%$ \\
\hline Asaee et al. (2016) & Solar Combi-system & $37 \%$ & $19 \%$ & $19 \%$ \\
\hline \multirow[t]{3}{*}{ Asaee et al. (2017a) } & Solar-assisted HP* & $37 \%$ & $21 \%$ & $19 \%$ \\
\hline & Space Heating & & & \\
\hline & \& DHW & & & \\
\hline Asaee et al. (2017) & Roof-mounted PV & $35 \%$ & $3 \%$ & $5 \%$ \\
\hline Asaee et al. (2017) & $\mathrm{BIPV} / \mathrm{T}$ & $25 \%$ & $18 \%$ & $17 \%$ \\
\hline \multirow[t]{3}{*}{ Asaee et al. (2017b) } & Air-to-Water HP & $71 \%$ & $36 \%$ & $23 \%$ \\
\hline & Space Heating & & & \\
\hline & \& DHW & & & \\
\hline \multirow[t]{2}{*}{ Asaee et al. (2015) } & Internal Combustion & $71 \%$ & $13 \%$ & $35 \%$ \\
\hline & Co-generation & & & \\
\hline
\end{tabular}

* Heat pump

\footnotetext{
${ }^{1}$ Combi-systems are solar thermal systems which provide both space heating and DHW.
} 
Asaee et al. (2017) used the same PV performance parameters for both the PV only and building integrated photovoltaic/thermal (BIPV/T) systems. The collector was modelled as a typical crystalline-silicon collector with a nominal efficiency of $11.7 \%$. The BIPV/T system pre-heated the inlet air of an air-to-water heat pump by circulating it across the underside of the roof-mounted PV system. The heat pump supplied thermal energy for space heating and DHW preparation.

Other studies considering the retrofit of new and renewable technologies in existing buildings have taken a different approach from CHREM. For example, Izquierdo et al. (2008) utilized satellite imagery, population and building density statistics, and geographic information systems (GIS) to estimate the roof area available for PV within municipalities. PV generation potential was estimated by using calculated annual solar radiation incident on tilted collector surface area, and PV collector test data.

Hofierka and Kaňuk (2009) used a different approach, developing a digital 3-D city model using GIS with data supplied from orthophoto, topographical, and large city maps. Building characteristics such as height, roof type and inclination, were mapped using a "laser distance device" (Hofierka and Kaňuk, 2009). Solar radiation models integrated in the GIS software were then used to determine incident solar radiation on roofs, accounting for shading of adjacent buildings. An annual PV generation potential was determined using the PV-GIS tool from Súri et al. (2005, 2007).

\subsection{Community-scale Retrofit Projects in Prac- tice}

Introduced previously in Chapter 1, the Now House Project (Now House, 2017) has focused on retrofitting existing Canadian dwellings and communities to achieve energy reductions and net-zero. Their pilot project was the retrofit of a 60 year old post-war 1 1/2 storey SD dwelling in Toronto, Ontario to achieve near net-zero (CMHC, 2010). The retrofit strategy included a combination of active and passive 
design measures. A window on the south facing façade was enlarged to increase solar energy gains during the winter, and retractable awnings were also installed to control passive gains during the summer months.

Cracks and air gaps were sealed to increase envelope airtightness, and a heat recovery ventilator (HRV) was also retrofitted to efficiently provide fresh air to occupants. The attic insulation above the finished ceiling was increased from R-32 to R-72, and insulation in the sloped ceiling adjacent to occupied spaces was increased from R-8 to R-18. The existing main walls had R-8 rock wool insulation in the stud space, with a three layer exterior cladding system consisting of wood, asbestos board, and aluminium siding. The exterior cladding was removed, and closed-cell spray foam was applied to the exterior walls, supported by vertical trusses. This added an additional R-31 to the main walls. The original basement walls were poured concrete with no insulation. The exterior perimeter was excavated and R-25 of extruded polystyrene (XPS) insulation was installed. The pre-existing concrete basement slab was removed, and R-10 XPS was installed, with R-5 insulation added between the slab and the footing. Dwelling envelope retrofits were found to decrease air leakage from 5.6 air changes per hour $(\mathrm{ACH})$ at $50 \mathrm{~Pa}$ de-pressurization to 2.6 $\mathrm{ACH}$ (CMHC, 2009).

On-site renewable energy generation was achieved with a $2.7 \mathrm{~kW}$ e PV system, and a solar thermal system supplied by two evacuated tube collector (ETC) panels. The solar thermal system provided both space heating and DHW. A in-floor hydronic system provided heat for the basement, and a fan-coil system heated the abovegrade spaces. The heating system was backed up with a $90 \%$ efficient natural gas tankless water heater which replaced the old 56\% efficient gas-fired tank. Other energy conservation measures implemented included replacement of appliances with higher efficiency model, replacing all incandescent lights with light-emitting diodes (LED), waste water heat recovery systems, and low-flow water fixtures (CMHC, 2010).

These retrofit measures were estimated to reduce on-site natural gas and electricity consumption by 78 and $60 \%$, respectively. Annual site solar thermal and PV 
energy production was estimated to be 1.46 and $1.93 \mathrm{MWh} / \mathrm{yr}$, respectively. Calculating the site net-zero balance, CMHC (2010) estimated that the house still needed to export an additional $6.42 \mathrm{MWh} / \mathrm{yr}$ to achieve net-zero. They also estimated that GHG emissions would be reduced by $55 \%$. These retrofit measures were estimated to reduce on-site natural gas and electricity consumption by 78 and $60 \%$, respectively. Annual site solar thermal and PV energy production was estimated to be 1.46 and $1.93 \mathrm{MWh} / \mathrm{yr}$, respectively. Calculating the site net-zero balance, CMHC (2010) estimated that the house still needed to export an additional $6.42 \mathrm{MWh} / \mathrm{yr}$ to achieve net-zero. They also estimated that GHG emissions would be reduced by $55 \%$.

Using lessons learned from the Toronto project, the group then retrofitted five SD post-war dwellings in Windsor, Ontario. The dwellings are owned by the Windsor Essex Community Housing Corporation, and were used as proof of concept for a planned additional 95 properties owned by the housing corporation. Each of the five properties received different retrofit packages. The common retrofit measures implemented were (CDML, 2010; CMHC, 2012):

- Air sealing and insulation;

- Replace all light fixtures with compact fluorescent lamps (CFL);

- Low-flow water fixtures;

- ENERGY STAR ${ }^{\circledR}$ fridge and clothes washer;

- New natural gas stove and dryer;

- New doors;

- New siding;

- Tankless water heaters;

- High efficiency air conditioning;

- HRV.

Dwelling specific upgrades are summarized in Table 2.3 (CMHC, 2012): 
Table 2.3: Now House Windsor 5 Retrofit Measures

\begin{tabular}{|c|c|c|c|c|c|}
\hline \multirow[b]{2}{*}{ Retrofit Measure } & \multicolumn{5}{|c|}{ Dwelling } \\
\hline & 1 & 2 & 3 & 4 & 5 \\
\hline High efficiency gas furnace & & $\checkmark$ & & $\checkmark$ & $\sqrt{ }$ \\
\hline Hydronic heating system & $\checkmark$ & & $\checkmark$ & & \\
\hline ENERGY STAR ${ }^{\circledR}$ windows & & & $\checkmark$ & & \\
\hline $2.1 \mathrm{~kW}_{\mathrm{e}}$ roof-mounted PV & & $\checkmark$ & $\checkmark$ & & \\
\hline Solar DHW system & & & & $\checkmark$ & \\
\hline
\end{tabular}

CDML (2010) conducted an energy analysis using post-retrofit utility data. The data was used to develop energy consumption regressions models to compare performance of pre and post retrofit dwellings over the same climate year. The results of the analysis are summarized in Table 2.4 (CDML, 2010):

Table 2.4: Efficacy of Now House Windsor 5 retrofits for reducing annual fuel consumption

\begin{tabular}{lccccc}
\hline & \multicolumn{5}{c}{ Dwelling } \\
On-site Fuel & $\mathbf{1}$ & $\mathbf{2}$ & $\mathbf{3}$ & $\mathbf{4}$ & $\mathbf{5}$ \\
\hline \hline Electricity & $19.5 \%$ & $42.7 \%$ & $84.2 \%$ & $28.2 \%$ & $17.4 \%$ \\
Natural Gas & $43.2 \%$ & $60.1 \%$ & $77.5 \%$ & $55.6 \%$ & $47.9 \%$ \\
\hline
\end{tabular}

It should be noted that the savings estimated for dwelling 3 are not indicative of true operation of the building. Dwelling 3 was largely unoccupied, and functioned primarily as a demonstration house.

Annual PV system generation estimates for both dwellings 2 and 3 are 2,956 $\mathrm{kWh} / \mathrm{yr}$ (CDML, 2010). All PV generation is sold directly to the grid (CMHC, 2012). Using the on-site consumption and generation estimates from CDML (2010), dwelling 2 needs to export an additional $3600 \mathrm{kWh} / \mathrm{yr}$ in order to achieve a site net-zero balance. The PV system is only capable of providing $45 \%$ of the on-site energy demand. To calculate the total on-site energy demand, volumetric natural 
gas consumption was converted to energy consumption using an assumed ${ }^{2}$ higher heating value (HHV) of $38 \mathrm{MJ} / \mathrm{m}^{3}$.

The cost effectiveness of each retrofit package was evaluated based on EnerGuide for Houses (EGH) energy rating improvement, operating cost savings, energy conserved, and emissions reduction (CMHC, 2012). Dwelling 2 was found to be the most cost-effective solution, and was applied to an additional 95 dwellings in the housing corporation's portfolio (without the roof-mounted PV system) (Gauthier, 2014; Steele, 2013).

\subsection{On-site and Renewable Energy Generation Options}

A net-zero energy balance implies there is a form of on-site energy generation to offset energy imports from the connected infrastructure to the building or community site. Carlisle et al. (2009) stated that net-zero communities offset their import of energy from the connected infrastructure by export of on-site "renewable" energy generation. NRCan (2016a) used the following classification for renewable energy technologies:

- hydroelectric;

- bioenergy;

- wind power;

- solar energy;

- geothermal energy;

- and ocean energy.

Some of these renewable energy classes are only feasible in specific locations. For example, only coastal communities could could consider the use of ocean energy. Hydroelectricity has seen widespread adoption within Canada, but again is only

\footnotetext{
${ }^{2}$ Value recommended by Johnson et al. (2017).
} 
feasible in specific regions which are geologically suited for such a technology. The generalized approach taken in the current work to simulate and analyze existing communities retrofitting for net-zero assumes that these communities are situated in established urban/suburban environments which likely do not have access to a nearby feasible hydroelectric or ocean resources.

Bioenergy is continuing to grow in Canada with the support of both federal and provincial policies. Effective December 2010, the federal government mandated that $5 \%$ of the gasoline supply pool needs to be derived from renewable content. Effective July 2011, 2\% of diesel supply must also be renewable content (NRCan, 2016a). While biofuels will continue to be an important renewable energy resource in Canada, consideration of biofuels is deferred in the current work. The infrastructure to transport biofuel to the community-site is still being developed in Canada. Additionally, it is assumed that urban/suburban communities will not currently have ready access to nearby wood or agricultural waste to use as biofuel.

Wind generation also faces certain challenges when being considered for community energy projects. Typically regulations and bylaws create barriers for the construction of large-scale wind turbines within city limits or near buildings. For example, City of Toronto (2013) states that only one wind generation device may be placed on the property, must comply with all building setback requirements, and for non-apartment residential buildings no part of the generator may be $2.5 \mathrm{~m}$ above the permitted maximum height of the building. Additionally, the wind intensity within urban environments is relatively low compared to open/flat spaces (Bahaj et al., 2007), and adjacent buildings can cause wind shadow (Walker, 2011).

The two remaining renewable energy technologies, geothermal and solar, were identified as potential candidates for retrofit on-site energy generation in existing communities and are considered in the current work. These technologies are described in the following subsections. Although not classified as a renewable energy technology, natural gas-fired microturbines were also considered in this work as a potential retrofit option. This technology is also described below, along with the rational for including them in this thesis work. 


\subsubsection{Geothermal Energy}

Geothermal energy encapsulates naturally occurring underground steam which may be used to drive thermodynamic cycles, and taking advantage of the temperature differential between ground or ground water to provide heating and cooling (NRCan, 2016a). Ground-source heat pumps (GSHP) are part of the latter category of geothermal energy, using refrigeration cycles to transfer thermal energy between ground heat exchangers and the thermal load. As of 2010, NRCan (2016a) stated that over 95,000 GSHP systems have been installed in Canada, representing an approximate capacity of 1,045 $\mathrm{MW}_{\text {th }}$. The coefficient of performance (COP) of GSHPs range from 3 to 5 , whereas air-source heat pumps typically range between 2.3 and 3.5, and high efficiency furnaces between 0.88 and 0.97 (Self et al., 2013). GSHPs have also been shown to be economically viable for residential buildings in Canadian climates (Healy and Ugursal, 1997).

GSHPs may be open or closed cycle (NRCan, 2017). Open cycle systems draw water directly from underground aquifers to connected heat pumps, and reject the return water back into the aquifer. Closed systems use buried pipes which circulate a thermal transport fluid. The buried pipes act as a ground heat exchanger (GHX), exchanging thermal energy between the soil and the connected heat pump. The two commonly-used GHX arrangements are "horizontal" and "vertical."

Horizontal pipe GHX systems are typically buried in a trench with a depth between 1 and $1.8 \mathrm{~m}$ deep (NRCan, 2017). The length of pipe laid in the trench depends on the heat pump capacity. The rule of thumb suggested by NRCan (2017) is 120 to $180 \mathrm{~m}$ of pipe per ton of heat pump capacity. Horizontal pipe systems are more common in rural areas since large lot spaces are required to bury the pipe.

Vertical pipe GHX systems are a more appropriate choice for suburban/urban areas where lot space is usually limited (NRCan, 2017). These systems use pipe inserted in boreholes which are drilled to depths between 80 and $110 \mathrm{~m}$ with a nominal diameter of $15 \mathrm{~cm}$ (NRCan, 2017). Piping is inserted in a U-loop configuration, and multiple loops may be placed within a single borehole. The borehole is then backfilled with grout to ensure good thermal contact between the pipes and ground (Florides 
and Kalogirou, 2007). A system may be comprised of one or several boreholes. Figure 2.2 illustrates a simple vertical borehole GSHP system. The condensor may transfer thermal energy to building air or water, and can supply either or both space heating and DHW.

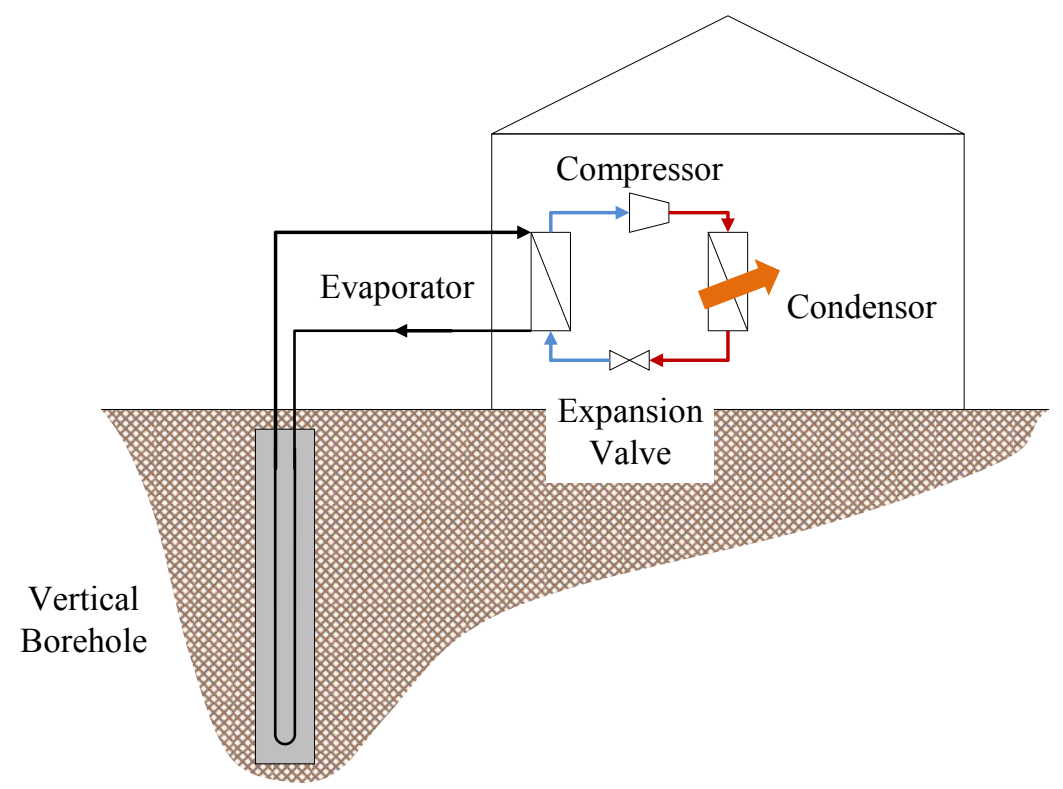

Figure 2.2: Simple vertical borehole GSHP system

\subsubsection{Solar Energy}

Passive solar design and solar energy systems are widely used in low energy and net-zero building projects. Historically, solar energy was considered in buildings through passive design. Such designs strive to utilize and control incident thermal radiation through strategic placement/orientation of buildings and their elements, such as glazing placement and size, external shading, or use of building thermal mass (NRCan, 2016a). Solar energy technologies however, are becoming more common (NRCan, 2016a).

Solar technologies may be either 'active' or 'passive', and use some form of solar 
energy collector to convert incident solar radiation to another form of useful energy. Active systems require some form of mechanical or electrical equipment to operate (NRCan, 2016a), whereas in passive systems the collection, transport, and storage of solar energy is achieved without the intervention of external mechanisms such as pumps or controllers. Solar technologies used in building energy systems may be classified as either 'thermal' or 'photovoltaic'. Solar thermal systems are principally used to convert solar radiation into thermal energy for use in a specific application (Cruickshank, 2009). PV systems use semiconductors to convert a portion of incident solar radiation directly into electrical energy (Duffie and Beckman, 2013).

As a renewable energy source, there is a lot of potential for solar energy in buildings. Weiss (2003) stated that solar radiation incident on earth is over 10,000 times the global primary energy demand. Pinel et al. (2011) stated that the solar radiation on a typical home exceeds its annual energy consumption requirements. For the current work, both solar thermal and PV systems were considered for retrofit in communities. Typically solar collectors are mounted on the roof of the building, or onto existing structures such as a detached garage, in residential applications.

The following subsections provide brief backgrounds for solar thermal and PV technologies.

\subsubsection{Solar Thermal}

According to 2014 data from OEE (2017), 83.1\% of secondary energy use in the residential sector was attributed to space heating and DHW preparation. Solar thermal is a potential technology for meeting these end-uses and offsetting conventional GHG emitting sources by directly converting solar to useful thermal energy. In terms of solar availability, prairie cities such as Calgary, Regina, and Winnipeg have well above average solar potential (NEB, 2016).

Solar thermal collectors may be viewed as a specialized heat exchanger which converts incident solar radiation into thermal energy (Duffie and Beckman, 2013). The simplest example is a roof-mounted DHW tank with a high solar absorptivity exterior coating. Such systems are practical in warm climates where thermal losses from 
the tank aren't as much of a concern. Additionally active and passive may be further categorized as direct or indirect systems (Cruickshank, 2009). A roof-mounted tank is an example of a direct system, where solar energy is directly transfered to the thermal storage medium. Indirect systems use an intermediate thermal energy transport fluid. These types of systems are typically used in colder climates, where an anti-freeze solution is circulated through the collectors and heat is transfered to the thermal energy storage via a heat exchanger.

By the end of 2015, the total installed capacity of solar thermal collectors in Canada was $80.9 \mathrm{MW}_{\text {th }}$ (Werner Weiss, 2017). This capacity was achieved through a combination of solar thermal collector types. Werner Weiss (2017) documents ETCs, FPCs, and unglazed water collectors in the solar thermal market. As of 2015, the majority of collectors installed in Canada and the U.S. were unglazed water collectors (83\%) (Werner Weiss, 2017). NRCan (2016c) stated that most installed unglazed collectors are for pool heating.

FPCs are a relatively simple technology which transfers solar energy captured by an absorber surface to a thermal energy transport fluid like water or air. FPCs can typically operate up to $100{ }^{\circ} \mathrm{C}$ above ambient conditions, making them suitable for domestic applications. Additionally, FPCs do not require a sun-tracking system, require little maintenance, and are mechanically simpler compared to other types of collectors (Duffie and Beckman, 2013).

Around 1\% of installed collectors in Canada/U.S. in 2015 were ETCs. Globally however, ETCs are the largest share of installed collectors, at 71.5\% (Werner Weiss, 2017). They also continue to be a dominant collector sold in the market, representing $72.3 \%$ of all newly installed global capacity in 2015, mostly in China. Figure 2.3 illustrates the cross-section of a heat pipe ETC. The collector plate is the means by which solar energy is transferred to a transport fluid inside the heat pipe. The heat plate is placed inside an evacuated tube to reduce the convective and radiative losses. The heat pipe penetrates the vacuum tube via a glass-to-metal seal (Morrison et al., 2004), and transfers heat to a transport fluid in the manifold. Morrison et al. (2004) described three other methods of extracting thermal energy from evacuated tubes: 


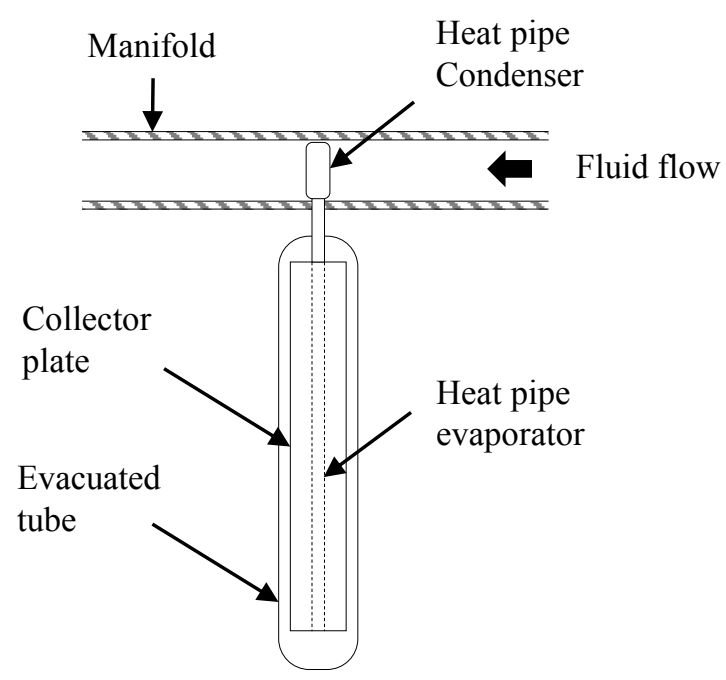

Figure 2.3: Cross-section of heat pipe evacuated collector, adapted from Kalogirou (2004)

- Flow through absorber: the fluid in the collector manifold is directly circulated through the absorber;

- All-glass tubes: similar to a Dewar flask, the vacuum-side of the inner tube acts as absorber and conducts energy to a transport fluid that is in thermal contact with the inner tube;

- Storage absorber: tubes greater than $100 \mathrm{~mm}$ in diameter may function as absorber and insulated thermal storage.

Compared to FPCs, ETCs generally have higher collection efficiencies, and higher performance in lower ambient temperatures. These characteristics make ETCs an attractive candidate for Canadian applications. ETCs also have higher efficiencies at low incidence angles, giving them an advantage over FPCs for full day performance (Kalogirou, 2004). The operating temperature of ETCs are between 50 and 200 ${ }^{\circ} \mathrm{C}$ (Kalogirou, 2004), making them suitable for domestic applications. Historically, ETCs were more expensive. Ayompe et al. (2011) stated that a $3 \mathrm{~m}^{2}$ heat pipe ETC cost approximately twice as much as $4 \mathrm{~m}^{2}$ of FPC. More recently Qiu et al. (2015) showed that initial investment costs of ETC systems are lower than comparable FPC 
systems in the Chinese market. For example, they stated an average FPC system with a $100 \mathrm{~L}$ tank has an initial cost more than double that for a system with ETCs and a comparable tank size. For these reasons ETC systems were considered in the current work over FPC systems.

\subsubsection{Solar Photovoltaics}

Canada generally has a higher solar potential compared to Germany, which as of 2014 had the largest installed capacity of PV (NEB, 2016). The installed capacity in Canada however, remains modest. As of 2013, PV accounted for only $0.3 \%$ of total Canadian electrical production. Growth of PV capacity in Canada continues to increase however. In 2013, installation of solar electric systems grew by $60 \%$ compared to the previous year (CanSIA, 2014). The majority of this growth was in Ontario, where CanSIA (2014) reported that $99 \%$ of solar electricity was generated in Canada. A large driver for growth in PV installations is the reduction is collector price. NEB (2016) stated that between 2000 and 2013, the price of PV panels decreased from $\$ 10.70 \mathrm{CAD} /$ Watt to $\$ 0.95 \mathrm{CAD} /$ Watt, driven by technological advances and mass production.

Early cells had an efficiency of approximately 5\%, while recent experimental cells have reported efficiencies in excess of 30\% (Duffie and Beckman, 2013). The most common type of PV cell is single-crystal silicon, shown in Figure 2.4. The n-type silicon is doped with phosphorous, giving it excess electrons in its outer shell. The

p-type silicon is doped with boron, giving it a deficiency of electrons. The doping creates a barrier in the form of a thin layer of static charge, inhibiting the free flow of electrons. When a photon of sufficient energy is absorbed by a silicon atom in the n-type crystal lattice, an electron is freed creating a hole-electron pair. If the contact grid is connected to the metal base, current can be generated when the electron flows from the n-type layer, through a connected circuit, and to the p-type layer (Duffie and Beckman, 2013).

An advantage of PV over solar thermal is that the incident solar radiation is converted into the higher quality form of electrical energy. In domestic applications, 


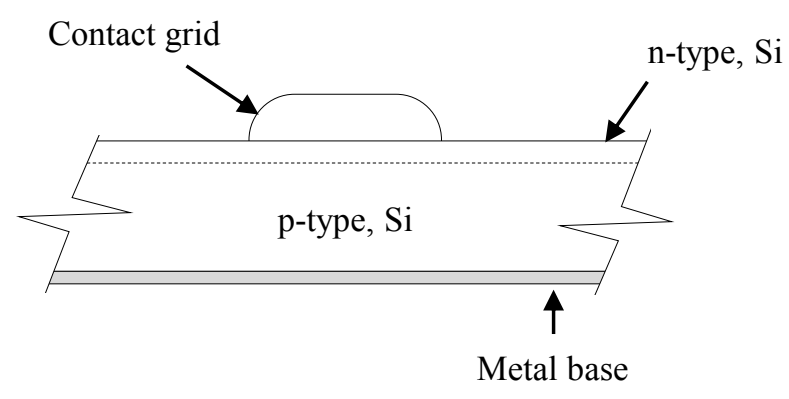

Figure 2.4: Cross-section of PV silicon cell, adapted from Duffie and Beckman (2013)

this may provide opportunities for more on-site energy consumption, since generated electricity may be used to meet appliance and lighting demands, as well as space heating and DHW. Additionally, electrical distribution systems exist with some capacity to export excess electrical production to other consumers. Thermal energy infrastructure, such as district heating systems, is not as common in Canada.

\subsubsection{Microturbines}

One of the challenges of using a renewable energy resource like solar is that it is not a dispatchable generator. Solar energy can only be harnessed during the day when there is little or no overcast. To bridge the gap between supply and demand, different forms of energy storage are often used. For solar thermal systems some form of TES is often used. For solar PV systems, some form of electrical energy storage may be used to bridge the supply-demand gap.

For net-zero buildings, the connected electrical infrastructure is sometimes used as a form of virtual electrical storage. Excess generation is exported to other consumers connected to the infrastructure, and during production deficits electricity is imported. NEB (2016) noted that grid-connected PV presents some challenges for maintaining grid safety and reliability. Fluctuations in PV energy production can be substantial, and NEB (2016) suggested that flexible generators such as natural gas (NG) or hydro 
may be used to help balance PV production on the grid.

Rezaie and Rosen (2012) stated that natural gas is a commonly used energy source in current thermal networks, due to its "availability, price and relatively low emissions compared to other fossil fuels." For residential applications, microturbines have the benefit of being lightweight and compact, having low noise levels, and low vibrations (Eguia et al., 2010). Microturbines are also inverter based generators, making them well suited for dispatch in utility microgrids (Darrow et al., 2015). The exhaust gas of microturbines may also be coupled to heat recovery units for combined heat and power (CHP) applications. Klimstra (2008) (as cited in Rezaie and Rosen (2012)) stated that at the community-scale, CHP plants are often more economic and reduce both GHG emissions and fuel consumption.

Gas-fired microturbines are typically single-shaft recuperated open Brayton cycle machines (Borbely and Kreider, 2001). Figure 2.5 provides a simplified schematic of this cycle.

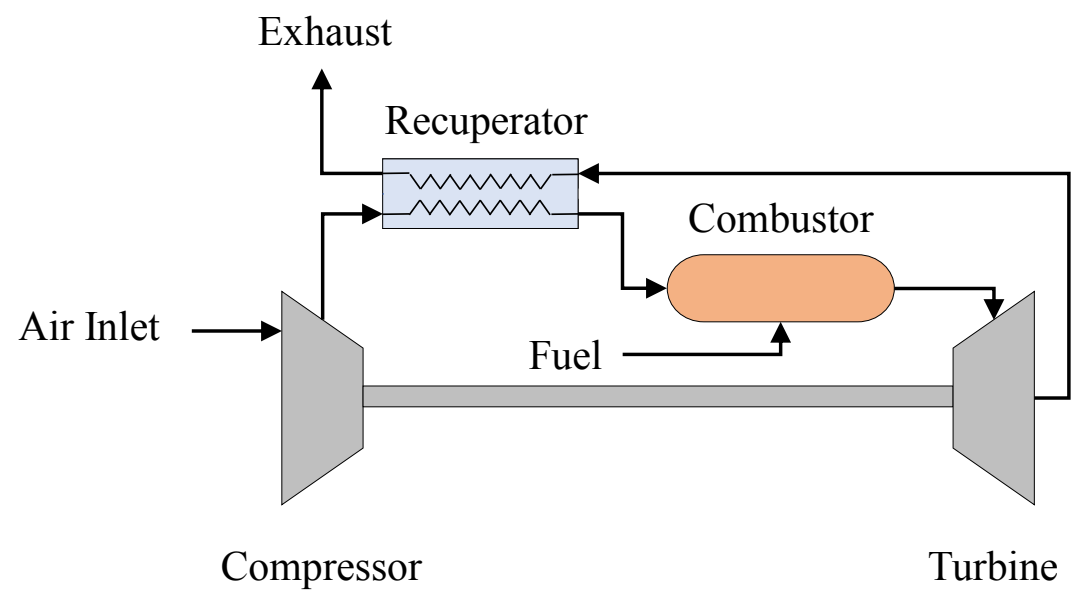

Figure 2.5: Recuperated Brayton cycle, adapted from Borbely and Kreider (2001)

In single shaft systems, electrical output is achieved through an alternator directly 
connected to the shaft (Bertani et al., 2004; Ismail et al., 2013). The high frequency $\mathrm{AC}$ output is converted to DC through a rectifier, then to 50 or $60 \mathrm{~Hz} \mathrm{AC}$ through an inverter. This single-shaft design reduces the number of moving parts, likely reducing maintenance costs and increasing reliability (Darrow et al., 2015).

What is problematic with considering microturbines for on-site generation in netzero projects is that the prime mover used is a conventional fossil fuel. There have been initiatives in recent years to establish a Canadian renewable natural gas (RNG) sector. The Canadian Gas Association (CGA, 2014) defined RNG as methane produced from biomass which has been refined to a level which meets pipeline specifications. This methane may be used interchangeably with conventional natural gas, or as a blend. In May 2016, the CGA announced that Canada's natural gas utilities set a target of 5\% RNG blends by 2025, and 10\% by 2030 (CGA, 2016). Additionally, some microturbine manufacturers state that their natural gas-fired units are also capable of running directly on methane produced from biomass (Capstone, 2017). This ability to fuel microturbines with biofuels and conventional NG makes them an attractive option for bridging the gap between conventional and renewable systems.

\subsection{Existing Net-Zero Communities}

Finkelor et al. (2010) previously stated that net-ZECs are uncommon compared to net-ZEBs. Over the past decade however, some net-ZEC projects have been realized in practice. One successful project is the Kaupuni Village in Oahu, Hawai'i (NREL, 2012). Built in 2011, Kaupuni Village is a community of 19 affordable singlefamily homes and a community resource centre. The average construction cost of each dwelling was $\$ 303,000$, a little more than half the median Oahu home price of $\$ 600,000$ (NREL, 2012). The homes were designed to be "all-electric", meaning all domestic end-uses were satisfied with electricity or on-site renewables. The following energy efficiency measures were implemented in the design of each dwelling (Norton et al., 2013):

\section{- high-efficiency windows}


- architectural shading

- well-insulated walls and roof

- light-coloured roofing

- SEER-16 air conditioning

- Solar DHW

- high-efficiency appliances and lighting

NREL (2012) stated that the dwellings in Kaupuni Village use $40 \%$ less energy compared to a baseline ${ }^{3}$. To bring the houses to net-zero, grid-connected $6.37 \mathrm{~kW}$ solar PV systems were installed on each dwelling. Norton et al. (2013) analysed measured Kaupuni Village electricity grid import and solar PV electricity export from August 2011 to August 2012, and found that the community as a whole came into $1 \%$ of its net-zero target. While not explicitly stated, Norton et al. (2013) reported electricity consumption and production at the site, implying that the Kaupuni Village was targeting a site net-zero energy balance. Interestingly, each dwelling was designed to be net-zero, and the balance was applied over the community to offset more energy intensive occupants with more energy conservative occupants.

The zHome in Issaquah, Washington (King County, 2017) was introduced in Chapter 1 as another net-zero community which has obtained its net-zero energy target. Like the Kaupuni Village project, this 10-unit townhouse development was designed to achieve site net-zero (MBA, 2015). Also like Kaupuni Village, each individual unit in the zHome project was designed to be net-zero, but the balance was evaluated over the entire complex.

The first design step for the zHome was to reduce the on-site energy consumption. This was accomplished through the installation of GSHP systems, HRVs, and hydronic heat systems (MBA, 2015; Milligan, 2015). The building envelope was highly insulated with R-38 walls, R-60 ceilings, and an R-55 roof (MBA, 2015). To reduce occupant-driven demands LED and fluorescent lighting was installed as well as Energy Star@ appliances. To encourage reduced lighting demands, zHome was also

\footnotetext{
${ }^{3}$ NREL (2012) does not explicitly state what the baseline is.
} 
designed to utilize natural daylighting (MBA, 2015). Using two years of monitored data for eight units, MBA (2015) found that the average monthly electricity consumption of the dwellings was between $37 \%$ and $91 \%$ less than the typical dwellings in Issaquah.

On-site energy generation was accomplished using solar PV systems. Each dwelling in zHome was allocated a PV array congruent with dwelling size, ranging from $4.8 \mathrm{~kW}$ to $7.2 \mathrm{~kW}$ (MBA, 2015). During the first year of monitored operation, April 2013 to April 2014, zHome did not achieve site net-zero with 1,636 kWh of net electricity imported. During the April 2014 to April 2015 period however, the zHome exceed net annual electricity export by 2,199 kWh. Using both years as the balancing period, zHome exceeded the required on-site electricity export to achieve net-zero energy by $3.5 \%$ (MBA, 2015).

Both Kaupuni Village and zHome employ similar strategies and design options to achieve net-zero. First the on-site energy demand was reduced using efficient AL, building envelope airtightness and insulation, and efficient HVAC. On-site energy generation was accomplished with solar energy technologies. Solar PV was the primary generation system for both communities. Additionally, dwellings in both communities were designed as all electric, maximizing the utility of the on-site electrical generation. Even though PV is a non-dispatchable technology, neither zHome nor Kaupuni Village used on-site electrical energy storage to match the PV generation to the community demands. Rather the connected electrical grid acts as buffer between load and generation.

\subsection{Thesis Tasks}

There are few examples in the literature of retrofit net-ZEC projects. The most relevant to the current work is the Now House projects described in Section 2.5. The Now House project was able to demonstrate the significant energy savings and economies of scale that are achievable in community energy retrofit projects, but the demonstration houses did not meet a net-zero balance. It is unclear in the literature if retrofitting existing residential communities to achieve net-zero is feasible. 
Stated previously in Chapter 1, in order to practically determine the feasibility and performance of various community retrofit options for achieving net-zero, a detailed simulation methodology is required. Several building stock modelling methodologies were reviewed in Section 2.1, and for considering the existing Canadian residential stock in the current work the Canadian Hybrid Residential Energy End-Use and GHG Emissions Model (CHREM) developed by Swan et al. (2013) was selected. An objective of this thesis was to adopt the CHREM methodology to model community-scale energy retrofit options.

It was shown in Section 2.2 that several other studies have used the CHREM to determine the potential performance and efficacy of new and renewable technologies retrofit in the existing Canadian residential stock. Stated in Section 2.1.3.1, CHREM uses a relatively small set of pre-defined sub-hourly demand profiles to represent occupant driven AL and DHW demands. This approach was suitable for past CHREM studies, since only dwelling-scale technology retrofits were considered. For the current work however, this approach is not applicable. Aggregate community demand estimates using this approach would effectively superimpose multiple instances of identical single-dwelling demands, over-estimating aggregate peak demand and daily variation.

Other challenges to using CHREM for analyzing retrofit community applications include:

- CHREM's limitation to analyzing the performance and efficacy of dwellingscale retrofits. The modelling scope of the underlying simulation engine ESP-r is mostly limited to analysis of single buildings. Chapter 1 introduced the simulation tool TRNSYS as a candidate simulation tool for evaluating communityscale and district energy systems. Previous work using TRNSYS has been performed which simulated district solar thermal energy systems in Canadian communities (Quintana and Kummert, 2015; Sibbitt et al., 2012).

- Requirement of additional results post-process in CHREM. CHREM reports annual energy consumption and GHG emissions of the building stock and individual dwellings. These are disaggregated by fuel source and end-use. For the 
current work additional performance metrics need to be defined, with formal definition of their calculation procedure. Pertinent metrics include net-zero balances, as well as other performance metrics like load matching and grid interaction factors suggested by Sartori et al. (2012).

- Requirement of a decision framework in CHREM to determine the "best" or feasible retrofit options to achieve net-zero. Chapter 1 introduced the use of optimization tools with BPS for designing cost and energy optimal net-zero buildings and communities. GenOpt ${ }^{\circledR}$ was identified as a potential singleobjective optimization tool which has been used in other net-zero research applications, and was adopted for the current work.

Once a simulation methodology was established, it was possible to examine technically and economically feasible retrofit solutions for existing communities to achieve net-zero. As noted in Chapter 1, there lacks a formal and universally accepted definition of net-zero in practice. Several proposed formal definitions do exist in the literature however. There is an a priori understanding of how these various definitions influence net-zero project designs and performance, but quantitative studies focused on net-zero definition influence have not been described in the literature. Thus, the simulation objectives in the current work are two-fold: determine the combination of feasible energy retrofit options to convert and existing Canadian residential community to net-zero, and to examine the influence of net-zero definition on retrofit design and performance.

A summary of the specific tasks completed to achieve the thesis objects are summarized in the following:

1. Improvement of the occupant-driven AL and DHW demand modelling methodology in CHREM to enable estimation of aggregate community demands. A relatively small set of sub-hourly AL and DHW demand profiles were implemented into CHREM Swan (2010) which under-estimate the diversity of these demands within existing residential communities.

2. Development of three virtual communities located in Québec and Ontario to 
function as case studies to analyze feasible retrofit options for achieving netzero, as well as evaluating the impact of net-zero definition on retrofit design and performance. These two provinces were selected for their differences in typical fuel used for HVAC and DHW systems, as well as differences in their provincial fuel mixes for electricity generation.

3. Identification of dwelling and community-scale retrofits and community renewable on-site generation technologies. Completion of this task was facilitated by generation technology review of Section 2.4, and the dwelling-scale retrofits described in Sections 2.2 and 2.5.

4. Implementation of a new simulation framework in CHREM to analyse the performance of retrofitted communities for achieving net-zero. CHREM was initially developed to analyze the impact of technology retrofits on residential sector energy consumption and GHG emissions. To meet the goals of the current work, several modifications of the CHREM methodology needed to be updated. This included integrating simulation tool TRNSYS, introduced previously in Chapter 1, to add community-scale energy system modelling capabilities to CHREM, as well as algorithms to determine additional performance metrics like net-zero balances, electrical grid interaction factors and on-site load/generation matching. Single-objective optimization was also selected for the current work as a tool to determine the feasible net-zero design solutions of communities, and need to be integrated into CHREM.

5. Simulation of different community retrofit measures for existing communities using the newly developed simulation framework. The goal of these simulations were to determine the feasibility and performance of net-zero retrofits for all the virtual communities. These simulations were also meant to demonstrate the capabilities of the framework developed in this thesis.

6. Comparison of the design and performance of communities designed to achieve site and source net-zero. Site net-zero is the most widely applied and simple net-zero definition. Source net-zero is becoming more popular in the literature, but requires the determination of primary energy factors which is a non-trivial 
task. These primary energy factors are typically meant to account for conversion, transmission, and distribution losses. Thus, another task of this research was to determine appropriate primary energy factors for Ontario and Québec. 


\section{Chapter 3}

\section{Simulation Methodologies of Dwelling-scale Retrofit Options}

Chapter 1 stated that the building stock modelling tool CHREM developed by Swan et al. (2013) was selected for this research to examine various strategies for retrofitting existing Canadian residential communities to achieve net-zero. CHREM is a detailed building stock model which uses the BPS tool ESP-r to calculate the energy consumption of dwellings by both fuel type and end-use. Other researchers introduced in Chapter 2 previously used CHREM to evaluate the impact of various dwellingscale retrofits to promote energy conservation and GHG emissions reductions in the residential sector.

A common first approach to achieving net-zero is the implementation of energy conservation measures. For example, both Kaupuni Village and zHome, described previously in Chapter 2, were designed to use $40 \%$ and $25 \%$ less energy compared to similar dwellings in their locales, respectively (Milligan, 2015; NREL, 2012). Researchers such as Sartori et al. (2012) and Carlisle et al. (2009) have suggested that energy efficiency requirements should be incorporated into net-zero energy targets. Achieving the net-zero energy target requires some form of on-site energy generation to offset energy imports and consumption. Reducing the on-site demands also reduces the required capacity and costs of generation equipment.

This chapter describes the dwelling-scale energy retrofits considered in this research to reduce the energy consumption of existing Canadian communities striving 
to achieve net-zero. Since dwelling energy demands are modelled in ESP-r for this research, a brief description of the software's solution methodology is provided in Section 3.1. The dwelling-scale retrofit options considered in this work are then described in Section 3.2. Information is provided regarding how these retrofits were represented in CHREM/ESP-r, and the input parameters used to characterize these retrofits.

To explore these different retrofit options and determine feasible designs for retrofit net-zero residential communities, case study communities were derived from dwelling records in the CSDDRD. Section 3.3 describes the three communities de-

fined for this research. Two of these case studies were representative of existing Toronto, Ontario single-detached communities, and the third is representative of a Montréal, Québec single-detached community. These two municipalities were selected since they represent two major population centres in Canada containing 29.4\% of Canada's entire population as of 2016 (Statistics Canada, 2017a,c).

\subsection{ESP-r Solution Methodology}

ESP-r was initially developed as a tool to solve the transient heat transfer through building systems; however, since its inception additional simulation "domains" have been incorporated into the software such as building acoustics, moisture and air flow, and electrical networks (ESRU, 2017). Originally conceived by Clarke (1977), ESP-r continues to be developed under a community of worldwide code developers and researchers. ESP-r has been validated using building simulation validation tests developed by the International Energy Agency (IEA) Annexes, European standards (CEN), and other large-scale national programs (Strachan et al., 2008).

CHREM primarily uses the thermal and air flow building domains to determine the energy performance of existing dwellings. The solution methodologies of these two domains are briefly described below. 


\subsubsection{Thermal Simulation Domain}

ESP-r solves transient heat transfer using a finite-difference numerical discretization approach (Beausoleil-Morrison, 2000a; Clarke, 2001). Numerical building models are constructed in ESP-r using a three step process described by Clarke (2001). The first step is to divide the building into a set of "thermal zones." Each thermal zone represents a single fully-mixed volume of air which is bounded by multilayer constructions (MLC) such as walls, windows, floors, and ceilings. The number of thermal zones a building is divided into depends on several factors including the objectives of the simulation, the availability of input data, and user preference. Typically rooms that are assumed to be at thermally similar conditions can be lumped together as a single zone to simplify the model and decrease computation time.

Once the user establishes a thermal zoning strategy, the second step to constructing a numerical building models is to define the explicit surfaces which bound the thermal zones. Again, the level of discretization is dependent on the user and the objectives of the simulation. The user may opt to explicitly represent each window surface on a building façade, or may simplify the model by aggregating all windows into a single surface. With surfaces defined, they are then divided into finite-difference nodes. By default ESP-r uses a one-dimensional scheme, illustrated in Figure 3.1, to solve for transient heat transfer through building MLCs. 


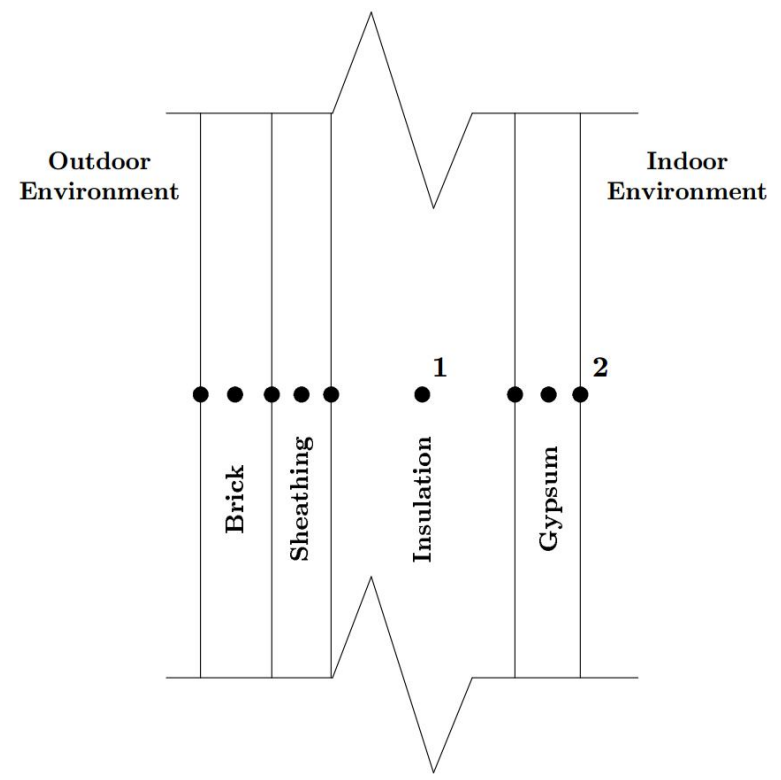

Figure 3.1: ESP-r discretization of an external opaque wall, adapted from Beausoleil-Morrison (2000a)

The final step is to then define energy conservation equations for each node. This involves identifying boundary conditions and thermal connections for all nodes in the system. Further details of the finite-difference method used in ESP-r is omitted here for clarity. The interested reader is directed to Clarke (2001), Beausoleil-Morrison (2000a), Hensen (1991), and Lomanowski (2008) for additional information.

\subsubsection{Air Flow Simulation Domain}

The air flow simulation domain is used by CHREM to characterize air leakage into building envelopes (infiltration), and air flow between zones within a building. Several models are available in ESP-r to represent these flow paths. The simplest method is scheduled air flow, which is a constant or scheduled flow rate specified by the user. CHREM uses this method to model residential ventilation systems, coupled with an algorithm which determines the energy performance of the mechanical ventilation unit.

Building infiltration is modelled in ESP-r/CHREM using the empirical Alberta 
Infiltration Model (AIM-2) developed by Walker and Wilson (1990). This model was developed for low-rise residential buildings, and approximates the whole-dwelling infiltration, $\dot{V}_{\text {inf }}\left[\mathrm{m}^{3} / \mathrm{s}\right]$, as a function of the indoor/outdoor air pressure differential, $\Delta P[\mathrm{~Pa}]$, using a power law:

$$
\dot{V}_{\text {inf }}=C_{0}(\Delta P)^{n}
$$

$C_{0}\left[\mathrm{~m}^{3} / \mathrm{s} \cdot \mathrm{Pa}^{n}\right]$ is the leakage coefficient, and $n[-]$ is the building leakage exponent. Both $C_{0}$ and $n$ for a dwelling are determined experimentally by least squares fitting to blower door test results. This experimental procedure is described by NRCan (2005), and is omitted here for clarity. An extensive discussion of the AIM-2 model is provided in Appendix A.

Equation 3.1 is typically used to characterize flow through an orifice, where exponent $n$ has values between 0.5 and 1.0. For fully turbulent flow through the orifice $n=0.5$, and for fully laminar flow $n=1.0$ (Sherman and T, 1980). When applying Equation 3.1 to determine building infiltration, Canadian standard CAN/CGSB149.10-M86 states that the value of $n$ must also be between 0.5 and 1.0 (Standards Council of Canada, 1986). As $n$ approaches 1 the building envelope leakage is said to be predominately through small and long cracks, whereas if $n$ approaches 0.5 then the leakage is dominated by specific openings, such as a flue (Chan and Sherman, 2012; NRCan, 2005).

Both $C_{0}$ and $n$ are calculated internally in AIM-2 using two commonly reported values for building leakage: equivalent or effective air leakage area, $A_{\text {leak }}\left[\mathrm{cm}^{2}\right]$, and air leakage at $50 \mathrm{~Pa}, A C H_{50}$ [ach]. Details of the AIM-2 calculation procedure are omitted here for clarity. An extended discussion of the ESP-r implementation of AIM-2 is provided in Appendix A.

Air flow between CHREM dwelling zones is modelled using the air flow network approach implemented in ESP-r. Air flow networks discretize the building envelope into discrete volumes of well-mixed air with unknown pressures. Air flow networks are constructed by linking nodes to one another to represent the physical flow connections between spaces. All connections are characterized by flow components which 
represent cracks, openings, or fans. Network flow is driven by flow inducing components such as fans, and by wind-induced pressure boundary nodes. CHREM uses air flow networks to calculate the attic infiltration through roof and eave vents. Air flow networks and constant flow rate fans are used to approximate the exchange of air between occupied zones in CHREM dwellings.

Flow through open windows are also modelled in CHREM using air flow networks. Swan (2010) used a conservative ON/OFF window control with deadband to model residential window operation. The windows are only open if the indoor air is above $25^{\circ} \mathrm{C}$, the outdoor air is above $21^{\circ} \mathrm{C}$, and the difference between indoor and outdoor air is greater then $1{ }^{\circ} \mathrm{C}$. Swan (2010) acknowledged that this is simplified approach to window control, however there is sparse data on residential window operation in the literature. Further discussion of ESP-r air flow modelling methodologies are omitted here for clarity, and the interested reader is directed to Clarke (2001) and Hensen (1991) for additional information.

\subsection{Summary of Dwelling-scale Retrofits Consid- ered}

Selection of dwelling-scale retrofit options considered in the current work was informed by the Canadian residential retrofit studies of Guler et al. (2001) and Guler et al. (2008), described previously in Chapter 2. The retrofit options they considered may be broadly categorized as dwelling envelope upgrades, and DHW/HVAC upgrades. Both types of dwelling-scale upgrades were considered in the current work. Envelope upgrades included increased insulation of exterior main walls, ceilings, and foundation walls. Replacement of dwelling windows was also considered.

Two types of space heating retrofits were considered in this thesis. One is the supply of space heating from a retrofitted district heating system, described later in Chapter 4. The other is the retrofit of GSHP space heating systems. Mentioned previously in Chapter 2, GSHPs are considered to be a renewable geothermal energy technology with COP values between 3 and 5. Two types of DHW system retrofits 
were also considered for the current work. The first option is the replacement of existing systems with heat pump (HP) hot water tanks. Biaou and Bernier (2008) previously simulated the performance of a HP hot water tank installed in a typical Montréal, QC dwelling. Compared to a conventional electrically heated tank, the HP system consumed 53\% less energy. The second option is supplying dwelling DHW using the district heating system which is also supplying space heating.

For each of the retrofit options, several "levels" were defined which indicate the retrofit's perceived increase in building energy performance. For example, a level 0 ceiling insulation retrofit is "do nothing," level 1 is increasing ceiling insulation to R-40 (RSI 7.04), level 2 is increasing insulation to R-60 (RSI 10.57), etc. In contrast to other retrofit studies using CHREM, the current modelling approach considers retrofits in combination with other options instead of individually.

The dwelling-scale retrofits were added to CHREM ESP-r models using preprocessing scripts written in Perl (Perl, 2017) and integrated into the CHREM model architecture. These pre-processing scripts used sets of heuristics to scan dwelling model input files, identify dwellings that are eligible to receive a specified retrofit, then update the model input files to represent the retrofit. The following sections describe the eligibility criteria, model implementation, and input parameters for the dwelling-scale retrofits considered in this research.

\subsubsection{Retrofit Insulation on Dwelling Envelopes}

All retrofit dwelling insulation was modelled in ESP-r by inserting additional material layers into existing model MLCs. The exception to this was modelling foundation heat loss, which was determined using the BASESIMP model developed by Beausoleil-Morrison and Mitalas (1997). The pre-processing scripts scan model geometry and material/constructions data to determine if a dwelling is eligible for an upgrade. The existing constructions of the dwelling are factored into how new insulation layers are added to the model to represent an insulation retrofit. The eligibility and method of implementation varies slightly for each insulation upgrade type and is described below. 


\subsubsection{Ceiling}

Ceiling insulation was assumed to be upgraded using loose-fill insulation. The user specifies the final upgraded RSI value. In the current study, two eligibility criteria were specified for ceiling insulation retrofits:

- The dwelling roof type must be hip or gable;

- Existing RSI value must be less then upgraded RSI.

Due to a lack of detailed geometric information in the CSDDRD, Swan (2010) represented only three types of roof geometries in CHREM, shown in Figure 3.2. Flat roofs were not considered eligible, since there is limited to no space within flat roof constructions to add blown-in insulation.

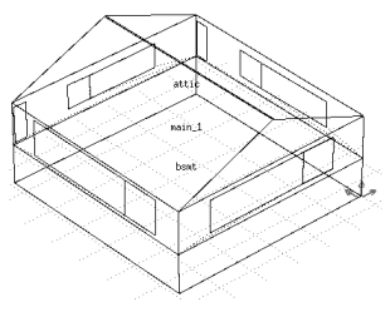

(a) Gable

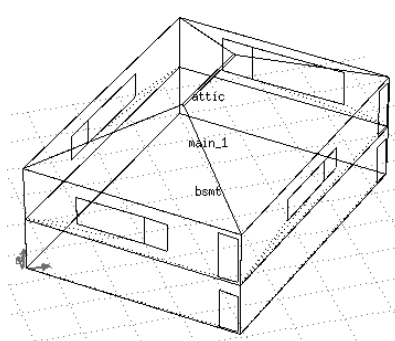

(b) Hip

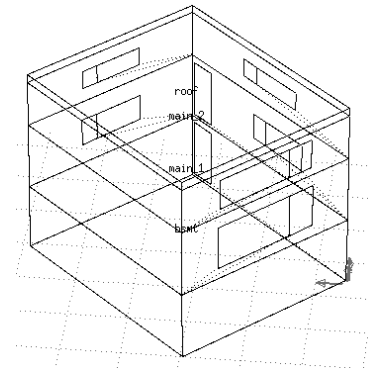

(c) Flat

Figure 3.2: Roof geometries considered in CHREM

The existing RSI of the ceiling was determined using all material layers. If the existing RSI value of the ceiling was below the user requested value, an additional layer of loose-fill insulation was added until the desired RSI value was achieved. Figure 3.3 illustrates a typical ceiling construction modelled in CHREM, and the addition of a blown-in insulation layer. 


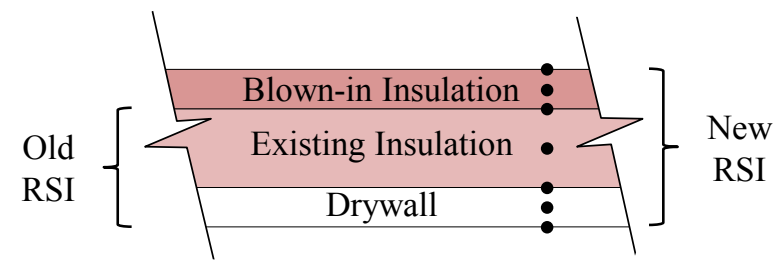

Figure 3.3: Typical CHREM ceiling multi-layer construction with retrofit insulation

In the current study three ceiling insulation levels were considered, and are provided in Table 3.1. Also provided in Table 3.1 are the minimum insulation levels prescribed for Climate Zone 5 (Toronto) and 6 (Montréal) in Subsection 9.36.2 of the 2015 National Building Code of Canada (CCBFC, 2015)․ Upgrade levels 2 and 3 were selected to exceed code minimum.

Table 3.1: Ceiling insulation retrofit levels considered

\begin{tabular}{lc|cc}
\hline & & multicolumn2cCode Minimum & \\
\cline { 3 - 4 } $\begin{array}{l}\text { Upgrade } \\
\text { Level }\end{array}$ & New RSI Value & multicolumn2cClimate Zone & \\
\hline \hline 0 & No change & $\mathbf{5}$ & $\mathbf{6}$ \\
1 & $7.04(\mathrm{R}-40)$ & $8.67(\mathrm{R}-49)$ & \\
2 & $10.57(\mathrm{R}-60)$ & & \\
3 & $14.09(\mathrm{R}-80)$ & & \\
\hline
\end{tabular}

The thermophysical properties of the new ceiling insulation are provided in Table 3.2. It was assumed that the new insulation is blown-in glass fibre. The properties of this material were derived from the existing attic fibreglass batting material specified previously by Swan (2010).

\footnotetext{
${ }^{1}$ Subsection 9.36 .2 provides to sets of minimums dependent upon whether an HRV is present or not. The values reported in Table 3.1 are for dwellings without HRVs which require higher insulation levels
} 
Table 3.2: Ceiling insulation thermophysical properties

\begin{tabular}{lc}
\hline Parameter & Value \\
\hline \hline Thermal conductivity, $k_{\text {ins }}[\mathrm{W} / \mathrm{mK}]$ & 0.043 \\
Specific heat, $c_{p, i n s}[\mathrm{~J} / \mathrm{kgK}]$ & 835 \\
Density, $\rho_{\text {ins }}\left[\mathrm{kg} / \mathrm{m}^{3}\right]$ & 16 \\
\hline
\end{tabular}

The maximum spatial discretization of the new insulation layer was $200 \mathrm{~mm}$. By default, ESP-r issues a warning when any defined layer in an MLC exceeds $200 \mathrm{~mm}$. This limit is implemented in ESP-r to limit spatial discretization errors and maintain solution stability. If the required layer thickness exceeded $200 \mathrm{~mm}$, additional insulation material layers were defined.

It should be noted that eave compression was not considered in this study. Eave compression refers to the geometric limit of applying blown-in insulation on an attic floor with sloped roof overhead. Moving closer to the edge where an attic floor meets a sloped roof there is less vertical space available to install insulation to achieve desired thermal insulation values. Given the lack of geometric information regarding roof topology in the CSDDRD, and simplified geometry of the footprint, eave compression was neglected and all ceiling areas were assumed to be capable of achieving the upgrade options uniformly across the attic floor surface.

\subsubsection{Exterior Wall}

Exterior wall insulation retrofits were added insulation to the external surface, illustrated in Figure 3.4. It is assumed that during the retrofit process of existing dwellings that occupants continue to occupy the space. Insulating the main walls from the exterior is less invasive and disruptive to occupants compared to interior insulation retrofits. This was the reasoning and methodology employed in the Now House Projects described previously in Chapter 2. 


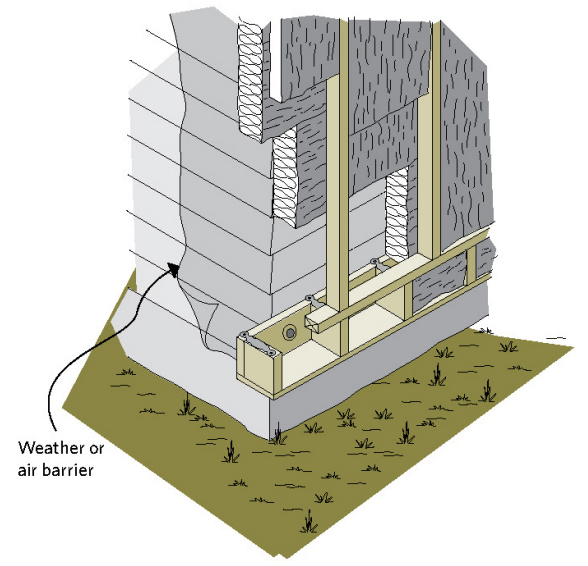

(a) Batt

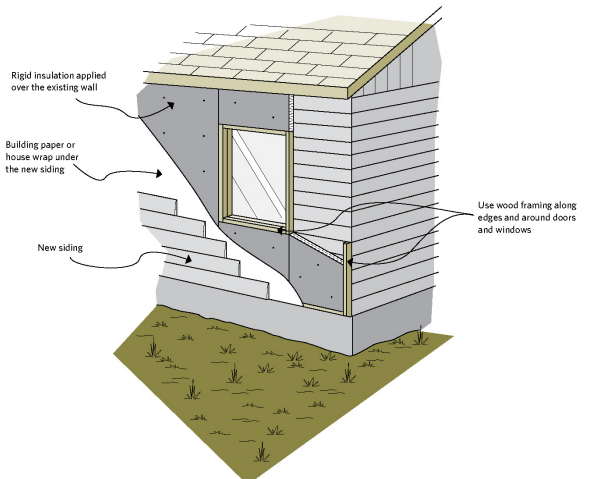

(b) Rigid board

Figure 3.4: Exterior wall insulation retrofit, from NRCan (2016b)

Similar to the ceiling upgrade, the pre-processing scripts scan ESP-r model geometry and construction inputs and determine the existing RSI value of the entire main wall assembly. This RSI value is compared against a user requested RSI value. In the current work, three levels of exterior wall insulation retrofits were used, shown in Table 3.3. These insulation levels were informed by thermal performance requirements for existing buildings in Ontario Standard SB-12 from MMA (2016). Also provided in Table 3.3 is the code minimum for exterior walls in climate zones 5 and 6 (for dwellings with no HRV). It can be seen that all upgrade levels exceed code minimum. 
Table 3.3: Exterior wall insulation retrofit levels considered

\begin{tabular}{|c|c|c|c|}
\hline \multirow[b]{2}{*}{$\begin{array}{l}\text { Upgrade } \\
\text { Level }\end{array}$} & \multirow[b]{2}{*}{ New RSI Value } & \multicolumn{2}{|l|}{ multicolumn2cCode Minimum } \\
\hline & & $\underset{5}{\operatorname{multicolumn} 2 \mathrm{c} C \text { limate Zone }}$ & 6 \\
\hline 0 & No change & \multirow{4}{*}{$3.08(\mathrm{R}-17.5)$} & \multirow{4}{*}{$3.08(\mathrm{R}-17.5)$} \\
\hline 1 & $4.23(\mathrm{R}-24)$ & & \\
\hline 2 & $4.75(\mathrm{R}-27)$ & & \\
\hline 3 & $5.46(\mathrm{R}-31)$ & & \\
\hline
\end{tabular}

The only eligibility criteria specified for this retrofit is that the existing exterior wall RSI must be less than the new RSI requested. The method used to apply the new insulation layers however, varies with the type of existing cladding on the dwelling. Figure 3.5 illustrates two typical wall assemblies modelled in CHREM. If the existing dwelling has aluminium, wood, or vinyl siding, and is eligible for additional insulation, the old siding construction layer is removed and the new insulation layer is added to the sheathing layer. A new siding layer is then added, shown in Figure 3.5(a). For dwellings with brick cladding, the new insulation and siding as added directly to the brick, shown in Figure 3.5(b).
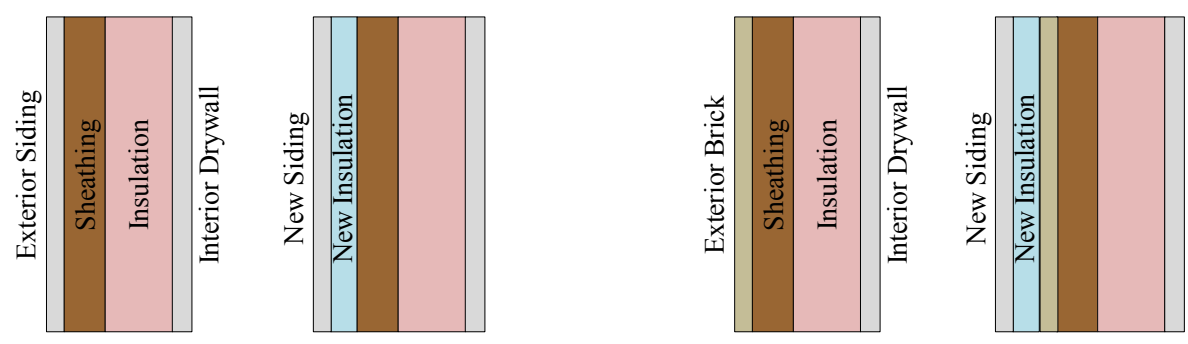
(a) Siding cladding
(b) Brick cladding

Figure 3.5: Typical CHREM exterior wall assemblies and retrofit insulation placement 
ESP-r exterior wall retrofit simulations were conducted assuming the exterior insulating material was glass-fibre batt mounted in a frame, such as Figure 3.4(a). For the ceiling insulation retrofit discussed previously, the additional insulation layer thickness was determined as a function of the additional RSI required. For the exterior wall retrofits, however, only discrete layer thicknesses could be applied. Wood framing studs and insulation boards are often marketed in discrete measurements. In the current work insulation layer thickness retrofit to exterior walls was incremented by $1 / 2 "(12.7 \mathrm{~mm})$ with a minimum thickness of $1 "(25.4 \mathrm{~mm})$. The thermophysical properties of the batt and cladding are provided in Table 3.4. The batt was assumed to have the same properties as the glass-fibre specified by Swan (2010). The cladding properties were also derived from the vinyl siding properties specified by Swan (2010).

Table 3.4: Exterior wall retrofit layers thermophysical properties

\begin{tabular}{lcc}
\hline Parameter & $\begin{array}{c}\text { Siding } \\
\text { Value }\end{array}$ & $\begin{array}{c}\text { Insulation } \\
\text { Value }\end{array}$ \\
\hline \hline Thermal conductivity, $k_{\text {ins }}[\mathrm{W} / \mathrm{mK}]$ & 0.16 & 0.043 \\
Specific heat, $c_{p, \text { ins }}[\mathrm{J} / \mathrm{kgK}]$ & 1000 & 835 \\
Density, $\rho_{\text {ins }}\left[\mathrm{kg} / \mathrm{m}^{3}\right]$ & 1380 & 16 \\
\hline
\end{tabular}

It was later decided to consider extruded polystyrene (XPS) as an insulation material for exterior walls, since lower thicknesses are required to achieve the same thermal insulation, and less exterior framing is required. For existing dwellings, lotline restrictions may prevent extension of the building envelope with thick layers of insulation (NRCan, 2016b). Instead of running additional simulations, an equivalent XPS thickness, $l_{X P S}[\mathrm{~m}]$, was determined using Equation 3.2 for each retrofitted exterior wall batt layer.

$$
l_{X P S}=k_{X P S} \cdot \frac{l_{\text {Batt }}}{k_{\text {Batt }}}
$$

where $l_{\text {Batt }}[\mathrm{m}]$ and $k_{\text {Batt }}[\mathrm{W} / \mathrm{mK}]$ are the thickness and thermal conductivity of the 
batt layer, respectively. A conservative estimate of XPS thermal conductivity, $k_{X P S}$, of $0.03 \mathrm{~W} / \mathrm{mK}$ was assumed from ASHRAE (2013). The difference in insulation layer thickness has a negligible impact on thermal energy calculations, since both have equivalent RSI values. There is however, implications in the economic analysis described later in Chapter 6.

\subsubsection{Basement}

The basement insulation upgrades considered are summarized in Table 3.5. Two eligibility criteria were defined for this retrofit: the dwelling must have a basement, and the RSI of the existing insulation is below the requested level of upgraded insulation. Also provided are the code-minimum foundation wall insulation levels. Shown later in Table 3.16, the average foundation insulation in the two Toronto communities considered for case studies in this work had average foundation insulation of 1.37 and $1.81 \mathrm{~m}^{2} \mathrm{~K} / \mathrm{W}$. Upgrade levels 1 and 2 provide incremental improvements in existing insulation. Upgrade level 3 brings the foundations to "better than code."

Table 3.5: Basement insulation retrofit levels considered

\begin{tabular}{lc|cc}
\hline & & multicolumn2cCode Minimum & \\
\cline { 3 - 4 } $\begin{array}{l}\text { Upgrade } \\
\text { Level }\end{array}$ & New RSI Value & $\mathbf{5}$ & $\mathbf{6}$ \\
\hline \hline 0 & No change & & \\
1 & $1.76(\mathrm{R}-10)$ & & \\
2 & $2.64(\mathrm{R}-15)$ & & \\
3 & $3.52(\mathrm{R}-20)$ & & \\
\hline
\end{tabular}

Although it is assumed that glass-fibre batt is used as the retrofit insulation material, the type of insulating material does not have to be explicitly stated. Foundation heat loss is calculated in CHREM using the ESP-r implementation of BASESIMP developed by Beausoleil-Morrison and Mitalas (1997). This model uses a regressionbased approach to determine foundation heat loss. Beausoleil-Morrison and Mitalas 
(1997) validated BASESIMP by comparing several foundation heat loss calculations to the validated Mitalas method (Mitalas, 1987), and were found to have good agreement. BASESIMP was also compared to BASECALC using 228 randomly generated foundation configurations, and the average foundation heat loss error was found to be $0.55 \mathrm{GJ} /$ year, indicating good agreement.

BASESIMP regression coefficients were derived from over 100,000 simulations performed in the residential foundation heat loss simulation tool BASECALC ${ }^{2}$. The independent variables used in the regression include foundation configuration, geometry, and the RSI value of insulation. Beausoleil-Morrison and Mitalas (1997) developed heat loss correlations for several two-dimensional foundation configurations, and identified each configuration with a foundation type number. Examples of these foundation configurations are provided in Figure 3.6. ESP-r currently has regression coefficients for 145 different foundation configurations (Beausoleil-Morrison, 1996; ESP-rCommunity, 2017) to represent a wide range of residential foundation systems.

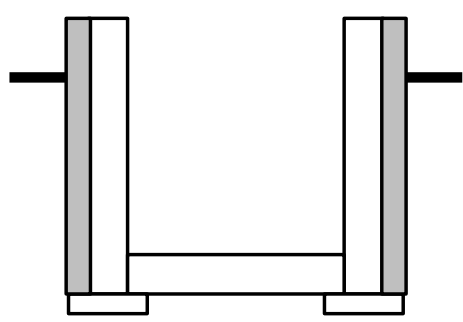

Foundation Type 6

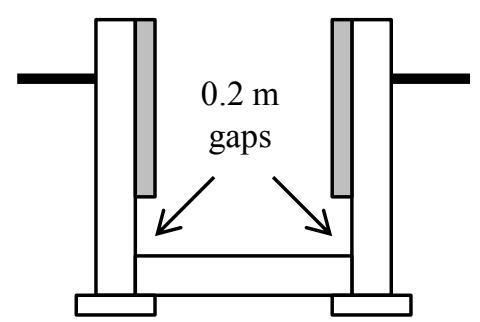

Foundation Type 2

Figure 3.6: Example of BASESIMP foundation configurations, adapted from Beausoleil-Morrison (1996)

To model retrofit foundation insulation, both the insulation RSI value and foundation configuration type inputs were updated. The pre-processing scripts determined

\footnotetext{
${ }^{2}$ BASECALC uses a quasi-three-dimensional method developed by Beausoleil-Morrison et al. (1995) to calculate foundation heat loss.
} 
existing dwelling foundation configurations, and updated the foundation configuration to represent the newly added insulation. For the current work, insulation was assumed to be added to the full height of the interior foundation walls. Details of how the pre-processing scripts determined the retrofitted foundation configuration are provided in Appendix C.

\subsubsection{Glazing Retrofit}

The final dwelling envelope upgrade considered was window retrofits. Nikoofard et al. (2013) noted that windows in heating-dominated climates like Canada are useful for permitting solar energy into building spaces to offset heating demands. These solar gains also contribute to cooling loads during the summer; however, as of 2014 space cooling accounted for $1.2 \%$ of Canadian residential sector energy demands (OEE, 2017). Windows may also be a significant source of dwelling heat loss during the winter, since their thermal insulating value may be much lower compared to surrounding walls (Nikoofard et al., 2013).

Three primary performance metrics are used to characterize windows/glazing systems:

1. U-factor representing the thermal conductivity of the window or glazing system $\left[\mathrm{W} / \mathrm{m}^{2} \mathrm{~K}\right]$

2. Solar heat gain coefficient (SHGC) which characterizes the transmission of solar energy through windows;

3. Visible light transmittance $\tau_{v i s}$ characterizing the fraction of visible light passing through the glazing system.

Nikoofard et al. (2013) stated that the ideal combination of these properties depends on several factors including local climate, building type, and building design. For example, a low U-factor and high SHGC is desirable for heating dominated climates, whereas low SHGC is desirable for applications where overheating is problematic (Nikoofard et al., 2013). 
Using CHREM, Nikoofard et al. (2013) considered the retrofit of windows in the existing Canadian residential stock with six different glazing systems; three doubleglazed systems, and three triple-glazed with various low-emissivity (low-e) coatings and gas fills between the glass panes ${ }^{3}$. They showed that potential dwelling retrofit energy savings of $6.7 \mathrm{GJ} / \mathrm{yr}$ and $8.8 \mathrm{GJ} / \mathrm{yr}$ could be realized in Québec and Ontario, respectively, using triple-glazed, low-e, argon-filled windows.

For this work, three different glazing system upgrades were considered, based upon commercially-available products:

1. Double-glazed, low-e, $16 \mathrm{~mm}$ argon gap;

2. Double-glazed, double low-e, $16 \mathrm{~mm}$ argon gap;

3. Triple-glazed, double low-e, $12 \mathrm{~mm}$ argon gaps.

To determine the thermal and optical properties of each glazing system, the calculation tool Window 7.4 (LBNL, 2016) was used. Window 7.4 is used to determine centre-of-glass glazing system performance using a one-dimensional steady-state thermal network modelling approach ${ }^{4}$. Window 7.4 comes packaged with several example glazing system configurations, as well as detailed libraries of commercially-available glazing material optical and thermal properties developed and maintained by the National Fenestration Rating Council (NFRC, 2017).

For the current work, the libraries in Window 7.4 were used to construct and model three retrofit glazing systems. The calculated centre-of-glass performance values of these glazing systems are summarized in Table 3.6. These values were determined using temperature and solar radiation boundary conditions specified by NRFC standard 100-2010 (NFRC, 2010). Detailed optical and thermal values calculated by Window 7.4 and used to model these glazing systems in ESP-r are provided in Appendix E.

\footnotetext{
${ }^{3}$ Air and argon.

${ }^{4}$ Coupled with other tools, Windows 7.4 may also provide the total-product area-weighted performance of windows which accounts for thermal bridging through the frame and other heat transfer phenomena.
} 
Table 3.6: Retrofit glazing systems centre-of-glass performance metrics

\begin{tabular}{lccc}
\hline $\begin{array}{l}\text { Glazing } \\
\text { System }\end{array}$ & $\begin{array}{c}\text { U-factor } \\
{\left[\mathrm{W} / \mathrm{m}^{2} \mathrm{~K}\right]}\end{array}$ & $\begin{array}{c}\text { SHGC } \\
{[-]}\end{array}$ & $\begin{array}{c}\boldsymbol{\tau}_{\boldsymbol{v} \text { is }} \\
{[-]}\end{array}$ \\
\hline \hline 1 & 1.703 & 0.775 & 0.76 \\
2 & 1.138 & 0.468 & 0.69 \\
3 & 0.993 & 0.607 & 0.64 \\
\hline
\end{tabular}

NFRC 100-2010 test conditions

The three glazing systems considered were selected due to differences in their performance metrics. Glazing system 1 provides relatively low thermal insulation, but has the largest SHGC of all glazing systems considered. Glazing system 2 has a higher thermal resistance at the expense of a reduced SHGC. System 3 provides a compromise between systems 1 and 2, with relatively high thermal resistance and SHGC. The drawback to system 3 is that triple-glazed windows are often significantly more expensive than double-glazed.

Swan (2010) implemented a three-digit window type code system in CHREM to describe the construction and characteristics of windows. The digits indicated number of glazing layers, coatings or tints applied, and the gap spacing and gas fill between the panes. Nikoofard et al. (2013) later revised CHREM with a four-digit code, which used separate digits for indicating gap spacing and gas fill, summarized in Table 3.7. 
Table 3.7: Four-digit CHREM window identifier code, adapted from Nikoofard et al. (2013)

\begin{tabular}{lcccc}
\hline $\begin{array}{l}\text { Code } \\
\text { Digit Value }\end{array}$ & $\begin{array}{c}\text { Glazing* } \\
\text { type }(\text { digit 1) }\end{array}$ & $\begin{array}{c}\text { Coating** } \\
(\text { digit 2) }\end{array}$ & $\begin{array}{c}\text { Fill Gas } \\
\text { (digit 3) }\end{array}$ & $\begin{array}{c}\text { Fill Gas } \\
\text { (digit 4) }\end{array}$ \\
\hline \hline 0 & - & Clear glass & Air & $13 \mathrm{~mm}$ \\
1 & SG & Low-e $(0.04)$ & Argon & $9 \mathrm{~mm}$ \\
2 & DG & Low-e $(0.10)$ & - & $6 \mathrm{~mm}$ \\
3 & TG & Low-e $(0.20)$ & - & - \\
4 & - & Low-e $(0.40)$ & - & - \\
\hline$*$ SG single-glazed, DG=double-glazed, TG=triple-glazed & & \\
$* *$ Low-e coating is applied to gap facing side of inner-most layer &
\end{tabular}

For the current work the glazing codes applied to retrofit glazing systems 1 to 3 were 2310, 2110, and 3310, respectively.

To determine if a dwelling window was eligible for retrofit, both the glazing type and coating digits were compared between the existing and retrofit windows. If the existing glazing type digit was less than the retrofit, the window was not eligible for an upgrade. If the existing glazing type digit was less than or equal to the retrofit digit, the coating digits were then compared. For the current work only existing windows with coating digit 0 (clear glass) were determined to be eligible for retrofit.

To simulate the glazing retrofit the pre-processing scripts updated the thermal and optical properties of the upgraded glazing surfaces in ESP-r. CHREM models windows as two lumped surfaces representing the glass and frame, respectively (Swan, 2010). To model the retrofit windows in ESP-r, the pre-processing scripts also update the frame thermal properties. For the current work the retrofitted frames were assumed to be vinyl, and were modelled using the default multi-layer construction configuration defined by Swan (2010) in CHREM. The effective RSI of these frames is $0.84 \mathrm{~m}^{2} \mathrm{~K} / \mathrm{W}$. 


\subsubsection{Ground Source Heat Pump Retrofit}

Retrofit GSHP systems were simulated using the ideal HVAC model implemented in ESP-r and developed by Purdy and Morrison (2003). The GSHP model is divided into a water-to-air heat pump solver, and a ground heat exchanger (GHX) solver. The water-to-air heat pump solver uses a quadratic expression, which is a function of rated unit $\mathrm{COP}$ and entering water temperature, to calculate the instantaneous part-load performance of the GSHP. A full description of the water-to-air heat pump may be found in Purdy (2002).

By default, CHREM assumes all dwellings with a GHSP system have a rated COP of 3.0. According to NRCan (2017), typical closed-cycle GSHP systems have a COP of 3.1 to 4.9. For this work the retrofit GHSP was specified with a conservative COP of 3.0. The capacity of all retrofit GSHP systems were assumed to be $7.5 \mathrm{~kW}$, which is also the default heat pump capacity in CHREM (Swan, 2010). A back-up electric furnace was also included with retrofit GSHPs. The capacity of the retrofit furnace was determined as the difference between the reported dwelling heating capacity in the CSDDRD and $7.5 \mathrm{~kW}$. The thermal efficiency was assumed to be $100 \%$ which is typical for an electrically heated system.

The entering water temperature of the heat pumps was determined using the GHX model. Implemented into ESP-r by Purdy and Morrison (2003), the GHX model is an adaptation of the GS2000 ${ }^{\mathrm{TM}}$ model developed by Morrison (1997). This model approximates buried pipes as infinite line heat sources, and the heat transfer between the ground and pipes are calculated using the approximation to Kelvin's one-dimensional line source conduction solution proposed by Hart and Couvillion (1986) (Caneta, 1992). Unlike the heat pump, the GHX model requires detailed inputs such as system geometry and soil thermophysical properties. Proper sizing of GHXs depends on several factors including climate, soil type and moisture content, winter snow cover over the GHX, and heating demands of the dwelling (Canadian GeoExchange Coalition, 2009).

The current research uses representative case study communities to test different retrofit design strategies for net-zero. Specific information related to site geological 
properties is not available. Additionally, the sizing and design of GHX systems is outside the scope of the current work. Therefore, an applicable GHX system from the literature was used to define the detailed GHX inputs required by ESP-r. The retrofit systems were assumed to be vertical closed-system boreholes. According to NRCan (2017) these types of systems are well suited for urban and suburban applications where lot area is limited.

All dwellings retrofit with a GSHP used the same GHX system which was based on the system described by Kummert and Bernier (2008). They performed simulations of a vertical borehole GHX system installed in a typical single-detached dwelling located in Québec, Canada. The dwelling had annual heating and cooling loads of 6.5 MWh and 4 MWh, respectively. Since the current work considered dwellings in Ontario and Québec, this GHX system configuration and size was assumed to be applicable. The model parameters for the GHX are summarized in Table 3.8. 
Table 3.8: Ground heat exchanger model parameters, adapted from Kummert and Bernier (2008)

\begin{tabular}{lc}
\hline Parameter & Value \\
\hline \hline Pipe inside dia. $[\mathrm{mm}]$ & 21.88 \\
Pipe outside dia. $[\mathrm{mm}]$ & 24.88 \\
Pipe conductivity [W/mK] & 0.4 \\
Pipe length [m] & 394 \\
Pipe spacing [mm] & 127.5 \\
Number of U-bends [-] & 2 \\
\hline Borehole dia. $[\mathrm{mm}]$ & 152.4 \\
Borehole depth $[\mathrm{m}]$ & 100 \\
Borehole top depth $[\mathrm{m}]$ & 1.5 \\
Grout conductivity $[\mathrm{W} / \mathrm{mK}]$ & 0.73 \\
\hline GHX fluid density $\left[\mathrm{kg} / \mathrm{m}^{3}\right]$ & 1038 \\
GHX fluid specific heat $[\mathrm{kJ} / \mathrm{kgK}]$ & 3.75 \\
GHX fluid flow rate $[\mathrm{L} / \mathrm{s}]$ & 0.35 \\
\hline Soil domain depth $[\mathrm{m}]$ & 120 \\
Soil conductivity $[\mathrm{W} / \mathrm{mK}]$ & 2.0 \\
Soil diffusivity $\left[\mathrm{m}^{2} / \mathrm{s}\right]$ & $8.68 \mathrm{e}-7$ \\
Day of minimum surface temp. & Feb $9^{\text {th }}$ \\
\hline
\end{tabular}

No eligibility criteria were defined for this retrofit; all dwellings received the upgrade. The only exception to this is if the existing dwelling already has a GSHP system. According to the CSDDRD however, only $0.2 \%$ of existing single-detached and double/row dwellings in Canada have a GSHP space heating system.

\subsubsection{Heat Pump DHW System Retrofit}

Existing and retrofit DHW systems were modelled in CHREM/ESP-r using the ideal DHW model developed by Lopez (2001). This is simplified model which uses DHW 
system performance metrics typically reported by manufacturers, summarized in Table 3.9.

Table 3.9: Retrofit heat pump hot water tank model inputs

\begin{tabular}{lc}
\hline Parameter & Value \\
\hline \hline Volume [1] & 180 \\
COP [-] & 2.4 \\
$\dot{Q}_{D H W, \text { backup }}[\mathrm{kW}]$ & 3.0 \\
\hline
\end{tabular}

The tank volume and electric backup capacity, $\dot{Q}_{D H W, b a c k u p}$, inputs were assumed from CHREM default values defined by Swan (2010). The retrofit tank COP was based on the value used previously by Biaou and Bernier (2008). A COP of 2.4 was determined to be a conservative estimate for performance. Surveying commerciallyavailable heat pump hot water tanks reported by ENERGY STAR (2017), Energy Factors $^{5}$ which are similar to COP ranged from 2.3 to 3.5, with an average of 2.9.

By default the ideal DHW module assumes that heat pump hot water tanks have no thermal losses. Since the tank is using a heat pump, however, thermal energy extracted from the zone containing the tank is coupled to the thermal zone energy balance calculated in ESP-r.

Similar to the GSHP retrofit upgrade, the only eligibility criteria defined was that a dwelling must not already contain a heat pump hot water tank. According to the CSDDRD, only $0.06 \%$ of existing single-detached and double/row dwellings had a heat pump hot water tank installed.

\subsubsection{Envelope Airtightness}

Sections 3.2.1 and 3.2.2 described the envelope retrofits considered in the current study. To simulate the energy performance of these upgrades in CHREM, the dwelling layer constructions were modified to represent new insulation materials

\footnotetext{
${ }^{5}$ Ratio of tank thermal energy supplied to total energy consumed by tank over 24 hour period (OEE, 2012).
} 
added to the envelope. What is often overlooked in building retrofit simulations, like those reviewed in Chapter 2, is that changes in the building envelope will alter envelope airtightness as well as the thermal properties. This has been demonstrated in recent publications. Sinnott and Dyer (2012) studied airtightness measurements tests of 28 homes located in Ireland with vintages of 1944 to 2008. Several of these dwellings had received one or more of the following upgrades during their service life: new doors and windows, wall cavity insulation, attic insulation, and new gas-fired heating. Comparing dwellings of similar vintages, Sinnott and Dyer (2012) found that dwellings which had received one or more of these upgrades generally had a higher airtightness compared to dwellings which had no upgrades.

Chan and Sherman (2012) performed an additional analysis on an airtightness measurements database of 134,000 single-detached dwellings across the U.S. The source of this database was from American weatherization assistance and residential energy efficiency programs. Within this database were 23,100 homes which had both pre and post-retrofit airtightness measurements. Chan and Sherman (2012) found that building leakage, expressed using normalized leakage area $F_{\text {leakage }}{ }^{6}$, reduced by a median value of $25 \%$. Unfortunately Chan and Sherman (2012) did not have information on the explicit retrofits applied to the dwellings in their database. They stated that U.S. efficiency programs include retrofits of wall insulation, air sealing, and acoustic storm windows.

The impact of building retrofits on airtightness is often overlooked since there is a lack of data in the literature. In this research, however, a detailed database of dwelling measurements was made available. A unique characteristic of this database is that it contains blower door test data for several dwellings across Canada that received retrofits as part of government incentive programs. Both pre and post-retrofit blower door data is available, as well as information on dwelling characteristics such as geometry and building envelope RSI values. Another beneficial feature of this database is the information regarding the retrofit measures is also provided for each dwelling. The following sections provide details of this database and how it was utilized in the current work.

\footnotetext{
${ }^{6}$ The effective leakage area is normalized with respect to floor area and building height.
} 


\subsubsection{Description of Airtightness Measurements Database}

The Energy Efficiency Database was developed and maintained by NRCan. This database was compiled from several Canadian residential energy incentive programs over the past 30 to 40 years including ENERGY STAR ${ }^{\circledR}$, EnerGuide for New Houses (EGNH), and R-2000. These programs sought to inform and provide energy retrofit solutions to Canadian homeowners, and typically involved an NRCan trained energy auditor assessing the property, and performing a blower door test in accordance with Canadian standard CAN/CGSB-149.10-M86 (Standards Council of Canada, 1986).

Previous analysis of this database was conducted by Proskiw Engineering (2015), who was supplied a processed version of the Energy Efficiency Database from NRCan. This database subset only contained records of dwellings which received only one building retrofit option, and had both post and pre-fit blower door test results. The types of retrofits represented in the subset and sample sizes are provided in Table 3.10 .

Table 3.10: Energy Efficiency Database subset retrofit options and sample sizes

\begin{tabular}{ll}
\hline Retrofit & Sample Size \\
\hline \hline Air leakage sealing (without incentives) & 43,360 \\
Air leakage sealing (with incentives) & 2813 \\
Wall insulation & 36,136 \\
Attic insulation & 9989 \\
Foundation insulation & 23,214 \\
Windows & 44,230 \\
Mechanical systems & 19,431 \\
\hline
\end{tabular}

Each record characterized dwelling airtightness using $A C H_{50}$, and reported both the pre and post-retrofit values. Each record additionally included pre and postretrofit dwelling information on:

- DHW system fuel type and energy factor; 
- space heating system fuel type and efficiency;

- number of storeys;

- $A C H_{50}$;

- ceiling, foundation, and main wall RSI;

- floor area and dwelling footprint;

- vintage (decade of construction);

- and province.

Proskiw Engineering (2015) characterized the change in dwelling airtightness as the fractional reduction of $A C H_{50}$ due to retrofit, $\triangle A C H_{50}$ [\%]. The subset was then analyzed using a clustering approach. Records were grouped by retrofit type, and Proskiw Engineering (2015) determined the sample mean, minimum, maximum, standard deviation, and coefficient of variation of each group. It was found that the mean $\triangle A C H_{50}$ values for the retrofit options were between $7 \%$ and $15 \%$. This was interesting since the majority of the retrofit options focused on increasing dwelling thermal insulation. Proskiw Engineering (2015) also stated that in some cases the energy conservation benefits from increased airtightness may outweigh the benefits from increased thermal insulation. Therefore, in order to have an accurate estimate of the efficacy of residential building retrofits, the retrofit impacts on both the envelope thermal resistance and airtightness need to be considered.

Within each retrofit group, Proskiw Engineering (2015) also clustered each database by vintage, province, and number of storeys to separately examine the bivariate relationships between these independent variables and $\triangle A C H_{50}$. The general conclusions they drew from this analysis were that newer dwellings were more airtight then older dwellings, dwellings in the Prairies were generally tighter than in more temperate regions, and partial-storey buildings were generally leakier then full-storey dwellings. Similar to the findings from Chan et al. (2005) and Chan and Sherman (2012), however, Proskiw Engineering (2015) observed significant variation of dwelling airtightness and $\triangle A C H_{50}$ within each retrofit option database. In some cases, retrofits even made the dwelling less airtight. Without additional information 
on the dwellings and the retrofit, Proskiw Engineering (2015) was unable to explain the variation. For example, for wall insulation retrofits the only provided information is the change in wall RSI value. No information is provided on the materials or construction methods used.

\subsubsection{Analysis of Airtightness Measurements Database}

The subset provided to Proskiw Engineering (2015) was obtained from NRCan CanmetENERGY (Ferguson, 2016) for the current work. Two separate analyses were performed: a multivariate regression analysis using the artificial neural network (ANN) tool in Matlab (MathWorks, 2017b), and a clustering analysis which grouped the data by retrofit option, region, and vintage. It was stated previously in Chapter 2 that ANNs are universal approximators due to the non-linearities within the neuron models. This enables ANNs to map complex solution spaces. A feed-forward type of ANN structure was used in the current work. This network architecture is illustrated in Figure 3.7.

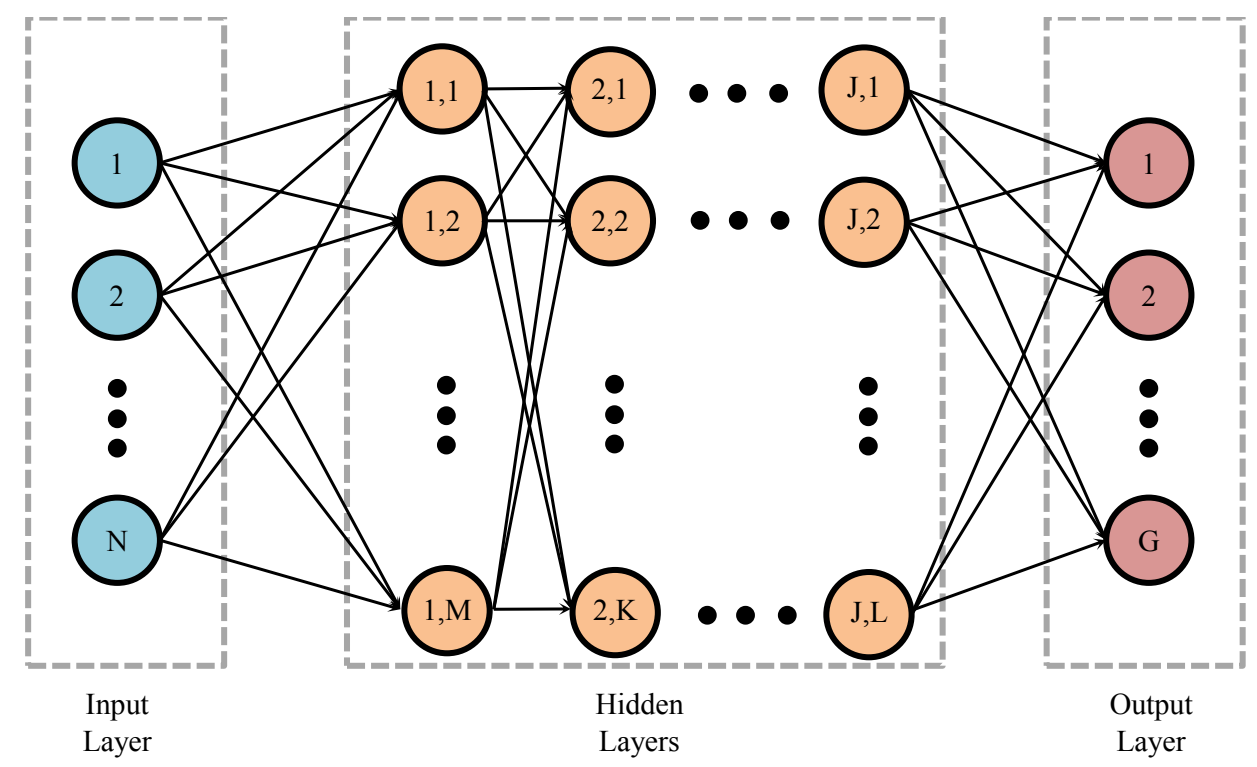

Figure 3.7: Multi-layer feed-forward artificial neural network 
Typically, the computation performed at the neuron level has two steps (Larochelle, 2013): pre-activation and neuron activation. Pre-activation involves the gathering and weighting of neuron inputs. The pre-activation neuron function, $a(\boldsymbol{X})$, used in MATLAB is based on the Adaline (ADaptive LInear NEuron) model from Widrow and Hoff (1960), which may be expressed as:

$$
a(\boldsymbol{X})=b_{i}+\sum_{i} w_{i} \cdot x_{i}
$$

where $x_{i}$ is the scalar input from the connected neuron $i, w_{i}$ is the weight for connection $i$, and $b_{i}$ is the scalar bias term.

The scalar value $a(\boldsymbol{X})$ is then passed to a neuron activation function, $h(\boldsymbol{X}) \equiv$ $g(a(\boldsymbol{X}))$. In this analysis the sigmoid (logistic) function was used for all hidden layer neurons, and the linear (identity) function was used for the output layer. There is no pre-activation or neuron activation for the input layer.

The connection weights and biases in the ANN are determined through a "training" process. For this study the Bayesian Regularization training function in MATLAB was used (MathWorks, 2017a). To train (regress) the ANN, the subset data was randomly subdivided into training, testing, and validation set. By default in MATLAB , 70\% of the data are used for training, and the remaining data are divided evenly amongst testing and validation.

The following describes the regression performed on dwellings that received ceiling insulation upgrades. The independent variables used in the ANN training were:

- Decade of dwelling construction;

- Existence of DHW flue $[0,1]$;

- Existence of furnace flue $[0,1]$;

- Location of dwelling (region);

- Number of dwelling storeys;

- Floor area $\left[\mathrm{m}^{2}\right]$;

- Dwelling footprint $\left[\mathrm{m}^{2}\right]$; 
- Foundation and main wall RSI;

- Original ceiling RSI;

- and New ceiling RSI.

Dwelling regions were numbered 1 to 5, representing Atlantic Canada, Québec, Ontario, Prairies, and British Columbia, respectively. The number of storey descriptors in the database and their assigned integer values are summarized in Table 3.11 .

Table 3.11: Number of storey descriptors in database

\begin{tabular}{ll}
\hline Descriptor & Integer Value \\
\hline \hline One storey & 1 \\
One and a half & 2 \\
Two storey & 3 \\
Two and a half & 4 \\
Split level & 5 \\
Split entry/raised basement & 6 \\
Three storey & 7 \\
\hline
\end{tabular}

The dependent variable, or "target", was $\triangle A C H_{50}$, which was supplied to the ANNs as scalars (not percentages). Four different ANN architectures were trained to estimate $\triangle \mathrm{ACH}_{50}$ from the independent variables. The performance of the regression was evaluated using the MATLAB default mean squared error (MSE) of the estimate. The default number of MATLAB epochs ${ }^{7}$ equal to 1000 was used. Four different ANN architectures were considered, which are described in Table 3.12. Also described in Table 3.12 is the performance of the regressions, expressed using both Pearson correlation coefficients, $R$, and the root MSE (RMSE) of the testing sets (out-ofsample).

\footnotetext{
${ }^{7}$ One epoch is one forward and backward pass of all training data.
} 
Table 3.12: ANN regression analysis for determining $\triangle A C H_{50}$ for ceiling insulation retrofits

\begin{tabular}{lllll}
\hline $\begin{array}{l}\text { ANN } \\
\text { Number }\end{array}$ & $\begin{array}{l}\text { \# of Hidden } \\
\text { Layers }\end{array}$ & $\begin{array}{l}\text { \# of Neurons } \\
\text { per layer }\end{array}$ & $\begin{array}{l}\text { Test Set } \\
\boldsymbol{R}[-]\end{array}$ & $\begin{array}{l}\text { Test Set } \\
\text { RMSE [\%] }\end{array}$ \\
\hline \hline 1 & 1 & 20 & 0.2285 & 18.1 \\
2 & 1 & 30 & 0.2373 & 16.1 \\
3 & 1 & 40 & 0.2707 & 16.0 \\
4 & 2 & 20 & 0.0849 & 22.7 \\
\hline
\end{tabular}

All ANN architectures considered had a poor correlation between targets and calculated outputs, illustrated by the relatively low $R$ values. Additionally, the RMSE values are relatively high and do not appear to be improving with an increasing number of neurons. In the absence of additional independent variables, this approach was not pursued further to estimate $\triangle A C H_{50}$ for various residential retrofits. Instead, a clustering approach similar to Proskiw Engineering (2015) was used to estimate the airtightness efficacy of envelope upgrades.

The subset database from NRCan was first clustered by retrofit option. Then each cluster was grouped by region, then vintage. Both Chan et al. (2005) and Proskiw Engineering (2015) had previously identified dwelling vintage as a strong predictor of air leakage. Chan and Sherman (2012) and Proskiw Engineering (2015) also noticed variation of dwelling airtightness across states/provinces. For each of these subgroups, the statistical parameters mean, median, sample standard deviation, maximum, minimum, skewness, and kurtosis. An example of results is provided in Table 3.13. A full set of results is provided in Appendix F. 
Table 3.13: $\triangle A C H_{50}$ for ceiling insulation retrofits in Québec dwellings, by dwelling vintage

\begin{tabular}{lllllllll}
\hline $\begin{array}{l}\text { Vintage } \\
\text { Decade }\end{array}$ & Mean & Median & $\begin{array}{l}\text { Std. } \\
\text { Dev. }\end{array}$ & Skew. & Kurt. & Max. & Min. & $\begin{array}{l}\text { Sample } \\
\text { Size }\end{array}$ \\
\hline \hline 1980 & $11.3 \%$ & $10.5 \%$ & $11.1 \%$ & 0.411 & 0.299 & $45.3 \%$ & $-21.4 \%$ & 682 \\
1990 & $10.1 \%$ & $10.0 \%$ & $10.3 \%$ & 0.499 & 1.13 & $45.1 \%$ & $-20.8 \%$ & 433 \\
\hline
\end{tabular}

Within each cluster there continued to be significant variation of $\triangle A C H_{50}$. For the clusters shown in Appendix $\mathrm{F}$, the sample standard deviations of $\triangle A C H_{50}$ were between $9.5 \%$ and $14.6 \%$. The results from both the ANN and clustering analyses supported the statement from Proskiw Engineering (2015) that additional independent variables are required to explain variation.

\subsubsection{Implementing Airtightness Efficacy of Retrofits in CHREM/ESP-r}

In this research no explicit airtightness retrofit option was considered. Instead, airtightness improvements were considered as a by-product of the envelope upgrades that were included in the research. To estimate the airtightness efficacy of these retrofits, the clustering analysis described above was used. For each retrofit option applied, a corresponding $\triangle A C H_{50}$ was determined as a function of the retrofitted dwelling's decade of construction and vintage using the mean values reported tables in Appendix F.

Stated previously in Section 3.1.2, dwelling infiltration was calculated in CHREM using the empirical AIM-2 model implemented in ESP-r. In order to model the increase in dwelling airtightness in AIM-2, the following assumptions were made:

- the leakage exponent $n$ remains constant after retrofits;

- the terrain and shelter parameters remain constant;

- the leakage distributions are constant; 
- the airtightness efficacy of separate retrofit options may be linearly superimposed.

The primary leakage description inputs to AIM-2 are the blower door test results $A C H_{50}$ and $A_{\text {leak }}$. Updating the $A C H_{50}$ was straightforward, since $\triangle A C H_{50}$ values had been derived from database and analysis described above. Unfortunately, the measured data provided in the current work did not include $A_{\text {leak }}$. It is a priori knowledge that $A_{\text {leak }}$ would also decrease with decreasing $A C H_{50}$ for a retrofitted dwelling. It can be shown that $A_{\text {leak }}$ and $A C H_{50}$ can be related through Equation 3.4. Derivation of this expression is provided in Appendix A.

$$
A_{\text {leak }}=\sqrt{\frac{\rho_{r}}{2}}\left[\frac{A C H_{50} \cdot V_{\text {zone }}}{3600 \cdot(50 P a)^{n}}\right] \Delta P_{r}^{\left(n-\frac{1}{2}\right)}
$$

Equation 3.4 shows that $A_{\text {leak }}$ increases proportionally to $A C H_{50}$ only if $n$ remains constant. In practice $n$ will likely increase with dwelling increasing airtightness, since the envelope leakage paths become increasingly dominated by laminar flow through smaller cracks as opposed to turbulent flow through large openings. Assuming $n$ remains constant yields higher estimates of $\dot{V}_{\text {inf }}$ compared to increasing $n$, which can be shown using Equation 3.1 over typical operating $\Delta P$ values ${ }^{8}$. Therefore, the fractional reduction of $A_{\text {leak }}, \Delta A_{\text {leak }}$, is assumed equal to $\triangle A C H_{50}$ in this work.

The leakage distribution of the dwelling is also assumed to be constant. Described in Appendix A, the leakage distribution specifies the fractions of $\dot{V}_{\text {inf }}$ which passes through the ceiling, walls, and floors. In CHREM they are assumed to be 0.3, 0.5, and 0.2, respectively (Swan, 2010). Walker and Wilson (1990) and Wang et al. (2009) both demonstrated that the leakage distribution is a major source of uncertainty in AIM-2, and determining these values is non-trivial. Wang et al. (2009) also noted that there continues to be a lack of reliable leakage distribution data. Thus, in the absence of any new data the CHREM default leakage distributions were used and assumed constant.

Lastly, the measured data provided in the current work did not provide samples

\footnotetext{
${ }^{8}$ Sherman and $\mathrm{T}(1980)$ stated that in practice dwellings experience $\Delta P$ values between 0 Pa to $10 \mathrm{~Pa}$.
} 
where multiple retrofits were applied. It is unknown how the retrofit options interact with one another in terms of increasing airtightness. It is assumed that each retrofit option considered in the current work contributes to $\Delta A_{\text {leak }}$ in separate building components, and therefore the efficacy of dwelling retrofits on airtightness may be linearly superimposed.

Considering all the assumptions described above, new AIM-2 values for $A C H_{50}$ and $A_{\text {leak }}$ are determined for a retrofitted dwelling only. The new $A C H_{50}$ after the retrofit, $A C H_{50, \text { new }}$, is determined from:

$$
A C H_{50, \text { new }}=A C H_{50, \text { old }} \cdot\left(1-\sum_{i=1}^{N} \Delta A C H_{50, i}\right)
$$

where $A C H_{50, \text { old }}$ is the pre-retrofit $A C H_{50}$, and $\triangle A C H_{50, i}$ is the fractional decrease of $A C H_{50}$ due to retrofit option $i$. And since $n$ is assumed constant, the new effective leakage area $A_{L, \text { new }}$ is estimated from the pre-retrofit $A_{\text {leak }}, A_{L, \text { old }}$ using:

$$
A_{L, \text { new }}=A_{L, \text { old }} \cdot\left(1-\sum_{i=1}^{N} \Delta A C H_{50, i}\right)
$$

\subsubsection{Analysis of Energy Performance and Airtightness Consideration}

A single-detached Toronto 1946-1960 vintage dwelling model generated using CHREM was selected as a case study to analyze the impact of including airtightness effects with envelope retrofits on building energy estimates. The dwelling is a two-storey with full basement, shown in Figure 3.8, and heated floor area of 173 $\mathrm{m}^{2}$. The nominal main wall, basement wall, and ceiling RSI values are 1.96, 2.1, and $2.12 \mathrm{~m}^{2} \cdot \mathrm{K} / \mathrm{W}$, respectively. The window-to-wall ratio (WWR) of the dwelling is $17.4 \%$, and all existing windows are double-glazed clear coat with $6 \mathrm{~mm}$ air gap. The dwelling is equipped with a natural gas furnace with nominal efficiency of $90 \%$, and an air-source heat pump cooling system with a nominal COP of 3.0. 


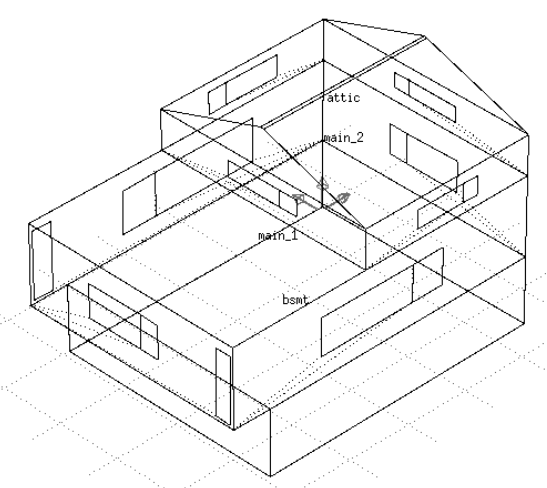

Figure 3.8: Two-storey 1946-1960 Toronto single-detached dwelling rendered in ESP-r

The base case annual space heating and cooling demands of the dwelling are 61.7 GJ/year and 10.4 GJ/year, respectively. Upgrades to the exterior walls, ceiling, windows, and basement walls were individually applied to the dwelling. For each retrofit scenario upgrade level 3 was used. Details on these upgrades were provided previously in Section 3.2.1. Figure 3.9 plots the changes in annual space heating and cooling demands with respect to the un-retrofitted values, both including and excluding consideration of increased airtightness. 


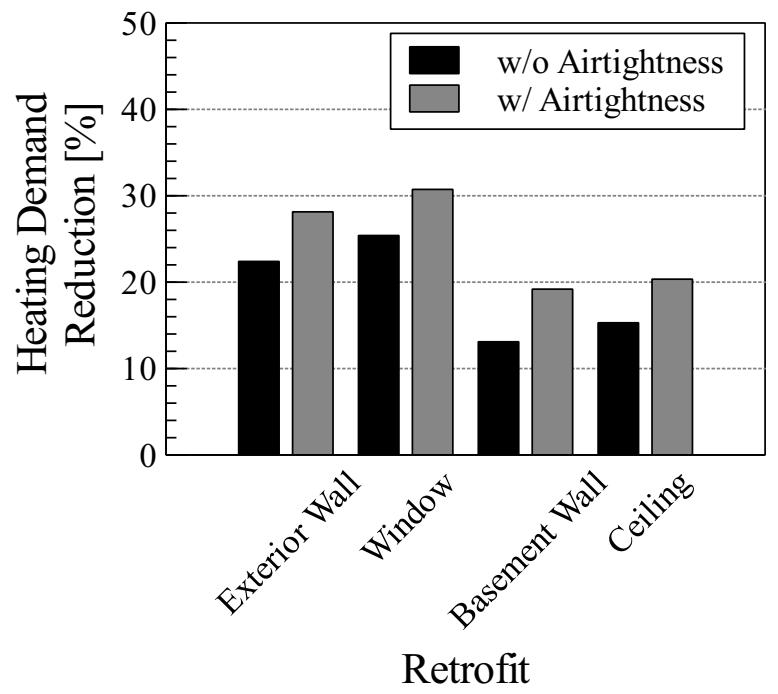

(a) Space Heating

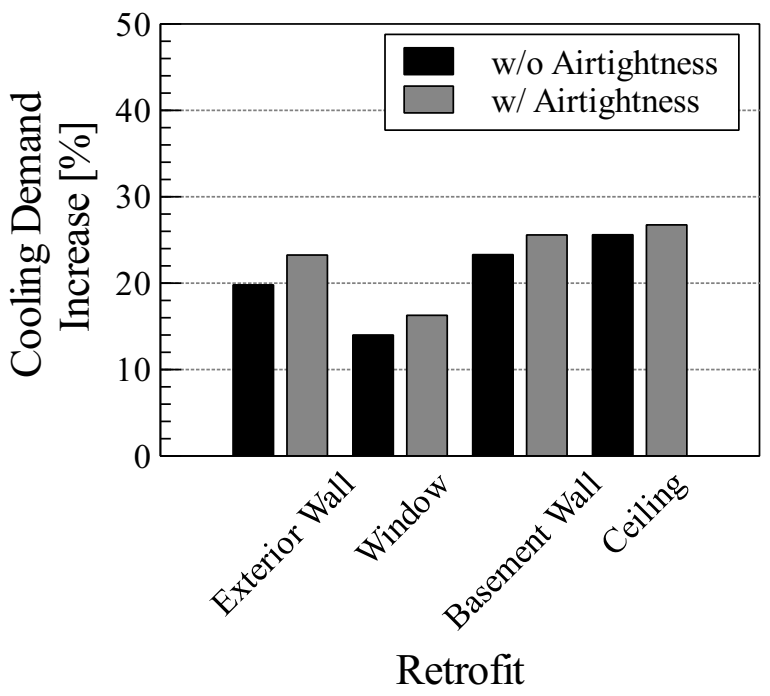

(b) Space Cooling

Figure 3.9: Changes in annual dwelling energy demands due to envelope retrofits, with and without considering airtightness

Replacing the existing windows with triple-glazed, and increasing the main wall RSI value to $5.46 \mathrm{~m}^{2} \cdot \mathrm{K} / \mathrm{W}$, had the greatest impact on annual heat demand. This was expected, since these envelope components represent the majority of the envelope surface area. Without considering airtightness increases, the reductions in annual heating demand for these retrofits were determined to be $25.5 \%$ and $22.4 \%$, respectively. When airtightness improvements were included with the window and main wall retrofits the reduction in annual space heating were found to be $30.7 \%$ and $28.1 \%$, respectively. For each of the retrofits considered in Figure 3.9a the calculation including the airtightness effects increased annual energy demand reduction estimates by $5.0 \%$ and $6.1 \%$ compared to the estimates which excluded airtightness changes.

Figure $3.9 \mathrm{~b}$ shows that the envelope retrofits also result in a nominal increase of the dwelling annual space cooling demands. The ceiling and basement retrofits were found to have the largest impact, increasing annual space cooling demand by $25.6 \%$ and $23.3 \%$, respectively, when airtightness is not included in the calculation. The 
added insulation in the foundation reduces the "free cooling" the dwelling receives during the summer from the relatively cold ground. The increased ceiling insulation also reduces free cooling provided by the ventilated attic. Given that the base cooling demand of the dwelling is 10.4 GJ, these energy increases are relatively small. When airtightness is included in the calculation the annual space cooling demand increases by an additional $1.1 \%$ to $3.5 \%$ for each retrofit in Figure $3.9 \mathrm{~b}$.

Section 3.2.5.3 previously stated that the combined effect of multiple envelope retrofits on dwelling airtightness were estimated using linear superposition. The basis of this assumption was that each envelope retrofit reduced the leakage area in separate envelope components. Therefore it is expected that as combinations of envelope retrofits are applied to a dwelling the discrepancy between the energy estimates determined with and without airtightness effects will have larger discrepancies. To illustrate this, all envelope retrofits were applied to the case study dwelling, and the annual space heating and cooling demands were calculated with and without airtightness effects. For each retrofit option the maximum retrofit level was used. A summary of the results are provided in Table 3.14.

Table 3.14: Comparison of annual space heating and cooling demand estimates for the case study dwelling including and excluding airtightness effects

\begin{tabular}{ccc}
\hline & \multicolumn{2}{c}{ Airtightness } \\
\cline { 2 - 3 } Annual Demand & Included & Excluded \\
\hline \hline Space heating [GJ] & 23.6 & 38.6 \\
Space cooling [GJ] & 12.0 & 10.6 \\
\hline
\end{tabular}

These results demonstrate that as dwelling envelope retrofit solutions become more comprehensive, with significant changes to the leakage area, the effect of dwelling airtightness changes can potentially have a significant impact on the annual space heating demands. In Table 3.14, insulation was increased for the ceiling, main exterior walls, and foundation, and triple-glazed windows were installed. When airtightness effects were included the leakage was estimated to decrease from 9.41 
$\mathrm{ACH}$ at $\Delta \mathrm{P}=50 \mathrm{~Pa}$ to $4.40 \mathrm{ACH}$ based on the methodology proposed in this work. When airtightness effects were neglected the annual space heating demand estimate for the retrofit dwelling increased by $64 \%$. The results in Table 3.14 may also be interpreted as incidental airtightness improvements contributing to $39 \%$ of the potential energy savings.

It is potentially important to not only include airtightness effects for impacts on energy consumption, but also on thermal comfort of the occupants. As building envelopes become more thermally insulated and airtight there is greater risk for overheating and occupant discomfort. To evaluate the impact of including airtightness effects on thermal comfort estimates, the retrofit case study used in Table 3.14 was re-visited.

Thermal comfort of the occupied spaces was characterized using the methodology of Peeters et al. (2009), introduced previously in Section 6.3.3. The fraction of time the predicted percentage of dissatisfied (PPD) was above $10 \%$ and $20 \%$ was determined for the main and second floor zones. Thermal comfort of the basement was not considered. Thermal comfort was estimated for every simulation timestep, regardless of the presence of active occupants. The results are summarized in Table 3.15 .

Table 3.15: Comparison of PPD estimates for the case study dwelling considering and neglecting airtightness increases

\begin{tabular}{ccccc}
\hline & & \multirow{2}{*}{ Base } & \multicolumn{2}{c}{ Airtightness } \\
\cline { 4 - 5 } PPD & Case & Included & Excluded \\
\hline \hline \multirow{2}{*}{$10 \%$} & Too hot & $5.5 \%$ & $12.9 \%$ & $8.8 \%$ \\
& Too cold & $21.9 \%$ & $0.0 \%$ & $0.1 \%$ \\
$20 \%$ & Too hot & $0.5 \%$ & $1.7 \%$ & $0.8 \%$ \\
& Too cold & $14.1 \%$ & $0.0 \%$ & $0.0 \%$ \\
\hline
\end{tabular}

For the base un-retrofitted case there are very few periods of overheating. There is however, a significant portion of the year where occupants are too cold. In CHREM, 
the thermostat is modelled in the main floor. Throughout the heating season the main floor is consistently held at $21{ }^{\circ} \mathrm{C}$. The second floor, however, is below 21 ${ }^{\circ} \mathrm{C}$ for $58 \%$ of the year. For the month of January for example, the average second floor air temperature was $17.4{ }^{\circ} \mathrm{C}$.

Once the envelope retrofits were applied, the under-heated periods became negligible. Periods of overheating, however, are shown to increase as both dwelling insulation and airtightness increase ${ }^{9}$. When airtightness effects are included in the calculation the fraction of time the PPD (too hot) is $10 \%$ or higher increases by $4.1 \%$ compared to the case where airtightness effects are excluded.

It was noted that this case study dwelling was equipped with a space cooling system. In the CSDDRD 59\% of the Ontario single-detached dwellings are not equipped with a space cooling system. Therefore the thermal comfort of the retrofit case study dwelling was re-calculated assuming no space cooling system. For the retrofit simulation without including airtightness effects, the fraction of time the PPD (too hot) was greater than or equal to $10 \%$ increased from $8.8 \%$ to $15.0 \%$ of the time. When airtightness was included the fraction of time increased from $12.9 \%$ to $23.5 \%$.

The case study presented here demonstrated the sensitivity of simulation estimates to the inclusion of dwelling envelope airtightness increases. Excluding airtightness effects provides a conservative estimate for annual space heating; however, it likely under-estimates the thermal comfort of the retrofit dwelling. Based on the analysis described previously in Section 3.2.5, there is strong evidence to support the assumption that dwelling thermal envelope improvements are often accompanied by increased airtightness. Based on the case study, the impact of this increased airtightness on performance is potentially significant.

\footnotetext{
${ }^{9}$ It is important to note that by default CHREM does not include any shading devices to mitigate overheating.
} 


\subsubsection{Mechanical Ventilation}

Since the envelope upgrades are assumed to increase dwelling airtightness, the ventilation retrofits were included to ensure that occupants receive sufficient ventilation air. Dwellings are eligible for a ventilation system retrofit if no ventilation is present, the existing system does not supply sufficient ventilation air, or the existing system is inefficient compared to the retrofitted system. In the current work, only HRV systems were considered as a retrofit option. Canada is a heating-dominated climate, and HRVs offer an efficient method for ventilation by recuperating thermal energy from building exhaust and transferring it to incoming fresh air.

Ventilation fans and HRVs are modelled in CHREM/ESP-r using the steadystate empirical model developed previously by Bradley (1993a) and implemented into ESP-r by NRCan. This model was later updated by Pinel (2014) to include energy recovery ventilators (ERV), and to be compatible with performance test data from the Home Ventilating Institute (HVI, 2017). The model assumes that the ventilation system provides a continuous flow rate, $\dot{V}_{\text {vent }, \text { act }}[\mathrm{L} / \mathrm{s}]$, to the occupied spaces of the dwelling specified by the user. At each timestep calculation, the effectiveness of the HRV and the electrical consumption of the fan is calculated. Four typical HRV units were considered in the current work, with rated flow rates between $22 \mathrm{~L} / \mathrm{s}$ and 51 L/s. The performance data of these HRVs were derived from HVI (2017), and are described in Appendix F.

To determine which HRV was suitable for a retrofit dwelling, $\dot{V}_{\text {vent }, \text { act }}$ was calculated using ASHRAE Standard 62.2 (ASHRAE, 2016). The nominal ventilation flow rate requirement for residential dwellings, $\dot{V}_{\text {vent,nom }}[\mathrm{L} / \mathrm{s}]$, was first calculated from:

$$
\dot{V}_{\text {vent }, \text { nom }}=0.15 A_{\text {floor, heated }}+3.5 N_{\text {bedrooms }}
$$

where $A_{\text {floor, heated }}$ is the heated floor area $\left[\mathrm{m}^{2}\right]$, and $N_{\text {bedrooms }}$ is the number of dwelling bedrooms. The CSDDRD does not report $N_{\text {bedrooms }}$; therefore, it is estimated from:

$$
N_{\text {bedrooms }}=\left\{\begin{array}{l}
N_{\text {adults }}+N_{\text {kids }} \text { if } \quad N_{\text {adults }}<2 \\
N_{\text {adults }}+N_{\text {kids }}-1 \quad \text { otherwise. }
\end{array}\right.
$$


where $N_{\text {adults }}$ and $N_{k i d s}$ are the number of dwelling adults and children reported in the CSDDRD, respectively. Equation 3.8 assumed that if there is more than one adult, at least one couple shares a bedroom.

The actual dwelling ventilation requirement, $\dot{V}_{\text {vent }, \text { act }}[\mathrm{L} / \mathrm{s}]$, is then estimated from:

$$
\dot{V}_{\text {vent }, a c t}=\dot{V}_{\text {vent }, \text { nom }}-\dot{V}_{\text {inf,nom }}
$$

where $\dot{V}_{\text {inf,nom }}$ is the annual average infiltration rate for the dwelling. $\dot{V}_{\text {inf,nom }}$ is determined as a function of the dwelling eaves height, $H_{\text {eave }}[\mathrm{m}], A_{\text {leak }}, A_{\text {floor }}$, and a climate-specific weather and shielding factor (wsf) provided in the Appendix of Standard 62.2. As a conservative estimate, Standard 62.2 provides the following expression for $\dot{V}_{\text {inf,nom }}$ :

$$
\dot{V}_{\text {inf }, \text { nom }}=\frac{2}{3} \cdot \dot{V}_{\text {vent }, \text { nom }}
$$

For this research, the conservative estimate of $\dot{V}_{\text {inf,nom }}$ was assumed. Further details on the ventilation requirement calculations were omitted here for clarity, and the interested reader is directed to ASHRAE (2016) for additional information.

\subsection{Description of Case Study Communities}

To examine the feasible pathways for achieving retrofit net-zero, as well as the impact of the formal definition of net-zero on design and performance, case study communities of single-detached dwellings were derived from records in the CSDDRD. Two Canadian population centres were selected for analysis: Toronto, Ontario, and Montréal, Québec. What is interesting about these two municipalities is that they are geographically close with a similar climate, but have significantly different energy supply mixes. Québec electricity is 95\% supplied by hydro generation (Hydro-Québec, 2017), whereas $61 \%$ of Ontario electricity is generated from nuclear. Different current and historical fuel prices between Ontario and Québec have also lead different fuel mixes being used in the building stock. In $2014,68 \%$ and $74 \%$ of 
Ontario residential sector space heating and DHW systems were natural gas-fired ${ }^{10}$ (OEE, 2017). In contrast, 77\% and 92\% of Québec space heating and DHW systems were electric (OEE, 2017).

In addition to location, the case study communities are also defined by vintage. Figure 3.10 plots the distributions of the single-detached dwelling stocks in Toronto and Montréal. The vintage periods in Figure 3.10 were defined by Statistics Canada (2011), and align with the Canadian dwelling vintage periods defined by Parekh (2005). Parekh (2005) stated that these periods represent changes in relevant codes and standards in Canada.

\footnotetext{
${ }^{10}$ Including dual fuel systems.
} 


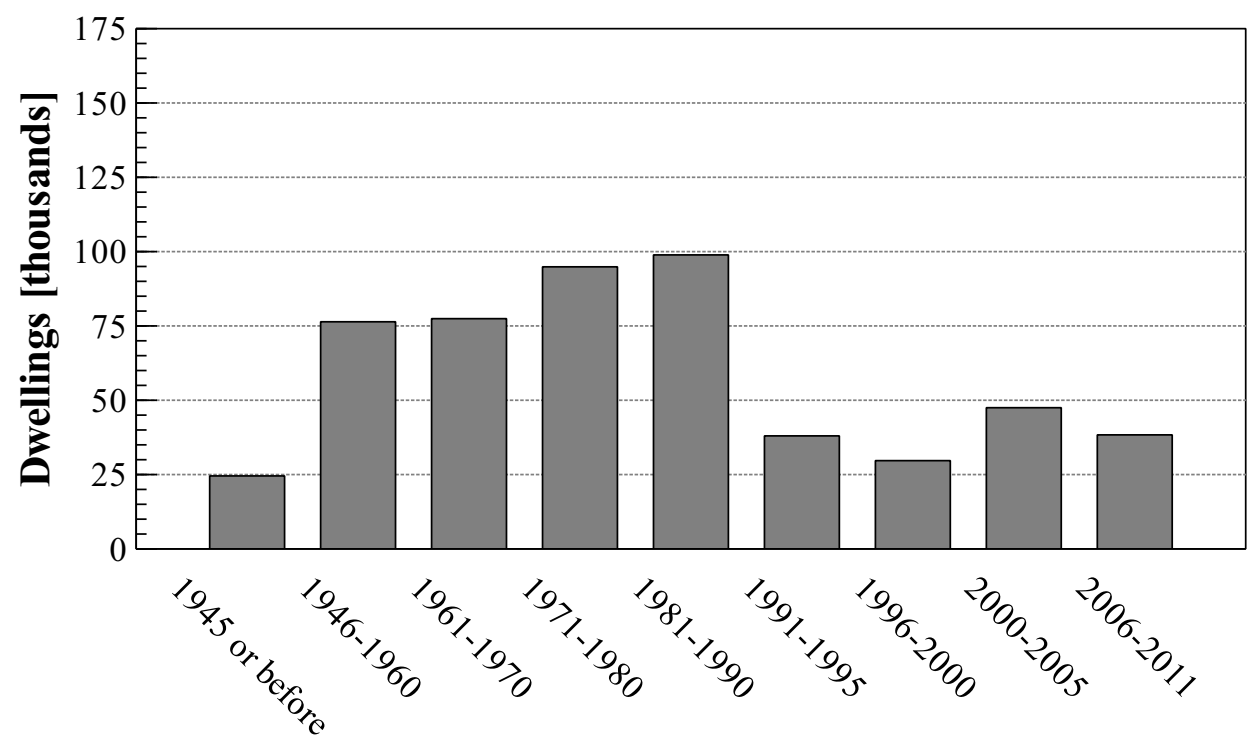

Vintage

(a) Montréal

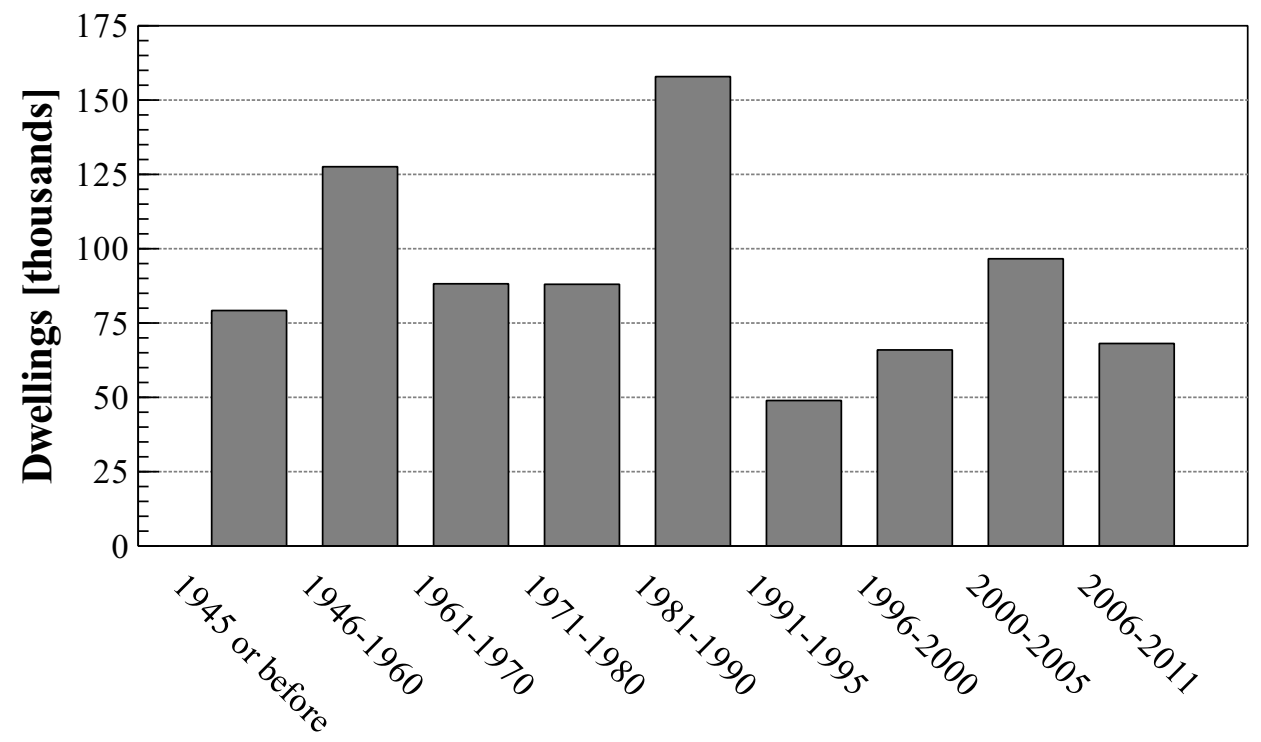

Vintage

(b) Toronto

Figure 3.10: Distributions of single-detached dwelling vintages, data from Statistics Canada (2011) 
For the current work, two separate Toronto communities were derived from the CSDDRD: a 1946-1960 vintage community, and a 1981-1990 community. It can be seen in Figure 3.10 that these are the most significant periods in the Toronto single-detached dwelling stock. A 1981-1990 Montréal community of single-detached dwellings was also derived from the CSDDRD and considered in the current work. Shown in Figure 3.10, this period contains the largest share of single-detached dwellings.

Each case study community was populated with 50 dwellings. There is no clearly defined minimum threshold for the number of dwellings required to qualify as a "community." A community of 50 was deemed to be an appropriate number, and is similar to the Drake Landing Solar Community introduced previously in Chapter 1 which has 52 single-detached dwellings. As the number of dwellings increases, the shape of the aggregate energy demands becomes more normalized and not as influenced by stochastic behaviours of individual dwellings. For example, the ratio of peak system electrical load and the sum of connected customer peak loads, often referred to as the coincidence factor, gradually decreases with the number of customers and is essentially constant after 20 customers (Short, 2003). It is assumed that 50 dwellings will provide sufficient diversity of residential energy demands, and results may be scaled up or down to estimate the performance of different community sizes.

To populate the communities, the CSDDRD was filtered by location and vintage. In order to populate the communities with more "typical" dwellings, additional dwelling stock characteristics were filtered in the CSDDRD. These characteristics were foundation and roof type, and space heating and DHW system fuel type. In both Montréal and Toronto, approximately $89 \%$ and $93 \%$ of single-detached dwellings have a full basement (Swan et al., 2009). Thus, only dwellings with full basements were eligible for inclusion in the case study communities. This also ensured that every dwelling in the community could be considered for a basement insulation retrofit.

Dwellings with a flat roof were also excluded from the current analysis. According to the CSDDRD, only $2 \%$ and $1 \%$ of Montréal and Toronto single-detached dwellings have flat roofs, respectively. Described later in Chapter 4, roof-mounted PV systems are considered in this thesis. Nikoofard et al. (2014a) and Asaee et al. (2017) previously considered the retrofit of solar collectors in the existing residential stock, and 
assumed that flat roofs were ineligible for such retrofits. While solar collectors may be mounted on flat roofs, the additional mounting structures required to properly orient the collectors increases both costs and dead load on the roof.

Lastly, the CSDDRD records were filtered by space heating and DHW fuel type. It was noted previously that Ontario dwellings primarily use natural gas for these end-uses, whereas the Québec residential sector chiefly uses electricity. For each case study community defined in this work, all dwellings used the same fuel for space heating and DHW end-uses. It is assumed that dwellings within a similar geographic area will utilize the same utilities and fuel sources available. Additionally, this allowed for examining community fuel-switching for these end-uses.

Once the CSDDRD was filtered for the characteristics described above, records were randomly selected to populate the communities. A summary of the case study community characteristics is provided in Table 3.16 :

Table 3.16: General characteristics of the case study communities

\begin{tabular}{lccc}
\hline Community & Montréal & Toronto & Toronto \\
Characteristic & $\mathbf{1 9 8 1 - 1 9 9 0}$ & $\mathbf{1 9 4 6 - 1 9 6 0}$ & $\mathbf{1 9 8 1 - 1 9 9 0}$ \\
\hline \hline Space heating fuel & Electric & Natural Gas \\
DHW fuel & Electric & Natural Gas \\
Mean heated floor area* ${ }^{*} \mathrm{~m}^{2} /$ dwelling $]$ & 203 & 198 & 301 \\
Mean main wall RSI & 2.95 & 1.33 & 2.39 \\
Mean foundation RSI & 3.14 & 1.37 & 1.81 \\
Foundation type & \multicolumn{3}{c}{ Full basement } \\
Roof type & \multicolumn{3}{c}{ Hip/Gable } \\
\hline
\end{tabular}

* CHREM assumes full basements are heated.

\subsection{Final Remarks}

One aspects of energy retrofit which was of interest in this thesis was the inclusion of community-scale energy systems. While both ESP-r and CHREM are detailed 
and robust, the modelling scopes of those tools are limited to energy simulation of building-scale systems. Recognizing this limitation, the transient energy simulation tool TRNSYS was used to model the energy performance of district heating systems, central thermal energy storage, community solar thermal and PV systems, and community microturbine systems. The next chapter describes the community energy systems considered in this study, and the underlying modelling methodologies used to characterize these systems in TRNSYS. 


\section{Chapter 4}

\section{Community-scale Retrofit Systems Considered and Modelling Methodologies}

All of the dwelling-scale envelope upgrades described in the previous chapter were modelled directly in the BPS tool ESP-r. The purpose of those retrofits was to reduce the energy demand of existing dwellings. This research, however, is focused on retrofits to achieve net-zero in existing communities. In order to achieve this target, there needs to be some form of on-site energy generation to both supply energy to the community, as well as supply energy back to the connected infrastructure to offset energy imports. Several on-site energy generation technologies were reviewed previously in Chapter 2 and selected for this research. In contrast to previous renewable generation retrofit studies conducted using CHREM, such as Nikoofard et al. (2014a) and Asaee et al. (2016), this research considered the retrofit of communityscale central and distributed generation. The modelling scope of ESP-r is largely limited to individual buildings. Therefore, TRNSYS 17 (SEL, 2017) was integrated into CHREM for this work to simulate the performance of large-scale generation systems.

Two types of community energy networks were considered in this research: a community district heating $(\mathrm{DH})$ system providing space heating and DHW to the dwellings, and a community electrical generation and distribution system. Each of these networks were simulated in TRNSYS using several models in the standard library, and some models developed for this research. Section 4.1 first provides a 
brief overview of the solution method utilized by TRNSYS to calculate the transient heat and mass transfer of energy systems. Section 4.2 then describes the thermal and electrical retrofit community energy systems considered in this research. The remainder of this chapter then describes the modelling methodologies and input parameters used to characterize the retrofit energy network parameters.

\subsection{TRNSYS Simulation Methodology}

TRNSYS was developed previously by Klein et al. (1975) as a tool to simulate the "dynamic thermal response of transient systems". TRNSYS includes an extensive library of various solar energy, HVAC, and other energy system component models, referred to as "Types". Types are connected to one another by the user to form a system model. Each Type is implemented in TRNSYS as separate subroutines, which are called and managed by an executive routine, or kernel (Klein et al., 1975). From the perspective of the TRNSYS kernel, Types are viewed as "black boxes". Because Types are black boxes, underlying Type modelling methodologies may vary from simple steady-state to detailed transient models.

Both "input" and "parameter" values are provided to Types as boundary conditions. Parameters are characterized as static values specified by the user prior to simulation, and may be used to represent model constants, such as the thermal mass of an HVAC component. Inputs may be specified as static values, or can vary between simulation timesteps. System networks are developed in TRNSYS by connecting Type outputs to other Type inputs. For example, the outlet fluid temperature and mass flow rate output of a pump Type may be connected to the inlet temperature and mass flow rate of a heat exchanger Type. The TRNSYS kernel manages the mapping of Type outputs to connected Type inputs. Type data and Type networks are illustrated in Figure 4.1. 

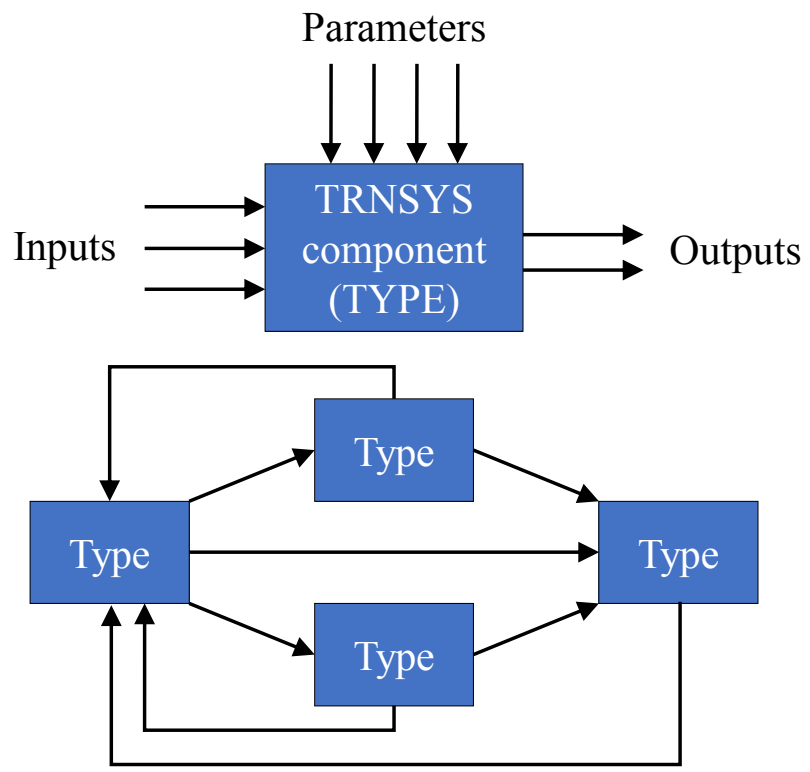

Figure 4.1: TRNSYS type and networking, adapted from Beausoleil-Morrison et al. (2014)

At each simulation timestep Types in the TRNSYS network are iteratively called by the TRNSYS kernel and supplied with their connected inputs. Iterations on the timestep continue until all Type inputs in the network have not changed beyond a user-specified tolerance (Beausoleil-Morrison et al., 2014). This tolerance may be specified as relative or absolute error. The default in TRNSYS is a relative tolerance of $0.1 \%$. This tolerance is used for all Type inputs, regardless of input units (temperature,pressure,etc.) (Beausoleil-Morrison et al., 2014). For the current work, the default tolerance was used. Once all normal Types have converged, the TRNSYS kernel proceeds to the next timestep. This process is illustrated in Figure 4.2 . 


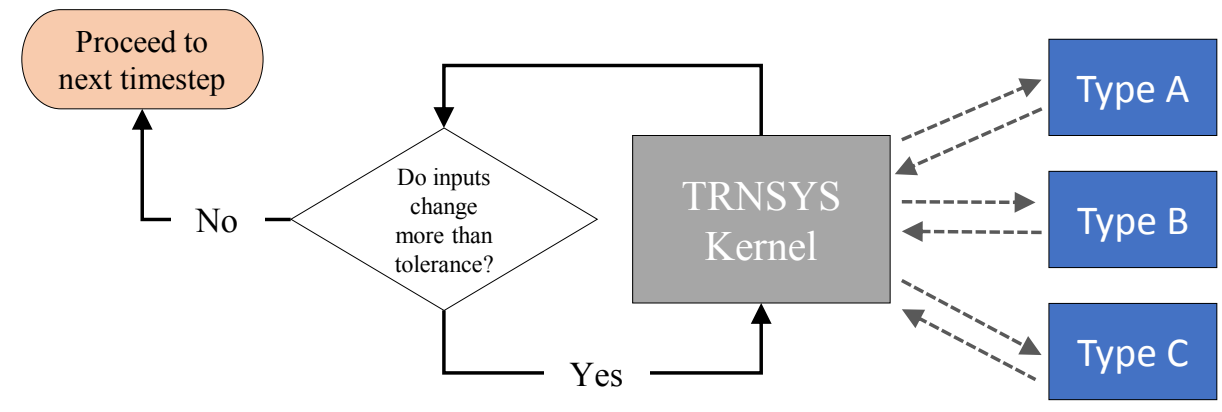

Figure 4.2: TRNSYS solution method, adapted from Beausoleil-Morrison et al. (2014)

Additional details on the TRNSYS solution methodologies are omitted here for clarity, and the interested reader is directed to SEL (2017), Klein et al. (1975), or Beausoleil-Morrison et al. (2014) for more information.

\subsection{Community Energy System Overview}

Part of the rationale of converting an entire community to net-zero, as opposed to individual dwellings, is that the community will likely benefit from economies of scale. The Now House Project (Now House, 2017), introduced in Chapter 1, demonstrated $47 \%$ in capital cost savings per dwelling when retrofits were applied to 95 dwellings instead of 5. Another benefit of considering net-zero at the community-scale is the potential to utilize central energy systems. Rezaie and Rosen (2012) noted that the majority of residential sector energy consumption and GHG emissions is due to space heating and DHW thermal demands, which was shown in Chapter 1. They argued that DH and cooling with central generation has the potential to reduce energy consumption and GHG emissions. They also stated that renewable technologies used for central generation in the residential sector would have the advantage of being simpler and more economical compared to retrofitting dwelling-scale renewable systems. 
For the current work DH systems were considered as a retrofit option for residential communities converting to net-ZEC. In Canada, DH systems are primarily used in building complexes with well defined ownership, such as university campuses or government facilities (Dalla Rosa et al., 2012). DH systems have faced several obstacles in Canada, including a historical lack of appreciation for thermal by-products of electricity generation, extensive availability of natural resources, and a lack of provincial and federal policy frameworks (Dalla Rosa et al., 2012). Despite these challenges, DH has been gaining traction in Canada. The Drake Landing Solar Community (DLSC) in Okotoks, Alberta (DLSC, 2017) is one successful demonstration project which uses solar thermal and DH to provide over $90 \%$ of its space heating and $50 \%$ of its DHW demands (McDowell and Thorton, 2008; Sibbitt et al., 2012; Wamboldt, 2009).

Chapter 2 identified two potential on-site thermal generation technologies which could be retrofit in existing communities: solar thermal ETCs, and natural gas-fired microturbines. Figure 4.3 illustrates the topology of the thermal energy network considered in this research and modelled in TRNSYS. The layout of the thermal network was based upon the system installed at the DLSC. The DLSC thermal energy system used a central thermal energy storage (TES) as the primary energy hub (McDowell and Thorton, 2008). Thermal energy generation from the distributed solar thermal collectors in the community supplies the DLSC central TES system. The 52 single-detached dwellings in the community are then supplied space heating energy from the central TES via a DH loop. In this way all thermal energy collected in the community is made available to all dwellings. 


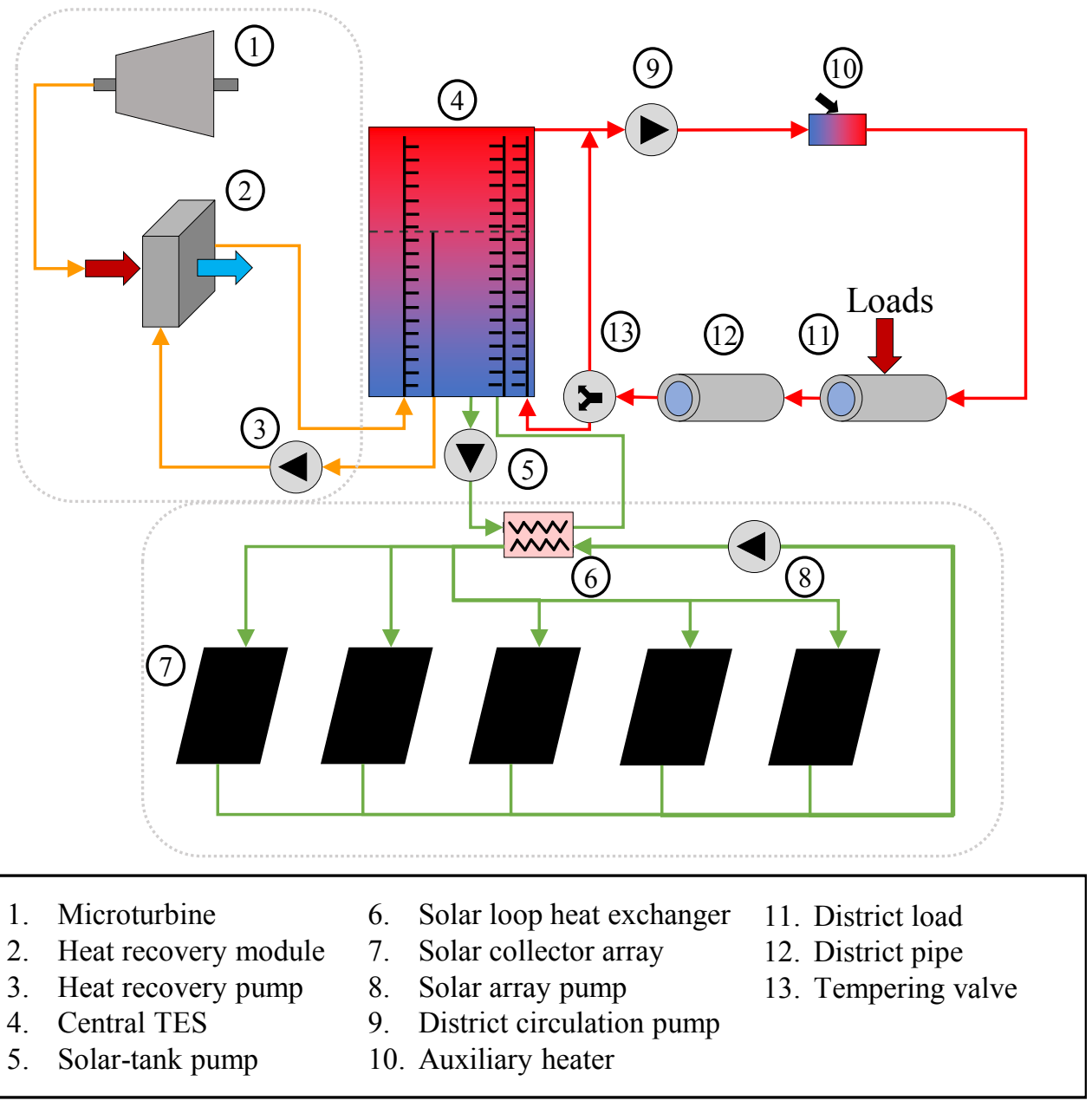

Figure 4.3: Schematic of the community thermal energy network modelled in TRNSYS

The thermal energy system in Figure 4.3 contains two thermal energy supply loops. The first is the solar thermal loop, composed of units 5 to 8 in Figure 4.3. Unit 7, the solar collector array, was modelled in TRNSYS using five instances of the ETC model Type538 (TESS, 2012b). Each instance represented the aggregated collector area of all the solar thermal collectors in the community with the same orientation $^{1}$. The solar thermal loop is an indirect system, where a heat exchanger is

\footnotetext{
${ }^{1}$ Depending on the distribution of solar collectors in the community, some of the ETC instances
} 
used to transfer thermal energy between the collectors and TES. This was done since solar thermal systems installed in Canada require some form of freeze protection. The energy transport fluid flowing through the collector arrays were assumed to be 50/50 percent propylene glycol-water mixture by volume. Not shown explicitly in Figure 4.3 is a diverter valve which directs inlet flow to the ETC Types. Each ETC Type is independently controlled. If the controller determines an ETC Type is capable of useful thermal gain, the solar-tank and solar array pumps are turned on and the diverter valve directs flow to the ETC Type. Multiple ETC Types can receive flow simultaneously. The control strategy for the solar thermal system is described later in Section 4.3.1.

The second supply loop is the microturbine heat recovery. This is composed of units 1 to 3 in Figure 4.3. During microturbine operation, the exhaust gas is routed to a heat recovery module (HRM). The HRM acts as a heat exchanger between the microturbine and central TES. The HRM attempts to achieve a specified load-side outlet temperature by bypassing a portion of the inlet microturbine exhaust gas around the internal heat exchanger. Modelling and control of the HRM is described later in Section 4.7.3. Return water from the HRM is supplied directly to the central TES. The inclusion of the microturbine and heat recovery loop in the model is optional, allowing the user to considered a solar thermal only system. The solar thermal system in Figure 4.3 may also be optionally excluded.

Both thermal supply loops connect to a central TES, unit 4 in Figure 4.3. For this research a water-based sensible energy storage was considered. Pinel et al. (2011) previously reviewed several large TES systems for residential applications. They stated that sensible TES systems, compared to other storage mechanisms such as latent or chemical, are the simplest and most well understood. Several media may be used for sensible storage; however, water is an attractive option due to its relatively high thermal capacitance $(\sim 4.2 \mathrm{~kJ} / \mathrm{kgK})$ and low costs. The operational temperature range of water-based TES, between roughly $20^{\circ} \mathrm{C}$ and $80^{\circ} \mathrm{C}$, is well suited to residential DHW and space heating demands. This is also the operational range of most solar thermal collectors. The parameters of the central TES system may not be simulated if there are no collectors in that orientation. 
are provided later in Section 4.6.

Thermal energy is supplied to community loads through a retrofitted DH system. For the current work a simplified representation was used for the DH system, composed of units 9 to 13 in Figure 4.3. Simulation of the space heating and DHW thermal demands, and the DH and central energy system were decoupled. The aggregate community thermal demands are determined prior to simulation using the ESP-r methodology described previously in Chapter 3. The annual aggregate community thermal demand profile, expressed in $\mathrm{kW}_{\text {th }}$, is then supplied as a boundary condition to unit 11 in Figure 4.3. This demand boundary condition was derived assuming that there was always sufficient capacity to meet the load. To ensure sufficient capacity in the TRNSYS DH, a natural gas-fired backup boiler was included and is shown as unit 10 in Figure 4.3. The DH loop is controlled for both flow rate and supply temperature, described later in Section 4.8.

Embedded on-site community electrical generation was also considered for this research. Both PV and microturbine systems were determined to be feasible retrofit systems for existing communities and were considered in this thesis. Figure 4.4 illustrates the community electrical network topology model used in this work. Similar to the thermal network in Figure 4.3, a simplified approach was used to represent the electrical distribution system. 


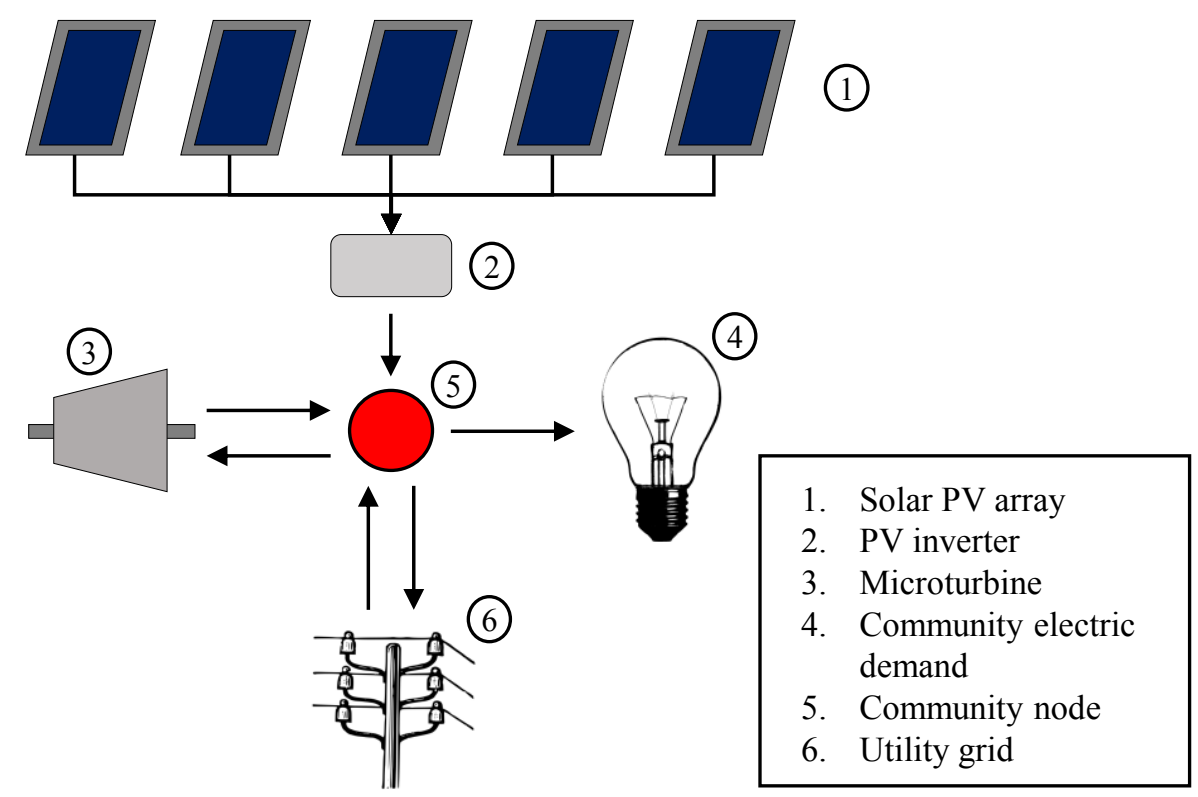

Figure 4.4: Schematic of the community electrical network modelled in TRNSYS

According to Abdel-Galil et al. (2007), the topology of an electrical distribution network depends on type of customers, geography of the area, reliability requirements, standards, and the national electric code. Benchmark electrical distribution network topologies have been developed to study distributed generation, such as Dick and Narang (2005) or Kersting (2001); however, detailed treatment of energy distribution systems was outside of the scope. Rather, the impact of the distributed generation on the connected distribution system was considered using simplified 'grid interaction' factors, introduced later in Chapter 6. For the current work the community electrical distribution system was represented as a single node, shown as unit 5 in Figure 4.4. The node has no capacitance and functions to determine the balance of supply and demand at each simulation timestep.

\subsection{Solar Thermal Loop Simulation Methodology}

This section describes the modelling methodologies, input parameters, and controls for the community solar thermal loop. Stated previously, an indirect solar thermal 
system was selected for this work. The majority of Canadian systems are indirect (Cruickshank, 2009) to protect against freezing in the solar array. An anti-freeze mixture is circulated through the collector array, and thermal energy is exchanged with a TES via a heat exchanger. For this work, a 50/50 propylene glycol-water mixture was assumed for the collector array. Fluid density and specific heat were taken as constant values ${ }^{2}$ of $1.02 \mathrm{~kg} / \mathrm{m}^{3}$ and $3.70 \mathrm{~kJ} / \mathrm{kg} \cdot \mathrm{K}$, respectively. These values were derived from Bosch Thermotechnology Corp. (2009) for 50/50 propylene glycolwater at $60{ }^{\circ} \mathrm{C}$.

The solar loop heat exchanger was modelled in TRNSYS using Type 5b TESS (2014c). This model determines fluid heat transfer using a user specified overall heat transfer coefficient, $U A_{h x}[\mathrm{~W} / \mathrm{K}]$. For this work, $U A_{h x}$ was determined at each timestep using Equation 4.1:

$$
U A_{h x}=30 \cdot A_{\text {coll }, \text { active }}
$$

where $A_{\text {coll,active }}\left[\mathrm{m}^{2}\right]$ is the gross area of "active" solar collectors. Equation 4.1 is derived from the sensitivity study conducted previously by Streicher et al. (2007). They evaluated the sensitivity of annual residential solar thermal combi-system performance to $U A_{h x}$, and found that beyond $30 \mathrm{~W} / \mathrm{K} \cdot \mathrm{m}^{2}$ there was little change in performance. The active collector area was determined at each timestep from the area of solar thermal collectors which had an inlet fluid flow rate greater than zero. This was done as a modelling simplification, rather than specifying explicit heat exchangers with a fixed $U A_{h x}$ for each of the five solar arrays in Figure 4.3.

\subsubsection{Solar Thermal Loop Controls}

Figure 4.5 provides details of the components and connections of the solar thermal loop in Figure 4.3.

\footnotetext{
${ }^{2}$ Several TRNSYS Types can only specify constant thermophysical properties.
} 


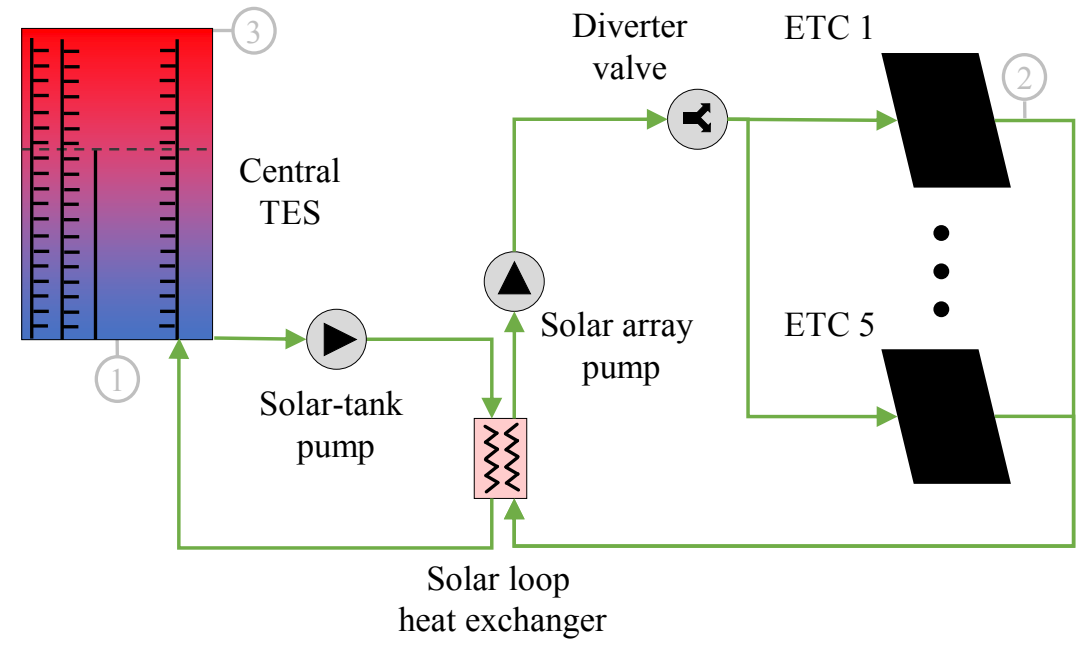

Figure 4.5: Solar thermal loop

Stated previously, each of the ETC arrays in Figure 4.5 is controlled independently. To describe this control startegy, consider ETC 1 in Figure 4.5. ETC 1 is controlled using TRNSYS standard library Type 2b (TESS, 2014c), which a differential temperature controller with hysteresis. The logic implemented in Type $2 \mathrm{~b}$ is summarized in Figure 4.6.s

The low temperature input, $T_{L}\left[{ }^{\circ} \mathrm{C}\right]$, was determined from point 1 in Figure 4.5, and the high temperature input, $T_{H}$ was determined from point 2 in Figure 4.5. The $\Delta T_{L}$ and $\Delta T_{H}$ represent the lower and upper temperature difference deadbands, respectively, which prevent unrealistic $\mathrm{ON} / \mathrm{OFF}$ oscillations in the controller. The values of $\Delta T_{L}$ and $\Delta T_{H}$ in the current work were equal to $10{ }^{\circ} \mathrm{C}$ and $3{ }^{\circ} \mathrm{C}$, respectively, and were derived from the residential solar thermal combi-system modelled previously by Heimrath (2003).

Type $2 \mathrm{~b}$ also has a high limit monitoring temperature, $T_{\text {lim }}\left[{ }^{\circ} \mathrm{C}\right]$, which monitored the TES temperature at point 3 in Figure 4.5. Since the TES selected for this work is a water-based sensible energy system, the high limit temperature was set to 95 ${ }^{\circ} \mathrm{C}$ to prevent boiling of the storage medium. If $T_{\text {lim }}$ was greater than or equal to $95^{\circ} \mathrm{C}$ then the control output was an OFF state. 


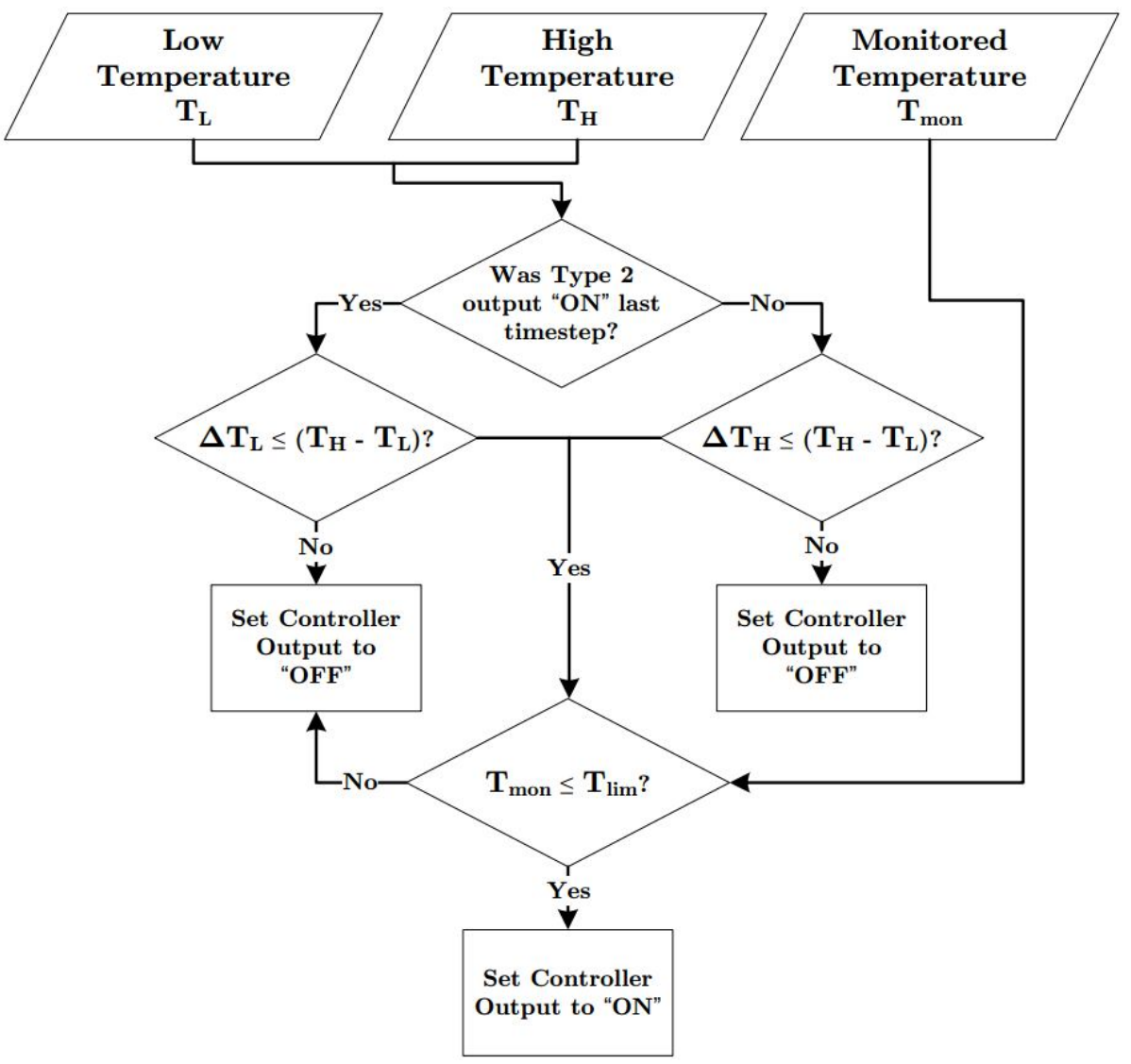

Figure 4.6: TRNSYS Type 2 control logic, reproduced with permission from Wills (2013)

When one or more of the solar thermal collector array controllers outputs an ON state, both solar array and solar-tank pumps in Figure 4.5 are turned on and provide a mass flow rate, $\dot{m}_{\text {coll }}[\mathrm{kg} / \mathrm{s}]$ determined by:

$$
\dot{m}_{\text {coll }}=0.003 \overline{3} \cdot A_{\text {coll }, \text { active }}
$$

Equation 4.2 produces a relatively low solar collector array flow rate. Typical specific solar collector flow rates vary between 0.0025 and $0.02 \mathrm{~kg} / \mathrm{s}$ per $\mathrm{m}^{2}$ of collector area (Andersen, 2007). Kozlowski (1989) previously analyzed central solar heating plants with seasonal TES, and found that a low specific flow rate of $0.005 \mathrm{~kg} / \mathrm{s}$ per $\mathrm{m}^{2}$ 
of collector area produced higher temperature lift across the collector and helped promote stratification in the storage tank. Streicher et al. (2007) stated that typical low specific flow rates were between 0.0028 and $0.0042 \mathrm{~kg} / \mathrm{s}$ per $\mathrm{m}^{2}$ of collector area. For this research the midpoint of the range of values reported by Streicher et al. (2007), $0.003 \overline{3}$ was used as the specific collector flow rate and is shown in Equation 4.2 .

The electrical consumption of the solar thermal loop circulation pumps were also determined as a function of $A_{\text {coll, active }}$ using the correlations reported by Weiss (2003). These correlations are not reproduced here for clarity, and the interested reader is directed to Weiss (2003) for more details.

\subsubsection{Evacuated Tube Collectors Simulation Methodology and Inputs}

\subsubsection{Modelling Methodology}

The ETCs were modelled in TRNSYS using TESS library Type 538 (TESS, 2012b). Type 538 is an empirical model which uses commonly reported performance data and efficiency curves described by Duffie and Beckman (2013). The steady-state efficiency curve of a solar thermal collector, $\eta_{\text {coll }}$, may be expressed as:

$$
\eta_{\text {coll }}=\eta_{\text {coll }, 0}-a \frac{\left(T_{i n}-T_{a m b}\right)}{G_{T}}-b \frac{\left(T_{i n}-T_{a m b}\right)^{2}}{G_{T}}
$$

where $\eta_{c o l l, 0}$ is an experimentally determined intercept efficiency, $T_{i n}$ and $T_{a m b}$ are collector inlet fluid and ambient temperatures $[\mathrm{K}]$, respectively, and $G_{T}$ is the total solar radiation incident on the collector $\left[\mathrm{W} / \mathrm{m}^{2}\right]$. The coefficients $a$ and $b$ are experimentally determined curve-fitting values with units $W /\left(\mathrm{m}^{2} \cdot \mathrm{K}\right)$ and $\mathrm{W} /\left(\mathrm{m}^{2} \cdot \mathrm{K}^{2}\right)$, respectively.

Typically steady-state models are used to represent solar thermal collectors. Klein et al. (1974) previously compared performance estimates from zero-capacitance and transient flat plate collector (FPC) models. They found that the zero-capacitance 
FPC models were as accurate as their one-node capacitance model. Type 538 however, is a transient model. The thermal capacitance was considered to promote simulation stability. Beausoleil-Morrison et al. (2014) stated that at least one component in a TRNSYS model loop should contain a form of capacitance to avoid solution divergence.

\subsubsection{Model Parameters}

The ETC model parameters used in this study were based on the commercially available AP-30 collector from Apricus (2016b), and are summarized in Table 4.1. The performance metrics of this collector are typical for ETCs available on the market. Test data for the AP-30 collector was provided by SRCC (2009), TÜV Rheinland (2009) and TÜV Rheinland (2014).

Table 4.1: ETC model parameters for Type 538

\begin{tabular}{ll}
\hline Parameter & Value \\
\hline \hline Gross collector area, $A_{\text {coll,gross }}\left[\mathrm{m}^{2}\right]$ & 4.158 \\
Collector capacitance, $C_{\text {coll }}[\mathrm{kJ} / \mathrm{K}]$ & 34.7 \\
Intercept efficiency, $\eta_{\text {coll }, 0}[-]$ & 0.456 \\
$a\left[\mathrm{~W} /\left(\mathrm{m}^{2} \cdot \mathrm{K}\right)\right]$ & 1.351 \\
$b\left[\mathrm{~W} /\left(\mathrm{m}^{2} \cdot \mathrm{K}^{2}\right)\right]$ & 0.0038 \\
Test flow rate, $\dot{m}_{\text {coll,test }}\left[\mathrm{kg} /\left(\mathrm{s} \cdot \mathrm{m}^{2}\right)\right]$ & 0.02 \\
\hline
\end{tabular}

In addition to considering thermal capacitance, Type 538 uses a one-dimensional discretization to approximate the temperature distribution across the collector in the flow direction. Wills (2013) previously conducted a discretization sensitivity study on the similar Type 539 TESS (2012b). Type 539 is a transient model of flat plate solar thermal collectors which uses the same underlying modelling methodology as Type 538. Wills (2013) varied the level of discretization between 1 and 40 nodes, and found that annual collector performance was insensitive to mesh size beyond 10 
nodes. For this study, 15 nodes were used for each instance of Type 538.

Lastly, Type 538 corrects for the incidence angle of solar beam radiation using non-dimensional incidence angle modifiers. These modifiers are determined as a function of the transverse and longitudinal incidence angles on the collector. Incidence angle modifiers represent the ratio of the collector transmittance-absorptance product at solar incidence angle $\theta$ to the transmittance-absorptance product at normal incidence. Details of incidence angle modifiers are omitted here for clarity, and the interested reader is directed to Duffie and Beckman (2013) for further details. For this research, values of the incidence angle modifiers at various angles were derived from TÜV Rheinland (2014).

Recall that only five instances of Type 538 are used to model the community's overall solar thermal array. Each instance of Type 538 represents an aggregation of all collectors in the same orientation. To model the aggregate performance of collectors in the same orientation, the methodology developed previously by Wills (2013) was used. This approach assumes all collectors in the same orientation are connected in parallel, and flow entering each collector is equal to the total flow rate entering the collector array divided by the number of collectors in the array. The number of collectors modelled is an input which will be varied in this study.

Appendix B describes a sensitivity study conducted modelling 20 solar thermal collectors in different series and parallel connection configurations. It was found that when all collectors were modelled in parallel there was a $2.9 \%$ reduction in annual useful energy gain compared to all collectors connected in series. Therefore, aggregating all solar thermal collectors by connecting them in parallel was assumed to be the more conservative estimate.

\subsubsection{Solar Thermal Collector Eligibility Criteria}

Figure 4.3 previously showed that five explicit instances of the ETC TRNSYS Types were used to represent the community solar thermal collector array. Each represented an aggregation of community ETCs which are mounted in the same orientation. The 
geometric resolution of CHREM limited the number of eligible roof-mounting orientations in communities. Swan (2010) stated that the CSDDRD lacked pertinent geometric information to develop detailed floor plans in ESP-r. They therefore used a rectangularization process which reduced both geometric and computational complexity while preserving relevant heat transfer parameters such as surface area and internal air volume, illustrated in Figure 4.7.

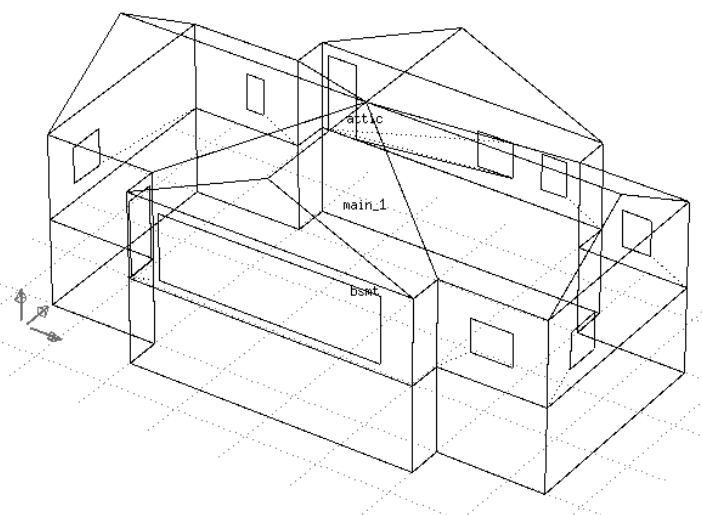

(a) Detailed

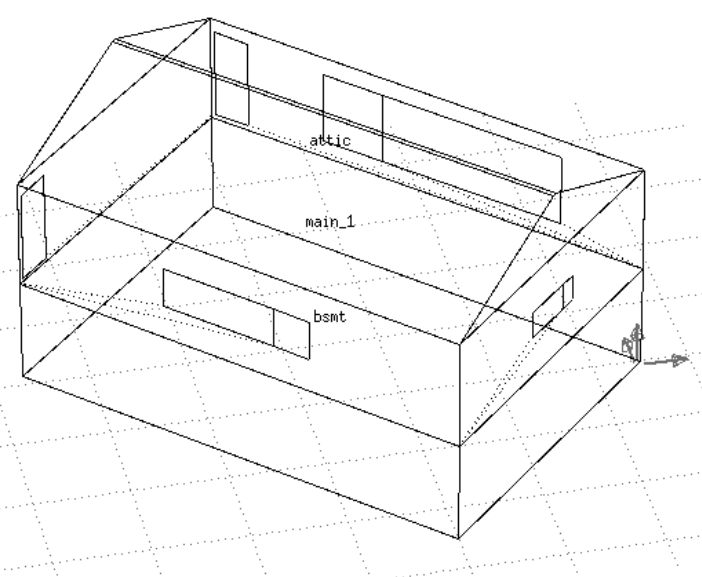

(b) Simplified

Figure 4.7: Three-dimensional renderings of CSDDRD dwellings, adapted from Swan et al. (2013)

Coarse geometric data pertaining to dwelling orientation was also provided in the CSDDRD. The facing of the front façade had a resolution of the cardinal and intermediate compass directions (i.e. north, southwest, etc.). Shown previously in Figure 3.2, there was also limited information on dwelling roof geometry. Swan (2010) developed explicit geometry for three roof types, and all inclined roof surfaces had a slope of $23^{\circ}$ from horizontal. According to Swan (2010), $23^{\circ}$ was a typical roof slope for Canadian dwellings. 


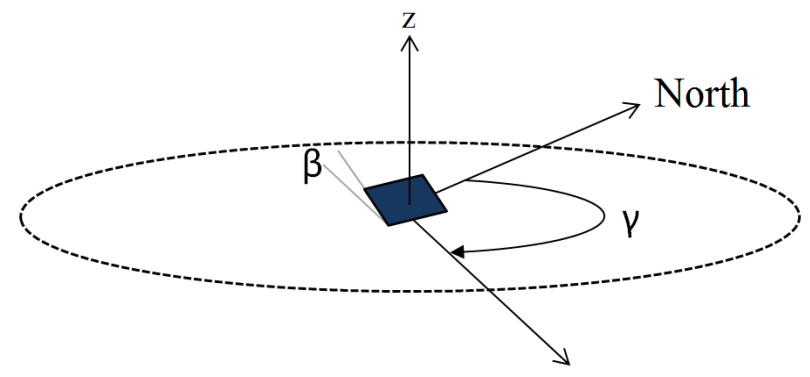

Figure 4.8: Solar orientation angles, reproduced with permission from Wills et al. (2016)

Using Figure 4.8 as a reference, the following eligibility criteria were used to identify community roof surfaces eligible for roof-mounted solar collectors:

- Surface azimuth $\gamma$ between $90^{\circ}$ and $270^{\circ}$ inclusive;

- Surface slope $\beta$ equal greater than $0^{\circ}$;

- and surface area and geometry sufficient to accommodate at least one collector.

Given the above criteria, it can be seen that only five possible roof surface orientations exist in CHREM. All collectors are assumed to be mounted flush with the roof surface in order to reduce installation costs and roof structural loads. Therefore all collectors are assumed to have a slope $\beta$ equal to $23^{\circ}$. Shown in Appendix B however, both solar thermal and PV collector performance is relatively insensitive to $\beta$ over the range of practical values. To determine if and how many collectors can be mounted in a roof surface, a bin packing algorithm described later in Section 4.5 is used.

\subsection{Solar PV Simulation Methodology and Inputs}

\subsubsection{Modelling Methodology}

Solar PVs were modelled in the current research using TRNSYS standard library Type 194 (TESS, 2014c). This model was developed by De Soto et al. (2006), who represented PV collectors as equivalent circuits shown in Figure 4.9. 


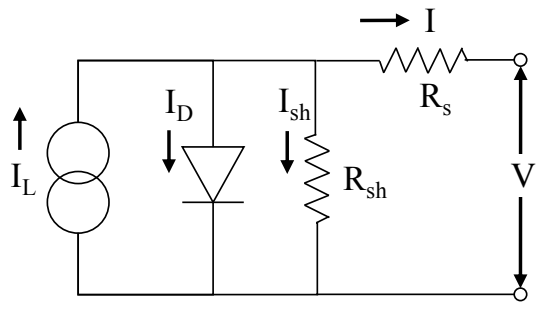

Figure 4.9: Equivalent PV circuit, adapted from De Soto et al. (2006)

The current and voltage of the circuit are determined using environmental conditions and five parameters:

1. Light current, $I_{L}[\mathrm{~A}]$;

2. Diode reverse saturation current, $I_{D}[\mathrm{~A}]$;

3. Series resistance, $R_{s}[\Omega]$;

4. Shunt resistance, $R_{s h}[\Omega]$;

5. Modified idealty factor, $\alpha_{P V}[-]$.

Generally these parameters are determined as a function of incident solar radiation, temperature, and performance data commonly reported by manufacturers. Unlike the solar thermal collector model described previously, Type 194 is a steady-state model. De Soto et al. (2006) validated their model against annual measured data at a five-minute temporal resolution collected from four different PV cell technologies $^{3}$. For each cell the current, voltage, and cell temperature was recorded. They found their model was able to reasonably predict current, voltage, and maximum power compared to the measured cells. They additionally obtained good agreement with the collector model developed from King et al. (2004). An in-depth discussion of Type 194's solution methodology is omitted here for clarity, and the interested reader is directed to De Soto et al. (2006) or TESS (2014c) for further details.

\footnotetext{
${ }^{3}$ Single-crystalline, poly-crystalline, silicon thin film, and triple-junction amorphous.
} 


\subsubsection{Model Parameters}

For this research a $250 \mathrm{~W}$ poly-crystalline solar panel from Canadian Solar (2014) was assumed for the retrofit PV systems. Crystalline silicon cells are the most common type of PV technology, representing 85\% of the world's market sales in 2011 (US DOE, 2017). According to Duffie and Beckman (2013), PV modules with efficiencies over $15 \%$ may be purchased on the market, and experimental single-crystalline PV cells have been found to achieve $25 \%$ efficiency. The $250 \mathrm{~W}$ panel from Canadian Solar (2014) considered here has a typical efficiency rating of $15.54 \%$ determined at standard testing conditions (STC) ${ }^{4}$. The input parameters used in Type 194 to characterize this PV panel is provided in Table 4.2.

\footnotetext{
${ }^{4}$ Spectrum AM 1.5 solar irradiance of $1000 \mathrm{~W} / \mathrm{m}^{2}$ and cell temperature of $25{ }^{\circ} \mathrm{C}$.
} 
Table 4.2: PV model parameters for Type 194

\begin{tabular}{|c|c|}
\hline Parameter & Value \\
\hline Short-circuit current at STC, $I_{s c}[\mathrm{~A}]$ & 8.87 \\
\hline Open-circuit voltage at STC, $E_{o c}[\mathrm{~V}]$ & 37.2 \\
\hline Voltage at $\mathrm{MPP}^{*}$ and STC, $E_{m p p}[\mathrm{~V}]$ & 30.1 \\
\hline Current at $\mathrm{MPP}^{*}$ and STC, $I_{m p p}[\mathrm{~A}]$ & 8.3 \\
\hline Temperature coefficient of $I_{s c}$ at STC $[\mathrm{A} / \mathrm{K}]$ & 0.00577 \\
\hline Temperature coefficient of $E_{o c}$ at STC $[\mathrm{V} / \mathrm{K}]$ & -0.1265 \\
\hline No. of cells wired in series [-] & 60 \\
\hline No. of modules in series [-] & 1 \\
\hline No. of modules in parallel [-] & variable \\
\hline Module temperature at NOCT $\left[{ }^{\circ} \mathrm{C}\right]$ & 45 \\
\hline Ambient temperature at $\mathrm{NOCT}\left[{ }^{\circ} \mathrm{C}\right]$ & 20 \\
\hline Module active area, $A_{P V}\left[\mathrm{~m}^{2}\right]$ & 1.43 \\
\hline$\alpha_{P V}$ at $\mathrm{STC},[-]$ & 1.6141 \\
\hline$I_{L}$ at $\mathrm{STC},[\mathrm{A}]$ & 8.8778 \\
\hline$I_{D}$ at $\mathrm{STC},[\mathrm{A}]$ & $8.586 \mathrm{E}-10$ \\
\hline$R_{s}$ at $\mathrm{STC},[\Omega]$ & 0.29 \\
\hline$R_{s h}$ at $\mathrm{STC},[\Omega]$ & 328.5 \\
\hline$\tau \alpha$ at normal incidence [-] & 0.95 \\
\hline Semiconductor bandgap $[\mathrm{eV}]$ & 1.12 \\
\hline Extinction coefficient product of cover, $K L[-]$ & 0.0128 \\
\hline
\end{tabular}

* Maximum power point

The top block of parameters listed in Table 4.2 were derived from test values reported from Canadian Solar (2014). The second block of parameters in Table 4.2 were determined using a plug-in for Type 194. This plug-in determines the five parameters in the second block iteratively using the other input parameters provided 
(TESS, 2014c). The transmissivity and absorptivity product, $\tau \alpha$, was taken as the Type 194 default. The semiconductor bandgap was derived from the typical value reported by Duffie and Beckman (2013) and TESS (2014c) for silicon cells.

Canadian Solar (2014) stated that the PV cells were covered with $3.2 \mathrm{~mm}$ tempered glass. According to Duffie and Beckman (2013), a typical value for the extinction coefficient of PV module glazing is $4 \mathrm{~m}^{-1}$. Therefore, the extinction coefficient product of the cover, KL, was assumed to be 0.0128. Table 4.2 lists the number of modules in parallel as variable. Similar to the solar thermal collectors, only five instances of Type 194 were used to model the community solar array. Each instance represents an aggregation of PV collector area in the same orientation, and the number of collectors is a varied input in this study.

The power output of the PV arrays was assumed to be the maximum power point (MPP) of the panels. All PV arrays were assumed to be connected to an inverter to convert the array DC output to $\mathrm{AC}$ for integration into the electrical distribution system. Rather than explicitly model the performance of the inverters, a constant inverter efficiency of 95\% was assumed. Wills et al. (2015) and Wills et al. (2016) previously conducted PV retrofit studies for Canadian residential buildings. They explicitly modelled inverters using the ESP-r implementation of the model developed by Ulleberg (1998), and performance data for 17 different inverters from the database developed by Driesse (2009) with nominal power ratings between $200 \mathrm{~W}$ to $250 \mathrm{~kW}$. Reviewing the simulation data from Wills et al. (2016), the average monthly inverter efficiency was found to be $94.8 \%$ with a standard deviation of $1.8 \%$. Therefore a constant inverter efficiency of $95 \%$ was determined to be an appropriate estimate.

No curtailment of PV generation was considered. Curtailment refers to the reduction of generation output from the maximum possible given the current availability of resources. Curtailment can occur for several reasons, such as transmission constraints and over-supply or line outages (Bird et al., 2014). Net-zero however, is often designed assuming the grid always has capacity to accept PV generation, although this may not always be the case.

The eligibility criteria for PV retrofit was identical to the criteria defined for solar thermal collectors. The number of collectors that could be mounted on an eligible 
surface was determined using the bin packing algorithm described later in Section 4.5. Another consideration in this work was the interaction of PV and solar thermal collectors. When populating an existing community with solar collectors, the same roof area cannot contain both solar thermal and PV collectors. The methodology used to allocate community roof area to PV and solar thermal collectors is described later in Section 4.9.

\subsection{Solar Collector Roof-mounting Algorithm}

Section 4.3.3 provided the eligibility criteria for roof-mounted solar collector retrofit. Once a dwelling roof surface was determined to be suitable for collector mounting, the number of collectors that can be mounted on that surface needed to be determined. Nikoofard et al. (2014a) and Asaee et al. (2017) previously used CHREM to model the retrofit of solar collector systems in the Canadian residential sector. To determine the number of collectors that could be placed on an eligible surface, $N_{\text {mount }}$, they used the expression:

$$
N_{\text {mount }} \leq \frac{G_{r e f} \cdot \eta_{\text {pack }} \cdot A_{\text {roof }, \text { surf }}}{\dot{Q}_{P V, \text { rated }}}
$$

where $G_{r e f}$ is the reference solar insolation $\left[\mathrm{W} / \mathrm{m}^{2}\right], \eta_{\text {pack }}$ is a user defined efficiency [-], $A_{\text {roof,surf }}$ is the roof surface area $\left[\mathrm{m}^{2}\right]$, and $\dot{Q}_{P V \text {,rated }}$ is the rated output of each PV module $\left[\mathrm{W} / \mathrm{m}^{2}\right]$.

The eligibility criteria was similar to the criteria defined here; however, only inclined rectangular roof surfaces were considered eligible for collector mounting, eliminating hip type roof geometries.

For this research a different approach was used to estimate the amount of collectors that can be mounted on an eligible roof surface. The structured thermal zone naming convention and surface characterization used in CHREM was exploited to develop a fit-for-purpose algorithm which processed the geometric data of ESP-r model roof surfaces. Information on CHREM dwelling roof type is held directly in the CSDDRD. Therefore dwellings which had a flat type roof, which were ineligible 
for roof-mounted retrofit in this study, were not processed for collector mounting.

For dwellings with hip and gable type roofs, the algorithm processed the dwelling model geometry. All inclined roof surfaces in CHREM used an ESP-r multilayer construction whose string identifier had the suffix 'slop', which was used by the algorithm to recognize the sloped roof surfaces. The Cartesian vertex data used to define each inclined surface was loaded by the algorithm, and the surface normal was calculated to determine surface orientation. If the surface orientation satisfied the eligibility criteria defined previously in Section 4.3.3, the surface vertexes were transformed to a two-dimensional Cartesian coordinate system and processed by the Perl module Math::Polygon developed by Overmeer (2011).

The Perl module reported the area and edge lengths of the surface. If the surface area was greater than the area of a single solar collector, the shape of the surface was then determined from the reported edge lengths. CHREM only used three fundamental shapes for inclined roof surfaces: rectangle, isosceles triangle, and isosceles trapezoid. To determine the number of collectors that could be mounted onto the inclined surface, a finite first-fit algorithm described by Berkey and Wang (1987) was used.

The user provides the major length and width dimensions of the collector, then the rectangular panels are packed within the boundaries of the roof surface starting from the bottom left, then moving left to right and bottom to top. For PV panels, each surface is separately packed with all collectors oriented vertically, then horizontally. Whichever orientation yielded the largest number of collectors packed was determined $N_{\text {mount }}$ for the surface. Figure 4.10 illustrates the packing of a triangular roof surface with PV panels. 


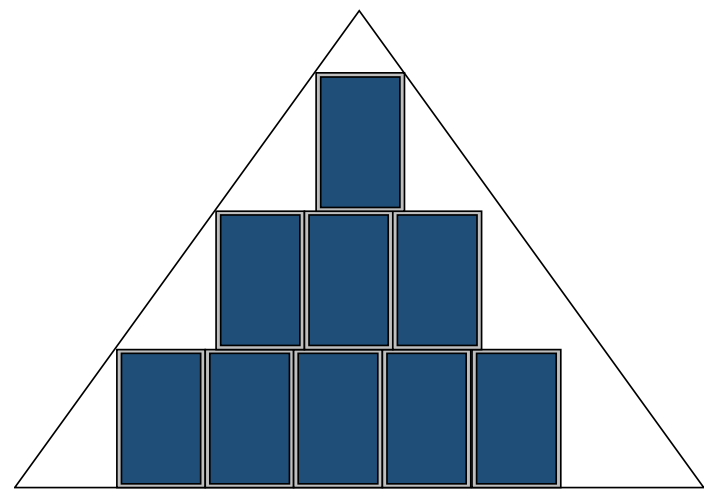

(a) Vertical

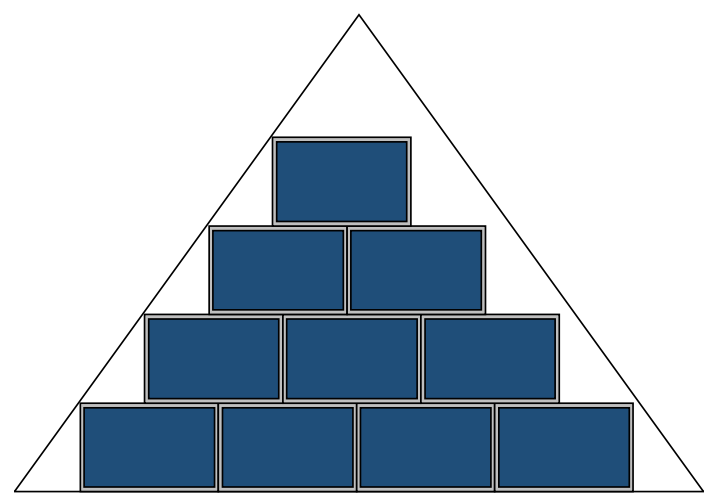

(b) Horizontal

Figure 4.10: PV packing on triangular roof roof surfaces

Similar to Equation 4.4, the user could specify a packing efficiency value $\eta_{\text {pack }}$. The purpose of $\eta_{\text {pack }}$ was to recognize that the roof surfaces represented in CHREM were ideal, and in reality the roof geometry is more complex and contain obstacles such as vents and electric utility roof masts. The number of collectors that may be packed on the surface, $N_{\text {mount }}$, is multiplied by $\eta_{\text {pack }}$ and rounded down to the nearest integer. For this work however, it is unknown what an appropriate value of $\eta_{\text {pack }}$ is. In the absence of additional roof geometry, $\eta_{\text {pack }}$ was taken as 1 . It should be noted that while this provides an optimistic estimate of available roof area in the community, other community structures such as detached garages were not explicitly considered in this research, but would be feasible for roof-mounted collectors in practice.

In contrast to PV collectors, ETCs could only be packed onto eligible surfaces in the orientation shown in Figure 4.11. The AP-30 collectors selected for this study are heat pipe type collectors, which were described previously in Chapter 2. In order to function properly, the header must be elevated above the heat pipes in the glass tubes. The heat pipe transfers heat and mass through buoyancy effects, which would not be effective if the collectors were rotated $90^{\circ}$ from the position shown in Figure 4.11 . 


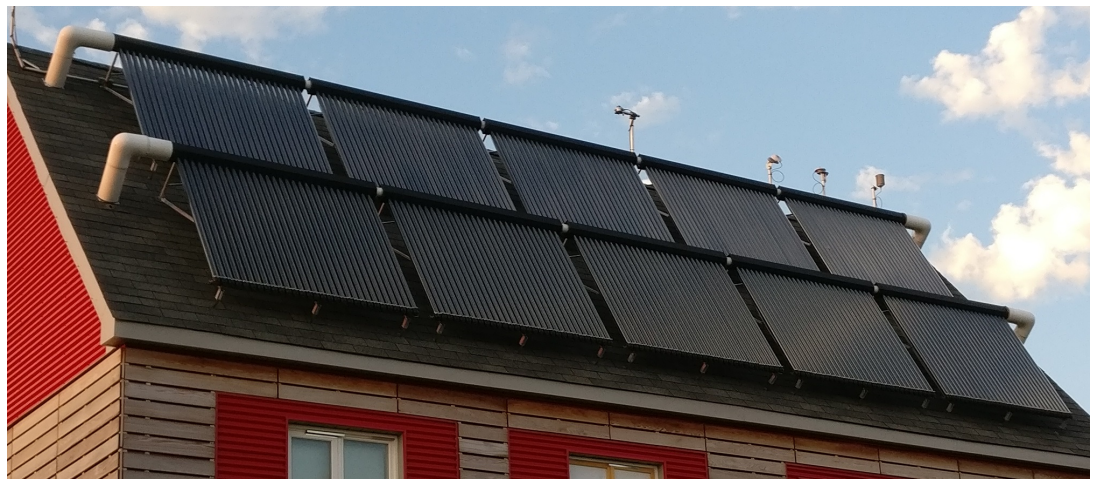

Figure 4.11: Roof-mounted ETC system

Figure 4.12 provides the major dimensions of the PV and ETC collectors considered in this research. The dimensions were provided from Canadian Solar (2014) and Apricus (2016a), respectively.

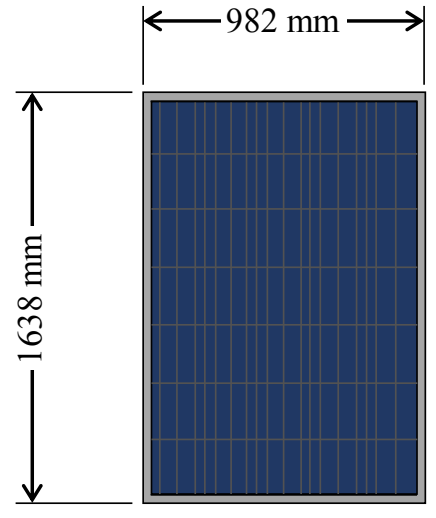

(a) PV

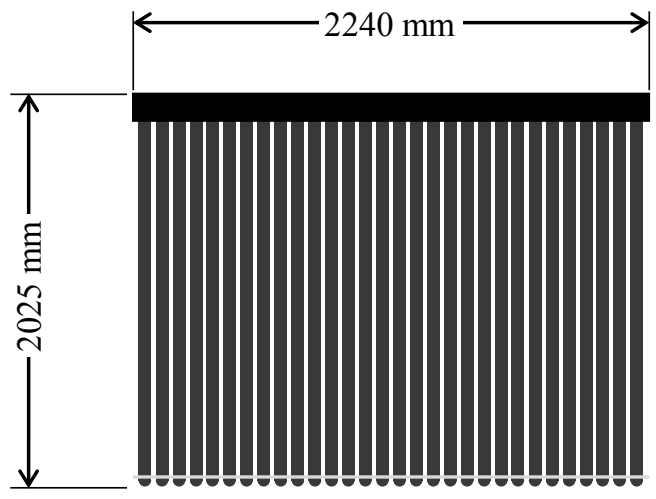

(b) ETC

Figure 4.12: Solar collector dimensions 


\subsection{Thermal Energy Storage Simulation Method- ology and Inputs}

Stated previously, a central water-based sensible TES system was considered in this work due to its simplicity, relatively low costs, and operational temperatures wellaligned with residential space heating and DHW demands. Several different modelling methodologies are available to model TES systems in TRNSYS. For this work, a stratified tank model was selected. For water-based systems, stratification is the existence of a temperature gradient along the vertical direction which develops as a result of density differences in the fluid. Since the 1960's, thermal stratification has been extensively studied to improve the usability of sensible TES (Andersen et al., 2008).

Stratification helps increase the exergy of sensible TES systems. Duffie and Beckman (2013) previously indicated that lower temperatures supplied from a nearly fully charged stratified TES improve solar collector efficiency and reduce losses to ambient. Cruickshank (2009) also noted that a stratified TES can potentially deliver early morning thermal demands when the TES is nearly fully discharged. Lund (1988) and Han et al. (2009) both simulated large central heating systems with water-based seasonal TES, and found that when stratification was considered compared to fullymixed tanks, system performance improved by 35\% to 60\%. Wills (2013) previously used TRNSYS and ESP-r to model a $250 \mathrm{~m}^{3}$ water-based seasonal TES supplied by solar thermal providing space heating to a single-detached dwelling in Canada. They found that when a 10 node tank was considered instead of a fully-mixed tank, the system annual solar fraction ${ }^{5}$ increased by $17.5 \%$. Extensive discussion of stratification in TES systems is omitted here for clarity, and the interested reader is directed to Dinçer and Rosen (2008), Cruickshank (2009), and Pinel et al. (2011) for further information.

\footnotetext{
${ }^{5}$ Fraction of total system demand met by solar energy.
} 


\subsubsection{Modelling Methodology}

For this work, Type 534 from TESS (2014b) was used. This Type models a stratified vertical cylindrical storage tank using a one-dimensional finite-difference discretization based on the method described by Newton (1995), illustrated in Figure 4.13. One-dimensional heat transfer along the vertical direction is a common assumption used to model fluid-based TES systems (Kozlowski, 1989). Compared to two or three-dimensional models, Zurigat et al. (1989) stated that this approach is simpler and suitable for large energy system simulations. They additionally stated that tank designers should be targeting one-dimensional flow to reduce fluid mixing and destratification.

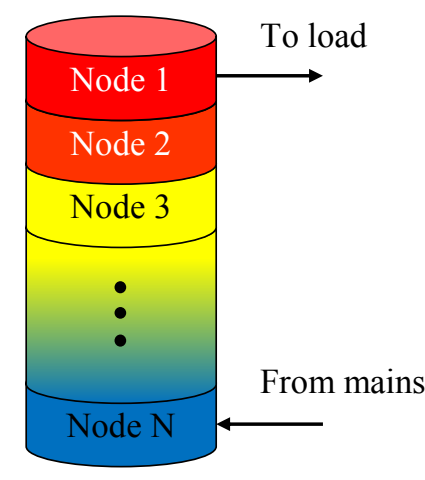

Figure 4.13: One-dimensional discretization of a stratified tank, adapted from Wills (2013)

At each simulation timestep, an energy balance is determined over each nodal control volume, illustrated in Figure 4.14. Both convective and conductive heat transfer is considered between adjacent nodes. Conduction between fluid layers is determined, as well as conduction along the storage tank wall using the $\Delta k$ term shown in Figure 4.14. Additional information on the solution methodology of Type 534 is omitted here for clarity, and the interested reader is directed to TESS (2014b), Newton (1995), Duffie and Beckman (2013), and Cruickshank (2009) for further details. 


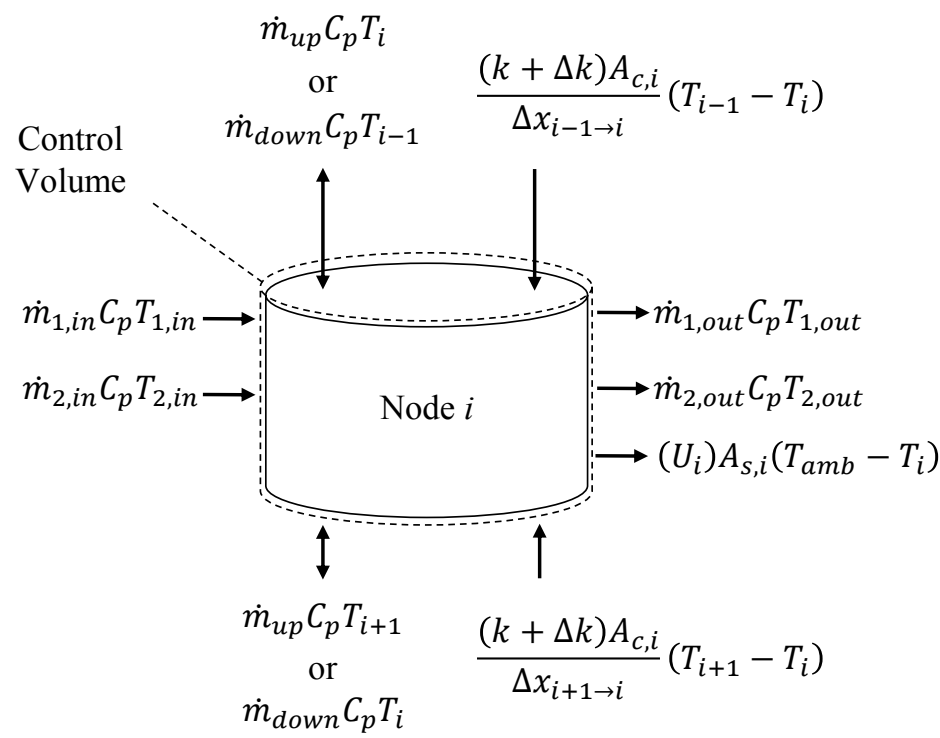

Figure 4.14: Tank node control volume energy balance, adapted from Cruickshank (2009)

Zurigat et al. (1989) compared the performance calculations of six published one-dimensional TES models with measured data from charging tests ${ }^{6}$ of an approximately $188 \mathrm{~L}$ hot water tank with inlet flow rated between 0.5 and $3 \mathrm{gpm}$. Four of the models used a finite-difference method, while the other two used analytical solutions. Zurigat et al. (1989) found that all models had varying degrees of agreement with the measured development and distribution of the TES thermocline ${ }^{7}$; however, two of the finite-difference models and the one analytical model were found to have the best agreement. Allard et al. (2011) compared performance estimates of Type 534 to other TES models in TRNSYS and measured data from an electrically heated commercial 270 L DHW tank. They found that Type 534 and Type 340 from Drück (2006) both had the highest accuracy compared to the measured data.

One-dimensional multi-node node TES models have also been compared to measured data from relatively large TES systems. Dalenbäck (1993) used measured data

\footnotetext{
${ }^{6}$ Hot water added to the top of the tank and cold water extracted from the bottom.

${ }^{7}$ Vertical distribution of fluid temperature in the TES
} 
from the Särö project located near Götenborg, Sweden. This was a central heating project which used a $640 \mathrm{~m}^{3}$ buried cylindrical steel tank which provided space heating and DHW to 48 apartments. The storage system was modelled in TRNSYS using the XST model developed by Marazella (1992). The XST model uses a modelling approach similar to Type 534. Dalenbäck (1993) found that the XST model could represent the system temperatures in a realistic way. Raab et al. (2005) validated the XST model in TRNSYS using temperature and flow rate data from a $2795 \mathrm{~m}^{3}$ buried cylindrical central TES system located in Hannover, Germany which supplied space heating and DHW to 106 units in multi-family buildings. They found deviations between measured and modelled TES temperatures to be less than $\pm 3 \%$. The deviation of annual tank energy quantities were also found to be less than $2 \%$.

\subsubsection{Model Parameters}

For this research the central TES was assumed to be a vertical cylindrical tank. The tank parameters are summarized in Table 4.3. Fluid thermophysical properties are not stated in Table 4.3, since they were determined internally by Type 534 assuming pure water.

Table 4.3: TES model parameters for Type 534

\begin{tabular}{ll}
\hline Parameter & Value \\
\hline \hline Volume, $V_{T E S}\left[\mathrm{~m}^{2}\right]$ & variable \\
Tank height, $H_{T E S}[\mathrm{~m}]$ & variable \\
Insulation conductivity, $k_{T E S, i n s}[\mathrm{~W} / \mathrm{m} \cdot \mathrm{K}]$ & 0.04 \\
Insulation thickness, $l_{T E S, i n s}[\mathrm{~m}]$ & 0.1408 \\
Additional conductivity $\Delta k_{T E S, i n s}[\mathrm{~W} / \mathrm{m} \cdot \mathrm{K}]$ & 0 \\
No. of nodes, $N_{T E S}$ & 10 \\
\hline
\end{tabular}

The tank volume $V_{T E S}$ was a design variable in this study which could vary between 5 and $500 \mathrm{~m}^{3}$. The tank height $H_{T E S}$, however, is determined as a function of the 
specified volume. Based on a survey of commercially available water-based TES systems, Heimrath and Haller (2007) suggested the relationship between $V_{T E S}$ and $H_{T E S}$ which was used in the current research:

$$
H_{T E S}=\left\{\begin{array}{l}
\left(0.32 \cdot V_{T E S}\right)+1.65 \text { if } V_{T E S} \leq 14 \mathrm{~m}^{3} \\
\left(0.09302 \cdot V_{T E S}\right)+4.698 \text { if } V_{T E S}>14 \mathrm{~m}^{3}
\end{array}\right.
$$

The tank conductivity $k_{T E S \text {,ins }}$ value of $0.04 \mathrm{~W} / \mathrm{m} \cdot \mathrm{K}$ selected for this study was the prescribed value for tank insulation defined for the comparative solar combisystems simulation studies conducted previously by IEA-SHC Task 26 (Weiss, 2003). This value also lies within the range of conductivities of insulating materials for waterbased TES systems reviewed by Schultz (2005). For typical insulating materials mineral wool, polystyrene, and polyurethane Schultz (2005) reported conductivity ranges of 0.036 to $0.05 \mathrm{~W} / \mathrm{m} \cdot \mathrm{K}, 0.034$ to $0.05 \mathrm{~W} / \mathrm{m} \cdot \mathrm{K}$, and 0.024 to $0.05 \mathrm{~W} / \mathrm{m} \cdot \mathrm{K}$, respectively.

The insulation thickness $l_{T E S, i n s}$ was selected such that the resulting RSI value was $3.52 \mathrm{~m}^{2} \cdot \mathrm{K} / \mathrm{W}$ (R-20). This is the rated insulation level Rysanek (2009) assumed when modelling the hot water buffer tanks installed at the DLSC. Type 534 does not use insulation thickness and conductivity directly as an input, rather the effective $\mathrm{U}$-value of the tank wall is provided as a model parameter. The top and bottom of the tank are assumed to be flat surfaces with U-value equal to the inverse of 3.52 $\mathrm{m}^{2} \cdot \mathrm{K} / \mathrm{W}$. Since the tank is cylindrical, the effective U-value of the side of the tank, $U_{T E S, \text { ins,side }}\left[\mathrm{W} / \mathrm{m}^{2} \cdot \mathrm{K}\right]$, was determined with respect to the insulation inside surface area:

$$
U_{T E S, \text { ins }, \text { side }}=\left\{\frac{r_{T E S}}{k_{T E S, i n s}} \cdot \ln \left[\frac{\left(r_{T E S}+l_{T E S, i n s}\right)}{r_{T E S}}\right]\right\}^{-1}
$$

where $r_{T E S}[\mathrm{~m}]$ is the interior radius of the tank determined from $V_{T E S}$ and $H_{T E S}$.

The additional conductivity of the TES, $\Delta k_{T E S, \text { ins }}$, was not considered in this work. The purpose of this value is to model the conduction along the walls of the tank, which has the effect of inducing destratification in TES systems. An approximation of $\Delta k_{T E S, \text { ins }}$ suggested by Newton (1995) is: 


$$
\Delta k_{T E S, \text { ins }}=k_{\text {wall }} \cdot \frac{A_{T E S, \text { wall }, \text { cross }}}{A_{T E S, \text { fluid,cross }}}
$$

where $k_{\text {wall }}[\mathrm{W} / \mathrm{m} \cdot \mathrm{K}]$ is the conductivity of the TES wall material, $A_{T E S, \text { wall,cross }}$ $\left[\mathrm{m}^{2}\right]$ is the cross-sectional area of the TES wall, and $A_{T E S, f l u i d, c r o s s}\left[\mathrm{~m}^{2}\right]$ is the crosssectional area of the TES fluid. Since the TES volumes considered in this work are relatively large, $\Delta k_{T E S, \text { ins }}$ is assumed to be negligibly small.

The boundary temperature was assumed to be a constant $20{ }^{\circ} \mathrm{C}$. Rysanek (2009) assumed a constant boundary temperature of $20{ }^{\circ} \mathrm{C}$ when they modelled the buffer tank system installed at the DLSC. The two $125 \mathrm{~m}^{3}$ horizontal cylindrical buffer tanks at the DLSC are housed inside the Energy Centre building constructed to also house the DH system pumps, heat exchangers and controls (McDowell and Thorton, 2008). It is assumed that the central energy system considered in this work will also be housed inside an enclosed building to shelter the tank and equipment.

Figure 4.15 illustrates the locations of the inlet and outlet ports of the TES system. It is assumed that the TES is equipped with three inlet stratifiers connected to the returns from the $\mathrm{DH}$, microturbine, and solar loops. In practice, inlet stratifiers are used to direct fluid entering a TES to a region in the storage at similar temperature. Descriptions various types of stratifier devices may be found in Andersen et al. (2008) and Shah et al. (2005). To model these devices in Type 534, variable inlets are used. The incoming fluid stream is injected to the tank node at the closest temperature of the fluid stream. 


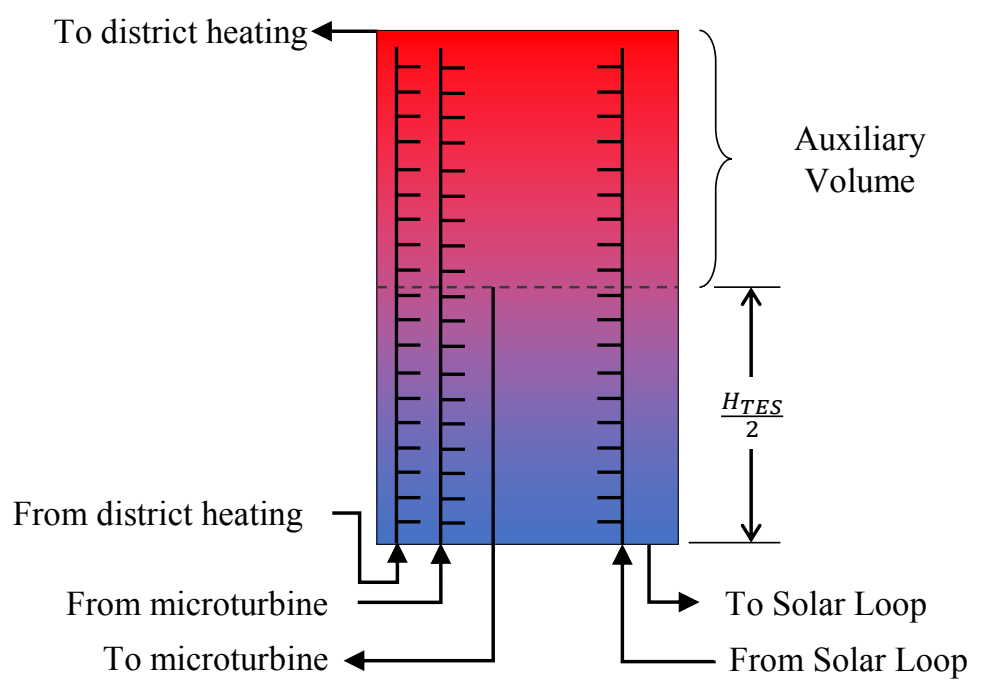

Figure 4.15: Port locations of the community TES system

The TES outlet port locations, however, were fixed. The solar loop draws from the bottom of the tank to access the lowest tank temperatures to improve collector efficiency. The DH loop draws from the top of the tank to provide the highest temperatures to the thermal demand. The microturbine loop, however, is only active in the auxiliary volume shown in Figure 4.15. Lundh et al. (2010) previously studied the sensitivity of TES auxiliary volumes for solar combi-systems installed in a singlefamily dwelling using TRNSYS. Based on their findings they suggested that the auxiliary volume should be no more than $50 \%$ of the total TES volume ${ }^{8}$. They also found that large TES systems were relatively insensitive to auxiliary volume size. For this work it was assumed that the supply to the microturbine was drawn from the middle of the TES. This reserved the cooler temperatures at the bottom of the TES to supply the primary solar thermal system.

Lastly, the TES was discretized using 10 nodes. Heimrath (2003) previously used 50 nodes $/ \mathrm{m}^{3}$ to a maximum of 150 nodes when modelling a central solar heat plant. Newton (1995) previously stated that few nodes assumes more mixing occurs within the tank, whereas more nodes assumes higher degrees of stratification. Zurigat et al.

\footnotetext{
${ }^{8}$ It should be noted that Lundh et al. (2010) did not consider inlet stratifiers.
} 
(1989) stated that the number of nodes should be correlated with flow rates, since higher flow rates are expected to yield more mixing and require less nodes. The 10 nodes selected for the current work is assumed to be a conservative estimate of the stratification achievable in the TES compared to the recommendations of Heimrath (2003).

\subsection{Microturbine Simulation Methodology and Inputs}

\subsubsection{Modelling methodology}

Microturbines were simulated using the steady-state empirical model developed previously by Shirey (2008). Shirey (2008) implemented their model into the U.S DOE's EnergyPlus $^{\mathrm{TM}}$ simulation tool. For the current work, the source code of this model was accessed from NREL (2017) and ported into TRNSYS as a new TRNSYS Type. The full-load electrical output capability of a microturbine, $\dot{Q}_{t u r b, F L}[\mathrm{~kW}]$, is determined each simulation timestep using Equation 4.8 (Shirey, 2008):

$$
\dot{Q}_{\text {turb }, F L}=\dot{Q}_{\text {turb }, F L, n o m} \cdot \dot{\bar{Q}}_{\text {turb }, F L}\left(T_{\text {turb,air,inlet }}, H_{\text {elev }}\right)
$$

where $\dot{Q}_{t u r b, F L, n o m}$ is the nominal full load electrical output $[\mathrm{kW}]$, and $\dot{\bar{Q}}_{\text {turb,FL }}\left(T_{\text {turb,air,inlet }}, H_{\text {elev }}\right)$ is the normalized full-load performance curve at various air inlet temperatures, $T_{\text {turb,air,inlet }}\left[{ }^{\circ} \mathrm{C}\right]$, and elevations, $H_{\text {elev }}[\mathrm{m}]$. Performance curve $\dot{\bar{Q}}_{\text {turb }, F L}\left(T_{\text {turb,air,inlet }}, H_{\text {elev }}\right)$ is normalized with respect to $\dot{Q}_{\text {turb,FL,nom }}$. It was noted that microturbine performance varies with elevation due to changes in atmospheric pressure, and consequently the total pressure at the turbine inlet. For the current work, $H_{\text {elev }}$ was replaced with turbine inlet total pressure, $P_{\text {turb,inlet }}[\mathrm{kPa}]$. The value of $P_{\text {turb }, \text { inlet }}$ is taken as the atmospheric pressure calculated at each timestep by the weather data reading processing Type 15 from the TRNSYS standard library (TESS, 2014c). 
The model also accounts for microturbine ancillary equipment power consumption, $\dot{Q}_{\text {turb,ancil }}\left[\mathrm{kW}\right.$, and standby power consumption, $\dot{Q}_{\text {turb,standby }}[\mathrm{kW}]$. Ancillary electrical consumption of the microturbine is due to operation of unit control packages, electrical systems, safety protection systems, and fuel supply systems (Borbely and Kreider, 2001). The current implementation of the microturbine model assumes constant ancillary power consumption during operation, although the model implementation of Shirey (2008) allows for variation of $\dot{Q}_{\text {turb,ancil }}$ as a function of fuel mass flow rate.

The actual delivered power, $\dot{Q}_{\text {turb,act }}[\mathrm{kW}]$, is determined using Equation 4.9 (Shirey, 2008):

$$
\begin{aligned}
& \dot{Q}_{\text {turb }, a c t}=\operatorname{MAX}\left[0,\left(\dot{Q}_{\text {load }, \text { elec }}+\dot{Q}_{\text {turb,ancil }}\right)\right] \\
& \dot{Q}_{\text {turb }, a c t}=\operatorname{MIN}\left[\dot{Q}_{\text {turb }, a c t}, \dot{Q}_{\text {turb }, F L}\right]
\end{aligned}
$$

where $\dot{Q}_{\text {load,elec }}[\mathrm{kW}]$ is the electrical load demand on the microturbine. In addition to the constraints defined in Equation 4.9, the user may specify a minimum electrical operating point $\dot{Q}_{t u r b, m i n}[\mathrm{~kW}]$. The model implementation developed for this work included two low power modes. In mode 1 , if the demand is below $\dot{Q}_{\text {turb,min }}$ the microturbine does not output any power. In mode 2 , turbine output is a constant $\dot{Q}_{\text {turb,min }}$ if the demand is below $\dot{Q}_{\text {turb,min }}$. For this work all microturbines were operated in low power mode 2 .

One of the benefits of microturbines is that they are lightweight and have a relatively fast response to dynamic loads Ismail et al. (2013). Yinger (2001) previously tested both a $30 \mathrm{~kW}$ and $75 \mathrm{~kW}$ microturbine. Microturbine response behaviours were examined through a series of ramp-up and ramp-down tests. Under high-load conditions, the $30 \mathrm{~kW}$ unit was found to have response times of 1.2 to 3.6 seconds $/ \mathrm{kW}$. Under low-load conditions this reduced to 4.4 to 7.6 seconds $/ \mathrm{kW}$. When the $75 \mathrm{~kW}$ unit was ramped up from 0 to full-load, Yinger (2001) observed a response of approximately 2 seconds $/ \mathrm{kW}$. The microturbines considered in the current work, introduced next in Section 4.7.2, have comparable ratings to the units studied 
by Yinger (2001). Given the relatively fast response times of the unit, a steadystate model was assumed to be appropriate for conducting annual energy analyses performed in the current work.

Additional details of the microturbine modelling methodology are omitted here for clarity, and the interested reader is directed to Shirey (2008) and NREL (2017) for further information.

\subsubsection{Model Parameters}

For the current work, three different microturbines were considered for community energy retrofit, and are summarized in Table 4.4. Performance data of these turbines were derived from commercially available units from the Capstone Turbine Corporation (Capstone, 2006, 2008, 2009). 
Table 4.4: Model parameters for the Capstone microturbines

\begin{tabular}{|c|c|c|c|}
\hline \multirow[b]{2}{*}{ Parameter } & \multicolumn{3}{|c|}{ Microturbine } \\
\hline & C30 & C65 & $\mathrm{C} 200$ \\
\hline Rated electrical output, $\dot{Q}_{t u r b, F L, n o m}\left[\mathrm{~kW}_{\mathrm{e}}\right]$ & 30 & 65 & 200 \\
\hline Min. electrical output, $\dot{Q}_{t u r b, \min }[\mathrm{kW}$ e $]$ & 2 & 2 & 15 \\
\hline Ref. electrical efficiency, $\eta_{\text {turb,elec,ref }}[-]$ & 0.26 & 0.29 & 0.328 \\
\hline Standby power, $\dot{Q}_{t u r b, \text { standby }}\left[\mathrm{kW}_{\mathrm{e}}\right]$ & 0.3 & 0.3 & 0.3 \\
\hline Ancillary power, $\dot{Q}_{t u r b, a n c i l}\left[\mathrm{~kW}_{\mathrm{e}}\right]$ & 2.6 & 4.5 & 10 \\
\hline Ref. exhaust flow rate, $\dot{m}_{\text {turb }, \text { exh,ref }}[\mathrm{kg} / \mathrm{s}]$ & 0.295 & 0.490 & 1.329 \\
\hline Ref. exhaust temperature, $T_{\text {turb,exh,ref }}\left[{ }^{\circ} \mathrm{C}\right]$ & 243.9 & 308.9 & 279.5 \\
\hline Ref. inlet temperature, $T_{\text {turb }, \text { inlet,ref }}\left[{ }^{\circ} \mathrm{C}\right]$ & & 15 & \\
\hline Ref. inlet humidity ratio, $T_{\text {turb, inlet,ref }}[-]$ & & 0.00635 & \\
\hline Ref. inlet pressure, $P_{\text {turb,inlet,ref }}[\mathrm{atm}]$ & & 1 & \\
\hline Fuel LHV* $[\mathrm{kJ} / \mathrm{kg}]$ & & 48980 & \\
\hline Fuel $\mathrm{HHV}^{* *}[\mathrm{~kJ} / \mathrm{kg}]$ & & 54370 & \\
\hline
\end{tabular}

The fuel mass flow rate of the microturbines was determined in terms of the LHV of the fuel. In this work, all microturbines are assumed to be natural gas-fired. Both Union Gas (2017) and Johnson (2016) report a HHV value of $38 \mathrm{MJ} / \mathrm{m}^{3}$ for natural gas distributed in Ontario, Canada. To express this value in terms of mass instead of volume, the specific gravity of natural gas was assumed to be 0.58 (Union Gas, 2017). To determine the LHV value of natural gas, a factor of 1.11 for converting from HHV to LHV was assumed, which was recommended by Johnson (2016).

In addition to the parameters provided in Table 4.4, the performance of the microturbines was characterized using a set of seven performance curves derived from date reported by Capstone (Capstone, 2006, 2008, 2009). The form and coefficients of these performance curves are not provided here for clarity, and are provided in 
Appendix H.

\subsubsection{Exhaust Heat Recovery Simulation Methodology and Inputs}

Shown previously in Figure 4.3, the exhaust stream of the microturbine is connected to a heat recovery module (HRM), unit 2 in Figure 4.3. The unit modelled in this work was based on a commercial HRM from Capstone (2012) and Unifin (2017). Thermal energy is extracted from the microturbine exhaust flow stream through a fan-coil heat exchanger within the HRM. The unit from Capstone (2012) includes a PID-controlled diverter valve located upstream of the exhaust inlet to the fancoil. The controller attempts to achieve a setpoint temperature at the coil outlet by diverting a fraction of the exhaust stream past the fan-coil heat exchanger.

To model the HRM in TRNSYS, a new Type was developed based on the cooling coil model Type 508a from TESS (2014a). Type 508a uses the bypass approach to model the heat transfer between moist air and a liquid through a fan-coil heat exchanger. The user specifies a coil bypass factor, $B F$ [-], which is related to heat exchanger effectiveness, $\varepsilon[-]$, (Raustad, 2013):

$$
B F \equiv 1-\varepsilon
$$

$B F$ is representative of the air that passes through the coil unaffected by the heat transfer, or "bypasses" the coil. Based on the performance metrics reported in Unifin (2017), a constant BF value of 0.15 was assumed for the HRM.

Figure 4.16 illustrates the structure of the HRM model implemented in TRNSYS for the current work. Type 508a is used internally to calculate the heat transfer across the fan-coil. Rather than explicitly model a PID controller to determine the fraction of exhaust flow diverted to the fan-coil, $\gamma$, an iterative approach was used to calculate $\gamma$ at each simulation timestep. The Golden Section Search described by Chapra (2011) was used to determine the value of $\gamma$ which minimized the error between the HRM outlet temperature, $T_{\text {load,out }}\left[{ }^{\circ} \mathrm{C}\right]$, and the specified setpoint temperature $T_{\text {load,set }}\left[{ }^{\circ} \mathrm{C}\right]$. 


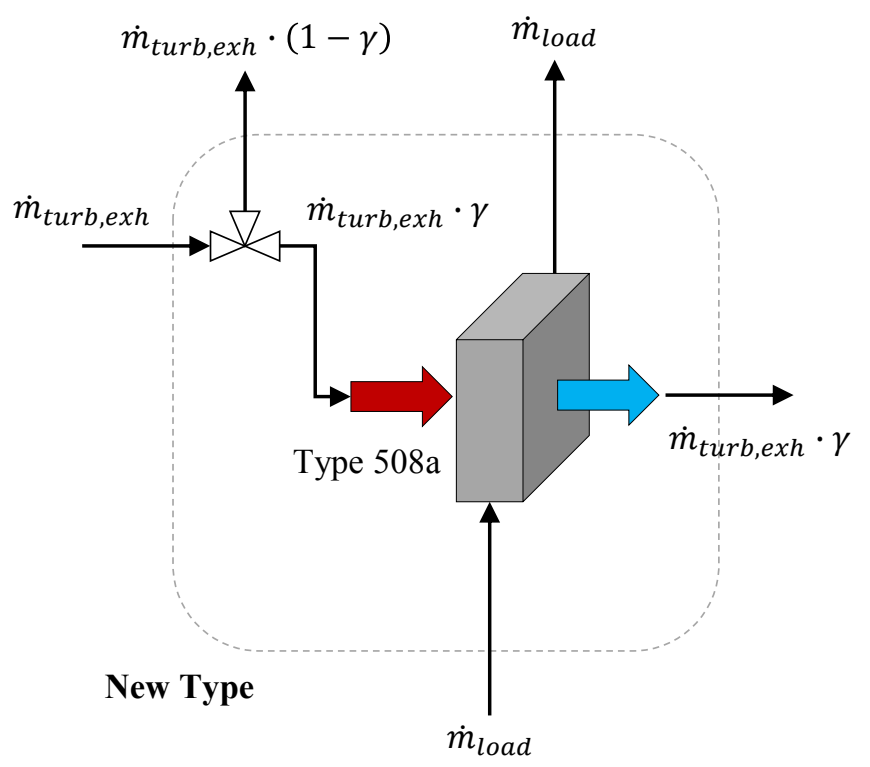

Figure 4.16: Flow schematic of the HRM model

The new HRM Type internally iterated until the estimated error, $\zeta_{a}[\%]$, was less than a user specified tolerance. $\zeta_{a}$ was determined using Equation 4.11 (Chapra, 2011):

$$
\zeta_{a}=(2-\phi)\left|\frac{\gamma_{H}-\gamma_{L}}{\gamma_{o p t}}\right| \cdot 100 \%
$$

where $\phi$ is equal to the golden ratio, $\gamma_{H}$ is the upper boundary of the search space, $\gamma_{L}$ is the lower boundary of the search space, and $\gamma_{o p t}$ is the optimal value determined for the iteration. For further details on the Golden Section Search method, the interested reader is directed to Chapra (2011). For this work, a tolerance of $2 \%$ was selected to balance accuracy with computational overhead.

\subsubsection{HRM Circulation Pump}

The HRM circulation pump, unit 3 in Figure 4.3, was modelled in TRNSYS using standard library Type 3b (TESS, 2014c). Type 3b is a simple steady-state variable speed pump model. The maximum rated flow rate of the pump was specified as 5.68 
$\mathrm{kg} / \mathrm{s}$ based on the maximum HRM inlet flow rate reported by Unifin (2017). Two control models were used to operate the pump in TRNSYS. A heating aquastat, modelled using Type 2 from the TRNSYS standard library TESS (2014c), was used to determine if the connected TES system required heating. The aquastat monitored the top temperature of the TES, and was set to hold the top of the tank to a setpoint of $93{ }^{\circ} \mathrm{C}$ with a deadband of $\pm 2{ }^{\circ} \mathrm{C}$.

In order for the pump to turn $\mathrm{ON}$, two conditions need to be met: the aquastat indicates heating is needed, and there is exhaust flow entering the HRM. If both of these conditions are satisfied, a secondary controller is then used to specify pump flow rate. Type 627 is a heat recovery model developed by TESS (2013). This model represents a combined HRM and supply circulation pump, but only sensible heat transfer is modelled between the moist air and water using the heat exchanger effectiveness method. Type 627 modulates both $\gamma$ and pump flow rate to achieve the desired outlet temperature specified by the user. If there is insufficient exhaust flow the pump flow rate is reduced, else the pump operates at maximum flow rate and microturbine exhaust is diverted away from the fan-coil. Rather then use this Type directly, the estimated flow rate of Type 627 was used to specify the flow rate the HRM circulation pump. Inlet mass flow rates and temperature for both the moist air and water was monitored by Type 627, and effectiveness was estimated using Equation 4.10. For further details of Type 627, the interested reader is directed to TESS (2013).

\subsubsection{Microturbine Operation Strategies}

The microturbine model is controlled using both the electrical demand $\dot{Q}_{l o a d, e l e c}$ and control signal input. The microturbine control signal is a binary value which indicates if the unit is ON and ready to meet electrical demands, or OFF. For the current work, however, the microturbines are operated in a combined heat and power (CHP) mode. Control of CHP units is non-trivial, since both forms of energy are produced simultaneously. While meeting an electrical demand, thermal output is also produced which may not be required, and vice versa. Kopf (2012) had previously noted that 
micro-CHP uses different operational strategies based on various objectives, such as reducing costs or GHG emissions.

Hawkes and Leach (2007) stated that micro-CHP operation strategies are typically simple, either being thermal or electric load following. They also noted that from an industry viewpoint, micro-CHP is primarily thermal following with electrical output being a secondary product. Kavvadias et al. (2010) modelled a tri-generation system $^{9}$, and identified five common operation strategies from the literature:

1. Thermal load following;

2. Electric load following;

3. Continuous operation;

4. Peak shaving;

5. Base load operation.

Kavvadias et al. (2010) characterized continuous operation as operation over a pre-defined time period regardless of demands. They stated this is common for technologies which cannot operate at part-load, and sell excess production to the electric utility. Peak shaving is dispatching the generator during periods of high energy demand, and base load operation is when the system is designed to cover a constant amount of the load.

Hawkes and Leach (2007) modelled the operation of three type of micro-CHP for residential applications in the UK: Stirling engine, gas engine, and solid-oxide fuel cell (SOFC). Each technology was coupled to a TES, and excess electricity production was exported to the grid. In addition to thermal and electric load following, Hawkes and Leach (2007) also defined a "least cost" operation strategy which dispatched the micro-CHP such that operational costs were minimized. Under this operational strategy, electrical import and export is determined based on fuel prices, electricity rates, and the interactions with system efficiency profiles. They found that using both electric and thermal demand signals was the least cost operation during the

\footnotetext{
${ }^{9} \mathrm{CHP}$ system where thermal output is supplied to an absorption chiller to also produce cooling.
} 
winter months, but summer operation varied by technology. They also found that the least cost operation does not always coincide with lowering carbon emissions.

Kopf (2012) modelled a proton-exchange membrane fuel cell (PEMFC) microCHP deployed in a Canadian single-detached dwelling. The PEMFC was connected to both a TES and lithium-ion battery electrical storage system. The TES system supplied the dwelling with space heating and DHW. Kopf (2012) studied nine different control strategies for charging the batteries. The operational strategy of the PEMFC was to operate at full load during the heating season, and minimum output during the cooling season when thermal demands are lower. McMurtry (2013) also modelled the PEMFC unit considered by Kopf (2012) deployed in low, medium, and high energy demand single-detached Canadian dwellings. The PEMFC was connected to a TES system which provided space heating and DHW, however no electrical storage was considered. McMurtry (2013) defined four different operation strategies:

1. Continuous/Seasonal;

2. Tank temperature following;

3. Electric price following;

4. Hybrid.

The tank temperature following was a form of thermal following, where the output of the PEMFC is linearly modulated as a function of return temperatures connected to the PEMFC from the TES system. For the continuous/seasonal control, the PEMFC operated at maximum output during the heating season, and minimum output during the cooling season. The hybrid approach used a weighted control signal from the electric price following and tank temperature following operational strategies. The weighting factor was determined using an optimization algorithm to minimize the annual operating cost of the system. McMurtry (2013) found that the hybrid operation had the most economical annual performance, and was mostly biased toward tank temperature following. 
Cao et al. (2014) modelled four different types of micro-CHP systems installed in a single-family Finnish dwelling, along with thermal and electrical load following operational strategies. They found that a fuel cell micro-CHP with an electrical to thermal ratio (ETTR) of 0.8 provided the best dwelling demand matching under a thermal following scheme. For electric following, they found that a Sterling engine with an ETTR of 0.25 provided the best matching.

Optimal design of micro-CHP control and operation was outside the scope of the current work. Instead, three microturbine control strategies were considered based strategies published in the literature:

1. Continuous/Seasonal;

2. Electric load following;

3. Full electrical output.

For all operational strategies microturbine electrical output is first supplied to the community net-electrical demand, which is determined as the aggregate dwelling electric loads minus community PV system output. Excess electrical production is then exported to the electrical grid. Thermal energy is also recovered from microturbine exhaust based on the control strategy described in Section 4.7.3.1.

The continuous/seasonal operation strategy used here was based on the strategy from McMurtry (2013). During the heating season the microturbine operates at constant $\dot{Q}_{t u r b, F L, n o m}$, and during the cooling season the constant output is reduced to $\dot{Q}_{t u r b, m i n}$. For this work, the cooling season was defined as May $1^{\text {st }}$ to October $31^{\text {st }}$ based on the heating and cooling degree days reported by ASHRAE (2009) for Toronto, Ontario. The microturbine is operated in low power mode during the cooling season to avoid wasting thermal output.

For the electric load following operational strategy, the microturbine electrical output was modulated to match the community net-electrical demand. If the netdemand was less than $\dot{Q}_{t u r b, m i n}$, the microturbine output was set to $\dot{Q}_{t u r b, m i n}$ and the excess electricity was exported to the grid. If the net-demand exceeded $\dot{Q}_{t u r b, F L, n o m}$, the microturbine was operated at full-load and additional electricity was imported 
from the electrical grid. Finally, the full electrical output operational strategy operates the microturbine continuously at $\dot{Q}_{t u r b, F L, n o m}$, which coincides with its maximal efficiency point. The drawback to this strategy is the excess thermal output that is

potentially wasted during the cooling season. Such a situation could potentially be addressed is a sufficiently large TES is implemented to carry summer heat production to meet winter demands (seasonal TES).

A thermal following control strategy was initially considered for this research, where microturbine output was modulated to match concurrent thermal demands imposed on the DH loop. It is shown in Appendix $\mathrm{H}$ however, that the aggregate thermal demands of the communities considered in this work often exceeded the output capabilities of the microturbines considered in this work. Thus, during the heating season the microturbines would continually operate at their maximum output.

\subsection{District Heating Simulation Methodology and Inputs}

Johansson and Wernstedt (2005) noted that dynamic simulation of a DH system may quickly become overwhelming. A DH system can be comprised of hundreds of kilometers of buried pipe laid out in various loops and parallel branches spread over a large geographic area. To accurately model these systems numerous parameters need to be considered which in practice cannot be precisely determined (Johansson and Wernstedt, 2005). The current work is focused primarily on simulation of the energy supply and demand systems. Therefore, a simplified approach was used to represent the DH system, illustrated in Figure 4.17. 


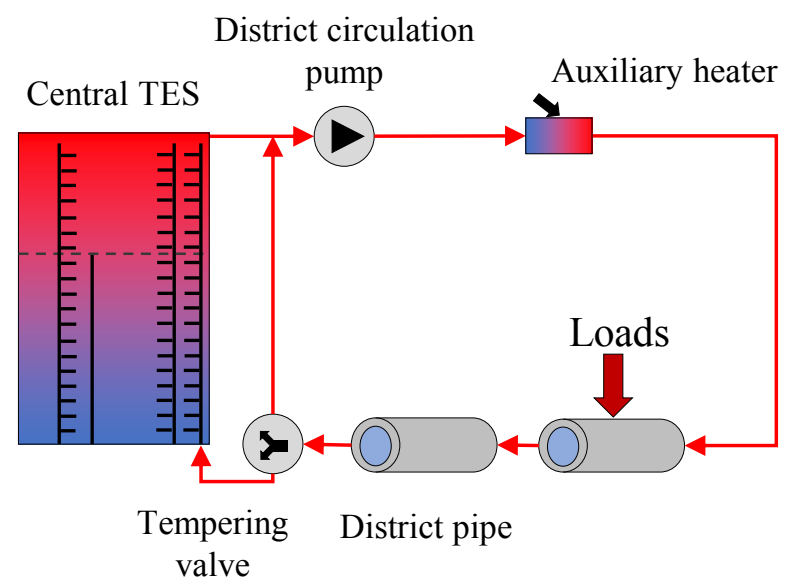

Figure 4.17: District heating loop

A de-coupled simulation approach was used in the current work due to capability limitations of TRNSYS and ESP-r, as well as to reduce computational complexity and overhead. For case study where communities received a DH system retrofit, the efficacy of dwelling-scale retrofits were first determined in ESP-r, described previously in Chapter 3. The aggregate community thermal and electrical demands were then determined from the ESP-r results and passed to the TRNSYS community energy model as a boundary condition.

The annual aggregate thermal demand profile of a retrofit community, expressed in $\mathrm{kW}_{\mathrm{th}}$, was determined by outputting and aggregating the thermal energy injected into dwelling occupied zones and DHW systems at each timestep. The HVAC and DHW system fuel consumption outputs were discarded, since the space heating and DHW demands are assumed to be met with the connected DH system. The community thermal demand profile was then imposed as a boundary condition in the DH loop using Type 682 from TESS (2012a). This is a simple TRNSY Type which performs a first law energy balance to determine the return temperature of the fluid.

A constant DH loop loss of $10 \%$ was also assumed for the current work. This estimate was based in the simulation results from Dalla Rosa et al. (2012). They 
modelled retrofit low temperature DH systems installed in Ottawa, Ontario for providing building space heating and DHW. Of the neighbourhoods they considered was an area with 407 single-detached dwellings, which is assumed to have similar energy demand densities and climates to the communities considered in the current work. Using supply/return temperatures of 90/55 and 90/40, Dalla Rosa et al. (2012) determined heat losses of 8.7 and 7.7\%, respectively. Skagestad and Mildenstein (2002) also reported that modern DH distribution systems experience annual heat losses between 5 and $20 \%$.

A district "pipe" was also included in the TRNSYS model, shown in Figure 4.17. The pipe was modelled using Type 31 from the TRNSYS standard library (TESS, 2014c). This pipe was not meant to physically represent the retrofit piping system for the district heating system, but was a modelling artifact used to promote numerical stability. Beausoleil-Morrison et al. (2014) previously stated that network loops in TRNSYS which do not contain any energy capacitance can cause solution oscillations and divergence. The pipe in Figure 4.17 was modelled with an adiabatic boundary condition along the pipe wall. An arbitrarily small length of $3 \mathrm{~m}$ and diameter of 0.5 $\mathrm{m}$ was selected to provide a capacitance with negligible influence on thermal results.

\subsubsection{Temperature Control}

The DH loop considered in this work is a "low-temperature" system. This is partially due to the use of hot water as the thermal energy transport medium, where an upper temperature limit of $100{ }^{\circ} \mathrm{C}$ is assumed. Low temperature $\mathrm{DH}$ systems also have the potential to increase system efficiencies (Torío and Schmidt, 2010) and reduce thermal losses (Dalla Rosa et al., 2011). Lund et al. (2014) noted the benefits of lower DH systems include higher heat recovery from flue gas condensation, higher conversion efficiencies for central solar collector fields, and higher capacities for TES systems.

BRECSU (2002) classified low temperature DH systems as those that operate up to $90{ }^{\circ} \mathrm{C}$. They stated that the these systems can be less expensive compared to higher temperature systems, since the lower temperatures permit the usage of plastic 
piping. They also noted that low temperature systems permit direct connection of the DH system with terminal devices within the building. Compared to other connection techniques, direct connection is the cheapest. Due to safety concerns, the upper temperature limit of direct connection systems is between 95 and 100 ${ }^{\circ} \mathrm{C}$ (BRECSU, 2002; Dalla Rosa et al., 2012; Danfoss, 2008). Schematics of DH direct connections may be found in Danfoss (2008).

There is a large body of literature describing the design supply and return temperatures of low temperature DH systems. Frederiksen and Werner (2013) reviewed 142 DH systems installed in Sweden. They found the national annual average supply temperature, weighted by system size, was $86^{\circ} \mathrm{C}$, and weighted average annual return temperatures were $47.2^{\circ} \mathrm{C}$. Gadd and Werner (2014) reported annual average supply and return temperatures of 207 Danish DH systems was $77.6^{\circ} \mathrm{C}$ and 43.1 ${ }^{\circ} \mathrm{C}$ respectively. Andrews et al. (2012) stated that a supply temperature of $75{ }^{\circ} \mathrm{C}$ is realistic for new large DH systems supplying a variety of buildings. BRECSU (2002) stated that for modern radiator and DHW systems DH systems can operate at supply/return temperatures of $80 / 50{ }^{\circ} \mathrm{C}$. Cuadrado (2009) stated that new network designs in Scandinavia use a maximum supply temperature of $90{ }^{\circ} \mathrm{C}$. They also stated that older dwelling space heating systems were designed for supply/return temperatures of $80 / 60{ }^{\circ} \mathrm{C}$, and modern systems are designed for $60 / 45^{\circ} \mathrm{C}$. Danish standards state that direct connection space heating systems should operate at 70/40 ${ }^{\circ} \mathrm{C}$ at design ambient temperatures of $-12{ }^{\circ} \mathrm{C}$, and DHW systems should operate at $60 / 40{ }^{\circ} \mathrm{C}$ under summer conditions (Bohm et al., 2008).

For the current work, the maximum supply temperature was assumed to be $90{ }^{\circ} \mathrm{C}$. Supply temperatures of DH systems however, are often modulated as a function of ambient temperature (Danfoss, 2008; Skagestad and Mildenstein, 2002). According to Skagestad and Mildenstein (2002), DH supply temperature setpoints are typically modulated using outdoor reset control. This is a common approach used to control hydronic heating systems, and involves specifying the supply temperature, $T_{D H, \text { sup }}$, as a function of ambient temperature. Figure 4.18 illustrates the outdoor reset control curve used in the current work. $T_{D H \text {,sup }}$ was provided as a setpoint temperature for both the auxiliary heater and tempering valve in Figure 4.17. 


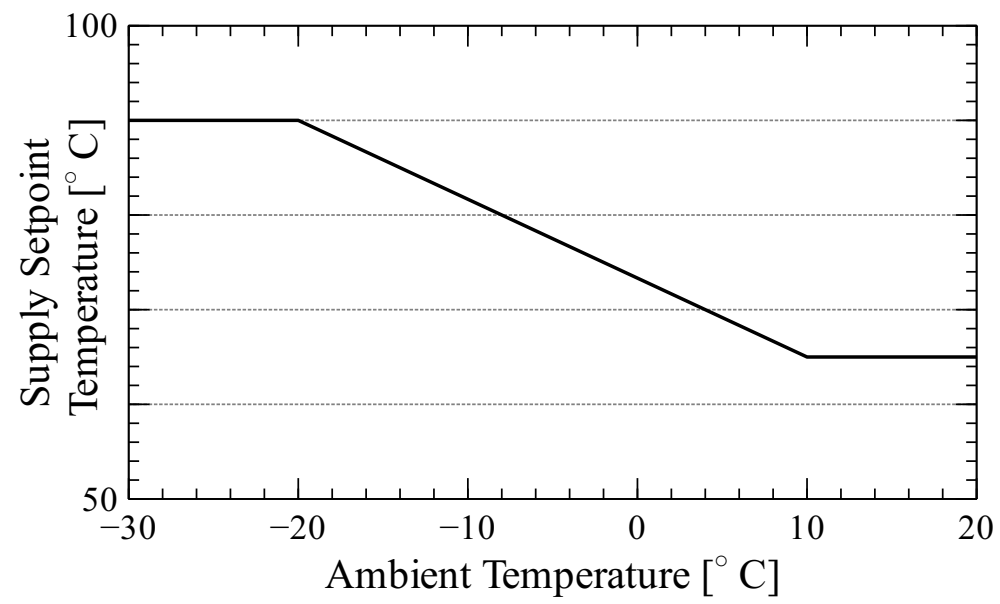

Figure 4.18: District heating outdoor reset curve

The lower limit $T_{D H \text {,sup }}$ was assumed to be $65^{\circ} \mathrm{C}$. BRECSU (2002) recommended a minimum $T_{D H \text {,sup }}$ of $70{ }^{\circ} \mathrm{C}$ to avoid legionella growth in DHW systems. Danfoss (2008) recommended minimum $T_{D H \text {,sup }}$ values of 65 to $70{ }^{\circ} \mathrm{C}$. Dalla Rosa et al. (2012) considered $T_{D H \text {,sup }}$ down to $60{ }^{\circ} \mathrm{C}$ for providing building space heating and DHW preparation. The ambient temperature coinciding with the minimum $T_{D H \text {,sup }}$ varies between 5 and $15{ }^{\circ} \mathrm{C}$ in the literature (Cuadrado, 2009; Danfoss, 2008; Frederiksen and Werner, 2013; Skagestad and Mildenstein, 2002). For this work the minimum $T_{D H \text {,sup }}$ was set to coincide with an ambient temperature of $10^{\circ} \mathrm{C}$. The maximum $T_{D H \text {,sup }}$ of $90^{\circ} \mathrm{C}$ coincided with an ambient temperature of $-20{ }^{\circ} \mathrm{C}$. This ambient temperature was selected based on the dry bulb temperature corresponding to $99.6 \%$ annual cumulative frequency of occurrence for Toronto, Ontario weather stations reported in ASHRAE (2009).

\subsubsection{Flow Control}

In addition to temperature modulation, Skagestad and Mildenstein (2002) stated that the other basic principle of $\mathrm{DH}$ system control is flow modulation. Compared to temperature modulation, flow modulation provides quicker response to changing demand, and variable speed pumps are important elements of modern distribution 
systems (Skagestad and Mildenstein, 2002).

Based on the design DH loop temperature drop values described in Section 4.8.1, a constant DH loop temperature drop, $\Delta T_{D H}$, of $35^{\circ} \mathrm{C}$ was assumed. The district circulation pump mass flow rate, $\dot{m}_{D H}(t)[\mathrm{kg} / \mathrm{s}]$, at each timestep is then determined from:

$$
\dot{m}_{D H}(t)=\frac{\dot{Q}_{\text {load }, t h}(t) \cdot\left(1-F_{\text {loss }}\right)}{c_{p, \text { water }} \cdot \Delta T_{D H}}
$$

where $\dot{Q}_{\text {load,th }}(t)\left[\mathrm{kW}_{\mathrm{th}}\right]$ is the aggregate community thermal load at timestep $t, F_{\text {loss }}$ is the fraction of DH system losses $(10 \%)$, and $c_{p, w a t e r}$ is the specific heat of water taken as a constant $4.18 \mathrm{~kJ} / \mathrm{kg} \cdot \mathrm{K}$.

The electrical consumption of the pump at each timestep, $\dot{Q}_{D H, \text { elec }}(t)\left[\mathrm{kW}_{\mathrm{e}}\right]$, was determined as a function of pump mass flow rate:

$$
\dot{Q}_{D H, \text { elec }}(t)=\dot{Q}_{D H, \text { elec, } \max } \cdot\left(\frac{\dot{m}_{D H}(t)}{\dot{m}_{D H, \max }}\right)^{3}
$$

where $\dot{m}_{D H, \max }[\mathrm{kg} / \mathrm{s}]$ is the maximum flow rate of the DH circulation pump and $\dot{Q}_{D H, \text { elec,max }}$ is the corresponding pump electrical consumption at the maximum flow rate. For the current research, the maximum flow rate was estimated from Equation 4.12 with and a maximum $\dot{Q}_{l o a d, t h}(t)$ of $650 \mathrm{~kW}_{\text {th }}$ (13 $\mathrm{kW}_{\text {th }}$ per dwelling). Equation 4.13 was derived based on assumptions of the community DH piping network. $\dot{Q}_{D H, \text { elec,max }}$ was estimated to be $3.1 \mathrm{~kW}_{\mathrm{e}}$. Details on the derivation of these values are omitted here for clarity, and the interested reader is directed to Appendix G for additional information.

\subsubsection{Auxiliary Heater}

One of the constraints on the district heating loop is that the system must always be capable of meeting the thermal demands. Similar to other utilities, there is an assumed guarantee of service for customers connected to the heating loop. Additionally, the thermal demand and supply simulations were decoupled. Thermal demand simulations were performed separately in ESP-r, and loaded into TRNSYS 
as boundary conditions to the DH loop. These thermal demand profiles were generated assuming that sufficient capacity was always available to meet demand. If the district heating system modelled in TRNSYS is incapable of meeting the thermal demand, unrealistic return temperatures from the district heating loop will occur.

To ensure that capacity is always available for thermal demands on the DH system, a natural gas fired back-up condensing boiler was included in the system, represented as unit 10 in Figure 4.3. The boiler was modelled in TRNSYS using standard library Type 6 (TESS, 2014c). Type 6 is a simplified type used to model auxiliary fluid heaters. The type receives a temperature setpoint as an input, then uses a first-principle energy balance to determine the quantity of thermal energy to inject in the fluid stream to meet the setpoint.

Boiler efficiency and fuel consumption was calculated using external algorithms implemented through the EQUATIONS utility in TRNSYS. The external methodology for calculating boiler efficiency and fuel consumption used in the current work were derived from the Boiler:HotWater object found in EnergyPlus (LBNL, 2015). This model is based on three equations:

$$
\begin{gathered}
P L R=\frac{\dot{Q}_{\text {boiler,load }}}{\dot{Q}_{\text {boiler,nom }}} \\
\dot{Q}_{\text {boiler,fuel,theo }}=\frac{\dot{Q}_{\text {boiler,load }}}{\eta_{\text {boiler }, \text { nom }}} \\
\dot{Q}_{\text {boiler,fuel,act }}=\frac{\dot{Q}_{\text {boiler,fuel,theo }}}{\bar{\eta}_{\text {boiler }}\left(P L R, T_{\text {boiler }, \text { in }}\right)}
\end{gathered}
$$

where PLR is the part-load ratio of the boiler, $\dot{Q}_{b o i l e r, l o a d}$ is the load on the boiler $[\mathrm{kW}], \dot{Q}_{b o i l e r, n o m}$ is the nominal capacity of the boiler $[\mathrm{kW}], \dot{Q}_{b o i l e r, f u e l, t h e o}$ is the theoretical boiler fuel consumption $[\mathrm{kW}], \dot{Q}_{b o i l e r, f u e l, a c t}$ is the actual boiler fuel consumption $[\mathrm{kW}], \eta_{b o i l e r, n o m}$ is the nominal boiler efficiency, and $\bar{\eta}_{\text {boiler }}\left(P L R, T_{\text {boiler,in }}\right)$ is the normalized boiler efficiency curve as a function of $P L R$ and boiler inlet water temperature, $T_{\text {boiler }, \text { in }}\left[{ }^{\circ} \mathrm{C}\right]$.

The value of $\dot{Q}_{\text {boiler,load }}$ is a direct output of Type 6 , and represents the total energy 
transfered to the fluid stream. In order to determine the quantity of fuel added to the boiler using Equations 4.15 and 4.16, $\eta_{\text {boiler,nom }}$ needs to represent the fuel-to-fluid efficiency. This efficiency accounts for both the effectiveness of the heat exchanger as well as radiant and convective losses of the boiler (Cleaver-Brooks, 2010). To estimate the efficiency and fuel consumption of the auxiliary boiler under nominal and part-load conditions, efficiency performance data was derived from the Viessmann Vitocrossal 200 gas-fired condensing boiler (Viessmann, 2014). (Viessmann, 2014) reported a nominal combustion efficiency, $\eta_{\text {boiler,comb }}$, of $95.1 \%{ }^{10}$. Condensing boilers typically operate in the combustion efficiency range of 88 to $95 \%$ ASHRAE (2008). Details of the boiler efficiency performance curve used in the current work is provided in Appendix G.

For each retrofit scenario simulated, the thermal and electrical demands are determined first in ESP-r, then passed as a boundary condition into the TRNSYS system simulation. Since the characteristics of the thermal demand is known prior to the TRNSYS simulation, an appropriate value of $\dot{Q}_{b o i l e r, n o m}$ can be determined. The peak thermal demand is calculated, then rounded up to the nearest $100 \mathrm{~kW}_{\text {th }}$ and allocated to $\dot{Q}_{\text {boiler,nom }}$.

To estimate emissions of fuel costs of the boiler operation, $\dot{Q}_{b o i l e r, f u e l, a c t}$ was converted to a volumetric flow rate of natural gas using the HHV and fuel density reported previously in Section 4.7.2. According to ASHRAE (2009), gas appliance efficiencies are typically determined with respect to the HHV of the fuel.

\subsection{Solar Roof-Mounting Parameters}

Presented previously in Section 4.5, a finite bin packing algorithm was used to determine the number of solar collectors that could be mounted on eligible surfaces in a community. For each case study community considered in this research, the bin packing algorithm was run twice: once for PV modules, and again for solar thermal collectors. For each calculation the number of collectors that could be packed onto

\footnotetext{
${ }^{10}$ Boiler combustion efficiency if the ratio of input energy minus stack losses, to input energy
} 
each eligible surface were stored in a database. The surface azimuths of the eligible surfaces were also stored in the database.

In this research, both PV and solar thermal collectors may be retrofitted in the same upgrade scenario. To acknowledge that there is limited space in the community to mount collectors, and that the collectors must share roof space, additional solar collector mounting parameters were defined. The first is the collector type bias, $C_{\text {coll,bias }}$. Collector type bias is an integer, with values of either 0 or 1 . If $C_{\text {coll,bias }}=0$, then solar thermal collectors have priority for installation in the community. When solar thermal collectors are applied to a surface in the community, that surface is no longer able to receive PV modules. Eligible surfaces in the community are allocated with solar thermal collectors up to the requested amount, or until there are no eligible surfaces left. If PV modules are also to be retrofitted, they are placed on remaining surfaces. If $C_{\text {coll,bias }}=1$, then PV modules have retrofit priority.

The other solar collector parameter defined in this work is orientation bias, $C_{\text {orient,bias. }}$ A separate orientation bias is defined for both PV and solar thermal collectors. $C_{\text {orient,bias }}$ is an integer, with values of $-1,0,1$, and 2 :

- $C_{\text {orient,bias }}=-1$; collectors are allocated to west-facing eligible surfaces first, then on surfaces facing southwest, then south, etc.

- $C_{\text {orient,bias }}=0 ;$ collectors are first allocated to south facing surfaces. Once south-facing surfaces are saturated, the remaining collectors to be retrofitted are split evenly between more southeast and southwest facing surfaces, then east and west surfaces.

- $C_{\text {orient,bias }}=1$; then collectors are first allocated to east-facing surfaces.

- $C_{\text {orient,bias }}=2$; collectors are evenly divided between east and west facing eligible surfaces.

Appendix I provides a demonstration of the community solar collector allocation algorithm. 


\subsection{Final Remarks}

This and the previous chapter described the dwelling and community energy systems simulation methodologies. In order to drive these simulations, boundary conditions need to be assumed. In building performance simulation, the principle boundary conditions are typically climate and occupant driven loads. Several data sources exist for climates across Canada. Capturing occupant behaviours, however, is a complex task since they often tend to be stochastic. The next chapter describes the data and modelling methodologies used to characterize the appliance and lighting and hot water consumption of residential dwellings in this work. 


\section{Chapter 5}

\section{Model Boundary Conditions}

In building performance simulation the two principle model boundary conditions are climate and occupant-driven demands. Swan (2010) sourced climate boundary condition data from the Canadian Weather Year for Energy Calculation (CWEC) from ECCC (2017b). This database contains hourly annual weather data for 80 Canadian locations. Each climate file doesn't represent a "true" weather year. Rather the CWEC climate files are constructed from 12 typical meteorological months selected from approximately 30 years of monitored data. The earliest and latest climate data used to derive the CWEC files are 1953 and 2001, respectively. For the current work these climate files were used. It should be noted however, that ECCC (2017b) very recently released a second generation of CWEC files based on more recent climate data. Unfortunately this data became available late in this dissertation and was not used in the current work.

One of the largest sources of uncertainty in estimating building performance with BPS is characterizing occupant-driven loads. Douthitt (1989) previously stated that "engineering studies do a superior job at predicting energy use of homes with no occupants". The thermal energy transfer through building fabrics is generally well understood, but characterizing occupancy-driven demands in BPS presents several challenges. In the residential sector there is generally a lack of available measured data regarding occupant behaviours, and interactions of occupants with controls tend to be governed by stochastic rather than definite relationships (Nicol, 2001). 
This is problematic, since occupant behaviour has a significant influence on building energy performance (Yan et al., 2015). This is especially true for energy efficient buildings, where occupant-driven demands are responsible for a larger portion of the total building demand.

Occupants influence the energy demand of buildings through the operation of appliances and lighting, hot water consumption, use of operable windows and shading devices, and thermostat settings (Yan et al., 2015). Given the lack of data, CHREM uses a simplified approach for several of these loads. Chapter 3 described the simplified method implemented in CHREM to acknowledge that occupants will typically open windows to achieve some degree of "free cooling." Additionally Swan (2010) assumed all dwellings in CHREM use a fixed heating setpoint of $21^{\circ} \mathrm{C}$ from September $17^{\text {th }}$ to June $3^{\text {rd }}$. Swan (2010) demonstrated the impact of this assumption by reducing the setpoint of all CSDDRD dwellings to $19{ }^{\circ} \mathrm{C}$, and found a $10 \%$ reduction in residential sector energy consumption. Without additional data however, Swan (2010) needed to make this simplifying assumption. "Smart" thermostat units which use sophisticated control algorithms and record temperatures and control settings are being installed in Canadian residential homes may provide interesting data which may provide valuable insight in occupant-interaction with HVAC equipment; however, data are not yet widely available and such a study is deferred to future work.

What was of interest in the current work was to update CHREM with more recent and relevant data pertaining to residential A\&L and DHW demands. It was described previously in Chapter 2 that CHREM used a relatively small set of sub-hourly demand profiles to estimate dwelling A\&L and DHW demands. This was problematic for the current work since aggregate community demands needed to be estimated for sizing of community-scale energy systems. Using a small set of sub-hourly demand profiles would under-estimate community demand diversity and exaggerate peak demands, since identical profiles would be superimposed over themselves. Two different approaches were used in the current work to update the CHREM DHW and A\&L models, and are described in the following sections. 


\subsection{Domestic Hot Water Demands}

Swan (2010) implemented a two-step process in CHREM to estimate the DHW consumption of dwellings in the CSDDRD. The annual DHW consumption is first determined using the ANN model developed previously by Aydinalp et al. (2004). This model used dwelling demographics, appliance stock, and DHW system characteristics to determine the dwelling annual DHW energy consumption, $Q_{D H W, a n n}$ $[\mathrm{J}]$. A more useful metric is the annual DHW draw volume, $V_{D H W, a n n}\left[\mathrm{~m}^{3} / \mathrm{yr}\right]$. Swan (2010) related $V_{D H W, a n n}$ to $Q_{D H W, a n n}$ using Equation 5.1:

$$
V_{D W H, a n n}=\frac{Q_{D H W, a n n} \cdot \frac{\eta}{100}}{\rho \cdot c_{p}\left(55-T_{G, a n n}\right)}
$$

where $T_{G \text {,ann }}\left[{ }^{\circ} \mathrm{C}\right]$ is the average annual ground temperature, and $\rho\left[\mathrm{kg} / \mathrm{m}^{3}\right]$ and $c_{p}[\mathrm{~J} / \mathrm{kg} \mathrm{K}]$ are the density and specific heat of water, respectively. Swan (2010) assumed that the setpoint temperature for all residential dwellings was $55^{\circ} \mathrm{C}$. The system energy factor values, $\eta[\%]$, were taken from Aydinalp et al. (2002). This factor accounted for the conversion between fuel source and supplied thermal energy.

Once $V_{D H W, a n n}$ was calculated, the second step was to link the CSDDRD dwelling with an annual sub-hourly DHW demand profile with a similar annual consumption volume. Swan (2010) used the sub-hourly DHW demand profiles developed by Jordan and Vajen (2001a). Jordan and Vajen (2001a) constructed several demand profiles from German and Swiss statistical data as part of IEA-SHC Task 26 (Jordan and Vajen, 2001b). During the development of CHREM Swan (2010) did not have access to more relevant Canadian data. Recently however, several Canadian residential DHW studies and measured data have been published in the literature.

Edwards et al. (2015) constructed 12 representative annual residential DHW demand profiles from measurements of 73 instrumented hot water heaters in southern Québec homes. Continuous measurements were made for 60 to 165 days at fiveminute intervals between November 2006 and April 2007. Edwards et al. (2015) analyzed the data to produce the 12 representative profiles at five-minute timesteps. 
These profiles represent four consumption levels and three temporal consumption parameters. Consumption levels were defined as the mean, median, $20^{\text {th }}$ percentile, and $40^{\text {th }}$ percentile of mean daily DHW consumption. Temporal consumption parameters were morning, evening, and dispersed DHW users. Annual DHW consumption of the profiles is between $116 \mathrm{~L} / \mathrm{yr}$ and and $246 \mathrm{~L} / \mathrm{yr}$.

George et al. (2015) measured the flow rate and temperatures of DHW systems installed in 119 dwellings as part of the Solar City Program in Halifax, Nova Scotia. Measurements were taken at a one-minute resolution from 2014 to 2015. George et al. (2015) found that the average daily dwelling DHW draw was 172 L/day, with a maximum and minimum of 21 and $615 \mathrm{~L} /$ day, respectively. Of the 119 dwellings monitored, 45 contained a year or more worth of data. George et al. (2015) filled missing data and cropped these 45 profiles to generate a set of DHW demand profiles suitable for use in BPS tools. While George et al. (2015) verified that DHW consumption strongly correlated with the number of dwelling occupants, there were no typical average hourly draw patterns ${ }^{1}$. Rather they found an even distribution of varying consumption patterns. They concluded that publishing all 45 profiles best captured the inter-dwelling variation of DHW demands.

For the current work the 12 DHW profiles from Edwards et al. (2015) and 45 profiles from George et al. (2015) replaced the Jordan and Vajen (2001a) profiles in CHREM. The ANN model from Aydinalp et al. (2004) was still used to estimate dwelling annual DHW volume consumption and to match CSDDRD dwellings with sub-hourly profiles. Since district energy systems were of interest in the current work, each dwelling modelled in a community was allocated a unique DHW profile to estimate a realistic aggregate community DHW demand. Similar to the previous method used in CHREM, the allocated sub-hourly demand profiles were linearly scaled to precisely match the dwelling $V_{D W H, a n n}$ estimated by the ANN model.

To maximize the utility of the DHW profiles gathered for this thesis, and additional 114 profiles were derived from profiles from Edwards et al. (2015) and George et al. (2015) and integrated into CHREM. These profiles were constructed by temporally shifting each of the 57 profiles forward and backward by a week. Both Edwards

\footnotetext{
${ }^{1}$ i.e. primary evening users, primary morning users, etc.
} 
et al. (2015) and George et al. (2015) observed stochastic week-to-week variations in DHW demand. By temporally shifting the profiles to generate new profiles, the shifted and aggregated profiles may be aggregated with a improved estimate of demand diversity compared to aggregating the same profiles. Additionally this method of profile construction preserves both the profile starting day of the week, and the seasonal variation of the DHW demands.

Appendix D describes a brief study which compared the modelled aggregate DHW demand estimated using the old and new DHW profiles. The results of this study indicated that using the old approach yields significantly larger peak DHW demands compared to using the unique profiles used for this work. Since both modelling approaches rely upon annual DHW consumption estimates from the ANN model developed by Aydinalp et al. (2002), this new approach therefore does not change the distribution of annual DHW energy consumption in the existing building stock.

\subsection{Appliance and Lighting Demands}

CHREM originally calculated the annual A\&L demand of CSDDRD dwellings using the ANN model developed previously by Aydinalp et al. (2002). Once the annual A\&L demand was established for a dwelling, the algorithms in CHREM matched the dwelling with one of the synthetic sub-hourly A\&L demand profiles developed previously by Armstrong et al. (2009), and scaled to precisely match the annual energy consumption determined by the ANN model. Like the DHW demand model described above, this approach was sufficient for previous studies with CHREM which only dwelling-scale retrofits.

This section describes the new A\&L modelling methodology implemented in CHREM. This section was previously published as: Wills, A. D., I. BeausoleilMorrison, and V. I. Ugursal. "Adaptation and validation of an existing bottom-up model for simulating temporal and inter-dwelling variations of residential appliance and lighting demands." Journal of Building Performance Simulation (2017): 1-19. It is reprinted here under the terms of the Author Publishing Agreement with Tay-

lor \& Francis Group. Adam D. Wills is the principal researcher and author of the 
article, who conducted this as a component of his dissertation under the supervision of Dr. Ian Beausoleil-Morrison and Dr. V. Ismet Ugursal. Minor editorial changes were made to better integrate the article into the thesis. An additional brief analysis comparing CHREM whole-dwelling electrical demand estimates to hourly metered data may be found in Appendix L.

\subsubsection{Abstract}

The design and analysis of community-scale energy systems and incentives is a nontrivial task. The challenge of such undertakings is the well documented uncertainty of building occupant behaviours. This is especially true in the residential sector, where occupants are given more freedom of activity compared to work environments. Further complicating matters is the dearth of available measured data. Building performance simulation tools are one approach to community energy analysis, however such tools often lack realistic models for occupant-driven demands, such as appliance and lighting (AL) loads. For community-scale analysis, such AL models must also be able to capture the temporal and inter-dwelling variation to achieve realistic estimates of aggregate electrical demand.

This work adapts the existing Centre for Renewable Energy Systems Technology (CREST) residential energy model to simulate Canadian residential AL demands. The focus of the analysis is to determine if the daily, seasonal, and inter-dwelling variation of $\mathrm{AL}$ demands estimated by the CREST model is realistic. An in-sample validation is conducted on the model using 22 high-resolution measured AL demand profiles from dwellings located in Ottawa, Canada. The adapted CREST model is shown to broadly capture the variation of $\mathrm{AL}$ demand variations observed in the measured data, however seasonal variation in daily AL demand behaviour was found to be under-estimated by the model. The average and variance of daily load factors was found to be similar between measured and modelled. The model was found to under-predict the daily coincidence factors of aggregated demands, although the variance of coincident factors was shown to be similar between measured and modelled. A stochastic baseload input developed for this work was found to improve 
estimates of the magnitude and variation of both baseload and peak demands.

\subsubsection{Introduction}

Interest in distributed generation (DG), or embedded generation, continues to grow in both the power infrastructure and building energy fields. DG systems represent a paradigm shift in electrical infrastructure design by situating generation systems near the consumer, reducing transmission losses and potentially improving power quality in the transmission and distribution system (Short, 2003). The proximity of DG to the load also provides greater potential for cogeneration, where excess thermal energy from electricity generation may be used to offset building thermal demands. In order to optimally design DG systems, accurate knowledge of the electrical consumer loads is needed (Paatero and Lund, 2006). Low-voltage residential networks are especially challenging for DG design and planning, since these types of loads tend to be both stochastic and diverse (Dickert and Schegner, 2010).

Ideally, residential electrical demand profile measurements would be taken directly from a community considering DG for planning and design of the system. Such data acquisition campaigns are often costly, and require long monitoring periods to capture seasonal variations in demand behaviour (Saldanha and BeausoleilMorrison, 2012). There are however, published measurements in the literature which may be used as reasonable estimates for demand analysis. For example, Parker (2003) analysed data from a utility load research project. Detailed total and enduse electrical load data collected from 204 residential dwellings located in Florida, US at a 15-minute resolution. Electricity end-uses monitored include space heating, cooling, domestic hot water (DHW), dryers, cooking, and swimming pools. Firth et al. (2008) monitored the 5-minute whole-house average power consumption of 72 residential dwellings located in 5 different regions in the UK for two years. Saldanha and Beausoleil-Morrison (2012) and Johnson and Beausoleil-Morrison (2017) measured the annual electrical consumption of 22 single-detached (SD) and double/row (DR) houses located in Ottawa, Canada at a 1-minute resolution. Kolter and Johnson (2011) created a database of monitored whole-house, individual circuit, 
and plug level electrical energy consumption data from ten Boston, USA homes with a combined total of 119 monitored days.

In the absence of measured data, analysis of residential energy demand may be realized through the use of various modelling techniques. One approach is building performance simulation (BPS) tools. Armstrong et al. (2009) stated that BPS tools are ideal for assessing the performance of distributed energy systems, especially those employing cogeneration. Their reasoning was that BPS tools use well-defined physical thermodynamic and heat transfer relationships to calculate temporal thermal demands. Several BPS tools include explicit models of building HVAC equipment using analytical or empirical methods.

However, BPS tools lack models for estimating the occupancy-driven loads, such as appliance and lighting (AL) demands (Armstrong et al., 2009; Swan and Ugursal, 2009). At a community-scale, occupancy-driven loads vary both temporally and between dwellings. Under or over-estimation of load diversity during analysis leads to over or under-estimation of aggregate peak demand, respectively. For residential AL demands, there are several modelling techniques in the literature which may be applied to BPS tools and community-scale energy analysis.

\subsubsection{Review of appliance and lighting models}

Several AL modelling techniques may be broadly classified as 'bottom-up'. Bottomup methods rely upon statistical or engineering principles to estimate residential energy consumption (Swan and Ugursal, 2009). Statistical approaches utilize histor-

ical data and regressions to estimate the energy consumption of a particular end-use, such as either appliances or lighting. Engineering approaches estimate end-use energy consumption by using power ratings and equipment usage data, and/or physically based thermodynamic and heat transfer relationships.

Bottom-up AL models may be further categorized as either explicit or implicitoccupancy models. Explicit-occupancy models, referred to by Flett and Kelly (2017) as occupancy-to-demand models, are driven by inputs or estimates of explicit occupant presence in dwellings at each timestep. Alternatively, implicit-occupancy 
models often rely on AL usage statistics to determine when AL devices are turned on. The explicit presence of occupants is not determined for the dwelling.

Walker and Pokoski (1985) developed an explicit-occupancy bottom-up model for residential energy load shapes based on occupant 'availability' and 'proclivity'. Probability functions for occupant availability at home were determined for weekdays and weekends. The model uses the probability of availability functions with a MonteCarlo method to estimate actual availability in a dwelling or group of houses. The behaviours and actions of available occupants are then determined using a similar method, instead of using sets of proclivity functions. These functions include the likelihood of operating clothes washers and having a meal. Capasso et al. (1994) built upon this principle, developing a bottom-up model using sets of 'behavioural' and 'engineering' functions. The behavioural functions included histograms for occupant availability, appliance usage percentage distributions, number of available human resources (number of available hands, eyes, and ears to perform tasks), and appliance ownership. Engineering functions included information on appliance cycle time and power demand. Capasso et al. (1994) also used a Monte-Carlo method to determine individual appliance ON/OFF cycles.

Other researchers have adopted a similar approach to residential energy demand modelling. For example, Richardson et al. (2010) developed the open-source Centre for Renewable Energy Systems Technology (CREST) demand model ${ }^{2}$, available under the GNU General Public License 3. The CREST model determines occupancy at ten-minute timsteps using the high-resolution occupancy model developed previously by Richardson et al. (2008). A first-order Markov-Chain is used to determine the number of active occupants in the dwellings. The transition probability matrices (TPMs) were derived using UK TOU survey data, where the time-of-use (TOU) data was subdivided by weekday or weekend, and number of dwelling residents. The CREST model explicitly models each appliance and lighting fixture demand. Electric space heating was also included in the CREST version published by Richardson et al. (2010). Trigger ON events for appliances are determined from the number

\footnotetext{
${ }^{2}$ The CREST demand model is publicly available for download at http://www.lboro.ac.uk/ research/crest/demand-model/
} 
of available occupants, whether it is a weekday or weekend, and specific occupant activity probabilities for the particular time of day (e.g. cooking). Each lighting fixture is explicitly modelled using the method developed previously by Richardson et al. (2009). The CREST model incorporated 'calibration scalars', which allowed users to tune model output to desired average annual AL consumption per dwelling.

Richardson et al. (2010) validated their model using 22 measured annual wholedwelling electrical consumption profiles collected from UK dwellings at a one-minute resolution. All measured dwellings did not contain electric space heating equipment, and the validation of the CREST model was limited to the AL demand component of the model. Richardson et al. (2010) found annual consumption distribution, annually-averaged daily profiles, and load diversity calculated for 22 demand profiles modelled in the CREST had good agreement with the measured data. However, Richardson et al. (2010) noted that the CREST model tended to under-estimate the baseload demand and seasonal variation seen in the measured data.

Examples of implicit-occupancy bottom-up models include the work of Paatero and Lund (2006). They used measured electrical consumption from Finnish households to model residential appliance use. The model was composed of two components. First, the daily 'social random factor' was determined for the entire group of dwellings to be modelled. When analysing their measured data, Paatero and Lund (2006) observed a daily fluctuation in energy consumption which was not explained by seasonal and weekday/weekend variation. They attributed this variation to a social random factor, and found that it followed a normal distribution. They attributed this variation to fluctuations in weather and entertainment experienced simultaneously by all dwellings. The second component of the model randomly assigns appliance stock to each household based on published appliance saturation levels, and for each timestep, an appliance ON event probability is determined using seasonal, hourly, mean daily starting frequency, and random social factor. Paatero and Lund (2006) compared output for 10,000 simulated dwellings with 702 measured Finnish dwellings, and found that hourly differences between the mean-daily load profiles were generally below $3 \%$. 
Other models use the implicit-occupancy approach, such as the Canadian residential electric profiles model of Armstrong et al. (2009). Their model used appliance specific time-of-use (TOU) curves from Pratt et al. (1989), usage, and power characteristics to stochastically determine demand profiles for lighting and appliances. A 'chance factor' was included in the model to enable it to be calibrated to achieve desired annual energy consumption targets. They validated their model against 2.5 years worth of data collected by Hydro Québec, and found that the measured profiles exhibited more repetitive behaviour compared to modelled. They also found that the generated profiles had lower base load consumption compared to the measured values. Yilmaz et al. (2015) used sub-metered data from 5,000 appliances located in 250 UK dwellings to develop their appliance demand model. The measured data was used to derive trigger ON probabilities for each appliance, frequency of usage, distributions of cycle durations, and distributions of power consumed. This data was used to stochastically determine the demand profiles of residential appliances.

Fischer et al. (2015) also used an implicit-occupancy bottom-up approach in their synPRO model for AL energy consumption in the German residential sector. AL stock and usage were defined using socio-economic characteristics such as dwelling type (single or semi-detached, etc.), and number and ages of occupants. These characteristics were combined to define 14 separate dwelling classes. Fischer et al. (2015) performed an out-of-sample validation for seven of the classes using 430 dwelling measurements from cities in Germany at a one-hour resolution. They found the synPRO had accuracy around $91 \%$ for mean yearly, monthly, and daily energy consumption. They also stated that the current version of synPRO partly covered the intra-group variation and weekend noon peak loads.

There are also residential energy demand models which do not fit neatly into either the implicit or explicit-occupancy definition. Widén and Wäckelgård (2010) utilized TOU to define 9 different activity states, including sleeping, dish washing, and computer. The TOU survey data were used to construct sets of transition probabilities for each timestep modelled. A first order Markov-Chain approach was then used to estimate what activities each occupant were engaged in throughout the day. Each activity had an associated ON electrical demand profile, which was used 
to convert from activity to electrical consumption profiles. Widén and Wäckelgård (2010) found that this simplified method of activity to power demand conversion could produce realistic demand patterns, and required lower-resolution input data.

Applications in Community Energy Simulation Several of the aforementioned bottom-up AL and residential modelling techniques have been adopted to community-scale energy models. Marszal-Pomianowska et al. (2016) and Wagner et al. (2016) both used implicit-occupancy approaches in their residential demand models. Marszal-Pomianowska et al. (2016) developed a community-scale energy model which included HVAC energy consumption. Occupants were defined as interested, neutral, and disinterested in electricity use/savings, and each type had an associated scalar multiplier which was applied to the frequency of use for the 35 different appliances considered in the model. Lighting demand was modelled using the method previously developed by Stokes et al. (2004). To validate their model, Marszal-Pomianowska et al. (2016) performed an out-of-sample validation using 89 dwelling measurements at one-hour resolution, and 16 dwelling whole house and heat pump energy consumption at a five-minute resolution. They found the model represented the diversity of demand among dwellings, however individual dwelling high-end energy consumption was under-predicted by the model. Additionally they found mean annual energy consumption estimated by the model agreed with relevant Danish statistics.

Wagner et al. (2016) developed a model for aggregate residential electrical demands for designing distribution systems. They considered 13 appliances, each with its own representative load profile. Trigger ON events for non-baseload appliances were modelled using a first-order Markov-Chain technique. Wagner et al. (2016) also included electrical demand for instantaneous DHW. Validation of the model was conducted by comparing simulated aggregate dwelling demands to relevant German standard profiles. They found that the model tended to over-estimate demands from 00h00 to 06h00, and under-estimate demand between 06h00 and 22h00. They stated the discrepancies were likely due to the 15-minute resolution and relatively small 
number of appliance classes defined. Wagner et al. (2016) also considered the annual energy consumption for each appliance class, and found the contribution of each class to whole-dwelling consumption was similar to the portions published by government statistics for average dwellings in Germany. Additionally, the annual average dwelling energy consumption estimated by the modelled differed by $3 \%$ compared to German statistics.

Nijhuis et al. (2016) and Flett and Kelly (2017) both used explicit-occupancy approaches in their community energy demand models. Similar to Wagner et al. (2016), Nijhuis et al. (2016) developed a model of aggregate whole-dwelling electrical demands. Occupancy was determined using a first-order Markov-Chain and TPMs derived from Dutch TOU data at a 15-minute resolution. Heating and cooling loads were also included in their aggregate demand model. Validation was performed using smart meter data from 100 Dutch dwellings, at a 15-minute resolution, and two transformer data sets connected to 107 and 94 dwellings at a ten-minute resolution. They found the variation and general behaviour of the measured data was largely captured by the model.

Flett and Kelly (2017) used a higher-order Markov-Chain occupancy model developed previously by Flett and Kelly (2016) in their explicit-occupancy domestic electricity demand model. The higher-order approach considers the previous occupant state as well as the duration of an activity when estimating future occupancy. To better capture the diversity of occupancy characteristics, Flett and Kelly (2016) developed separate TPMs based on occupant, household, and day types. To model appliance demands, Flett and Kelly (2017) used two-minute resolution individual appliance measurements from 251 dwellings in the UK, monitored for at least one month. They additionally had 26 full annual electrical consumption measurements at a ten-minute resolution. Flett and Kelly (2017) used a differentiated, probabilistic, bottom-up approach to simulate residential electrical demands. The appliance modelling approach was event based, where the number of appliance triggers on events is determined for the day, rather than the time of occurrence of the events. In contrast, models such as the CREST by Richardson et al. (2010) use per-timestep probabilities 
to model trigger ON events. Flett and Kelly (2017) performed an in-sample validation demonstrating that the model was capable of replicating the variable demand behaviours seen in the measured data used for calibration. They stated that initial analysis with two small out-of-sample UK data sets also showed similar performance as the in-sample validation.

Other researchers directly adopted published AL demand models into their community-scale energy models. Muratori et al. (2013) used the modelling technique of Widén and Wäckelgård (2010) to simulate the occupant driven demands, developing their TPMs using the 2003-2009 American Time Use Survey (ATUS). Building HVAC demands were modelled using first law energy balances, expressing the building envelope using overall thermal resistance theory from ASHRAE Fundamentals (ASHRAE, 2009) and mechanical equipment efficiencies and ratings. They performed both an in-sample and out-of-sample validation, integrating their model demands to hourly profiles for comparison with the metered data. Muratori et al. (2013) compared the distribution and variance between the measured and modelled sets, and found no statistically significant differences.

Baetens and Saelens (2016) adopted the CREST appliance load model of Richardson et al. (2010) in their 'Stochastic Residential Occupant Behaviour', or StROBe, model. To determine occupancy, Baetens and Saelens (2016) characterized three occupancy states: present and awake, present and asleep, or absent. Belgian TOU data was sub-grouped using agglomerative hierarchical clustering and the Levenshtein distance as the distance metric to define seven clusters of TOU data. Each occupant of a dwelling is defined as full-time, part-time, retired, or minor, and allocated to a cluster. Transitions of occupancy are determined using event and survival time densities, defined for weekdays, Saturdays, and Sundays. The StROBe model additionally models lighting loads using the method of Widén et al. (2009), internal heat gain from occupants, heating setpoints, and DHW draws. When evaluating the epistemic (systematic) uncertainty of the StROBe model, Baetens and Saelens (2016) found that the model under-estimated average annual electricity consumption. They noted that bottom-up AL models often under-estimate load due to the exclusion of some appliances. They also stated that the annual consumption used for comparison 
also included demands from pumps and fans. Baetens and Saelens (2016) also determined that the simultaneity (coincidence) factors of StROBe electrical and DHW draws was found to have good agreement with pertinent reference standards.

\subsubsection{Research objectives}

When evaluating the performance of appliance and lighting models, researchers often examine mean or annually averaged metrics. It is sometimes unclear that the variation of performance metrics, such as daily energy consumption, are also being captured by the model. The current work adopts the CREST model developed by Richardson et al. (2010) to simulate the residential AL demands of Canadian single-detached (SD) and double/row (DR) dwellings. Richardson et al. (2010) had demonstrated previously that the CREST model is capable of capturing the majority of daily and inter-dwelling variations of AL demand that exists in practice.

The objective of the work is to determine if the adapted CREST model is capable of not only reproducing the nominal performance characteristics, such as daily load factors and energy consumption, seen in practice in Canada, but also the variation of those metrics between dwellings and throughout the year. Models capable of achieving both the nominal characteristics as well as the variation seen in practice would be a valuable tool for analysis of both individual dwelling energy consumption as well as aggregate community demands.

To analyse and validate the CREST model, 22 one-minute resolution annual AL demand measurements collected previously by Saldanha and BeausoleilMorrison (2012) and Johnson and Beausoleil-Morrison (2017) are used for comparison. Richardson et al. (2010) similarly used high-resolution whole-dwelling electrical demands from $22 \mathrm{UK}$ dwellings to validate the CREST model. This high-resolution

provides an opportunity to evaluate the model's capability of simulating momentary peak demands and short-term variations seen in practice. Several of the AL models found in the literature use lower resolution data for validation, sometimes collected over short time periods, from different geographic regions, and not during the same time of the year. The measured data used here is from a similar geographic location 
monitored over coincident time periods.

Section 5.2.3 provides a brief summary of the architecture and methodologies used in the CREST model. Relevant data sources for modelling Canadian residential dwellings are also described in this section. Richardson et al. (2010) had previously noted that the CREST model tended to under-predict night-time (baseload) demands. To improve night-time energy demand estimation in the current work an unattributed constant baseload demand is stochastically determined for each simulated dwelling, and is described in Section 5.2.3.5.

Section 5.2.4 discusses the in-sample validation carried out using the available measured data. Performance characteristics considered in the validation include mean daily AL demand profile, distribution of mean daily AL energy consumption by weekday and month, distribution of dwelling daily load factors, and distribution of aggregate demand daily coincidence factors. Section 5.2.5 then evaluates the impact of the stochastic baseload input on model performance. The final two sections of the paper then provide conclusions and recommendations.

\subsubsection{Model summary}

The summary presented here is based on version 1.1 of the CREST model. This was the version of the model available at the beginning of this work and was adapted for Canadian dwellings. Since then updates have been published to the CREST model. McKenna et al. (2015) extended the previous occupancy model of Richardson et al. (2008) by defining four occupancy states: not home and inactive, not home and active, at home and inactive, and at home and active. The state of occupants were determined using a first-order Markov-Chain technique. McKenna and Thomson (2016) later added additional modelling domains to the CREST model, including loworder building envelope modelling, DHW consumption, and solar thermal collectors. For the current work however, solely the AL modelling capabilities of the CREST model were of interest and were present in version 1.1. 


\subsubsection{Model structure}

This section provides a brief summary of the CREST model, as presented by Richardson et al. (2010). The general structure of the model is described, and the pertinent underlying methods are highlighted. The current work primarily deals with the determination of inputs and modifications to the CREST model occupancy and appliance modules, and brief descriptions of these modules are provided below. Details of the lighting module is provided by Richardson et al. (2009). The lighting module requires outdoor solar irradiance data for each simulation timestep. For the current work, this value is assumed to be the global horizontal solar irradiance at the dwelling site.

Occupancy module Stated previously in Section 5.2.2.1, the CREST model uses an explicit-occupancy approach. The occupancy module was developed by Richardson et al. (2008), and uses a first-order Markov-Chain technique to determine the number of active occupants at each timestep. The TPMs were derived from the United Kingdom Time Use Survey (ONS, 2003), and separate TPMs were defined based on the number of occupants in a dwelling in the source data, as well as day type $d$. Richardson et al. (2008) divided day types as weekday and weekend.

Statistics Canada has been conducting time-use surveys as a part of the General Social Survey (GSS) Program since 1986 (Statistics Canada, 2016). Information is collected using a retrospective 24-hour diary provided by respondents. Respondents are asked about what activities they were engaged in starting at 04h00, as well as where they were. The current work extracts occupancy and activity data from the GSS, Cycle 24, 2010: Time-Stress and Well-Being Survey (Statistics Canada, 2010). Sampling was conducted in 6 waves between January and December 2010. The GSS 2010 survey contains 15391 individual diaries sampled from across Canada. Demographic information is also provided with each diary, providing information such as household size, location, ages, income, etc. The GSS 2010 also asked respondents if they were engaged in simultaneous activities, such as listening to the radio while cleaning the house. Up to three simultaneous activities were recorded. 
The diaries were sorted by household number, from one to five dwelling residents, and by weekday and weekend. The corresponding number of diaries for each subcategory are summarized in Table ??. Richardson et al. (2008) had been able to construct household occupancy profiles by superimposing individual occupancy profiles provided from the same dwelling. Unlike the UK survey however, the GSS 2010 does not provide information on whether diaries were collected from the same household. Household profiles were constructed by randomly combining diaries from dwellings with the same number of residents. For dwelling sizes two to five, and weekday and weekend day types, 5000 random combinations of individual occupancy profiles were generated. From the household profiles, the TPMs were developed using the method described by Richardson et al. (2008).

Table 5.1: Number of 24-hour diaries from the GSS 2010

\begin{tabular}{lcc}
\hline \multirow{2}{*}{$\begin{array}{l}\text { Number of } \\
\text { dwelling occupants }\end{array}$} & \multicolumn{2}{c}{ Day type } \\
Weekday & Weekend \\
\hline \hline one & 2723 & 1061 \\
two & 4113 & 1675 \\
three & 1692 & 643 \\
four & 1630 & 657 \\
five & 615 & 239 \\
\hline
\end{tabular}

Appliance module Richardson et al. (2010) noted that usage of appliances are dependent on the time of day as well as the presence of occupants. To recognize this in the CREST model, Richardson et al. (2010) re-analyzed the UK TOU survey data, and developed sets of 'activity' probability distributions, $P_{A, d}\left(t, N_{\text {occupants }}(t)\right)$, for different activities $A$ and day types $d$, as functions of both the time of day, and number of active $N_{\text {occupants }}$ determined previously in the occupancy module. For the current study, the activity types $A$ considered were: cooking, watching television, laundry, house cleaning, ironing, washing/dressing, computer use, and other. The 
'other' activity implies that the probability of a trigger ON event does not vary with time. For appliances that do not conveniently fit into one of the activity categories, and is occupant-dependent to trigger $\mathrm{ON}, P_{A, d}\left(t, N_{\text {occupants }}(t)\right)$ is equal to 1.

The GSS 2010 diaries (Statistics Canada, 2010) were used to determine $P_{A, d}\left(t, N_{\text {occupants }}(t)\right)$ using the method described by Richardson et al. (2010). Activities in the GSS 2010 were identified with a integer code. Statistics Canada (2010) defined several hundred different acitivity codes. These codes were reviewed and associated with the seven activities considered in the current study.

For each appliance $i$ modelled, the user must specify:

- appliance activity type, $A_{i}$;

- if appliance operation is occupant dependent;

- average number of cycles per year, $N_{i, c y c l e s}$;

- cycle length, $t_{i, c y c l e}[\mathrm{~min}]$;

- reset delay, $t_{i, r e s e t}[\mathrm{~min}]$;

- mean ON power, $\bar{Q}_{i, a p p l, O N}[\mathrm{~W}]$;

- standby power, $Q_{i, a p p l, s t a n d b y}[\mathrm{~W}]$.

The trigger ON events of each appliance are determined separately for each appliance $i$. For each timestep $t$, the probability of appliance $i$ triggering $\mathrm{ON}$, $P_{i, a p p l, O N}\left(d, t, N_{\text {occupants }}(t)\right)$, is determined based on number of active occupants at time $t$ and day type $d$ using Equation 5.2:

$$
P_{i, a p p l, O N}\left(d, t, N_{\text {occupants }}(t)\right)=C_{i, a p p l} \cdot P_{A, d}\left(t, N_{\text {occupants }}(t)\right)
$$

The appliance scalar for appliance $i, C_{i, a p p l}$, is determined prior to simulation using the inputs for appliance $i$. The calculation procedure for $C_{i, a p p l}$ is omitted here for clarity, and the interested reader is directed to Richardson et al. (2010) for additional details. 
When appliance $i$ is triggered ON, the CREST model then determines the appliance's power consumption. Prior to simulation, the power demand for appliance $i$, $Q_{i, a p p l, O N}[\mathrm{~W}]$, is randomly determined from a Gaussian distribution with a mean of $\bar{Q}_{i, a p p l}$ and standard deviation of $1 / \bar{Q}_{i, a p p l, O N}$. Richardson et al. (2010) included this in the CREST to induce variability between dwellings. To determine the appliance power consumption during operation, Richardson et al. (2010) defined two different cycle types in the CREST model: 'simple' and 'complex'.

For simple cycle appliances, the power demand for appliance $i$ is a constant $Q_{i, a p p l, O N}$ for cycle duration $t_{a p p l, c y c l e}$, or until no occupants are active ${ }^{3}$. Complex cycles are associated with appliances such as washing machines and dishwashers, which have varying power demand during its operational cycle. Richardson et al. (2010) incorporated measured profiles of washing machines and washer/dryers into the CREST model to simulate their complex cycle power demands.

Richardson et al. (2010) also incorporated a global appliance calibration scalar, $C_{\text {appl,calibrate, in the CREST model. This scalar enables users to tune the CREST }}$ model to achieve a specified nominal dwelling annual appliance energy consumption. For each appliance $i$ simulated in each dwelling, $N_{i, c y c l e s}$ is multiplied by $C_{\text {appl,calibrate }}$. A separate but similar calibration scalar is also included in the lighting module,

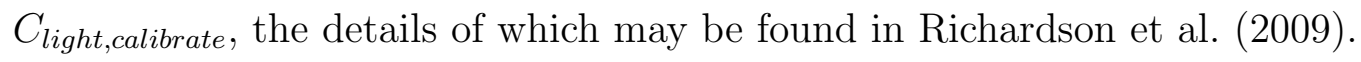

\subsubsection{Appliance \& lighting inputs}

Shown in Section 5.2.3.1, the CREST model requires detailed input information for each appliance explicitly considered in the model. For the current work, 31 appliances were considered and are listed in Appendix J. Several sources were consulted to estimate the appliance inputs. The mean appliance ON and standby power demands, $\bar{Q}_{i, a p p l}$ and $Q_{i, a p p l, s t a n d b y}$, for each appliance $i$ were estimated using recommended values from a local electrical distribution company (Hydro One Networks Inc., 2017), the U.S Department of Energy (DOE) Building America Analysis Spreadsheet for Existing Homes (DOE, 2011), and the Lawrence Berkeley National Laboratory (LBNL)

\footnotetext{
${ }^{3}$ Unless appliance is independent of occupancy, or continues to run in the absence of occupants.
} 
Standby Power Summary Table (LBNL, 2017).

Mean cycle lengths, $t_{i, c y c l e}$, and cycles per year, $N_{i, c y c l e s}$, were estimated using the GSS 2010 (Statistics Canada, 2010), and the Survey of Household Energy Use (SHEU 2011) from Natural Resources Canada (NRCan, 2014c). For the current work stove appliances were divided into five separate components: two large and two small ranges, and an oven. Annual stove usage was estimated using SHEU 2011, and $t_{i, c y c l e}$ and $N_{i, c y c l e s}$ for each stove component was estimated using the Cooking Appliance Use report from LBNL (Klug et al., 2011).

For appliances with complex cycle power demand, measured data was used. The current work identified three appliances with complex cycles: dishwashers, clothes washers, and clothes dryers. Typical dryer and dishwasher cycle power demand profiles were estimated using the plug-load measurements collected by Saldanha and Beausoleil-Morrison (2012) and Johnson and Beausoleil-Morrison (2017). These data sets collectively contain the annual consumption profiles of 5 dryers and 4 dishwashers. Washing machine cycle power consumption was estimated using measurements from a 1990's vintage vertical-axis washing machine. Data was collected at a 1minute resolution using a Watts Up? PRO ES datalogger (Watts up?, 2008).

The complex cycles used in the current work are plotted in Figure 5.1. Each profile is normalized with respect to its peak demand. The user provides a value for $\bar{Q}_{i, a p p l, O N}$, and the associated complex cycle profile in Figure 5.1 is multiplied by $Q_{i, a p p l, O N}$ to determine the time-varying power demand of the appliance. 


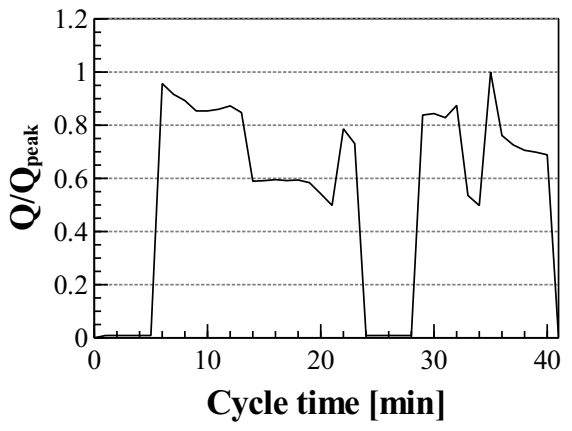

(a) Clothes washer

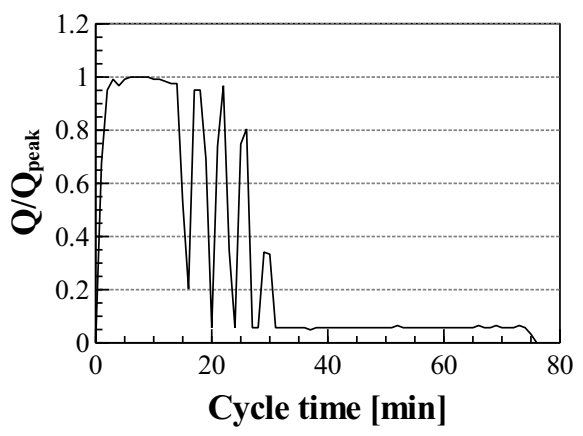

(b) Clothes dryer

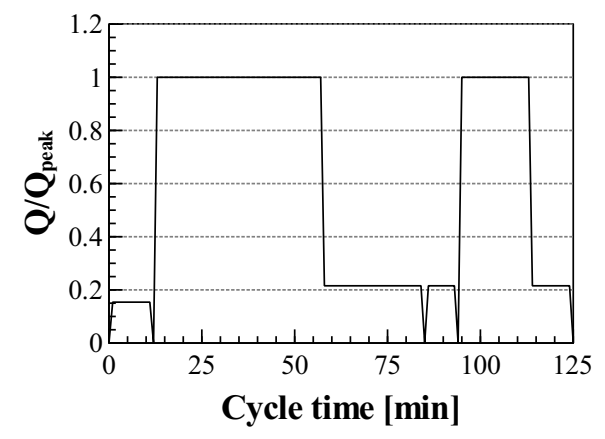

(c) Dishwasher

Figure 5.1: Normalized complex appliance cycle profiles

Each appliance $i$ considered in the CREST model is associated with an activity $A_{i}$. Richardson et al. (2010) had defined six activity types: watching TV, cooking, laundry, washing and dressing, ironing, and house cleaning. For each activity, Richardson et al. (2010) developed daily activity profiles which quantified the probability of an activity occurring as a function of time-of-day, number of active occupants, and day type. These activity profiles were derived using the UK TOU data. The current work developed profiles for the six activities defined in the CREST model using the GSS 2010 TOU diaries. Additionally, the activity 'using computer' was defined for the current work. 
For the lighting module, average power demand values for residential incandescent, halogen, compact fluorescent lamp (CFL), linear fluorescent (tube), and other (light-emitting diode (LED)) lamp types were extracted from the DOE 2010 U.S. Lighting Market Characterization Report (Ashe et al., 2012). The report provides average wattages for each lamp type, as well as average wattages for lamp sub-types, such as general service and reflector halogen lamps. The wattages for each sub-type were used as inputs into the lighting module.

\subsubsection{Appliance \& lighting dwelling stock allocation}

Richardson et al. (2010) used appliance stock distribution data to allocate dwelling appliances in the CREST model. For the current work, the majority of dwelling appliance stock was drawn directly from the CSDDRD. One limitation of the CSDDRD is that it has not been updated in over a decade to reflect technological and economic changes. For example, penetration rates of gaming consoles were included in SHEU 2011, but were not reported in the CSDDRD. To address this limitation, a stochastic method for assigning these new devices similar to the method used by Richardson

et al. (2010) was used. Randomly assigned devices included gaming consoles, television receiver boxes, and printers. Penetration levels of these appliances were defined separately for five Canadian regions: Atlantic Canada, Québec, Ontario, Prairies, and British Columbia. The original Richardson et al. (2010) also included appliances that are not reported in either the CSDDRD or SHEU 2011; specifically irons, kettles, and vacuums. For those appliances, the UK penetration rates reported by Richardson et al. (2010) were used. No data was available for hair dryer ownership. In the absence of data it was assumed $90 \%$ of dwellings have a hair dryer.

The GSS 2010 data indicated that televisions are used frequently by occupants throughout evening periods. The current implementation of the CREST model used available data to take a detailed approach to television power consumption. The CSDDRD provides the total number of colour and black \& white televisions in each dwelling. For the current implementation of the CREST model, the total number of televisions in the dwelling are determined directly from the CSDDRD, and for each 
unit the type of television is determined from stock distributions provided in SHEU 2011. Five television types were considered based on the information provided in SHEU 2011: Regular, plasma, LED, LCD, DLP, and projector. Input parameters for each television type were identical with the exception of $\bar{Q}_{i, a p p l}$. Values of $\bar{Q}_{i, a p p l}$ for each type were estimated from Hydro One Networks Inc. (2017) and DOE (2017), and are provided in Appendix J.

\subsubsection{Cold appliance modelling}

Cold appliances, such as fridges and freezers, largely form the baseload for residential electrical demand. The CREST model defined four types of cold appliances ${ }^{4}$, each with a defined set of inputs. A different approach was used in the current implementation of the CREST model to capture the diversity of cold appliance efficiencies found in the Canadian residential stock. Detailed information on cold appliance unit energy consumption (UEC) values were collected from the Energy Consumption of Major Household Appliances Shipped in Canada: Trends for 1990-2010 report from NRCan (2012). This report lists average UEC values of cold appliances by type and year they were shipped in Canada.

For the current CREST model implementation three cold appliance types were considered: refrigerator, upright freezer, and chest freezer. For each type, $N_{i, c y c l e s}$, $t_{i, c y c l e}$, and $t_{i, r e s e t}$ values are defined by the user. For the current work these values were estimated from Richardson et al. (2010) and Armstrong et al. (2009), and are provided in Table 5.2. Dwelling cold appliance stock and sizes are drawn directly from the CSDDRD, and cold appliance vintages are randomly selected from vintage distributions estimated from the SHEU 2011.

\footnotetext{
${ }^{4}$ Chest freezer, fridge freezer, refrigerator, and upright freezer
} 
Table 5.2: Cold appliance inputs

\begin{tabular}{lccc}
\hline Cold Appliance & \multicolumn{3}{c}{ Input } \\
Type & $N_{i, \text { cycles }}[$ cycles/yr] & $t_{i, \text { cycle }}[\mathrm{min}]$ & $t_{i, \text { reset }}[\mathrm{min}]$ \\
\hline \hline Refrigerator & 6116 & 35 & 35 \\
Upright Freezer & 6116 & 20 & 40 \\
Chest Freezer & 6116 & 14 & 56 \\
\hline
\end{tabular}

For refrigerators, the $U E C$ is read directly from Table A.13 in NRCan (2012). For freezers, NRCan (2012) provided five different classifications: upright manual defrost, upright auto defrost, chest, compact upright, and compact chest and other. The type of freezer is randomly selected from distributions by vintage provided in Table A.17 in NRCan (2012). The $U E C$ for the freezer is then read directly from Table A.22 in NRCan (2012). The UEC and other inputs are then used to determine $Q_{i, a p p l, O N}$ for each cold appliance in the dwelling us the equation:

$$
Q_{i, a p p l, O N}=\frac{U E C}{N_{i, c y c l e s} \cdot t_{i, c y c l e}} \cdot 60,000
$$

where 60,000 is a unit conversion factor.

\subsubsection{Dwelling baseload}

When Richardson et al. (2010) compared AL profiles generated by the CREST to measured profiles, they noted that the CREST model tended to under-predicted night-time (baseload) AL demands. A simplified approach was taken in the current work to address these discrepancies. Widén et al. (2009) had found that using TOU surveys to derive their electrical consumption profiles captured the majority of electricity end-uses, but neglected to capture a nearly constant unspecified demand seen in their measured data. To address this discrepancy, Widén and Wäckelgård (2010) included an 'additional constant load' in their demand model. A similar approach was adopted here, where each dwelling AL demand generated also included 
a stochastically determined constant baseload demand.

This stochastic baseload was incorporated into the appliance module. Two global variables are used in determining baseload demand for each dwelling: mean baseload demand $\bar{Q}_{\text {baseload }}[\mathrm{W}]$, and baseload standard deviation $Q_{\text {baseload,std.dev }}$ [W]. For the current study these values were estimated from the measured data of Saldanha and Beausoleil-Morrison (2012) and Johnson and Beausoleil-Morrison (2017) to be 250 $\mathrm{W}$ and $70 \mathrm{~W}$, respectively. For each dwelling AL demand generated, the dwelling baseload is randomly selected from a Gaussian distribution. The baseload is then added to the aggregated AL demands determined by the CREST model. The appliance module calibration scalar, $C_{a p p l, c a l i b r a t e}$, is not applied to the baseload inputs since the scalar operates on the number of annual cycles of appliances and does not impact constant demand appliances.

\subsubsection{Model validation}

Richardson et al. (2010) validated the CREST model against 22 measured one-minute resolution whole-dwelling demands from volunteers in the UK. Richardson et al. (2010) stated that none of the dwellings had electric heating systems installed. Each of the 22 dwellings was modelled in the CREST, and characteristics of both the annual measured and modelled AL demands were compared. Richardson et al. (2010) noted a few discrepancies, namely an under-prediction of night-time demand, variation of dwelling annual demands, and under-prediction of seasonal variation. These differences were largely attributed to a lack of data pertaining to, for example, socioeconomic factors, multi-tasking of activities, seasonal behaviour of occupants, and attitudes towards energy conservation. Richardson et al. (2010) found the CREST model was particularly good at capturing the time coincidence and diversity of AL demands amongst dwellings. A difference of $1 \%$ in diversity factors was found between the data, and both sets of AL demand profiles tended towards the same after diversity maximum demand (ADMD).

For the current implementation of the CREST model, the annual one-minute resolution AL demand measurements from Saldanha and Beausoleil-Morrison (2012) 
and Johnson and Beausoleil-Morrison (2017) are used for validation. (Saldanha and Beausoleil-Morrison, 2012) collected measurements from eight SD and three DR volunteer dwellings in Ottawa, Canada, between 2009 and 2010. Johnson and Beausoleil-Morrison (2017) collected data from an additional eleven DR dwellings in Ottawa, Canada between 2011 and 2012. The AL demands were determined from whole-house measurements by subtracting the sub-metered measurements of the HVAC equipment.

The validation of the CREST implementation performed here differs from the validation performed by Richardson et al. (2010). An in-sample validation is performed, since both the average annual AL demands, and baseload demands, of the measured validation set were used as model inputs and for calibration. Additionally, the measured dwellings from Saldanha and Beausoleil-Morrison (2012) and Johnson and Beausoleil-Morrison (2017) could not be modelled directly, since insufficient information is provided pertaining to the dwelling's small appliance stock. Instead several modelled profiles are generated, and 22 are paired to the measured profiles based on dwelling annual AL consumption characteristics. The calibration of the CREST model and development of the modelled validation set are described below.

\subsubsection{Calibration}

Stated previously in Section 5.2.3.1, the lighting and appliance modules require the user to provide module calibration scalars, $C_{\text {light,calibrate }}$ and $C_{\text {appl,calibrate }}$, respectively. Module calibration scalars were determined separately for SD and DR dwellings in Ontario Canada. Each module required a calibration target, corresponding to the desired average annual energy consumption per dwelling. For the lighting module, these targets were determined from the Comprehensive Energy Use Database (CEUD) (OEE, 2017). The average annual lighting energy consumption targets for SD and DR dwellings were 1064 and $719 \mathrm{kWh} /$ year/dwelling, respectively. The CEUD also provides estimates for appliance energy consumption, but does not disaggregate between electrical and other fuel types. Instead, the appliance energy targets were estimated by subtracting the average annual lighting consumption from 
the average annual AL consumption determined from the measured profiles. SD and DR dwelling appliance calibration targets were assumed to be 5759 and 3583 $\mathrm{kWh} /$ year/dwelling.

Calibration for each dwelling type was performed by randomly selecting $377^{5}$ Ontario dwellings from the CSDDRD. Annual AL profiles were generated for each dwelling at a 1-minute timestep using the modified AL model. The calibration scalars were iteratively adjusted until the absolute percentage error between the model output and target was below $1 \%$. Once iterations were terminated all Ontario singledetached and double/row CSDRRD dwellings ${ }^{6}$ were modelled, and the percentage error of the model-predicted average annual energy consumption for each module and dwelling type are provided in Table 5.3.

Table 5.3: Average annual energy consumption percentage errors

\begin{tabular}{|c|c|c|}
\hline \multirow{2}{*}{$\begin{array}{l}\text { Dwelling } \\
\text { type }\end{array}$} & \multicolumn{2}{|c|}{ CREST module } \\
\hline & Lighting & Appliance \\
\hline SD & $4.6 \%$ & $1.5 \%$ \\
\hline DR & $1.8 \%$ & $2.1 \%$ \\
\hline
\end{tabular}

\subsubsection{Modelled validation set}

To produce the modelled AL demand validation set annual AL demand profiles were generated for all Ottawa, Canada SD and DR records in the CSDDRD, corresponded to 811 and 260 records, respectively. Each measured AL demand profile was paired to a modelled profile which had a minimum weighted difference of annual AL energy consumption, annual baseload demand ${ }^{7}$, and annual peak demand. Annual AL energy energy consumption was assumed to be the most important characteristic, and was assigned a weight of 0.7 . The annual baseload and peak demands were assigned

\footnotetext{
${ }^{5}$ Minimum number of samples required for $95 \%$ confidence in large populations

${ }^{6}$ The CSDDRD contained 5404 and 1231 SD and DR records for Ontario, respectively.

${ }^{7}$ Baseload characterized as $5^{\text {th }}$ percentile of AL demand, and peak as $95^{\text {th }}$ percentile
} 
weights of 0.2 and 0.1 , respectively. Baseload was given a higher weight since the influence of the adding the baseload input, described previously in Section 5.2.3.5, was of interest for this work. These related pairs of AL demands were used to assess the capability of the CREST model implementation to replicate the temporal and inter-dwelling variations in AL demand. Figure 5.2 illustrates the distribution of the measured and modelled AL demand profile's annual energy consumption, baseload, and peak demand. 


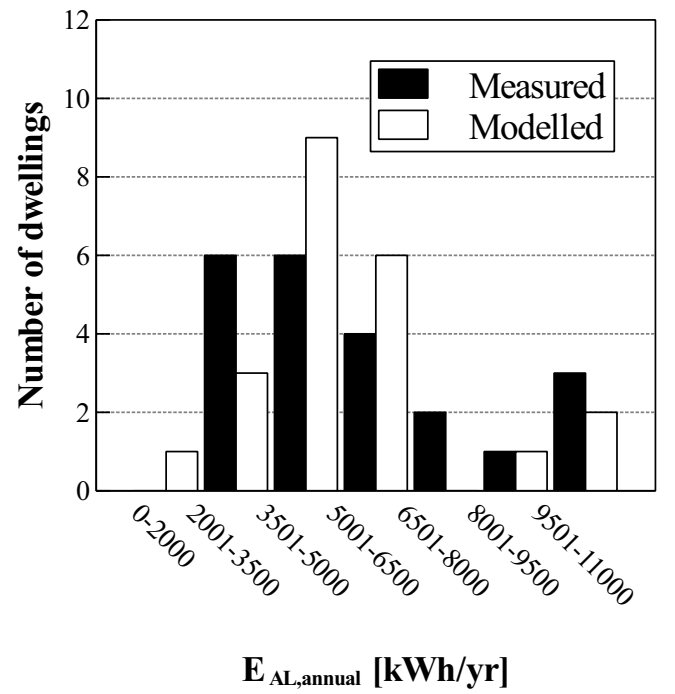

(a) Annual consumption

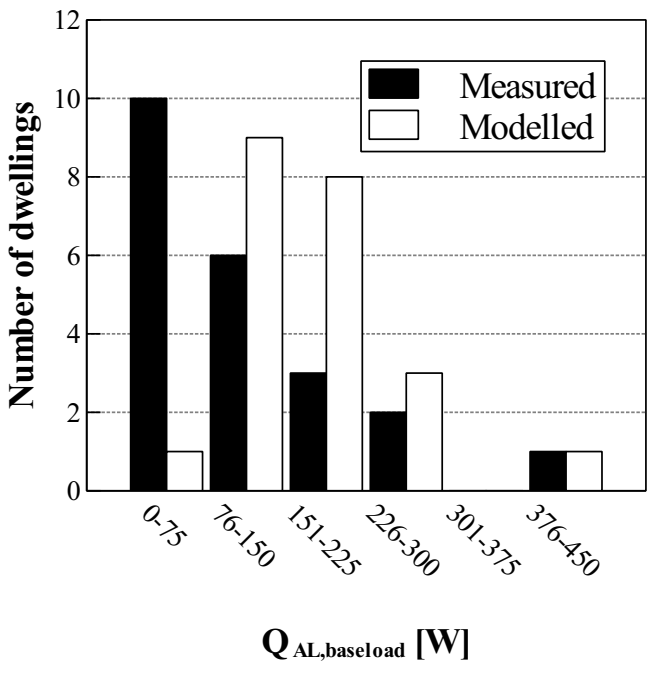

(b) $5^{\text {th }}$ percentile of the load

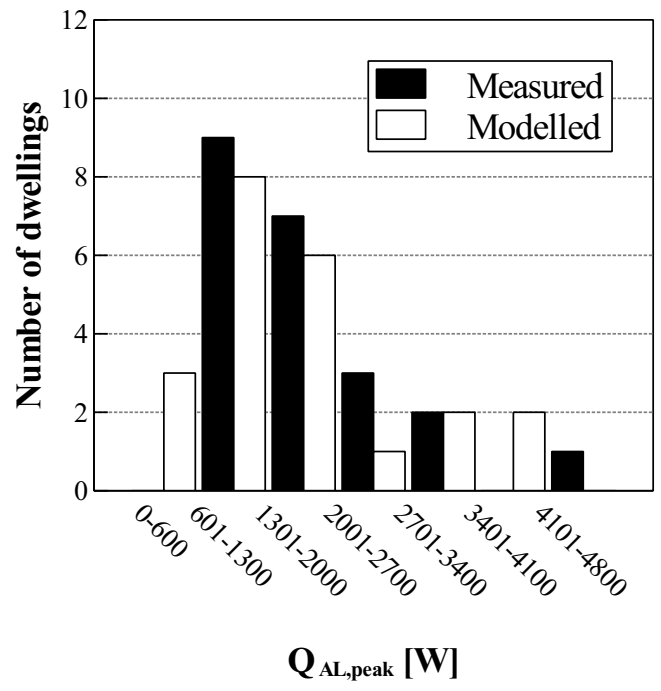

(c) $95^{\text {th }}$ percentile of the load

Figure 5.2: Distribution of annual appliance and lighting load parameters for the measured and modelled sets 


\subsubsection{Results of in-sample validation}

The measured and modelled validation sets described above were used to perform the in-sample validation of the CREST model. To characterize model performance and behaviour, several metrics commonly used in power distribution analysis were determined and compared for the measured and modelled demand profiles. It is important to note that measured data used for validation is relatively small, and since data collection was voluntary it may be biased. Nonetheless, the measured data is of high resolution and spans an entire year for each sample.

Annual mean daily demand profile Figure 5.3 plots the weekday and weekend annual mean daily demand profiles for both the measured and modelled validation sets. Each profile in Figure 5.3 represents the average over all 22 profiles. The profiles were smoothed using a simple moving average at 15-minute intervals. To express the variation of $\mathrm{AL}$ demand for each period of the day, the interquartile range (IQR) of the demands are plotted as the shaded regions in Figure 5.3. The IQR was used as to not exaggerate the variation of the AL demand, but rather illustrate the more typical variation of the demand. 


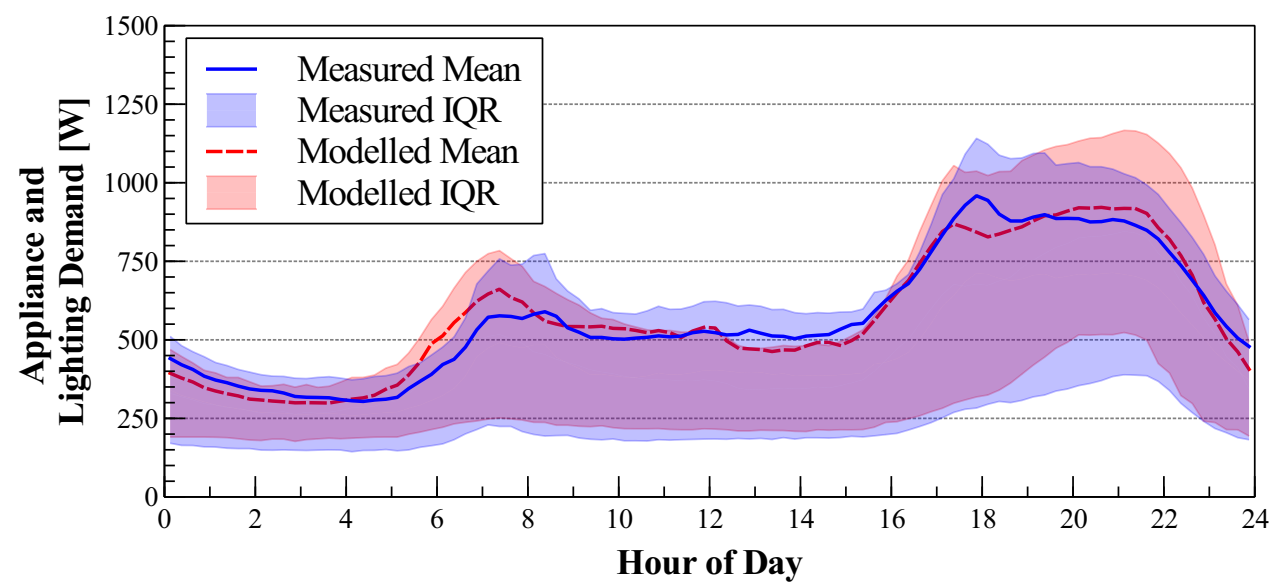

(a) Weekday profile

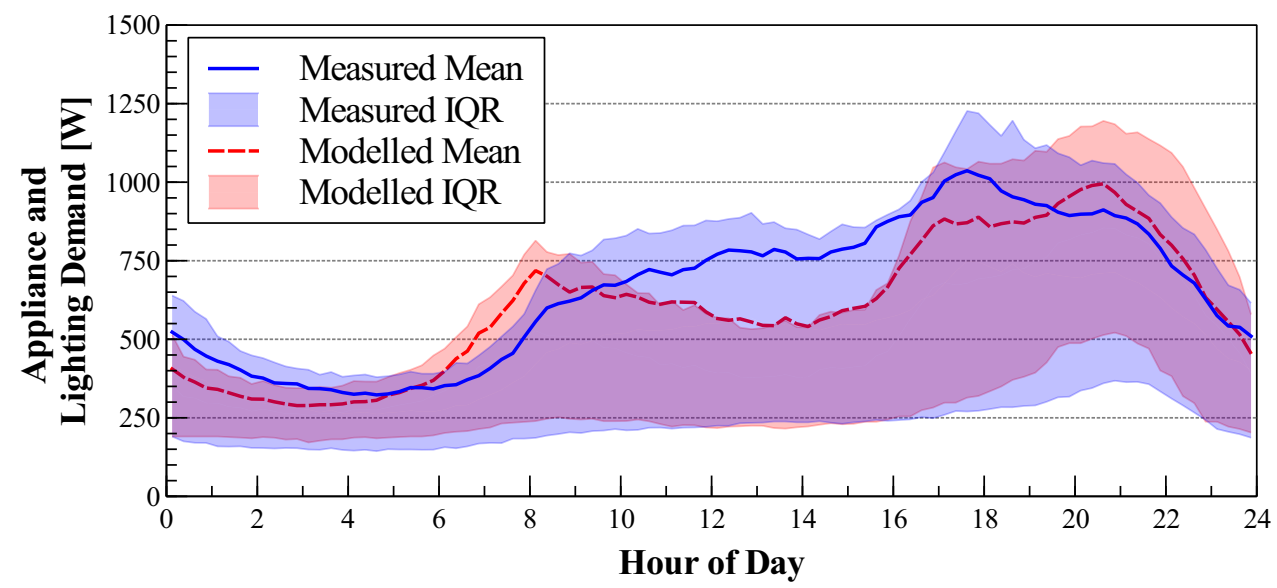

(b) Weekend profile

Figure 5.3: Annual mean daily demand profiles for all 22 demand profiles

The weekday mean measured and modelled profiles in Figure 5.3(a) are shown to follow a similar trend, although there are some notable differences. The modelled morning peak demand occurs between $07 \mathrm{~h} 15$ and $07 \mathrm{~h} 30$, whereas the measures profile exhibits two morning peaks at 07h15-07h30 and 08h15-08h30. The presence of two peaks in the measured profile suggests behavioural differences between dwellings (i.e. 
some households starting their day at 07h00, while others start at 08h00), which is not obvious in the modelled demand profile.

The occupancy TPMs developed in the current work were derived from Canadian TOU data which was only differentiated by number of household occupants, averaging out occupant behaviours and likely leading to the single morning peak seen in the modelled data. Evening AL demands are shown to be similar, however the measured weekday profile has a distinct peak between $17 \mathrm{~h} 45$ and $18 \mathrm{~h} 00$ whereas the modelled show two less prominent evening peaks. To quantify the differences in the weekday mean daily demand profiles, the mean absolute error (MAE) between the profiles were determined and found to be $37 \mathrm{~W}$. This relatively small error suggests that the CREST model broadly captures the average daily demand variations observed in the measured data.

The weekend mean profiles in Figure 5.3(b) have more obvious discrepancies, especially around midday. The MAE between the two profiles were determined to be $98 \mathrm{~W}$ however, suggesting that the CREST broadly captures the average daily AL demand variations during weekends. Qualitatively comparing the two profiles, the measured profile in Figure 5.3(b) has a steady increase in AL demand throughout the day, whereas the modelled mean profile decreases to a minimum during midday before realizing an evening peak.

Seasonal variation of these mean profiles were considered as a possible explanation for the differences in weekend demand. It was noted that the weekend TPMs and activity probability distributions were derived using all weekend diaries in the TOU survey, and were not differentiated by month or season. Conceivably, occupant presence and behaviours will change with the weather. Figure 5.4 plots the measured and modelled weekend seasonal mean daily demand profiles for summer and winter ${ }^{8}$. For the measured data profiles, there is a visible increase in evening demand likely due to increased use of lighting and entertainment appliances (i.e. TVs). The modelled profiles are shown to be similar for both seasons, with only a nominal increase during the evening likely due to increased lighting demand.

\footnotetext{
${ }^{8}$ Summer was defined as June 21 to September 22, and Winter from December 21 to March 20.
} 


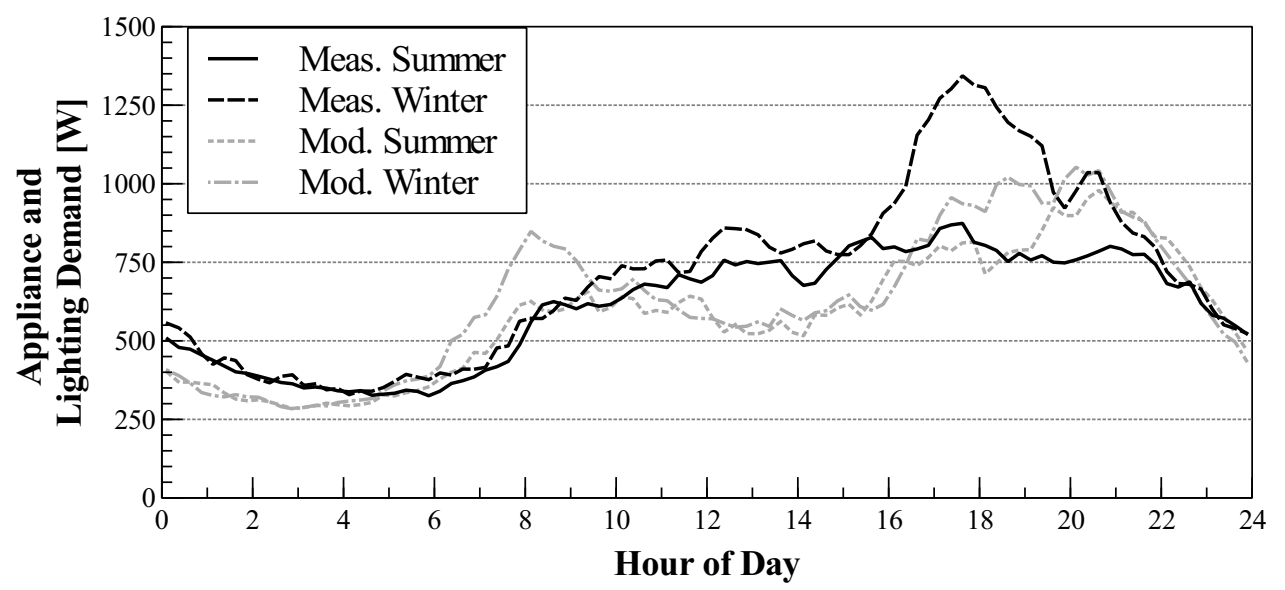

Figure 5.4: Weekend seasonal mean daily demand profiles for all 22 demand profiles

During the midday periods in Figure 5.4 however, the measured summer and winter demand profiles are shown to be similar. They are also higher than the modelled profiles, as was the case in Figure 5.3(b). This suggests that the differences between the measured and modelled weekend midday demands are not due solely to annual aggregation of the TOU weekend diaries. In the absence of plug-level or occupancy information for the measured data, it is difficult to determine the underlying reasons for differences in the weekend demand profiles. Figure 5.4 suggests however, that greater consideration of seasonal occupant behaviour should be considered in the CREST model.

Lastly, Figure 5.3 was used to examine the variation of the daily weekday and weekend demands. Qualitatively, the weekday profiles exhibit similar variation in AL demand. During weekend periods however, the CREST model appears to underestimate the variation in midday demand. To quantify the profile differences the MAE of the IQRs at each 15-minute interval were determined, and found to be to be $77 \mathrm{~W}$ and $138 \mathrm{~W}$ for weekdays and weekends, respectively. Again, the weekday profiles largely capture the variance of the AL demand, however discrepancies remain for weekend periods. 
Seasonal and weekly variation Richardson et al. (2010) previously examined the seasonal variation of AL demand in 22 simulated UK dwellings, and found that the CREST model had under-estimated the variation compared to measured data. The current work uses a similar approach to Richardson et al. (2010) to evaluate the seasonal variation behaviour of the measured and modelled AL demands. Figure 5.5 plots the measured and modelled overall mean daily AL demands subdivided by month of the year.

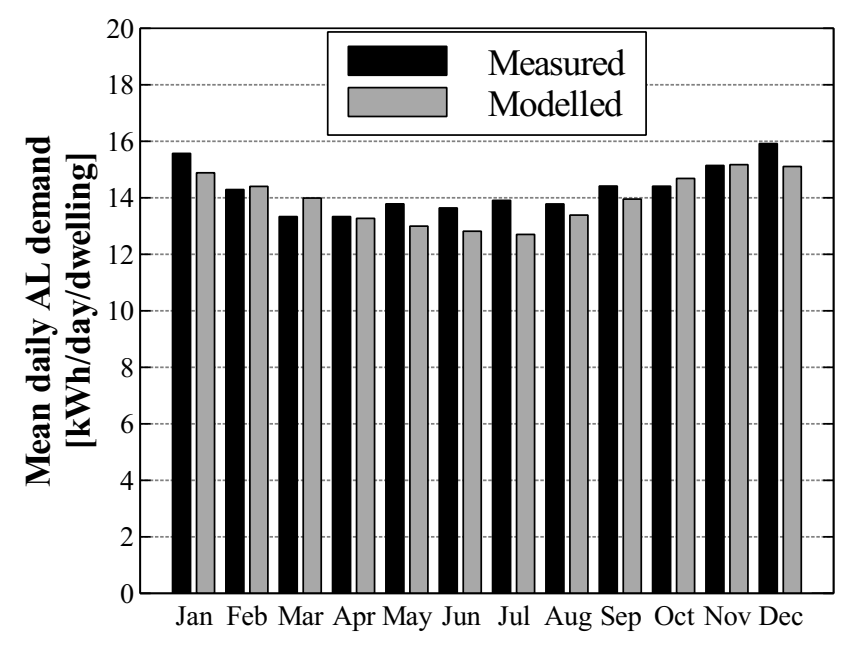

Figure 5.5: Overall monthly mean daily AL demand

Qualitatively both measured and modelled follow a similar trend of seasonal variation in Figure 5.5. The measured overall monthly mean daily AL demand varied by $2.6 \mathrm{kWh} /$ day/dwelling during the year. The modelled mean daily demand had a similar variation of $2.5 \mathrm{kWh} /$ day/dwelling, a difference of $4.5 \%$ from measured. The peak overall monthly mean daily AL demand occurs in December and November for the measured and modelled, respectively. The minimum mean daily demand occurs in March and July for the measured and modelled, respectively. For the modelled data this was expected, as July is a period of high solar irradiance and low lighting usage. In the absence of plug-level data and occupancy information, it is difficult to speculate why the measured data is a minimum in March. 
The overall mean daily AL demands for each day of the week is plotted in Figure 5.6. Mentioned previously, Richardson et al. (2010) had categorized day types as either weekday or weekend. The implicit assumption is that there is little variation in AL demand within those day types. To test this assumption the daily AL demands were determined for each day and demand profile, and were subdivided based on day of the week. The distribution of the measured and modelled daily demands are plotted in Figure 5.6.

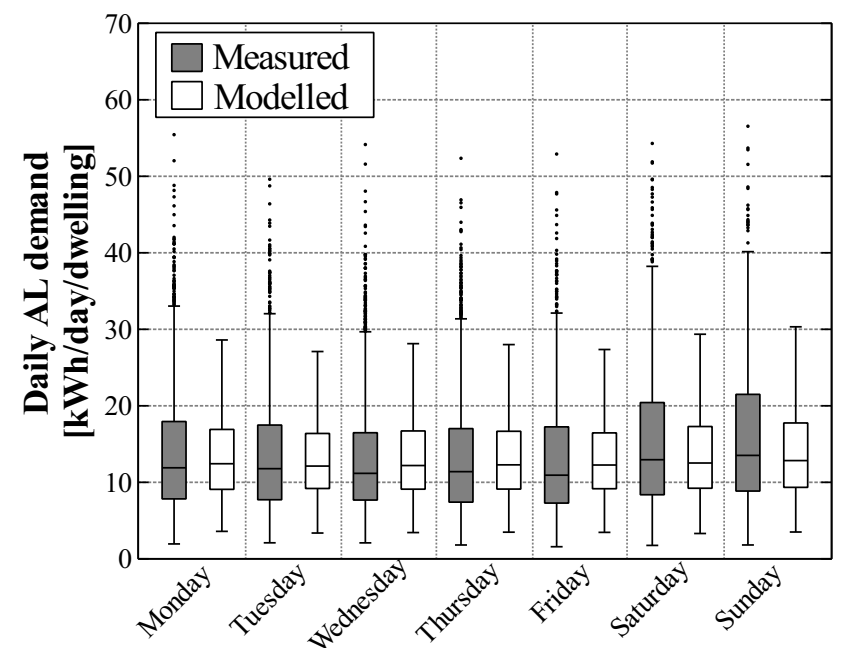

Figure 5.6: Distribution of weekday daily AL demands

To test the validity of lumping day types into weekday and weekend groups, the distributions of measured daily AL demand within each group were compared. A Brown-Forsythe test was used to compare the variance of daily AL demands. The null hypothesis of this test is that variance is the same for all groups. For the measured weekday and weekend groups in Figure 5.6, p-values of 0.812 and 0.649 were determined, respectively. This indicates that weekdays have the same daily AL demand variance, and Saturdays and Sundays have the same variance. When both groups were tested together however, the p-value was in the order of $10^{-7}$ indicating significant differences in variance between weekday and weekend daily AL demands.

A balanced one-way ANOVA test was used to determined if the mean values of 
the measured daily AL demands in Figure 5.6 were similar for all weekdays, and if the mean values for Saturday and Sunday were similar. The null hypothesis of this test is that all groups are drawn from populations with the same mean. All weekdays were found to have a similar mean value with a p-value of $0.102^{9}$. The measured Saturday and Sunday daily AL demands also have a similar mean, with a p-value of 0.160. The similarity of both the mean and variance of daily AL demand in the measured profiles giving validity to disaggregating day types as weekday and weekend.

Figure 5.6 shows that the model under-predicts variation in daily AL demand compared to measured. All measured and modelled weekday groups were compared using the Brown-Forsythe test. The p-value was in the order of $10^{-28}$, indicating that the variance is statically different between measured and modelled weekday daily demands. The measured and modelled weekend daily AL demand variances were also found to be different, with a p-value on the order of $10^{-21}$. To quantify how different the variances are between measured and modelled, the standard deviations of the weekday and weekend demands were compared. The standard deviations for measured and modelled weekday daily demands were 8.5 and $6.6 \mathrm{kWh} /$ day/dwelling, respectively, yielding a difference of $24.7 \%$. The weekend measured and modelled standard deviations were 9.4 and $7.4 \mathrm{kWh} /$ day/dwelling, respectively, yielding a difference of $23.8 \%$.

Load factors Richardson et al. (2010) also used the diversity factor and ADMD to analyse the modelled load diversity. The reciprocal of the diversity factor is often referred to as the 'load factor', $f_{\text {load }}$. This factor represents the ratio of the total energy demand during period $\Delta t[\mathrm{~h}]$, and the peak power demand over the same period multiplied by $\Delta t$, shown in Equation 5.4:

$$
f_{\text {load }}=\frac{E_{\Delta t}}{Q_{\text {peak }} \Delta t}
$$

where $Q_{\Delta t}[\mathrm{kWh}]$ is the electrical energy consumed over period $\Delta t$, and $\dot{Q}_{\text {peak }}[\mathrm{kW}]$ is

\footnotetext{
${ }^{9}$ Significance level $\alpha=0.05$
} 
the peak load for $\Delta t$. The values of $f_{\text {load }}$ can vary between zero and one. At $f_{\text {load }} \approx 1$, the load is relatively constant over period $\Delta t$, whereas a $f_{\text {load }} \approx 0$ would indicate widely varying electrical load (Short, 2003). The daily $f_{\text {load }}$ values, $f_{\text {load,daily, were }}$ determined for each modelled and measured profile, and for each day of the year. To calculate $f_{\text {load,daily }}$, both modelled and measured profiles were smoothed using a simple moving average at a 15-minute interval. Weekday and weekend $f_{\text {load,daily }}$ values for all days and profiles were aggregated separately for the measured and modelled sets, and the range of values are illustrated using box and whisker plots in Figure 5.7.

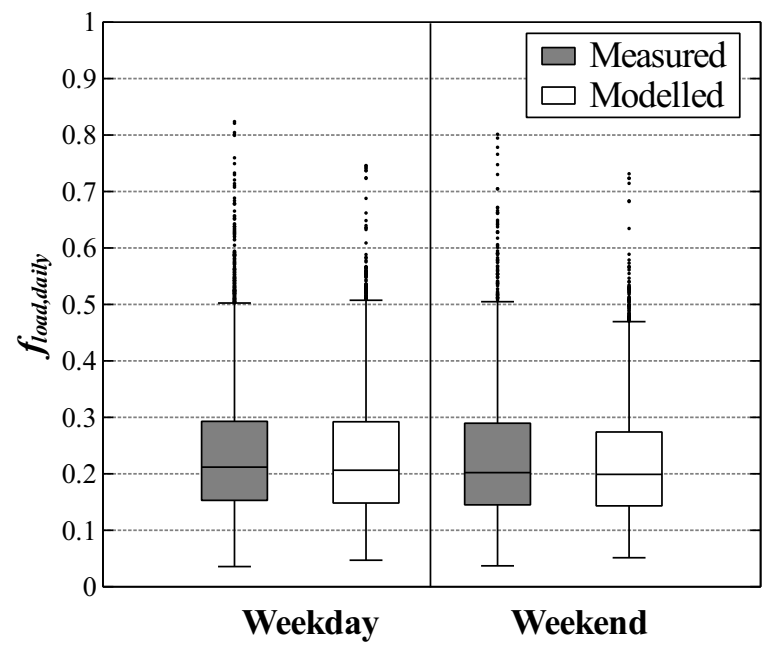

Figure 5.7: Distribution of measured and modelled weekday and weekend daily load factors

The variation of $f_{\text {load,daily }}$ appears to be similar in Figure 5.7. To test if the variance was statistically similar, the Brown-Forsythe test was used. For weekday

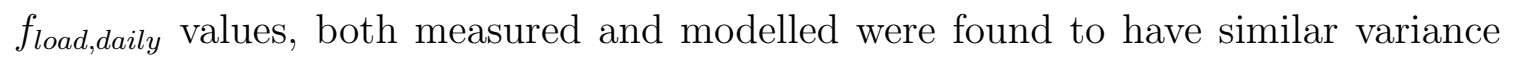
with a p-value of 0.382 . For weekend $f_{\text {load,daily }}$ values however, the p-value was determined to be 0.003 indicating that the variances of weekend $f_{\text {load,daily }}$ values are different between measured and modelled values. The standard deviation of the measured and modelled weekend $f_{\text {load,daily }}$ values were determined to be 0.119 and 
0.108 , respectively.

To compare the mean $f_{\text {load,daily }}$ values of the measured and modelled data, a two-sample t-test was used. For weekdays, the t-test p-value was found to be 0.140 suggesting that the mean value of $f_{\text {load,daily }}$ is similar between measured and modelled. Again for the weekend periods, the means were found to be statistically different, with a p-value of 0.023 . For weekends, the measured and modelled $f_{\text {load,daily }}$ mean values were 0.231 and 0.224 , respectively.

Coincidence factors The final parameter considered in the verification study was the 'coincidence factor', $f_{\text {coinc }}$. This factor represents the ratio between the system peak demand for a group of dwellings over time period $\Delta t$, to the sum of the individual dwelling peaks over the same period. The calculation of $f_{\text {coinc }}$ is shown in Equation 5.5:

$$
f_{\text {coinc }}=\frac{Q_{\text {peak }, \text { system }}}{\sum_{i} Q_{\text {peak }, i}}
$$

$Q_{\text {peak,system }}[\mathrm{kW}]$ is the maximum coincidental total demand for a group of customers during period $\Delta t$, and $Q_{\text {peak,i }}[\mathrm{kW}]$ is the peak load for customer $i$ over the same time period (Gönen, 1986). Like $f_{\text {load }}, f_{\text {coinc }}$ varies between zero and one. When $f_{\text {coinc }} \approx 1$, all customers are achieve peak demand at the same time. Short (2003) stated that $f_{\text {coinc }}$ is often much less than one, since customers typically do not realize peak demand at the same time.

Comparison of $f_{\text {coinc }}$ between the measured and modelled is an important metric to consider for applicability of the AL model for estimating demands for DG system design. Large values of $f_{\text {coinc }}$ in the model would over-estimate the peak demand of the aggregated load, leading to over-sizing of generation equipment. Conversely, under-estimation of $f_{\text {coinc }}$ by the AL model would lead to under-estimation of system peak demands and equipment size.

Two 'system' AL demand profiles were constructed from concurrently measured AL demands collected by Saldanha and Beausoleil-Morrison (2012) and Johnson and Beausoleil-Morrison (2017), identified as 'group 1' and 'group 2', respectively. Each 
group of AL demand profiles were paired with their corresponding modelled profiles, described in Section 5.2.4.2, yielding eleven measured and eleven modelled profiles per group. To account for weather and social factors, measured system AL demands were developed by aggregating demands over coincident measurement periods. The data from Saldanha and Beausoleil-Morrison (2012) and Johnson and Beausoleil-Morrison (2017) contained 300 and 333 days of concurrent demand measurement, respectively. Daily coincident factors were determined for each concurrently measured day in each group. For the modelled profiles, all 356 days of demand were used in the aggregation.

The individual and aggregated AL demands were used to determine the daily coincidence factors, $f_{\text {coinc,daily }}$. The distributions of $f_{\text {coinc,daily }}$ are plotted in Figure 5.8.

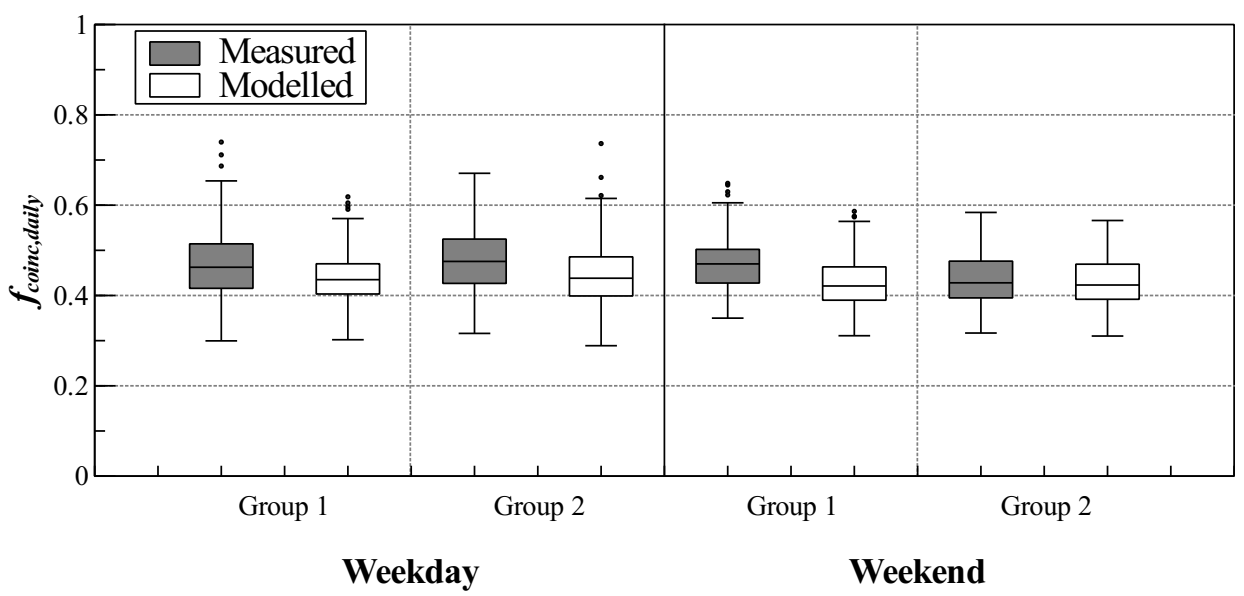

Figure 5.8: Weekday and weekend daily coincidence factors

Comparing measured to modelled in each group for each day type, Figure 5.8 shows that the model tends to under-predict $f_{\text {coinc,daily }}$ compared to the measured values. The modelled mean $f_{\text {coinc,daily }}$ values were between $1.3 \%$ to $9.1 \%$ smaller than the corresponding measured $f_{\text {coinc,daily }}$ values in the same group. Two-sample t-tests were used to examine the significance of these differences. For weekdays, the differences of the means in groups 1 and 2 were significant, with p-values of $2.88 \mathrm{e}^{-6}$ and $4.46 \mathrm{e}^{-9}$, respectively. The mean weekend $f_{\text {coinc,daily }}$ values were also found to be different for 
group 1, with a p-value of $4.00 \mathrm{e}^{-6}$. For group 2 however, the means were found to be similar, with a p-value of 0.531 .

The lower $f_{\text {coinc,daily }}$ values produced by the model suggest that there is greater diversity in peak AL demand occurrence amongst the dwellings compared to the measured profiles. In the absence of detailed information on occupancy and plug-load demand in the measured data, it is difficult to discern the reason for this difference. One possible explanation is the exclusion of a social factor in the CREST model. Paatero and Lund (2006) had previously defined a social factor in their residential electrical load consumption model to account for groups of dwellings influenced simultaneously by large events such as climate and television. The CREST model partially accounts for climate by using solar irradiance as input to the lighting module, but not other factors such as temperature and precipitation.

The variation of $f_{\text {coinc,daily }}$ between measured and modelled in each group was also compared using the Brown-Forsythe test. Variance was found to be similar between measured and modelled, with the exception of weekday $f_{\text {coinc,daily }}$ in group 1 . The p-value for that group was determined to be in the order of $10^{-4}$. All other day types and groups have p-values between 0.550 and 0.657 .

\subsubsection{Impact of baseload implementation}

The current implementation of the CREST model added an unallocated constant baseload demand to each AL demand profile generated. The magnitude of the baseload demand was determine stochastically for each profile generated, using a Gaussian distribution defined by mean and standard deviation values provided by the user. To examine the impact of this added baseload, the baseload value was set to zero and the appliance module in the CREST model was re-calibrated using the procedure described previously in Section 5.2.4.1. Inputs for standby power demand of appliances were still included in the model.

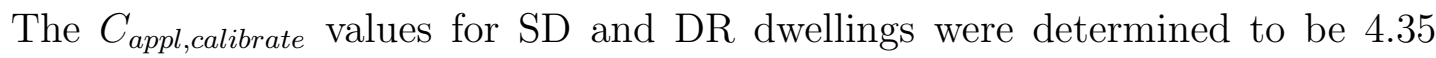
and 2.11, respectively. When the baseload was included in the CREST model, these 
values were 2.36 and 0.50 , respectively. $C_{a p p l, c a l i b r a t e}$ is a scalar which is directly multiplied to the $N_{i, \text { cycles }}$ for each appliance $i$. For the set without a baseload, $N_{i, \text { cycles }}$ had to be increased to achieve the same user specified nominal annual AL consumption

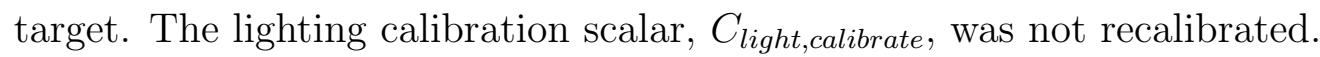

To compare the two calibrated CREST models, 330 available CSDDRD Ottawa, $\mathrm{ON}$ records were randomly selected. The ratio of SD to DR dwellings was 4:7 to reflect the ratio of dwelling types in the measured data. Annual AL demand profiles were generated for each of these profiles using both calibrated CREST models. The annual mean daily weekday demand profile were determined for both sets, and are plotted in Figure 5.9. The profile for the measured data is also included for reference.

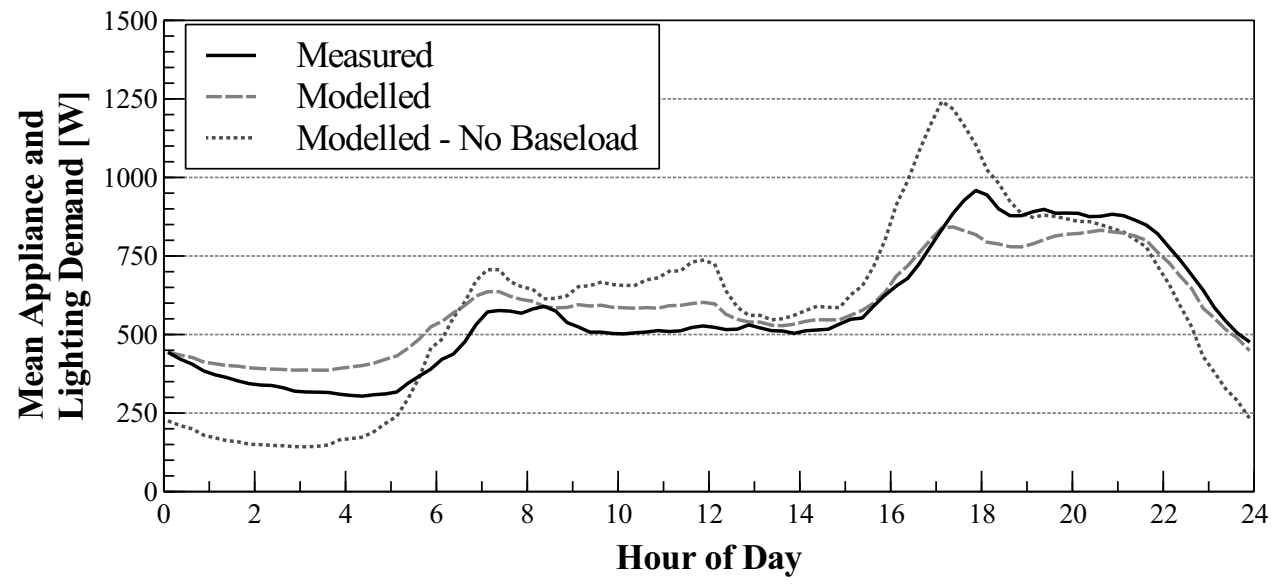

Figure 5.9: Comparison of annual mean daily weekday demand profiles with and without baseload input

It can be seen in Figure 5.9 that the inclusion of the baseload demand improves agreement with measured data in terms of mean night-time demand. Additionally, the inclusion of the constant baseload also reduced the baseload to peak demand variation. To quantify the differences between the models, the annual baseload and peak demands were determined for each profile in both sets. The mean baseload demand was 292 and $43 \mathrm{~W}$ for the sets with and without the stochastic baseload input, respectively. The mean annual peak demands were found to be 1.42 and 
$2.64 \mathrm{~kW}$, respectively. Both baseload and peak demand differences were found to be significant using a two-sample t-test. For reference, the mean annual baseload and peak demands of the measured data was $133 \mathrm{~W}$ and $1.7 \mathrm{~kW}$, respectively.

The variation of the annual baseload and peak demands were also compared between modelled sets. The standard deviation of the annual baseload with and without the stochastic baseload input was determined to be 76 and $17 \mathrm{~W}$, respectively. For annual peak demand, the standard deviation was 825 and $625 \mathrm{~W}$, respectively. The Brown-Forsythe test also determined that the differences of variance were significant for both baseload and peak demands. For reference, the standard deviation of the annual baseload and peak demands of the measured data was 100 and $987 \mathrm{~W}$, respectively.

Caution should be taken when comparing the absolute values of measured and modelled baseloads, since the mean and variation inputs of the stochastic baseload input included here were derived from the measured data. What this section highlights however, is that in the absence of the stochastic baseload input the model tends to under-predict the mean and variation of baseload demands. Additionally the absence of the stochastic baseload input also increased the mean annual peak demand and reduced the variation of annual peak demand among simulated profiles.

\subsubsection{Conclusions}

The current work adapted the CREST model previously developed by Richardson et al. (2010) to simulate the appliance and lighting (AL) demands of Canadian singledetached and double/row dwellings. Relevant Canadian data was collected and integrated into the CREST model, and an in-sample validation was performed using 22 measured annual AL demand profiles. The purpose of this validation was to examine if the nominal AL demand characteristics were similar between measured and modelled, as well as examine if the variation of AL demand characteristics within and between dwellings were also realistic. Overall the results show that the CREST

model has the potential to generate the temporal and inter-dwelling diversity of 
AL demands seen in the practice. Such capabilities are useful for analysing residential community-scale energy demands and studying the design and feasibility of retrofitted distributed generation systems.

The results of the in-sample validation indicate that the adapted CREST model is capable of largely capturing the mean daily AL demands observed in the measured data. The variation of the daily AL demand was also found to be similar to measured for weekday periods, however the model under-estimated midday demand and variation compared to the measured data. The model was found to be follow similar seasonal variation of daily AL energy consumption as the measured data, however the variation in seasonal evening demand was found to be under-estimated in the model. The current CREST model only incorporates seasonal variation through changes in lighting use.

Two additional power demand characteristics were used to compare the measured and modelled AL demand characteristics: daily load and coincidence factors. Weekday and weekend load factors were considered separately. The model was shown to largely reproduce the daily variation of both factors, however the model tended to under-predict the mean daily coincidence factors. This indicates that there is generally larger variation in peak occurrence in the modelled AL demand profiles compared to the measured data. The good agreement of the mean and variation of the daily load factors indicates the model properly captures the typical daily fluctuation in AL demand, as well as the periods of high and low daily AL demand fluctuation seen in the measured data.

A stochastically determined AL baseload demand was also developed and implemented as part of this study. The inclusion of an unallocated baseload demand was shown to improve model annual baseload demand estimation, as well as annual peak demand estimation. In the absence of the stochastic baseload input, the model was found to under-estimate baseload demand as well as over-estimate annual peak demand.

Finally, the measured annual AL demand profiles were used to validate the aggregation of day types into weekdays and weekends. Using balanced one-way ANOVA and Brown-Forsythe tests, the mean and variation of daily AL demands was found 
to be statistically similar within weekdays and weekends. This finding added validity to the aggregation of day types as weekdays and weekends.

It is important to note that the sample of measured dwellings used in this study is relatively small, and is not necessarily representative of the larger Canadian residential stock. The results presented here give a strong indication that the CREST model can produce realistic and diverse AL demand profiles. Further work and validation should be carried out as data becomes available. Recommendations are provided in the following section.

\subsubsection{Recommendations and Future Work}

A major challenge for the current work was the lack of measured data available. Electrical consumption data is typically reported as the aggregate dwelling demand, which includes the dwelling HVAC and domestic hot water preparation systems. In order to validate and calibrate the appliance and lighting modelling capabilities of the CREST model, additional profiles similar to the non-HVAC profiles collected by Saldanha and Beausoleil-Morrison (2012) and Johnson and Beausoleil-Morrison (2017) are required. The 22 profiles from Saldanha and Beausoleil-Morrison (2012) and Johnson and Beausoleil-Morrison (2017) were used in the current work, however it would be irresponsible to claim that they are representative of the entire Canadian housing stock. A larger sample size, over a broader geographic area would be ideal. Additionally, new samples should be collected over a coincident period to permit valid aggregation of the demands.

Richardson et al. (2010) had previously noted that the CREST model underestimated the seasonal variation of $\mathrm{AL}$ demands. In the current work, the model was found to follow the seasonal variation in mean daily AL energy demand. When the seasonal differences in the mean daily demand profile was considered in Figure 5.4 however, it was found that winter evening demands were higher for weekends compared to summer. Lighting and entertainment appliances (i.e. televisions) are

primarily used during this period, along with cooking. Seasonal variation of appliance usage may be integrated into the CREST model by varying the appliance 
$N_{i, \text { cycles }}$ variable at each timestep. Flett and Kelly (2017) varied kettle, microwave, and dryer usage sinusoidally in their UK residential energy demand model. Sets of activity profiles could also be constructed for different months and seasons, however Fischer et al. (2015) had previously analyzed TOU data from Germany, and found that the number of daily appliance starts varied seasonally, not the time of occurrence. Currently, there is little information on the seasonal variation of appliances in Canada. The SHEU 2011 report (NRCan, 2014c) does provide some information on seasonal dryer variation. Seasonal usage data for cooking and entertainment activities, largely performed in the evening, would likely improve model performance.

The current work used several sources to estimate appliance power demand, ON duration, and usage. The only plug-load data used in the current work however, was to define the cycle demand profile for washers, dryers, and dishwashers. Plug-load appliance data would be beneficial for determining cycle demand characteristics and durations, seasonal variation, and time of use. Additionally, all appliances modelled in the CREST use nominal power ratings supplied by the user. When each appliance is modelled, the actual ON power demand is determined stochastically using a Gaussian distribution with a mean equal to the nominal ON power demand and standard deviation assumed to be $10 \%$ of the nominal demand. The actual variation of nominal power demand for several of the appliances listed in Table J.2 are unknown. Future work would examine if model performance would improve with improved estimates in the variation of power demand within each appliance type.

Lastly, it was noted in Section 5.2.4.3 that the CREST model tended to underpredict the daily coincidence factors for the groups of demands considered. It would be interesting to consider methods of implementing a social factor similar to what has been suggested by Paatero and Lund (2006). Currently, the CREST model uses solar irradiance as a common boundary condition to all modelled dwellings. Consideration of social factor in the CREST model could potentially increase the values of the daily coincidence factors and improve agreement with the measured data. 


\subsection{Temporal Matching of Boundary Conditions}

What is apparent from the previous sections is that occupant behaviours vary both temporally and between dwellings. General patterns of occupant-driven demands have been observed in the measured data however. George et al. (2015) found that there was a notable seasonal variation of DHW demands in their measured data. Winter consumption was $2.9 \%$ higher than the daily annual average of $172 \mathrm{~L} /$ day, whereas summer consumption was $5.8 \%$ below the average. They also observed weekly variation in consumption. Compared to the global average, Fridays were found to be $9 \%$ below the average, whereas Sundays were $12 \%$ above the average. Similar observations have been found in A\&L demands. Shown previously in Figure 5.6, weekend A\&L demands tended to be higher compared to weekdays. Additionally Figure 5.4 highlighted the differences between winter and summer A\&L demands.

It was therefore important that all the boundary conditions imposed on the CHREM models be temporally synchronized. This was to ensure that a "Sunday" DHW demand did not coincide with a "Friday" A\&L demand, for example. Asynchronicity of these demands may potentially lead to poor estimates of, for example, combined heat and power systems. Of equal important is that all profiles within a boundary condition type are synchronized to produce realistic estimates of aggregate community demands. CHREM uses the conventional simulation period of January $1^{\text {st }}$ to December $31^{\text {st }}$. CHREM also specifies the simulation year as 2009, setting the initial simulation day as a Thursday. Simulation starting on a Thursday was taken as convention in the current work.

Dwelling A\&L demand profiles generated using the model described in Section 5.2 assumed that the initial day was a Thursday. Serendipitously, the DHW demand profiles from George et al. (2015) also begin on Thursday January $1^{\text {st }} 2015$. It was not apparent in the DHW profiles from Edwards et al. (2015), however, which day of the week their profiles began on. These profiles were constructed from measured data, although Edwards et al. (2015) stated that data was filled in these profiles to maintain the sequence of weekdays and weekends. It is implicit that their profiles commence on a Monday based on the dates of data collection. In the current work 
the profiles of Edwards et al. (2015) were integrated into CHREM "as is" since they only make up $21 \%$ of the the DHW demand profile database implemented, and are an improvement over the European-based profiles used previously in CHREM.

\subsection{Final Remarks}

This chapter described the completion of the first research task described previously in Section 2.6, which was to update the A\&L and DHW modelling methodologies in CHREM in order to improve model estimates of aggregate residential energy demands. The measured residential A\&L and DHW consumption data presented here represent the most detailed information most widely available for Canadian homes. Collection of residential energy use data continues to be challenging, however, and as more data from more locations in Canada becomes available in the literature, it will be important to revisit the profiles and methodologies for occupant behaviours in CHREM and update them as needed.

This chapter also concludes the discussion of energy modelling methodologies used in the current work. The next chapter describes the completion of task four from Section 2.6. This task was concerned with the development of a simulation framework to manage the exchange of simulation data between ESP-r and TRNSYS, as well as the interactions between the simulation tools and the optimization algorithm introduced in Chapter 1. The purpose of the optimization algorithm in the current research was to search the solution space to determine cost-optimal solutions for achieving net-zero retrofit. The metrics used to characterize economic and energy performance are also described in the following chapter, as well as additional metrics used to characterize reductions in GHG emissions and impacts on occupant comfort. 


\section{Chapter 6}

\section{Simulation Framework and Performance Metrics}

This chapter describes the methodology developed to manage the exchange of data between the ESP-r and TRNSYS community energy models. Given the complexity and detail of the models, a de-coupled approach to modelling was used. The efficacy of dwelling-scale retrofits were modelled in ESP-r, and the resulting aggregate community thermal and electrical demands were then passed as boundary conditions to the community energy model developed in TRNSYS. This data exchange process is illustrated in Section 6.1.

Also included in Section 6.1 is the methodology used to integrate the optimization tool GenOpt into the simulation framework. Given the relatively large number of retrofit options assessed in this work, it was not feasible to simulate all possible combinations of retrofits. Instead an optimization algorithm in GenOpt was used to search the solution space to determine the most economical community retrofit solution for achieving net-zero. A description of the optimization problem and algorithm used is provided in Section 6.1.1.

Chapter 1 previously introduced net-zero energy as a conceptually simple energy target which has not yet received a universally accepted formal definition and calculation procedure. To analyse the impact of net-zero definition on the design of community retrofit solutions, two types of net-zero balances were drawn from the 
literature and are described in Section 6.2. Finally, Section 6.3 provides the calculation methodologies of additional metrics used to evaluate the performance of the net-zero communities.

\subsection{Simulation Framework}

Figure 6.1 illustrates the simulation framework developed for this research. Prior to optimization, the performance of all combinations of dwelling-scale retrofits were simulated in ESP-r, and the results were stored in a database. During optimization, the aggregate community thermal and electrical demands were drawn from this database and set as boundary conditions to the community energy system model in TRNSYS.

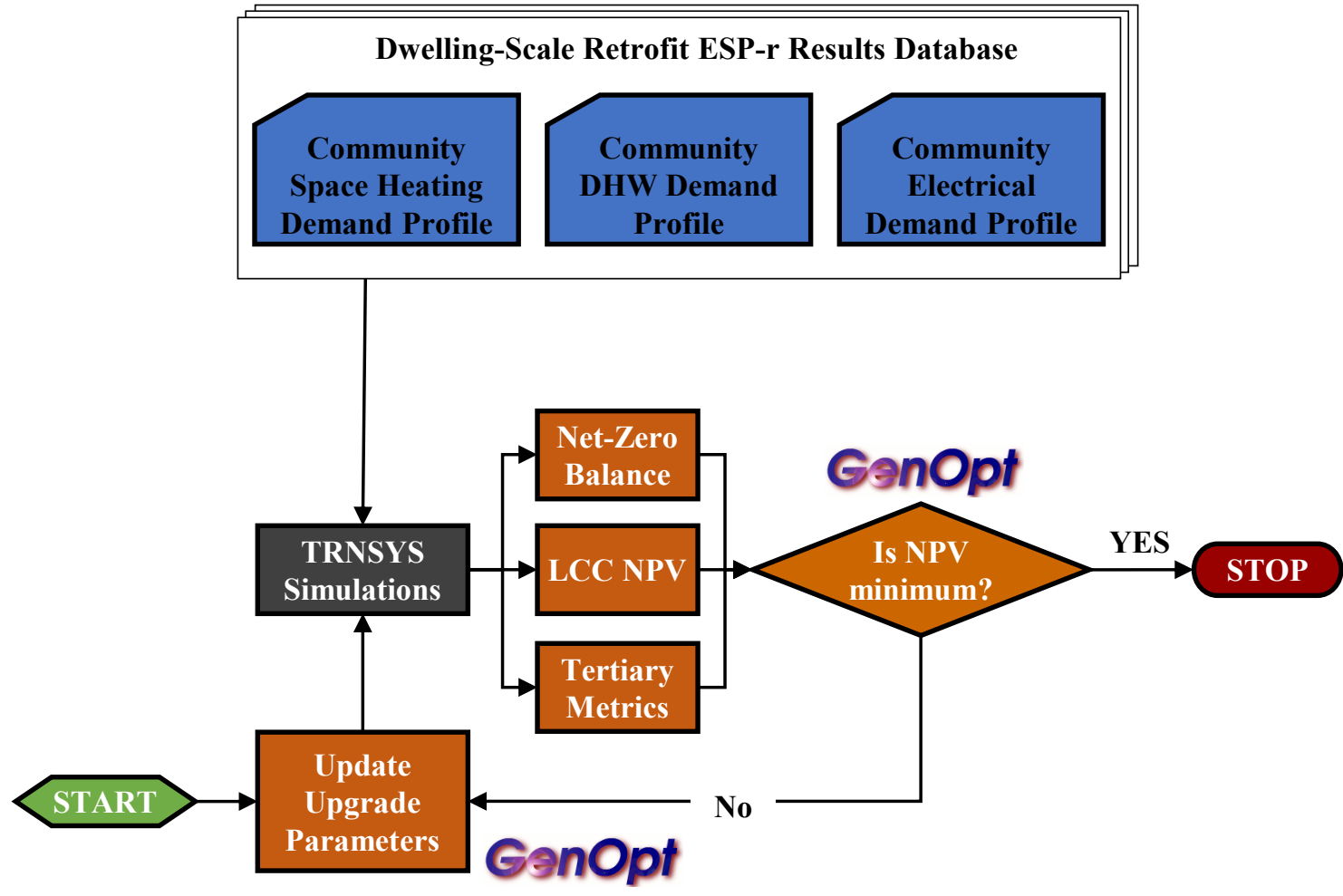

Figure 6.1: Simulation framework and data exchange between models 
To facilitate the data exchange illustrated in Figure 6.1, a simulation control script was written in Perl. This script acted as both a supervisory layer between GenOpt and the energy model, as well as a post-processor for simulation results. As a single-objective generic optimization tool, GenOpt views the system being optimized as a black box. The optimization algorithm specifies model input parameters, and receives a single value of the objective function to be minimized.

For this research the objective function was the net-present value (NPV) of the retrofit life cycle costs (LCC), described later in Section 6.1.2. Attia et al. (2013) stated that objective functions are typically economic or energy related in BPS optimization studies. How the net-zero balance was incorporated into the optimization problem will be shown later in Section 6.1.1.2.

\subsubsection{The Optimization Problem}

GenOpt was used in the current work to solve the optimization problem, $P$ :

$$
\begin{aligned}
& P: \operatorname{minimize} N P V \\
& \text { s.t. } Q_{\text {net-zero }} \geq 0
\end{aligned}
$$

where $Q_{\text {net-zero }}[\mathrm{GJ}]$ is the annual net-zero energy balance described later in Section 6.2. GenOpt contains several algorithms which may be used to solve singleobjective optimization problems. For this work, a stochastic particle-swarm optimization (PSO) algorithm was used to solve the problem illustrated in Equation 6.1. Wetter (2016) suggested PSO algorithms for optimization problems where all the independent variables are discrete. This was the case for the current work, shown later in Section 6.1.3, and was therefore selected as an appropriate algorithm.

Additionally PSO and other population based optimization algorithms have recently seen greater use in the BPS field, having been "shown to be very successful in optimizing one or many performance criteria while handling search constraints for large design problems" (Attia et al., 2013). PSO and similar algorithms are often 
better able to handle the highly constrained and discontinuous optimization problems present in BPS (Attia et al., 2013), whereas deterministic algorithms require smooth, continuous solution spaces (Wetter and Wright, 2003, 2004).

The PSO methodology is based upon the modelling of flocks of birds or schools of fish (Wetter, 2016). Each set of independent variables is referred to as a "particle." The user specifies the number of particles, $N_{p}$, which is sometimes referred to as the "population." At the initial "generation," the particles are randomly populated in the design space. Each particle determines its value of the objective function, and a particle update equation is used to determine the location of the particles in the next generation. The value of the particle update equation is analogous to a particle velocity, and is used to accelerate the particles toward (swarm) the location in the design space with the best or "fittest" objective function evaluation (Eberhart and Kennedy, 1995). A particle is updated a number of times equal to the number of generations, $N_{G}$, specified by the user. Thus, $N_{G}$ acts as a termination criterion for the optimization. The algorithm is said to have converged if the particles have all swarmed to a single region in the solution space at the final generation. There is not guarantee however, that this is the "global" minimum in the solution space. To be certain the global minimum has been determined, a full parametric simulation is required.

Details of the PSO algorithm and update equation is omitted here for clarity, and the interested reader is directed to Wetter (2016) for further information.

\subsubsection{Optimization Algorithm Parameters}

Three types of PSO algorithms are available in GenOpt, as well as a hybrid algorithm uses both PSO and the deterministic gradient-free Hooke-Jeeves method (Hooke and Jeeves, 1961). For the current work, the PSO with constriction coefficient (Clerc and Kennedy, 2002) was used. The algorithm parameters are summarized in Table 6.1. 
Table 6.1: Particle Swarm Algorithm Parameters

\begin{tabular}{lc}
\hline Parameter & Value \\
\hline \hline Neighborhood Topology & gbest \\
Number of Particles, $N_{p}$ & 10 \\
Number of Generations, $N_{G}$ & 110 \\
Seed & 4 \\
Cognitive Acceleration & 2.8 \\
Social Acceleration & 2.3 \\
Max Velocity Gain - Continuous & 0.5 \\
Max Velocity - Discrete & 2.0 \\
Constriction Gain & 1 \\
\hline
\end{tabular}

The parameters in Table 6.1 were informed by recommended values from Wetter (2016) and Bucking (2013). As part of their research on optimization tools and BPS, Bucking (2013) used the PSO algorithm in GenOpt to optimize the annual energy consumption of a near net-zero dwelling located in Montréal, QC with 19 design parameters. Bucking (2013) conducted five optimization calculations to examine the sensitivity of algorithm inputs. The values for number of particles, social acceleration, and max velocity-discrete determined in their work was adopted for this research as fixed optimization algorithm parameters.

All other parameters in Table 6.1 were determined from the recommendations from Wetter (2016). To determine $N_{G}$, Wetter (2016) cited Parsopoulos and Vrahatis (2002) who used $N_{G}=10 \cdot n$ for $10 \leq n \leq 20$, where $n$ is the number of variables to be optimized. Initially 11 parameters were to be varied in the current work, thus $N_{G}=110$ was specified. For cognitive acceleration, Wetter (2016) cited Carlisle and Dozier (2001) who recommended a value of 2.8. This value was also used by Bucking (2013). For the max velocity gain - continuous, Wetter (2016) stated that a common value is 0.5 .

The final parameter, constriction gain, was set to 1 . Valid values were between 
0 and 1. Wetter (2016) stated that as the gain tends toward 1, the algorithm is less constrained to move through the design space to search for the global minimum. The disadvantage of this approach is that it typically requires a relatively large number generations for all the particles to swarm to a single point. As the gain tends toward 0 , particle movement is more constrained and the particles more quickly swarm to a point, which may or may not be the global minimum. A more thorough search was selected for this work.

\subsubsection{Optimization Constraints}

Once the optimization algorithm was selected, the constraints of the optimization needed to be defined. Specifying the set of feasible values for independent variables is straightforward in GenOpt. For each variable, the user must specify whether it is discrete or continuous, and indicate the maximum and minimum boundary. The constraints on the discrete independent variables used in this work are described later in Section 6.1.3. Constraints on the dependent variables in the optimization calculation however, cannot be directly specified in GenOpt. According to the optimization problem statement in Equation 6.1, solutions for the minimum LCC are constrained to solutions which also satisfy $Q_{\text {net-zero }}=0$ GJ.

Wetter (2016) suggests the use of "barrier" or "penalty" functions as an indirect method to implement dependent variable constraints. These functions are added as an additional term to the objective function, and act as a weighted "punishment" to the objective function to steer the optimization algorithm away from undesirable areas in the solution space. In this way a constrained optimization may be approximated and solved by an unconstrained optimization algorithm (Bryan and Shibberu, 2005). Penalty functions are one of the most popular approaches to constrained optimization because they are both simple and easy to implement (He and Wang, 2007; Parsopoulos et al., 2002).

Barrier functions impose punishment on the objective function if the algorithm approaches the boundary of the feasible solution space. A disadvantage of this approach is that it discourages searches along the boundary (Wetter, 2016). Penalty 
functions however, allow crossing of the boundary. As the algorithm moves further into the unfeasible solution space, the value of the penalty function increases proportionally. Since the optimization problem is interested in minimum cost functions along the $Q_{\text {net-zero }}=0$ GJ boundary, a penalty function approach was used. Equation 6.2 provides the penalty function which was added to the objective function value:

$$
F_{\text {penalty }}=10 \cdot i_{G} \cdot\left[\min \left(Q_{\text {net-zero }}, 0\right)\right]^{2}
$$

where $i_{G}$ is the current generation number. The form of Equation 6.2 was informed by Wetter (2016) and Bryan and Shibberu (2005). For solutions where $Q_{\text {net-zero }} \geq 0$ the penalty function evaluates to zero. Under this condition the retrofit community is at least net-zero, or is exporting more energy to the connected infrastructure than it is importing in a year. If the retrofit solution yields a net-importing community, however, the penalty function scales with the deficit in the energy balance.

Equation 6.2 can be defined as a dynamic penalty. Smith and Coit (1997) and Aziz et al. (2011) described dynamic penalty functions as monotonically nondecreasing in value with length of search. Here the length of the search is defined by generation number $i_{G}$. The purpose of dynamic scaling is to allow greater exploration during the initial stages of the optimization including infeasible solutions. Smith and Tate (1993) (as cited in Stanley and Mudge (1995)) noted that optimal solutions typically reside along the boundary of the feasible and infeasible regions. Therefore the penalty should not initially be so severe as to drive the optimization away from the boundary. As the optimization progresses, however, penalties for constraint violations increase to steer the algorithm away from infeasible solutions.

It is important to note that while penalty functions are widely used, they provided an approximation to the optimization problem in Equation 6.1 (Bryan and Shibberu, 2005). There are also some disadvantages to this approach. As $i_{G}$ increases, the gradients of the penalized objective function also increase. Another disadvantage is that solutions may still stray beyond the boundary. While this is not a particular issue for this work, as it would represent near net-zero solutions, some systems may 
be undefined beyond the boundary.

\subsubsection{The Objective Function Cost Model}

Life cycle cost analyses have been recommended by ASHRAE (2011) as an appropriate method to compare the economic viability of different building energy projects. The general expression for the NPV LCC of a community retrofit solution, $L C C_{N P V}$, was based upon the cost model presented by Bucking (2013), and may be expressed as:

$$
\begin{aligned}
L C C_{N P V}= & D_{\text {capital }, N P V}+D_{O \& M, N P V}+D_{u t i l i t y, N P V} \\
& -D_{\text {salvage }, N P V}-D_{\text {revenue }, N P V}
\end{aligned}
$$

where $D_{\text {capital }, N P V}$ is the NPV of the capital costs, $D_{O \& M, N P V}$ is the NPV of the annual operation and maintenance (O\&M) costs, $D_{u t i l i t y, N P V}$ is the NPV of the annual utility costs, $D_{\text {salvage }, N P V}$ is the NPV of the residual value of assets, and $D_{\text {revenue, } N P V}$ is the NPV of the project revenue. In this research, all costs were expressed in 2017 Canadian dollars (CAD).

NPV is used in the current work to acknowledge that there is a time value of money. For example, inflation changes the purchasing power of a set amount of money. Additionally, revenue now is more valuable than revenue later, since revenue now may be invested to build capital (Fraser et al., 2006). The value of a future cost or revenue $N$ years from the present time may be expressed in present monetary units, $D_{N P V}$ using Equation 6.4 (Fraser et al., 2006):

$$
D_{N P V}=D_{N} \cdot \frac{1}{\left(1+M A R R_{A}\right)^{n}}
$$

where $D_{N}$ is the future "actual" cost or revenue, and $M A R R_{A}$ is the "actual" minimum acceptable rate of return (MARR). "Actual" denotes that the monetary units represent value at the time of the cash flow (Fraser et al., 2006). Monetary units may also be expressed as "real" dollars. Real dollars is a unit of constant purchasing 
power, and is defined relative to a base year (e.g. 2005 dollars). For this research, the base year was taken as 2017.

The MARR represents the interest rate that must be earned for a project to be acceptable. Projects that earn below the MARR are undesirable, since the investment could be put to better use in other investments (Fraser et al., 2006). The value of the MARR varies from company to company. Fraser et al. (2006) reviewed "real" MARR values, $M A R R_{R}$, used in the Canadian Public Sector and reported values between $0 \%$ and $13 \%$. According to the Treasury Board of Canada, a $M A R R_{R}$ of $10 \%$ is recommended (as cited in Fraser et al. (2006)) and was assumed for this work. The $M A R R_{A}$ is calculated from (Fraser et al., 2006):

$$
M A R R_{A}=M A R R_{R}+f+\left(M A R R_{R} \cdot f\right)
$$

where $f$ is the rate of inflation. Using annual inflation rates from 1997 to 2016 from Statistics Canada (2017b), a constant annual $f$ of $1.855 \%$ was assumed for this work.

Similar to Equation 6.4, the NPV of annuities over $N$ years, $D_{a n n, N P V}$, is determined from (Fraser et al., 2006):

$$
D_{a n n, N P V}=D_{a n n} \cdot \frac{\left(1+M A R R_{A}\right)^{N}-1}{M A R R_{A} \cdot\left(1+M A R R_{A}\right)^{N}}
$$

where $D_{a n n}$ is the actual value of the annuity. Both Equations 6.4 and 6.6 are used to determine the NPVs in Equation 6.3.

To determine the LCC of a project, a project life needs to be defined. Bucking (2013) previously used an evaluation period of 30 years. They noted that beyond 30 years estimates of inflation and energy price escalation become highly uncertain. They also noted there there are few standards which recommend an appropriate evaluation period. For this research, an evaluation period of 25 years was assumed, based on the estimated life of retrofit equipment described later in Section 6.1.2.4.

The following subsections describe how each term in Equation 6.3 for the retrofit options considered in this research. 


\subsubsection{Capital Costs}

Only capital costs related to material and labour were considered in this analysis. Other costs such as engineering consulting, purchasing permits, etc. were not included. Capital costs, as well as other associated costs, were also not considered for retrofits which are present for all design alternatives. The objective here was not to gain an accurate estimate of the total costs of each retrofit solution, but rather recognize the cost differences between options to determine the most economically desirable option.

In this work, all retrofit dwellings received a HRV retrofit regardless of other design options selected. Therefore the material and installation costs for HRVs were not considered. Discussed later in Chapter 7, two different optimization studies were taken for some communities. The first optimization assumed every retrofit scenario used a district heating system. The second study assumed no district heating system, and all dwellings are retrofit with GSHP space heating systems. Therefore, capital costs were not considered for district heating or dwelling-scale GSHP space heating systems.

Table 6.2 summarizes the capital costs for the dwelling-scale retrofit options. Envelope retrofit values were estimated from Lane (2016) and Ferguson (2016). The HP DHW tank retrofit material cost was estimated from Lowes (2017) ${ }^{1}$, and demo and installation was estimated from Lane (2016). All monetary units are expressed in 2017 CAD, and were assumed to be the same for both Québec and Ontario.

\footnotetext{
${ }^{1}$ Including sales tax.
} 
Table 6.2: Summary of dwelling-scale retrofit capital costs

\begin{tabular}{l|ccc}
\hline Retrofit & Labour & Materials & Units \\
\hline \hline Ceiling ins. & 34 & 18 & $\$ / \mathrm{m}^{3}$ \\
Basement wall ins. & 26 & 34 & $\$ / \mathrm{m}^{3}$ \\
Exterior wall ins. & 238 & 769 & $\$ / \mathrm{m}^{3}$ \\
Glazing system 1 & 299 & 461 & $\$ / \mathrm{m}^{2}$ \\
Glazing system 2 & 299 & 461 & $\$ / \mathrm{m}^{2}$ \\
Glazing system 3 & 299 & 550 & $\$ / \mathrm{m}^{2}$ \\
HP DHW system & 446 & 2,147 & $\$ / \mathrm{unit}$ \\
\hline
\end{tabular}

The labour costs in Table 6.2 included the cost of equipment rental (i.e. attic insulation blower). The labour costs to demo existing material is also included where applicable. All basement walls were assumed to be unfinished, and no demo costs were assumed to remove existing drywall or insulation. The volumes used to calculate the total costs was based on the volume of insulation added, which was estimated from the surface area of insulation applied multiplied by the thickness. Building envelope surface areas were estimated directly from the ESP-r model geometry. The glazing surface area included both the aperture and frame area.

Table 6.3 provides the capital cost estimates for the community-scale equipment retrofits. All data sources were from the United States. To express the estimates in 2017 CAD monetary units, the nominal currency exchange rate from USD to CAD was first determined for the year in which the cost estimate was published. Historical exchange rates and an on-line inflation calculator were then used from Bank of Canada (2017) to convert monetary units to 2017 CAD. 
Table 6.3: Summary of community-scale retrofit capital costs

\begin{tabular}{l|ccc}
\hline Retrofit & $\begin{array}{c}\text { Mean } \\
\text { Installed Cost }\end{array}$ & Units & $\begin{array}{c}\text { Data } \\
\text { Source }\end{array}$ \\
\hline \hline Solar thermal & 2,340 & $\$ / \mathrm{m}^{2 *}$ & NREL $(2016)$ \\
PV $<10 \mathrm{~kW}$ & 5,230 & $\$ / \mathrm{kW}^{* *}$ & NREL $(2016)$ \\
PV 10 to $100 \mathrm{~kW}$ & 4,650 & $\$ / \mathrm{kW}^{* *}$ & NREL $(2016)$ \\
PV 100 to $1000 \mathrm{~kW}$ & 3,350 & $\$ / \mathrm{kW}^{* *}$ & NREL $(2016)$ \\
PV 1 to $10 \mathrm{MW}$ & 2,720 & $\$ / \mathrm{kW}^{* *}$ & NREL $(2016)$ \\
C30 turbine & 134,660 & $\$ /$ unit & Darrow et al. $(2015)$ \\
C65 turbine & 217,500 & $\$ /$ unit & Darrow et al. $(2015)$ \\
C200 turbine & 665,540 & $\$ /$ unit & Darrow et al. $(2015)$ \\
\hline
\end{tabular}

* Gross collector area

** Nominal rated power

NREL (2016) only reported a mean installed cost value which was used directly in this work. Darrow et al. (2015), however, provided a more detailed breakdown of the installation and operation costs. The values reported in Table 6.3 represent the total installed cost minus the engineering and project management costs. Not reported in Table 6.3 is the capital costs associated with the community TES system. Bembry IV (2011) previously performed an energy and economic analysis for large TES systems. They contacted several TES manufacturers to gain accurate estimates of TES capital and maintenance costs. Based on the data presented in their document, the capital cost of the community TES, $D_{\text {capital }, T E S}$ [2017 CAD], was estimated from:

$$
D_{\text {capital }, T E S}=5.1573 \cdot V_{T E S}^{2}+1162.19 \cdot V_{T E S}+3694
$$

It should be noted that Bembry IV (2011) only provided cost data for TES volumes between $50 \mathrm{~m}^{3}$ and $95 \mathrm{~m}^{3}$. In the absence of additional data, however, the extrapolation of the data was assumed to provide a reasonable estimate. 


\subsubsection{Annual Operation and Maintenance}

The estimated annual O\&M costs are summarized in Table 6.4. It should be noted that only energy related O\&M costs were considered. Similar to Bucking (2013), non-energy O\&M such as painting is not considered. The source of the O\&M cost estimates were the same as the sources listed in Table 6.3. It was assumed that there were no annual O\&M costs associated with the dwelling-scale retrofits listed previously in Table 6.2. Additionally, maintenance costs of the community TES were assumed to be similar for all design alternatives, and was neglected in this analysis.

Table 6.4: Summary of community-scale retrofit annual O\&M costs

\begin{tabular}{l|cc}
\hline Retrofit & $\begin{array}{c}\text { Mean } \\
\text { Installed Cost }\end{array}$ & Units \\
\hline \hline Solar thermal & 1\% of capital cost & $\$ / \mathrm{m}^{2}$ \\
PV $<10 \mathrm{~kW}$ & 28 & $\$ / \mathrm{kW}$ \\
PV 10 to $100 \mathrm{~kW}$ & 26 & $\$ / \mathrm{kW}$ \\
PV 100 to $1000 \mathrm{~kW}$ & 26 & $\$ / \mathrm{kW}$ \\
PV 1 to $10 \mathrm{MW}$ & 21 & $\$ / \mathrm{kW}$ \\
C30 turbine & 0.017 & $\$ / \mathrm{kWh}^{*}$ \\
C65 turbine & 0.017 & $\$ / \mathrm{kWh}^{*}$ \\
C200 turbine & 0.021 & $\$ / \mathrm{kWh}^{*}$ \\
\hline
\end{tabular}

\subsubsection{Utility Costs}

Only energy-related utility costs were considered in this analysis. For this research, the only energy carriers delivered to the case study communities were natural gas and electricity. The utility rate for natural gas was estimated from Enbridge (2017). For billing purposes, the community was assumed to be a single commercial large volume purchaser classified as Rate 6 by Enbridge (2017). As of July 2017 this rate scheme included supply and transportation charges of $17.8247 \mathrm{c} / \mathrm{m}^{3}$, and an additional six 
tiered billing scheme provided in Table 6.5. A sales tax of $13 \%$ was also included in the monthly cost calculation.

Table 6.5: 2016 Ontario natural gas tiered rates, data from Enbridge (2017)

\begin{tabular}{ll}
\hline $\begin{array}{l}\text { Volume of NG } \\
\text { Consumption }\left[\mathbf{m}^{\mathbf{3}}\right]\end{array}$ & $\begin{array}{l}\text { Rate } \\
{\left[\mathbf{\Phi} / \mathbf{m}^{\mathbf{3}}\right]}\end{array}$ \\
\hline \hline First 500 & 9.76 \\
Next 1050 & 7.82 \\
Next 4500 & 6.46 \\
Next 7000 & 5.58 \\
Next 15250 & 5.20 \\
Over 28300 & 5.10 \\
\hline
\end{tabular}

To estimate the price escalation of natural gas over the project life cycle, projected reference natural gas prices between 2014 and 2040 from NEB (2016) was used. No estimates for natural gas utility costs in Québec were determined, since the Québec case study community only used electricity.

For electric utility costs, a billing scheme needed to be determined which acknowledged the presence of distributed generation. In Ontario, feed-in tariff (FIT) programs have been in place since 2009 to promote the growth of distributed renewable generation projects ${ }^{2}$. The FIT programs were never anticipated to continue in perpetuity, and it is assumed that they will conclude by the end of 2017 (OREC, 2017).

What is expected to take over from FIT programs is net-metering, which has already been implemented by several utilities in Canada. The Ontario Electricity Act Regulation 541/04 outlines a framework for local distribution companies (LDC) to implement net-metering programs (OREC, 2017). Net-metering is a rate system in which generators receive credits on their electricity bill for exported generation. The value of generation exported is equal to the value of electricity imported, and

\footnotetext{
${ }^{2}$ Rated $500 \mathrm{~kW}$ or less
} 
is dictated by the rate class the generator is designated as by the LDC. Currently, LDCs such as Hydro One and Hydro Ottawa use a two-tier system, instead of timeof-use billing, to charge net-metering customers (Hydro Ottawa, 2017; OREC, 2017). For this work, Ontario and Québec tiered rates were estimated from OEB (2017) and Hydro Québec (2017), respectively, and are summarized in Table 6.6.

Table 6.6: 2016 tiered electricity rates, data from OEB (2017) and Hydro Québec (2017)

\begin{tabular}{lcc}
\hline & Ontario & Québec \\
\hline \hline Tier $\mathbf{1}[\mathbf{\Phi} / \mathbf{k W h}]$ & 9.1 & 5.82 \\
Tier $\mathbf{2}[\mathbf{\Phi} / \mathbf{k W h}]$ & 10.6 & 8.92 \\
Tier $\mathbf{1}$ consumption limit $[\mathbf{k W h}]$ & 600 & $1003.75^{*}$ \\
\hline
\end{tabular}

* $33 \mathrm{kWh}$ times number of days in the month

For the Ontario rates, an additional regulatory and delivery charge of 4.243 $\$ / \mathrm{kWh}$ was assumed, based on medium residential customer rates from OEB (2016). An additional goods and services tax of 5\% was applied to electric utility costs in both provinces. For each simulation month, the community aggregate electrical import and export was determined. If the community was in a credit position, the credits were carried to the next month. Credits were held for a period of 12 months as per the Ontario Electricity Act Regulation 541/04. The annual electric utility costs were also assumed to escalate over the life of the project. For Québec, a constant escalation rate of $0.7 \%$ was assumed (Wilton, 2017). For Ontario, the projected electricity rates reported by Crawley (2017) were used to estimate escalation.

It should be noted that no carbon tax was considered in this study. Carbon taxes levy a cost on fuels which emit carbon emissions. The Pan-Canadian Framework recognized carbon pricing as one potential method to reduce emissions in Canada and to help the country achieve its ambitious GHG reduction targets (ECCC, 2016). Estimates of Canada-wide carbon pricing schemes were not widely-available until late in the progression of this work, and it was therefore omitted. Carbon taxes 
potentially influence the selection of fuel sources, and future work should consider this cost.

\subsubsection{Salvage and Replacement Values}

Often when an asset reaches the end of its useful life, there is some residual value which may be recovered; for example, selling a broken machine for scrap metal. For this research, it was assumed that an asset at the end of its life had a value of zero. The assets which had remaining life at the end of the life period were assumed to have some residual value. The NPV of all residual values was estimated using a linear depreciation model (Fraser et al., 2006), with a value of zero at the end of the service life. The service lives estimated in this work are provided in Table 6.7. Not shown in Table 6.7 is the service life of the TES. It was assumed that the service life of the TES was equal to the evaluation period of 25 years, and there was no residual value.

Table 6.7: Assumed service life of retrofit generation technologies

\begin{tabular}{l|cc}
\hline Retrofit & Service Life [yrs] & Data Source \\
\hline \hline Solar thermal & 31 & NREL $(2016)$ \\
Solar PV & 33 & NREL (2016) \\
Microturbines & $9^{*}$ & Darrow et al. $(2015)$ \\
\hline
\end{tabular}

* 80,000 hours with overhaul

It can be seen in Table 6.7 that there will be residual value for both installed solar thermal and PV systems. The microturbine system however, will have to be replaced twice during the project life. The NPV of the replacement costs were considered in the analysis, and the residual value of the second replacement microturbine was determined using the linear depreciation model. This third microturbine is estimated to reach the end of its service life 27 years after the project start. For this reason a 25 year evaluation period instead of a 30 year was selected. 


\subsubsection{Sensitivity and Uncertainty of the Cost Estimates}

Given the computational overhead required to complete the optimizations of interest in this research, time and resources could not be allocated to a sensitivity analysis of the cost model. However, Bucking (2013) previously considered the sensitivity and uncertainty of a cost model developed to assess the NPV and capital paybacks of different options to design and build net-zero buildings, similar to the objectives and cost model in the current work. Using a Monte-Carlo approach to vary input variables, a generalized linear model regression approach was used to evaluate the sensitivity of cost variables.

Bucking (2013) developed a reference building using building codes and standards, and 180,000 samples from the EGHD. The reference building was then used to test the sensitivity of incremental NPV for different options to achieve net-zero. Ranked using p-values determined in the generalized linear model regression, the most influential variable was determined to be amortization rate. Other influential variable included period of the project $N$, and feed-in tariff rates. They found that "uncertainty in the economic model is approximately $\pm \$ 500$ given a single years cash-flow" (Bucking, 2013). This was assumed to be an acceptable estimate of uncertainty for this work given the similarity between cost models.

In their conclusion they stated the variables with the most influence are typically well defined and may be estimated precisely in the late design stage. Further details of this sensitivity analysis are omitted here for clarity, and the interested reader is directed to Bucking (2013).

\subsubsection{Summary of Varied Parameters}

Chapters 3 and 4 previously described the retrofit options considered in this research. Table 6.8 provides a summary of the community retrofit options presented in those chapters, as well as the range of their valid values. Each of these options were discrete variables which were considered in the optimization calculations. 
Table 6.8: Independent variables varied by the optimization algorithm

\begin{tabular}{|c|c|c|c|}
\hline Parameter & $\begin{array}{l}\text { Max. } \\
\text { Value }\end{array}$ & $\begin{array}{l}\text { Min. } \\
\text { Value }\end{array}$ & $\begin{array}{l}\text { Step } \\
\text { Value }\end{array}$ \\
\hline Ceiling insulation level & 3 & 0 & 1 \\
\hline Wall insulation level & 3 & 0 & 1 \\
\hline Basement insulation level & 3 & 0 & 1 \\
\hline Window upgrade level & 3 & 0 & 1 \\
\hline TES volume, $V_{T E S}\left[\mathrm{~m}^{3}\right]$ & 500 & 5 & 5 \\
\hline No. of PV, $N_{P V}$ & variable & 0 & 1 \\
\hline No. of $\mathrm{ST}^{*}, N_{S T}$ & variable & 0 & 1 \\
\hline Collector bias, $C_{\text {coll,bias }}$ & 1 & 0 & 1 \\
\hline PV collector orientation bias, $C_{\text {orient,bias }, P V}$ & 2 & -1 & 1 \\
\hline ST collector orientation bias, $C_{\text {orient }, \text { bias }, S T}$ & 2 & -1 & 1 \\
\hline Microturbine unit & 3 & 0 & 1 \\
\hline Microturbine control strategy & 3 & 1 & 1 \\
\hline
\end{tabular}

* $S T=$ solar thermal

The maximum number of solar PV and thermal panels varied community-tocommunity, and was determined using the bin-packing algorithm described previously in Chapter 4. Microturbine units 1, 2, and 3 corresponded to the C30, C65, and C200 microturbines, respectively, described previously in Table 4.4. If 0 was selected for the unit number, no microturbine was included in the community retrofit solution. The control strategies for microturbines was described previously in Section 4.7.4.

\subsection{Definitions of Net-Zero Considered}

Rather than provide a fixed definition of net-zero, Sartori et al. (2012) reviewed the literature and presented a framework for formulating net-zero definitions in a 
consistent and comprehensive manner. The definitions of site and source net-zero used in this work were formulated using this framework. This framework identifies specific criteria that needs to be defined for net-zero balance calculations. Some of this criteria deals with measurement and verification of achieving net-zero, and is not relevant here. The criteria pertinent to the current research are defining:

1. Building system boundary;

2. Weighting system;

3. Net-zero balance;

4. and Temporal energy match characteristics.

The following subsections briefly describe that criteria and the decisions that were made for this work.

\subsubsection{Building System Boundary}

Setting the boundaries of the building system is a necessary first step for determining the net-zero balance. The physical boundary of the system may be one building or a cluster of buildings, and may also encapsulate large systems such as solar PV or wind farms. These large systems would then be considered as "on-site" generation. The balance boundary also identifies what energy end-uses are considered in the net-zero balance. Sartori et al. (2012) states that typical building end-uses included are space cooling and heating, ventilation, DHW, and AL loads. Depending on the objectives of a project the net-zero balance may also include other uses such as water consumption. For this research, only the energy carriers electricity and natural gas were included in the balance.

For this research, the boundary encompassed all dwellings in the community, and any community-scale energy systems. Not included in this boundary are community infrastructure like streetlights or traffic signals. All the typical end-uses of the dwellings cited by Sartori et al. (2012) are included in the energy balance. Transportation and electric vehicles were excluded from the analysis; however, this would be an interesting energy end-use to consider in future work. 


\subsubsection{Net-zero Balance}

The general expression of the net-zero balance used in this research, $Q_{\text {net-zero }}[\mathrm{GJ}]$, is provided in Equation 6.8:

$$
Q_{\text {net-zero }}=\int_{t=0}^{t_{m}}\left\{\sum_{i=1}^{n}\left[w_{\text {exp }, i}(t) \cdot \dot{Q}_{\text {exp }, i}(t)\right]-\sum_{i=1}^{n}\left[w_{i m p, i}(t) \cdot \dot{Q}_{i m p, i}(t)\right]\right\} d t
$$

where $t_{m}$ is the total duration of the net-zero balancing period [s] (typically a year), $w_{i m p, i}(t)$ is the dimensionless weighting factor applied to imported energy carrier $i$ at time $t, \dot{Q}_{i m p, i}(t)$ is the rate of delivery of energy carrier $i[\mathrm{GW}], w_{\text {exp }, i}(t)$ is the dimensionless weighting factor applied to exported energy carrier $i$ at time $t$, $\dot{Q}_{\text {exp }, i}(t)$ is the rate of export of energy carrier $i[\mathrm{GW}]$.

In addition to satisfying $Q_{\text {net-zero }}=0$ for achieving net-zero, Sartori et al. (2012) suggested other energy performance and efficiency requirements may be mandated

to achieve net-zero status. For example, Sartori et al. (2012) pointed to the direct requirement proposed by Boermans et al. (2011), where $50 \%$ to $90 \%$ of energy covering building loads must be from renewable sources. Such additional requirements may be used to promote certain net-zero design paths, or certain energy carriers. For this work no such requirement was implemented.

\subsubsection{Weighting System}

Equation 6.8 was used as the fundamental expression to determine the net-zero balance of retrofit communities. What differentiated the site and source net-zero balances was the values of the weighting factors, $w_{\text {exp }, i}$ and $w_{i m p, i}$ in Equation 6.8. These weighting factors are able to serve several functions. One is to normalize all the energy carriers in the balance to a common normalized metric, such as energy or GHG emissions. For this work annual energy was used as the common metric. Expressing electricity in a unit of energy is straightforward, but natural gas delivered to a building site is often expressed in $\mathrm{m}^{3}$ of gas. To convert delivered natural gas to 
a common energy unit, a HHV value of $38 \mathrm{MJ} / \mathrm{m}^{3}$, suggested by Union Gas (2017) and Johnson (2016), was used.

Weighting factors may also be used to account for energy consumption which occurs along the energy supply chain, such as conversion efficiencies, and T\&D losses. For site net-zero energy balances these primary energy consumption values are unity. For source net-zero energy balance calculations, primary energy factors (PEF) were assumed for both $w_{i m p, i}$ and $w_{\text {exp }, i}$. PEFs are used to calculate the additional energy consumed to deliver energy carriers to the building site. The derivation and values of the PEFs used in this research are provided in Section 6.2.4.

Sartori et al. (2012) also included a symmetry criterion for defining the weighting system used in net-zero balance calculations. A symmetric weighting scheme applies equal weight to an energy carrier regardless of whether the carrier is imported or exported across the balancing boundary. This is the scheme that was implemented for the current work; however, asymmetric weighting schemes may be developed to, for example, encourage more self consumption of generation and limited import or to incentivize a technology. For this research import and export energy carriers were weighted equally, i.e. $w_{i m p, i}$ equaled $w_{\text {exp }, i}$. The rationale for this is that exported renewable energy will offset import from conventional sources elsewhere in the infrastructure and "save" primary energy associated with using that conventional source.

The final sub-criterion described by Sartori et al. (2012) for weighting systems is time-dependent accounting. The electrical generation fuel mix varies temporally, as well as associated emissions and PEFs. Sartori et al. (2012) described three methods for approaching time-dependent accounting. Static accounting uses average factors over the net-zero balancing period and is the simplest method to use. Quasi-static accounting uses seasonal/monthly average values, and/or daily periods to account for base and peak loads. Dynamic accounting uses weighting factors determined hourly. According to Sartori et al. (2012) dynamic accounting considerably increases the complexity of net-zero balance calculations; however, studies using this approach have begun to appear in the literature, such as Bucking et al. (2016). For this research annual average weighting factors were used. 


\subsubsection{Primary energy factors}

The fundamental concept of primary energy is illustrated in Figures 6.2 and 6.3. In Figure 6.2, energy is expended to extract, process, and deliver the fuel to an electricity generator. Energy conversion losses are also incurred as the primary fuel, such as coal or natural gas, is converted to electricity to be delivered to the transmission grid.

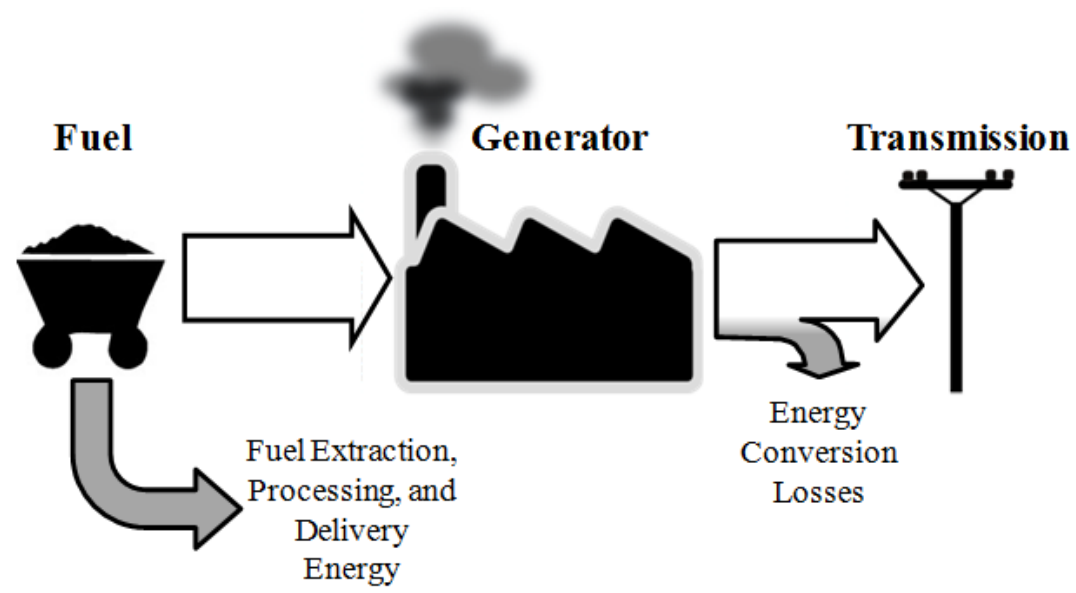

Figure 6.2: Simplified energy flow from fuel source to electricity transmission system

Figure 6.3 then describes the energy flow from the transmission system to final residential energy consumers. High voltage transmission systems are used to carry electricity over long distances. Local distribution systems then step down the voltage and deliver electricity to consumers (IESO, 2011).

A PEF is a scalar multiplier applied to the quantity of an energy carrier delivered to the net-zero balancing boundary. Typically greater than unity, the PEF adjusts the amount of energy delivered to include the energy expended to move the energy carrier to the final consumer. While conceptually simple, there is however no consensus on the method to determine PEFs. There is ambiguity regarding which losses illustrated in Figures 6.2 and 6.3 are included, how their values are determined, and 


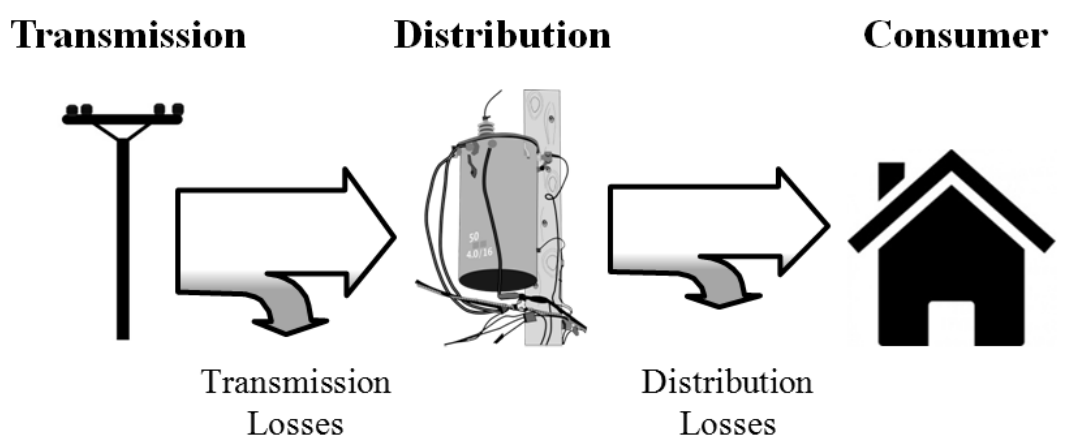

Figure 6.3: Simplified energy flow from transmission system to consumer

over which timescale the PEFs are calculated (i.e. hourly, monthly, annual).

Esser and Sensfuss (2016) identified and reviewed two principle PEF calculation methods: the Eurostat primary energy calculation method, and a method reflecting the total consumption of non-renewable sources. The general expression for determining the primary energy factor for electricity, $P E F_{\text {elec }}[\mathrm{kWh} / \mathrm{kWh}]$, provided by Esser and Sensfuss (2016) is:

$$
P E F_{\text {elec }}=\frac{P E F_{\text {fuel }}}{\eta_{\text {conv }}}
$$

where $P E F_{\text {fuel }}[\mathrm{kWh} / \mathrm{kWh}]$ is the primary energy factor of the fuel, and $\eta_{\text {conv }}$ is the conversion efficiency of the fuel. Depending on the calculation method, the derivation of $P E F_{\text {fuel }}$ and $\eta_{\text {conv }}$ will change. For the Eurostat method, Esser and Sensfuss (2016) stated that $P E F_{\text {fuel }}$ is unity for all fuel sources. This implies that the energy to extract, refine, and deliver the fuel to the generation plant is not considered in the $P E F_{\text {elec }}$ calculation.

The second calculation method considers the energy consumed and lost over the entire fuel chain. Thus $P E F_{\text {fuel }}$ is not necessarily unity for all fuels. $P E F_{\text {fuel }}$ of renewable sources is assumed to be zero to emphasize the positive impact of renewable technologies, but a life-cycle analysis is conducted to determine the upstream primary energy demand for supplying renewable energy generation and equipment (Esser and Sensfuss, 2016). Esser and Sensfuss (2016) reports a value of 1.1 for fossil fuels and 0.03 for wind power, for example. 
The other major difference between the principle PEF calculation methods is the treatment of combined heat and power (CHP) plants when determining $\eta_{\text {conv }}$. Esser and Sensfuss (2016) identified two different approaches: IEA and Finnish methods. The IEA method is the simplest approach, expressed in Equation 6.10:

$$
\eta_{\text {conv }, C H P}=\frac{\eta_{\text {conv }, C H P, \text { elec }}}{\eta_{\text {conv }, C H P, \text { elec }}+\eta_{\text {conv }, \text { CHP,heat }}}
$$

where $\eta_{c o n v, C H P, e l e c}$ is the conversion efficiency of the electricity process, and $\eta_{c o n v, C H P, \text { heat }}$ is the thermal conversion thermal efficiency.

The Finnish method instead uses reference systems to determine $\eta_{\text {conv }}$ :

$$
\eta_{c o n v}=\left(1-P E E_{r e f}\right) \cdot \frac{\eta_{c o n v, C H P, \text { elec }}}{\eta_{\text {conv }, \text { elec }, \text { ref }}}
$$

where

$$
P E E_{\text {ref }}=1-\frac{1}{\frac{\eta_{\text {conv }, \text { CHP,heat }}}{\eta_{\text {conv }, \text { heat }, \text { ref }}}+\frac{\eta_{\text {conv }, \text { CHP,elec }}}{\eta_{\text {conv }, \text { elec }, \text { ref }}}}
$$

and $\eta_{\text {conv,elec,ref }}$ and $\eta_{\text {conv,heat,ref }}$ are the conversion efficiencies of the electrical and thermal generation processes, respectively. Esser and Sensfuss (2016) suggested values of $40 \%$ and $90 \%$, respectively.

For this research, $P E F_{f u e l}$ was assumed to be unity for all fuel types. Esser and Sensfuss (2016) stated that this approach is less accurate; however, determining the primary energy to extract, refine, and deliver the fuel is non-trivial and complex. Data required are also likely to not be publicly available or exist. To determine $\eta_{\text {conv }}$ for CHP plants, the Finnish method was used. According to Esser and Sensfuss (2016), this approach provides better and more precise results, and yields a more balanced approach to considering the competitiveness of heat and power plants. The suggested reference system values from Esser and Sensfuss (2016) were assumed.

Stated previously in Section 6.2.3, a decision needs to be made on the timedependent accounting of weighting factors such as PEFs. For this research, annualaverage PEFs were developed. Esser and Sensfuss (2016) ranked different timescale approaches based on several criteria such as data availability, broad acceptance, and 
precision, and found the annual approach to be the most desirable currently. Several PEF sources only report annual values, such as Deru and Torcellini (2007), CEN 15603:2008, U.S. Environmental Protection Agency (2013), and Esser and Sensfuss (2016).

The following subsections describe the derivation of PEFs for the current research. PEFs were defined for both electricity and natural gas. To acknowledge the interprovincial differences in electricity generation fuel mixes, separate sets of PEFs were determined for Ontario and Québec.

\subsubsection{Electricity Generation Primary Energy Factors}

In order to determine the PEFs for electricity generation in Québec and Ontario, the annual fuel mixes needed to be determined. The annual fractions of generated electricity by fuel type for Ontario and Québec are provided in Table 6.9.

Table 6.9: 2016 shares of annual electricity generation by fuel type and province, data from IESO (2017b) and Hydro-Québec (2017)

\begin{tabular}{lcc}
\hline \multirow{2}{*}{ Fuel } & \multicolumn{2}{c}{ Share of total generation } \\
\cline { 2 - 3 } & Ontario & Québec \\
\hline \hline Nuclear & $60.9 \%$ & $0.0 \%$ \\
Hydroelectric & $23.7 \%$ & $94.9 \%$ \\
Thermal & $8.5 \%$ & $0.1 \%$ \\
Wind & $6.2 \%$ & $4.0 \%$ \\
Solar (PV) & $0.3 \%$ & $0.0 \%$ \\
Biofuel & $0.3 \%$ & $1.0 \%$ \\
\hline
\end{tabular}

For each fuel in Table 6.9, the conversion efficiencies needed to be determined. For wind and PV, the conversion efficiency is assumed to be $100 \%$. This assumption aligns with values reported by Deru and Torcellini (2007), CEN 15603:2008 (as cited in Bucking et al. (2016)), and Esser and Sensfuss (2016). There is debate on an appropriate value for hydroelectric however. Deru and Torcellini (2007) and Esser and 
Sensfuss (2016) report a value of $100 \%$ for North America and Europe, respectively. CEN 15603:2008 however, suggests a value of 71.4\%. For this research, hydroelectric is treated as a renewable energy source with an efficiency of $100 \%$.

The following subsections describe how conversion efficiencies were determined for nuclear and thermal generation plants. Shown in Table 6.9, the contribution of biofuel to total generation in both Ontario and Québec is relatively small. Thus the choice of PEF will have little impact on the PEF for delivered electrical energy. For the current work, the value of $22.1 \%$ suggested by Deru and Torcellini (2007) was assumed.

\section{Nuclear}

Esser and Sensfuss (2016) identified three methods for determining the conversion efficiency of nuclear-fuelled electricity generation: direct equivalent, physical energy content, and technical conversion efficiencies. In the direct equivalent approach, nuclear is assumed to be $100 \%$ efficient since no fossil fuels are burned for generation. Both the physical content and technical approaches, however, assume the same conversion efficiency, which Esser and Sensfuss (2016) report as 33\% typically. While not explicitly stated in the report, it is assumed that this value represents the nominal thermal efficiency of nuclear plants.

In Ontario, all nuclear generators use CANDU reactors (CNA, 2017). The thermal efficiency of CANDU reactors is approximately 31\% (Andseta et al., 1998). Therefore $31 \%$ was assumed for nuclear conversion efficiency in Ontario. There is currently no nuclear energy generation in Québec (Hydro-Québec, 2017).

\section{Thermal}

The majority of thermal-based electricity generation in Ontario is natural gasfired, with some plants using oil or biofuel as a secondary fuel. Gas-fired generation plants generally operate either a simple cycle, like the Brayton cycle described in Chapter 2, or a combined cycle where the thermal output of an open Brayton cycle is used to drive a second steam turbine cycle. Both of these cycles can potentially operate with (w/) or without (w/o) combined thermal output utilization. The conversion efficiencies and associated GHG emissions of these cycles operating in Ontario 
were determined using the life cycle inventory database from ecoinvent (2016), and are summarized in Table 6.10 .

Table 6.10: Ontario natural gas-fired generator performance and emissions characteristics, data from ecoinvent (2016)

\begin{tabular}{lcccc}
\hline Plant Type & $\eta_{\text {elec }}$ & $\eta_{\text {therm }}$ & $\mathbf{k g ~ C O} \mathbf{~} \mathbf{k W h}$ & $\mathbf{k g ~ C O} \mathbf{C O}_{\mathbf{e}} / \mathbf{k W h}_{\mathrm{e}}$ \\
\hline \hline Simple w/o CHP & $29.7 \%$ & N/A & 0.64727 & 0.781 \\
Simple w/ CHP & $36.5 \%$ & $10.0 \%$ & 0.52668 & 0.636 \\
Combined w/o CHP & $49.2 \%$ & N/A & 0.39073 & 0.447 \\
Combined w/ CHP* & $49.2 \%$ & $10.0 \%$ & 0.39073 & 0.447 \\
\hline
\end{tabular}

${ }^{*}$ Emissions and electrical efficiency approximated from combined $w / o$ CHP.

Thermal efficiency estimated from simple w/ CHP.

Electrical efficiency determined using LHV.

All four types of plants listed in Table 6.10 are currently used in Ontario, in addition to a gas-fired steam cycle plant operated by Ontario Power Generation (OPG, 2017). The contribution of total annual energy production, $Q_{\text {gen,elec,ann }}$ [TJ], from each plant type in 2016 in Ontario is provided in Table 6.11. The generation contribution and plant type of each individual gas-fired generator in Ontario is provided in Appendix K.

Table 6.11: 2016 shares of annual Ontario natural gas-fired generation by plant type, data from IESO (2017b)

\begin{tabular}{lcc}
\hline Plant Type & $Q_{\text {gen,elec,ann }}[\mathrm{TJ}]$ & Share of total $Q_{\text {gen,elec,ann }}$ \\
\hline \hline Simple w/o CHP & 145 & $0.3 \%$ \\
Simple w/ CHP & 1428 & $3.1 \%$ \\
Combined w/o CHP & 28589 & $61.2 \%$ \\
Combined w/ CHP & 16246 & $34.7 \%$ \\
Steam & 345 & $0.7 \%$ \\
\hline \hline Total & 46751 & $100.0 \%$ \\
\hline
\end{tabular}


Stated previously, the Finnish method was used to derive $\eta_{\text {conv }}$ for CHP plants. Using the data in Tables 6.10 and 6.11, and the Finnish method, a weighted annual average $\eta_{\text {conv }}$ for Ontario thermal plants was estimated to be $50.0 \%$. Each plant type conversion efficiency was weighted by share of total $Q_{\text {gen,elec,ann }}$.

In Québec, the only thermal generators used are the Bécancour simple-cycle natural gas-fired generation plant, and distributed diesel generators (Hydro-Québec, 2017). The Bécancour plant is rated at $411 \mathrm{MW}$, and is not a CHP system. Hydro Québec operates 23 diesel powered generators with a combined capacity of $130 \mathrm{MW}$ (Hydro-Québec, 2017). For this research, $\eta_{\text {conv }}$ for Québec gas-fired generation was assumed to be the same as simple cycle w/o CHP in Table 6.10.

\subsubsection{Electricity Transmission and Distribution Losses}

One of the benefits of distributed electricity generation compared to traditional central generation is the reduction of transmission and distribution (T\&D) losses, illustrated previously in Figure 6.3. For this research, the T\&D losses were considered in the calculation of electricity PEFs. Johnson et al. (2017) previously analyzed hourly Independent Electricity System Operator data (IESO, 2017b) from 2008 and 2013, and determined the average transmission efficiency in Ontario to be 97.4\%. Similar data was unfortunately unavailable for electrical distribution systems. In Ontario these are typically managed by local distribution companies, and a wide variety of distribution network topologies exist. To derive a nominal distribution efficiency for Ontario, Johnson et al. (2017) used an efficiency of $96.7 \%$ from an urban distribution modelling study from Navigant (2014). Using these values, a nominal annual T\&D efficiency of $94.2 \%$ was assumed for both Québec and Ontario in this work.

\subsubsection{Natural Gas}

Like electricity, energy is expended to move natural gas from its source to final consumer. The bulk of natural gas delivered to Québec and Ontario is extracted in Alberta and Saskatchewan (Statistics Canada, 2003). Natural gas is transported via pipeline which uses compressors along the line to maintain pressure. According 
to Mora and Ulieru (2005) natural gas-fired turbines are the most commonly used compressor in North America, and according to Wu et al. (2000) they consume between $3 \%$ and $5 \%$ of transported gas to operate.

It is non-trivial, however, to determine the number of compressor stations a volume of natural gas has travelled through to reach a customer. The number will vary based on location of the customer in Québec or Ontario. For this research, the transport efficiency of natural gas was determined using data from ecoinvent (2016). They reported values for transportation of natural gas from Alberta to Québec with an assumed transportation distance of $3800 \mathrm{~km}$. For each $1 \mathrm{~m}^{3}$ of natural gas delivered, 1.65 MJ of natural gas is burned. Using their reported heating value of $36.3 \mathrm{MJ} / \mathrm{m}^{3}$, an average transportation efficiency of $95.7 \%$ was determined and assumed for natural gas delivered to Québec and Ontario customers.

\subsubsection{Summary of Primary Energy Factors}

Table 6.12 summarizes the annual average PEFs determined for both Québec and Ontario, expressed as kWh of source energy per kWh of energy delivered. The electric PEFs were determined using the conversion efficiencies and T\&D losses described above. The natural gas PEF was determined from the transportation efficiency described above.

Table 6.12: Summary of derived annual average primary energy factors

\begin{tabular}{lcc}
\hline \multirow{2}{*}{$\begin{array}{l}\text { Energy } \\
\text { Carrier }\end{array}$} & \multicolumn{2}{c}{ Province } \\
\cline { 2 - 3 } & Ontario & Québec \\
\hline \hline Electricity & 2.60 & 1.10 \\
Natural gas & 1.04 & 1.04 \\
\hline
\end{tabular}




\subsection{Secondary Performance Metrics}

Historically, the selection and planning of new and alternative energy systems focused solely on cost minimization (Georgopoulou et al., 1997). Increasingly the environmental impacts of conventional power generation have entered the public consciousness, and net-zero energy targets have been one approach to addressing these concerns. For community net-zero projects, there are several potential stakeholders: the dwelling occupants, the municipality, as well as the local utility, each with a separate set of objectives. From the utility perspective for example, a net-zero building or community should operate in such a way as to have a neutral or minimal impact on the transmission and distribution infrastructure (Sartori et al., 2012).

Detailed analysis of utility interactions with embedded generation is often not practical in the design phase, since electrical distribution systems tend to be both complex and varied. Alternatively, simpler and more practical approaches for acknowledging interactions with the connected infrastructure have been described by Lund et al. (2011), Sartori et al. (2012), and Salom et al. (2014). These approaches may be broadly classified as load matching and grid interaction factors. Load matching indicators are used to evaluate the temporal match between on-site generation and load. Similarly, grid interaction indicators are used to assess the site import/export of energy with respect to the needs of the connected grid. Sartori et al. (2012) noted that these indicators have no inherent positive or negative value associated with them, and are mainly used to study differences between design solutions. In this research three different load factors, and two grid interaction factors, were considered and are described below.

In contrast to the utility, community occupant stakeholders are likely not as concerned with their impact on the connected infrastructure. Their priorities are typically related to thermal comfort and utility costs. For this research, occupant comfort was considered using the methodology proposed by Peeters et al. (2009), and is briefly described in Section 6.3.3. Occupants and the municipality are also likely concerned with the environment impacts of net-zero retrofit projects. In this 
research environmental impacts were characterized using $\mathrm{CO}_{2 \mathrm{e}}$ emissions. The emission factors and the methodology of their derivation are described in Section 6.3.4.

\subsubsection{Load Matching}

Some of the load matching factors identified by Salom et al. (2014) were the load and supply cover factors, and the loss of load probability. The load cover factor, $f_{l c}$, is defined here as:

$$
f_{l c}=\frac{\int_{t=0}^{t_{m}} \min \left[Q_{\text {gen }}(t), Q_{\text {load }}(t)\right] d t}{\int_{t=0}^{t_{m}} Q_{\text {load }}(t) d t}
$$

where $Q_{g e n}(t)[\mathrm{kWh}]$ is the electric on-site community generation over time period $t$, and $Q_{\text {load }}(t)[\mathrm{kWh}]$ is the total aggregate community load over time period $t$, including the community energy system and its components. Both of these values are from the perspective of the community distribution system, taking into account energy conversion losses. In essence, $f_{l c}$ represents the ratio of on-site electrical demand met by on-site generation. Ideally this ratio is high, meaning the community is able to meet most of its demands.

The supply cover factor, $f_{s c}$, is similar:

$$
f_{s c}=\frac{\int_{t=0}^{t_{m}} \min \left[Q_{\text {gen }}(t), Q_{\text {load }}(t)\right] d t}{\int_{t=0}^{t_{m}} Q_{\text {gen }}(t) d t}
$$

This factor represents the ratio of on-site generation which is used to meet the on-site demand. $f_{l c}$ and $f_{s c}$ are often not equal for a given system. For example, a net-ZEC may have a $f_{l c}$ close to 1 indicating that all demand is met by on-site generation, but a $f_{s c}$ closer to 0.5 indicating that approximately half of on-site generation is exported. Such a result would suggest the implementation of on-site energy storage to better utilize generation on-site and reduce required generation system sizes.

The loss of load probability, $L O L P_{b}$, represents the fraction of time on-site generation is insufficient and energy must be imported from the grid. $L O L P_{b}$ may be calculated as: 


$$
L O L P_{b}=\frac{\int_{t=0}^{t_{m}} f_{L O L P}(t)}{t_{m}}
$$

where

$$
f_{L O L P}(t)=\left\{\begin{array}{lll}
0 & \text { if } & {\left[Q_{\text {exp }}(t)-Q_{\text {imp }}(t)\right] \geq 0} \\
1 & \text { if } & {\left[Q_{\text {exp }}(t)-Q_{\text {imp }}(t)\right]<0}
\end{array}\right.
$$

and $Q_{e x p}(t)$ and $Q_{i m p}(t)$ are the community electric energy export and import [kWh] over time period $t$, respectively, and

$$
\begin{aligned}
& Q_{\text {exp }}(t) \geq 0 \\
& Q_{\text {imp }}(t) \geq 0
\end{aligned}
$$

\subsubsection{Grid Interaction}

Salom et al. (2014) defined the generation multiple, GM, as:

$$
G M=\frac{\max \left[Q_{\text {gen }}(t)\right]}{\max \left[Q_{\text {load }}(t)\right]}
$$

$G M$ compares the rated size of the generation system to the maximum design demand of the community. A ratio of one would indicate that the on-site generation has the potential to meet the maximum community demands; however, given the variable nature of renewable energy technologies, maximum generation output may not coincide with maximum demand. For this reason it is important to consider GM alongside the other load and grid interaction factors.

The second grid interaction factor considered in this study is grid interaction index, $f_{\text {grid,i },}$, described by Sartori et al. (2012). It was expressed here as:

$$
f_{\text {grid }, i}=S t D e v\left[\frac{Q_{\text {export }}(t)-Q_{\text {import }}(t)}{\max \left|Q_{\text {export }}(t)-Q_{\text {import }}(t)\right|}\right]
$$

Sartori et al. (2012) stated that $f_{\text {grid, } i}$ represents the variability of the energy flow 
with the grid over the net-zero balancing period, normalized with the maximum net-flow of electricity. It terms of performance, a low value of $f_{\text {grid }, i}$ is desirable, indicating there are relatively small fluctuations in the magnitude of power flow with the grid.

\subsubsection{Occupant Comfort}

Peeters et al. (2009) noted that the majority of BPS tools such as TRNSYS and ESP-r use ISO 7730 to characterize thermal comfort in buildings. This approach is based on the predicted mean vote (PMV) and predicted percentage of dissatisfied (PPD) equations from Fanger (1970). Peeters et al. (2009) pointed out that Fanger's approach was developed in laboratory settings under steady-state conditions with participants wearing standard uniforms performing sedentary tasks. They argued that the underlying data used to develop the models do not reflect the typical conditions occupants experience in the residential environment. Peeters et al. (2009) stated that conditions and clothing levels can change rapidly in dwellings, and occupants are more likely to adapt to the environment compared to a commercial setting.

Using available residential comfort studies and data, Peeters et al. (2009) developed expressions for residential comfort for two different zones within residential dwellings: bedroom, and bathroom and others. To determine if an occupant is comfortable, a weighted average of ambient temperatures from the previous three days is used to determine the upper and lower bounds of the occupant operative temperature for PPD values greater than $10 \%$ and $20 \%$.

The approach proposed by Peeters et al. (2009) was used to characterize the thermal comfort of residential occupants in this work. Given the low geometric resolution of the dwelling models, all thermal zones were considered as "bathroom and other." The simplifed geometry of the models also made accurate estimates of the occupant operative temperatures impractical. Therefore operative temperatures were approximated using the zone drybulb temperature. ASHRAE (2004) stated that this was an acceptable assumption under four conditions: there is no radiant heating or cooling system in the space, the average wall and window U-factors are 
below a prescribed threshold, window SHGC coefficients are less than 0.48 , and there is no major heating equipment in the space. The dwellings considered here meet the first and last criteria, but the retrofit glazing described in Chapter 3 had SHGC values greater than 0.48. Nonetheless, given the lack of geometric data, drybulb temperature was assumed as an operative substitute temperature.

\subsubsection{Emissions}

Swan (2010) used the method developed by Farhat and Ugursal (2010) to determine GHG emissions in the residential building sector. Farhat and Ugursal (2010) used publicly available Canadian data and reports to derive monthly and annuallyaveraged emission intensity factors (EIF) for Canadian provinces. These EIF values are expressed in grams of $\mathrm{CO}_{2}$ equivalent $\left(\mathrm{CO}_{2 \mathrm{e}}\right)$ per $\mathrm{kWh}$ of electricity delivered to the building site. $\mathrm{CO}_{2 \mathrm{e}}$ is determined by comparing the global warming potential (GWP) of gases to $\mathrm{CO}_{2}$, and is calculated by:

$$
M_{\mathrm{CO}_{2 e}, \text { gas }}=M_{\text {gas }} \cdot G W P
$$

where $M_{\mathrm{CO}_{2 e} \text { gas }}$ [g] is the mass of $\mathrm{CO}_{2 \mathrm{e}}$, and $M_{\text {gas }}[\mathrm{g}]$ is the mass of the gas.

Farhat and Ugursal (2010) defined two types of EIF: average and marginal. The average EIF, $E I F_{A}$, is determined from the weighted average of all generators supplying to the electrical infrastructure. The marginal EIF, $E I F_{M}$, however, is determined from a weighted average of the generators which operate on the margins, i.e. flexible generators which are dispatched to meet peak loads. Farhat and Ugursal (2010) stated that any reductions in GHG emissions from on-site renewable energy generation would be reflected in reduced emissions from the marginal generation.

The values reported by Farhat and Ugursal (2010), however, were determined to be out of date. At publication, Farhat and Ugursal (2010) reported an installed coalfired generation capacity of $6420 \mathrm{MW}$ and wind providing $1 \%$ of annual generation in Ontario. As of 2016, however, all coal-fired plants in Ontario had been taken off-line, and wind generation accounted for $6.2 \%$ of total generation output (IESO, 2017b). Therefore, updated values for $E I F_{A}$ and $E I F_{M}$ were developed for Ontario 
and Québec using the 2016 data described previously in Section 6.2.4.1. For this work, only annual average values were determined to remain consistent with the annual average PEF values defined previously in Section 6.2.4.

To derive $E I F_{A}$ and $E I F_{M}$, it was assumed that hydroelectric and nuclear produced zero GHG emissions (Farhat and Ugursal, 2010). Wind and solar were also assumed to be zero emissions. Emissions from biofuel were also neglected. Farhat and Ugursal (2010) stated that "emissions from biogenic materials are considered as a complement of the natural carbon cycle. $\mathrm{CO}_{2 \mathrm{e}}$ emissions is emitted by the combustion of biogenic materials will return to the atmosphere where it was originally removed by photosynthesis." Therefore, only emissions from thermal generators is considered.

The EIF for four types of natural gas-fired generation plants were provided previously in Table 6.10, where $\mathrm{CO}_{2 \mathrm{e}}$ was calculated using the emissions data reported from ecoinvent (2016) and the on-line $\mathrm{CO}_{2 \mathrm{e}}$ calculator from EPA (2017). The weighted annual average EIFs for thermal generators were then estimated using the data reported previously in Tables 6.9 and 6.11. Marginal generation was assumed to only include thermal generators. The annual average EIFs for both provinces are summarized in Table 6.13.

Table 6.13: 2016 annual average EIF values for electricity generation

\begin{tabular}{lcccc}
\hline EIF & \multicolumn{2}{c}{ New values } & \multicolumn{2}{c}{ Farhat and Ugursal (2010) } \\
{$\left[\mathrm{g} \mathrm{CO}_{2 \mathrm{e}} / \mathrm{kWh}_{\mathrm{e}}\right]$} & Ontario & Québec & Ontario & Québec \\
\hline \hline$E I F_{A}$ & 38.8 & 0.8 & 199 & 7 \\
$E I F_{M}$ & 456 & 781 & 862 & 723 \\
\hline
\end{tabular}

It can be seen in Table 6.13 that the new $E I F_{A}$ values were determined to be lower compared to the values reported by Farhat and Ugursal (2010). This was expected given the changes in the energy mix and increases in wind generation in both provinces. The $E I F_{M}$ reduced for Ontario, which was expected given the removal of coal from the energy mix. The $E I F_{M}$ for Québec was found to be similar 
to the value reported by Farhat and Ugursal (2010).

To determine the GHG emissions related to electricity import to the community, the electricity delivered to the community was first corrected to represent T\&D losses. The corrected consumption value was then multiplied by $E I F_{A}$ to determine the associated GHG emissions. For on-site electricity generation export, the GHG emissions "saved" were determined by multiplying corrected electricity export energy by $E I F_{M}$. Therefore it is assumed that any exported on-site generation will reduce electricity generation on the margin.

The other source of GHG emissions considered in this work is on-site combustion of natural gas. For this work, the EIF value of $1902 \mathrm{~g} \mathrm{CO}_{2 \mathrm{e}} / \mathrm{m}^{3}$ was assumed. This is the default value used by CHREM (Swan, 2010). The conversion between energy and volume of natural gas was determined using the HHV and LHV values described previously in Section 4.7.2.

\subsection{A Note on Timestep and Simulation Period}

Both ESP-r and TRNSYS discretize building and energy systems in both time and space. Historically, BPS simulation timesteps were hourly. This was related to the timescale of available climate data which provided a boundary condition to BPS. Hourly simulations are often an appropriate trade-off between computational efficiency and accuracy, since buildings tend to be thermally massive with long response times. When considering energy systems, however, smaller simulation timesteps are more appropriate to capture the sub-hourly control actions which occur.

For this research, a simulation timestep of 5-minutes was used. This was the largest timescale of the DHW data used as a boundary condition, described previ-

ously in Chapter 5. Smaller timescales could have been feasible for this research; however, it is unclear if this would provide increased accuracy of the results. The climate data used in this work, also described in Chapter 5, were provided at the typical one-hour resolution, and values were interpolated to facilitate sub-hourly simulations. It is unlikely that further interpolation of the climate data would improve estimates. A 5-minute timestep was assumed to permit reasonable estimates of energy system 
performance and control actions, as well as an appropriate computational overhead.

For the period of simulation, typically one year is sufficient. This covers the performance of the building under all operating conditions. ESP-r initializes all system nodes to a temperature of $15^{\circ} \mathrm{C}$ by default. A "warm-up" period is typically used prior to results recording in ESP-r. In CHREM, the default start-up period is 4 days and the simulation period is one year. These defaults were maintained for the ESP-r simulations in this work. For the community-scale energy system simulations, however, a warm-up period of one-year was used with an additional year of simulation. This was done to allow the community TES system to achieve steady seasonal temperatures. TES node temperatures were initialized at $10{ }^{\circ} \mathrm{C}$.

\subsection{Final Remarks}

The feasibility and desirability of a retrofit solution depends upon the goals of the stakeholders. For this work, the popular energy target of net-zero was considered. The introduction of this thesis previously showed several formal definitions of netzero exist in the literature, and there continues to be a lack of consensus among policy makers. Section 6.2 provided two proposed formal recognized definitions of net-zero: site and source. Each was formulated following the definition framework proposed by Sartori et al. (2012).

The principle difference between site and source net-zero is the weighting factors applied to different energy carriers crossing the balancing boundary. Torcellini et al. (2006) stated that the differences in definitions can influence the final design of a net-zero project; however, the magnitude of influence is unclear. Both site and source net-zero definitions were used along with the simulation framework developed in this thesis to examine the influence of definition on cost-optimal solution. The results of these simulations are provided in the next chapter. The secondary performance metrics were also calculated for the cost-optimal solutions to assess the impact of the net-zero solutions on the connected infrastructure and the environment. 


\section{Chapter 7}

\section{Results and Discussion}

Preceding chapters described the data, assumptions, and methodologies used and developed to simulate the energy performance of existing and retrofitted residential buildings. These detailed building and energy system tools were cast into a simulation framework which utilized an optimization algorithm to search through solution spaces to determine the cost-optimal retrofit solutions for communities to achieve net-zero. To explore potential techno-economically feasible solutions for community net-zero retrofit in Canadian locations, three representative existing communities defined in Chapter 3 were used as case studies. These case studies also served to examine the influence of net-zero definition on design.

The base case current energy and emissions performance of these communities are first provided in Section 7.1. The first case study explores the feasibility and potential solutions for community net-zero retrofit projects that incorporate district heating (DH) systems, and the results are presented in Section 7.2. DH system configurations and energy generation systems considered were described in Section 4.2. The second case study presented in Section 7.3 considers the retrofit of an existing community which uses electricity for space heating and DHW preparation. The purpose of this study was to examine the potential performance of communities which consider only deep envelope retrofits and distributed PV generation opposed to a large-scale central system or DH retrofit. The final case study, also presented in Section 7.3, builds upon the results of the second, and includes the retrofit of 
GSHP space heating and heat pump hot water systems in the community dwellings to further reduce the on-site energy demand and achieve net-zero.

\subsection{Base Energy Consumption and GHG Emis- sions of the Communities}

Annual energy consumption results are expressed as demand intensities. These intensities were determined by normalizing annual energy consumption by heated floor area of the dwellings. The heated floor areas of the communities was provided in Table 3.16, and includes the floor area of the basement. Figure 7.1 plots the base case annual secondary energy consumption intensities of the communities, disaggregated by end-use and by fuel type. Annual natural gas energy consumption was determined assuming an $\mathrm{HHV}$ of $38 \mathrm{MJ} / \mathrm{m}^{3}$, mentioned in Section 6.2.3.

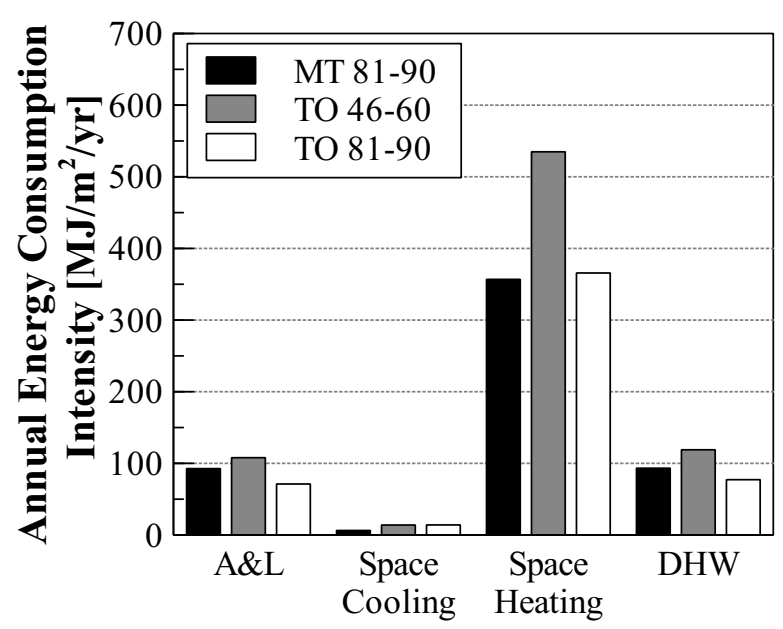

End-use

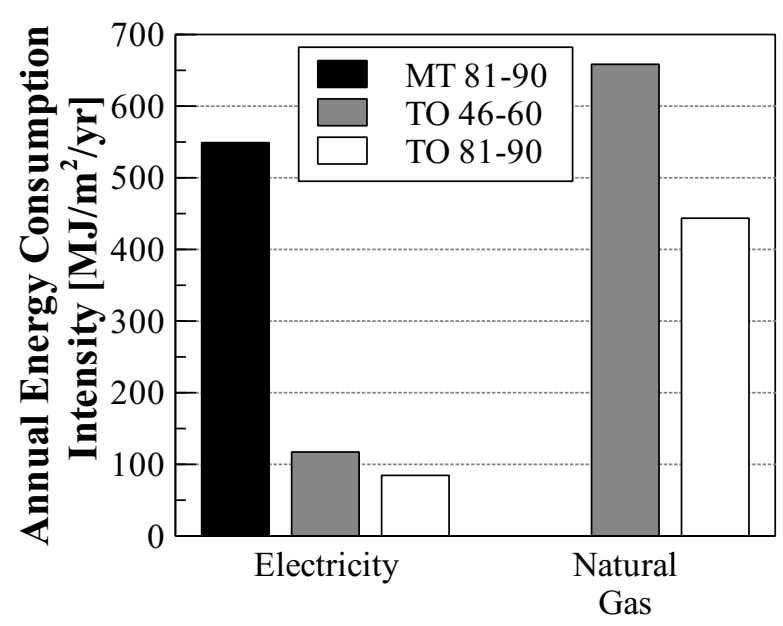

Fuel

(a) by end-use

(b) by fuel type

Figure 7.1: Base communities annual secondary energy consumption intensities

Figure 7.1(a) shows that end-use energy consumption intensities are similar between the Montréal (MT 81-90) community and the 1981-1990 vintage Toronto (TO 
81-90) community. The 1946-1960 vintage Toronto (TO 46-60) community, however, has higher demand intensities. Compared to the other communities, TO 46-60 has lower envelope thermal resistance values as shown in Table 3.16. The envelopes in this vintage also have looser airtightness values according to the CSDDRD. For the TO 46-60 community, the average $\Delta P_{50 P a}$ is $7.89 \mathrm{ACH}$. The airtightness of the TO 81-90 and MT 81-90 communities, however, has average $\Delta P_{50 \mathrm{~Pa}}$ values of $4.55 \mathrm{ACH}$ and 5.49 ACH, respectively. The average thermal efficiency of the space heating equipment for both Toronto communities is approximately $80 \%$.

Table 7.1 summarizes the annual energy demand and GHG emission intensities. The energy unit intensity (EUI) reported in the table is the sum of the intensities shown in Figure 7.1(a), and encompasses the efficiency of HVAC and DHW equipment. In order to evaluate the thermal performance of the dwelling envelopes the thermal energy demand intensity (TEDI) was used $\left[\mathrm{MJ} / \mathrm{m}^{2} / \mathrm{yr}\right]$. The TEDI is formally defined in Section 9.36.6.1(3) of the 2012 British Columbia Building Code, and represents the annual heating demand of the conditioned spaces in the building, per heated floor area. The casual gains from appliances, lighting, occupants, and ventilation/infiltration are considered when the TEDI is calculated.

Table 7.1: Community annual secondary energy use and emissions intensities

\begin{tabular}{lcccc}
\hline & EUI & TEDI & \multicolumn{2}{c}{ Emissions $\left[\mathrm{kg} \mathrm{CO}_{2 \mathrm{e}} / \mathrm{m}^{2} / \mathrm{yr}\right]$} \\
Community & {$\left[\mathrm{MJ} / \mathrm{m}^{2} / \mathrm{yr}\right]$} & {$\left[\mathrm{MJ} / \mathrm{m}^{2} / \mathrm{yr}\right]$} & Natural Gas & Electricity \\
\hline \hline MT 81-90 & 549 & 363 & 0 & 0.07 \\
TO 46-60 & 776 & 414 & 33.8 & 4.5 \\
TO 81-90 & 528 & 268 & 22.8 & 3.3 \\
\hline
\end{tabular}

To calculate the annual GHG emissions intensities in Table 7.1 the new EIF values provided in Table 6.13 were assumed. For on-site natural gas consumption, an EIF of $51.3 \mathrm{~g} \mathrm{CO}_{2 \mathrm{e}} / \mathrm{MJ}$ was assumed. This is the default value used in CHREM. Swan (2010) derived this value from Environment Canada and the Canadian National Energy Board (as cited in Swan (2010)). 


\subsection{District Heating Retrofit}

The first study explored the feasibility and potential solutions for community netzero retrofit projects which incorporated district heating (DH) systems. DH system configurations and energy generation systems considered were described in Section 4.2. Both Toronto, Ontario communities were examined in this study, and both site and source net-zero retrofit solutions were sought to investigate the impact on design, energy performance, and potential GHG emissions reductions.

The Montréal, Québec community described in Chapter 3 was not considered in this case study. That community utilized electricity for all residential energy enduses, which is typical for the residential building stock in Québec (OEE, 2017). The purpose of retrofitting a DH system was to analyze potential energy benefits and emissions reductions from using a large-scale natural gas-fired boiler and microturbine compared to distributed space heating and DHW systems. The distributed electrical space heating and DHW systems present in the Montréal community have $100 \%$ thermal efficiency, and moving to a natural gas fired DHW system would reduce efficiency through conversion and distribution losses. Additionally the electrical supply in Québec was shown in Section 6.2.4.1 to consume less primary energy compared to Ontario, with an annual average primary energy factor (PEF) of $1.10 \mathrm{kWh} / \mathrm{kWh}$ determined in this research compared to $2.60 \mathrm{kWh} / \mathrm{kWh}$ for Ontario. Both provinces were assumed to have an annual average natural gas PEF of $1.04 \mathrm{kWh} / \mathrm{kWh}$. Therefore, there is no oppourtunity for primary energy savings in Québec by switching to a natural gas DH from existing electrical space heating and DHW systems.

The results of this case study found that neither site nor source net-zero energy could be achieved with the retrofit options and design constraints assumed in this research. Therefore, this section provides the results of the "near" net-zero solutions determined by the simulation framework. Discussed previously in Section 6.1.1, the optimization algorithm used in the simulation framework used the net present value of the incremental life cycle cost, $L C C_{N P V}$ [2017 CAD], as an objective function to minimize. A dynamic penalty function was included in the objective function which added a penalty to solutions which did not achieve net-zero. This penalty 
scaled with both distance from net-zero and iteration. Since no retrofit solutions achieved net-zero, the penalty function was always non-zero. Thus the optimization algorithm objective switched from determining minimal $L C C_{N P V}$ to determining solutions which were closest to net-zero to minimize the penalty function.

None of these near net-zero solutions include microturbines. It was however of interest in this work to examine the potential energy and emissions reductions benefits of retrofitting a microturbine system. Therefore a retrofit solution evaluated by the optimization algorithm which included a microturbine system was selected for additional analysis.

\subsubsection{Toronto 1940-1960 Community DH Retrofit}

\subsubsection{Retrofit Options Applied}

The retrofit measures applied to achieve near site and source net-zero for the TO 46-60 community are provided in Table 7.2. The retrofit envelope RSI values given in Table 7.2 correspond to the maximum thermal resistance values considered in this study. The window retrofits used in both solutions are also the windows with the lowest U-value considered in this research. Ventilation of the retrofit dwellings was supplied by retrofit HRVs described previously in Section 3.2.6.

Both near net-zero retrofit solutions saturated the available roof area for solar collector mounting. For the near source net-zero solution, only PV collectors were included. The site net-zero solution included $511 \mathrm{~m}^{2}$ of gross solar thermal collector area $^{1}$. The maximum PV capacity that can be installed on the eligible roof surfaces is $452 \mathrm{~kW}$. The maximum solar thermal that may be installed is $2450 \mathrm{~m}^{2}$.

\footnotetext{
${ }^{1}$ Total aperture area is $343 \mathrm{~m}^{2}$.
} 
Table 7.2: Summary of near net-zero DH system retrofit measures applied to the Toronto 1946-1960 community

\begin{tabular}{lcc}
\hline & \multicolumn{2}{c}{ Near net-zero solution } \\
\cline { 2 - 3 } Retrofit measure & Site & Source \\
\hline \hline \multicolumn{3}{c}{ Envelope retrofits } \\
\hline Retrofit ceiling RSI & 14.09 & 14.09 \\
Retrofit main wall RSI & 5.46 & 5.46 \\
Retrofit basement RSI & 3.52 & 3.52 \\
Retrofit windows & triple-glazed & triple-glazed \\
\hline \multicolumn{3}{c}{ Commity energy system retrofits } \\
\hline Community PV $[\mathrm{kW}]^{*}$ & 361.2 & 435.5 \\
Community solar thermal $\left[\mathrm{m}^{2}\right]^{* *}$ & 511 & 0 \\
Roof area utilization $[\%]$ & 100 & 100 \\
TES $\left[\mathrm{m}^{3}\right]$ & 500 & 5 \\
\hline
\end{tabular}

* Based on manufacturer-rated output

** Based on gross collector area

Section 4.9 described the solar collector priority input. This input was used to instruct the roof packing algorithm of which type of collector, PV or solar thermal, was to be mounted first on the eligible roof area in the community. The collector bias inputs then instructed the roof packing algorithm on the orientations of eligible roof areas that the collectors were to be mounted on first. For the near site net-zero solution in Table 7.2, solar thermal collectors were mounted first and placed on south facing surfaces. PV was then mounted to all remaining available roof area. For the near source net-zero solution PV was mounted first on all eligible roof surfaces.

Stated previously, electricity imports and exports are weighted by a PEF of 2.60 $\mathrm{kWh} / \mathrm{kWh}$ for source net-zero balances, whereas natural gas imports are weighted with a PEF of $1.04 \mathrm{kWh} / \mathrm{kWh}$. Thus this definition of net-zero biases toward solutions which reduce electricity import and increase export, both of which can be achieved with on-site PV generation. For site net-zero, both electricity and natural 
gas are weighted by equal factors of one.

The retrofit DH system considered in this case study included a central TES system. The purpose of this system was to act as a buffer between excess solar and microturbine thermal generation and community thermal demands. The range of potential buffer storage volumes was assumed to be between 5 and $500 \mathrm{~m}^{3}$. It can be seen in Table 7.2 that the TES sizes for the near net-zero retrofit solutions were at the boundaries of the assumed range. For the near source net-zero solution no solar thermal and microturbine systems were included. The natural gas-fired backup boiler system is assumed to have sufficient capacity to meet peak DH system demands. Therefore, in the absence of other constraints such as time-of-use cost variations, there is no need for a TES system and the near source net-zero retrofit used the smallest TES volume permissible.

To characterize the solar thermal system of the near site net-zero solution in Table 7.2, the ratio of TES volume to collector area was analyzed. Using the gross solar thermal collector area and TES volume for the near site net-zero solution in Table 7.2, the TES volume to collector area ratio was determined to be $978 \mathrm{~L} / \mathrm{m}^{2}$. Braun et al. (1981) previously studied the sizing of solar thermal collector array areas and TES volumes and stated that systems with volume-to-collector ratios of $100 \mathrm{~L} / \mathrm{m}^{2}$ have sufficient capacity to dampen out the effects of daily climate variation. As this ratio increases the system begins to behave as a seasonal storage system, storing summer solar gains for use during the winter when demands are high and solar availability is low. The relatively large ratio of $978 \mathrm{~L} / \mathrm{m}^{2}$ in Table 7.2 suggests that solar thermal with large and seasonal scale TES systems have greater potential to reduce energy and achieve net-zero compared to smaller-scale TES systems.

\subsubsection{Annual Energy, Emissions, and Economic Performance}

Table 7.3 summarizes the annual metered energy, and economic performance of the retrofit near net-zero solutions for the TO 46-60 community. Energy consumption was normalized with respect to the heated floor area reported previously in Table 3.16. For each retrofit scenario, the net-zero energy balance was calculated using 
Equation 6.8 provided in Section 6.2.2. Each energy carrier considered in the net-zero energy balance of Equation 6.8 was multiplied by weighting factors corresponding to the type of net-zero balance calculated, discussed previously.

The highlighted annual energy balance values in Table 7.3 indicates the type of net-zero energy balance sought in the optimization. It can be seen in Table 7.3 that both site and source net-zero balances are less than zero for each retrofit solution, indicating additional energy exports or conservation measures are required to achieve net-zero. 
Table 7.3: Summary of the annual energy and economic performance of the near net-zero DH system retrofit applied to the Toronto 1946-1960 community

\begin{tabular}{|c|c|c|c|}
\hline & \multirow[b]{2}{*}{ Base case } & \multicolumn{2}{|c|}{ Near net-zero solution } \\
\hline & & Site & Source \\
\hline \multicolumn{4}{|c|}{ Metered site annual energy import $\left[\mathrm{MJ} / \mathrm{m}^{2} / \mathrm{yr}\right]$} \\
\hline Electricity & 117 & 62 & 59 \\
\hline Natural gas & 658 & 189 & 258 \\
\hline Total & 775 & 251 & 317 \\
\hline \multicolumn{4}{|c|}{ Annual energy import reductions } \\
\hline Electricity & & $47 \%$ & $49 \%$ \\
\hline Natural gas & & $71 \%$ & $61 \%$ \\
\hline Total & & $68 \%$ & $59 \%$ \\
\hline \multicolumn{4}{|c|}{ Metered site annual energy export $\left[M J / m^{2} / y r\right]$} \\
\hline Electricity & 0 & 98 & 143 \\
\hline \multicolumn{4}{|c|}{ Annual space heating demand $\left[M J / m^{2} / y r\right]$} \\
\hline TEDI & 414 & 149 & 149 \\
\hline \multicolumn{4}{|c|}{ Annual net-zero energy balance $\left[M J / m^{2} / y r\right]$} \\
\hline Site & -775 & -153 & -174 \\
\hline Source & -989 & -103 & -50 \\
\hline \multicolumn{4}{|c|}{ Incremental net present values [thousands CAD 2017] } \\
\hline$L C C_{N P V}$ & $\mathrm{~N} / \mathrm{A}$ & $\$ 5840$ & $\$ 2780$ \\
\hline$N P V_{e}$ & $\$ 579$ & $\$ 1.12$ & $\$ 0.085$ \\
\hline$N P V_{N G}$ & $\$ 508$ & $\$ 149.0$ & $\$ 206$ \\
\hline
\end{tabular}

It can be seen in Table 7.3 that the near site and source net-zero retrofit solutions significantly reduce both annual metered electricity and natural gas energy consumption. Compared to the base case, the near site and source net-zero retrofit solutions reduce electrical energy consumption by $47 \%$ and $50 \%$, respectively. Annual natural 
gas consumption was reduced by $71 \%$ and $61 \%$, respectively. These energy reductions were realized through combined envelope retrofits and, as shown in Figures 7.2 and 7.3, consumption of on-site renewable energy generation. The efficacy of the envelope retrofits were characterized by reductions in TEDI values presented in Table 7.3. Both solutions used the maximum envelope retrofit measures which reduced the community TEDI by $64 \%$.

Since electricity was weighted 2.5 times higher than natural gas for the source netzero balance, it was desirable to import natural gas instead of electricity, and export electricity to capitalize on the relatively large weighting factor. This is evident in the differences in annual energy import between the near net-zero solutions reported in Table 7.3. The near source net-zero solution imported 37\% more natural gas per year compared to the near site net-zero solution, and exported $46 \%$ more electricity.

The cost model used in this research was described in Section 6.1.2. The objective function to be minimized by the optimization algorithm was the incremental net present value of the life-cycle cost $L C C_{N P V}$ of retrofit solutions. Incremental signifies that only costs expected to vary between solutions were considered in the calculation of $L C C_{N P V}$. This included fixed monthly and annual utility costs, and retrofits which are present in all retrofit solutions. This case study assumed every solution utilized a DH system, and therefore the capital and annual costs of a retrofit DH system were not included in the $L C C_{N P V}$. Thus $L C C_{N P V}$ could not be reported for the base case in Table 7.3.

Table 7.3 shows that the near source net-zero retrofit solution is able to get closer to its annual energy target with lower life-cycle costs compared to the near site net-zero solution. At an incremental $L C C_{N P V}$ of $\$ 5,840,000$ the near site netzero solution needs to either reduce energy consumption or increase export by 153 $\mathrm{MJ} / \mathrm{m}^{2} / \mathrm{yr}$. In contrast, with an incremental $L C C_{N P V}$ of $\$ 2,780,000$ the near source net-zero solution needs to reduce primary energy consumption or increase primary energy export by $50 \mathrm{MJ} / \mathrm{m}^{2} / \mathrm{yr}$. Since exported electricity has a higher weighting in source compared to site net-zero balances, the additional export capacity required to meet source net-zero is even less than what is required to meet site net-zero. These findings suggest that under energy weighting schemes which favour electricity, source 
net-zero may be a more economical energy target to achieve.

To compare the economic performance between the base case and retrofit solutions the net present values of the variable electrical and natural gas utility costs, $N P V_{e}$ and $N P V_{N G}$, respectively, were determined and presented in Table 7.3. Both retrofit solutions achieve significant reductions in utility costs. However since neither solution achieved net-zero, which net-zero definition yields lower utility costs cannot be concluded.

The annual flow of metered thermal and electrical energy in the near net-zero retrofit communities are illustrated using Sankey diagrams in Figures 7.2 and 7.3, respectively. The data in theses figures is also summarized in Table 7.4 and is used to analyze the performance of the retrofit community energy systems. 


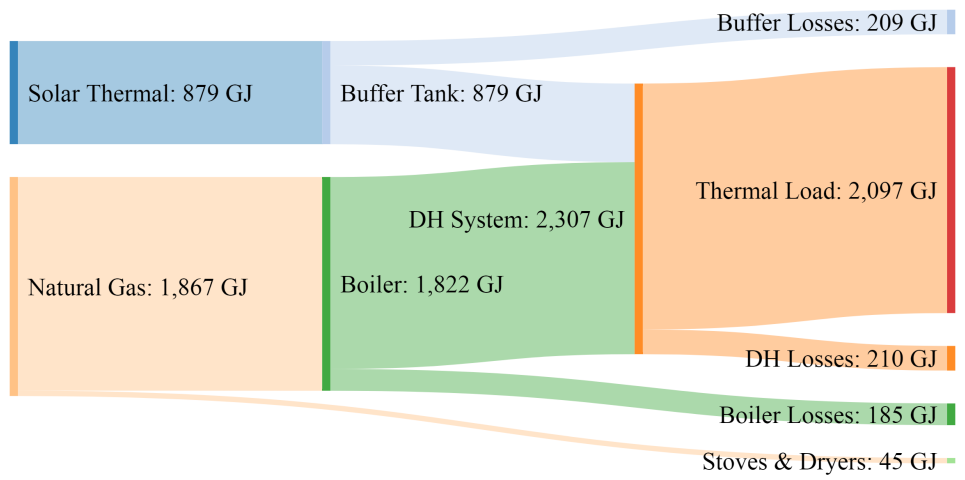

(a) site

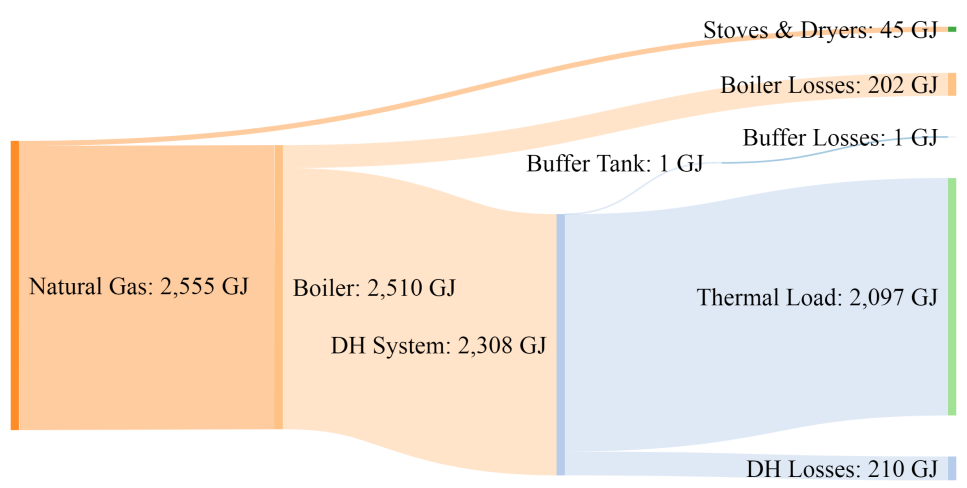

(b) source

Figure 7.2: Annual thermal energy balance of the near net-zero retrofits for the Toronto 1946-1960 community 


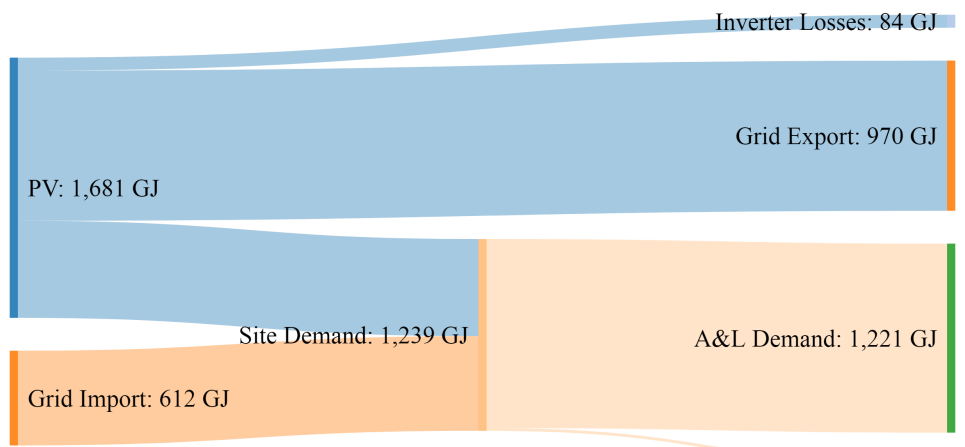

System Pumps: 18 GJ -

(a) site

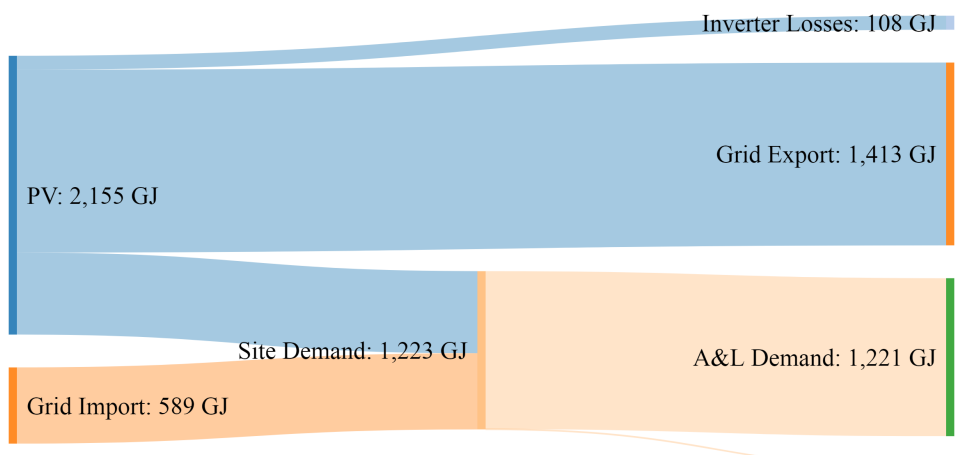

System Pumps: 2 GJ

(b) source

Figure 7.3: Annual electrical energy balance of the near net-zero retrofits for the Toronto 1946-1960 community

The gross PV generation in Table 7.4 refers to the energy delivered to the inverters from the solar array. Net generation then represents the energy delivered from the PV inverters. For both PV and solar thermal systems, annual array efficiency was determined, $\bar{\eta}_{P V}$ and $\bar{\eta}_{S T}$, respectively. These efficiencies were determined by dividing total annual array electrical generation or useful energy gain by total annual solar radiation incident on the array aperture area. The PV arrays in both retrofit solutions achieved an annual efficiency of 17\%. Duffie and Beckman (2013) stated that PV modules on the market have typical rated efficiencies of $15 \%$. The solar thermal array in the near site net-zero solution achieved an annual efficiency of $48 \%$. 
Table 7.4: Summary of the annual technology performance of the near net-zero DH system retrofit applied to the Toronto 1946-1960 community

\begin{tabular}{lcc}
\hline & \multicolumn{2}{c}{ Near } \\
\cline { 2 - 3 } & Site & Source \\
\hline \hline \multicolumn{2}{c}{ Annual PV array performance } \\
\hline Gross generation [GJ] & 1681 & 2155 \\
Inverter losses [GJ] & 84 & 108 \\
Net generation [GJ] & 1597 & 2047 \\
Grid Export [GJ] & 970 & 1413 \\
Site consumption [GJ] & 627 & 634 \\
$\bar{\eta}_{P V}[\%]$ & 17 & 17 \\
\hline \multicolumn{2}{c}{ Annual solar thermal array performance } \\
\hline Net generation [GJ] & 879 & N/A \\
$\bar{\eta}_{S T}[\%]$ & 48 & N/A \\
\hline \multicolumn{3}{c}{ Annual TES performance } \\
\hline Charge [GJ] & 879 & N/A \\
Discharge [GJ] & 670 & N/A \\
Losses [GJ] & 209 & N/A \\
\hline
\end{tabular}

Stated previously, electricity is weighted higher than natural gas in the source net-zero balance calculation used in this case study. Thus it is desirable to import natural gas instead of electricity to meet on-site demands, and to export additional on-site electrical generation. The near source net-zero solution in Table 7.4 has $28 \%$ more net PV generation and $46 \%$ more PV export to the grid. Despite the increase in PV capacity in the near source net-zero solution, annual electrical imports only decreased by $4 \%$, largely driven by reduced on-site electrical demands from the absence of community system solar thermal circulation pumps. Therefore the quantity of PV generation consumed on-site did not scale proportionally with increased on-site production. 
The energy consumption reductions realized in the retrofit communities were accompanied by significant emissions reductions. Compared to the base case, the near site net-zero solution reduced annual emissions from electricity and natural gas energy import by $68 \%$, as shown in Table 7.5. The near source net-zero solution emissions were reduced by $59 \%$. Both the base and retrofit communities emissions were calculated using the annual average emissions intensity factors $E I F_{A}$ derived in Section 6.3.4.

In addition to reducing consumption, renewable PV generation exported by the retrofit communities to the grid is expected to reduce emissions. Exported renewable generation supplied back to the grid will offset consumption of conventionally produced electricity to supply energy to other grid-connected customers. Swan (2010) reasoned that the marginal generators supplying the grid will be offset by incremental changes in grid demand and supply. Introduced in Section 6.3.4, marginal generation refers to generators which supply incremental loads which are added to the overall system demands over short periods of time (i.e. days, hours). In Canada these generators are typically fossil fuel or hydro (Farhat and Ugursal, 2010). Therefore to calculate the amount of displaced emissions by renewable PV generation export, the marginal annual average emissions intensity factors $E I F_{M}$ presented in Section 6.3.4 were used.

It can be seen in Table 7.5 that the emissions displaced by PV export exceed the emissions due to community electricity and natural gas imports for both near site and source solutions. It could then be argued that both solutions analyzed in this case study have achieved "emissions" net-zero, illustrated by the net annual emissions offset values in Table 7.5. The near site net-zero solution was able to offset 12.4 $\mathrm{kg} \mathrm{CO} 2 \mathrm{e} / \mathrm{m}^{2} / \mathrm{yr}$ while producing $12.1 \mathrm{~kg} \mathrm{CO} 2 \mathrm{e} / \mathrm{m}^{2} / \mathrm{yr}$ due to imports. Therefore the net offset of annual emissions is $0.3 \mathrm{~kg} \mathrm{CO}_{2 \mathrm{e}} / \mathrm{m}^{2} / \mathrm{yr}$. Although the source net-zero solution produced more annual emissions compared to the site net-zero solution, it achieved greater net annual emissions offsets, as shown in Table 7.5. 
Table 7.5: Summary of the annual emissions performance of the near net-zero DH system retrofit applied to the Toronto 1946-1960 community

\begin{tabular}{|c|c|c|c|}
\hline & \multirow[b]{2}{*}{ Base case } & \multicolumn{2}{|c|}{ Near net-zero solution } \\
\hline & & Site & Source \\
\hline \multicolumn{4}{|c|}{ Annual emissions due to energy import $\left[\mathrm{kg} \mathrm{CO}_{2 e} / \mathrm{m}^{2} / \mathrm{yr}\right]$} \\
\hline Electricity & 4.5 & 2.4 & 2.3 \\
\hline Natural gas & 33.8 & 9.7 & 13.2 \\
\hline Total & 38.3 & 12.1 & 15.5 \\
\hline \multicolumn{4}{|c|}{ Annual emissions reductions } \\
\hline Electricity & & $47 \%$ & $49 \%$ \\
\hline Natural gas & & $71 \%$ & $61 \%$ \\
\hline Total & & $68 \%$ & $59 \%$ \\
\hline \multicolumn{4}{|c|}{ Annual emissions offset due to $P V$ export $\left[\mathrm{kg} C \mathrm{CO}_{2 e} / \mathrm{m}^{2} / \mathrm{yr}\right]$} \\
\hline & 0 & 12.4 & 18.1 \\
\hline \multicolumn{4}{|c|}{ Net annual emissions offset $\left[\mathrm{kg} C \mathrm{CO}_{2 e} / \mathrm{m}^{2} / \mathrm{yr}\right]$} \\
\hline & -38.3 & 0.3 & 2.6 \\
\hline
\end{tabular}

Lastly Table 7.6 summarizes the load matching and grid interaction performance for the near net-zero retrofit solutions. Load matching performance indicators were described in Section 6.3.1, and included the supply cover factor $f_{s c}$ [\%], load cover factor $f_{l c}[\%]$, and loss of load probability $L O L P_{b}[\%]$. Recall that $f_{s c}$ represents the fraction of on-site generation energy supplied to on-site demand, and $f_{l c}$ represents the fraction of on-site energy demands met by on-site generation. $L O L P_{b}$ provides the fraction of time energy is imported from the grid. As shown in Figures 7.2 and 7.3 the majority of on-site energy generation in the retrofit communities is achieved using PV. Therefore $f_{s c}, f_{l c}$, and $L O L P_{b}$ were used characterize matching of electrical generation with load, identified with subscript $e$.

Thermal demands of the retrofit communities in this case study were met with either natural gas or solar thermal. To characterize the performance of the solar 
thermal system the annual solar fraction, $\Im[\%]$, was used. Described previously by Duffie and Beckman (2013), $\Im$ was calculated in this work as the ratio of energy delivered to the DH system from the buffer storage to the total energy demand of the DH system. $\Im$ was calculated using the values in Figure 7.2.

Table 7.6: Summary of the annual load matching and grid interaction performance of the near net-zero DH system retrofit applied to the Toronto 1946-1960 community

\begin{tabular}{|c|c|c|c|}
\hline & \multirow[b]{2}{*}{ Base case } & \multicolumn{2}{|c|}{ Near net-zero solution } \\
\hline & & Site & Source \\
\hline \multicolumn{4}{|c|}{ Annual PV system performance } \\
\hline Net generation $[\mathrm{GJ}]$ & 0 & 1597 & 2047 \\
\hline \multicolumn{4}{|c|}{ Load matching } \\
\hline$f_{s c, e}[\%]$ & $\mathrm{N} / \mathrm{A}$ & 39.3 & 31.0 \\
\hline$f_{l c, e}[\%]$ & 0 & 50.6 & 51.9 \\
\hline$L O L P_{b, e}[\%]$ & 100 & 68.5 & 66.0 \\
\hline$\Im[\%]$ & 0 & 38.1 & 0.0 \\
\hline \multicolumn{4}{|c|}{ Electrical grid interaction } \\
\hline$G M[-]$ & 0 & 2.78 & 3.68 \\
\hline$f_{\text {grid, }, i}[-]$ & 0.124 & 0.227 & 0.224 \\
\hline
\end{tabular}

Interaction of the retrofit community PV systems and the grid were characterized using the generation multiple GM [-] and grid interaction index $f_{\text {grid,i } i}[-]$ described previously in Section 6.3.2. GM represents the ratio of maximum PV generation during the year over the annual peak electrical demand. Since there is no gener-

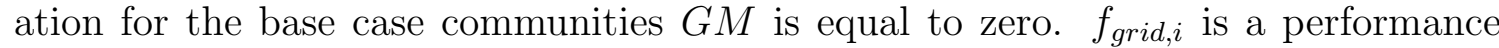
metric which can vary between 0 and 1 and is used to compare the impact different distributed generation systems have on the connected infrastructure. $f_{\text {grid,i }}$ values close to zero indicate steady power flow and are desirable from the perspective of grid operation and stability. Higher values of $f_{\text {grid,i }}$ indicate larger variations in the 
magnitude and direction of power flow on the electrical infrastructure.

The PV systems in both retrofit solutions have similar load matching performance. Stated above, decreases in electrical grid imports do not scale proportionally with increases in PV system capacity. Indicated by the load cover factors in Table 7.6, the site and source retrofit PV systems directly meet $50.6 \%$ and $51.9 \%$ of the on-site demand, respectively. The source net-zero PV system is $28 \%$ larger however. The additional generation in the near source net-zero solution was primarily supplied to the grid. Increased PV export yields a larger $G M$ value in the near source net-zero retrofit solution as well, with peak generation 3.68 time larger than peak site electrical demand. Interestingly both solutions have similar $f_{\text {grid,i }}$ values. This similarity is examined in Section 7.2.4.

\subsubsection{Toronto 1981-1990 Community DH Retrofit}

Like the case study in the previous section, the TO 81-90 community considered in this case study is unable to achieve either site or source net zero balances. Therefore this case study focused on the analysis of the near site and source net-zero solutions determined by the simulation framework. The findings in this case study are similar to those in the previous case study; however, there were some notable differences which are discussed below.

\subsubsection{Retrofit Options Applied}

The retrofit measures applied to achieve cost-optimal near site and source net-zero for the TO 81-90 community are provided in Table 7.8. Like the TO 46-60 community considered previously, the maximum envelope upgrades were applied to the community. Ventilation of the retrofit dwellings was supplied by retrofit HRVs described in Section 3.2.6. Additionally all eligible roof area was utilized for solar collector mounting. The TO 81-90 community dwellings were larger than the TO 46-60 community, with 52\% more heated floor area. This community also had more eligible roof area for collector mounting. The maximum PV capacity that could be installed in TO $81-90$ was $554 \mathrm{~kW}, 20 \%$ more than TO 46-60. A total of $2689 \mathrm{~m}^{2}$ of 
solar thermal collectors could be installed in TO 81-90, $10 \%$ more than TO 46-60. For both solutions in Table 7.8 solar thermal collectors were mounted first facing due south. PV was applied to all remaining eligible roof surfaces.

Table 7.7: Summary of near net-zero DH system retrofit measures applied to the Toronto 1981-1990 community

\begin{tabular}{|c|c|c|}
\hline \multirow[b]{2}{*}{ Retrofit measure } & \multicolumn{2}{|c|}{ Near net-zero solution } \\
\hline & Site & Source \\
\hline \multicolumn{3}{|c|}{ Envelope retrofits } \\
\hline Retrofit ceiling RSI & 14.09 & 14.09 \\
\hline Retrofit main wall RSI & 5.46 & 5.46 \\
\hline Retrofit basement RSI & 3.52 & 3.52 \\
\hline Retrofit windows & triple-glazed & triple-glazed \\
\hline \multicolumn{3}{|c|}{ Community energy system retrofits } \\
\hline Community PV $[\mathrm{kW}]^{*}$ & 502.5 & 530.6 \\
\hline Community solar thermal $\left[\mathrm{m}^{2}\right]^{* *}$ & 266 & 129 \\
\hline Roof area utilization [\%] & 100 & 100 \\
\hline TES $\left[\mathrm{m}^{3}\right]$ & 45 & 5 \\
\hline
\end{tabular}

* Based on manufacturer-rated output

** Based on gross collector area

Like the community analyzed in the previous section, the near source net-zero solution in Table 7.8 allocated more roof area to PV generation rather than solar thermal to increase electrical export. The near source net-zero solution in Table 7.8, however, includes a solar thermal system in addition to PV collectors. For source net-zero energy balances it is desirable to import natural gas and export electricity since electricity was weighted 2.5 times higher than natural gas under the current source net-zero calculation assumptions.

Another difference is that the TES volume for the near site net-zero solution in Table 7.8 is $91 \%$ smaller than the near site net-zero retrofit community in the 
previous section. The TES volume to collector area ratio is $169 \mathrm{~L} / \mathrm{m}^{2}$ if calculated using gross area, or $251 \mathrm{~L} / \mathrm{m}^{2}$ if assuming aperture area. Stated previously, beyond $100 \mathrm{~L} / \mathrm{m}^{2}$ the TES is typically able to dampen out daily climate variations. Thus like the system in the previous section, the near site net-zero TES system in Table 7.8 has capacity for weekly and potentially seasonal thermal storage.

One potential reason for these differences is the distribution of eligible roof area orientations. Figure 7.4 illustrates the distribution of eligible roof area by orientation for both Toronto case study communities. It can be seen that for TO 46-60 southfacing surfaces contain the largest portion of eligible roof area; however, for TO 81-90 east and west have the largest portions of eligible roof area. Although electricity is weighted 2.5 times higher, it was shown in Table 7.4 that the annual average efficiency of solar thermal collectors is significantly higher than PV. Similar efficiencies were found in this case study. The implication of efficiency differences on achieving source net-zero is discussed further in the following section.

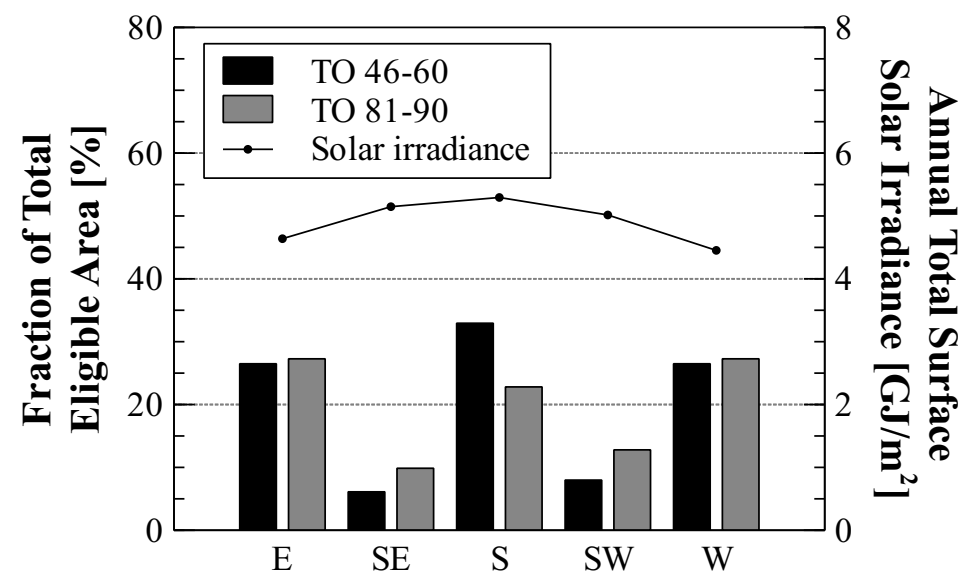

Surface Azimuth

Figure 7.4: Distribution of eligible roof surface area by orientation for the Toronto case study communities

Another potential reason for the differences between the near source net-zero solutions in this and the previous section is the conditioning of the optimization 
algorithm used in this framework. This is explored later in Section 7.3.1.1.

\subsubsection{Annual Energy, Emissions, and Economic Performance}

Table 7.8 summarizes the metered energy and emissions performance of the retrofit near net-zero solutions for the TO 81-90 community, normalized with respect to the heated floor area reported in Table 3.16. It can be seen in Table 7.8 that both retrofit solutions were unable to achieve either site or source net-zero balances; however, these solutions were closer to their net-zero targets compared to the solutions analyzed for the TO 46-60 community. This is partly due to higher reductions in site space heating demand achieved in this case study. The TEDI for both retrofit TO 81-90 communities is $134 \mathrm{MJ} / \mathrm{m}^{2} / \mathrm{yr}$, whereas the TEDI for the TO $46-60$ community is reduced to $149 \mathrm{MJ} / \mathrm{m}^{2} / \mathrm{yr}$ for both retrofits. 
Table 7.8: Summary of the annual energy and economic performance of the near net-zero DH system retrofit applied to the Toronto 1981-1990 community

\begin{tabular}{|c|c|c|c|}
\hline & \multirow[b]{2}{*}{ Base case } & \multicolumn{2}{|c|}{ Near net-zero solution } \\
\hline & & Site & Source \\
\hline \multicolumn{4}{|c|}{ Metered site annual energy import $\left[\mathrm{MJ} / \mathrm{m}^{2} / \mathrm{yr}\right]$} \\
\hline Electricity & 84.6 & 41.0 & 41.0 \\
\hline Natural gas & 444 & 184 & 199 \\
\hline Total & 529 & 225 & 240 \\
\hline \multicolumn{4}{|c|}{ Annual energy import reductions } \\
\hline Electricity & & $53 \%$ & $53 \%$ \\
\hline Natural gas & & $59 \%$ & $55 \%$ \\
\hline Total & & $57 \%$ & $55 \%$ \\
\hline \multicolumn{4}{|c|}{ Metered site annual energy export $\left[M J / m^{2} / y r\right]$} \\
\hline Electricity & 0 & 100 & 109 \\
\hline \multicolumn{4}{|c|}{ Annual space heating demand $\left[\mathrm{MJ} / \mathrm{m}^{2} / \mathrm{yr}\right]$} \\
\hline TEDI & 268 & 134 & 134 \\
\hline \multicolumn{4}{|c|}{ Annual net-zero energy balance $\left[\mathrm{MJ} / \mathrm{m}^{2} / \mathrm{yr}\right]$} \\
\hline Site & -529 & -124 & -131 \\
\hline Source & -682 & -38 & -30 \\
\hline \multicolumn{4}{|c|}{ Incremental net present values [thousands CAD 2017] } \\
\hline$L C C_{N P V}$ & $\mathrm{~N} / \mathrm{A}$ & $\$ 4040$ & $\$ 3690$ \\
\hline$N P V_{e}$ & $\$ 635$ & $\$ 0.096$ & $\$ 0$ \\
\hline$N P V_{N G}$ & $\$ 520$ & $\$ 223$ & $\$ 243$ \\
\hline
\end{tabular}

It can be seen in Table 7.8 that the near site and source net-zero retrofit solutions significantly reduce both annual metered electricity and natural gas energy consumption. Compared to the base case, both the near site and source net-zero retrofit solutions reduced electrical energy consumption by 53\%. Annual natural gas consumption was reduced by $59 \%$ and $55 \%$, respectively. The envelope retrofits 
reduce the TEDI by $50 \%$.

While the near source net-zero solution utilized more natural gas than the site net-zero solution, the retrofit solutions described in this section are much more similar to one another compared to the TO 46-60 near site and source net-zero solutions. Previously the TO 46-60 near source net-zero solution used 37\% more natural gas per year compared to the near site net-zero solution. Using the data in Table 7.8 the near source net-zero solution only used only $8 \%$ more natural gas than the site net-zero solution. While the results in the previous section showed that using a source net-zero approach may lead to solutions with high PV export and natural gas consumption, this is not necessarily true for all cases.

A common characteristic of the near net-zero retrofit solutions in this and the previous section is that all solutions first used all possible measures to reduce site energy demand. Envelope thermal resistances were retrofit to the highest levels considered in this study for every solution. Renewable generation was then deployed to meet on-site demands and offset infrastructure energy imports to move toward the net-zero target. Another common result between this and the previous case study is that the near source net-zero solutions get closer to their annual net-zero target at lower $L C C_{N P V}$ values compared to the near site net-zero solutions. This indicates that near source net-zero may be more economical compared to near site net-zero balances.

The annual flow of metered thermal and electrical energy in the near net-zero retrofit communities are illustrated using Sankey diagrams in Figures 7.5 and 7.6, respectively. The data in these figures are also summarized in Table 7.9 and is used to analyze the performance of the retrofit community energy systems. 
Buffer Losses: 24 GJ

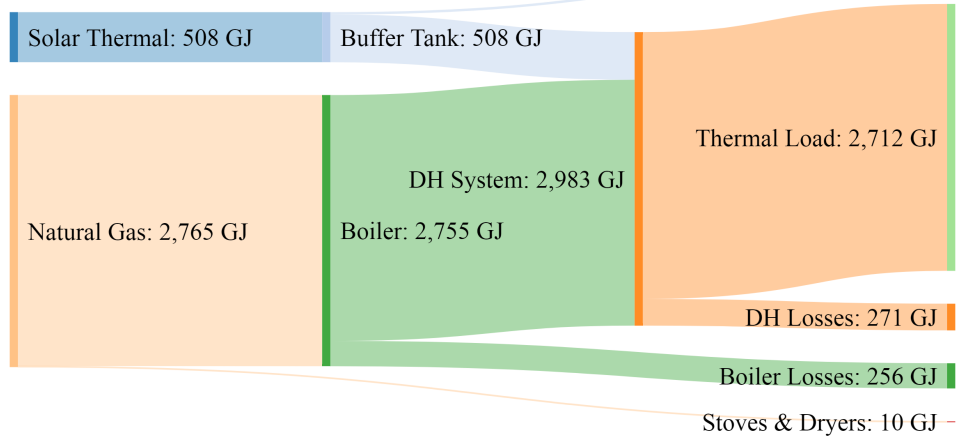

(a) site

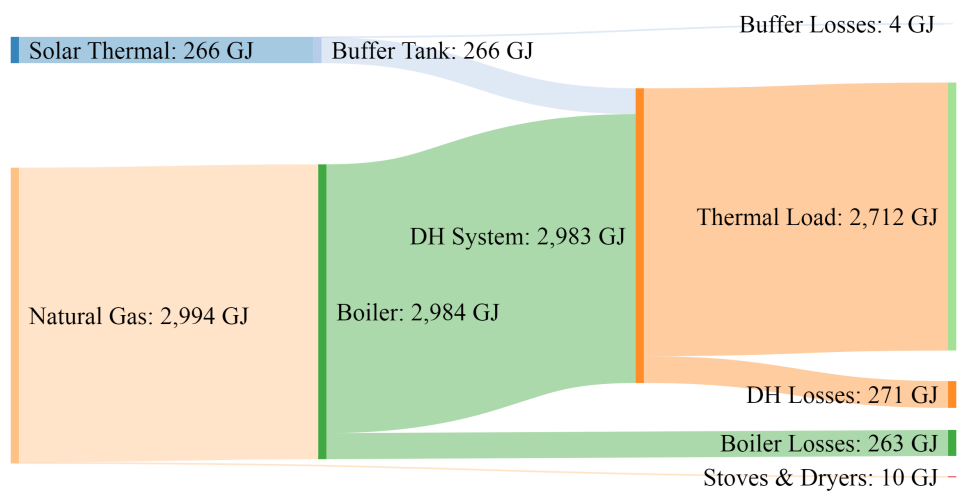

(b) source

Figure 7.5: Annual thermal energy balance of the near net-zero retrofits for the Toronto 1981-1990 community 


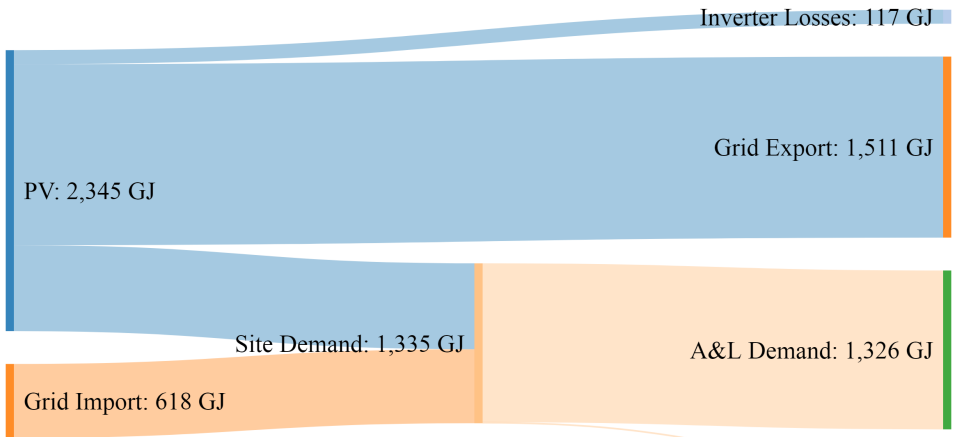

System Pumps: 9 GJ

(a) site

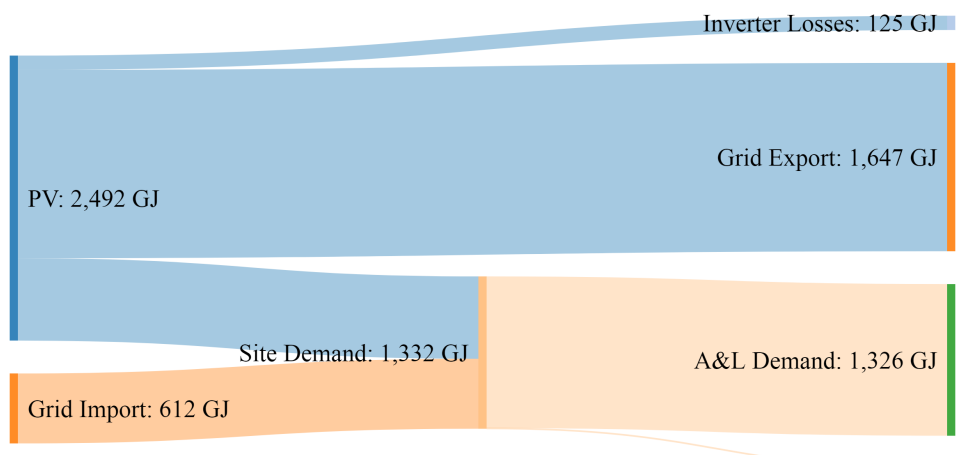

System Pumps: 6 GJ

(b) source

Figure 7.6: Annual electrical energy balance of the near net-zero retrofits for the Toronto 1981-1990 community

Like the retrofit PV systems considered in the previous section, the annual average efficiency of the PV system was determined to be $17 \%$ for both the near site and source net-zero solutions. The solar thermal systems in Table 7.9, however, were found to have higher annual performance. The retrofit near site net-zero TO 46-60 community was previously determined to achieve an annual system efficiency of $48 \%$. The near site and source net-zero solutions in Table 7.9 achieve annual efficiencies of $54 \%$ and $58 \%$, respectively.

Additionally, the TES systems were found to operate more efficiently in this case study. Characterizing annual TES efficiency as the ratio of discharged to charged 
energy, the TES system in the previous case study was found to have a value of $76 \%$. The near site and source net-zero solutions in Table 7.9 were found to have annual efficiencies of $95 \%$ and $98 \%$, respectively. The TES systems in the previous case study near site net-zero retrofit and the current near site net-zero retrofit had similar surface area to volume ratios of $1.8 \mathrm{~m}^{2} / \mathrm{m}^{3}$ and $1.2 \mathrm{~m}^{2} / \mathrm{m}^{3}$, respectively. The TES volume to collector ratios ${ }^{2}$ however, were $978 \mathrm{~L} / \mathrm{m}^{2}$ and $169 \mathrm{~L} / \mathrm{m}^{2}$. At lower capacity to collector ratios, the TES is charged/discharged more frequently, and the reduced dwell time of thermal energy in the TES reduces thermal losses to ambient.

Table 7.9: Summary of the annual technology performance of the near net-zero DH system retrofit applied to the Toronto 1981-1990 community

\begin{tabular}{lcc}
\hline & \multicolumn{2}{c}{ Near net-zero solution } \\
\cline { 2 - 3 } & Site & Source \\
\hline \hline \multicolumn{2}{c}{ Annual PV array performance } \\
\hline Gross generation [GJ] & 2345 & 2492 \\
Inverter losses [GJ] & 117 & 125 \\
Net generation [GJ] & 2228 & 2367 \\
Grid Export [GJ] & 1511 & 1647 \\
Site consumption [GJ] & 717 & 720 \\
$\bar{\eta}_{P V}[\%]$ & 17 & 17 \\
\hline \multicolumn{2}{c}{ Annual solar thermal array } & performance \\
\hline Net generation [GJ] & 508 & 266 \\
$\bar{\eta}_{S T}[\%]$ & 54 & 58 \\
\hline \multicolumn{2}{c}{ Annual TES performance } \\
\hline Charge [GJ] & 508 & 266 \\
Discharge [GJ] & 484 & 262 \\
Losses $[\mathrm{GJ}]$ & 24 & 4 \\
\hline
\end{tabular}

The annual emissions performance of the near net-zero solutions is provided in ${ }^{2}$ Calculated using gross area. 
Table 7.10. Like the retrofits in the previous case study, these near net-zero solutions achieve significant reductions in annual emissions. Shown in Table 7.10, annual emissions from electricity import are reduced by $52 \%$ for both solutions compared to the base case. The near site and source net-zero solutions reduced emissions from natural gas import by $58 \%$ and $55 \%$, respectively.

As discussed in the previous case study, export of renewable energy will offset consumption from conventional generators elsewhere on the grid. Therefore emissions offset from renewable export were calculated using $E I F_{M}$. Using this assumption it can be seen in Table 7.10 that both near net-zero solutions displace more GHG emissions per year than they produced from electricity and natural gas imports. Therefore these solutions could be considered to be emissions net-zero or net-positive.

Table 7.10: Summary of the annual emissions performance of the near net-zero DH system retrofit applied to the Toronto 1981-1990 community

\begin{tabular}{|c|c|c|c|}
\hline & \multirow[b]{2}{*}{ Base case } & \multicolumn{2}{|c|}{ Near net-zero solution } \\
\hline & & Site & Source \\
\hline \multicolumn{4}{|c|}{ Annual emissions due to energy import $\left[\mathrm{kg} \mathrm{CO}_{2 e} / \mathrm{m}^{2} / \mathrm{yr}\right]$} \\
\hline Electricity & 3.3 & 1.6 & 1.6 \\
\hline Natural gas & 22.8 & 9.4 & 10.2 \\
\hline Total & 26.1 & 11.0 & 11.8 \\
\hline \multicolumn{4}{|c|}{ Annual emissions reductions } \\
\hline Electricity & & $52 \%$ & $52 \%$ \\
\hline Natural gas & & $59 \%$ & $55 \%$ \\
\hline Total & & $58 \%$ & $55 \%$ \\
\hline \multicolumn{4}{|c|}{ Annual emissions offset due to $P V$ export $\left[\mathrm{kg} C O_{2 e} / \mathrm{m}^{2} / \mathrm{yr}\right]$} \\
\hline & 0 & 12.7 & 13.9 \\
\hline \multicolumn{4}{|c|}{ Net annual emissions offset $\left[\mathrm{kg} \mathrm{CO}_{2 e} / \mathrm{m}^{2} / \mathrm{yr}\right]$} \\
\hline & -26.1 & 1.7 & 2.1 \\
\hline
\end{tabular}

Table 7.11 summarizes the annual load matching and grid interaction performance 
of the retrofit solutions. Both solutions have similar site energy demands, which can be seen in Figures 7.5 and 7.6. They also have similar installed PV capacities. Thus, the annual electrical load matching performance is similar for both solutions. Interestingly they are similar to the electrical load matching performances reported in the previous case study shown in Table 7.6. Stated previously, since no electrical storage was considered in this research there is a limit to the portion of PV generation which may be used to directly cover on-site demands.

Table 7.11: Summary of the annual load matching and grid interaction performance of the near net-zero DH system retrofit applied to the Toronto 1981-1990 community

\begin{tabular}{|c|c|c|c|}
\hline & \multirow[b]{2}{*}{ Base case } & \multicolumn{2}{|c|}{ Near net-zero solution } \\
\hline & & Site & Source \\
\hline \multicolumn{4}{|c|}{ Annual PV system performance } \\
\hline Net generation $[\mathrm{GJ}]$ & 0 & 2228 & 2367 \\
\hline \multicolumn{4}{|c|}{ Load matching } \\
\hline$f_{s c, e}[\%]$ & $\mathrm{N} / \mathrm{A}$ & 32.2 & 30.4 \\
\hline$f_{l c, e}[\%]$ & 0 & 53.7 & 54.1 \\
\hline$L O L P_{b, e}[\%]$ & 100 & 65.8 & 65.3 \\
\hline$\Im[\%]$ & 0 & 17.0 & 8.9 \\
\hline \multicolumn{4}{|c|}{ Electrical grid interaction } \\
\hline$G M[-]$ & 0 & 3.00 & 3.21 \\
\hline$f_{\text {grid }, i}[-]$ & 0.127 & 0.220 & 0.220 \\
\hline
\end{tabular}

The solar fractions, $\Im$, in Table 7.11 were found to be lower than the near site net-zero solution in the previous case study. The space heating thermal demands of these retrofit communities, characterized by the TEDI, are $10 \%$ smaller than the TEDIs of the retrofit communities in the previous case study. The outputs of the near site and source net-zero solutions are however $42 \%$ and $70 \%$ smaller than the retrofit in the previous case study due to smaller installed solar thermal collector 
areas.

The grid interaction performance shown in Table 7.11 is similar to those reported in the previous case study. Both retrofit solutions in Table 7.11 utilize large PV arrays to meet and offset on-site demands. The capacities of the retrofit PV arrays are 3.00 to 3.21 times higher than the peak electrical demand of the communities, indicated by GM in Table 7.11. This is an undesirable operating condition, since the existing electrical distribution systems supplying these communities are 1) likely not designed for these power magnitudes, and 2) were not designed for reversed power

flow. The increase in $f_{\text {grid }, i}$ relative to the base case also indicates increased volatility in the demands on the electrical grid which may lead to voltage stability issues and premature wear on components such as load tap changers (Ari and Baghzouz, 2011).

\subsubsection{Discussion of Results}

The results of the two case studies were presented in this Sections 7.2.1 and 7.2.2. Both utilized the simulation framework developed in this work to retrofit a representative existing residential community to achieve site and source net-zero using deep envelope retrofits, roof-mounted solar PV, and a district heating system (DH) to provide space heating and DHW. This DH system is equipped with a back-up boiler with sufficient capacity to meet peak thermal demands, and optionally solar thermal and a natural gas-fired microturbine thermal generation. It was shown that neither site nor source net-zero energy could be achieved with the retrofit options considered. Therefore the "near" net-zero solutions determined by the simulation framework were analyzed.

A common result observed among these near net-zero solutions was that deep envelope retrofits were utilized to reduce the community thermal demands. PV was then installed on the majority of eligible roof surfaces to meet some on-site demands, and provide energy export to offset electrical and natural gas imports. Below is a discussion of some of the other findings of these case studies. 


\subsubsection{Influence of Net-Zero Definition}

One of the principle objectives of these case studies was to examine the influence of the net-zero definition on design and performance. A general observation made in the results of the case study was that assuming electrical and natural gas PEFs of $2.60 \mathrm{kWh} / \mathrm{kWh}$ and $1.04 \mathrm{kWh} / \mathrm{kWh}$, respectively, the near source net-zero balance solutions tended to favour higher natural gas imports to meet thermal demands, and utilize available roof area for PV generation to benefit from the higher PEF weighting applied to electrical exports. This generally leads to less potential emissions reductions for source net-zero solutions.

Another observation that can be made from the results of this case study is that although the net-zero balances were not obtained in either study, the source net-zero retrofits consistently get closer to their targets compared to the site netzero retrofits, and with lower incremental life-cycle costs. This indicates that for the weighting factors and PEFs assumed in this study source net-zero or near source netzero energy targets may be more economical to achieve compared to site. If exported renewable generation is assumed to offset marginal generation and their associated emissions, then all case studies achieve net-positive annual emission balances. This means more GHG emissions from marginal generation were offset then produced from community electricity and natural gas consumption.

All solutions in the case studies allocated a majority of eligible roof area for PV generation. It will be shown in Section 7.3.2 that in the absence of on-site storage there is a limit to the portion of PV generation which may directly meet site demands. Under both site and source net-zero balances, the grid is viewed as an ideal energy storage. Imported and exported electricity is equally weighted in the annual energy balances. Use of an on-site battery storage would be detrimental to the annual netzero balance, since some of the stored energy is lost in the battery charge/discharge rather than contributing to the annual balance. If viewed from the perspective of grid operation; however, the inclusion of electrical storage to buffer PV generation is critical. Shown in retrofit solutions of these case studies, peak PV generation is approximately three times higher than peak electrical demand. The volatility of the 
demand, assessed using $f_{\text {grid,i }}$, almost doubles from the typical fluctuations. The base

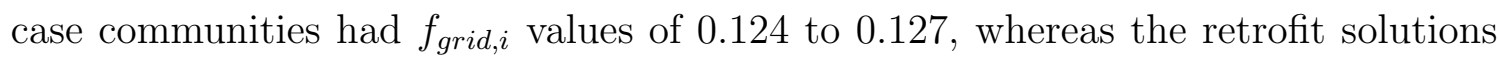
had $f_{\text {grid }, i}$ values of 0.220 to 0.227 .

\subsubsection{Comparison of PV and Solar Thermal Generation}

For the TO 46-60 near source net-zero solution all eligible roof area was allocated to PV generation, and the annual source net-zero balance was determined to be -50 $\mathrm{MJ} / \mathrm{m}^{2} / \mathrm{yr}$. For the near source net-zero TO 81-90 community, some available roof area was allocated to solar thermal collectors and the annual source net-zero balance was determined to be $-30 \mathrm{MJ} / \mathrm{m}^{2} / \mathrm{yr}$. It was shown in both case studies that solar thermal was able to achieve high annual efficiencies compared to the PV arrays. The solar thermal system in the TO $46-60$ case study achieved a $\bar{\eta}_{S T}$ of $48 \%$. For the TO 81-90 case study the solar thermal systems achieved $\bar{\eta}_{S T}$ values of $54 \%$ and $58 \%$. All PV arrays considered in these case studies achieved annual efficiencies, $\bar{\eta}_{P V}$, of $17 \%$.

The practical challenge that was encountered when using the solar thermal collectors considered in this research was the geometric differences between them and PV collectors. The gross-to-aperture area ratios of the solar thermal ETCs is 1.49, whereas for PV collectors this ratio is 1.12. Therefore to achieve the same installed aperture area the ETC collectors need $25 \%$ more gross area compared to PV.

The impact these differences in efficiencies and gross-to-aperture ratios have on source net-zero performance was examined using Figure 7.7. $Q_{\text {sol,ann }}[\mathrm{MJ}]$ is the total annual solar energy incident over a discrete surface with gross area $A_{\text {gross }}\left[\mathrm{m}^{2}\right]$. For a PV collector with gross area $A_{\text {gross }}$ and gross-to-aperture ratio of $1.12,89 \%$ of $Q_{\text {sol,ann }}$ is incident on aperture area $A_{\text {aper }}\left[\mathrm{m}^{2}\right]$. Assuming $17 \%$ efficiency, energy output $Q_{\text {coll,ann }}[\mathrm{MJ}]$ is equal to $15 \%$ of $Q_{\text {sol,ann }}$. 


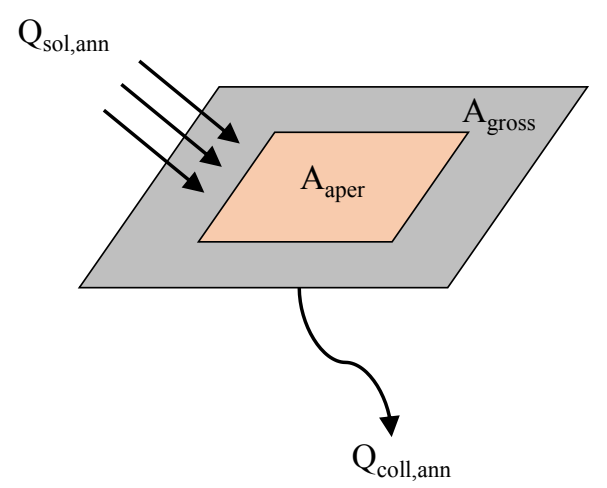

Figure 7.7: Utility of incident solar over gross collector area

Assuming a solar thermal collector with an equal $A_{\text {gross }}$ to the PV collector, and a gross-to-aperture ratio of $1.49,67 \%$ of $Q_{\text {sol,ann }}$ is incident on the aperture area. If $48 \%$ annual efficiency is assumed, then $Q_{\text {coll,ann }}$ is equal to $32 \%$ of $Q_{\text {sol,ann }}$. Therefore for a given gross area, solar thermal collectors better utilize incident radiation. This demonstrates the benefit of using solar thermal collectors for achieving site net-zero energy balances.

Recall that for the source net-zero calculation used in this research exported PV energy is weighted using PEF $2.6 \mathrm{kWh} / \mathrm{kWh}$. Therefore annual electrical export from the PV array with gross area $A_{\text {gross }}$ can provide 2.60 times $Q_{\text {coll,ann }}$, or $39 \%$ of $Q_{\text {sol,ann }}$, of annual energy in the source net-zero balance. Solar thermal generation is reflected in the source net-zero balance as a reduction of natural gas energy imports. With natural gas assumed to be weighted by $1.04 \mathrm{kWh} / \mathrm{kWh}$ for the source net-zero balance, solar thermal collector with gross area $A_{\text {gross }}$ provides $Q_{\text {sol,ann }}$ times 1.04, or $33 \%$ of $Q_{\text {sol,ann }}$ energy offset in the source net-zero balance.

Therefore a given gross area of solar thermal provides $6 \%$ less of an energy benefit in a source net-zero balance compared to PV installed with the same gross area. This difference in performance is relatively small, and may explain why both solar thermal and PV systems were included in the TO 81-90 near source net-zero solution in Section 7.2.2. Additionally, the TO 81-90 retrofit solar thermal systems achieved 
higher annual efficiencies of $54 \%$ and $58 \%$, whereas the retrofit system in the TO 46-60 community achieved 48\%. This may explain why solar thermal was included in the near source net-zero retrofit solution for TO 81-90, but not for TO 46-60.

This analysis demonstrates the significance of assumed PEF values on the feasibility of different technologies and retrofit solutions. As more efficient and renewable generation is integrated into the grid, the PEF will reduce and the relative

performance of solar thermal systems in source net-zero applications will improve compared to PV. This analysis also highlights the significance of considering the gross-to-aperture area ratios of solar technologies when making design decisions.

\subsubsection{Microturbine}

None of the near net-zero solutions analyzed in the previous section included a microturbine system. One objective of this research was to determine if there is any energy or environmental benefit to using a distributed microturbine system over conventional systems. It was also of interest to determine if a microturbine could be useful in net-zero applications by improving load covering and interaction of on-site generation with the connected infrastructure. This section describes a retrofit solution evaluated by the optimization algorithm for the TO 81-90 community which was closest to achieving source net-zero and included a microturbine. A source net-zero balance is considered since this definition tends to favour natural gas-fired systems, as shown in the previous sections.

A summary of the retrofit parameters is provided in Table 7.12. Like the near source net-zero solutions in the previous section, preference is given to PV over solar thermal for the available community roof area. The maximum envelope retrofits were also applied, and ventilation was provided by retrofit HRVs, which reduce the TEDI from to 268 to $134 \mathrm{MJ} / \mathrm{m}^{2}$ per year. This solution, and the 14 other solutions closest to source net-zero which include a microturbine, use the $30 \mathrm{~kW}_{\mathrm{e}}$ microturbine with electric load following control. The annual thermal and electrical Sankey diagrams for the microturbine retrofit solution are provided in Figure 7.8. 
Table 7.12: Summary of near net-zero microturbine system retrofit measures applied to the Toronto 1981-1990 community

\begin{tabular}{|c|c|}
\hline Retrofit measure & Retrofit Value \\
\hline \multicolumn{2}{|c|}{ Envelope retrofits } \\
\hline Retrofit ceiling RSI & 14.09 \\
\hline Retrofit main wall RSI & 5.46 \\
\hline Retrofit basement RSI & 3.52 \\
\hline Retrofit windows & triple-glazed \\
\hline \multicolumn{2}{|c|}{ Community energy system retrofits } \\
\hline Community PV $[\mathrm{kW}]^{*}$ & 553.8 \\
\hline Community solar thermal $\left[\mathrm{m}^{2}\right]^{* *}$ & 0 \\
\hline Roof area utilization [\%] & 100 \\
\hline TES $\left[\mathrm{m}^{3}\right]$ & 40 \\
\hline Microturbine $[\mathrm{kW}]^{* * *}$ & 30 \\
\hline Microturbine control & Electric load follow \\
\hline
\end{tabular}




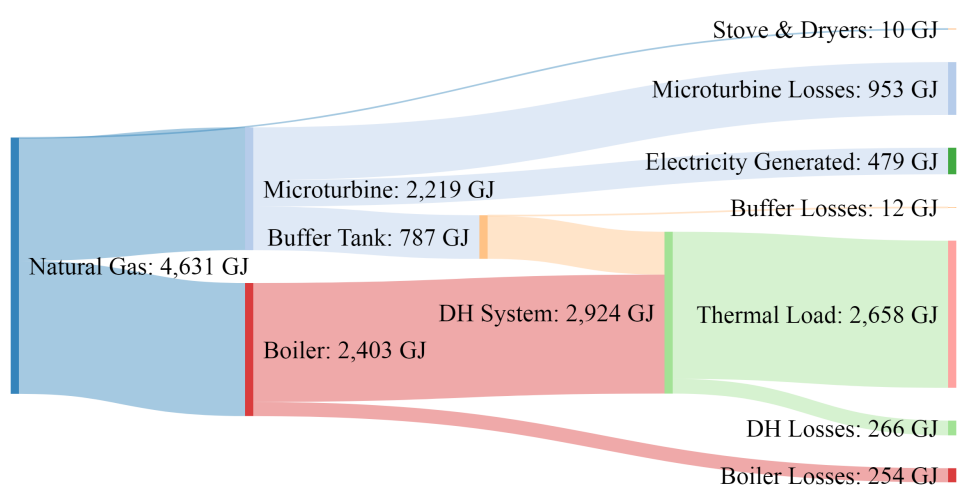

(a) thermal

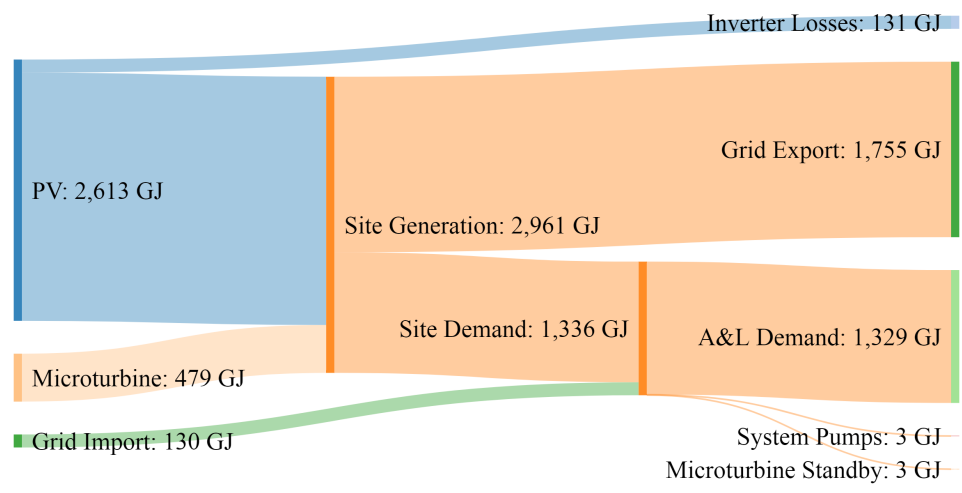

(b) electrical

Figure 7.8: Annual energy balance of the near source net-zero microturbine retrofit for the Toronto 1981-1990 community

Table 7.13 summarizes the annual energy and life cycle economic performance of the retrofit microturbine system. The annual source net-zero energy balance for this retrofit solution is $-40 \mathrm{MJ} / \mathrm{m}^{2} / \mathrm{yr}$. Recall that the near source net-zero solution in Section 7.2.2 achieved an annual balance of $-30 \mathrm{MJ} / \mathrm{m}^{2} / \mathrm{yr}$. Thus the microturbine retrofit solution does not significantly under-perform relative to the near source netzero solutions in the previous case study. 
Table 7.13: Summary of the annual energy and economic performance of the near net-zero microturbine system retrofit applied to the Toronto 1981-1990 community

\begin{tabular}{lcc}
\hline & Base case & Microturbine retrofit \\
\hline \hline \multicolumn{2}{c}{ Metered site } & annual energy import $\left[\mathrm{MJ} / \mathrm{m}^{2} / \mathrm{yr}\right]$ \\
\hline Electricity & 84.6 & 9.0 \\
Natural gas & 444 & 308 \\
Total & 529 & 317 \\
\hline \multicolumn{3}{c}{ Annual energy import reductions } \\
\hline Electricity & $89 \%$ \\
Natural gas & $31 \%$ \\
Total & $40 \%$ \\
\hline \multicolumn{2}{c}{ Metered site } & annual energy export $\left[\mathrm{MJ} / \mathrm{m}^{2} /\right.$ yr] \\
\hline Electricity & 0 & 117 \\
\hline \multicolumn{2}{c}{ Annual space heating demand $\left[\mathrm{MJ} / \mathrm{m}^{2} /\right.$ yr] } \\
\hline TEDI & 268 & 134 \\
\hline \multicolumn{2}{c}{ Annual net-zero energy balance $\left[\mathrm{MJ} / \mathrm{m}^{2} /\right.$ yr] } \\
\hline Site & -529 & -200 \\
Source & -682 & -40 \\
\hline \hline Incremental net & present values $[$ thousands CAD 2017] \\
\hline$L C C_{N P V}$ & $\mathrm{~N} / \mathrm{A}$ & $\$ 4818$ \\
$N P V_{e}$ & $\$ 635$ & $\$ 0$ \\
$N P V_{N G}$ & $\$ 520$ & $\$ 373$ \\
\hline
\end{tabular}

Table 7.14 summarizes the annual performance of the retrofit PV and microturbine system. The annual electrical efficiency of the retrofit microturbine, $\bar{\eta}_{M T, e}$, was calculated to be $24.0 \%^{3}$. This value is similar to the manufacturer-reported nominal

\footnotetext{
${ }^{3}$ Determined using the LHV of natural gas
} 
efficiency of 26\% (Capstone, 2006). In comparison, the Ontario central combinedcycle CHP generators described in Section 6.2.4.1 have an average annual electrical efficiency of $49 \%$. Accounting for average annual T\&D losses ${ }^{4}$, this efficiency reduces to $46 \%$. This difference in efficiency is expected, since smaller gas turbines tend to have lower efficiencies (Boyce, 2012). Net thermal generation of the microturbine reported in Table 7.14 was calculated as the total annual useful thermal energy supplied to the TES. This value is less than total annual thermal output since there is the potential for periods in which the microturbine is operating, but the TES is fully charged and the thermal output is rejected.

\footnotetext{
${ }^{4}$ Estimated to be $94.2 \%$, described in Section 6.2.4.2
} 
Table 7.14: Summary of the annual technology performance of the near net-zero microturbine system retrofit applied to the Toronto 1981-1990 community

\begin{tabular}{lc}
\hline \multicolumn{2}{c}{ Annual PV array performance } \\
\hline Gross generation [GJ] & 2613 \\
Inverter losses [GJ] & 131 \\
Net generation [GJ] & 2482 \\
$\bar{\eta}_{P V}[\%]$ & 17 \\
\hline \multicolumn{1}{c}{ Annual microturbine performance } \\
\hline Net elec. generation [GJ] & 479 \\
Net thermal generation [GJ] & 787 \\
$\bar{\eta}_{M T, e}[\%]$ & 24.0 \\
Natural gas consumption [GJ] & 2219 \\
\hline Annual site electrical generation performance \\
\hline Total generation [GJ] & 2961 \\
Grid export [GJ] & 1755 \\
Site consumption [GJ] & 1206 \\
\hline \multicolumn{2}{c}{ Annual TES performance } \\
\hline Charge [GJ] & 787 \\
Discharge [GJ] & 775 \\
Losses [GJ] & 12 \\
\hline
\end{tabular}

In order to fully assesses the benefits of the microturbine retrofits over conventional systems, thermal energy production was also considered. Shown in Section 6.2.4.1, Ontario combined-cycle CHP generators have a nominal thermal efficiency, $\eta_{\text {therm }}$, of approximately 10\%. The retrofit C30 microturbine considered here was estimated to have an average annual $\eta_{\text {therm }}$ of $36 \%$. The average annual CHP efficiency, $\eta_{\text {conv }}$, was also determined for both the microturbine and central combined-cycle CHP generators in Ontario using the Finish method described in Section 6.2.4, and were found to be $54 \%$ and $58 \%$, respectively. 
The annual emissions performance of this retrofit solution is summarized in Table 7.15. Compared to the base case, the microturbine retrofit solution reduces import electricity and natural gas emissions by $91 \%$ and $31 \%$, respectively. Overall emissions from energy import are reduced by $38 \%$. While not as high as the retrofit solutions in the previous case studies, these findings illustrate that significant GHG emissions reductions are achievable with envelope retrofits and microturbine CHP. Unlike the case studies analyzed previously, however, the microturbine retrofit solution does not achieve annual emissions net-zero, as shown in Table 7.15. The community produced $1.3 \mathrm{~kg} \mathrm{CO} \mathrm{CO}_{2 \mathrm{e}} / \mathrm{m}^{2} / \mathrm{yr}$ more than it offset with electrical exports.

Table 7.15: Summary of the annual emissions performance of the near net-zero microturbine system retrofit applied to the Toronto 1981-1990 community

\begin{tabular}{|c|c|c|}
\hline & Base case & Microturbine retrofit \\
\hline \multicolumn{3}{|c|}{ Annual emissions due to energy import $\left[\mathrm{kg} C \mathrm{CO}_{2 e} / \mathrm{m}^{2} / \mathrm{yr}\right]$} \\
\hline Electricity & 3.3 & 0.3 \\
\hline Natural gas & 22.8 & 15.8 \\
\hline Total & 26.1 & 16.1 \\
\hline \multicolumn{3}{|c|}{ Annual emissions reductions } \\
\hline Electricity & & $91 \%$ \\
\hline Natural gas & & $31 \%$ \\
\hline Total & & $38 \%$ \\
\hline \multicolumn{3}{|c|}{ Annual emissions offset due to electrical export $\left[\mathrm{kg} \mathrm{CO}_{2 e} / \mathrm{m}^{2} / \mathrm{yr}\right.$} \\
\hline & 0 & 14.8 \\
\hline \multicolumn{3}{|c|}{ Net annual emissions offset $\left[\mathrm{kg} \mathrm{CO}_{2 e} / \mathrm{m}^{2} / \mathrm{yr}\right]$} \\
\hline & -26.1 & -1.3 \\
\hline
\end{tabular}

Finally, the impact of this retrofit solution on the connected electrical infrastructure is considered. The reason microturbines were considered as an option for 
retrofit was to provide a dispatchable on-site electrical generation. Unlike the nondispatchable PV systems considered in the previous section, the microturbine is capable of modulating its output to match demand, and potentially improve the grid interactions of the retrofit net-zero community. The microturbine retrofit reduces annual electrical imports by 89\%. The previous TO $81-90$ retrofit solutions only utilized on-site PV generation and reduced annual electrical import by $53 \%$. The microturbine covers more of the on-site electrical demands since it is a dispatchable generator. The load matching and grid interaction annual performance of the retrofit microturbine system are summarized in Table 7.16.

Table 7.16: Summary of the annual load matching and grid interaction performance of the near net-zero microturbine system retrofit applied to the Toronto 19811990 community

\begin{tabular}{lcc}
\hline \multicolumn{4}{c}{ Base case } & Source \\
\hline \hline \multicolumn{4}{c}{ Annual electrical generation system } & performance \\
\hline Net PV generation $[\mathrm{GJ}]$ & 0 & 2482 \\
Net microturbine generation [GJ] & 0 & 479 \\
\hline \hline \multicolumn{4}{c}{ Load matching } \\
\hline$f_{\text {sc,e }}[\%]$ & $\mathrm{N} / \mathrm{A}$ & 40.7 \\
$f_{l c, e}[\%]$ & 0 & 90.3 \\
$L O L P_{b, e}[\%]$ & 100 & 50.0 \\
\hline \multicolumn{4}{c}{ Electrical grid interaction } \\
\hline$G M[-]$ & 0 \\
\hline$f_{\text {grid,i } i-]}[-127$ & 0.202 \\
\hline
\end{tabular}

The microturbine solution in this section uses an electric following control, and on-site generation is supplemented with roof-mounted PV. Under this configuration, the annual electric load cover factor $f_{l c, e}$ was determined to be $90.3 \%$. The TO 81-90 source net-zero retrofit in the previous case study was found to have a $f_{l c, e}$ of $54.1 \%$. 
The fraction of time the on-site generation system was not able to fully cover the onsite electrical demand, characterized by $L O L P_{b, e}$, also improved using microturbine generation. The previous TO 81-90 retrofit systems considered in the previous case study were unable to fully cover the on-site electrical demand $65.3 \%$ to $65.8 \%$ of the time. For this retrofit solution the $L O L P_{b, e}$ reduced to $50.0 \%$.

The grid interaction performance metrics are similar for solutions with and without a microturbine. For the PV-only electrical generation solutions in the previous retrofit solutions, the electrical generation multiple $G M$ ranges between 2.78 and 3.68. For the microturbine retrofit, $G M$ is equal to 3.38. Therefore this and the previous solutions have on-site generation capacities approximately three times larger than their site demands. This similarity is expected since all solutions have similarly rated PV capacities. The $f_{\text {grid,i,e }}$ value of 0.202 in Table 7.16 is similar to the PV-only solutions which have $f_{\text {grid,i,e }}$ values between 0.220 to 0.227 . Therefore this microturbine retrofit yields negligible improvements to electrical grid integrations. This similarity in grid interaction performance is examined in Figure 7.9 which plots the total annual mean daily community electrical demand and generation profiles for the TO 81-90 source net-zero retrofit solutions with retrofit microturbine. Also plotted in Figure 7.9 is the average PV generation profile. 


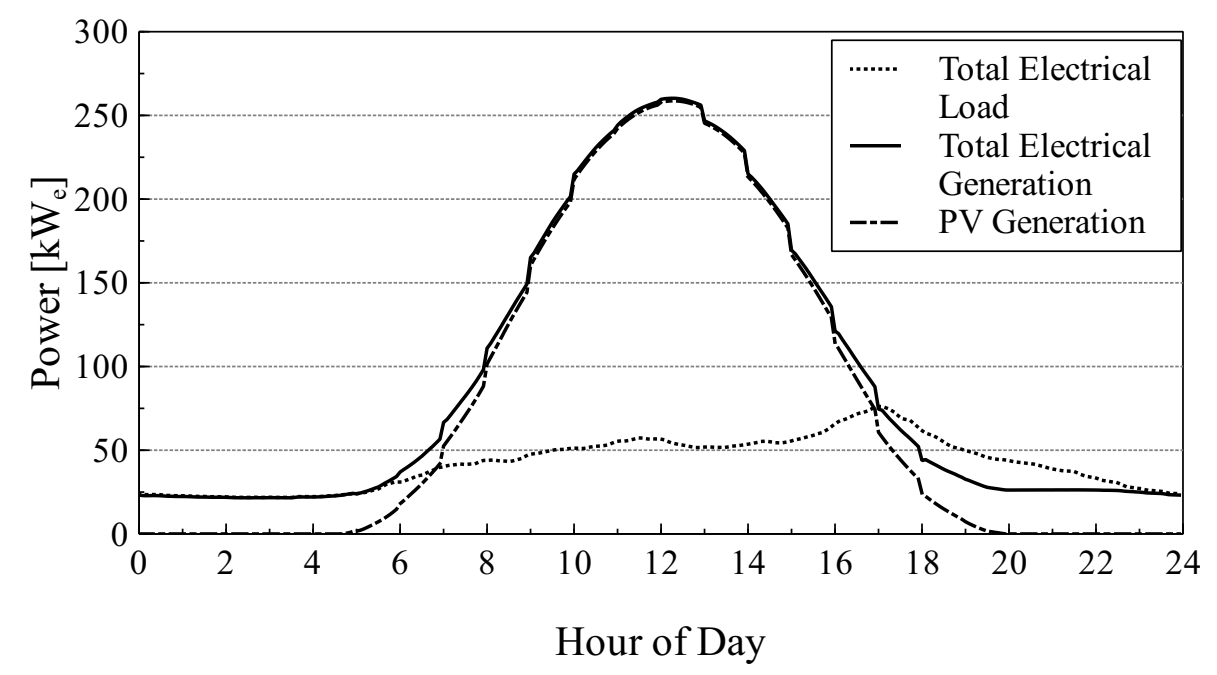

Figure 7.9: Annual mean daily electrical demand and on-site generation profiles for the 1981-1990 Toronto community

Figures 7.8(b) and 7.9 show that PV generation is the primary on-site electrical generation system for the retrofit solution. The $30 \mathrm{~kW}_{\mathrm{e}}$ microturbine is able to provide for the baseload demands of the community; however, as shown in Figure 7.9 PV production both greatly exceeds on-site demands and is mismatched with the on-site peak demand occurrence. Between $06 \mathrm{~h} 00$ and $17 \mathrm{~h} 00$ the retrofit community nominally operates as a grid-connected generator, and during evening peak switches to a net-consumer. Liu et al. (2008) stated that these reversing energy flows are often not anticipated in the design of conventional electrical distribution systems and can introduce voltage stability issues.

This simulation study illustrates potential GHG emission reductions and comparability of microturbines with conventional central natural gas-fired generation systems. There are, however, challenges to incorporating microturbines as a component of a source net-zero retrofit solution, and were not found to be a viable option for this case study. Microturbines are not as scalable as PV and solar thermal energy systems for this application. Collector modules can be incrementally added to meet the needs of the 50 dwellings assumed in this study. Only three microturbine units were considered here, and multiple units were not considered. Another challenge 
was that the microturbines require an import of natural gas to operate, which in turn require offsets via exports of on-site generation to meet the annual balance. If the natural gas and electrical PEF values of $1.04 \mathrm{kWh} / \mathrm{kWh}$ and $2.60 \mathrm{kWh} / \mathrm{kWh}$, respectively, are assumed, a microturbine with a nominal annual electrical efficiency of $44 \%$ could theoretically operate as a "net-zero" if all electricity is exported. There is therefore merit in future work investigating retrofit of larger and more efficient turbines for source net-zero communities.

\subsection{Electrical Only Systems}

The case studies analyzed in Section 7.2 used either natural gas or solar thermal to meet community space heating and DHW demands. This prevented on-site electrical generation from directly meeting the largest portions of community energy demands. It was shown in Section 7.2 that this can lead to net-zero solutions where installed PV systems are sized to provide excess generation to the grid to offset natural gas imports, and the peak power outputs of these arrays can be over three times the peak electrical demands of these communities. The existing radial distribution systems in Canada were not designed for these types of operating conditions, and issues with voltage stability and premature system component failure may occur.

The two case studies presented in this section consider communities with electrically-driven space heating and DHW to 1) determine if net-zero can be achieved in these communities, and 2) if more on-site PV production may be utilized on-site to improve grid interactions. The first case study uses the Montréal community introduced in Section 3.3. This community contains existing electric space heating and DHW systems in each dwelling. Only envelope and roof mounted PV retrofit measures are considered in this study. The community would use existing equipment to provide space heating and DHW.

The second case study re-visits the TO 81-90 community. Instead of using a DH system to supply space heating to the community, this case study explores solutions where all dwellings are retrofitted with individual GSHP space heating systems. A 
description of the GSHP systems were presented in Section 3.2.3. Switching the existing natural gas-fired DHW systems with hot water heat pump systems is included as a potential retrofit measure in the optimization. This is an electrically-driven system which was described in Section 3.2.4.

\subsubsection{Montréal Community}

Section 7.2 considered community retrofits to achieve both site and source net-zero annual energy balances. For the source net-zero balance definition used in this research, different static weighting factors were applied to different energy carriers. The source net-zero weighting factors were assumed to be equal to the annual average PEF values derived in Section 6.2.4. If only one type of energy carrier is moving across the balancing boundary of a community, however, the weighting factors being applied to the energy balance are equal and the source and site net-zero energy balances become identical. Therefore in this case study the simulation framework was only used to seek out site net-zero solutions for the MT 81-90 community, since only electricity is crossing the balancing boundary.

\subsubsection{Retrofit Options Applied}

Like the previous case studies, the simulation framework was unable to determine a retrofit net-zero solution with the retrofit measures considered in this research. Therefore the near net-zero solution determined by the simulation framework for the MT 81-90 community is analyzed in this section. Table 7.17 summarizes the retrofit measures applied for this solution. PV was applied to all eligible roof surfaces. 
Table 7.17: Summary of near net-zero system retrofit measures applied to the Montréal 1981-1990 community

\begin{tabular}{lc}
\hline Retrofit measure & Retrofit Value \\
\hline \hline \multicolumn{2}{c}{ Envelope retrofits } \\
\hline Retrofit ceiling RSI & 14.09 \\
Retrofit main wall RSI & none \\
Retrofit basement RSI & 3.52 \\
Retrofit windows & triple-glazed \\
\hline \multicolumn{2}{c}{ Community energy system retrofits } \\
\hline Community PV $[\mathrm{kW}]^{*}$ & 387.8 \\
\hline * Based on manufacturer-rated output \\
** Based on gross collector area \\
*** Maximum electrical output \\
\hline
\end{tabular}

\section{Conditioning of the Optimization Algorithm}

Maximum thermal envelope retrofits were applied in this solution except for main walls, which were not upgraded. These retrofits along with HRV ventilation systems reduced the community TEDI from 363 to $221 \mathrm{MJ} / \mathrm{m}^{2} / \mathrm{yr}$, or by $39 \%$. If the maximum wall retrofit had been applied to the community, the TEDI would have decreased by $52 \%$. The algorithm settling on this solution rather than a solution with maximum envelope retrofits may be related to the conditioning of the optimization algorithm. The objective of the optimization in this work was to minimize the net present value of retrofit incremental life cycle costs, $L C C_{N P V}$. Section 6.1.1.2 described the dynamic penalty function approach that was used to constrain cost-optimal solutions to those which achieve net-zero or net-positive annual energy balances. The penalty function, $F_{\text {penalty }}$, is calculated as a function of the magnitude of the annual net-zero energy balance deficit, and is multiplied by a scalar that is monotonically increasing with iteration number. The penalty function is added directly to the life cycle cost calculation to approximate the constrained optimization problem using an unconstrained algorithm. 
Since no net-zero solutions could be found for this case study, the value of the penalty function was always non-zero and increasing with each iteration. Therefore the relative weight of the life cycle costs in the objective function diminish as the optimization progresses, transitioning the objective from minimizing costs to minimizing the net-zero energy balance deficit. For the current research this was acceptable since the algorithm would then search for solutions which minimize the net-zero energy balance deficit.

This approach may lead to ill-conditioning of the algorithm; however, since earlier iterations are more affected by the value of $L C C_{N P V}$ in the objective function and initially move toward solutions which minimize $L C C_{N P V}$. As the iterations progress and no net-zero or net-positive solutions are found, the value of $F_{\text {penalty }}$ becomes more dominant in the objective function and steers the algorithm toward solutions where $F_{\text {penalty }}$ is minimum. To illustrate this, Table 7.18 provides the solutions with minimum $L C C_{N P V}$ for the first and last generations of the MT $81-90$ case study in Section 7.3.1.

Table 7.18: Comparison of first and last generation minimum solutions for the MT 81-90 net-zero community

\begin{tabular}{lcc}
\hline & \multicolumn{2}{c}{ Generation $i_{G}$} \\
\cline { 2 - 3 } & $\mathbf{1}$ & $\mathbf{1 1 0}$ \\
\hline \hline$L C C_{N P V}[2017 \mathrm{CAD}]$ & $2.75 \cdot 10^{6}$ & $2.92 \cdot 10^{6}$ \\
$Q_{\text {net-zero }}[\mathrm{GJ} / \mathrm{yr}]$ & $-2.31 \cdot 10^{3}$ & $-2.50 \cdot 10^{3}$ \\
$F_{\text {penalty }}[2017 \mathrm{CAD}]$ & $5.35 \cdot 10^{7}$ & $6.86 \cdot 10^{9}$ \\
\hline$L C C_{N P V, F}[2017 \mathrm{CAD}]$ & $5.63 \cdot 10^{7}$ & $6.86 \cdot 10^{9}$ \\
\hline
\end{tabular}

The penalized objective function, $L C C_{N P V, F}$, in Table 7.18 is the sum of $L C C_{N P V}$ and $F_{\text {penalty. }}$. Shown in Table 7.18 , the value of $F_{\text {penalty }}$ in the initial generation is one order of magnitude larger than $L C C_{N P V}$. As the optimization progresses and no solutions in the feasible space are determined, $F_{\text {penalty }}$ continues to grow. By the final generation for the MT 81-90 study, $F_{\text {penalty }}$ was three orders of magnitude larger 
than $L C C_{N P V}$.

Another potential source for ill-conditioning in the optimization algorithm is the inability to define relationships between input variables. In this work the mounting of solar collectors depended on three input variables:

1. Collector bias, $C_{\text {coll,bias }}$;

2. Number of collectors to mount;

3. Orientation bias, $C_{\text {orient,bias }}$

The maximum number of collectors that could be mounted for each solar collector type was defined as the value that would saturate the roof area if only that type of collector is mounted in the community. The actual amount of collectors mounted in the community is determined by $C_{\text {coll,bias }}$, which specifies which collector type is mounted first. Once all collectors of that type are mounted, the other collector type is added up to the amount specified if there is sufficient space left. Additionally requested collectors that cannot be mounted are not considered in the energy simulations; however, they are considered in the calculation of $L C C_{N P V}$ as a built-in penalty. For optimizations like those in Table 7.18, however, where the net-zero solutions cannot be located, the impact of $L C C_{N P V}$ and the cost penalty incurred by the unused collectors becomes negligible. Thus solutions which request 10 and 15 more solar collectors, and all other inputs identical, will evaluate to approximately the same $L C C_{N P V, F}$. This may potentially create several minima and introduce noise into the optimization algorithm.

Similarly the input $C_{\text {orient,bias }}$ becomes less significant to annual energy performance as the roof surfaces in the community become more saturated. At saturation $C_{\text {orient,bias }}$ has no impact on energy performance since collectors are mounted on all eligible surfaces and orientations. This also yields several minima and likely introduces noise to the optimization algorithm. 


\subsubsection{Annual Energy, Emissions, and Economic Performance}

Table 7.19 summarizes the annual energy and life cycle economic performance of the retrofit solution. The annual net-zero energy balance is $-246 \mathrm{MJ} / \mathrm{m}^{2} / \mathrm{yr}$. The envelope retrofits and PV installation reduces electrical consumption by $43 \%$. Additionally the net-present value of variable utility costs are reduced by $55 \%$.

Table 7.19: Summary of the annual energy and economic performance of near net-zero system retrofit applied to the Montréal 1981-1990 community

\begin{tabular}{|c|c|c|}
\hline & Base case & Retrofit \\
\hline \multicolumn{3}{|c|}{ Metered site annual energy import $\left[M J / m^{2} / y r\right]$} \\
\hline Electricity & 549 & 312 \\
\hline \multicolumn{3}{|c|}{ Annual energy import reductions } \\
\hline Electricity & & $43 \%$ \\
\hline \multicolumn{3}{|c|}{ Metered site annual energy export $\left[M J / m^{2} / y r\right]$} \\
\hline Electricity & 0 & 66 \\
\hline \multicolumn{3}{|c|}{ Annual space heating demand $\left[M J / m^{2} / y r\right]$} \\
\hline TEDI & 363 & 221 \\
\hline \multicolumn{3}{|c|}{ Annual net-zero energy balance $\left[\mathrm{MJ} / \mathrm{m}^{2} / \mathrm{yr}\right]$} \\
\hline Site & -549 & -246 \\
\hline \multicolumn{3}{|c|}{ Incremental net present values [thousands CAD 2017] } \\
\hline$L C C_{N P V}$ & $\mathrm{~N} / \mathrm{A}$ & $\$ 2921$ \\
\hline$N P V_{e}$ & $\$ 1339$ & $\$ 602$ \\
\hline
\end{tabular}

The annual electrical energy flow for the retrofit community is illustrated in the Sankey diagram in Figure 7.10. Gross annual PV generation is 1808 GJ with 90 GJ in annual inverter losses. Thus annual net PV generation is 1781 GJ. The PV system directly supplies 1047 GJ to the site electrical demands, and exports the remaining 671 GJ. The annual efficiency of the PV system, $\bar{\eta}_{P V}$, is $17.2 \%$, similar to the efficiencies determined in the previous case studies. 


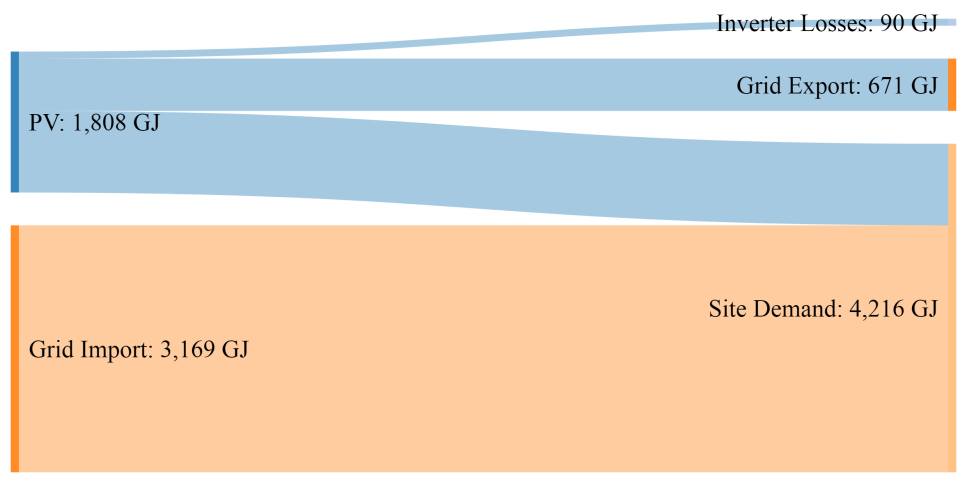

Figure 7.10: Annual energy balance of the near net-zero retrofit for the Montréal 1981-1990 community

Annual emissions performance of the retrofit MT 81-90 community is summarized in Table 7.20. Electricity generation in Québec is $98.9 \%$ hydro and wind, as shown in Section 6.2.4.1. Therefore both the base case and retrofit communities have negligible GHG emissions. The emissions offset in Table 7.20 was determined using EIF determined for Québec in Section 6.3.4. Marginal generation was assumed to be provided by a simple-cycle turbine and distributed diesel generators. Farhat and Ugursal (2010) noted that these marginal generators are typically only operated in January to meet peak heating demands. Since the EIF for the fossil fuel generators was assumed for marginal generation for the entire year, the emissions offsets reported in Table 7.20 are likely an over-estimation. Given Québec's energy mix, current buildings are near emissions net-zero. 
Table 7.20: Summary of the annual emissions performance of the near net-zero system retrofit applied to the Montréal 1981-1990 community

\begin{tabular}{|c|c|c|}
\hline & Base case & Net-zero retrofit \\
\hline \multicolumn{3}{|c|}{ Annual emissions due to energy import $\left[\mathrm{kg} \mathrm{CO} \mathrm{C}_{2 e} / \mathrm{m}^{2} / \mathrm{yr}\right]$} \\
\hline Electricity & 0.07 & 0.07 \\
\hline \multicolumn{3}{|c|}{ Annual emissions reductions } \\
\hline Electricity & & $0 \%$ \\
\hline \multicolumn{3}{|c|}{ Annual emissions offset due to electrical export $\left[\mathrm{kg} C O_{2 e} / \mathrm{m}^{2} / \mathrm{yr}\right]$} \\
\hline & 0 & 14.3 \\
\hline \multicolumn{3}{|c|}{ Net annual emissions offset $\left[\mathrm{kg} C \mathrm{O}_{2 e} / \mathrm{m}^{2} / \mathrm{yr}\right]$} \\
\hline & -26.1 & 14.2 \\
\hline
\end{tabular}

The annual load covering and grid interactions of the retrofit MT $81-90$ community are provided in Table 7.21. $f_{l c, e}$ and $f_{s c, e}$ are $24.8 \%$ and $60.9 \%$, respectively. $f_{l c, e}$ cannot be directly compared to the Toronto community retrofits presented in the previous section since the electrical loads are significantly different. The annual electrical demand of the Montréal community is over $200 \%$ larger than the Toronto communities considered previously. 
Table 7.21: Summary of the annual load matching and grid interaction performance of the near net-zero system retrofit applied to the Montréal 1981-1990 community

\begin{tabular}{lcc}
\hline \multicolumn{4}{c}{ Base case } & Source \\
\hline \hline \multicolumn{4}{c}{ Annual electrical generation } & system & performance \\
\hline Net PV generation $[\mathrm{GJ}]$ & 0 & 671 \\
\hline \hline \multicolumn{4}{c}{ Load matching } \\
\hline$f_{\text {sc,e }}[\%]$ & $\mathrm{N} / \mathrm{A}$ \\
$f_{l c, e}[\%]$ & 0 & 60.9 \\
$L O L P_{b, e}[\%]$ & 100 & 79.5 \\
\hline \multicolumn{4}{c}{ Electrical grid interaction } \\
\hline$G M[-]$ & 0 & 0.724 \\
\hline$f_{\text {grid,i } i[-]}$ & 0.189 & 0.256 \\
\hline
\end{tabular}

Comparing $f_{s c, e}$ between the retrofit communities, however, provides insight as to how switching to all electric fuels can impact utilization of on-site PV generation. Both the Toronto and Montréal retrofit solutions have similar installed capacities; however, the Montréal community is able to directly utilize $60.9 \%$ of on-site PV production, indicated by the $f_{s c, e}$ value. The retrofit Toronto communities analyzed in Sections 7.2.1 and 7.2.2 were able to utilize between $30.4 \%$ and $39.3 \%$ of on-site $\mathrm{PV}$ production. These results suggest that utilization of on-site PV production can increase by approximately $20 \%$ if fossil fuel-fired HVAC and DHW equipment is replaced with conventional electrically-driven systems. Indicated by the $L O L P_{b, e}$, this retrofit solution cannot fully meet the on-site electrical demands for $79.5 \%$ of the year.

The grid interaction metrics reported in Table 7.21 cannot be directly compared to the Toronto retrofit solutions presented in Table 7.11. The net-zero balance deficit for the Montréal near net-zero solution is significantly larger than the Toronto solutions. One interesting finding, however, is the similarity of the grid interaction index, $f_{\text {grid,i,e }}$ 
between the Toronto and Montréal solutions. Both the Toronto and Montréal retrofit

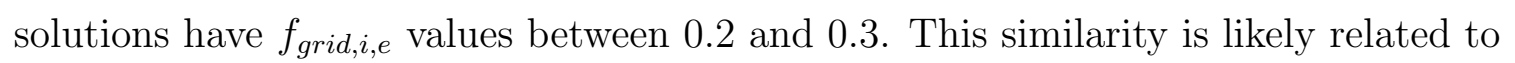
the mismatch of PV production and on-site loads seen in both communities. This mismatch is plotted in Figure 7.11 for the near net-zero Montréal community.

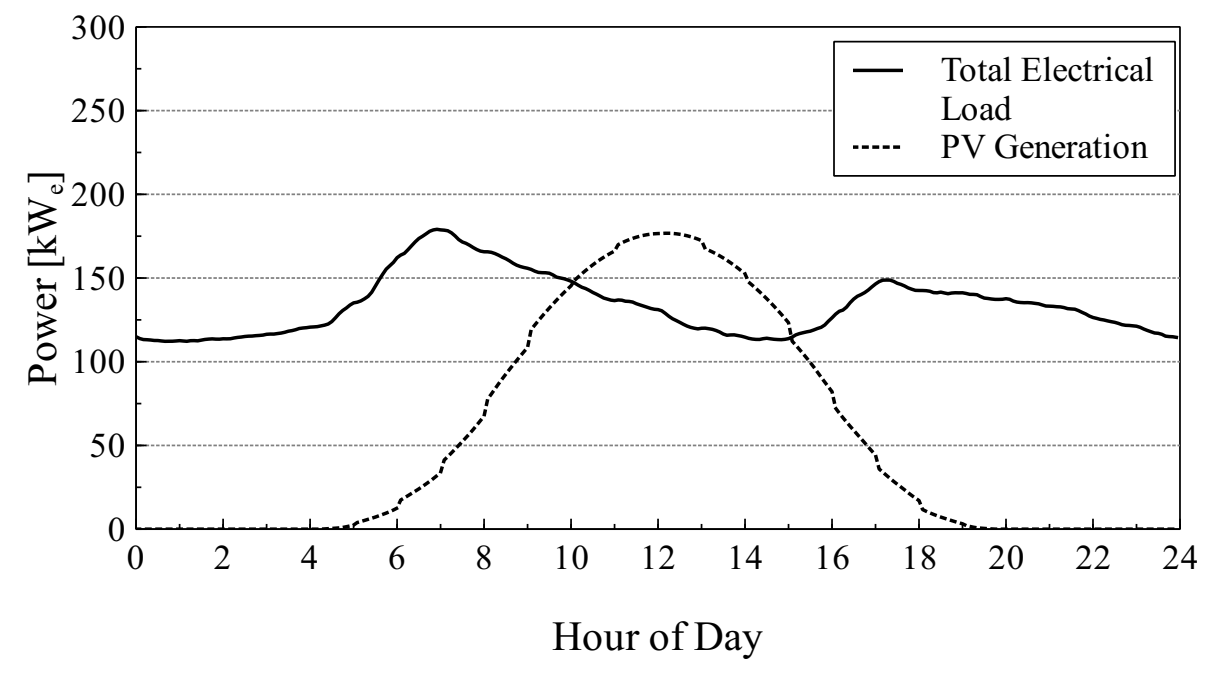

Figure 7.11: Annual mean daily electrical demand and on-site generation profiles for the 1981-1990 Montréal community

The similarity of $f_{\text {grid,i,e }}$ values for Toronto and Montréal retrofit solutions indicate that the fluctuation of power demand on the electrical infrastructure does not improve by changing space heating and DHW demands to electrically-driven systems. As shown in Figure 7.11, there is a mismatch between peak PV production and on-site demand.

$G M$, however, is lower compared to the Toronto retrofit solutions. The retrofit solutions described in Sections 7.2.1 and 7.2.2 have $G M$ values between 2.78 and 3.68. For those solutions the PV maximum power production is approximately three times the aggregate community peak electrical demand. This indicates that the connected infrastructure needs to potentially receive three times the maximum amount of power it is required to supply. For the Montréal retrofit solution, $G M$ is 0.724 , indicating better matching between on-site generation capacity and on-site peak demand, and 
lower magnitudes of reversed power flow onto the grid relative to peak demand.

\subsubsection{Toronto 1981-1990 Community}

The final case study re-analyzes the TO 81-90 community. For this study all dwellings were modelled with a retrofit GSHP space heating system. The model parameters of the GSHP system were described in Section 3.2.3. The results of Section 7.3.1 indicate that switching the space heating system from natural gas to electricity could potentially reduce the relative peak PV export power to the grid. Additionally, the GSHP systems studied for retrofit in the existing community have a nominal COP

rating of 3.0; thus, this technology offers potential for further reductions in on-site space heating energy demand compared to the retrofits considered previously.

Only PV retrofit was considered for on-site renewable generation in this study. The existing natural gas-fired DHW systems in the community were optionally retrofitted with electrically-driven hot water heat pump systems described in Section 3.2.4. The optimization algorithm and simulation framework was used to determine if the cost-optimal net-zero solution includes retrofit DHW systems.

\subsubsection{Retrofit Options Applied}

Both site and source net-zero optimizations were conducted to determine if the definition had an influence on switching the DHW fuel from natural gas to electricity. It was found however that both solutions determined by the optimization algorithm include retrofit of the DHW system, and both collapse to similar solutions. The retrofit measures applied to these solutions are summarized in Table 7.23. The only difference between the site and source net-zero solutions is the capacities of the PV arrays; however, this difference is only $0.3 \%$. 
Table 7.22: Summary of cost-optimal net-zero system retrofit measures applied to the Toronto 1981-1990 community

\begin{tabular}{lcc}
\hline & \multicolumn{2}{c}{ Near net-zero solution } \\
\cline { 2 - 3 } Retrofit measure & Site & Source \\
\hline \hline \multicolumn{2}{c}{ Envelope } & retrofits \\
\hline Retrofit ceiling RSI & 10.57 & 10.57 \\
Retrofit main wall RSI & 5.46 & 5.46 \\
Retrofit basement RSI & 3.52 & 3.52 \\
Retrofit windows & triple-glazed & triple-glazed \\
\hline \multicolumn{2}{c}{ Community energy } & system retrofits \\
\hline Community PV [kW]* & 551.0 & 552.8 \\
Roof area utilization [\%] & 99.5 & 99.8 \\
DHW system & Heat pump & Heat pump \\
\hline
\end{tabular}

* Based on manufacturer-rated output

** Based on gross collector area

The maximum envelope retrofits were applied to both net-zero solutions except for ceiling insulation. It can be seen in Table 7.23 that the ceiling was insulated to RSI 10.57 instead of the maximum RSI 14.09 considered in this study. RSI 10.57 is a relatively high thermal insulation, and it is expected to have diminishing returns with increasing insulation. The DH retrofit case study described previously used the maximum envelope retrofits for the TO 81-90 community and was found to have a TEDI of $134 \mathrm{MJ} / \mathrm{m}^{2} / \mathrm{yr}$. If RSI 10.57 ceiling insulation was retrofitted instead, the TEDI increases to $136 \mathrm{MJ} / \mathrm{m}^{2} / \mathrm{yr}$.

\subsubsection{Annual Energy, Emissions, and Economic Performance}

Since both solutions were nearly identical, detailed analysis was only conducted on the source net-zero solution, hereafter referred to as the net-zero solution. Table 7.23 summarizes the annual energy performance of the net-zero community, as well as the estimated incremental life cycle and utility costs. The retrofit community 
approximately achieves an annual net-zero balance of $-1 \mathrm{MJ} / \mathrm{m}^{2} / \mathrm{yr}$, as shown in Table 7.23. Both significant energy and utility cost savings are realized in the netzero solution. Site natural gas consumption is reduced $100 \%$, from $444 \mathrm{MJ} / \mathrm{m}^{2} / \mathrm{yr}$ to $1 \mathrm{MJ} / \mathrm{m}^{2} / \mathrm{yr}$. The remaining site natural gas consumption is due to two dwellings in the community which use natural gas for the stove and dryer. The net-present value of the variable natural gas utility cost for the retrofit community are negligible. The community retrofit reduces the net present value of the variable electricity costs by 97\%. 
Table 7.23: Summary of the annual energy and economic performance of the costoptimal net-zero system retrofit applied to the Toronto 1981-1990 community

\begin{tabular}{lcc}
\hline & Base case & Net-zero retrofit \\
\hline \hline \multicolumn{2}{c}{ Metered site } & annual energy import $\left[\mathrm{MJ} / \mathrm{m}^{2} / \mathrm{yr}\right]$ \\
\hline Electricity & 84.6 & 103 \\
Natural gas & 444 & 1 \\
Total & 529 & 113 \\
\hline \multicolumn{3}{c}{ Annual energy import reductions } \\
\hline Electricity & $-22 \%$ \\
Natural gas & $100 \%$ \\
Total & $79 \%$ \\
\hline \multicolumn{2}{c}{ Metered site annual energy export $\left[\mathrm{MJ} / \mathrm{m}^{2}\right]$} \\
\hline Electricity & 0 & 103 \\
\hline \multicolumn{2}{c}{ Annual space heating demand $\left[\mathrm{MJ} / \mathrm{m}^{2} /\right.$ yr] } \\
\hline TEDI & 268 & 146 \\
\hline \multicolumn{2}{c}{ Annual net-zero energy balance $\left[\mathrm{MJ} / \mathrm{m}^{2} /\right.$ yr] } \\
\hline Site & -529 & -1 \\
Source & -682 & -1 \\
\hline \hline Incremental net & present values $[$ thousands CAD 2017] \\
\hline LC $C_{N P V}$ & $\mathrm{~N} / \mathrm{A}$ & $\$ 3241$ \\
$N P V_{e}$ & $\$ 635$ & $\$ 17$ \\
$N P V_{N G}$ & $\$ 520$ & $\$ 0$ \\
\hline
\end{tabular}

The envelope retrofits reduce the TEDI by $45 \%$. In addition to the envelope and HRV ventilation retrofits applied, the community TEDI is also affected by the presence of the hot water HP system. These systems operate by transferring thermal energy from the surroundings to the tank fluid. Consequently the space heating load of the zone containing the hot water HP tank will increase. To quantify this increase the TEDI of the retrofit community with identical envelope retrofits as the solution 
above and no casual gains from DHW systems was calculated and found to be 136 $\mathrm{MJ} / \mathrm{m}^{2}$. Therefore the presence of the hot water HP tanks in the community increase the community space heating load by $7 \%$. Khalaf (2017) used an empirical model to simulate a hot water HP system installed in a single-detached dwelling located in Ottawa, Ontario. They found that during the heating season the presence of the HP system increased heating loads by approximately $6 \%$.

The annual community electrical energy consumption attributed to space heating was determined using direct output from CHREM, and when normalized with respect to heated floor area was found to be $62 \mathrm{MJ} / \mathrm{m}^{2} / \mathrm{yr}$. Using the TEDI, the average COP of community GSHP systems was calculated to be 2.4. The annual DHW load of the TO 81-90 community is $644 \mathrm{GJ} / \mathrm{yr}$, and the total electrical consumption to meet DHW end-uses is $249 \mathrm{GJ} / \mathrm{yr}$. Therefore the average COP of the retrofit hot water HP systems is 2.6. The annual flow of metered electrical energy in the netzero retrofit community is illustrated using the Sankey diagram in Figure 7.12. The data in these figures are also summarized in Table 7.24 and are used to analyze the performance of the retrofit community energy systems.

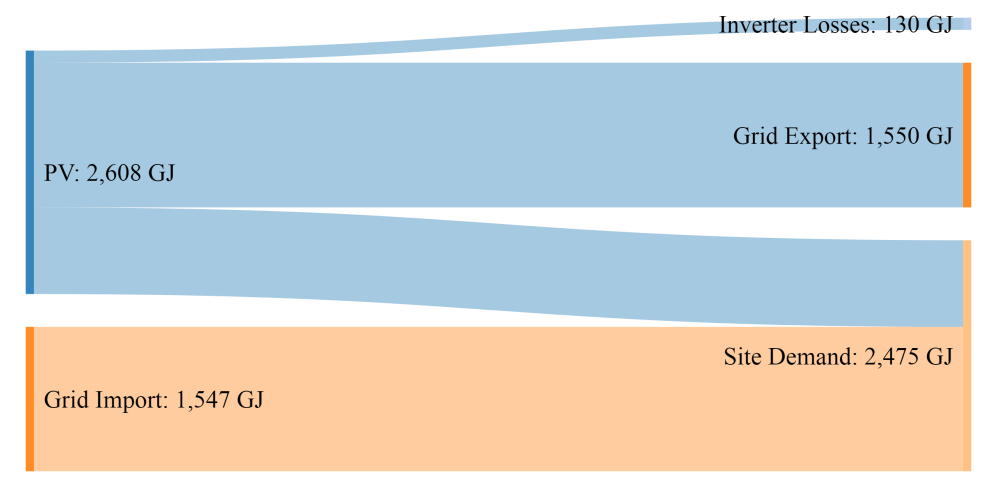

Figure 7.12: Annual energy balance of the cost-optimal net-zero retrofit for the Toronto 1981-1990 community 
Table 7.24: Summary of the annual technology performance of the cost-optimal net-zero system retrofit applied to the Toronto 1981-1990 community

\begin{tabular}{|c|c|}
\hline \multicolumn{2}{|c|}{ Annual PV array performance } \\
\hline Gross generation $[\mathrm{GJ}]$ & 2608 \\
\hline Inverter losses [GJ] & 130 \\
\hline Net generation [GJ] & 2478 \\
\hline Grid Export [GJ] & 1550 \\
\hline Site consumption $[\mathrm{GJ}]$ & 928 \\
\hline $\bar{\eta}_{P V}[\%]$ & 17 \\
\hline \multicolumn{2}{|c|}{ Annual average heat pump performance } \\
\hline GSHP COP [-] & 2.4 \\
\hline Hot water HP COP [-] & 2.6 \\
\hline
\end{tabular}

Table 7.25 summarizes the load matching and grid interaction performance for the retrofit net-zero community. For communities which consume only electricity, $f_{l c, e}$ and $f_{s c, e}$ must be equal for the net-zero energy balance to equal to zero. If it were possible to retrofit additional PV panels and make the community "net-positive", $f_{l c, e}$ would not be expected to increase significantly. 
Table 7.25: Summary of the annual load matching and grid interaction performance of the cost-optimal net-zero system retrofit applied to the Toronto 1981-1990 community

\begin{tabular}{lcc}
\hline \multicolumn{4}{c}{ Base case } & Net-zero retrofit \\
\hline \hline \multicolumn{3}{c}{ Annual electrical generation system performance } \\
\hline Net PV generation [GJ] & 0 & 2478 \\
\hline \hline \multicolumn{4}{c}{ Load matching } \\
\hline$f_{\text {sc,e }}[\%]$ & $\mathrm{N} / \mathrm{A}$ & 37.4 \\
$f_{l c, e}[\%]$ & 0 & 37.5 \\
$L O L P_{b, e}[\%]$ & 100 & 69.9 \\
\hline \multicolumn{4}{c}{ Electrical grid interaction } \\
\hline$G M[-]$ & 0 & 2.38 \\
\hline$f_{\text {grid,i }[-]}[-127$ & 0.262 \\
\hline
\end{tabular}

Figure 7.13 plots $f_{l c, e}$ versus the number of installed PV panels for this and the retrofit Montréal community considered previously. Each data point for the retrofit Toronto community had the same envelope and DHW retrofits applied as the solution described in Table 7.23. For each Montréal community data point the maximum envelope retrofits were applied, and the electrically-driven space heating and DHW systems were not retrofitted. For each data point the collector mounting bias was due south. 


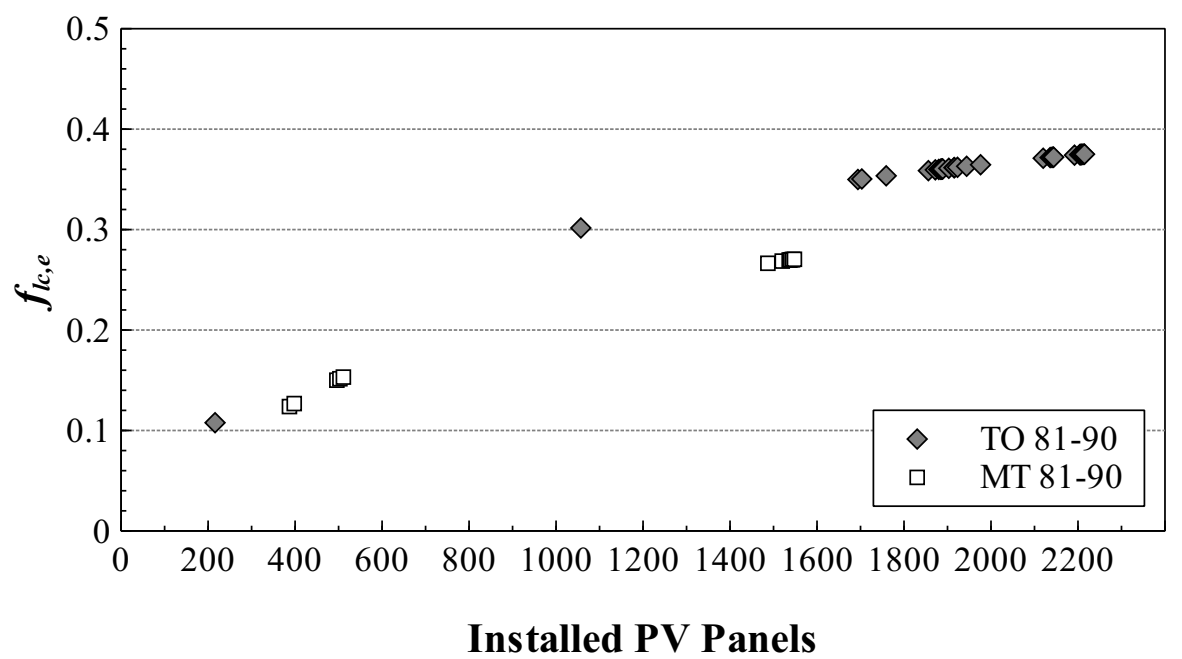

Figure 7.13: Increase in $f_{l c, e}$ with respect to south-biased PV collectors mounted in the retrofit Toronto 1981-1990 community

It can be seen in Figure 7.13 that increases in $f_{l c, e}$ diminish with increasing PV. As shown previously in Figures 7.9 and 7.11, PV generation and residential energy demands are mismatched. Without any generation during the night, it is not possible for roof-mounted PV to directly meet the $100 \%$ of the on-site demands without energy storage. For the retrofit Toronto community considered in this section Figure 7.13 shows $f_{l c, e}$ approaching $40 \%$ with an EUI of $103 \mathrm{MJ} / \mathrm{m}^{2} / \mathrm{yr}$. For the Montréal community, $f_{l c, e}$ approaches $30 \%$ with an EUI of $312 \mathrm{MJ} / \mathrm{m}^{2} / \mathrm{yr}$.

Another consequence of the generation/demand mismatch is that during periods of solar availability excess PV production is required to offset the grid-satisfied demands. For the net-zero solution analyzed in this section, the generation multiple $G M, e$ was determined to be 2.38. Therefore the peak electrical power output of the community PV system is 2.38 times higher than the annual community peak electrical demand. The grid interaction index $f_{\text {grid,i,e }}$ of 0.262 is similar to other PV retrofit solutions presented in previous sections.

Finally Table 7.26 summarizes the annual GHG emissions performance of the net-zero community. Since both space heating and DHW systems are switched from natural gas to electric, the annual emissions from natural gas imports in the retrofit 
community are negligible. Annual import of electricity increases however, as shown in Table 7.23. This increases emissions due to electrical import by $21 \%$.

Table 7.26: Summary of the annual emissions performance of the cost-optimal net-zero system retrofit applied to the Toronto 1981-1990 community

\begin{tabular}{lcc}
\hline & Base case & Net-zero retrofit \\
\hline \hline \multicolumn{2}{c}{ Annual emissions due to energy import $\left[\mathrm{kg} \mathrm{CO}_{2 e} / \mathrm{m}^{2} / \mathrm{yr}\right]$} \\
\hline Electricity & 3.3 & 4.0 \\
Natural gas & 22.8 & 0.0 \\
Total & 26.1 & 4.0 \\
\hline \multicolumn{3}{c}{ Annual emissions reductions } \\
\hline Electricity & $-21 \%$ \\
Natural gas & $100 \%$ \\
Total & $85 \%$ \\
\hline \hline Annual emissions offset due to electrical export $\left[\mathrm{kg} \mathrm{CO}_{2 e} / \mathrm{m}^{2} / \mathrm{yr}\right]$ \\
\hline \multicolumn{3}{c}{ Net annual emissions offset $\left[\mathrm{kg} \mathrm{CO}_{2 e} / \mathrm{m}^{2} / \mathrm{yr}\right]$} \\
\hline \multicolumn{2}{c}{-26.1} & 9.0 \\
\hline
\end{tabular}

When total reductions of emissions from imports are considered, however, the retrofit net-zero community has $85 \%$ less emissions. This result demonstrates the potential significant emission reductions that may be achieved using a net-zero energy target. The export of renewable PV generation was also determined to offset 13.0 $\mathrm{kg} \mathrm{CO} 2 \mathrm{e} / \mathrm{m}^{2} / \mathrm{yr}$. Therefore the retrofit community offsets $9.0 \mathrm{~kg} \mathrm{CO} 2 \mathrm{e} / \mathrm{m}^{2} / \mathrm{yr}$ more emissions than it produces from energy imports.

\subsection{Final Remarks}

Several case studies were examined in this section. Each of these case studies used the simulation framework developed in this thesis to determine net-zero energy retrofit 
solutions which have minimum incremental costs. Section 7.2 focused on the netzero retrofit of district heating systems into existing communities. Using the envelope and community energy system retrofits described in Chapters 3 and 4, respectively, it was found that neither site nor source net-zero energy balances were attainable. The "near" net-zero solutions were therefore analyzed and summarized in Section 7.2 .

One of the objectives of this thesis was to compare and contrast site and source net-zero balances, and their influence on system design. While not at net-zero, the near net-zero results in Section 7.2 provide valuable insights. Given the same retrofit options for both net-zero definitions, the source net-zero solutions were found to be closer to achieving their annual balance. Interestingly, the annual energy consumption and emissions of the source net-zero solutions also tends to be larger compared to the near site net-zero solutions for both communities. The TEDI values are equal between near site and source net-zero solutions.

The principle difference between the two definitions is the weighting factors applied to energy carriers. For the near source net-zero solutions, import of electricity was penalized 2.5 times more than natural gas imports. Comparing the annual performance of PV and solar thermal arrays analyzed in this research, however, it was found that solar thermal systems achieve higher efficiencies compared to the PV systems. This suggests that allocating eligible roof area to solar thermal rather than PV may be a potential solution for achieving source net-zero. Nominal annual efficiencies of $48 \%$ to $58 \%$ were determined for the retrofit solar thermal collectors. These collectors may better utilize incident solar for source net-zero balances by offsetting energy imports for space heating and DHW. Alternately roof area may be allocated to PV, which was found to have nominal annual efficiencies of $17 \%$ in this research. Exported PV generation, assumed to be weighted with a constant PEF of $2.60 \mathrm{kWh} / \mathrm{kWh}$ in Ontario, may be used to offset community energy imports to achieve source net-zero.

Section 7.3.2 described the only net-zero solution achieved in this work. This was achieved by reducing the community energy demand through deep envelope retrofits, and retrofitting GSHP space heating systems and heat pump hot water tanks in each 
of the dwellings. To both supply energy to the community as well as offset electricity imports, roof mounted PV systems were installed. This retrofit solution was shown to significantly reduce community energy consumption and GHG emissions, as well as reduce utility costs.

No on-site energy storage was included in this research, since net-zero strategies often rely on the grid to act as a form of energy storage. In fact, use of on-site battery storage is penalized under net-zero energy balancing schemes. Using the netzero balancing equation provided previously in Section 6.2.2, it can be shown that it is more beneficial to export PV generation rather than store it on-site. Energy stored on-site will incur losses through the charge/discharge cycle, energy which is not credited in the net-zero balance. The intermittent nature of PV production, however, poses challenges to the grid. For the net-zero solution in Section 7.3.2, the annual peak production of the PV system is 2.38 times higher than the annual peak demand. Conventional electrical distribution systems are not designed for severe reversed power flow, and such operating conditions can potentially lead to voltage stability issues and premature wear of system components.

Estimated error was not considered in the current study. Assumptions were maintained across compared simulation scenarios to facilitate valid comparisons between solutions. Characterization of model sensitivity to input parameters requires extensive computation time, and could not be justified in the time line and scope of this work. Building performance simulation sensitivity and uncertainty analyses have been undertaken by other researchers such as MacDonald (2002) and Bucking (2013), and the interested reader is referred to those sources for analyses of building energy modelling uncertainty.

Lastly, limitations and potential sources of optimization algorithm ill-conditioning was discussed. Despite these limitations, the simulation framework was shown in this chapter to produce interesting and informative approximate optimal near netzero and cost-optimal net-zero solutions. The penalty function was shown to be a useful approach to defining constraints, able to locate cost-optimal solutions along the boundary of feasible solutions. Future work, discussed in the next chapter, will consider additional optimization techniques that may be integrated into the 
simulation framework developed in this research. The next chapter also summarizes the major findings and conclusions of this research. 


\section{Chapter 8}

\section{Conclusions, Contributions and Future Work}

Two primary objectives of this work were identified at the beginning of this thesis. The first was to establish a simulation model which had sufficient resolution to realistically estimate the energy performance of envelope and energy system retrofits for existing residential communities in Canada. The second objective of this thesis was to then utilize this tool to explore potential retrofit solutions for converting existing Canadian communities to net-zero, and to analyze the impact of net-zero definition on cost-optimal design solutions.

The majority of residential energy consumption in Canada is from single-detached and double/row dwellings. Therefore strategies and policies to achieve any meaningful impacts on energy consumption and GHG emissions in this sector should focus on these dwelling types. A survey of the literature identified the building energy stock model CHREM developed previously by Swan (2010) as potential tool for this research. Previous researchers have used CHREM to evaluate the energy and emissions impacts of envelope and HVAC technology retrofits.

One challenge of adopting CHREM for this application was that it was developed to assess the efficacy of dwelling-scale energy retrofits. Several different building envelopes and HVAC systems present in the CSDDRD developed by Swan et al. (2009) provided a diversity of space heating thermal demands which is likely present 
in existing communities. The methodology used in CHREM to model occupantdriven AL and DHW loads however relied on a relatively small set of annual high temporal resolution profiles. Therefore more recent modelling methodologies and measured data were sought out in the literature.

The CREST AL demand model developed by Richardson et al. (2010) was identified as a simulation tool capable of generating high temporal resolution residential electrical demand profiles. Originally developed for the U.K., relevant Canadian data was collected in this thesis and integrated into the model. An additional unallocated constant "baseload" was defined in this work to address the under-estimation of baseload demands by CREST reported by Richardson et al. (2010). Validation of the model was performed using 22 measured annual AL demand profiles from Saldanha and Beausoleil-Morrison (2012) and Johnson and Beausoleil-Morrison (2017). The purpose of the validation was to determine if the nominal AL demand characteristics were similar between measured and modelled, as well as examine if the variation of $\mathrm{AL}$ demand characteristics within and between dwellings were also realistic. It was found that the adapted CREST model had the potential to generate the temporal and inter-dwelling diversity of AL demands seen in practice.

The CHREM was also determined to have a limited modelling approach for DHW consumption. The methodology implemented by Swan (2010) used three unique profiles coupled with scaling factors to estimate dwelling DHW loads. For this work a realistic estimate of DHW demand diversity was required. A total of 57 highresolution Canadian annual DHW demand profiles developed previously by Edwards et al. (2015) and George et al. (2015) were integrated into CHREM. Using the unique profiles, estimated aggregate annual peak DHW demand decreased by $94 \%$. The aggregate DHW demands determined using the new profiles implemented in this research were assumed to be realistic compared to using the original profiles implemented in CHREM since the new approach utilized unique measured profiles for each dwelling model. Therefore omitting consideration of the temporal variation of DHW demands was shown to produce significant over-estimates of aggregate DHW thermal demands.

The final improvement to the CHREM modelling approach implemented in this 
work was the development of a methodology to include the impact of building envelope retrofits on dwelling airtightness. Commonly the efficacy of dwelling envelope retrofits is simulated by considering only the change of envelope heat transfer characteristics. Literature surveyed in this work indicated that envelope thermal improvements are often accompanied with increases in envelope airtightness. To quantify the increases in dwelling airtightness due to envelope retrofits, pre and post-retrofit blower door test data from NRCan CanmetENERGY (Ferguson, 2016) of 113,569 dwellings were analyzed. Each dwelling in the database received only one type of building envelope retrofit, and the envelope retrofits analyzed in this work included window retrofits and main wall, attic, and foundation wall insulation retrofits. A methodology was developed in this work which utilized this data set to estimate the increase in dwelling airtightness due to these envelope retrofits.

When only one envelope retrofit was modelled for a dwelling, inclusion of impacts on airtightness increased estimated space heating demand reductions by $5.0 \%$ to $6.1 \%$. When all envelope retrofit options considered in this research were applied to a case study single-detached dwelling, it was found that $39 \%$ of annual space heating demand reductions were due to increases in envelope airtightness. Therefore exclusion of impacts on dwelling airtightness for thermal retrofits of envelopes will yield a conservative estimate of the energy conservation achievable, and the extent of this under-estimation is potentially $40 \%$. The methodology developed in this research provides a method for future researchers to consider the impact of envelope retrofits on dwelling airtightness and potential energy reductions achievable.

Once the changes described above were implemented into CHREM, a simulation framework was developed which utilized CHREM and the energy system simulation tool TRNSYS. The purpose of this framework was to explore potential retrofit solutions for existing Canadian communities to achieve net-zero, and examine the impact of net-zero definition on the annual performance of economical retrofit solutions. Integral to this framework was the use of an optimization algorithm as a method to search the solution space. The premise of this framework was that the lowest cost retrofit solution which achieves the defined net-zero target is the most desirable. The development and implementation of this framework was provided in sufficient detail 
such that future researchers may adopt this framework to explore additional retrofit options and definitions of net-zero.

Survey of the literature revealed that there continues to be disagreement on a formal definition of net-zero and its procedure for calculation. Two commonly used types of net-zero energy balances were identified and analyzed in this research: site and source net-zero. Formal definitions for each of these types of net-zero balances were proposed in this research. Determination of source net-zero energy balances required the determination of primary energy factors (PEFs). These factors represent the embodied energy to convert and deliver energy carriers to the building site. PEFs for electricity and natural gas were developed for the provinces of Ontario and Québec in Canada. The methodology used to derive these PEFs were sufficiently described in this thesis such that future researchers may develop or update PEFs to suit the infrastructure and energy mix for the location of interest.

To analyze the impact of net-zero definition on community retrofit solutions, three test case virtual communities were derived from dwellings described in the CSDDRD. Two of the communities were located in Toronto, Ontario and the third was a community located in Montréal, Québec. Each community was composed of 50 dwellings. The first case study analyzed the retrofit of a district heating system in the two Toronto communities. Given the retrofit options considered, no site or source net-zero solutions were achievable. Therefore the "near" net-zero solutions determined by the optimization algorithm were analyzed.

Assuming average annual electric and natural gas primary energy factors (PEFs) of $2.60 \mathrm{kWh} / \mathrm{kWh}$ and $1.04 \mathrm{kWh} / \mathrm{kWh}$ in Ontario, it was shown that source netzero balances could be achieved with lower life cycle costs compared to site net-zero. Additionally, the near source net-zero solutions were found to be closer to achieving their targets compared to the near site net-zero solutions. Both net-zero targets were considered using the same set of potential retrofit measures. This finding also indicates that source net-zero may be a technically and economically simpler energy target to achieve in locations where grid electricity has a higher PEF compared to natural gas.

While the near site net-zero solutions were found to be further from their annual 
balance compared to source for the district heating retrofit case studies, the near site net-zero solutions nominally achieved greater annual GHG reductions. The near site net-zero communities reduced their GHG emissions by $58 \%$ to $68 \%$. The near source net-zero solutions reduced annual GHG emissions by $55 \%$ to $59 \%$. For the PEFs assumed in this research electrical import was weighted 2.5 times higher than natural gas. This had the effect of biasing toward solutions which use natural gas to meet energy demands and use available roof area for PV generation and export to meet the net-zero balance.

The annual efficiency of solar thermal ETCs and PV analyzed in the these case studies was determined to be $48 \%-58 \%$ and $17 \%$, respectively. Therefore solar thermal systems are better able to utilize incident solar on the community to offset space heating and DHW demands. Under the source net-zero balancing scheme assumed in this research, exported PV energy has a higher value in the balance calculation than offset natural gas consumption. However when the higher efficiency of solar thermal systems is considered, the technology can potentially be feasible in source net-zero solutions rather than allocating all roof surfaces to PV. This observation was supported by the near source net-zero DH system retrofit solution for the TO 81-90 community, which used $129 \mathrm{~m}^{2}$ of roof mounted ETCs in addition to a $531 \mathrm{~kW}$ roof-mounted PV array.

A second case study considered the Montréal community. The purpose of this case study was to determine if a community which meets all its end-use needs with electricity could be converted to net-zero without retrofit of the existing HVAC and DHW systems. All existing heating systems were either electric furnaces or baseboard heaters. Only a near net-zero solution was determined using the simulation framework. The envelope upgrades were found to reduce the annual space heating demands of the community by $39 \%$; however, an additional $246 \mathrm{MJ} / \mathrm{m}^{2} / \mathrm{yr}$ of $\mathrm{PV}$ production was required to reach net-zero. Under the current retrofit options additional generation was not possible, since all available roof area was utilized. Therefore community energy demand needed additional reductions, or other renewable energy generation technologies need to be considered.

The final case study re-considered the 1980's vintage Toronto community. For 
this study all space heating systems in the community were simulated with retrofit GSHP space heating systems with a rated nominal COP of 3.0 which further reduced the space heating energy consumption of the community. The natural gas-fired DHW systems were also retrofitted with a heat pump hot water system. With PV applied to all eligible roof area and an EUI of $103 \mathrm{MJ} / \mathrm{m}^{2} / \mathrm{yr}$ the community was able to achieve an annual net-zero energy balance. The retrofit DHW system switched the fuel from natural gas to electricity, allowing for direct utilization of on-site PV production. However retrofit heat pump hot water system were found to increase space heating demands by $7 \%$. Achieving net-zero retrofit of the community was also found to have a significant impact on annual GHG emissions. The final case study found that the cost-optimal net-zero solution reduced the annual emissions by $95 \%$. This result demonstrates the potential environmental benefits of using net-zero energy targets.

To make up for this mismatch and provide sufficient offset, Also due to this mismatch of generation and demand, there is a limit to the fraction of the load which can be covered by on-site PV in the absence of energy storage.

Based upon the results of the case studies considered in this research, the following general observations were made:

- Deep envelope retrofits were present in all net-zero and near net-zero solutions. Reduction of the site demands is crucial for achieving net-zero since 1) higher site energy demands means larger on-site generation systems are needed to meet or offset the demands, and 2) in existing communities there is typically limited space/roof area;

- Microturbines have potential as distributed CHP; however, the lower efficiencies of microturbines compared to larger systems present challenges to including them as potential technological solutions to achieve net-zero;

- Heat pump technologies combined with large PV generation are potential solutions to achieve net-zero in existing communities.

In addition to energy and emissions performance, interaction of the retrofit communities with connected energy infrastructure was examined through the use of load 
matching and grid interaction factors. For this study no on-site electrical storage was considered. Under net-zero balancing schemes it is not beneficial to use electrical energy storage since energy lost through charge/discharge cannot be credited to the net-zero energy balance, and it is better to directly export generation to offset imports or use the generation directly. The results in this work indicated that between $30 \%$ and $40 \%$ on-site electrical demands could be met by direct PV production in all-electric residential communities which do not utilize any on-site energy storage.

To offset the non-coincident community energy demands, such as the demands during the night, excess PV production must be achieved during the day. For the Toronto net-zero retrofit community analyzed in this research, the community PV system capacity was required to be 2.38 times the peak community demand in order to produce enough export energy to offset imports during periods of low or no PV generation.

Additionally, peak PV production and peak residential demand are mismatched. Peak PV production occurs during midday, whereas the peak electrical demands of the community are early morning and in the evening. Therefore significant reverse flow of power is likely on the electrical distribution system. Liu et al. (2008) previously noted that these reverse energy flows are conditions which are not normally anticipated in distribution system design. According to researchers such as Liu et al. (2008), Omran et al. (2011), and Eftekharnejad et al. (2013), relatively large PV penetration in a distribution system may have adverse effects on the system voltage. These issues include voltage instabilities, difficulty scheduling generation dispatch, and premature wear of distribution equipment (Ari and Baghzouz, 2011).

Omran et al. (2011) recommended the use of battery storage to facilitate matching of on-site demand and generation, and improve interactions with the grid. Implementation of a battery retrofit option within the simulation framework would be trivial, however it was considered to be outside of the scope of the current work. The next section describes future work to continue the simulation framework development and pursue additional retrofit studies. 


\subsection{Future Work}

Sufficient detail of the simulation methodologies was provided in this thesis such that other researchers may adopt them to consider additional retrofit technologies and communities. The methodology offers both flexibility of retrofit options and technologies, as well flexibility of scale. For this research, a set of technologies and envelope retrofit options were explored for virtual communities comprised of 50 single-detached dwellings. The number of dwellings in the community may be reduced to a single dwelling, or scaled up to 100's or 1000's of single-detached and double/row dwellings. Since both ESP-r and TRNSYS are open-source tools, models

of new building envelope and energy generation technologies may be implemented and assessed. There is also flexibility in the objective function used in the framework. Cost-optimal solutions to achieve low emissions or optimal grid interaction may be considered. This section describes some of the future work that will build upon the work completed in this thesis.

Based on the positive results achieved in the third retrofit case study, it would be of interest to revisit the economic and technical feasibility of retrofitting a central GSHP plant to provide the community with space heating and DHW. It would also be of interest to revisit the modelling methodology of DH systems. DH systems were not explicitly modelled, and instead a constant fraction of heat loss was assumed between supply and demand. A constant temperature drop was also assumed across the DH system. The estimated return temperatures have implications on the performance of the thermal energy storage system and other connected systems such as the community solar thermal. Future work will examine if higher-resolution DH system models would yield significantly different results.

Electrical storage technologies were also not considered in this thesis. Often it is assumed in net-zero energy design that the electrical grid will behave as a virtual storage. It has been noted in the literature that the variability of PV generation can potentially cause voltage stability and other issues in the distribution system. The results in this thesis illustrated that for residential applications peak solar production and peak demands are mismatched, and in the absence of any energy storage on-site 
PV generation could directly meet approximately $30 \%$ to $40 \%$ of on-site demands. Battery technologies could potentially shift this value toward $100 \%$. Hoppmann et al. (2014) previously examined the economic viability of battery storage and PV systems installed in Germany and found that it is currently viable to include batteries for small PV systems. Future work will use the simulation framework to examine if costoptimal solutions for retrofit net-zero Canadian communities exist which incorporate on-site electrical storage.

A limited exploration of microturbine technologies was undertaken in this research. Only three units were considered with three different control strategies. The results presented in this thesis illustrated potential benefits to using a microturbine compared to drawing electricity from central turbine generation stations. Future work will examine two or more units installed in a community to provide heat and power. This work will explore if the different microturbine units described in this work may be operated in combination to improve overall efficiency. One potential scenario that will be considered is the combination of a large capacity microturbine providing baseload energy and a smaller unit to provide peak demands.

Another limitation of the current analysis was that communities of 50 dwellings was considered. The solar generation and envelope retrofits were assumed to scale with the number of dwellings; however, the microturbines considered have fixed capacities. Future work will vary the number of connected dwellings to the microturbine units to explore whether these units can be a feasible component of retrofit net-zero communities which are larger or smaller than the 50 dwellings considered in this work.

Annual average values of primary energy factors (PEFs) were used in the current work to calculate source net-zero energy balances. Bucking et al. (2016) previously used Ontario hourly generator output data from IESO (2017b) to determine hour PEFs based on the supply energy mix. Additionally, for the current work data from ecoinvent (2016) were used to derive PEFs for various energy conversion systems. ecoinvent (2016) also provides estimates of uncertainty for values reported in their database. Johnson (2016) also reviewed IESO documents, and found that the uncertainty of generator output reported by IESO (2017b) was $\pm 10 \mathrm{MW}$. With this 
uncertainty data, it is possible to estimate the uncertainty of PEF values and examine how the uncertainty of PEF values effects the design of net-zero buildings and communities.

As mentioned at the introduction of this thesis, one of the drivers for pursuing netzero buildings is to reduce energy and GHG emissions in an effort to reduce climate change. When estimating the energy performance of retrofit net-zero communities using the simulation framework, the climate data forming the boundary conditions to the energy models are sourced from the CWEC climate data from ECCC (2017b). This climate data was constructed using historic data to produce representative years for energy calculation, and does not necessarily capture climate change. Researchers such as Robert and Kummert (2012) and Jentsch et al. (2013) have used climate change estimates and other data to produce "future" climate data which can be used in building simulation. Future work will examine the resilience of the existing building stock against future climate, and the future performance of retrofit net-zero solutions designed using current weather data.

Finally, the particle swarm optimization algorithm in GenOpt was used as a tool to determine the cost-optimal retrofit solution for communities. All algorithms available in GenOpt are single-objective. Net-zero building and community projects have multiple stakeholders with often differing objectives. The homeowner is likely concerned with lowered utility cost, the municipality concerned with reduced GHG emissions, and the utility concerned with the stability of their infrastructure. Future work will integrate multi-objective optimization algorithms into the simulation framework in order to explore the trade-offs between different stakeholder objectives and the implications on net-zero design.

Other limitations of the optimization approach used in this research were noted. Mutually nonexclusive relationships could not be defined between optimization variables for the algorithm selected in this work. However, it was shown that some the inputs being optimized were dependent upon one another. For example, the number of solar thermal collectors that can be mounted is dependent upon remaining available roof area after PV has been mounted in the community. Future work will focus on literature review of optimization techniques which are capable of recognizing these 
types of relationships between variables, and integrating these new algorithms into the simulation framework developed in this research. This work will also focus on examining the tuning and definition of penalty functions for use in this simulation framework. 


\section{References}

Abdel-Galil, T. K., A. E. Abu-Elanien, E. F. El-Saadany, A. Girgis, Y. A.-R. I. Mohamed, M. M. A. Salama, and H. H. M. Zeineldin (2007, June). Protection coordination planning with distributed generation. Technical Report NRCan-060005136, Natural Resources Canada, CETC Varennes Energy Technology and Programs Sector, Varennes, QC.

Allard, Y., M. Kummert, M. Bernier, and A. Moreau (2011). Intermodel comparison and experimental validation of electrical water heater models in TRNSYS. In 12th Conference of International Building Performance Simulation Association, pp. 688-695. IBPSA.

Andersen, E. (2007). Solar combi systems. Ph.D., Technical University of Denmark.

Andersen, E., S. Furbo, M. Hampel, W. Heidemann, and H. Müller-Steinhagen (2008). Investigations on stratification devices for hot water heat stores. International Journal of Energy Research 32(May 2007), 255-263.

Andrews, D., A. K. Riekkola, E. Tzimas, J. Serpa, J. Carlsson, N. Pardo-Garcia, and I. Papaioannou (2012). Background report on EU-27 district heating and cooling potentials, barriers, best practice and measures of promotion. Technical Report Report EUR 25289 EN, European Commission, Joint Research Centre, Institute for Energy and Transport, Petten, The Netherlands.

Andseta, S., M. J. Thompson, J. P. Jarrell, and D. R. Pendergast (1998, May). CANDU reactors and greenhouse gas emissions. In Proc. of the 11th Pacific Basin Nuclear Conference, Banff, AB. International Atomic Energy Agency (IAEA). 
Apricus (2016a). Apricus evacuated tube: AP collectors. Technical Report SPEC_COLL_AP_0716_01, Apricus Australia, Seven Hills, Australia.

Apricus (2016b, August). ETC solar collector product overview. Technical Report A11-01.3.7-V10, Apricus Inc., Los Angeles, CA.

Ari, G. and Y. Baghzouz (2011). Impact of high pv penetration on voltage regulation in electrical distribution systems. In Proc. of the International Conference on Clean Electrical Power (ICCEP), pp. 744-748. IEEE.

Armstrong, M. M., M. C. Swinton, H. Ribberink, I. Beausoleil-Morrison, and J. Millette (2009). Synthetically derived profiles for representing occupant-driven electric loads in canadian housing. Journal of Building Performance Simulation 2(1), 1530.

Asaee, S. R., S. Nikoofard, V. I. Ugursal, and I. Beausoleil-Morrison (2017). Techno-economic assessment of photovoltaic (PV) and building integrated photovoltaic/thermal (BIPV/T) system retrofits in the Canadian housing stock. Energy and Buildings 152, 667-679.

Asaee, S. R., V. I. Ugursal, and I. Beausoleil-Morrison (2015). An investigation of the techno-economic impact of internal combustion engine based cogeneration systems on the energy requirements and greenhouse gas emissions of the Canadian housing stock. Applied Thermal Engineering 87, 505-518.

Asaee, S. R., V. I. Ugursal, and I. Beausoleil-Morrison (2016). Techno-economic study of solar combisystem retrofit in the Canadian housing stock. Solar Energy $125,426-443$.

Asaee, S. R., V. I. Ugursal, and I. Beausoleil-Morrison (2017a). Techno-economic assessment of solar assisted heat pump system retrofit in the Canadian housing stock. Applied Energy 190, 439-452. 
Asaee, S. R., V. I. Ugursal, and I. Beausoleil-Morrison (2017b). Techno-economic feasibility evaluation of air to water heat pump retrofit in the Canadian housing stock. Applied Thermal Engineering 111, 936-949.

Ashe, M., D. Chwastyk, C. de Monasterio, M. Gupta, and M. Pegors (2012, January). 2010 U.S. lighting market characterization. Technical report, U.S Department of Energy, Office of Energy Efficiency \& Renewable Energy, Washington, US.

ASHRAE (2004). Ansi/ashrae standard 55-2004: Thermal environmental conditions for human occupancy. Technical report, American Society of Heating Refrigerating and Air Conditioning Engineers, Atlanta, GA.

ASHRAE (2007). ASHRAE Handbook: HVAC Applications (SI ed.). Atlanta, GA: American Society of Heating, Refrigeration and Air-Conditioning Engineers.

ASHRAE (2008). ASHRAE Handbook: HVAC Systems \& Equipment (SI ed.). Atlanta, GA: American Society of Heating, Refrigeration and Air-Conditioning Engineers.

ASHRAE (2009). ASHRAE Handbook: Fundamentals (SI ed.). Atlanta, GA: American Society of Heating, Refrigeration and Air-Conditioning Engineers.

ASHRAE (2011). ASHRAE Handbook: HVAC Applications (SI ed.). Atlanta, GA: American Society of Heating, Refrigeration and Air-Conditioning Engineers.

ASHRAE (2013). ASHRAE Handbook: Fundamentals (SI ed.). Atlanta, GA: American Society of Heating, Refrigeration and Air-Conditioning Engineers.

ASHRAE (2016). Ansi/ashrae standard 62.2-2016: Ventilation and acceptable indoor air quality in low-rise residential buildings. Technical report, American Society of Heating Refrigerating and Air Conditioning Engineers, Atlanta, GA.

Attia, S., M. Hamdy, W. OBrien, and S. Carlucci (2013). Assessing gaps and needs for integrating building performance optimization tools in net zero energy buildings design. Energy and Buildings 60, 110-124. 
Aydinalp, M., V. I. Ugursal, and A. S. Fung (2002). Modeling of the appliance, lighting, and space-cooling energy consumptions in the residential sector using neural networks. Applied energy 71(2), 87-110.

Aydinalp, M., V. I. Ugursal, and A. S. Fung (2004). Modeling of the space and domestic hot-water heating energy-consumption in the residential sector using neural networks. Applied Energy 79(2), 159-178.

Aydinalp-Koksal, M. and V. I. Ugursal (2008). Comparison of neural network, conditional demand analysis, and engineering approaches for modeling end-use energy consumption in the residential sector. Applied Energy 85(4), 271-296.

Ayompe, L., A. Duffy, M. Mc Keever, M. Conlon, and S. McCormack (2011). Comparative field performance study of flat plate and heat pipe evacuated tube collectors (ETCs) for domestic water heating systems in a temperate climate. Energy $36(5), 3370-3378$.

Aziz, N. A. A., M. Y. Alias, A. W. Mohemmed, and K. A. Aziz (2011, April). Particle swarm optimization for constrained and multiobjective problems: A brief review. In Proc. of the 2011 International Conference on Management and Artificial Intelligence, Bali, Indonesia. IEDRC, IEEE.

Baetens, R. and D. Saelens (2016). Modelling uncertainty in district energy simulations by stochastic residential occupant behaviour. Journal of Building Performance Simulation 9(4), 431-447.

Bahaj, A., L. Myers, and P. James (2007). Urban energy generation: Influence of micro-wind turbine output on electricity consumption in buildings. Energy and buildings 39(2), 154-165.

Bank of Canada (2017). About the bank. Available online at http://www. bankofcanada.ca/ [Accessed Oct 12, 2017].

Bastounas, S. (2015, December). Personal communication. Enwin Utilities Ltd. 
Beausoleil-Morrison, I. (1996, May). Basesimp: A simplified foundation energy-loss model derived from basecalc simulations. Technical report, CanmetENERGY, Natural Resources Canada, Ottawa, ON. Revised Jul. 1999.

Beausoleil-Morrison, I. (2000a, May). The adaptive coupling of heat and air flow modelling within dynamic whole-building simulation. Ph.D., University of Strathclyde, Glasgow, Scotland.

Beausoleil-Morrison, I. (2000b, November). AIM-2 implementation into ESP-r. Technical report, Natural Resources Canada, Buildings Group, Ottawa, Ontario.

Beausoleil-Morrison, I., F. Macdonald, M. Kummert, R. Jost, and T. McDowell (2014). Co-simulation between ESP-r and TRNSYS. Journal of Building Performance Simulation 7(2), 133-151.

Beausoleil-Morrison, I. and G. Mitalas (1997). BASESIMP: A residential foundation heat loss algorithm for incorporating into whole-building energy-analysis programs. In Proc. of Building Simulation 97, Prague, Czech Republic, pp. 1-8. IBPSA.

Beausoleil-Morrison, I., G. Mitalas, and H. Chin (1995). Estimating threedimensional below-grade heat losses from houses using two-dimensional calculations. In Proc. of Thermal Performance of the Exterior Envelopes of Buildings VI Conference, Clearwater, FL, pp. 95-100. ASHRAE.

Beausoleil-Morrison, I., G. Mitalas, and C. McLarnon (1995). BASECALC ${ }^{\mathrm{TM}}$ : New software for modelling basement and slab-on-grade heat loss. In Proc. of Building Simulation 95, Madison, WI, pp. 698-700. International Building Performance Simulation Association.

Bembry IV, W. T. (2011). Emergency thermal energy storage: Cost 6 energy analysis. M.Sc., Kansas State University, Manhattan, KS.

Berkey, J. O. and P. Y. Wang (1987). Two-dimensional finite bin-packing algorithms. Journal of the operational research society, 423-429. 
Bertani, A., C. Bossi, F. Fornari, S. Massucco, S. Spelta, and F. Tivegna (2004). A microturbine generation system for grid connected and islanding operation. In Power Systems Conference and Exposition, 2004. IEEE PES, pp. 360-365. IEEE.

Biaou, A. and M. Bernier (2008). Achieving total domestic hot water production with renewable energy. Building and Environment 43(4), 651-660.

Bird, L., J. Cochran, and X. Wang (2014, March). Wind and solar energy curtailment: Experience and practices in the United States. Technical Report NREL/TP6A20-60983, National Renewable Energy Laboratory and Department of Energy, Golden, Colorado.

Blais, S., A. Parekh, and L. Roux (2005, August). Energuide for houses database - an innovative approach to track residential energy evaluations and measure benefits. In Proc. of Building Simulation 2005: 9th Conference of International Building Performance Simulation Association, Montréal, Canada. IBPSA.

Boden, T., B. Andres, and G. Marland (2017). Ranking of the world's countries by 2014 per capita fossil-fuel CO2 emission rates. Technical Report 10.3334/CDIAC/00001_V2017, Carbon Dioxide Information Analysis Center, Oak Ridge National Laboratory.

Bodycote (2006). Solar Collector Test Report. Technical Report 06-08-9133-1, Bodycote Materials Testing Canada Inc., Mississauga, Canada.

Boermans, T., A. Hermelink, S. Schimschar, J. Grözinger, M. Offermann, K. E. Thomsen, J. rgen Rose, and S. ren O. Aggerholm (2011). Principles for nearly zero-energy buildings. Technical report, Buildings Performance Institute Europe, Brussels, Belgium. Available online at http://www.institutebe. com/InstituteBE/media/Library/Resources/Existing\%20Building\%20Retrofits/ BPIE-Report-Principles-for-Nearly-Zero-Energy-Buildings.pdf [Accessed Apr 7, 2014].

Bohm, B., H. Kristjansson, U. Ottosson, M. Rämä, and K. Sipilä (2008, March). District heating distribution in areas with low heat demand density. Technical 
Report ANNEX VIII - 2008: 8DHC-08-03, IEA R\&D Programme on District Heating and Cooling, including the integration of CHP, Paris, France.

Borbely, A.-M. and J. F. . Kreider (2001). Distributed Generation: The Power Paradigm for the New Millennium. Boca Raton, FL: CRC Press.

Bosch Thermotechnology Corp. (2009). Tyfocor ${ }^{\circledR}$ L "G" Propylene Glycol-based Solar Fluid: Engineering submittal sheet. Available online at http://www.buderus. us/files/201003042213260.Tyfocor_L_G_HTF\%20Specification\%20ESS.pdf [Accessed Sep 2, 2013].

Boyce, M. P. (2012). 4 - performance and mechanical standards. In M. P. Boyce (Ed.), Gas Turbine Engineering Handbook (Fourth Edition ed.)., pp. 177 - 214. Oxford: Butterworth-Heinemann.

Bradley, B. (1993a). Development of the duct/HRV model for HOT2000. Technical report, Unies, Ottawa, ON. Prepared for NRCan.

Bradley, B. (1993b). Implementation of the aim-2 infiltration model in hot2000. Technical report, Unies Ltd., Winnipeg, Canada.

Braun, J. E., S. Klein, and J. Mitchell (1981). Seasonal storage of energy in solar heating. Solar Energy 26(5), 403-411.

BRECSU (2002). Guide to community heating and chp: Commercial, public and domestic applications. Technical Report GPG 234, Building Research Energy Conservation Support Unit, Garston, UK.

Bryan, K. and Y. Shibberu (2005). Penalty functions and constrained optimization. Available online at https://www.rose-hulman.edu/ bryan/lottamath/penalty.pdf [Accessed Aug 4, 2017]. Dept. of Mathematics, Rose-Hulman Institute of Technology.

Bucking, S. (2013, December). Pathways to Net-Zero Energy Buildings: An Optimization Methodology. Ph.D., Concordia University, Montréal, QC. 
Bucking, S., V. Dermardiros, and A. Athienitis (2016, May). The effect of hourly primary energy factors on optimal net-zero energy building design. In Proc. of eSim 2016 Building Performance Simulation Conference, Hamilton, ON. IBPSA.

Canadian GeoExchange Coalition (2009). A buyer's guide for residential ground source heat pump systems. Technical report, Montréal, QC. Available online at http://www.geo-exchange.ca/en/UserAttachments/article58_Residential_ Geothermal_Buyers_Guide_2009.pdf [Accessed Sept 7, 2017].

Canadian Solar (2014, May). CS6P-250 - 255 - 260P pv module product datasheet. Technical Report V4.13C5_EN, Guelph, Canada.

Caneta (1992, May). Development of algorithms for gshp heat exchanger length prediction and energy analysis. Technical report, Caneta Research Inc., Mississauga, ON.

CanSIA (2014, January). Roadmap 2020: Powering Canada's future with solar electricity. Technical report, Canadian Solar Industries Association, Ottawa, Ontario.

Cao, S., A. Mohamed, A. Hasan, and K. Sirén (2014). Energy matching analysis of on-site micro-cogeneration for a single-family house with thermal and electrical tracking strategies. Energy and Buildings 68, 351-363.

Capasso, A., W. Grattieri, R. Lamedica, and A. Prudenzi (1994). A bottom-up approach to residential load modeling. IEEE Transactions on Power Systems 9(2), 957-964.

Capstone (2006, April). Technical reference: Capstone model C30 performance. Technical Report 410004 Rev. D, Capstone Turbine Corporation, Chatsworth, CA.

Capstone (2008, August). Technical reference: Capstone model C65 performance. Technical Report 410048 Rev. B, Capstone Turbine Corporation, Chatsworth, CA. 
Capstone (2009, January). Capstone C1000 microturbine systems: Technical reference. Technical Report 410072 Rev. A, Capstone Turbine Corporation, Chatsworth, CA.

Capstone (2012, October). Capstone microturbine C200 heat recovery module (HRM) user's manual. Technical Report 400021 Rev B, Capstone Turbine Corporation, Chatsworth, CA.

Capstone (2017). Solutions: Renewable energy. Available online at https://www. capstoneturbine.com/solutions/renewable-energy [Accessed Aug 19, 2017]. Capstone Turbine Corporation.

Carlisle, A. and G. Dozier (2001). An off-the-shelf PSO. In Proc. of the Workshop on Particle Swarm Optimization, Indianapolis, IN, pp. 908-912. IEEE.

Carlisle, N., O. Van Geet, and S. Pless (2009, November). Definition of a "zero net energy" community. Technical Report NREL/TP-7A2-46065, National Renewable Energy Laboratory and Department of Energy, Golden, Colorado.

CCBFC (2015). National Building Code of Canada 2015. Ottawa, ON: National Research Council Canada.

CDML (2010, December). Now House Windsor 5 energy analysis. Technical report, CDML Consulting Ltd., Toronto, ON.

CEKAP (2017a, April). London's west five community - building a net zero energy community. Technical report, Community Energy Knowledge - Action Partnership.

CEKAP (2017b). Ottawa zibi development redevelopment of former industrial lands to net zero carbon. Technical report, Community Energy Knowledge - Action Partnership.

CGA (2014, December). Renewable natural gas technology roadmap for Canada. Technical report, Canadian Gas Association. Available online at http://www.cga.ca/wp-content/uploads/2015/04/ 
The-Renewable-Natural-Gas-Technology-Roadmap.pdf [Accessed Aug 19, 2017].

CGA (2016, May). Canada's natural gas utilities propose target for renewable natural gas content. Available online at http://www.cga.ca/news_item/ canadas-natural-gas-utilities-propose-target-for-renewable-natural-gas-content/ [Accessed Aug 19, 2017]. Canadian Gas Association.

Chan, W. R., W. W. Nazaroff, P. N. Price, M. D. Sohn, and A. J. Gadgil (2005). Analyzing a database of residential air leakage in the United States. Atmospheric Environment 39(19), 3445-3455.

Chan, W. R. and M. H. Sherman (2012, August). Analysis of air leakage measurements from residential diagnostics database. Technical report, Ernest Orlando Lawrence Berkeley National Laboratory, Environmental Energy Technologies Division, Berkeley, California.

Chapra, S. C. (2011). Applied numerical methods with MatLABfor engineers and scientists (second ed.). New York, NY: McGraw-Hill.

City of Toronto (2013). Revised by-law 569-2013. s 10.5.75.1. Zoning By-law.

Clarke, J. (2001). Energy Simulation in Building Design (second ed.). Oxford: Butterworth-Heinemann.

Clarke, J. A. (1977). Environmental Systems Performance. Ph.D., University of Strathclyde, Glasgow, Scotland.

Cleaver-Brooks (2010). Boiler efficiency guide: Facts about firetube boilers and boiler efficiency. Technical Report CB-7767, Cleaver-Brooks, Inc, Thomasville, GA.

Clerc, M. and J. Kennedy (2002). The particle swarm-explosion, stability, and convergence in a multidimensional complex space. IEEE transactions on Evolutionary Computation 6(1), 58-73. 
CMHC (2008, January). Research highlight: 2006 census housing series: Issue 1 - demographics and housing construction. Technical Report 65845, Canada Mortgage and Housing Corporation, Ottawa, ON.

CMHC (2009). Now House ${ }^{\mathrm{TM}}$ exterior envelope retrofit. Technical Report 66739, Canada Mortgage and Housing Corporation, Ottawa, ON.

CMHC (2010). Project Profile: Now HouseToronto, Ontario. Technical Report 65596, Canada Mortgage and Housing Corporation, Ottawa, ON.

CMHC (2012). Testing different approaches to energy reduction in five 1 1/2-storey post-war houses. Technical Report 67564, Canada Mortgage and Housing Corporation, Ottawa, ON.

CNA (2017). CANDU technology. Available online at https://cna.ca/technology/ energy/candu-technology/ [Accessed Aug 7, 2017]. Canadian Nuclear Association.

Crawley, M. (2017, May). How your hydro bill will rise over the next decade. CBC News Toronto.

Cruickshank, C. A. (2009). Evaluation of a stratified multi-tank thermal storage for solar heating applications. Ph.D., Queen's University, Kingston, ON.

Cuadrado, R. S. (2009, June). Return temperature influence of a district heating network on the CHP plant production costs. M.Sc., University of Gävle, Gävle, Sweden.

Dalenbäck, J.-O. (1993). Solar heating with seasonal storage. Some aspects of the design and evaluation of systems with water storage. Ph.D., Chalmers University of Technology, Gothenburg, Sweden.

Dalla Rosa, A., R. Boulter, K. Church, and S. Svendsen (2012). District heating (DH) network design and operation toward a system-wide methodology for optimizing renewable energy solutions (SMORES) in Canada: A case study. Energy 45(1), 960-974. 
Dalla Rosa, A., H. Li, and S. Svendsen (2011). Method for optimal design of pipes for low-energy district heating, with focus on heat losses. Energy 36(5), 2407-2418.

Danfoss (2008). 8 steps - control of heating systems. Technical report, Danfoss A/S, Nordborgvej, Denmark. Available online at http://heating.danfoss.com/pcmfiles/ 1/master/other_files/library/heating_book/chapter1.pdf [Accessed Oct 2, 2017].

Darrow, K., R. Tidball, J. Wang, and A. Hampson (2015, March). Catalog of CHP technologies. Technical report, U.S. Environmental Protection Agency, Combined Heat and Power Partnership, Washington, DC.

Davenport, A. G. (1960). Rationale for determining design wind velocities. Technical report, DTIC Document.

De Soto, W., S. Klein, and W. Beckman (2006). Improvement and validation of a model for photovoltaic array performance. Solar energy 80(1), 78-88.

Deru, M. and P. Torcellini (2007, June). Source energy and emission factors for energy use in buildings. Technical Report NREL/TP-550-38617, National Renewable Energy Laboratory and Department of Energy, Golden, Colorado.

Dick, E. P. and A. Narang (2005, July). Canadian urban benchmark distribution systems. Technical Report CETC-Varennes 2005-121, Natural Resources Canada, CETC Varennes Energy Technology and Programs Sector, Varennes, QC.

Dickert, J. and P. Schegner (2010). Residential load models for network planning purposes. In Modern Electric Power Systems (MEPS), 2010 Proceedings of the International Symposium, pp. 1-6. IEEE.

Dinçer, I. and M. Rosen (2008). Thermal Energy Storage: Systems and Applications (second ed.). John Wiley \& Sons.

DLSC (2017). About DLSC. Available online at http://www.dlsc.ca/index.htm [Accessed Jul 24, 2017]. Drake Landing Solar Community. 
DOE (2011, January). Building America Analysis - Existing Homes. Washington, DC: U.S. Department of Energy, Office of Energy Efficiency \& Renewable Energy. https://energy.gov/eere/buildings/downloads/ building-america-analysis-existing-homes (Accessed: 2017-03-31).

DOE (2017). Estimating appliance and home electronic energy use. https://energy. gov/energysaver/estimating-appliance-and-home-electronic-energy-use (2017-0331). U.S. Department of Energy, Office of Energy Efficiency \& Renewable Energy.

Douthitt, R. A. (1989). An economic analysis of the demand for residential space heating fuel in canada. Energy 14(4), 187-197.

Driesse, A. (2009). Power conditioning unit parameters database. Available online at http://sel.me.wisc.edu/trnsys/trnlib/library16.htm [Accessed Jan 15, 2016].

Drück, H. (2006, March). Multiport store - model for TRNSYS. Technical Report Version 1.99F, Institut für Thermodynamik und Wärmetechnik, Universität Stuttgart, Stuttgart, Germany.

Du, K.-L. and M. N. Swamy (2014). Neural networks and statistical learning. London, UK: Springer-Verlag.

Duffie, J. and W. Beckman (2013). Solar Engineering of Thermal Processes (fourth ed.). John Wiley \& Sons.

Eberhart, R. and J. Kennedy (1995). A new optimizer using particle swarm theory. In Proc. of the Sixth International Symposium on Micro Machine and Human Science MHS'95, pp. 39-43. IEEE.

ECCC (2016). Pan-canadian framework on clean growth and climate change. Technical Report En4-294/2016E-PDF, Environment and Climate Change Canada, Ottawa, Ontario. Available online at http://publications.gc.ca/site/eng/9.828774/ publication.html [Accessed Feb 20, 2018]. 
ECCC (2017a). Canadian environmental sustainability indicators: Global greenhouse gas emissions. Technical Report En4-144/63-2017E-PDF, Environment and Climate Change Canada, Gatineau, QC.

ECCC (2017b, May). Engineering climate datasets. Available online at http: //climate.weather.gc.ca/prods_servs/engineering_e.html [Accessed Aug 1, 2017]. Environment and Climate Change Canada.

Eckstein, J. H. (1990). Detailed modelling of photovoltaic system components. M.Sc., University of Wisconsin-Madison.

ecoinvent (2016). ecoinvent version 3.3 database. Available online at https://v33. ecoquery.ecoinvent.org/Search/Index [Accessed Aug 6, 2017].

Edwards, S., I. Beausoleil-Morrison, and A. Laperrière (2015). Representative hot water draw profiles at high temporal resolution for simulating the performance of solar thermal systems. Solar Energy 111, 43-52.

Eftekharnejad, S., V. Vittal, G. T. Heydt, B. Keel, and J. Loehr (2013). Impact of increased penetration of photovoltaic generation on power systems. IEEE Transactions on Power Systems 28(2), 893-901.

Eguia, P., I. Zamora, E. Torres, J. S. Martín, M. Moya, J. Bruno, and A. Coronas (2010, March). Modelling and simulation of a microturbine during transient events. In Proc. of the International Conference on Renewable Energies and Power Quality, Granada, Spain.

Enbridge (2017). Rate 6 - commercial and industrial. Available online at https://www.enbridgegas.com/businesses/accounts-billing/gas-rates/ large-volume-rates/rate-6.aspx [Accessed Oct 11, 2017]. Enbridge Gas Distribution Inc.

ENERGY STAR (2017). ENERGY STAR certified water heaters. Available online at https://www.energystar.gov/productfinder/product/certified-water-heaters/ results [Accessed Sept 7, 2017]. 
Environment Canada (2014). Engineering climate datasets. Available online at http: //climate.weather.gc.ca/prods_servs/engineering_e.html [Accessed Jul 8, 2014].

EPA (2017). Greenhouse gas equivalencies calculator. Available online at https: //www.epa.gov/energy/greenhouse-gas-equivalencies-calculator [Accessed Aug 7, 2017]. United States Environmental Protection Agency.

ESP-rCommunity (2017). ESP-rSource. https://github.com/ESP-rCommunity/ ESP-rSource.

ESRU (2017). Esp-r. Available online at http://www.esru.strath.ac.uk/Programs/ ESP-r.htm [Accessed Aug 2, 2017]. Energy Systems Research Unit, University of Strathclyde.

Esser, A. and F. Sensfuss (2016, May). Final report: Evaluation of primary energy factor calculation options for electricity. Technical Report ENER/C3/2013484/02/FV2014-558, Fraunhofer-Institut für System- und Innovationsforschung (ISI), Karlsruhe, Germany.

Fanger, P. (1970). Thermal comfort: analysis and applications in environmental Engineering. New York, NY: McGraw-Hill.

Farahbakhsh, H., V. Ugursal, and A. Fung (1998). A residential end-use energy consumption model for canada. International Journal of Energy Research 22(13), 1133-1143.

Farhat, A. A. and V. I. Ugursal (2010). Greenhouse gas emission intensity factors for marginal electricity generation in Canada. International Journal of Energy Research 34(15), 1309-1327.

Ferguson, A. (2016, December). Personal communication. CanmetENERGY, Natural Resources Canada. 
Finkelor, B., B. Sudhakaran, M. Hayakawa, M. Kurtovich, N. Zail, B. Dickinson, S. England, B. Segar, B. Dakin, O. Idrees, and E. Branch (2010, August). West village: A process \& business model for achieving zero-net energy at the communityscale. In Proc. of the ACEEE Summer Study on Energy Efficiency in Buildings, Pacific Grove, CA.

Firth, S., K. Lomas, A. Wright, and R. Wall (2008). Identifying trends in the use of domestic appliances from household electricity consumption measurements. Energy and Buildings 40(5), 926-936.

Fischer, D., A. Härtl, and B. Wille-Haussmann (2015). Model for electric load profiles with high time resolution for german households. Energy and Buildings 92, 170179 .

Flett, G. and N. Kelly (2016). An occupant-differentiated, higher-order markov chain method for prediction of domestic occupancy. Energy and Buildings 125, 219-230.

Flett, G. and N. Kelly (2017). A disaggregated, probabilistic, high resolution method for assessment of domestic occupancy and electrical demand. Energy and Buildings 140, 171-187.

Florides, G. and S. Kalogirou (2007). Ground heat exchangersa review of systems, models and applications. Renewable energy 32(15), 2461-2478.

Fonseca, J. A. and A. Schlueter (2015). Integrated model for characterization of spatiotemporal building energy consumption patterns in neighborhoods and city districts. Applied Energy 142, 247-265.

Fraser, N. M., E. M. Jewkes, I. Bernhardt, and M. Tajima (2006). Engineering Economics in Canada (3 ed.). Toronto, ON: Pearson Prentice Hall.

Frederiksen, S. and S. Werner (2013). District Heating and Cooling. Lund, Sweden: Studentlitteratur AB.

Gadd, H. and S. Werner (2014). Achieving low return temperatures from district heating substations. Applied energy 136, 59-67. 
Gauthier, L. (2014, December). Personal communication. Work Worth Doing - Now House.

George, D., N. S. Pearre, and L. G. Swan (2015). High resolution measured domestic hot water consumption of canadian homes. Energy and Buildings 109, 304-315.

Georgopoulou, E., D. Lalas, and L. Papagiannakis (1997). A multicriteria decision aid approach for energy planning problems: the case of renewable energy option. European Journal of Operational Research 103(1), 38-54.

Gönen, T. (1986). Electric power distribution system engineering (1st ed.). New York, US: McGraw-Hill.

Gram-Hanssen, K. (2010). Residential heat comfort practices: understanding users. Building Research E Information 38(2), 175-186.

Guler, B., A. S. Fung, M. Aydinalp, and V. I. Ugursal (2001). Impact of energy efficiency upgrade retrofits on the residential energy consumption in canada. International Journal of Energy Research 25(9), 785-792.

Guler, B., V. I. Ugursal, A. S. Fung, and M. Aydinalp-Koksal (2008). Impact of energy efficiency upgrade retrofits on the residential energy consumption and greenhouse gas emissions in canada. International Journal of Environmental Technology and Management 9(4), 434-444.

Han, Y., R. Wang, and Y. Dai (2009). Thermal stratification within the water tank. Renewable and Sustainable Energy Reviews 13(5), 1014-1026.

Hart, D. P. and R. Couvillion (1986). Earth coupled heat transfer. Technical report, National Water Well Association, Dublin, OH.

Hasan, A., M. Vuolle, and K. Sirén (2008). Minimisation of life cycle cost of a detached house using combined simulation and optimisation. Building and Environment 43(12), 2022-2034. 
Hawkes, A. and M. Leach (2007). Cost-effective operating strategy for residential micro-combined heat and power. Energy 32(5), 711-723.

Hayter, S., P. Torcellini, R. B. Hayter, and R. Judkoff (2001, September). The energy design process for designing and constructing high-performance buildings. In Proc. of Clima 2000/Napoli 2001 World Congress, Napoli, Italy. REHVA Federation of European HVAC Association.

He, Q. and L. Wang (2007). An effective co-evolutionary particle swarm optimization for constrained engineering design problems. Engineering applications of artificial intelligence 20(1), 89-99.

Healy, P. and V. Ugursal (1997). Performance and economic feasibility of ground source heat pumps in cold climate. International Journal of Energy Research 21(10), 857-870.

Heimrath, R. (2003). Report on solar combisystems modelled in task 26: Appendix 9: Generic system \# 19: Centralised heat production, distributed heat load. Technical report, International Energy Agency: Solar Heating \& Cooling Programme. Available online at http://archive.iea-shc.org/publications/downloads/ task26-c-combisystems_modelled-appendix9.pdf [Accessed Apr 26 2014].

Heimrath, R. and M. Haller (2007, May). The reference heating system: The template solar system of task 32. Technical Report Report A2 of Subtask A, Institute of Thermal Engineering, Graz University of Technology, Graz, Austria. A Report of IEA Solar Heating and Cooling programme - Task 32.

Hensen, J. L. (1991). On the thermal interaction of building structure and heating and ventilating system of building structure. Ph.D., Technische Universiteit Eindhoven, Eindhoven, Netherlands.

Hoes, P., J. Hensen, M. Loomans, B. De Vries, and D. Bourgeois (2009). User behavior in whole building simulation. Energy and buildings 41(3), 295-302. 
Hofierka, J. and J. Kan̆uk (2009). Assessment of photovoltaic potential in urban areas using open-source solar radiation tools. Renewable Energy 34(10), 2206-2214.

Hooke, R. and T. A. Jeeves (1961). Direct search solution of numerical and statistical problems. Journal of the Association for Computing Machinery 8(2), 212-229.

Hoppmann, J., J. Volland, T. S. Schmidt, and V. H. Hoffmann (2014). The economic viability of battery storage for residential solar photovoltaic systems-a review and a simulation model. Renewable and Sustainable Energy Reviews 39, 1101-1118.

Hornik, K., M. Stinchcombe, and H. White (1989). Multilayer feedforward networks are universal approximators. Neural networks 2(5), 359-366.

HVI (2017). Home Ventilating Institute. Available online at https://www.hvi.org/ [Accessed Sept 15, 2017].

Hydro One Networks Inc. (2017). Appliance calculator. http://www. hydroonenetworks.com/MyHome/SaveEnergy/Tools/calc_main.htm (Accessed: 2017-03-31).

Hydro Ottawa (2017). Net-metering. Available online at https://www.hydroottawa. com/accounts-and-billing/generation/net-metering [Accessed Oct 12, 2017]. Hydro Ottawa Ltd.

Hydro-Québec (2017). Hydro-Québec production. Available online at http://www. hydroquebec.com/generation/ [Accessed Aug 7, 2017].

Hydro Québec (2017). Rate D: Domestic rate for residential and farm customers. Available online at http://www.hydroquebec.com/residential/customer-space/ account-and-billing/understanding-bill/residential-rates/rate-d.html [Accessed Oct 11, 2017].

IEA-SHC (2014, March). Task 40/annex 52:net zero energy solar buildings. Available online at http://task40.iea-shc.org/ [Accessed Feb 26, 2014]. 
IESO (2011, Oct). Introduction to Ontario's physical markets. Technical report, Independent Electricity System Operator, Toronto, Ontario. Available online at http://www.ieso.ca/imoweb/pubs/training/IntroOntarioPhysicalMarkets. pdf [Accessed Nov 19, 2014].

IESO (2017a). Data directory. Available online at http://www.ieso.ca/en/ power-data/data-directory [Accessed Aug 7, 2017]. Independent Electricity System Operator.

IESO (2017b, April). Public reports. Available online at http://reports.ieso.ca/ public/ [Accessed Oct 13, 2017]. Independent Electricity System Operator.

IPCC (2013). Climate Change 2013: The Physical Science Basis, Contribution of Working Group I to the Fifth Assessment Report of the Intergovernmental Panel on Climate Change. Cambridge, United Kingdom and New York, NY, USA: Cambridge University Press.

IPCC (2014). Climate Change 2014: Impacts, Adaptation, and Vulnerability, Contribution of Working Group II to the Fifth Assessment Report of the Intergovernmental Panel on Climate Change. Cambridge, United Kingdom and New York, NY, USA: Cambridge University Press.

Ismail, M., M. Moghavvemi, and T. Mahlia (2013). Current utilization of microturbines as a part of a hybrid system in distributed generation technology. Renewable and Sustainable Energy Reviews 21, 142-152.

Izquierdo, S., M. Rodrigues, and N. Fueyo (2008). A method for estimating the geographical distribution of the available roof surface area for large-scale photovoltaic energy-potential evaluations. Solar Energy 82(10), 929-939.

Jentsch, M. F., P. A. James, L. Bourikas, and A. S. Bahaj (2013). Transforming existing weather data for worldwide locations to enable energy and building performance simulation under future climates. Renewable Energy 55, 514-524. 
Johansson, C. and F. Wernstedt (2005). Dynamic simulation of district heating systems. In Proc. of the Third European Simulation and Modelling Conference, Oporto, Portugal.

Johnson, G. and I. Beausoleil-Morrison (2017). Electrical-end-use data from 23 houses sampled each minute for simulating micro-generation systems. Applied Thermal Engineering 114, 1449-1456.

Johnson, G., I. Beausoleil-Morrison, and A. Wills (2017). Micro-cogeneration versus conventional technologies: Considering model uncertainties in assessing the energy benefits. Applied Thermal Engineering 114, 1457-1467.

Johnson, G. L. (2016, November). Developing a methodology for assessing the energy potential of residential micro-cogeneration systems. Ph.D., Carleton University, Ottawa, ON.

Jordan, U. and K. Vajen (2001a). Influence of the DHW load profile on the fractional energy savings: A case study of a solar combi-system with TRNSYS simulations. Solar Energy 69, 197-208.

Jordan, U. and K. Vajen (2001b). Realistic domestic hot-water profiles in different time scales. Technical Report V2.0, Universität Marburg, Marburg, Germany. Available online at http://sel.me.wisc.edu/trnsys/trnlib/iea-shc-task26/ iea-shc-task26-load-profiles-description-jordan.pdf [Accessed Aug 28, 2015].

Kalogirou, S. A. (2004). Solar thermal collectors and applications. Progress in energy and combustion science 30(3), 231-295.

Kavvadias, K., A. Tosios, and Z. Maroulis (2010). Design of a combined heating, cooling and power system: Sizing, operation strategy selection and parametric analysis. Energy Conversion and Management 51(4), 833-845.

Kersting, W. H. (2001). Radial distribution test feeders. In Proc. of the Power Engineering Society Winter Meeting, Volume 2, pp. 908-912. IEEE. 
Khalaf, K. (2017, August). Experimental Characterization and Modelling of a Heat Pump Water Heater. M.A.Sc., Carleton University, Ottawa, ON.

King, D., W. Boyson, and J. Kratochvill (2004, December). Photovoltaic array performance model. Technical Report SAND2004-3535, Sandia National Laboratories, Albuquerque, NM.

King County (2017). zHome. Available online at http://your.kingcounty.gov/ solidwaste/greenbuilding/zhome.asp [Accessed Sept 8, 2017]. King County Solid Waste Division.

Klein, S., P. Cooper, T. Freeman, D. Beekman, W. Beckman, and J. Duffie (1975). A method of simulation of solar processes and its application. Solar Energy 17(1), 29-37.

Klein, S., J. Duffie, and W. Beckman (1974). Transient considerations of flat-plate solar collectors. Journal of Engineering for Power 96(2), 109-113.

Klimstra, J. (2008). Five years of operational experience the Gyorho cogeneration plant. Wartsila Tech J 00, 4-8.

Klug, V. L., A. B. Lobscheid, and B. C. Singer (2011, August). Cooking appliance use in California homes - Data collected from a web-based survey. Technical report, Lawrence Berkeley National Laboratory, Environmental Energy Technologies Division, Berkeley, US.

Kolter, J. Z. and M. J. Johnson (2011). REDD: A public data set for energy disaggregation research. In Workshop on Data Mining Applications in Sustainability, Volume 25, San Diego, CA, pp. 59-62. SIGKDD.

Kopf, J. (2012). Economic potential of residential mirco-cogeneration coupled with thermal and electrical storage as a distributed energy resource in Ontario. M.A.Sc., Carleton University, Ottawa, ON.

Kozlowski, D. (1989, May). Modelling of seasonal thermal energy storage systems. Ph.D., University of Wisconsin-Madison. 
Kummert, M. and M. Bernier (2008). Sub-hourly simulation of residential ground coupled heat pump systems. Building Services Engineering Research and Technology $29(1), 27-44$.

Lane, T. (Ed.) (2016). Contractor's pricing guide: Residential repair $\&$ remodeling costs with RSMeans data. The Gordian Group Inc.

Larochelle, H. (2013). Neural networks. Available online at https://www.youtube. com/user/hugolarochelle [Accessed Aug 13, 2017]. Presentation.

LBNL (2015). Engineering reference: The reference to EnergyPlus calculations. Technical report, Lawrence Berkeley National Laboratory, Berkeley, CA. EnergyPlus Documentation, v8.4.0.

LBNL (2016). Berkeley Lab WINDOW. Available online at https://windows.lbl. gov/software/window/window.html [Accessed Sept 5, 2017]. Lawrence Berkeley National Laboratory,.

LBNL (2017). Standby power summary table. http://standby.lbl.gov/ summary-table.html (Accessed: 2017-03-23). Lawrence Berkeley National Laboratory, Building Technology and Urban Systems Division.

Lew, L. (1993). Evaluation of AIM-2. Technical report, Natural Resources Canada, Ottawa, ON.

Liu, Y., J. Bebic, B. Kroposki, J. De Bedout, and W. Ren (2008). Distribution system voltage performance analysis for high-penetration pv. In Proc. of Energy 2030 Conference, pp. 1-8. IEEE.

Lomanowski, B. (2008). Implementation of window shading models into dynamic whole-building simulation. M.A.Sc., University of Waterloo, Waterloo, ON.

Lopez, P. (2001, November). Design of domestic hot water model for Hot3000. Technical report, CanmetENERGY, Natural Resources Canada, Ottawa, ON. 
Lowes (2017). GE GeoSpring hybrid water heater, 50 gallons. Available online at https://www.lowes.ca/water-heaters/ge-geospring-hybrid-water-heater g2470020.html [Accessed Aug 30, 2017].

Lund, H., A. Marszal, and P. Heiselberg (2011). Zero energy buildings and mismatch compensation factors. Energy and Buildings 43(7), 1646-1654.

Lund, H., S. Werner, R. Wiltshire, S. Svendsen, J. E. Thorsen, F. Hvelplund, and B. V. Mathiesen (2014). 4th generation district heating (4gdh): Integrating smart thermal grids into future sustainable energy systems. Energy 68, 1-11.

Lund, P. (1988). Effect of storage thermal behavior in seasonal storage solar heating systems. Solar Energy 40(3), 249-258.

Lundh, M., K. Zass, C. Wilhelms, K. Vajen, and U. Jordan (2010). Influence of store dimensions and auxiliary volume configuration on the performance of mediumsized solar combisystems. Solar Energy 84(7), 1095-1102.

MacDonald, I. A. (2002, July). Quantifying the effects of uncertainty in building simulation. Ph.D., University of Strathclyde, Glasgow, UK.

Managan, K. (2012). Issue brief: Net zero communities, one building at a time. Technical report, Institute for Building Efficiency, Johnson Controls, Washington, DC. Available online at http://www.institutebe.com/InstituteBE/media/Library/ Resources/Existing\%20Building\%20Retrofits/Issue-Brief-Net-Zero-Communities. pdf [Accessed Jul 22, 2014].

Marazella, L. (1992). Multi-flow stratified thermal storage model with full-mixed layers PdM - XST. Technical report, Institut für Thermodynamik und Wärmetechnik Universität Stuttgart -FRG and Dipartimento di Energetica Politecnico di Milano.

Marszal, A. J., P. Heiselberg, J. S. Bourrelle, E. Musall, K. Voss, I. Sartori, and A. Napolitano (2011). Zero energy building-a review of definitions and calculation methodologies. Energy and buildings 43(4), 971-979. 
Marszal-Pomianowska, A., P. Heiselberg, and O. K. Larsen (2016). Household electricity demand profiles-a high-resolution load model to facilitate modelling of energy flexible buildings. Energy 103, 487-501.

MathWorks (2017a). fitnet. Available online at https://www.mathworks.com/help/ nnet/ref/fitnet.html [Accessed Sept 20, 2017].

MathWorks (2017b). MATLAB. Available online at https://www.mathworks.com/ products/matlab.html [Accessed Sept 13, 2017].

MBA (2015). zHome: Setting a national net zero energy and green building precedent: Outcomes and lessons learned. Technical report, Master Builders Association, Bellevue, WA.

McClenahan, D. (2011, April). Working towards 100\% solar heated communities. Available online at http://task45.iea-shc.org/Data/Sites/3/documents/ events/meeting-01/presentations/CA-DrakeLanding-DM-M1.pdf [Accessed Nov 29, 2017]. Presentation.

McDowell, T. P. and J. W. Thorton (2008, July). Simulation and model calibration of a large-scale solar seasonal storage system. In Proc. of the Third National Conference of IBPSA-USA, pp. 174-181. IBPSA-USA.

McKenna, E., M. Krawczynski, and M. Thomson (2015). Four-state domestic building occupancy model for energy demand simulations. Energy and Buildings 96, 30-39.

McKenna, E., I. Richardson, and M. Thomson (2012). Smart meter data: Balancing consumer privacy concerns with legitimate applications. Energy Policy 41, 807814.

McKenna, E. and M. Thomson (2016). High-resolution stochastic integrated thermal-electrical domestic demand model. Applied Energy 165, 445-461.

McMurtry, S. (2013). On configuration and control of the thermal plant for fuel cell micro-cogeneration. M.ASc., Carleton University, Ottawa, ON. 
Milligan, N. (2015, December). First zero net energy townhome in the U.S. zHome. Available online at https://www.issaquahhighlands.com/ first-zero-net-energy-townhome-in-the-u-s-zhome/ [Accessed Sept 10, 2017]. Issaquah Highlands Inc.

Mitalas, G. (1987). Calculation of below-grade residential heat loss: Low-rise residential building. ASHRAE transactions 93(Part 1), 743-783.

MMA (2016, July). Supplementary Standard SB-12: Energy Efficiency For Housing. Technical Report MR-16-S-26, Ministry of Municipal Affairs, Building and Development Branch.

Mora, T. and M. Ulieru (2005, November). Minimization of energy use in pipeline operations-an application to natural gas transmission system. In Proc. of the 31st Annual Conference of IEEE Industrial Electronics Society, IECON 2005, Raleigh, NC, pp. 2190-2197. IEEE.

Morrison, A. (1997, August). GS2000 ${ }^{\mathrm{TM}}$ software. In Proc. of 3rd International Conference on Heat Pumps in Cold Climates, Wolfville, NS, pp. 1-8. Acadia University.

Morrison, G., I. Budihardjo, and M. Behnia (2004). Water-in-glass evacuated tube solar water heaters. Solar energy 76 (1), 135-140.

Muratori, M., M. C. Roberts, R. Sioshansi, V. Marano, and G. Rizzoni (2013). A highly resolved modeling technique to simulate residential power demand. Applied Energy 107, 465-473.

Navigant (2014). Distribution line loss study. Technical report, Prepared for Hydro One Networks, Inc., Toronto, ON.

NEB (2016). Canada's energy future 2016: Energy supply and demand projections to 2040. Technical Report Cat. No. NE2-12E-PDF, National Energy Board, Ottawa, $\mathrm{ON}$. 
Newton, B. J. (1995). Modeling of Solar Storage Tanks. M.A.Sc., University of Wisconsin-Madison.

NFRC (2010). NFRC 100-2010: Procedure for determining fenestration product U-fators. Technical report, National Fenestration Rating Council, Greenbelt, MD.

NFRC (2017). National Fenestration Rating Council. Available online at http: //www.nfrc.org/ [Accessed Sept 6, 2017].

Ni, F., P. Nguyen, J. Cobben, H. van den Brom, and D. Zhao (2016, September). Uncertainty analysis of aggregated smart meter data for state estimation. In Proc. of the 2016 IEEE International Workshop on Applied Measurements for Power Systems (AMPS), Aachen, Germany, pp. 1-6. IEEE.

Nicol, J. F. (2001, August). Characterising occupant behaviour in buildings: towards a stochastic model of occupant use of windows, lights, blinds, heaters and fans. In Proc. of the Seventh International IBPSA Conference, Rio de Janeiro, Brazil, pp. 1073-1078. International Building Performance Simulation Association.

Nijhuis, M., M. Gibescu, and J. Cobben (2016). Bottom-up markov chain monte carlo approach for scenario based residential load modelling with publicly available data. Energy and Buildings 112, 121-129.

Nikoofard, S., V. I. Ugursal, and I. Beausoleil-Morrison (2013). Technoeconomic assessment of the impact of window improvements on the heating and cooling energy requirement and greenhouse gas emissions of the Canadian housing stock. Journal of Energy Engineering 140(2), 04013018.

Nikoofard, S., V. I. Ugursal, and I. Beausoleil-Morrison (2014a). An investigation of the technoeconomic feasibility of solar domestic hot water heating for the Canadian housing stock. Solar Energy 101, 308-320.

Nikoofard, S., V. I. Ugursal, and I. Beausoleil-Morrison (2014b). Technoeconomic assessment of the impact of window shading retrofits on the heating and cooling 
energy consumption and GHG emissions of the Canadian housing stock. Energy and Buildings 69, 354-366.

Nikoofard, S., V. I. Ugursal, and I. Beausoleil-Morrison (2015). Techno-economic assessment of the impact of phase change material thermal storage on the energy consumption and ghg emissions of the Canadian housing stock. Building Simulation 8(2), 225-238.

Norton, P., K. Kiatreungwattana, and K. J. Kelly (2013). Evaluation of model results and measured performance of net-zero energy homes in hawaii. ASHRAE Transactions 119(2).

Now House (2017). Community-scale retrofit projects. Available online at http: //www.nowhouseproject.com/workCommunityScaleRetrofit.php [Accessed Jul 28, 2017]. Work Worth Doing - Now House, Centre for Social Innovation.

NRCan (2005, December). Energuide for houses: Energy advisor workshop manual. Technical report, Natural Resources Canada, Office of Energy Efficiency, Ottawa, Ontario.

NRCan (2012). Energy consumption of major household appliances shipped in Canada: Trends for 1990-2010. Technical Report M141-16/1-2010, Office of Energy Efficiency, Natural Resources Canada, Ottawa, Canada.

NRCan (2014a, March). Additional statistics on energy. Natural Resources Canada.

NRCan (2014b, September). HOT2000. Natural Resources Canada. Available online at http://www.nrcan.gc.ca/energy/software-tools/7421.

NRCan (2014c). Survey of household energy use 2011: Detailed statistical report. Technical Report M144-120/2-2011E-PDF, Natural Resources Canada, Office of Energy Efficiency, Ottawa, Canada.

NRCan (2016a, June). About renewable energy. Available online at https://www. nrcan.gc.ca/energy/renewable-electricity/7295 [Accessed Jul 18, 2017]. Natural Resources Canada. 
NRCan (2016b, December). Keeping the heat in - chapter 7: Insulating walls. Available online at http://www.nrcan.gc.ca/energy/efficiency/housing/ home-improvements/keeping-the-heat-in/insulating-walls/15641 [Accessed Sept 4, 2017]. Natural Resources Canada.

NRCan (2016c, October). Solar thermal. Available online at http://www.nrcan.gc. ca/energy/renewable-electricity/solar-thermal/7301 [Accessed Jul 21, 2017]. Natural Resources Canada.

NRCan (2017, March). Ground-source heat pumps (earth-energy systems). Available online at http://www.nrcan.gc.ca/energy/publications/ efficiency/heating-heat-pump/6833 [Accessed Aug 17, 2017]. Natural Resources Canada.

NREL (2012, May). Kaupuni village: A closer look at the first net-zero energy affordable housing community in hawai'i. Technical Report DOE/GO-1020123465, National Renewable Energy Laboratory and Department of Energy, Golden, Co.

NREL (2016). Distributed generation renewable energy estimate of costs. Available online at https://wwww.nrel.gov/analysis/tech-lcoe-re-cost-est.html [Accessed Oct 10, 2017].

NREL (2017). EnergyPlus source code. Available online at https://github.com/NREL/EnergyPlus/blob/develop/src/EnergyPlus/ MicroturbineElectricGenerator.cc [Accessed May 17, 2017].

O'Brien, W. and H. B. Gunay (2014). The contextual factors contributing to occupants' adaptive comfort behaviors in offices-a review and proposed modeling framework. Building and Environment 77, 77-87.

OEB (2016, December). Decision and rate order: Hydro One Networks Inc. Technical Report EB-2016-0081, Ontario Energy Board, Toronto, ON. 
OEB (2017). Historical electricity rates. Available online at https://www.oeb.ca/ rates-and-your-bill/electricity-rates/historical-electricity-rates [Accessed Oct 11, 2017]. Ontario Energy Board.

OEE (2006). Survey of household energy use 2003: Detailed statistical report. Technical Report M144-120/2003E, Natural Resources Canada, Ottawa, Ontario. Available online at http://oee.nrcan.gc.ca/Publications/statistics/sheu03/ pdf/sheu03.pdf [Accessed May 14 2014].

OEE (2012). Water heater guide. Technical report, Natural Resources Canada, Office of Energy Efficiency, Ottawa, ON. Available online at http://www.nrcan.gc.ca/sites/www.nrcan.gc.ca/files/oee/files/pdf/equipment/ WaterHeaterGuide_e.pdf [Accessed Sept 7, 2017].

OEE (2013). Energy use data handbook: 1990 to 2010. Technical Report M14111/2010E, Office of Energy Efficiency, Natural Resources Canada, Ottawa, ON.

OEE (2017). Comprehensive energy use database. Available online at http://oee.nrcan.gc.ca/corporate/statistics/neud/dpa/menus/trends/ comprehensive_tables/list.cfm [Accessed Jun 21, 2017]. Natural Resources Canada, Office of Energy Efficiency.

Omran, W. A., M. Kazerani, and M. Salama (2011). Investigation of methods for reduction of power fluctuations generated from large grid-connected photovoltaic systems. IEEE Transactions on Energy Conversion 26(1), 318-327.

ONS (2003). The United Kingdom 2000 time use survey. Technical report, Office for National Statistics, Newport, UK.

OPG (2017). Generating power. Available online at http://www.opg.com/ generating-power/ [Accessed Aug 7, 2017]. Ontario Power Generation.

OREC (2017, May). Review of Net Metering Opportunities, Barriers, and Implications for Solar Projects in Ottawa. Technical report, Ottawa Renewable Energy Co-operative Inc., Ottawa, ON. 
Orme, M., M. W. Liddament, and A. Wilson (1998). Numerical data for air infiltration and natural ventilation calculations. Technical report, Air Infiltration and Ventilation Centre, Coventry, UK.

Overmeer, M. (2011). Math::polygon - class for maintaining polygon data. Available online at http://search.cpan.org/ markov/Math-Polygon-1.02/lib/Math/ Polygon.pod [Accessed Sept. 26, 2017]. Comprehensive Perl Archive Network (CPAN).

Paatero, J. V. and P. D. Lund (2006). A model for generating household electricity load profiles. International journal of energy research 30(5), 273-290.

Parekh, A. (2005, August). Development of archetypes of building characteristcs libraries for simplified energy use evalaution of houses. In Proc. of Building Simulation 2005: 9th Conference of International Building Performance Simulation Association, Montréal, QC. IBPSA.

Parker, D. S. (2003). Research highlights from a large scale residential monitoring study in a hot climate. Energy and Buildings 35(9), 863-876.

Parsopoulos, K. E. and M. N. Vrahatis (2002). Recent approaches to global optimization problems through particle swarm optimization. Natural Computing 42(5), $235-306$.

Parsopoulos, K. E., M. N. Vrahatis, et al. (2002). Particle swarm optimization method for constrained optimization problems. Intelligent Technologies-Theory and Application: New Trends in Intelligent Technologies 76(1), 214-220.

Parti, M. and C. Parti (1980). The total and appliance-specific conditional demand for electricity in the household sector. The Bell Journal of Economics, 309-321.

Peeters, L., R. De Dear, J. Hensen, and W. Dhaeseleer (2009). Thermal comfort in residential buildings: Comfort values and scales for building energy simulation. Applied Energy 86(5), 772-780. 
Perl (2017). Available online at https://www.perl.org [Accessed Sept 4, 2017].

Pinel, P. (2014, August). Development of an ERV model for ESP-r. Technical report, Ottawa, ON. Prepared for NRCan.

Pinel, P., C. A. Cruickshank, I. Beausoleil-Morrison, and A. Wills (2011). A review of available methods for seasonal storage of solar thermal energy in residential applications. Renewable and Sustainable Energy Reviews 15(7), 3341-3359.

Pratt, R., C. Conner, E. Richman, K. Ritland, W. Sandusky, and M. Taylor (1989, April). Description of electric energy use in single family residences in the Pacific Northwest, End-Use Load and Consumer Assessment Program (ELCAP). Technical Report DOE/BP-13795-21, Pacific Northwest Laboratory, Richland, US.

Proskiw Engineering (2015, June). Air infiltration: Cost of air-sealing measures. Technical report, Prepared for CanmetENERGY, Natural Resources Canada, Ottawa, ON.

Purdy, J. (2002, June). GSHP modelling in ESP-r/HOT3000. Technical report, CanmetENERGY, Natural Resources Canada, Ottawa, ON.

Purdy, J. and A. Morrison (2003, August). Ground-source heat pump simulation within a whole-building analysis. In Proc. of the Eighth international IBPSA conference, Eindhoven, Netherlands, pp. 1077-1084. IBPSA.

Qiu, S., M. Ruth, and S. Ghosh (2015). Evacuated tube collectors: A notable driver behind the solar water heater industry in China. Renewable and Sustainable Energy Reviews 47, 580-588.

Quintana, H. J. and M. Kummert (2015). Optimized control strategies for solar district heating systems. Journal of Building Performance Simulation 8(2), 79 96.

Raab, S., D. Mangold, and H. Müller-Steinhagen (2005). Validation of a computer model for solar assisted district heating systems with seasonal hot water heat store. Solar Energy $79(5), 531-543$. 
Raustad, R. (2013). A variable refrigerant flow heat pump computer model in energyplus. ASHRAE Transactions 119, 299-308.

Rehau (2017). INSULPEX@Bpre-insulated PEXa piping: Design guide. Technical Report 855.630 01.2017.

Reinhart, C. F. and C. C. Davila (2016). Urban building energy modeling-a review of a nascent field. Building and Environment 97, 196-202.

Rezaie, B. and M. A. Rosen (2012). District heating and cooling: Review of technology and potential enhancements. Applied Energy 93, 2-10.

Richardson, I., M. Thomson, and D. Infield (2008). A high-resolution domestic building occupancy model for energy demand simulations. Energy and buildings 40(8), $1560-1566$.

Richardson, I., M. Thomson, D. Infield, and C. Clifford (2010). Domestic electricity use: A high-resolution energy demand model. Energy and Buildings 42(10), 18781887.

Richardson, I., M. Thomson, D. Infield, and A. Delahunty (2009). Domestic lighting: A high-resolution energy demand model. Energy and Buildings 41(7), 781-789.

Robert, A. and M. Kummert (2012). Designing net-zero energy buildings for the future climate, not for the past. Building and Environment 55, 150-158.

Rysanek, A. (2009, September). Second law performance analysis of a large thermal energy storage vessel using CFD. M.Sc, Queen's University, Kingston, ON.

Saldanha, N. and I. Beausoleil-Morrison (2012). Measured end-use electric load profiles for 12 Canadian houses at high temporal resolution. Energy and Buildings 49, $519-530$.

Salom, J., A. J. Marszal, J. Widén, J. Candanedo, and K. B. Lindberg (2014). Analysis of load match and grid interaction indicators in net zero energy buildings with simulated and monitored data. Applied Energy 136, 119-131. 
Salom, J., J. Widén, J. Candanedo, I. Sartori, K. Voss, and A. Marszal (2011). Understanding net zero energy buildings: Evaluation of load matching and grid interaction indicators. In Proc. of Building Simulation 2011: 12th Conference of International Building Performance Simulation Association, Sydney, Australia. IBPSA.

Sartori, I., A. Napolitano, and K. Voss (2012). Net zero energy buildings: A consistent definition framework. Energy and buildings 48, 220-232.

Schultz, J. r. M. (2005). Insulation materials for advanced water storages, Chapter 7, pp. 47-59. Paris, France: International Energy Agency: Solar Heating \& Cooling Programme.

SEL (2017). A TRaNsient SYstems Simulation Program. Available online at https://sel.me.wisc.edu/trnsys/ [Accessed Aug 2, 2017]. Solar Energy Laboratory, University of Wisconsin-Madison.

Self, S. J., B. V. Reddy, and M. A. Rosen (2013). Geothermal heat pump systems: Status review and comparison with other heating options. Applied Energy 101, 341-348.

Shah, L. J., E. Andersen, and S. Furbo (2005). Theoretical and experimental investigations of inlet stratifiers for solar storage tanks. Applied Thermal Engineering 25(14-15), 2086 - 2099.

Sherman, M. H. and G. D. T (1980, March). Infiltration-pressurization correlation: simplified physical modeling. Technical Report LBL-10163, Lawrence Berkeley Laboratory, Energy and Environment Division, Berkeley, CA.

Shirey, III, D. B. (2008, May). Expand the modeling capabilities of DOEs EnergyPlus ${ }^{\mathrm{TM}}$ building energy simulation program. Technical Report FSEC-CR1760-08, Florida Solar Energy Center, University of Central Florida, Cocoa, FL.

Short, T. A. (2003). Electric Power Distribution Handbook (1st ed.). Boca Raton: CRC Press LLC. 
Sibbitt, B., D. McClenahan, R. Djebbar, J. Thornton, B. Wong, J. Carriere, and J. Kokko (2012). The performance of a high solar fraction seasonal storage district heating system-five years of operation. Energy Procedia 30, 856-865.

Sifton (2017). West 5. Available online at http://west5.ca/ [Accessed Aug 1, 2017].

Sinnott, D. and M. Dyer (2012). Air-tightness field data for dwellings in ireland. Building and Environment 51, 269-275.

Skagestad, B. and P. Mildenstein (2002). District heating and cooling connection handbook. Technical report, International Energy Agency District Heating and Cooling.

Smith, A. E. and D. W. Coit (1997). C5.2: Penalty functions. In T. Bäck, D. Fogel, and Z. Michalewicz (Eds.), The Handbook of Evolutionary Computation, pp. 1 6. New York, NY: Oxford University Press/IOP Publishing Ltd.

Smith, A. E. and D. M. Tate (1993). Genetic optimization using a penalty function. In Proceedings of the 5th International Conference on Genetic Algorithms, San Francisco, CA, pp. 499-505. Morgan Kaufmann Publishers Inc.

Spall, J. C. (2003). Introduction to stochastic search and optimization: estimation, simulation, and control. Hoboken, NJ: John Wiley \& Sons.

SRCC (2009, August). Certified solar collector: Apricus AP-30. Technical Report Certification \# 2007033A, Solar Rating \& Certification Corporation, North Haven, CT.

Standards Council of Canada (1986, December). Determination of the airtightness of building envelopes by the fan depressurization method. Standard can/cgsb149.10-m86. Canadian General Standards Board.

Stanley, T. J. and T. Mudge (1995, July). A parallel genetic algorithm for multiobjective microprocessor design. In Proc. of the 6th International Conference on Genetic Algorithms (ICGA), Pittsburgh, PA, pp. $597-604$. 
Statistics Canada (1995). Survey of household energy use. Available online at http://www23.statcan.gc.ca/imdb/p2SV.pl?Function=getSurvey\& SurvId=1141\&InstaId $=3479 \&$ SDDS $=4403 \&$ db=IMDB [Accessed Apr 12, 2014] .

Statistics Canada (2003, March). Natural gas transportation and distribution 2001. Technical Report Catalogue no. 57-205-XIB, Statistics Canada, Ottawa, ON.

Statistics Canada (2010). General Social Survey, Cycle 24, 2010 [Canada]: TimeStress and Well-Being, Episode File [version 5] [public-use microdata file]. Data Liberation Initiative, Statistics Canada. Statistics Canada, Social and Aboriginal Statistics Division.

Statistics Canada (2011). 2011 national household survey. Catalogue no. 99-012X2011031.

Statistics Canada (2016). The general social survey: An overview. http:// www.statcan.gc.ca/pub/89f0115x/89f0115x2013001-eng.htm (Accessed: 2017-0324). Statistics Canada Catalogue no. 89F0115X.

Statistics Canada (2017a). Census profile: 2016 census. Catalogue no. 98-316X2016001.

Statistics Canada (2017b). Consumer price index, historical summary (1997 to 2016). Available online at http://www.statcan.gc.ca/tables-tableaux/sum-som/ 101/cst01/econ46a-eng.htm [Accessed Oct 9, 2017].

Statistics Canada (2017c). Estimates of population by census metropolitan area, sex and age group for july 1, based on the Standard Geographical Classification (SGC). CANSIM Table 051-0056.

Steele, J. (2013, February). On the path to equilibrium lessons learned for sustainable housing and communities. Available online at https://www.fcm.ca/ Documents/presentations/2013/SCC2013/On_the_Path_to_EQuilibrium_EN.pdf [Accessed Aug 1, 2017]. Presentation. 
Stokes, M., M. Rylatt, and K. Lomas (2004). A simple model of domestic lighting demand. Energy and Buildings 36(2), 103-116.

Strachan, P., G. Kokogiannakis, and I. Macdonald (2008). History and development of validation with the ESP-r simulation program. Building and Environment 43(4), 601-609.

Streicher, W., R. Heimrath, and B. Chris (2007). Analysis of system reports of task 26 for sensitivity of parameters: A report of iea shc - task 26. Technical report, International Energy Agency: Solar Heating \& Cooling Programme, Paris, France.

Súri, M., T. A. Huld, and E. D. Dunlop (2005). PV-GIS: a web-based solar radiation database for the calculation of PV potential in Europe. International Journal of Sustainable Energy 24(2), 55-67.

Šúri, M., T. A. Huld, E. D. Dunlop, and H. A. Ossenbrink (2007). Potential of solar electricity generation in the European Union member states and candidate countries. Solar energy 81(10), 1295-1305.

Swan, L. G. (2010, August). Residential Sector Energy and GHG Emissions Model for the Assessment of New Technologies. Ph.D., Dalhousie University, Halifax, NS.

Swan, L. G. and V. I. Ugursal (2009). Modeling of end-use energy consumption in the residential sector: A review of modeling techniques. Renewable and sustainable energy reviews 13(8), 1819-1835.

Swan, L. G., V. I. Ugursal, and I. Beausoleil-Morrison (2009). A database of house descriptions representative of the Canadian housing stock for coupling to building energy performance simulation. Journal of Building Performance Simulation 2(2), $75-84$.

Swan, L. G., V. I. Ugursal, and I. Beausoleil-Morrison (2013). Hybrid residential end-use energy and greenhouse gas emissions model-development and verification for Canada. Journal of Building Performance Simulation 6(1), 1-23. 
TESS (2012a). TESSLibs 17 - Loads and structures library mathematical reference. Technical report, Thermal Energy System Specialists, LLC, Madison, WI. Volume 8.

TESS (2012b). TESSLibs 17: Solar Library Mathematical Reference. Technical Report Volume 10, Thermal Energy System Specialists.

TESS (2013). TESSLibs 17 - Combined heat and power (CHP) / CoGeneration library mathematical reference. Technical report, Thermal Energy System Specialists, LLC, Madison, WI. Volume 13.

TESS (2014a). TESSLibs 17 - HVAC library mathematical reference. Technical report, Thermal Energy System Specialists, LLC, Madison, WI. Volume 6.

TESS (2014b). TESSLibs 17 - storage tank library mathematical reference. Technical report, Thermal Energy System Specialists, LLC, Madison, WI. Volume 11.

TESS (2014c). TRNSYS 17 - Mathematical reference. Technical report, Thermal Energy System Specialists, LLC, Madison, WI. Volume 4.

Torcellini, P., S. Pless, and M. Deru (2006, June). Zero energy buildings: A critical look at definition. Technical Report NREL/CP-550-39833, National Renewable Energy Laboratory and Department of Energy, Golden, Colorado.

Torío, H. and D. Schmidt (2010). Development of system concepts for improving the performance of a waste heat district heating network with exergy analysis. Energy and Buildings 42(10), 1601-1609.

Townsend, T. U. (1989). A method for estimating the long-term performance of direct-coupled photovoltaic systems. M.Sc., University of Wisconsin-Madison.

TRNSYS (2012). TRNSYS 17: Mathematical Reference. Technical Report Volume 4, Solar Energy Laboratory, University of Wisconsin-Madison, Madison, WI. 
Tuhus-Dubrow, D. and M. Krarti (2010). Genetic-algorithm based approach to optimize building envelope design for residential buildings. Building and environment 45(7), 1574-1581.

TÜV Rheinland (2009, November). Summary of EN 12975 test results: annex to Solar KEYMARK certificate: Apricus solar co. Technical Report Registration \# 011-7S161 R, TÜVRheinland DIN CERTCO, Berlin, Germany.

TÜV Rheinland (2014, March). Test report: Qualification of a solar collector in accordance with DIN EN 12975-1: 2011; DIN EN 12975-2: 2006 . Technical Report 154035663_EN_ETC-30_Report_Gao, TÜV Rheinland Shanghai, Shanghai, China.

Ulleberg, O. (1998, December). Stand-alone power systems for the future: optimal design, operation and control of solar-hydrogen energy systems. Ph.D., Norwegian University of Science and Technology, Trondheim, Norway.

Unifin (2017). Heat recovery systems for micro turbines. Technical report, Unifin International, London, ON. Available online at http://physics.oregonstate.edu/ $\sim$ hetheriw/energy/topics/doc/elec/natgas/micro/capstone.heat.exchangers.pdf [Accessed Jul 16, 2017].

Union Gas (2017). Chemical composition of natural gas. Available online at https://www.uniongas.com/about-us/about-natural-gas/ chemical-composition-of-natural-gas [Accessed Sept 28, 2017]. Union Gas Limited.

US DOE (2017). Crystalline silicon photovoltaics research. Available online at https://www.energy.gov/eere/sunshot/crystalline-silicon-photovoltaics-research [Accessed Apr 24, 2014]. U.S. Department of Energy, Office of Energy Efficiency and Renewable Energy.

U.S. Environmental Protection Agency (2013, Jul). Portfolio manager technical reference: Source energy. Technical report, Washington, DC. Available online at https://portfoliomanager.energystar.gov/pdf/reference/Source\%20Energy.pdf? d47e-0b81 [Accessed Jul 27, 2014]. 
Viessmann (2014). Technical data manual: Vitocrossal 200 gas-fired condensing boiler. Technical Report 5773 596-03 06, Viessmann manufacturing Company Inc., Waterloo, ON.

Wagner, C., C. Waniek, and U. Häger (2016). Modeling of household electricity load profiles for distribution grid planning and operation. In Power System Technology (POWERCON), 2016 IEEE International Conference on, pp. 1-6. IEEE.

Walker, C. F. and J. L. Pokoski (1985). Residential load shape modelling based on customer behavior. IEEE Transactions on Power Apparatus and Systems (7), 1703-1711.

Walker, I. and D. Wilson (1990). The Alberta air infiltration model: Aim-2. Technical report, The University of Alberta, Edmonton, Canada.

Walker, S. L. (2011). Building mounted wind turbines and their suitability for the urban scalea review of methods of estimating urban wind resource. Energy and Buildings 43(8), 1852-1862.

Wamboldt, J. (2009, January). Central solar heating plants with seasonal storage for residential applications in Canada: A case study of the Drake Landing Solar Community. M.Es., Queen's University, Kingston, ON.

Wang, W., I. Beausoleil-Morrison, and J. Reardon (2009). Evaluation of the Alberta air infiltration model using measurements and inter-model comparisons. Building and Environment 44 (2), 309-318.

Wang, W., R. Zmeureanu, and H. Rivard (2005). Applying multi-objective genetic algorithms in green building design optimization. Building and environment 40(11), $1512-1525$.

Watts up? (2008, February). Operators manual: Power analyzer, Watt meter and electricity monitor (Rev 9 ed.). Aurora, CO. https://www.wattsupmeters.com/ secure/downloads/manual_rev_9_corded0812.pdf (Accessed: 2017-03-31). 
Weiss, W. (2003). Solar Heating Systems for Houses: A Design Handbook for Solar Combisystems. London, UK: James \& James.

Werner Weiss, Monika Spörk-Dür, F. M. (2017, May). Solar heat worldwide: Global market development and trends in 2016 detailed market figures 2015. Technical report, IEA Solar Heating \& Cooling Programme, Graz, Austria.

Wetter, M. (2016, March). Genopt ${ }^{\circledR}$ : Generic optimization program user manual. Technical Report Version 3.1.1, Simulation Research Group, Lawrence Berkeley National Laboratory, Berkeley, CA.

Wetter, M. and J. Wright (2003, August). Comparison of a generalized pattern search and a genetic algorithm optimization method. In Proc. of the Eighth International IBPSA Conference, Eindhoven, Netherlands, pp. 1401-1408. International Building Performance Simulation Association.

Wetter, M. and J. Wright (2004). A comparison of deterministic and probabilistic optimization algorithms for non-smooth simulation-based optimization. Building and Environment 39(8), 989-999.

Widén, J., M. Lundh, I. Vassileva, E. Dahlquist, K. Ellegård, and E. Wäckelgård (2009). Constructing load profiles for household electricity and hot water from time-use datamodelling approach and validation. Energy and Buildings 41(7), 753-768.

Widén, J., A. M. Nilsson, and E. Wäckelgård (2009). A combined markov-chain and bottom-up approach to modelling of domestic lighting demand. Energy and Buildings 41(10), 1001-1012.

Widén, J. and E. Wäckelgård (2010). A high-resolution stochastic model of domestic activity patterns and electricity demand. Applied Energy 87(6), 1880-1892.

Widrow, B. and M. E. Hoff (1960, June). Adaptive switching circuits. Technical Report 1553-1, Stanford University, Stanford Electronics Labs. 
Wieringa, J. (1986). Roughness-dependent geographical interpolation of surface wind speed averages. Quarterly Journal of the Royal Meteorological Society 112(473), 867-889.

Wills, A., I. Beausoleil-Morrison, and V. I. Ugursal (2015, December). A preliminary study of upgrading an existing Canadian community to source net-zero using building simulation. In Proc. of the Building Simulation 2015 Conference, Hyderabad, India, pp. 2663-2670. IBPSA.

Wills, A., I. Beausoleil-Morrison, and V. I. Ugursal (2016, May). Evaluation of source net-zero performance for residential community-scale retrofit photovoltaic systems in Canadian locations. In Proc. of eSim 2016, Hamilton, ON. IBPSA.

Wills, A. D. (2013, May). Design and co-simulation of a seasonal solar thermal system for a Canadian single-family detached house. M.A.Sc., Carleton University, Ottawa, ON.

Wilton, K. (2017, March). Hydro-québec raising rates 0.7 per cent on April 1.

Windmill Developments (2017). zibi. Available online at http://www.zibi.ca/ [Accessed Sept 7, 2017].

Wu, S., R. Z. Rios-Mercado, E. A. Boyd, and L. R. Scott (2000). Model relaxations for the fuel cost minimization of steady-state gas pipeline networks. Mathematical and Computer Modelling 31(2-3), 197-220.

Yan, D., W. OBrien, T. Hong, X. Feng, H. B. Gunay, F. Tahmasebi, and A. Mahdavi (2015). Occupant behavior modeling for building performance simulation: Current state and future challenges. Energy and Buildings 107, 264-278.

Yilmaz, S., S. K. Firth, and D. Allinson (2015, December). A novel methodology for generating residential buildings electricity demand profiles. In Proc. of the Building Simulation 2015 Conference, Hyderabad, India, pp. 656-663. IBPSA. 
Yinger, R. J. (2001, July). Behavior of Capstone and Honeywell microturbine generators during load changes. Technical Report LBNL-49095, Southern California Edison, Rosemead, CA.

Zhao, H.-x. and F. Magoulès (2012). A review on the prediction of building energy consumption. Renewable and Sustainable Energy Reviews 16(6), 3586-3592.

Zurigat, Y., K. Maloney, and A. Ghajar (1989). A comparison study of onedimensional models for stratified thermal storage tanks. Journal of Solar Energy Engineering 111(3), 204-210. 


\section{Appendix A}

\section{AIM-2 Simulation Methodology}

Dwelling air infiltration in CHREM was modelled using the Alberta Air Infiltration Model (AIM-2) developed by Walker and Wilson (1990) and implemented in ESPr. The AIM-2 uses a whole-building approach to characterize infiltration into the dwelling, rather than explicitly modelling each gap and crack in the façade. Sherman and T (1980) had noted that most air flows through building envelopes are in both laminar and turbulent regimes, as well as in transition between the regimes. A typical way to express this fact was to assume that air leakage through the envelope, $\dot{V}_{i n f}$ $\left[\mathrm{m}^{3} / \mathrm{s}\right]$, could be expressed as an empirical function of pressure difference between outdoor and indoor air, $\Delta P[\mathrm{~Pa}]$, using a power law:

$$
\dot{V}_{i n f}=C_{0}(\Delta P)^{n}
$$

$C_{0}\left[\mathrm{~m}^{3} / \mathrm{s} \cdot \mathrm{Pa}^{n}\right]$ is the leakage coefficient, and $n[-]$ is the building leakage exponent. Both $C_{0}$ and $n$ for a dwelling are determined experimentally by least squares fitting to blower door test results. Blower door tests are performed using a powerful fan mounted in a fabric or solid panel which is inserted in the frame of an exterior door. Manometers are used to measure $\Delta P$ and airflow through the fan. Further details are omitted here for clarity, and the interested reader is directed to NRCan (2005) for additional information.

Equation A.1 is typically used to characterize flow through an orifice, where exponent $n$ has values between 0.5 and 1.0. For fully turbulent flow through the orifice 
$n=0.5$, and fully laminar flow $n=1.0$ (Sherman and $\mathrm{T}, 1980$ ). When applying Equation A.1 to determine building infiltration, Canadian standard CAN/CGSB149.10-M86 states the value of $n$ must also be between 0.5 and 1.0 (Standards Council of Canada, 1986). As $n$ approaches 1 the building envelope leakage is said to be predominately through small and long cracks, whereas if $n$ approaches 0.5 then the leakage is dominated by specific openings, such as a flue (Chan and Sherman, 2012; NRCan, 2005).

Several values of $n$ have been reported in the literature for residential envelopes. Walker and Wilson (1990) stated that $n=2 / 3$ for most dwellings. Orme et al. (1998) examined 1758 building data samples from Canada, Netherlands, New Zealand, UK, and USA. The majority of the building samples were reported to be residential dwellings. They were unable to establish a clear correlation between $n$ and other building characteristics, such as vintage or construction materials. Rather they found that $n$ was normally distributed with a mean value of approximately 0.66 . More recently, Chan and Sherman (2012) analyzed 134,000 single-family detached dwelling blower door test data from the Lawrence Berkeley National Laboratory's Residential Diagnostics Database (ResDB). They also found a normal distribution of $n$, with a mean value of 0.646 and a standard deviation of 0.057 .

At each simulation timestep Equation A.1 is not used explicitly to determine $\dot{V}_{\text {inf }}$, rather $C_{0}$ and $n$ are used in separate expressions to determine the wind and stack effect induced air flow through the envelope, $\dot{V}_{i n f, w}$ and $\dot{V}_{i n f, s}\left[\mathrm{~m}^{3} / \mathrm{s}\right]$, respectively. Air leakage sites in the envelope are divided into flue, ceiling, floors, and walls, the the value of $n$ is assumed to be the same for each site (Walker and Wilson, 1990). The leakage coefficient $C_{0}$ may then be expressed as:

$$
C_{0}=C_{c}+C_{f}+C_{w}+C_{\text {flue }}
$$

where $C_{c}[-]$ is the leakage coefficient of the ceiling, $C_{f}[-]$ is the leakage coefficient of the floor, $C_{w}[-]$ is the leakage coefficient of the walls, and $C_{\text {flue }}[-]$ is the leakage coefficient of the flue. How values for $C_{f}, C_{w}, C_{c}$, and $C_{\text {flue }}$ are determined from inputs are described later in Section A.2. 
Dimensionless leakage distribution parameters $R$ and $X$ are defined using the method proposed by Sherman and T (1980):

$$
\begin{gathered}
R=\frac{C_{c}+C_{f}}{C_{0}} \\
X=\frac{C_{c}-C_{f}}{C_{0}}
\end{gathered}
$$

Walker and Wilson (1990) added an additional parameter $Y$ to account for flue leakage:

$$
Y=\frac{C_{\text {flue }}}{C_{0}}
$$

These dimensionless leakage parameters, along with $n$, and the height of the building eave and flue top $H_{\text {eave }}$ and $H_{\text {flue }}[\mathrm{m}]$, respectively, are used to determine the dimensionless stack and wind factors $f_{s}$ and $f_{w}$, respectively. The expressions for $f_{s}$ and $f_{w}$ are omitted here for clarity, and the interested reader is directed to Walker and Wilson (1990) for further information.

Once $f_{s}$ and $f_{w}$ are established for an envelope, the air flow due to stack and wind effects are defined by Walker and Wilson (1990) as:

$$
\begin{gathered}
V_{i n f, s}=C_{0} f_{s} P_{s}^{n} \\
V_{i n f, w}=C_{0} f_{w} P_{w}^{n}
\end{gathered}
$$

where $P_{s}$ and $P_{w}$ are reference stack and wind pressures $[\mathrm{Pa}]$. These reference pressures are determined using:

$$
\begin{gathered}
P_{s}=\rho_{o} g H_{\text {eave }}\left(\frac{T_{i}-T_{o}}{T_{i}}\right) \\
P_{w}=\rho_{o} \frac{\left(S_{w} U_{e}\right)^{2}}{2}
\end{gathered}
$$


where $\rho_{o}\left[\mathrm{~kg} / \mathrm{m}^{3}\right]$ is the density of outdoor air, $g\left[\mathrm{~m} / \mathrm{s}^{2}\right]$ is gravitational acceleration, and $T_{i}$ and $T_{o}[\mathrm{~K}]$ are the indoor and outdoor temperatures, respectively, $S_{w}[-]$ is the local wind shelter coefficient, and $U_{e}[\mathrm{~m} / \mathrm{s}]$ is the unobstructed wind speed at the eaves height at the building site. The methods for determining $S_{w}$ and $U_{e}$ are omitted here for clarity, and the interested reader is directed to Walker and Wilson (1990) and Bradley (1993b) for additional information.

Once $\dot{V}_{i n f, s}$ and $\dot{V}_{i n f, w}$ are determined, they are superimposed to calculate the total envelope infiltration $\dot{V}_{\text {inf }}$. Walker and Wilson (1990) stated that stack and wind effects are not independent, since both act simultaneously on the cracks and gaps in the envelope. To account for this they summed the stack and wind-induced infiltration non-linearly along with an additional term to account for the interaction between the two effects, shown in Equation A.10:

$$
\dot{V}_{i n f}=\left[\dot{V}_{i n f, s}^{\frac{1}{n}}+\dot{V}_{i n f, w}^{\frac{1}{n}}+\beta_{1}\left(\dot{V}_{i n f, s} \dot{V}_{i n f, w}\right)^{\frac{1}{2 n}}\right]^{n}
$$

Walker and Wilson (1990) defined $\beta_{1}$ [-] as an interaction parameter which they assumed was constant. Based on their experimental data, they stated a reasonable estimate of $\beta_{1}$ is $1 / 3$.

\section{A.1 Infiltration Characterization}

Air leakage of building envelopes is often reported using a single scalar, rather than a curve like Equation A.1. Two commonly reported values for building leakage are equivalent or effective air leakage area, $A_{L}\left[\mathrm{~cm}^{2}\right]$, and air leakage at $50 \mathrm{~Pa}, A C H_{50}$ [ach]. From ASHRAE Fundamentals, the effective leakage area of an envelope is estimated from Equation A.11 (ASHRAE, 2009):

$$
A_{L}=10000 \dot{V}_{r} \frac{\sqrt{\rho_{r} / 2 \Delta P_{r}}}{C_{D}}
$$

where $\dot{V}_{r}\left[\mathrm{~m}^{3} / \mathrm{s}\right]$ is the infiltration flow rate at reference pressure difference $\Delta P_{r}[\mathrm{~Pa}]$, $\rho_{r}\left[\mathrm{~kg} / \mathrm{m}^{3}\right]$ is the density of air, and $C_{D}$ is a discharge coefficient. ASHRAE (2009) 
recommends a $\Delta P_{r}$ of either 4 or $10 \mathrm{~Pa}$, as these pressure differences are similar to the pressures that induce flow in practice. In Canada, $\Delta P_{r}=10 \mathrm{~Pa}$ is used to calculate $A_{L}$ with $C_{D}=0.61$ (Orme et al., 1998). According to Canadian standard CAN/CGSB-149.10-M86, $A_{L}$ is to be calculated with $\rho_{r}$ at $20^{\circ} \mathrm{C}$ and $101.325 \mathrm{kPa}$ (Standards Council of Canada, 1986) and $\Delta P_{r}=10 \mathrm{~Pa}$. The recommended value of $C_{D}$ is not given explicitly in the standard; however, $C_{D}$ may be determined from Equation A.12 provided in the standard:

$$
A_{L}=11570 \cdot C_{0} \cdot \sqrt{\rho_{r}} \cdot 10^{n-0.5}
$$

Rearranging Equation A.1 to solve for $C_{0}$ at $\Delta P=\Delta P_{r}=10 \mathrm{~Pa}$ and $\dot{V}_{\text {inf }}=\dot{V}_{r}$, and substituting $C_{0}$ into Equation A.12 yields:

$$
A_{L}=11570 \cdot\left(\frac{\dot{V}_{r}}{10^{n}}\right) \cdot \sqrt{\rho_{r}} \cdot 10^{n-0.5}
$$

Equating Equations A.11, and A.13 at $\Delta P_{r}=10 \mathrm{~Pa}$, and solving for $C_{D}$ yields $C_{D}=0.611$.

The air leakage of an envelope at $50 \mathrm{~Pa}, A C H_{50}$, may be determined by first calculating, using Equation A.1, or measuring the flow rate at $\Delta P=50 \mathrm{~Pa}$. The flow rate at $50 \mathrm{~Pa}, \dot{V}_{50}$, may then be converted to $A C H_{50}$ by the following expression:

$$
A C H_{50}=\frac{3600 \cdot \dot{V}_{50}}{V_{\text {zone }}}
$$

where $V_{\text {zone }}\left[\mathrm{m}^{3}\right]$ is the internal air volume of the envelope.

\section{A.2 Infiltration Model Inputs}

The AIM-2 implementation in ESP-r requires six sets of model inputs:

- Leakage description;

- Leakage distribution;

- Shielding and terrain data; 
- Height of building eaves, $H_{\text {eave }}$;

- Flue diameters;

- Zone indices.

Some of these inputs are self-explanatory, such as flue diameters and height of building eaves. The zone indices input specifies which zones will be included in the calculation of $V_{z o n e}$ and receive infiltration from the AIM-2 subroutines.

\section{A.2.1 Shielding and Terrain Data}

The shielding and terrain data input set contains five values: terrain type at the weather station, terrain type at the building, wall shielding type, flue shielding type, and anemometer height. The wall and flue shielding inputs are used to determine the local wind shelter coefficient $S_{w}$, introduced previously in Equation A.9. Walker and Wilson (1990) stated that $S_{w}$ is used to account for direct wind shielding caused by trees and neighbouring structures located within two house heights of the building site. The determination of $S_{w}$ is omitted here for clarity, and the interested reader is directed to Walker and Wilson (1990) for further details.

The climate data used as a boundary condition for building simulation is typically obtained from nearby weather stations rather than the building site itself. To estimate the local wind velocity at the building site from the weather station data, the wind velocity is corrected by accounting for the effect of overall terrain roughness which extends for several kilometres upwind of the building site (Walker and Wilson, 1990). The method to estimate local building wind velocities from weather station data for the AIM-2 implemented in ESP-r uses a logarithmic profile suggested by Bradley (1993b). This method was based on the methods proposed by Davenport (1960) and Wieringa (1986). The details of this method are omitted here for clarity, and the interested reader is directed to Bradley (1993b) and Wieringa (1986) for further information. 


\section{A.2.2 Leakage Description}

Two input options are available for building air leakage description in the AIM-2 implementation in ESP-r: standard airtightness values, and blower door test data. Standard airtightness values are defined for "loose", "average", "present", and "energy tight" building envelopes. Each set of standard airtightness values have a prescribed $n$ and $\bar{C}_{0}$, where $\bar{C}_{0}$ is defined by:

$$
\bar{C}_{0}=\frac{C_{0}}{V_{\text {zone }}}
$$

These standard airtightness values are not listed here for clarity, and the interested reader is directed to Bradley (1993b) for further details. The user is not required to input a value for $V_{z o n e}$, since $V_{\text {zone }}$ is calculated internally by ESP-r using the geometry of the zone(s) receiving AIM-2 infiltration.

The blower door test data input option, which is used in the CHREM, generally requires four inputs: $A C H_{50}, A_{L}, \Delta P_{r}$, and $C_{D}$. Beausoleil-Morrison (2000b) described how $n$ and $C_{0}$ are determined by simultaneously solving two equations. The first equation is cast using Equation A.1, evaluated at $\Delta P=50 \mathrm{~Pa}$. The flow rate on the left side of Equation A.1 is expressed in terms of $A C H_{50}$ and $V_{z o n e}$ using Equation A.14 yielding:

$$
\frac{A C H_{50} \cdot V_{\text {zone }}}{3600}=C_{0}(50)^{n}
$$

The second equation is determined from Equation A.11, and substituting in Equation A.1 with $\dot{V}_{\text {inf }}=\dot{V}_{r}$, and $\Delta P=\Delta P_{r}$ :

$$
A_{L}=10000 \cdot C_{0}\left(\Delta P_{r}\right)^{n} \frac{\sqrt{\rho_{r} / 2 \Delta P_{r}}}{C_{D}}
$$

The explicit expressions for $n$ and $C_{0}$ in terms of the blower door inputs determined by Beausoleil-Morrison (2000b) may be expressed as:

$$
n=\frac{\ln \left[\frac{10000 \cdot A C H_{50} V_{\text {zone } \sqrt{\rho_{r}}}}{3600 \cdot C_{D} A_{L} \sqrt{2 \Delta P_{r}}}\right]}{\ln \frac{50}{\Delta P_{r}}}
$$




$$
C_{0}=\frac{\sqrt{2} A_{L} C_{D}}{10000 \cdot \sqrt{\rho_{r}}\left(\Delta P_{r}\right)^{n-0.5}}
$$

For each dwelling modelled in the CHREM, dwelling values for $A C H_{50}$ and $A_{L}$ were drawn directly from the CSDDRD. It was assumed that all blower door tests were performed according to Canadian standard CAN/CGSB-149.10-M86, thus $\Delta P_{r}$ was set to $10 \mathrm{~Pa}$ and $C_{D}$ equal to 0.611 for all dwellings. Stated previously, standard CAN/CGSB-149.10-M86 stated that the value of $\rho_{r}$ be determined at $20^{\circ} \mathrm{C}$ and $101.325 \mathrm{kPa}$, which is reported as $1.204097 \mathrm{~kg} / \mathrm{m}^{3}$. For each dwelling modelled in the CHREM, Equations A.18 and A.19 were used to determine the infiltration curve in Equation A.1.

\section{A.2.3 Leakage Distribution}

The final input set required by the AIM-2 model in ESP-r is the leakage distribution. Three values are required from the user; leakage fraction for the ceiling, floor, and walls, $\alpha_{1}, \alpha_{2}$, and $\alpha_{3}[-]$, respectively. The sum of the leakage fractions must equal one. These leakage fractions are used to estimate the air leakage coefficients for the different air leakage sites introduced in Equation A.2 using the relationships provided from Bradley (1993b):

$$
\begin{aligned}
& \alpha_{1}=\frac{C_{c}}{C_{0}} \\
& \alpha_{2}=\frac{C_{f}}{C_{0}} \\
& \alpha_{3}=\frac{C_{w}}{C_{0}}
\end{aligned}
$$

Similar to the the leakage description inputs, the user may opt to use default leakage distribution values. The default values for leakage distributions are based on guidelines provided by Lew (1993), which provides values for leakage fractions based on the type of dwelling (i.e. single-detached), number of storeys, and foundation type 
(as cited in Wang et al. (2009)). In the CHREM, the leakage distribution fractions were user defined as $0.3,0.5$, and 0.2 for the ceiling, walls, and floor, respectively, for each dwelling. Swan (2010) stated that these are typical values for detached dwellings. 


\section{Appendix B}

\section{Solar Collector Sensitivity Studies}

The communities considered in this research did not represent specific existing dwellings, but rather more general representative dwellings drawn from the CSDDRD were used to explore various retrofit solutions to achieve retrofit. Using this approach, several assumptions were required to produce estimates for the feasibility and performance of the solutions. Solar energy systems are a renewable generation technology often associated with net-zero design solutions. For this work, it was assumed that only roof-mounted solar collectors were practical for existing communities. Ground mounted solutions require space which is assumed to not be available in existing communities. There are several techniques available to mount solar collectors to the roof; however, the simplest and most economical is to mount them flat against the roof, and this was assumed for this study.

The geometry and orientation of available roof area in communities was drawn directly from the geometric output from CHREM. During development of CHREM, Swan (2010) stated that detailed information of existing dwelling roof geometry was limited. Swan (2010) reduced roof geometries in CHREM to three types: flat, gable, or hip. To represent these types as three-dimensional geometries, Swan (2010) assumed that inclined roof surfaces had a rise:run relationship of 5:12, which they stated was a common value for Canadian housing. Since this assumption was also used in this work to specify the tilt of retrofit solar collectors, a sensitivity study was undertaken to examine the impact of collector tilt on solar PV and thermal collector 
annual energy production, and is presented in Section B.1.

For on-site solar thermal energy production, another assumption was required regarding plumbing of the collectors. All collectors in the same orientation were modelled as operating in an identical manner. To model the solar collectors in TRNSYS, the user must define how the collectors in an array are piped together. All collectors in an array may be connected in series, or divided among parallel branches. To evaluate the impact of these different collector networking configurations on annual energy performance, a simple sensitivity study was conducted in TRNSYS and is described in Section B.2.

\section{B.1 Solar Collector Tilt Sensitivity}

Two simple test cases were developed in TRNSYS; a single $200 \mathrm{~W}$ PV module, and a single flat-plate solar thermal collector. The collector tilt angle, $\beta\left[^{\circ}\right]$, was varied for each collector type, and annual solar energy production was determined for each $\beta$. The modelling methods and results of these studies are provided below.

\section{B.1.1 Photovoltaic Panel}

Type 94 in TRNSYS was used to model a Canadian Solar CS54-200M (Canadian Solar, 2014) 200 W PV module. This TRNSYS component uses a modelling approach proposed by Townsend (1989), where the PV panel is expressed as the equivalent circuit shown in Figure B.1. 


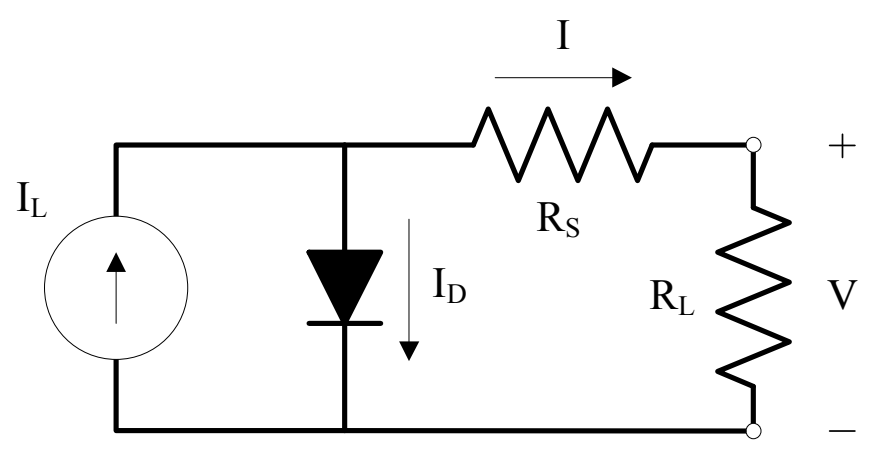

Figure B.1: 4 parameter PV cell equivalent circuit, adapted from Townsend (1989)

The four parameters used to define the circuit current-voltage characteristics are (Townsend, 1989):

- Photocurrent $I_{L}[\mathrm{~A}]$;

- Reverse saturation current $I_{0}[\mathrm{~A}]$;

- Completion factor $\gamma^{1}[-]$;

- and Series resistance $R_{S}[\Omega]$.

Model parameters for Type 94 are determined from commonly reported manufacturer's data. Details on the model parameters used in this study are provided in Table B.1. For clarity, the calculation procedure of Type 94 is omitted here. The interested reader is directed to Townsend (1989), Eckstein (1990), or TRNSYS (2012) for further details.

For the sensitivity study, three hourly Canadian weather for for energy calculation (CWEC) data (Environment Canada, 2014) sets were used for boundary conditions: Edmonton AB, Ottawa ON, and Windsor ON. These cities are located at latitudes, $\phi$, of $53.5^{\circ}, 45.3^{\circ}$, and $42.3^{\circ}$ respectively. The PV panel azimuth angle was set to $0^{\circ}$ from due south, and $\beta$ was varied between $0^{\circ}$ and $55^{\circ}$ at $1^{\circ}$ increments. The corresponding PV module annual energy production, $Q_{P V \text {,annual }}[\mathrm{kWh}]$, was determined

\footnotetext{
${ }^{1}$ The completion factor represents a measure of PV cellular imperfection (Townsend, 1989).
} 
Table B.1: Model parameters for Canadian Solar CS54-200M

\begin{tabular}{lr}
\hline Short-circuit current at ref. cond., $I_{s c, r e f}$ & $5.71 \mathrm{~A}$ \\
Open-circuit voltage at ref. cond., $V_{o c, r e f}$ & $45.3 \mathrm{~V}$ \\
Reference condition temperature & $298.15 \mathrm{~K}$ \\
Reference insolation, $G_{T, r e f}$ & $1000 \mathrm{~W} / \mathrm{m}^{2}$ \\
Voltage at max power point and ref. cond., $V_{m p p, r e f}$ & $37.4 \mathrm{~V}$ \\
Current at max power point and ref. cond., $I_{m p p, r e f}$ & $5.35 \mathrm{~A}$ \\
Short-circuit temp. coeff. of $I_{s c, r e f}, \mu_{I, s c}$ & $0.00343 \mathrm{~A} / \mathrm{K}$ \\
Open-circuit temp. coeff. of $V_{o c, r e f}, \mu_{V, o c}$ & $-0.145 \mathrm{~V} / \mathrm{K}$ \\
Number of cells wired in series, NOC & 72 \\
Module temp. at NOCT, $T_{N O C T}$ & $318.15 \mathrm{~K}$ \\
Ambient temp. at NOCT, $T_{N O C T, a m b}$ & $293.15 \mathrm{~K}$ \\
NOCT insolation, $G_{T, N O C T}$ & $800 \mathrm{~W} / \mathrm{m}^{2}$ \\
Module area, $A_{P V}$ & $1.28 \mathrm{~m}^{2}$ \\
Tau-alpha product for normal incidence, $(\tau \alpha)_{n}$ & 0.95 \\
Semiconductor bandgap, $E_{g}$ & 1.12 \\
Slope of I-V curve at $I_{s c}$ & $0 \mathrm{~A} / \mathrm{V}$ \\
\hline
\end{tabular}

using TRNSYS, and the results are shown in Figure B.2 and Table B.2. The PV module was assumed to always be operating at its maximum power point.

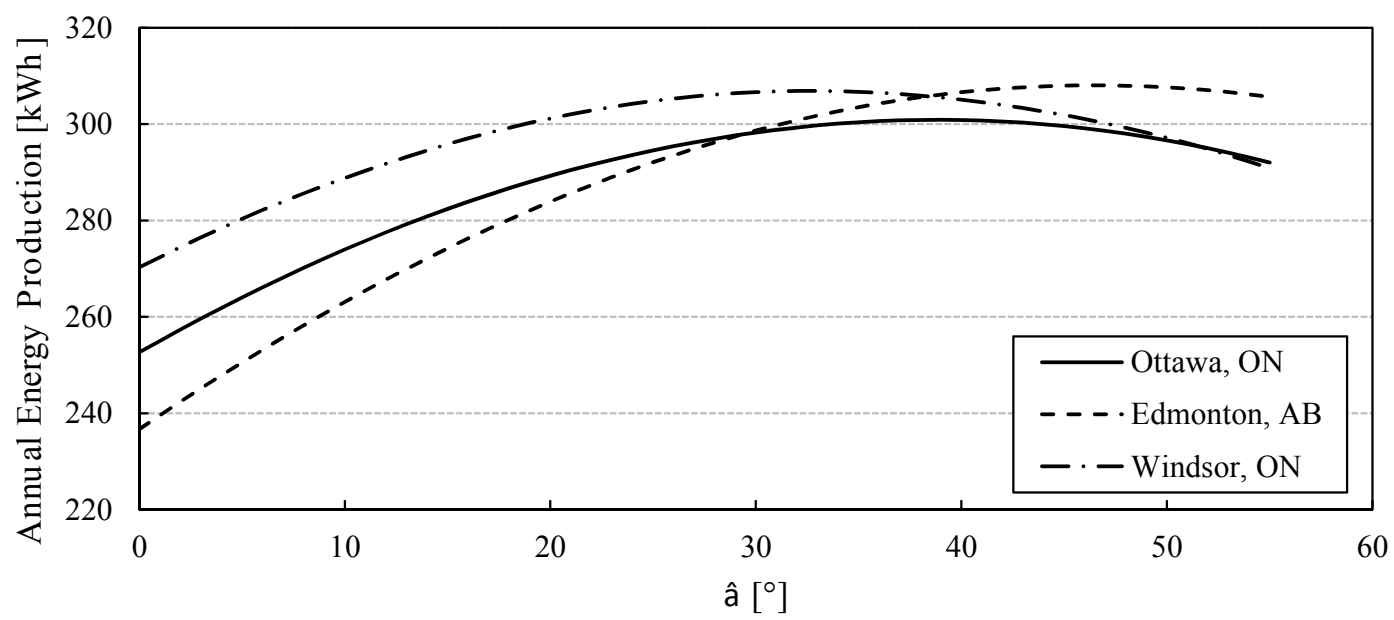

Figure B.2: Annual PV module electrical energy production versus module tilt angle 
Table B.2: Numerical results of the PV tilt study

\begin{tabular}{lccc}
\hline & Edmonton & Ottawa & Windsor \\
\hline \hline$Q_{P V, \text { annual }} @ \beta=0^{\circ}[\mathrm{kWh}]$ & 237 & 253 & 270 \\
Slope of the trend $@ \beta=0^{\circ}\left[\mathrm{kWh} /^{\circ}\right]$ & 3.05 & 2.49 & 2.22 \\
$Q_{P V, \text { annual }} @ \beta=23^{\circ}[\mathrm{kWh}]$ & 289 & 293 & 304 \\
Slope of the trend $@ \beta=23^{\circ}\left[\mathrm{kWh} /^{\circ}\right]$ & 1.56 & 1.01 & 0.678 \\
$\beta_{\text {max }}\left[^{\circ}\right]$ & 46 & 39 & 33 \\
$\phi-\beta_{\text {max }}\left[^{\circ}\right]$ & 7.5 & 6.3 & 9.3 \\
$Q_{P V, \text { annual,max }}[\mathrm{kWh}]$ & 308 & 301 & 307 \\
\hline
\end{tabular}

Shown in Figure B.2, initial increases of $\beta$ at $\beta=0^{\circ}$ yielded relatively large gains in $Q_{P V, \text { annual. }}$ As $\beta$ continued to increase, gains in $Q_{P V, \text { annual }}$ steadily decreased until reaching a maximum annual energy production, $Q_{P V, \text { annual,max }}$, at tilt angle $\beta_{\max }$. Higher latitudes corresponded to larger values of $\beta_{\max }$, which was related to increasing solar zenith angles. The sensitivity of $Q_{P V \text {,annual }}$ to the CHREM assumption of $\beta=23^{\circ}$ was found to increase as $\beta_{\max }$ increased, demonstrated by the slopes of the trends in Table B.2. However, increases in $Q_{P V \text {,annual }}$ from $\beta=23^{\circ}$ to $\beta_{\text {max }}$ for Edmonton, Ottawa, and Windsor were found to only be $6.6 \%, 2.8 \%$

\section{B.1.2 Solar Thermal Collector}

A similar study was conducted for a single flat plate solar collector modelled in TRNSYS, using Type 539 from the extended TESS component libraries (TESS, 2012b). Type 539 uses a one-dimensional discretization to solve the heat transfer across the collector, shown in Figure B.3. Each node is isothermal, and equal in size. 


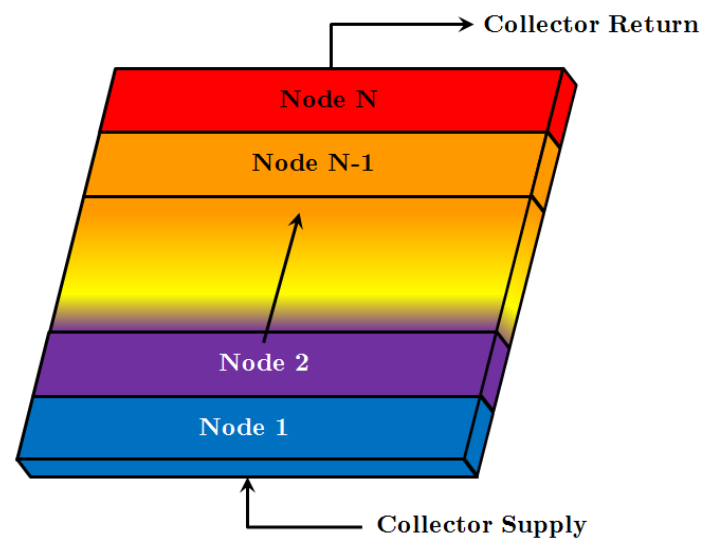

Figure B.3: One-dimensional discretization of a solar thermal collector, reproduced with permission from Wills (2013)

Similar to Type94 discussed previously, Type 539 uses commonly reported manufacturer's data to model the characteristics of the collector. The calculation procedure is omitted here for clarity, and the interested reader is directed to Duffie and Beckman (2013) and TESS (2012b) for further details.

For this study, Enerworks COL-4x8-TL-SGI-SD10 US flat-plate collector test data from Bodycote (2006) were used. This collector was modelled previously by Wills (2013), and details of the Type 539 input parameters may be found in that study. Similar to the PV slope study, the flat-plate collector azimuth was fixed at $0^{\circ}$, and the slope of the collector was varied between $0^{\circ}$ and $45^{\circ}$. CWEC data for Ottawa was used as the model boundary condition. Performance of the flat-plate collector was evaluated using the useful gain output, $\dot{Q}_{u s e f u l}[\mathrm{~W}]$, reported for every timestep of the simulation. $\dot{Q}_{u s e f u l}$ is calculated as:

$$
\dot{Q}_{u s e f u l}=\dot{m} c_{p, \text { fluid }}\left(T_{\text {out }}-T_{\text {in }}\right)
$$

where $T_{\text {out }}$ is the collector outlet temperature $\left[{ }^{\circ} \mathrm{C}\right] . \dot{Q}_{\text {useful }}$ was integrated over the simulation period to determine the annual useful energy gain, $Q_{\text {useful,annual }}[\mathrm{MWh}]$.

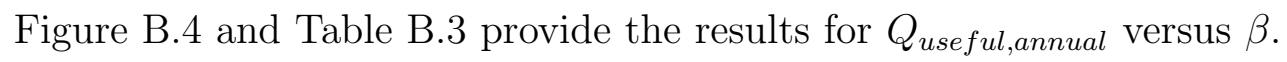




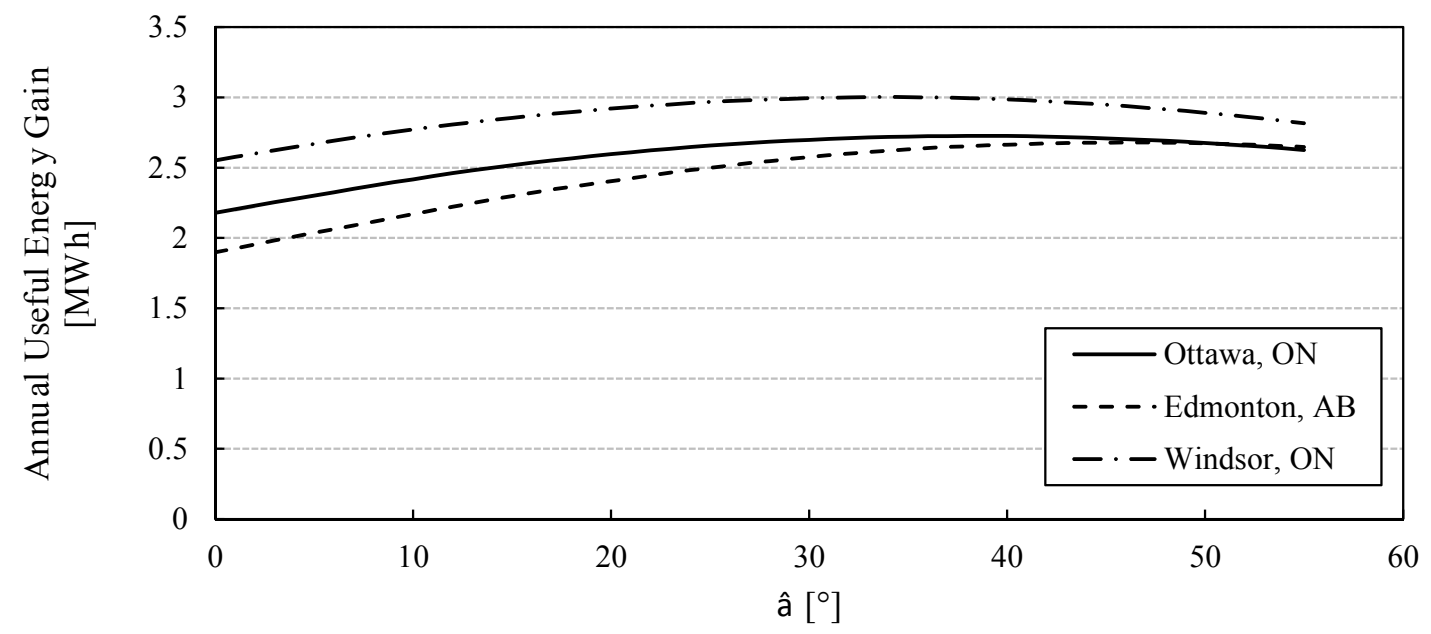

Figure B.4: Annual flate-plate collector useful energy gain versus module tilt

Table B.3: Numerical results of the flat-plate collector tilt study

\begin{tabular}{lccc}
\hline & Edmonton & Ottawa & Windsor \\
\hline \hline$Q_{\text {useful,annual }} @ 0^{\circ}[\mathrm{MWh}]$ & 1.90 & 2.18 & 2.55 \\
Slope of the trend $@ 0^{\circ}\left[\mathrm{MWh} /{ }^{\circ}\right]$ & 0.0339 & 0.0287 & 0.0269 \\
$Q_{\text {useful,annual }} @ 23^{\circ}[\mathrm{MWh}]$ & 2.46 & 2.64 & 2.95 \\
Slope of the trend $@ 23^{\circ}\left[\mathrm{MWh} /^{\circ}\right]$ & 0.0174 & 0.0116 & 0.00856 \\
$\beta_{\text {max }}\left[^{\circ}\right]$ & 46 & 39 & 34 \\
$\phi-\beta_{\text {max }}\left[^{\circ}\right]$ & 7.5 & 6.3 & 8.3 \\
$Q_{\text {useful,annual,max }}[\mathrm{MWh}]$ & 2.68 & 2.73 & 3.00 \\
\hline
\end{tabular}

The trends in Figure B.4 are similar to the trends found for the PV module in Figure B.2. Increasing the collector tilt angle from $\beta=23^{\circ}$ to $\beta_{\max }$ increased $Q_{u s e f u l, a n n u a l}$ for Edmonton, Ottawa, and Windsor by $6.6 \%, 2.8 \%$, and $1.1 \%$ respectively. 


\section{B.2 Solar Thermal Array Network Configuration Sensitivity Study}

For this sensitivity study, the flat-plate solar thermal collector described in Section B.1.2 was used and modelled with Type 539 in TRNSYS. An array of 20 collectors was modelled, and they were arranged in the six array configurations illustrated in Figure B.5. Each array was modelled with a constant $20{ }^{\circ} \mathrm{C}$ inlet temperature. Flow into the arrays was modelled using TRNSYS standard library Type 3b (TESS, 2014c), a simple $\mathrm{ON} / \mathrm{OFF}$ pump. The pump was controlled using temperature differential controller Type 2b (TESS, 2014c), which turns on the pump if the array outlet temperature is greater than inlet temperature with the user-specified deadband. For this study the deadband was set to $10{ }^{\circ} \mathrm{C}$ if the controller was OFF during the previous timestep, and $3{ }^{\circ} \mathrm{C}$ if the controller was previously $\mathrm{ON}$. 


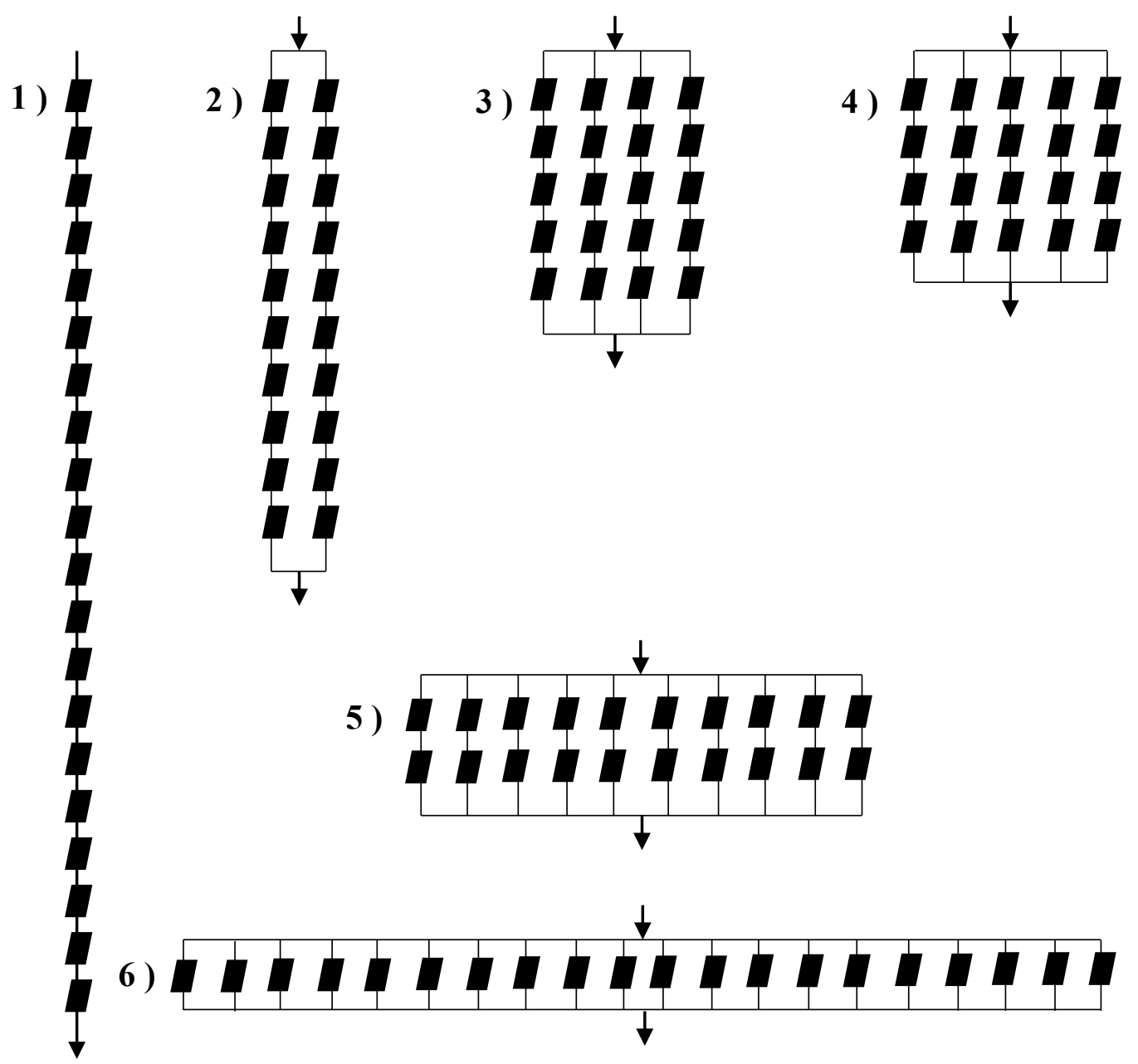

Figure B.5: Solar thermal collector array configurations considered

The mass flow rate into each array configuration was $690 \mathrm{~kg} / \mathrm{hr}$, or $12 \mathrm{~kg} / \mathrm{hr}$ per area of collector as recommended by Weiss (2003). Flow was divided evenly among each branch in the array. The version 1 Canadian weather year for energy calculations data for Ottawa from ECCC (2017b) was used to provide the boundary conditions to the solar thermal collectors. Annual simulations were run for each of the configurations shown in Figure B.5. For each simulation, a single instance of Type 539 was used. The number of collectors in series is a direct input into Type 539. The output from Type 539 was multiplied by the number of branches to represent 
the total output of the array.

For each simulation, $\dot{Q}_{u s e f u l, a n n u a l}$ and computation duration was recorded. The results are summarized in Table B.4. Simulations were performed on a machine with an i7 CPU at $2.10 \mathrm{GHz}$ with $8 \mathrm{~GB}$ of RAM, running a 64-bit Windows 7 operating system.

Table B.4: Results of the solar thermal collector array configuration sensitivity study with 15 nodes per collector

\begin{tabular}{|c|c|c|c|}
\hline No. in Series & $\begin{array}{l}\text { No. in } \\
\text { Parallel }\end{array}$ & $\begin{array}{c}\text { Array Annual } \\
\text { Useful Gain }[\mathrm{GJ}]\end{array}$ & $\begin{array}{l}\text { Compute } \\
\text { Time }[\mathrm{s}]\end{array}$ \\
\hline 20 & 1 & 148 & 246.94 \\
\hline 10 & 2 & 147 & 26.91 \\
\hline 5 & 4 & 146 & 20.79 \\
\hline 4 & 5 & 146 & 18.82 \\
\hline 2 & 10 & 145 & 17.46 \\
\hline 1 & 20 & 143 & 14.96 \\
\hline
\end{tabular}

It can be seen in Table B.4 that configuration of the collector array has a relatively small impact of annual useful energy gain estimates. The maximum difference of $\dot{Q}_{u s e f u l, a n n u a l}$ was $2.9 \%$, with all collectors in series providing the higher estimate and all collectors in parallel yielding the lowest estimate. In addition to annual useful gain, the computation times were recorded for each simulation. When all collectors were modelled in series the annual simulation took 246.94 seconds to complete. In contrast, the configuration with all collectors in parallel yielded the fastest simulation time. The differences in computational overhead were determined to be related to the finite-difference scheme used by Type 539.

Stated previously in Section B.1.2, Type 539 divides the solar collectors into a series of discrete nodes. In the Type inputs, the user must define the number of nodes per collector, as well as the number of collectors in series. The total number of nodes considered by the Type is then determined as a multiple of the two values. For 
example, for this study the number of nodes per collector was set to a static value of 15 . When 20 collectors were modelled in series, 300 nodes were used to define the system. In contrast, when all collectors were in parallel only a total of 15 nodes were considered.

To consider the sensitivity of collector heat transfer calculations to discretization, a single collector was modelled using the configuration described above. The number of nodes per collector was varied between 1 and 100, and all other parameters were held constant. It was found that for all discretization the fraction of time the solar collector circulation pump was ON was similar. For the single node case the pump was on $28.4 \%$. At 100 nodes this value increased to $28.5 \%$.

The relationship between $\dot{Q}_{\text {useful,annual }}$ and number of nodes is plotted in Figure B.6. It can be seen that with increasing discretization there is an increase in $\dot{Q}_{\text {useful,annual }}$. For example, when the number of nodes was increased from 1 to 5 , $\dot{Q}_{\text {useful,annual }}$ increased by $12 \%$ or an absolute increase of 21 GJ. Beyond 5 nodes however, the increases in $\dot{Q}_{u s e f u l, a n n u a l}$ are negligible. From 5 to 100 nodes for example, $\dot{Q}_{u s e f u l, a n n u a l}$ increased by $3 \%$.

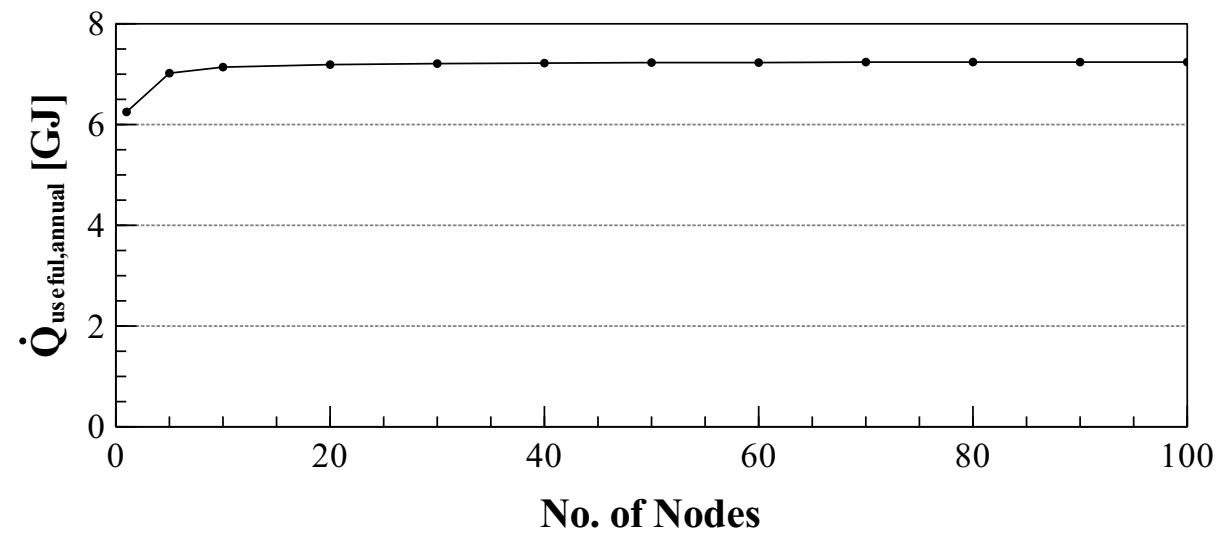

Figure B.6: Variation of collector annual useful gain with collector discretization

The array configuration study presented above was repeated using only one node per collector. The results of that study are presented in Table B.5. It can be seen that the variation in annual performance is much greater compared to the results 
presented in Table B.4. The maximum difference of $\dot{Q}_{\text {useful,annual }}$ in Table B.5 is $15.3 \%$, with all collectors in parallel yielding the lowest estimate and all collectors in series yielding the highest. This agrees with Figure B.6, where increased discretization increased $\dot{Q}_{\text {useful,annual }}$. For 20 collectors in series, the system is represented by 20 nodes, compared to a single node in the parallel configuration.

Table B.5: Results of the solar thermal collector array configuration sensitivity study with 1 node per collector

\begin{tabular}{|c|c|c|c|}
\hline No. in Series & $\begin{array}{l}\text { No. in } \\
\text { Parallel }\end{array}$ & $\begin{array}{c}\text { Array Annual } \\
\text { Useful Gain [GJ] }\end{array}$ & $\begin{array}{c}\text { Compute } \\
\text { Time }[\mathrm{s}]\end{array}$ \\
\hline 20 & 1 & 146 & 16.99 \\
\hline 10 & 2 & 144 & 16.55 \\
\hline 5 & 4 & 142 & 16.34 \\
\hline 4 & 5 & 141 & 16.66 \\
\hline 2 & 10 & 135 & 16.44 \\
\hline 1 & 20 & 125 & 16.37 \\
\hline
\end{tabular}

The results presented in this study demonstrated that the Type 539 collector model is sensitive to discretization, notably at lower resolutions. It is unclear however, if increasing the number of nodes in Type 539 increases the accuracy of the model. The underlying calculation methodology of Type 539 relies on performance data collected with respect to the whole-collector. This data is typically collected under a single flow condition, and relationships described in Duffie and Beckman (2013) are then used to relate test performance to performance under actual flow conditions.

Under lower flow conditions stronger temperature gradients would develop across the collector, which cannot be represented in single-node representation. For the results in Tables B.4 and B.5, the flow rate through the collectors for the case where all are in series is 20 times that of the all-parallel case. Even when there is a single node per collector, the configuration where all collectors are in series is able to 
represent a temperature gradient across the array which would be present in practice, and the results of this configuration are similar to the results found in Table B.4.

For this work it was assumed that the discretization method employed by Type 539 was valid, and 15 nodes per collector were assumed for mesh independence. Based on the similarities in performance calculations in Table B.4, all solar thermal collector retrofits modelled in this work were assumed to be in a parallel connection to take advantage of the reduced computational overhead. This also provided a more conservative estimate compared to the other configurations in Table B.4. It is recommended that future work consider the validity of the discretization method employed by Type 539 under high and low flow conditions. 


\section{Appendix C}

\section{Method to Determine Retrofit Foundation Configuration Type}

To model foundation heat loss in existing Canadian dwellings, CHREM used the regression-based model BASESIMP developed by Beausoleil-Morrison and Mitalas (1997). Independent variables considered in the regression included foundation geometry such as length, width, and depth, the RSI value of foundation insulation, depth of building-site water table, and soil conductivity. Several sets of regression coefficients were determined using quasi-three-dimensional simulations in the foundation heat loss tool BASECALC developed by Beausoleil-Morrison et al. (1995). As of writing, 145 sets of regression coefficients have been implemented in ESP-r (ESPrCommunity, 2017) representing various arrangements of foundation constructions and insulation placement.

Each dwelling model in CHREM has an associated foundation configuration type. To model the retrofit of these foundations with new interior insulation, first the insulation RSI needs to be updated to reflect the new value. If the original foundation configuration did not have full-height interior insulation, the model foundation configuration type needed to be updated as well. In the current work a set of mapping rules were defined to represent retrofitted foundations. These mapping rules are illustrated in Figures C.1, C.2, and C.3. 

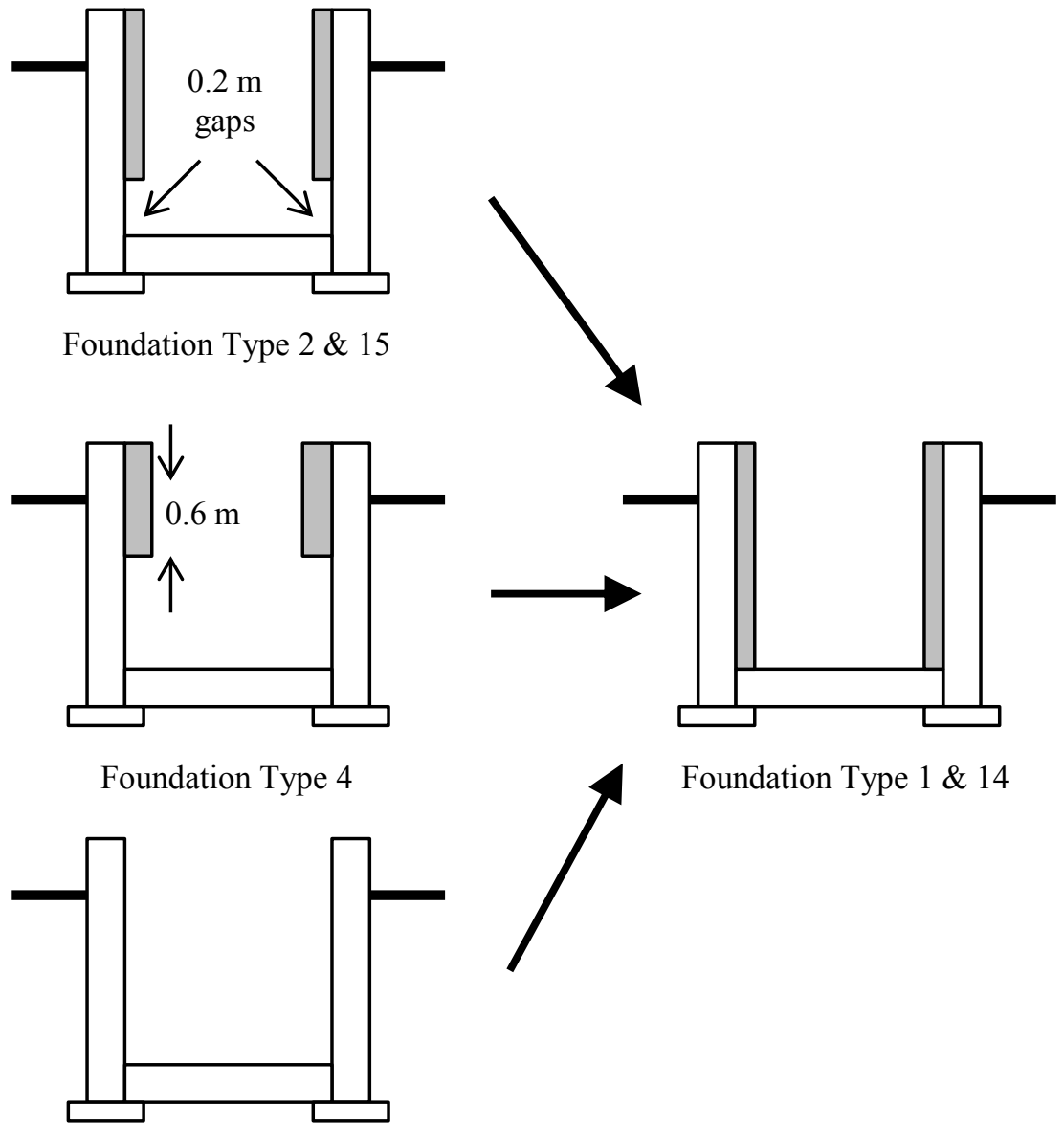

Foundation Type 10

Figure C.1: BASESIMP foundation configuration retrofit mapping rules 


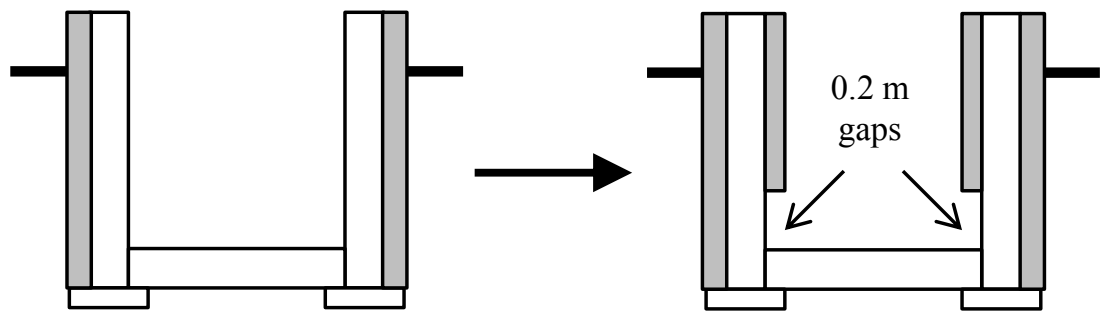

Foundation Type 6

Foundation Type 96

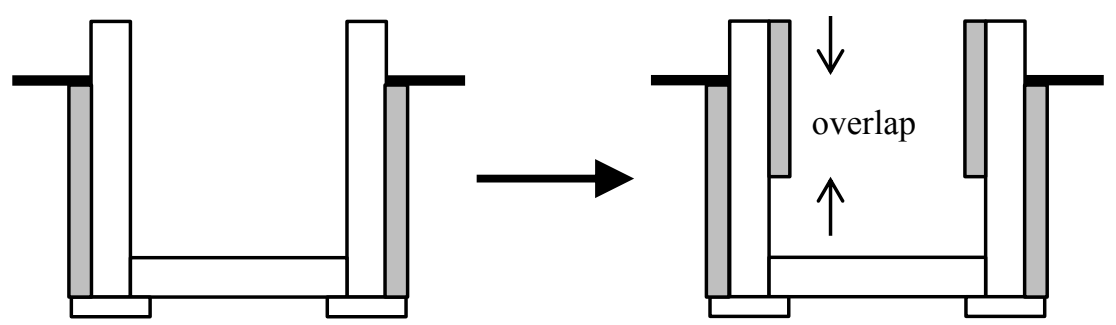

Foundation Type 8

Foundation Type 12

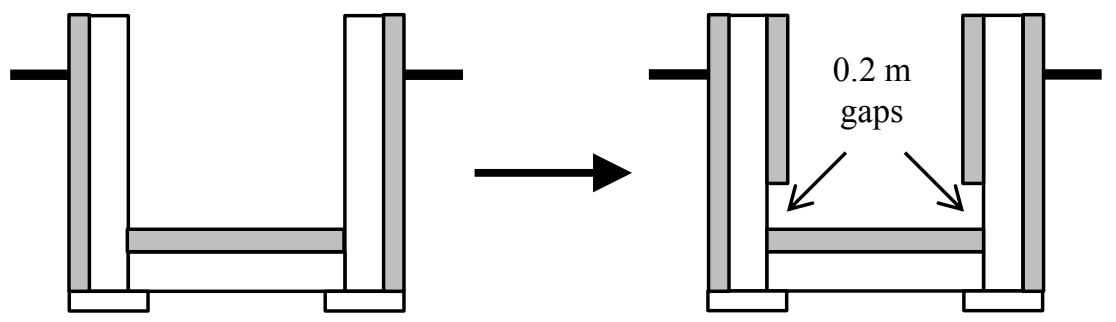

Foundation Type 71

Foundation Type 94

Figure C.2: BASESIMP foundation configuration retrofit mapping rules, cont'd 


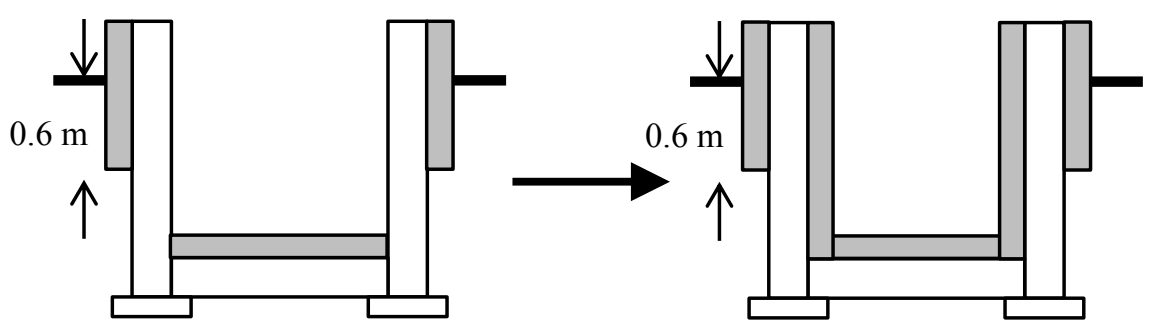

Foundation Type 98

Foundation Type 93

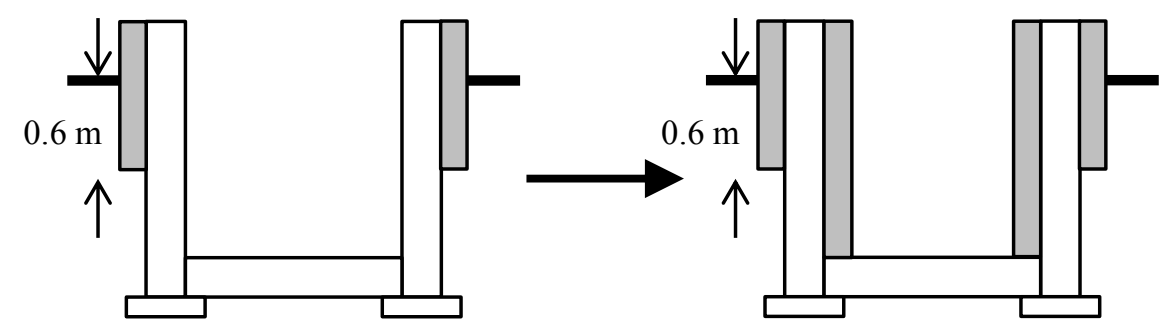

Foundation Type 110

Foundation Type 69

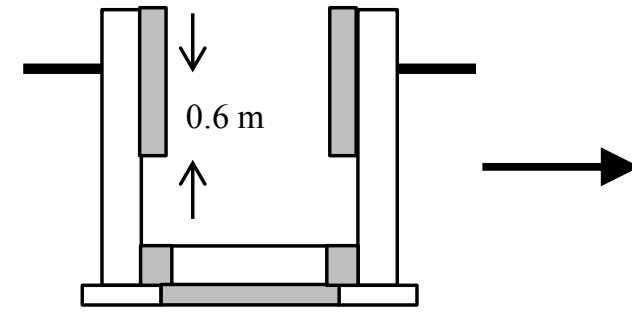

Foundation Type 119

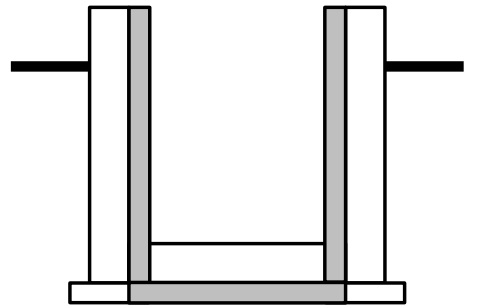

Foundation Type 22

Figure C.3: BASESIMP foundation configuration retrofit mapping rules, cont'd 


\section{Appendix D}

\section{Analysis of Modelled Aggregate Domestic Hot Water Demands}

To model DHW demand in CHREM, Swan (2010) used the artificial neural network (ANN) model developed previously by Aydinalp et al. (2004) to estimate the annual DHW consumption for each of the dwellings in the CSDDRD. The annual estimate was then used to map each CSDDRD record to one of three unique sub-hourly DHW demand profiles developed by Jordan and Vajen (2001a).

Since DH systems were considered in this work, a realistic representation of DHW demand diversity was required. A total of 57 high-resolution Canadian DHW demand profiles were collected from the literature and integrated into CHREM, described previously in Chapter 5. For each community modelled in this work, a unique DHW sub-hourly demand profile was assigned to each dwelling. The process to match the profiles to CSDDRD records is identical to the procedure implemented into CHREM by Swan (2010). The new profiles were also scaled to correspond to the annual DHW consumption estimated by the ANN model.

To demonstrate the impact of this methodology change, the 50 Windsor CSDDRD dwellings from the previous section were used. Two models of the 50 dwellings were produced; one using the profiles from Jordan and Vajen (2001a), and the other using the new 57 profiles. Simulations were performed at a 5-minute timestep. Since both modelling approaches use the same method to estimate the annual DHW consumption for CSDDRD records, annual performance metrics were not considered. 
Figure D.1 plots the load-duration curve for the aggregate DHW demands for the 50 dwellings. The DHW demands are expressed in $\mathrm{kW}_{\text {th }}$, and were provided as a direct output from the ideal DHW model in ESP-r (Lopez, 2001).

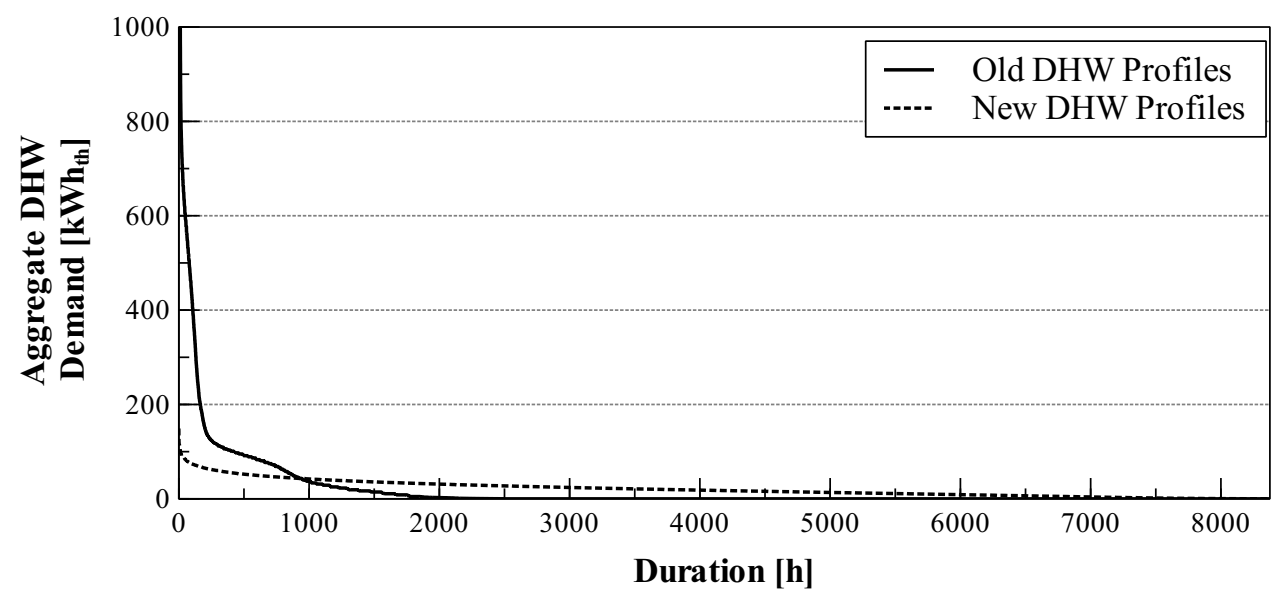

Figure D.1: DHW load-duration curves for the aggregate demand of 50 Windsor dwellings

Both aggregate DHW demands have the same annual DHW consumption, but it can be seen in Figure D.1 that the curve quickly reduces to zero using the old DHW profiles compared to the new. This indicates that the aggregate demands have numerous periods of no demand, and short intervals of relatively high demand. In contrast, the aggregated DHW profiles determined using the new approach have a flatter curve which does not reach zero until much later. This indicates higher diversity among the dwelling DHW demands which yields a smoother and more distributed aggregate DHW demand.

It is important to note that the load-duration curve for the old DHW profiles extends beyond the maximum y-axis coordinate shown. The scale of the y-axis was reduced in order to not obscure other details of the curves. The annual peak demand using the old profiles was $2449 \mathrm{~kW}_{\text {th }}$. Using 50 unique DHW profiles with the new DHW modelling method, the annual peak demand was found to be $145 \mathrm{~kW}_{\text {th }}$, a decrease of $94 \%$. The reason for this large discrepancy is that using the old DHW modelling methodology the same sub-hourly DHW demand profile was allocated to 
all 50 of the dwellings. Therefore all dwellings realize their peak DHW demands simultaneously.

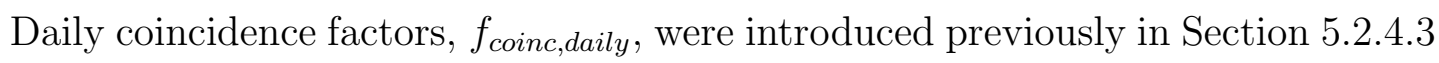
as a metric to characterize demand diversity. Values of $f_{\text {coinc,daily }}$ were determined for both DHW modelling approaches. As expected, $f_{\text {coinc,daily }}$ was equal to 1 for every simulation day. This means that the individual dwellings reach peak demand at the same time every day. When the new DHW profiles were used, values of $f_{\text {coinc,daily }}$ reduced to a mean value of 0.13 with a standard deviation of 0.02 . This indicates a relatively high variation in DHW peak demand occurrence among the dwellings.

Both DHW modelling approaches rely upon the estimates from the ANN model developed by Aydinalp et al. (2004), and the annual DHW consumption estimates for the dwellings were identical for both modelling techniques. Therefore when dwellingscale scale retrofits are considered either methodology will likely yield similar results. The relatively large difference in aggregate peak demand estimates between the two DHW approaches however, underscored the reason a new DHW model needed to be incorporated into CHREM to consider district energy systems in this work. 


\section{Appendix E}

\section{Optical and Thermal Properties of Retrofit Glazing Systems}

Three different window glazing systems were considered for retrofit into existing residential dwellings in the current work. The cross-sections of the fenestration systems are illustrated in Figure E.1. For each of the illustrations in Figure E.1, the exterior-facing side is to the left. The dotted lines represent the presence of a low-e coating.

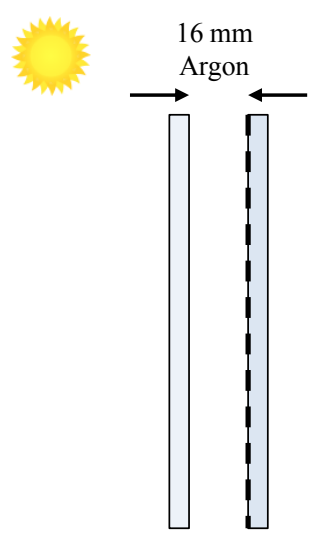

(a) System 1

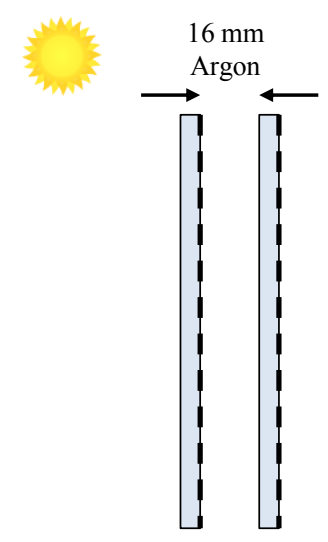

(b) System 2

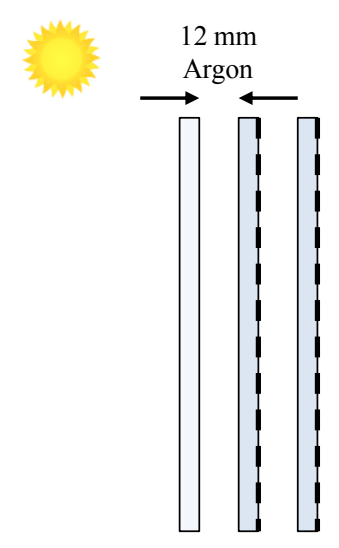

(c) System 3

Figure E.1: Configurations of the retrofit glazing systems 
The fenestration system cross-sections in Figure E.1 were used to define inputs to the WINDOW 7.4 software developed by LBNL (2016). The output from this software is the thermal performance of the fenestration systems according to standard NFRC 100-2010 (NFRC, 2017). The optical properties of the fenestration systems at various angles of solar incidence. To model fenestration systems in ESP-r, the solar transmissivity of the fenestration system is required at various angles of incidence. The solar absorptivity of each pane at different angles of incidence is also required. Figure E.2 plots the relevant optical properties for each of the fenestration systems illustrated in Figure E.1. 


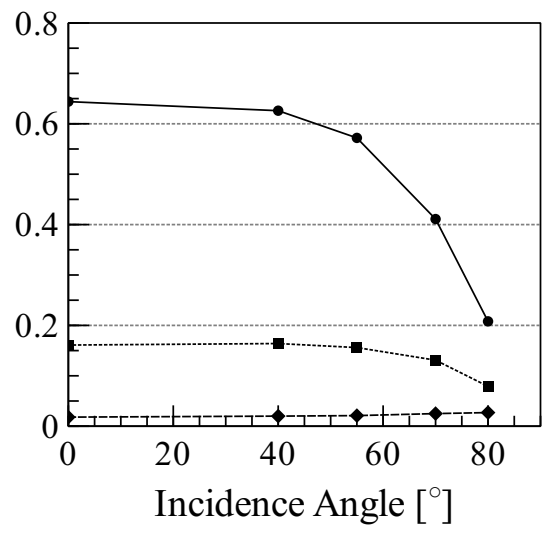

(a) System 1

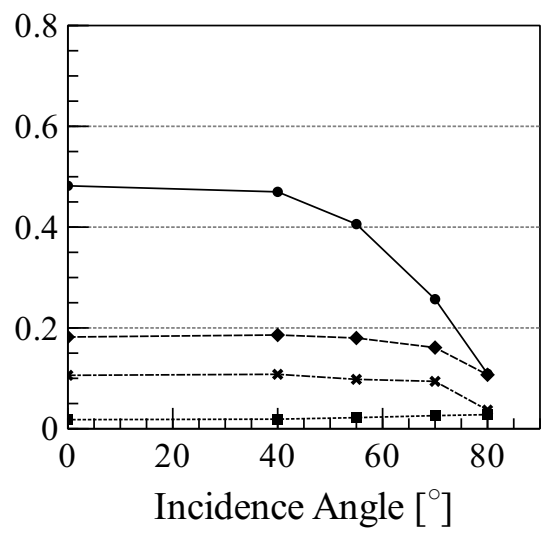

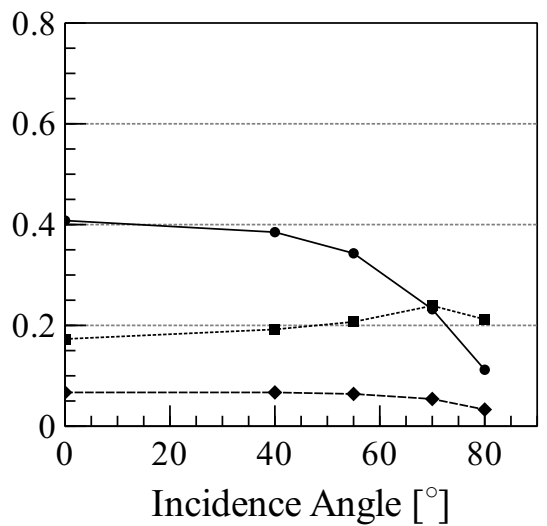

(b) System 2

(c) System 3

Figure E.2: Optical properties of the retrofit glazing systems 


\section{Appendix F}

\section{Impact of Envelope Retrofits on Dwelling Airtightness}

\section{F.1 Cluster Analysis}

Chapter 3 described the Energy Efficiency Database developed and maintained by NRCan. For this research, a filtered subset of this database was made available from Ferguson (2016). Dwellings which underwent only one type of retrofit were included in the subset. This subset was clustered by retrofit option, location, and decade of construction. The results of this statistical analysis are provided in the following subsections, where each section pertains to a specific retrofit option. Only retrofit options, vintages, and locations relevant to this research are included. 


\section{F.1.1 Ceiling Insulation Retrofits}

Table F.1: Percent decrease of $A C H_{50}$ for ceiling insulation retrofits in Ontario dwellings, by dwelling vintage

\begin{tabular}{lllllllll}
\hline $\begin{array}{l}\text { Vintage } \\
\text { Decade }\end{array}$ & Mean & Median & $\begin{array}{l}\text { Std. } \\
\text { Dev. }\end{array}$ & Skew & Kurtosis & Max. & Min. & $\begin{array}{l}\text { Sample } \\
\text { Size }\end{array}$ \\
\hline \hline 1940 & $12.5 \%$ & $11.0 \%$ & $11.9 \%$ & 0.536 & 0.073 & $46.9 \%$ & $-20.9 \%$ & 612 \\
1950 & $11.8 \%$ & $9.9 \%$ & $11.4 \%$ & 0.668 & 0.369 & $46.8 \%$ & $-22.9 \%$ & 1934 \\
1960 & $11.3 \%$ & $9.9 \%$ & $10.9 \%$ & 0.704 & 0.699 & $47.1 \%$ & $-23.0 \%$ & 2577 \\
1970 & $10.7 \%$ & $9.5 \%$ & $10.7 \%$ & 0.696 & 0.899 & $47.1 \%$ & $-23.3 \%$ & 3311 \\
1980 & $10.3 \%$ & $8.4 \%$ & $10.6 \%$ & 0.864 & 1.00 & $46.9 \%$ & $-20.4 \%$ & 2687 \\
1990 & $9.6 \%$ & $7.6 \%$ & $11.0 \%$ & 0.715 & 0.653 & $47.0 \%$ & $-21.1 \%$ & 1088 \\
\hline
\end{tabular}

Table F.2: Percent decrease of $A C H_{50}$ for ceiling insulation retrofits in Québec dwellings, by dwelling vintage

\begin{tabular}{lllllllll}
\hline $\begin{array}{l}\text { Vintage } \\
\text { Decade }\end{array}$ & Mean & Median & $\begin{array}{l}\text { Std. } \\
\text { Dev. }\end{array}$ & Skew & Kurtosis & Max. & Min. & $\begin{array}{l}\text { Sample } \\
\text { Size }\end{array}$ \\
\hline \hline 1980 & $11.3 \%$ & $10.5 \%$ & $11.1 \%$ & 0.411 & 0.299 & $45.3 \%$ & $-21.4 \%$ & 682 \\
1990 & $10.1 \%$ & $10.0 \%$ & $10.3 \%$ & 0.499 & 1.13 & $45.1 \%$ & $-20.8 \%$ & 433 \\
\hline
\end{tabular}




\section{F.1.2 Exterior Wall Insulation Retrofits}

Table F.3: Percent decrease of $A C H_{50}$ for exterior wall insulation retrofits in Ontario dwellings, by dwelling vintage

\begin{tabular}{lllllllll}
\hline $\begin{array}{l}\text { Vintage } \\
\text { Decade }\end{array}$ & Mean & Median & $\begin{array}{l}\text { Std. } \\
\text { Dev. }\end{array}$ & Skew & Kurtosis & Max. & Min. & $\begin{array}{l}\text { Sample } \\
\text { Size }\end{array}$ \\
\hline \hline 1940 & $15.7 \%$ & $14.3 \%$ & $14.6 \%$ & 0.303 & 0.075 & $54.8 \%$ & $-24.4 \%$ & 423 \\
1950 & $14.1 \%$ & $12.5 \%$ & $13.4 \%$ & 0.477 & 0.536 & $55.7 \%$ & $-27.0 \%$ & 947 \\
1960 & $13.5 \%$ & $10.8 \%$ & $14.2 \%$ & 0.886 & 0.616 & $55.2 \%$ & $-20.5 \%$ & 420 \\
1970 & $12.1 \%$ & $10.5 \%$ & $13.7 \%$ & 0.484 & 0.277 & $52.9 \%$ & $-24.8 \%$ & 544 \\
1980 & $12.0 \%$ & $10.3 \%$ & $13.2 \%$ & 0.541 & 0.794 & $51.5 \%$ & $-25.5 \%$ & 198 \\
1990 & $10.5 \%$ & $11.3 \%$ & $10.6 \%$ & -0.313 & 1.22 & $37.8 \%$ & $-22.7 \%$ & 52 \\
\hline
\end{tabular}

Table F.4: Percent decrease of $A C H_{50}$ for exterior wall insulation retrofits in Québec dwellings, by dwelling vintage

\begin{tabular}{lllllllll}
\hline $\begin{array}{l}\text { Vintage } \\
\text { Decade }\end{array}$ & Mean & Median & $\begin{array}{l}\text { Std. } \\
\text { Dev. }\end{array}$ & Skew & Kurtosis & Max. & Min. & $\begin{array}{l}\text { Sample } \\
\text { Size }\end{array}$ \\
\hline \hline 1980 & $14.1 \%$ & $13.2 \%$ & $14.3 \%$ & 0.335 & 0.029 & $53.1 \%$ & $-22.6 \%$ & 185 \\
1990 & $12.0 \%$ & $12.5 \%$ & $12.6 \%$ & -0.186 & 0.656 & $38.5 \%$ & $-24.3 \%$ & 52 \\
\hline
\end{tabular}




\section{F.1.3 Basement Insulation Retrofits}

Table F.5: Percent decrease of $A C H_{50}$ for basement insulation retrofits in Ontario dwellings, by dwelling vintage

\begin{tabular}{lllllllll}
\hline $\begin{array}{l}\text { Vintage } \\
\text { Decade }\end{array}$ & Mean & Median & $\begin{array}{l}\text { Std. } \\
\text { Dev. }\end{array}$ & Skew & Kurtosis & Max. & Min. & $\begin{array}{l}\text { Sample } \\
\text { Size }\end{array}$ \\
\hline \hline 1940 & $16.4 \%$ & $15.2 \%$ & $13.7 \%$ & 0.420 & -0.206 & $51.2 \%$ & $-23.6 \%$ & 506 \\
1950 & $14.5 \%$ & $13.1 \%$ & $12.9 \%$ & 0.395 & 0.104 & $50.7 \%$ & $-24.1 \%$ & 1151 \\
1960 & $14.0 \%$ & $12.1 \%$ & $12.7 \%$ & 0.540 & 0.276 & $51.5 \%$ & $-24.2 \%$ & 1035 \\
1970 & $14.3 \%$ & $12.6 \%$ & $13.2 \%$ & 0.336 & 0.003 & $50.7 \%$ & $-24.1 \%$ & 1135 \\
1980 & $12.5 \%$ & $10.9 \%$ & $12.5 \%$ & 0.599 & 0.506 & $50.8 \%$ & $-24.0 \%$ & 874 \\
1990 & $12.2 \%$ & $10.2 \%$ & $13.8 \%$ & 0.602 & 0.237 & $51.0 \%$ & $-24.4 \%$ & 528 \\
\hline
\end{tabular}

Table F.6: Percent decrease of $A C H_{50}$ for basement insulation retrofits in Québec dwellings, by dwelling vintage

\begin{tabular}{lllllllll}
\hline $\begin{array}{l}\text { Vintage } \\
\text { Decade }\end{array}$ & Mean & Median & $\begin{array}{l}\text { Std. } \\
\text { Dev. }\end{array}$ & Skew & Kurtosis & Max. & Min. & $\begin{array}{l}\text { Sample } \\
\text { Size }\end{array}$ \\
\hline \hline 1980 & $13.9 \%$ & $12.6 \%$ & $13.4 \%$ & 0.391 & -0.214 & $50.8 \%$ & $-24.8 \%$ & 439 \\
1990 & $14.1 \%$ & $13.9 \%$ & $12.7 \%$ & 0.097 & 0.194 & $51.2 \%$ & $-22.4 \%$ & 209 \\
\hline
\end{tabular}




\section{F.1.4 Window Retrofits}

Table F.7: Percent decrease of $A C H_{50}$ for window retrofits in Ontario dwellings, by dwelling vintage

\begin{tabular}{lllllllll}
\hline $\begin{array}{l}\text { Vintage } \\
\text { Decade }\end{array}$ & Mean & Median & $\begin{array}{l}\text { Std. } \\
\text { Dev. }\end{array}$ & Skew & Kurtosis & Max. & Min. & $\begin{array}{l}\text { Sample } \\
\text { Size }\end{array}$ \\
\hline \hline 1940 & $14.1 \%$ & $12.8 \%$ & $11.0 \%$ & 0.391 & -0.208 & $42.9 \%$ & $-18.7 \%$ & 556 \\
1950 & $12.8 \%$ & $11.8 \%$ & $10.8 \%$ & 0.425 & 0.013 & $43.1 \%$ & $-17.8 \%$ & 1323 \\
1960 & $12.0 \%$ & $10.5 \%$ & $10.9 \%$ & 0.519 & 0.155 & $43.3 \%$ & $-17.9 \%$ & 1710 \\
1970 & $11.7 \%$ & $10.7 \%$ & $10.1 \%$ & 0.501 & 0.385 & $43.1 \%$ & $-18.9 \%$ & 2502 \\
1980 & $10.3 \%$ & $9.3 \%$ & $9.8 \%$ & 0.684 & 0.798 & $43.2 \%$ & $-18.9 \%$ & 6439 \\
1990 & $8.7 \%$ & $7.3 \%$ & $9.5 \%$ & 0.834 & 1.50 & $43.3 \%$ & $-19.1 \%$ & 3558 \\
\hline
\end{tabular}

Table F.8: Percent decrease of $A C H_{50}$ for window retrofits in Québec dwellings, by dwelling vintage

\begin{tabular}{lllllllll}
\hline $\begin{array}{l}\text { Vintage } \\
\text { Decade }\end{array}$ & Mean & Median & $\begin{array}{l}\text { Std. } \\
\text { Dev. }\end{array}$ & Skew & Kurtosis & Max. & Min. & $\begin{array}{l}\text { Sample } \\
\text { Size }\end{array}$ \\
\hline \hline 1980 & $11.9 \%$ & $11.4 \%$ & $10.5 \%$ & 0.218 & 0.025 & $43.0 \%$ & $-17.6 \%$ & 1608 \\
1990 & $10.1 \%$ & $10.2 \%$ & $9.7 \%$ & 0.243 & 0.335 & $42.9 \%$ & $-19.0 \%$ & 482 \\
\hline
\end{tabular}

\section{F.2 HRV Retrofit Parameters}

Section 3.2.6 stated that each dwelling considered for retrofit in this study was assumed to have an HRV system system installed. The HRV system performance was modelled in ESP-r using the model developed by Bradley (1993a), and later modified by Pinel (2014). Four HRV units were modelled in this research, representing the range of rated flow rates reported by HVI (2017). The required ventilation flow-rate 
of post-retrofit dwellings was determined using ASHRAE Standard 62.2 (ASHRAE, 2016), and a suitable HRV unit was then allocated to the dwelling.

Table F.9 provides the performance data of the HRVs considered in this study. These performance metrics were derived from commercially-available units certified by HVI (2017), and reported on their website. Three tests are performed on HRV units, two of which are optional (Pinel, 2014). The heating season performance (HSP) test is mandatory, and uses $0{ }^{\circ} \mathrm{C}$ supply air, and $22{ }^{\circ} \mathrm{C}$ exhaust air. The two optional tests are very low temperature test (VLTT) and cooling season performance (CSP). For the VLTT supply air is reduced to $-25^{\circ} \mathrm{C}$, and exhaust air is at the same conditions for the HSP test. For the CSP test, supply air is at $35^{\circ} \mathrm{C}$ and exhaust air is at $24{ }^{\circ} \mathrm{C}$ (Pinel, 2014).

For the VLTT and HSP tests, the HRV sensible recovery efficiency (SRE) is measured and may be used as an input in the ESP-r HRV/ERV model. The SRE represents the ratio of the net-recovered ${ }^{1}$ sensible energy to the maximum recoverable energy plus the exhaust fan energy (Pinel, 2014). For the CSP test, the total recovery efficiency (TRE) is reported, and represents the ratio of total enthalpy recovery ${ }^{2}$ to maximum possible enthalpy recovery plus exhaust fan power. Power consumption of the HRV units are also reported.

Table F.9: HRV model parameters, derived from HVI (2017)

\begin{tabular}{lcccccc}
\hline Unit & $\begin{array}{c}\text { Flow } \\
\text { Rate [L/s] }\end{array}$ & $\begin{array}{c}\text { HSP SRE } \\
{[\%]}\end{array}$ & $\begin{array}{c}\text { HSP Elec. } \\
{[\mathbf{W}]}\end{array}$ & $\begin{array}{c}\text { VLTT SRE } \\
{[\%]}\end{array}$ & $\begin{array}{c}\text { VLTT Elec. } \\
{[\mathbf{W}]}\end{array}$ & $\begin{array}{c}\text { TRE } \\
{[\%]}\end{array}$ \\
\hline \hline 1 & 22 & 66.0 & 39.0 & 60.0 & 48.0 & 40.0 \\
2 & 31 & 75.0 & 54.0 & 70.0 & 72.0 & 40.0 \\
3 & 39 & 65.0 & 71.0 & 60.0 & 114.0 & 40.0 \\
4 & 51 & 70.0 & 92.0 & 60.0 & 104.0 & 40.0 \\
\hline
\end{tabular}

\footnotetext{
${ }^{1}$ Adjusted for electric consumption, case heat transfer, air leakage, mass flow imbalance, and defrost energy (Pinel, 2014)

${ }^{2}$ Adjusted for the same factors as SRE
} 


\section{Appendix G}

\section{Modelling Methodologies of Minor Community-scale System Components}

This appendix provides additional details of the performance metrics used to model the district heating system circulation pump and natural gas-fired back-up boiler system, introduced previously in Section 4.8 .

\section{G.1 District Heating Circulation Pump}

Frederiksen and Werner (2013) noted that under typical DH operating conditions the electrical demand for pumping is approximately $0.5 \%$ of the total thermal energy delivered. In this research, the thermal demands of the retrofit Toronto communities were found to vary between 2100 and $5100 \mathrm{GJ} / \mathrm{yr}$, which using the estimate from Frederiksen and Werner (2013) would correspond to annual pumping electrical consumption of 10.5 and $25.5 \mathrm{GJ} / \mathrm{yr}$, respectively. This demand is relatively small compared to the aggregate community A\&L and cooling electrical demands, which were determined to be between 1100 and 1400 GJ/yr.

In order to accurately determine the pumping power required for a DH system, detailed information regarding the piping network is required. Design and explicit analysis of DH systems were outside the scope of the current work, and thus a simplified approach to estimating pumping electrical demand was taken. The final expression used in this work to estimate pump electrical consumption at each timestep, 
$\dot{Q}_{D H, \text { elec }}(t)\left[\mathrm{kW}_{\mathrm{e}}\right]$, was provided previously in in Equation 4.13, and reproduced here for clarity:

$$
\operatorname{dot} Q_{D H, \text { elec }}(t)=\dot{Q}_{D H, \text { elec, } \max } \cdot\left(\frac{\dot{m}_{D H}(t)}{\dot{m}_{D H, \max }}\right)^{3}
$$

where $\dot{m}_{D H}(t)$ and $\dot{m}_{D H, \max }$ are the total inlet mass flow rate of the DH system at timestep $t$ and the maximum mass flow rate $[\mathrm{kg} / \mathrm{s}]$, respectively. $\dot{Q}_{D H, \text { elec,max }}$ is the electrical power consumption of the pump at maximum flow rate $[\mathrm{kW}]$.

The maximum mass flow rate was determined from the peak community thermal demand, $\dot{Q}_{\text {peak,th }}\left[\mathrm{kW}_{\mathrm{th}}\right]$. For the communities considered in this research this value was determined to be $650 \mathrm{~kW}_{\text {th }}$. The maximum mass flow rate was then determined from:

$$
\dot{m}_{D H, \text { max }}=\frac{\dot{Q}_{\text {peak }, \text { th }}}{c_{p, \text { water }} \cdot \Delta T}
$$

where the specific heat of water, $c_{p, w a t e r}$, was assumed to be a constant value of $4.18 \mathrm{~kJ} / \mathrm{kg} \cdot \mathrm{K}$. The temperature drop across the $\mathrm{DH}$ system, $\Delta T$, is $35 \mathrm{~K}$, described previously in Section 4.8.2. Therefore $\dot{m}_{D H, \max }$ was determined to be $4.44 \mathrm{~kg} / \mathrm{s}$.

The electrical power required for the $\mathrm{DH}$ system at maximum flow rate, $\dot{Q}_{D H, \text { pump,max }}[\mathrm{kW}]$, was then estimated using Equation G.3 (Frederiksen and Werner, 2013):

$$
\dot{Q}_{D H, \text { elec }, \text { max }}=\left(\frac{\Delta P_{D H, \text { max }}}{\eta_{\text {pump }}}\right) \cdot\left(\frac{\dot{m}_{D H, \max }}{\rho}\right)
$$

where $\Delta P_{D H, \max }[\mathrm{Pa}]$ is the head loss across the $\mathrm{DH}$ piping system, $\eta_{\text {pump }}$ is the pump efficiency, and $\rho$ is the density of the circulating fluid (assumed to be a constant 983 $\mathrm{kg} / \mathrm{m} 3)$. The pump was assumed to have a typical efficiency of $70 \%$.

The pressure drop across the DH loop, $\Delta P_{D H, \max }$, was estimated to be $480 \mathrm{kPa}$. The retrofit DH systems considered in this work were assumed to be low temperature. According to BRECSU (2002), low temperature systems typically operate at a maximum temperature and pressure of $90{ }^{\circ} \mathrm{C}$ and $600 \mathrm{kPa}$, respectively. This temperature range was well matched to the typical operating range of solar thermal 
collectors and residential terminal heating devices. Direct connection methods may also be used in low temperature DH systems which reduces the capital investment of DH systems (BRECSU, 2002). Less expensive PEX ${ }^{1}$ piping may also be used in low temperature DH systems. The maximum operating pressure of PEX varies by manufacturer. Rehau (2017) stated their insulated PEX product has maximum operating temperatures between 450 and $550 \mathrm{kPa}$. Thus $\Delta P_{D H, \max }$ equal to $480 \mathrm{kPa}$ was assumed to be an acceptable estimate.

Using the assumed values, Equation G.3 evaluates to $3.1 \mathrm{~kW}$. This was determined to be a reasonable estimate, given that the DH circulating pump installed at the Drake Landing Solar Community (DLSC) in Okotoks, Alberta has a rating of 3.8 $\mathrm{kW}$ (McClenahan, 2011). The DLSC was similar in character to the communities considered in this work. The DH system at the DLSC supplies low temperature water for space heating of 52 single-detached dwellings. The maximum flow rate of the DH loop at the DLSC is $5.35 \mathrm{~L} / \mathrm{s}$ (McDowell and Thorton, 2008), comparable to the $4.44 \mathrm{~kg} / \mathrm{s}$ assumed in this work.

To estimate the variation of pump electrical consumption to flow rate (Equation G.1), the simple equation for flow through a circular duct (Frederiksen and Werner, 2013) was used:

$$
\Delta P=-\frac{8 \cdot \lambda \cdot L}{d_{p i p e}^{5} \cdot \pi^{2} \cdot \rho} \cdot \dot{m}^{2}
$$

where $\lambda$ is the friction factor of the duct, $d_{\text {pipe }}$ is the inner pipe diameter [m], and $L$ is the length of the duct [m]. Equation G.4 shows that pressure drop across the duct is related to the inverse square of the mass flow rate in the duct, $\dot{m}$. Substituting Equation G.4 into Equation G.3 shows that the electrical consumption of the pump is proportional to the third power of $\dot{m}^{2}$. Therefore the variation of DH pump electrical power consumption, $\operatorname{dot} Q_{D H, \text { elec }}(t)$, was determined using Equation G.1, where $\operatorname{dot} Q_{D H, \text { elec }}(t)$ varies proportionally with the third power of $\dot{m}_{D H}(t)$. At maximum flow Equation G.1 evaluates to $\operatorname{dot} Q_{D H \text {,elec }}(t)=3.1 \mathrm{~kW}_{\mathrm{e}}$, and at no flow

\footnotetext{
${ }^{1}$ cross-linked polyethylene

${ }^{2}$ Assuming constant pump efficiency.
} 
$\operatorname{dot} Q_{D H, \text { elec }}(t)=0 \mathrm{~kW}_{\mathrm{e}}$

\section{G.2 Back-up Boiler}

Modelling of the DH system back-up boiler was described previously in Section 4.8.3. The boiler efficiency was assumed to vary as a function of the entering water temperature, $T_{\text {inlet }}\left[{ }^{\circ} \mathrm{C}\right]$, and the part-load ratio (PLR) of the boiler. The efficiency curves assumed for this research are plotted in Figure G.1, and are based on the commercially-available condensing boiler manufactured by Viessmann (2014).

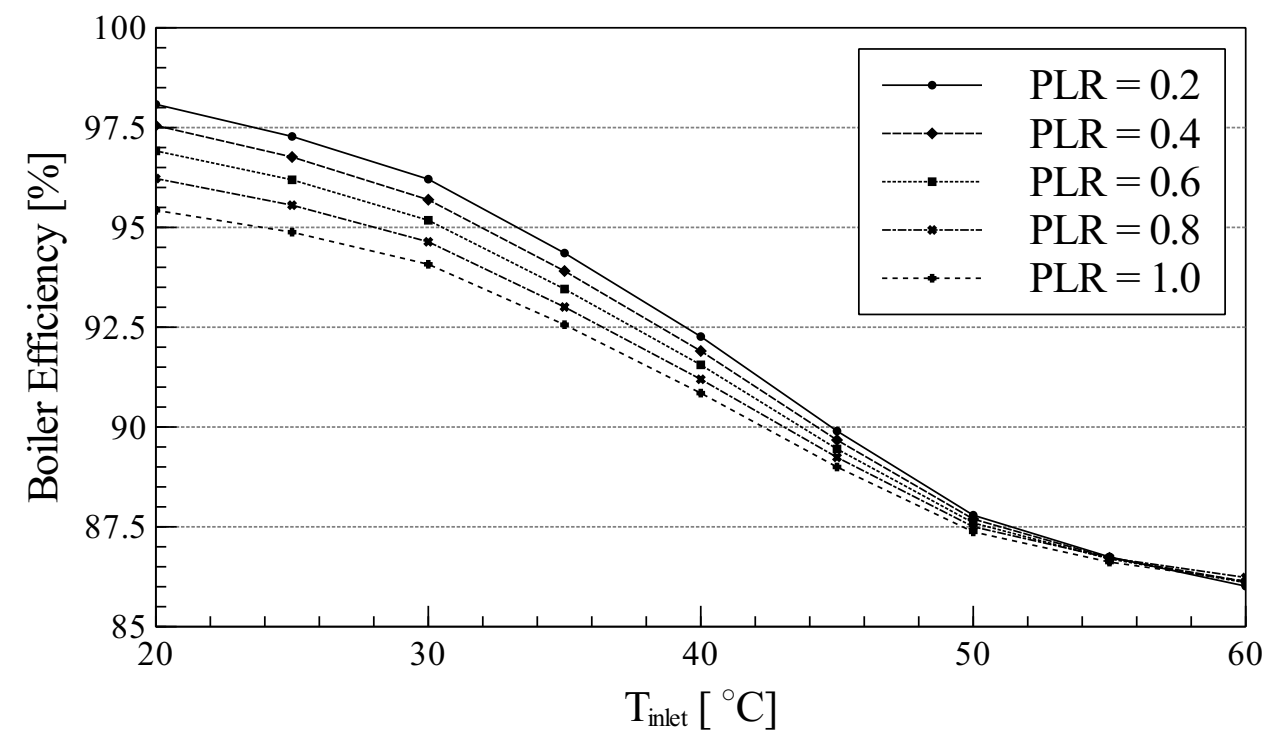

Figure G.1: DH system boiler efficiency curves, based upon data from Viessmann (2014) 


\section{Appendix $\mathbf{H}$}

\section{Microturbine Performance Curves and Thermal Load Following Control}

\section{H.1 Microturbine Performance Curves}

Introduced previously in Section 4.7, microturbines were modelled in this research using the steady-state empirical model developed by Shirey (2008). This model uses sets of performance curves and surfaces to determine microturbine fuel consumption and electrical and thermal output under different operating conditions. This model was previously implemented within the building simulation tool EnergyPlus (NREL, 2017), and was ported over to the simulation tool TRNSYS (SEL, 2017) for this work. Compared to EnergyPlus, TRNSYS offers greater flexibility for the development and implementation of energy system control strategies.

Three microturbines with rated electrical outputs of 30,65 , and $200 \mathrm{~kW}_{\mathrm{e}}$ were considered in this research. These microturbines are manufactured by the Capstone Turbine Corporation, and performance data was obtained from Capstone (2006), Capstone (2008), and Capstone (2009), respectively. Each report provided the variation of nominal microturbine operating parameters as a function of different ambient temperature and part-load ratio operating points. For each operation point considered, the following operation outputs were reported:

- net electrical power output; 
- net efficiency;

- exhaust temperature;

- exhaust mass flow rate;

- and fuel flow rate.

Each report also included the turbine power output derating as a function of ambient pressure.

Each microturbine was characterized in the model using a set of seven performance curves and surfaces. The following sections describe each of these performance curves and surfaces that were derived for the microturbines, as well as the performance curve coefficients determined for each of the microturbines. Performance data was fit to curves and surfaces using the fit function in MATLAB. Each performance curve is normalized with respect to the nominal operational performance reported by the manufacturer.

\section{H.1.1 Electrical Power Modifier Curve}

The electrical power modifier curve, PowerFTempElev, expresses the normalized electrical output of the microturbine as a function of the ambient temperature, $T_{a m b}\left[{ }^{\circ} \mathrm{C}\right]$, and pressure, $P_{a m b}[\mathrm{~atm}]$ :

$$
\text { PowerFTempElev }=a_{1}+a_{2} \cdot T_{a m b}+a_{3} \cdot T_{a m b}^{2}+a_{4} \cdot P_{a m b}+a_{5} \cdot P_{a m b}^{2}+a_{6} \cdot T_{a m b} \cdot P_{a m b}
$$

Table H.1 provides the nominal electrical power output of each of the microturbines, as well as the values of the coefficients in Equation H.1. The electrical output of the microturbine is determined at each timestep by multiplying Equation H.1 by the nominal electrical output of the microturbine. 
Table H.1: Coefficients of the microturbine electrical power modifier curve

\begin{tabular}{lccc}
\hline & C30 & C65 & C200 \\
\cline { 2 - 4 } Nominal Elec. & 30 & 65 & 200 \\
Output $[\mathrm{kW}]$ & & & \\
\hline \hline$a_{1}$ & $2.07 \mathrm{E}-02$ & $-2.18 \mathrm{E} 04$ & $-1.20 \mathrm{E} 05$ \\
$a_{2}$ & $3.20 \mathrm{E}-03$ & $2.93 \mathrm{E} 02$ & $3.27 \mathrm{E} 02$ \\
$a_{3}$ & $-1.07 \mathrm{E}-04$ & -6.40 & $-4.61 \mathrm{E} 01$ \\
$a_{4}$ & $9.89 \mathrm{E}-01$ & $3.31 \mathrm{E} 05$ & $1.11 \mathrm{E} 06$ \\
$a_{5}$ & $-1.07 \mathrm{E}-04$ & $-3.11 \mathrm{E} 04$ & $-1.68 \mathrm{E} 05$ \\
$a_{6}$ & $-4.84 \mathrm{E}-03$ & $-1.73 \mathrm{E} 03$ & $-3.82 \mathrm{E} 03$ \\
$\max . T_{a m b}\left[{ }^{\circ} \mathrm{C}\right]$ & 50.0 & 50.0 & 50 \\
$\min . T_{a m b}\left[{ }^{\circ} \mathrm{C}\right]$ & -20.0 & -20.0 & -20.0 \\
$\max . P_{a m b}[\mathrm{~atm}]$ & 1.0 & 1.0 & 1.0 \\
$\min . P_{a m b}[\mathrm{~atm}]$ & 0.56 & 0.69 & 0.075 \\
\hline
\end{tabular}

\section{H.1.2 Electrical Efficiency of the Microturbine}

Electrical efficiency of the microturbine is expressed as the ratio of electrical power output to fuel input, where fuel flow rate is expressed as power input using the lower heating value. The electrical efficiency of the microturbine is determined at each timestep as a function of the inlet temperature $T_{a m b}$ and the part-load ratio (PLR) or the microturbine. The effect of $T_{a m b}$ and PLR on efficiency is expressed separately in Equations H.2 and H.3, and the product of these two equations is multiplied with the nominal electrical efficiency to determine the operating efficiency.

$$
\text { ElecEfficiencyTemp }=a_{1}+a_{2} \cdot T_{a m b}+a_{3} \cdot T_{a m b}^{2}+a_{4} \cdot T_{a m b}^{3}
$$

$$
\text { ElecEfficiencyPLR }=a_{1}+a_{2} \cdot P L R+a_{3} \cdot P L R^{2}+a_{4} \cdot P L R^{3}
$$


The coefficients for Equations H.2 and H.3 which were determined for the microturbines considered in this study are provided in Tables H.2 and H.3, respectively.

Table H.2: Coefficients of the microturbine electrical efficiency-temperature modifier curve

\begin{tabular}{lccc}
\hline & C30 & C65 & C200 \\
\cline { 2 - 4 } Nominal & 26 & 29 & 32.8 \\
Efficiency [\%] & & & \\
\hline \hline$a_{1}$ & 1.05 & 1.04 & 1.03 \\
$a_{2}$ & $-2.45 \mathrm{E}-03$ & $-1.73 \mathrm{E}-03$ & $-1.53 \mathrm{E}-03$ \\
$a_{3}$ & $-5.06 \mathrm{E}-05$ & $-6.50 \mathrm{E}-05$ & $-2.96 \mathrm{E}-05$ \\
$a_{4}$ & $2.76 \mathrm{E}-07$ & $5.13 \mathrm{E}-07$ & $2.31 \mathrm{E}-07$ \\
\hline
\end{tabular}

Table H.3: Coefficients of the microturbine electrical efficiency modifier curve

\begin{tabular}{cccc}
\hline & C30 & C65 & C200 \\
\hline \hline$a_{1}$ & $2.07 \mathrm{E}-01$ & $2.15 \mathrm{E}-01$ & $2.82 \mathrm{E}-01$ \\
$a_{2}$ & 2.68 & 2.56 & 2.56 \\
$a_{3}$ & -3.25 & -3.25 & -3.11 \\
$a_{4}$ & 1.38 & 1.50 & 1.28 \\
\hline
\end{tabular}

\section{H.1.3 Exhaust Gas Flow Rate of the Microturbine}

Similar to the electrical efficiency in Section H.1.2, the mass flow rate of the microturbine exhaust is determined each timestep as a function of $T_{a m b}$ and PLR using Equations H.4 and H.5, respectively. The mass flow rate is determined by multiplying Equations H.4 and H.5 with the nominal exhaust flow rate.

$$
\text { ExhFlowTemp }=a_{1}+a_{2} \cdot T_{a m b}+a_{3} \cdot T_{a m b}^{2}+a_{4} \cdot T_{a m b}^{3}
$$




$$
\text { ExhFlowPLR }=a_{1}+a_{2} \cdot P L R+a_{3} \cdot P L R^{2}+a_{4} \cdot P L R^{3}
$$

The coefficients for Equations H.4 and H.5 which were determined for the microturbines considered in this study are provided in Tables H.4 and H.5, respectively.

Table H.4: Coefficients of the microturbine exhaust air flow rate-temperature curve

\begin{tabular}{lccc}
\hline & C30 & C65 & C200 \\
\cline { 2 - 4 } Nominal Exh. & 0.29 & 0.49 & 1.33 \\
Flow Rate $[\mathrm{kg} / \mathrm{s}]$ & & & \\
\hline \hline$a_{1}$ & $9.76 \mathrm{E}-01$ & $9.84 \mathrm{E}-01$ & 1.00 \\
$a_{2}$ & $1.17 \mathrm{E}-03$ & $6.77 \mathrm{E}-05$ & $-4.06 \mathrm{E}-04$ \\
$a_{3}$ & $-9.98 \mathrm{E}-06$ & $5.36 \mathrm{E}-05$ & $3.49 \mathrm{E}-05$ \\
$a_{4}$ & $-1.35 \mathrm{E}-06$ & $-2.13 \mathrm{E}-06$ & $-1.39 \mathrm{E}-06$ \\
\hline
\end{tabular}

Table H.5: Coefficients of the microturbine exhaust air flow rate-PLR curve

\begin{tabular}{cccc}
\hline & C30 & C65 & C200 \\
\hline \hline$a_{1}$ & $2.94 \mathrm{E}-01$ & $2.72 \mathrm{E}-01$ & $2.59 \mathrm{E}-01$ \\
$a_{2}$ & 1.06 & 1.31 & 1.08 \\
$a_{3}$ & $-6.78 \mathrm{E}-01$ & -1.05 & $-6.06 \mathrm{E}-01$ \\
$a_{4}$ & $3.24 \mathrm{E}-01$ & $4.62 \mathrm{E}-01$ & $2.67 \mathrm{E}-01$ \\
\hline
\end{tabular}

\section{H.1.4 Exhaust Gas Temperature of the Microturbine}

Lastly the exhaust air temperature is determined at each timestep by multiplying Equations H.6 and H.7 by the nominal exhaust temperature supplied as an input.

$$
\text { ExhTempTemp }=a_{1}+a_{2} \cdot T_{a m b}+a_{3} \cdot T_{a m b}^{2}+a_{4} \cdot T_{a m b}^{3}
$$




$$
\operatorname{ExhTempPLR}=a_{1}+a_{2} \cdot P L R+a_{3} \cdot P L R^{2}+a_{4} \cdot P L R^{3}
$$

The coefficients for Equations H.6 and H.7 which were determined for the microturbines considered in this study are provided in Tables H.6 and H.7, respectively.

Table H.6: Coefficients of the microturbine exhaust air temperature-temperature curve

\begin{tabular}{lccc}
\hline & C30 & C65 & C200 \\
\cline { 2 - 4 } $\begin{array}{l}\text { Nominal Exh. } \\
\text { Temperature }\left[{ }^{\circ} \mathrm{C}\right]\end{array}$ & 243.9 & 308.9 & 279.5 \\
\hline \hline$a_{1}$ & $9.29 \mathrm{E}-01$ & $9.25 \mathrm{E}-01$ & $9.07 \mathrm{E}-01$ \\
$a_{2}$ & $4.74 \mathrm{E}-03$ & $5.26 \mathrm{E}-03$ & $6.12 \mathrm{E}-03$ \\
$a_{3}$ & $-3.14 \mathrm{E}-05$ & $-1.97 \mathrm{E}-05$ & $1.04 \mathrm{E}-05$ \\
$a_{4}$ & $-2.35 \mathrm{E}-07$ & $-5.67 \mathrm{E}-07$ & $-1.08 \mathrm{E}-06$ \\
\hline
\end{tabular}

Table H.7: Coefficients of the microturbine exhaust air temperature-PLR curve

\begin{tabular}{cccc}
\hline & C30 & C65 & C200 \\
\hline \hline$a_{1}$ & $6.94 \mathrm{E}-01$ & $5.92 \mathrm{E}-01$ & $5.37 \mathrm{E}-01$ \\
$a_{2}$ & $2.76 \mathrm{E}-01$ & $8.79 \mathrm{E}-01$ & $7.29 \mathrm{E}-01$ \\
$a_{3}$ & $8.53 \mathrm{E}-02$ & $-8.80 \mathrm{E}-01$ & $-6.90 \mathrm{E}-01$ \\
$a_{4}$ & $-5.79 \mathrm{E}-02$ & $4.11 \mathrm{E}-01$ & $4.32 \mathrm{E}-01$ \\
\hline
\end{tabular}

\section{H.2 Microturbine Thermal Following Control}

Stated previously in Section 4.7.4, a thermal following strategy for retrofit microturbines was initially considered for this research. This control strategy analogous to 
the heat-led operating strategy described by Hawkes and Leach (2007), where direct thermal output of the microturbine attempts to meet, but not exceed, the on-site thermal demand. To model this control strategy in the TRNSYS model, standard library Type 22 (TESS, 2014c) was used. Type 22 is an ideal control model, where the iterative secant method is used each simulation timestep to minimize the error between the setpoint and the sensed control parameter. The simplicity of the control model comes at the expense of increased computational overhead.

Given the thermal demand characteristics of the communities considered however, a thermal following approach was determined not to be practical for this study. To illustrate, the thermal load-duration (L-D) curves for the unretrofit and retrofit 19811990 Toronto community are plotted in Figure H.1. For the retrofit case all envelope upgrades were applied at the maximum level, as well as HRV systems.

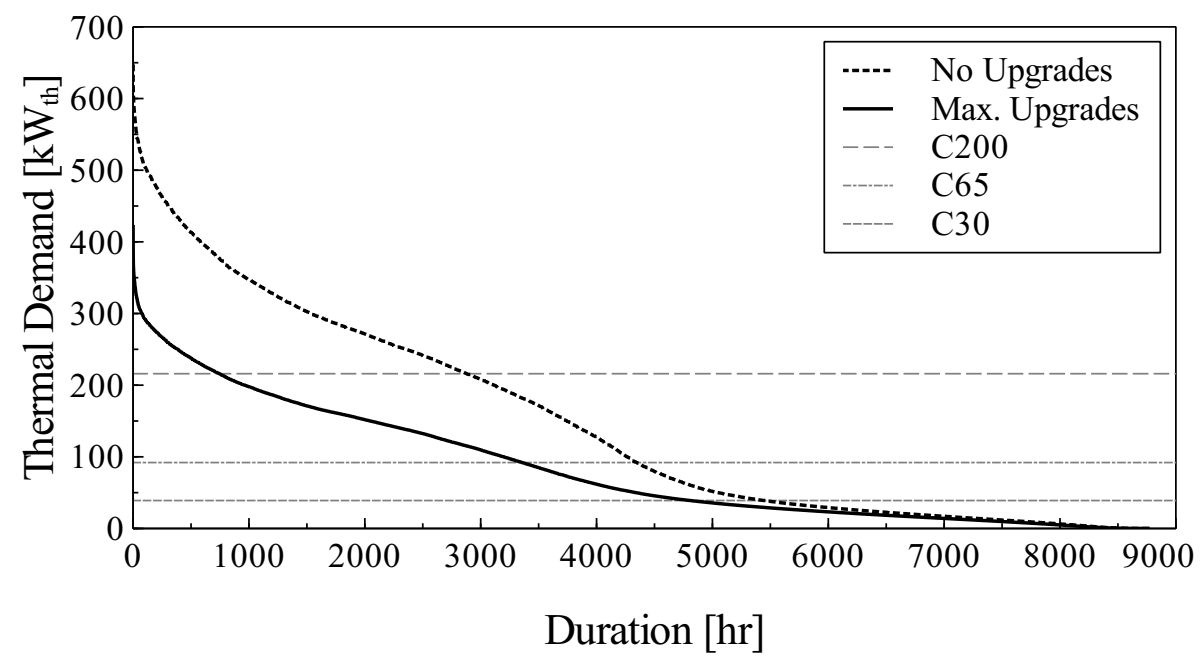

Figure H.1: Thermal load-duration curve for the 1981-1990 Toronto community

The nominal thermal output capabilities of the microturbines considered in this study are also plotted in Figure H.1. To determine these values, the microturbine model described previously in Section 4.7 was used. The microturbines were set to operate at maximum electrical output, and inlet temperature of the microturbine was determined from the Toronto, Ontario CWEC file introduced previously in Chapter 
5. Inlet pressure was assumed to be 1 atm. The microturbine exhaust flow was connected to the HRM model described previously in Section 4.7.3, with a constant load-side fluid inlet temperature of $55{ }^{\circ} \mathrm{C}^{1}$ and variable inlet flow rate described previously in Section 4.7.3.1. The load-side outlet temperature setpoint was $93{ }^{\circ} \mathrm{C}$.

Based on the data plotted in Figure H.1, the C200 microturbine is able to meet the community thermal demands $66 \%$ and $91 \%$ of the time for the unretrofit and retrofit community, respectively. For the C30 microturbine, these values reduce to $36 \%$ and $44 \%$, respectively. During the periods of unmet thermal demand, useful thermal gain is still extracted from the microturbine exhaust stream, but the load-side outlet fluid temperature is below the setpoint. Given the lack of available thermal capacity to meet the thermal demands considered in this study, analysis of thermal following control of the microturbines were deferred to future studies.

\footnotetext{
${ }^{1}$ The nominal return temperature of the DH loop during winter was assumed to be $55{ }^{\circ} \mathrm{C}$.
} 


\section{Appendix I}

\section{Procedure for Allocation of Solar Collectors on Eligible Surfaces}

Chapter 4 described the method used to allocate solar collectors to eligible surfaces. This appendix demonstrates the collector allocation procedure by means of an example. For this example, solar collectors are allocated with a west facing orientation bias. When this orientation bias is selected, an array of azimuth angles, $\boldsymbol{\theta}_{a z i m}$, is defined as:

$$
\boldsymbol{\theta}_{\text {azim }}=\left(90^{\circ}, 45^{\circ}, 0^{\circ},-45^{\circ},-90^{\circ}\right)
$$

Note that the azimuth angle convention follows the convention used in TRNSYS. South is the reference orientation at $0^{\circ}$, east and west are $-90^{\circ}$ and $90^{\circ}$, respectively. Also note that the azimuth angles are separated by increments of $45^{\circ}$. This is the resolution of the surface orientation of the surfaces in CHREM. developed previously by Swan et al. (2013).

Prior to collector allocation, the maximum number of collectors that can be placed on each eligible surface in the community is determined using the finite bin packing algorithm, described previously in Chapter 4. The number of collectors that can be mounted on the $j^{\text {th }}$ surface in the $i^{\text {th }}$ orientation is $N_{\text {avail }}(i, j)$. For each orientation $i$, there are $n(i)$ eligible surfaces ordered from most available collector space to the least. An array $\boldsymbol{N}_{\text {mount }}$ is initialized such that: 


$$
\boldsymbol{N}_{\text {mount }}=(0,0,0,0,0)
$$

where $N_{\text {mount }}(i)$ is the number of collectors allocated to the community with surface azimuth $\theta(i)$.

Total requested number of solar collectors, $N_{\text {tot }}$, is then allocated to the eligible surfaces using the following flowchart: 


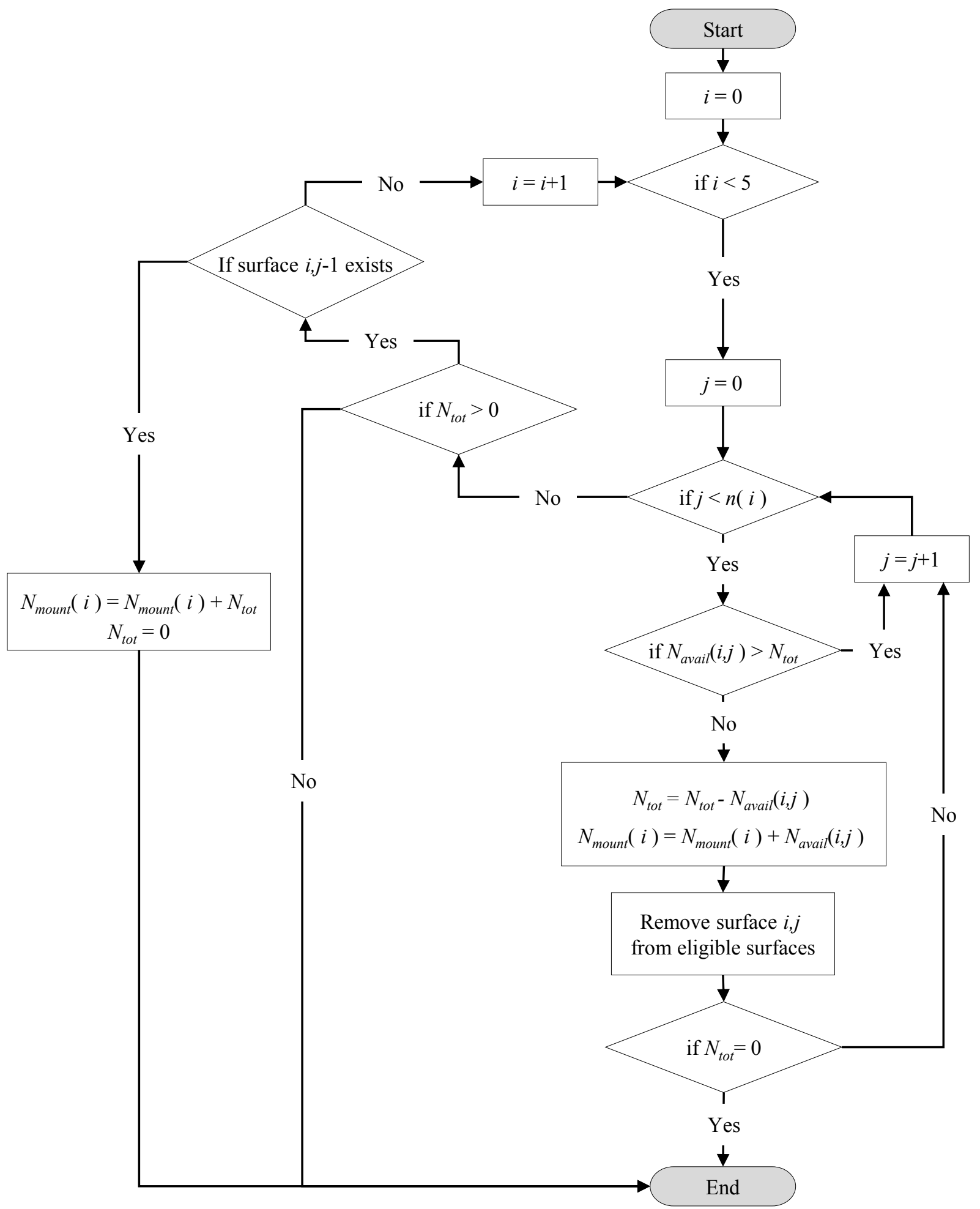

Figure I.1: Flowchart for solar collector allocation in existing communities 


\section{Appendix $\mathbf{J}$}

\section{Description of A\&L Model Inputs}

\section{J.1 GSS Activity Codes}

The activity probability distributions for the A\&L model described previously in Chapter 5 was derived using responses from the 2010 General Social Survey (GSS) from Statistics Canada (2010). The survey was conducted via phone call, and respondents were asked to describe their activities from the previous day starting at 4 a.m. The activity the respondent was engaged in was recorded using and activity code, ACTCODE, along with the time of occurrence. Respondents could also report up to three additional simultaneous activities they were engaged in which were recorded using SACT codes.

Table J.1 describes how the activity codes in the GSS were mapped to activities expressed in the A\&L model. For further information on survey activity codes, the interested reader is directed to Statistics Canada (2010).

\section{J.2 Estimated Appliance Inputs}

Table J.2 provides the assumed appliance power and cycle inputs used in the A\&L model described previously in Chapter 5. Data was gather from several sources which are provided below the table. 
Table J.1: GSS 2010 activity codes associated with each activity represented in the A\&L model

\begin{tabular}{lllll}
\hline Activity Name & ACTCODE & SACT1 & SACT2 & SACT3 \\
\hline \hline Act_TV & $911-913,914.9$ & 13 & 13 & 13 \\
Act_Cooking & $101,102,200.2$ & & & \\
Act_Laundry & 140 & 27 & 27 & 27 \\
Act_WashDress & 400 & & & \\
Act_Iron & 140 & 15 & 15 & 15 \\
Act_CleanHouse & 120 & 20,21 & & \\
Act_PC & $011,012,021-023$ & & \\
& $600,500,511,512$, & & \\
& $520,530,530.2$, & & & \\
& $080.1,080.2,181.2$, & & \\
& $302.3,310.2,310.3$, & & \\
& $955,980.1,914.1$, & & & \\
& $900.1,940.2,932.2$ & & & \\
\end{tabular}

1 (Statistics Canada, 2010)

2 (DOE, 2011)

3 (LBNL, 2017)

4 (Hydro One Networks Inc., 2017)

5 (NRCan, 2014c)

6 (Johnson and Beausoleil-Morrison, 2017; Saldanha and Beausoleil-Morrison, 2012)

7 (Klug et al., 2011)

8 (Richardson et al., 2010)

9 (DOE, 2017) 
Table J.2: Appliance inputs

\begin{tabular}{|c|c|c|c|c|c|}
\hline Appliance & $\begin{array}{l}\text { Mean ON } \\
\text { Power }[\mathrm{W}] \\
\end{array}$ & $\begin{array}{c}\text { Standby } \\
{[\mathbf{W}]} \\
\end{array}$ & $\begin{array}{c}\text { Cycle length } \\
{[\mathrm{min}]}\end{array}$ & $\begin{array}{l}\text { Cycles } \\
\text { per year }\end{array}$ & Activity \\
\hline Microwave & $1433^{3}$ & $3^{3}$ & $4^{5}$ & $365^{5}$ & cooking \\
\hline Small range 1 & $1200^{4}$ & 0 & $19^{7}$ & $12^{7}$ & cooking \\
\hline Large range 1 & $2400^{4}$ & 0 & $19^{7}$ & $37^{7}$ & cooking \\
\hline Small range 2 & $1200^{4}$ & 0 & $19^{7}$ & $188^{7}$ & cooking \\
\hline Large range 2 & $2400^{4}$ & 0 & $19^{7}$ & $581^{5}$ & cooking \\
\hline Dishwasher & $500^{4}$ & $0^{8}$ & $124^{6}$ & $181^{5}$ & cooking \\
\hline Clothes Washer & $500^{4}$ & $1^{8}$ & $40^{6}$ & $211^{5}$ & laundry \\
\hline Clothes Dryer & $5000^{4}$ & $1^{8}$ & $75^{6}$ & $177^{5}$ & laundry \\
\hline Regular TV & $80^{4}$ & $4^{2}$ & $168^{1}$ & $401^{1}$ & tv \\
\hline LED TV & $119^{4}$ & $4^{2}$ & $168^{1}$ & $401^{1}$ & tv \\
\hline Plasma TV & $219^{4}$ & $4^{2}$ & $168^{1}$ & $401^{1}$ & tv \\
\hline DLP TV & $175^{9}$ & $4^{2}$ & $168^{1}$ & $401^{1}$ & tv \\
\hline LCD TV & $150^{9}$ & $4^{2}$ & $168^{1}$ & $401^{1}$ & tv \\
\hline Projector & $225^{9}$ & $4^{2}$ & $168^{1}$ & $401^{1}$ & tv \\
\hline TV receiver & $30^{3}$ & $17^{3}$ & $168^{1}$ & $401^{1}$ & tv \\
\hline DVD/VCR & $14^{3}$ & $5^{3}$ & $131^{1}$ & $24^{1}$ & tv \\
\hline Central vacuum & $1600^{4}$ & 0 & $130^{1}$ & $97^{1}$ & house_clean \\
\hline Spa tub & $3040^{2}$ & 0 & $45^{1}$ & 52 & wash_dress \\
\hline $\mathrm{PC}$ & $106^{3}$ & $5^{3}$ & $71^{1}$ & $838^{1}$ & $\mathrm{PC}$ \\
\hline Printer & $9^{2}$ & $2^{2}$ & $7^{2}$ & $730^{2}$ & $\mathrm{PC}$ \\
\hline CD player & $10^{3}$ & $5^{3}$ & $94^{1}$ & $2^{1}$ & active_occ \\
\hline Stereo & $14^{3}$ & $8^{3}$ & $74^{1}$ & $4^{1}$ & active_occ \\
\hline Iron & $1350^{2}$ & $0^{2}$ & $35^{8}$ & $30^{8}$ & ironing \\
\hline Vacuum & $1080^{2}$ & $0^{2}$ & $130^{1}$ & $97^{1}$ & house_clean \\
\hline Kettle & $1500^{4}$ & 0 & $10^{4}$ & $365^{4}$ & active_occ \\
\hline Hair dryer & $1500^{2}$ & $0^{2}$ & 5 & 365 & wash_dress \\
\hline Game console & $27^{3}$ & $1^{3}$ & $140^{1}$ & $30^{1}$ & tv \\
\hline Sauna & 11000 & 0 & 15 & 52 & active_occ \\
\hline Aquarium & $39^{2}$ & $39^{2}$ & $\mathrm{~N} / \mathrm{A}$ & $\mathrm{N} / \mathrm{A}$ & other \\
\hline Water cooler & $160^{4}$ & $160^{4}$ & $\mathrm{~N} / \mathrm{A}$ & $\mathrm{N} / \mathrm{A}$ & other \\
\hline
\end{tabular}




\section{Appendix K}

\section{Transmission Connected Generation in Ontario}

\section{K.1 Data Tables}

Tables K.1 and K.2 provide the 2016 annual electrical output, $Q_{\text {gen,elec,ann }}$ [TJ], of gas-fired electricity generators in Ontario as reported by IESO (2017a). Generator stations are identified using the convention established by IESO. The energy conversion technology is identified by IESO (2017a), however the resolution of this disaggregation was only "simple/combined" and "combined heat and power". The conversion technology used by each generation station was independently determined, and the references are provided at the conclusion of this section. The conversion cycles were identified as either simple or combined, and were further disaggregated by having combined heat and power (CHP) or not. 
Table K.1: 2016 annual output of Ontario gas generators without CHP

\begin{tabular}{lcc} 
Generator Station & Technology & $Q_{\text {gen,elec,ann }}[\mathrm{TJ}]$ \\
\hline \hline BRIGHTON BEACH & Combined $^{1}$ & 899 \\
DESTEC & Combined $^{2}$ & 2579 \\
GREENFIELD ENERGY CENTRE & Combined $^{3}$ & 6506 \\
GREENFIELD SOUTH & Combined $^{4}$ & 34 \\
HALTONHILLS-LT & Combined $^{5}$ & 4166 \\
KAPGS & Combined $^{6}$ & 1185 \\
LENNOX & Steam $^{7}$ & 345 \\
NIPIGONGS & Combined $^{6}$ & 1064 \\
NORTHBAYGS & Combined $^{6}$ & 1117 \\
NPKIRKLAND & Combined $^{2}$ & 2427 \\
PORTLANDS & Combined $^{8}$ & 3777 \\
SITHE GOREWAY & Combined $^{9}$ & 1886 \\
STCLAIRCGS & Combined $^{10}$ & 2950 \\
YORKCGS & Simple $^{11}$ & 145 \\
\hline
\end{tabular}


Table K.2: 2016 annual output of Ontario gas generators with CHP

\begin{tabular}{lcc} 
Generator Station & Technology & $Q_{\text {gen,elec,ann }}[\mathrm{TJ}]$ \\
\hline \hline CARDINAL & Combined $^{12}$ & 283 \\
DOWCHEMICAL & Combined $^{13}$ & 493 \\
DPNTMTLND & Unknown $^{11}$ & 35 \\
EAST WINDSOR & Combined $^{11}$ & 181 \\
GTAA & Combined $^{14}$ & 164 \\
NPIROQFALLS & Combined $^{2}$ & 2528 \\
TADOUGLAS & Combined $^{13}$ & 3100 \\
TAOHSC & Combined $^{13}$ & 76 \\
TASARNIA & Combined $^{13}$ & 4946 \\
TAWINDSOR & Combined $^{13}$ & 1388 \\
THOROLDCGS & Combined $^{2}$ & 1533 \\
WESTWINDSOR & Combined $^{15}$ & 1517 \\
WHITBYCGS & Simple $^{3}$ & 1428 \\
\hline
\end{tabular}

Generators NPCOCHRANE and TUNISGS produced less than a TJ of electrical energy, and are ommitted here. It is also important to note that 24 records, or $0.3 \%$, of the annual generation data is missing for each generator in the IESO report.

\section{K.2 References}

1. ATCO Power. Brighton Beach combined-cycle generation plant. Available online at http://www.atcopower.com/Our-Facilities/Our-Power-Technologies/ Combined-Cycle-Plants/Brighton_Beach [Accessed Aug 8, 2017], 2017.

2. Northland Power. Operating assets. Available online at http://www. northlandpower.ca/What-We-Do/Operating-Assets/ [Accessed Aug 8, 2017], 2017.

3. Calpine. Power Operators: Ontario - Canada. Available online at http: //www.calpine.com/ontario-canada [Accessed Aug 8, 2017], 2017.

4. Greenfield South Power Corporation. Project Description. Available online at 
http://www.greenfieldsouth.ca/ [Accessed Aug 8, 2017], 2017.

5. Kable Intelligence Limited. Halton Hills Combined Cycle Plant, Canada. Available online at http://www.power-technology.com/projects/ halton-hills-combined-cycle-plant/ [Accessed Aug 8, 2017], 2017. power-technology.

6. Atlantic Power Corporation. Assets: Project List. Available online at http: //www.atlanticpower.com/assets/projects/ [Accessed Aug 8, 2017], 2017.

7. OPG. Generating power: Leading Ontarios Clean Power Future. Available online at http://www.opg.com/generating-power/Pages/generating-power.aspx [Accessed Aug 8, 2017], 2017. Ontario Power Generation.

8. Portlands Energy Centre. How It Works. Available online at http://www. portlandsenergycentre.com/operations/how-it-works/ [Accessed Aug 8, 2017], 2017.

9. Goreway Power Station. The Power Station. Available online at http:// gorewaypowerstation.com/the-power-station/ [Accessed Aug 8, 2017], 2017.

10. Sarnia Lambton Chamber of Commerce. St. Clair Power, LP (Invenergy). Available online at http://www3.sarnialambtonchamber.com/Membee.html\# action $=$ Listing $\&$ value $=5386 \&$ cid $=215 \&$ id $=201 \&$ searchID $=0$ [Accessed Aug 8, 2017], 2017.

11. Capital Power. All Facilities \& Projects. Available online at http: //www.capitalpower.com/generationportfolio/Pages/default.aspx [Accessed Aug 8, 2017], 2017.

12. Capstone Infrastructure. Cardinal Power: Gas cogeneration power. Available online at http://www.capstoneinfrastructure.com/Assets/Downloads/ InvestorBriefcase/FactSheets/2015/capstone\%20GAS\%20COGENERATION\% 20FACT\%20SHEET\%200315.pdf [Accessed Aug 8, 2017], 2017.

13. TransAlta. Plants in Operation. Available online at http://www.transalta. com/facilities/plants-operation/ [Accessed Aug 8, 2017], 2017.

14. IST. Greater Toronto Airports Authority, GTAA Cogeneration Plant. Available online at http://otsg.com/whitepapers/downloads/2012/01/Greater-Toronto. pdf [Accessed Aug 8, 2017], 2012. Innovative Steam Technologies.

15. wikimapia. West Windsor Power. Available online at http://wikimapia.org/ 11556151/West-Windsor-Power [Accessed Aug 8, 2017], 2012. 


\section{Appendix L}

\section{Comparison of Measured and Modelled Aggregate Whole-Dwelling Electrical Demands}

Chapter 5 described the AL model integrated into CHREM as part of this research. An in-sample validation was conducted due to a lack of available measured residential AL demands. With the increasing prevalence of smart-meters in practice, there are greater opportunities to collect and analyse residential energy demand. Additionally, finer timescales of data logging down to 1 minute have appeared in the market (McKenna et al., 2012). Several challenges are still faced by a researcher seeking to study residential energy demands however. Data is often not publicly shared in order to protect privacy. Electrical data is also often measured for the whole-dwelling, rather than the individual end-uses. This presented a challenge for validating the AL demand model, since there are few disaggregated electrical demand measurements in the literature.

This section extends the AL model validation study performed previously in Chapter 5. Measured hourly whole-dwelling residential demands were provided from ten Windsor, Ontario homes from a local distribution company (Bastounas, 2015). This data was then compared to whole-dwelling electric consumption estimates generated by CHREM using the new AL model. The data was collected in 2015 by the utility, and contained 8376 hours of continuous data concurrently measured for 
all locations. Neither smart-meter manufacturer model or uncertainty values were provided. ANSI CI12.20 defines smart-meter power measurement accuracy classes between $\pm 0.2 \%$ to $\pm 2 \%$ (as cited in Ni et al. (2016)).

Due to privacy concerns, limited metadata was provided for each dwelling. The available metadata for the dwellings are summarized in Table L.1. All dwellings were characterized as single-detached except Dwelling 7 which was identified as a duplex. No information was provided regarding the appliance stock of the dwellings, or the HVAC and DHW systems. Given the limited metadata, it was not feasible to directly model these dwellings in CHREM. The small sample size also presents challenges for analysis, and the average aggregate demand characteristics are sensitive to the individual behaviour variations between the dwellings. To compare CHREM to the measured data, 50 CSDDRD Windsor single-detached records were randomly selected and modelled.

Table L.1: Average daily whole-dwelling electrical demand and metadata of the Windsor smart-meter electrical demand measurements from Bastounas (2015)

\begin{tabular}{lcccc}
\hline Dwelling & Vintage & $A_{\text {floor }}\left[\mathrm{m}^{2}\right]$ & $N_{\text {bedrooms }}$ & $\begin{array}{c}\text { Average Daily Consumption } \\
{[\mathrm{kWh} / \mathrm{day}]}\end{array}$ \\
\hline \hline 1 & 80's/90's & 115 & 5 & 31.2 \\
2 & 70's/80's & 79 & 2 & 30.7 \\
3 & 80's/90's & 121 & 7 & 52.0 \\
4 & 80's/90's & 93 & 4 & 4.6 \\
5 & 70's/80's & 79 & 2 & 20.4 \\
6 & 80's/90's & 102 & 4 & 10.2 \\
7 & 60 's/70's & 74 & 4 & 7.9 \\
8 & 60 's & 307 & 3 & 7.6 \\
9 & 70's/80's & 93 & 4 & 7.0 \\
10 & 90 's/2000's & 130 & 3 & 12.8 \\
\hline
\end{tabular}

A 5-minute timestep was used for the simulations, and results were integrated 
to produce hourly energy demand profiles for each dwelling. Only the first 8376 simulation hours were considered, corresponding to the monitoring period of the measured data. Two sets of simulations were performed. The first used the AL modelling methodology implemented into CHREM by Swan (2010), and the second used the AL methodology implemented in the current work. All other model inputs were held constant between both sets. Figure L.1 plots the distributions of the measured and modelled average daily electrical demand intensities. The whiskers illustrate \pm 1.5 of the interquartile range, and the dots represent outliers.

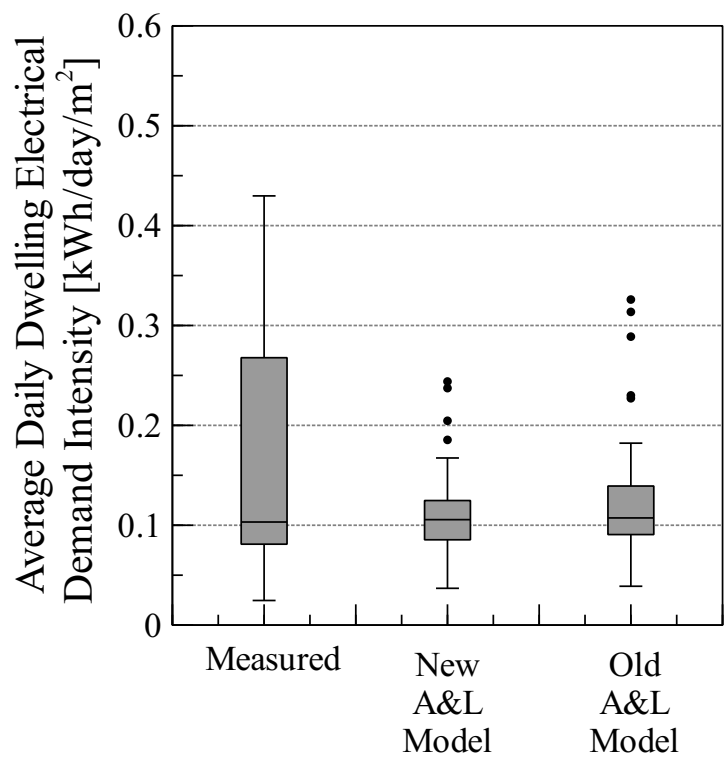

Figure L.1: Distributions of measured and modelled average daily whole-dwelling electrical demand intensities

No information was provided from the utility on how $A_{\text {floor }}$ was determined for the measured data. It was assumed for this work that $A_{\text {floor }}$ was the heated floor area, including the basement. $A_{\text {floor }}$ for the modelled dwellings were determined from the CSDDDRD, and included the main floors and basement. It can be seen in Figure L.1 that both modelling approaches yielded similar distributions of demand intensities, and the median values determined with both AL modelling approaches had a similar median value to the measured. Neither modelling approach however, 
captured the higher demand intensities observed in the measured data.

To analyse the temporal characteristics of the modelled aggregate electrical demands, the load-duration curves of aggregate community electrical demands were compared between measured and modelled. A total of four sets of modelled dwelling electrical profiles were defined, derived from the profiles described above. The first two sets were comprised of the ten highest annual electrical energy consumers determined using both AL modelling techniques. The next two sets were comprised of the ten lowest annual electrical energy consumers. The load-duration curves for the measured and modelled aggregate dwelling profiles are plotted in Figure L.2. The upper and lower boundaries of the shaded regions represent the load-duration curves for the high and low demand modelled dwellings, respectively.

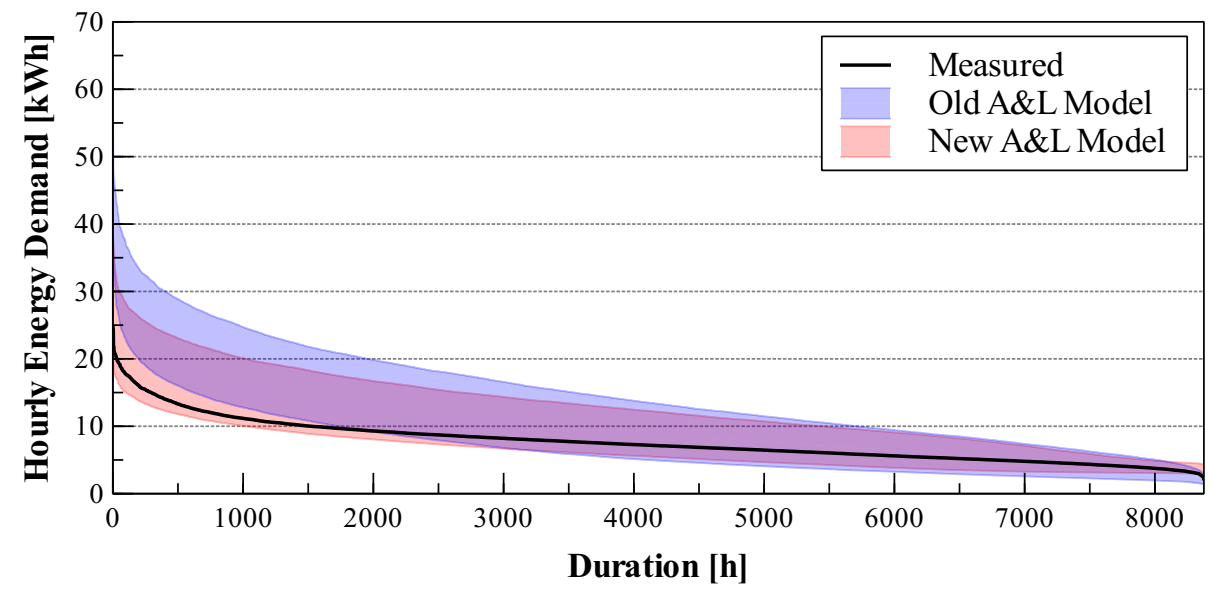

Figure L.2: Hourly electrical load-duration curves for the aggregate demand of 10 dwellings

It can be seen in Figure L.2 that the aggregate baseload electrical demands are similar for both modelling approaches and agree with measured. Moving from right to left on the load-duration curve however, the aggregate demands determined using the old AL modelling approach begins to deviate from both the new modelling approach results and the measured data. The peak demands determined by the old approach tend to be higher compared to the measured data. This can also be seen in the summary of peak and baseload demands shown in Table L.2. 
Table L.2: Comparison of measured and modelled peak and baseload aggregate electrical hourly demands

\begin{tabular}{lccccc}
\hline & & \multicolumn{4}{c}{ AL Model } \\
Demand & & \multicolumn{2}{c}{ Old } & \multicolumn{2}{c}{ New } \\
\cline { 3 - 6 }$[\mathbf{k W h}]$ & Measured & High & Low & High & Low \\
\hline \hline \multirow{2}{*}{ Peak } & 24.9 & 62.2 & 42.7 & 43.7 & 21.4 \\
Baseload & 2.2 & 2.9 & 1.4 & 4.3 & 2.8 \\
\hline
\end{tabular}

Discussed in Chapter 5, Swan (2010) used previously generated synthetic subhourly AL demand from Armstrong et al. (2009) to model the AL demand of dwellings in the CHREM. Profiles are matched to CSDDRD records based on the similarity of annual AL consumption estimates derived from an ANN model developed by Aydinalp et al. (2002). If several dwellings have similar annual consumption values, they will all use the same sub-hourly profile. For the Windsor community modelled here, only four unique profiles were used among the 50 dwelling considered. This resulted in an under-estimation of diversity in the electrical demands, and an over-estimation of the peak aggregate demands compared to the measured data.

Figure L.2 and Table L.2 both demonstrate the improvement of model agreement with the measured aggregate electrical loads when the new AL modelling approach integrated into CHREM is used. The improvement is related to capturing the diversity of dwelling electrical demands and estimating aggregate electrical loads. It can be seen in Figure L.1 however, that both the approach developed by Swan (2010) and the new AL model produce similar estimates for the diversity of annual electricity demands. Therefore, for analysis focused on dwelling-scale retrofits and energy performance both AL modelling approaches are likely to produce similar results. 